\title{
Smallholder vanilla agroforestry in Madagascar: biodiversity, ecosystem services and yields in a land-use context
}

\author{
Dissertation \\ zur Erlangung des mathematisch-naturwissenschaftlichen Doktorgrades \\ Doctor rerum naturalium \\ der Georg-August-Universität Göttingen \\ im Promotionsprogramm \\ Diversity Turn in Land Use Science \\ der Graduiertenschule Forst- und Agrarwissenschaften \\ vorgelegt von \\ Dominic Andreas Martin (M.Sc.) \\ aus \\ Zürich
}

Göttingen

2020 



\section{Betreuungsausschuss}

Prof. Dr. Holger Kreft, Biodiversität, Makroökologie und Biogeographie, Georg-August-Universität Göttingen, Deutschland.

Prof. Dr. Dirk Hölscher, Tropischer Waldbau und Waldökologie, Georg-August-Universität Göttingen, Deutschland.

Prof. Dr. Teja Tscharntke, Agrarökologie, Georg-August-Universität Göttingen, Deutschland.

Prof. Dr. Ingo Grass, Ökologie Tropischer Agrarsysteme, Universität Hohenheim, Deutschland.

\section{Mitglieder der Prüfungskommission}

Referent: Prof. Dr. Holger Kreft

Weitere Mitglieder der Prüfungskommission: Prof. Dr. Dirk Hölscher, Prof. Dr. Teja Tscharntke, Prof. Dr. Ingo Grass. 



\section{Abstract}

Land-use change threatens biodiversity and ecosystem services worldwide. Tropical areas are currently particularly affected: natural ecosystems are being transformed into largescale monocultures or small-scale mosaic landscapes characterized by smallholder agriculture. In both cases, the conversion of natural ecosystems into agriculturally used areas can greatly increase yield, at least in the short term.

A rapid change in land use is currently taking place in north-eastern Madagascar, driven by two main factors: the cultivation of rice through shifting cultivation and the conversion of forests and fallow land into vanilla agroforestry. The result of these processes is a smallscale and very heterogeneous agricultural landscape. This dissertation shows what this land-use change means for biodiversity and ecosystem services, how realized harvests and profitability influence land use decisions, and where there are opportunities for nature conservation through targeted policy interventions in north-eastern Madagascar. Importantly, this is a greatly under-researched topic, given that research on the conservation value of converted lands in Madagascar is still in its infancy. Indeed, nearly nothing has been published on biodiversity, ecosystem services, and yields in vanilla agroforests.

To compare different forms of land use, we selected 80 plots in 10 villages and in Marojejy National Park where we collected a large part of the biodiversity and ecosystem service data that underpins this dissertation. The seven land-use types were old-growth forest, forest fragment, forest-derived vanilla agroforestry, fallow-derived vanilla agroforestry, herbaceous fallow, woody fallow, and rice paddy. To obtain more precise data on tree dynamics and harvests in vanilla agroforests, we additionally researched a chronosequence with 209 vanilla agroforests. Furthermore, this thesis also contains a review on the importance of 
considering land-use history for biodiversity and ecosystem services in agroforestry systems (Chapter 2).

There are three principal findings: firstly, species communities of birds (Chapters $3 \& 4$ ), reptiles and amphibians (Chapter 5) differ greatly between land-use types and that oldgrowth forest is irreplaceable for many species, especially the endemic ones. Secondly, vanilla agroforestry systems offer conservation opportunities, especially if established on fallow land instead of inside forest (Chapters 3 - 9). Thirdly, vanilla harvests in agroforestry systems are independent of canopy cover, making vanilla cultivation in tree-rich agroforests feasible, thereby reaping the associated benefits for biodiversity and ecosystem services without yield costs (Chapters $7 \& 8$ ).

This dissertation thus provides a major advancement of our understanding of biodiversity change and ecosystem services in the agricultural smallholder landscape of north-eastern Madagascar. It also sheds some first light on the complex interplay between land-use history, shade trees, and management practices in determining vanilla yields in vanilla agroforests. Lastly, this thesis also provides a conceptual advancement of the field, by identifying the importance of land-use history in determining biodiversity and ecosystem services in tropical agroforests. 


\section{Zusammenfassung}

Änderungen der Landnutzung bedrohen weltweit die Artenvielfalt und Ökosystemdienstleistungen. Tropische Regionen sind heute davon besonders betroffen: natürliche Ökosysteme werden zu großflächigen Monokulturen oder zu kleinräumigen Mosaiklandschaften, letztere geprägt von kleinbäuerlicher Landwirtschaft. In beiden Fällen lassen sich durch die Umwandlung natürlicher Ökosysteme in landwirtschaftlich genutzte Flächen die Erträge zumindest kurzfristig stark vergrößern.

In Nordost-Madagaskar findet zurzeit ein rapider Landnutzungswandel statt, getrieben durch Anbau von Reis durch Brandrodung sowie die Umwandlung von Wäldern und Brachflächen in Vanille-Agroforste. Das Resultat dieser Prozesse ist eine kleinräumige, von Kleinbauern bewirtschaftete, sehr heterogene Kulturlandschaft. Diese Dissertation zeigt, was dieser Landnutzungswandel für die Biodiversität und Ökosystemdienstleistungen bedeutet, wie Ernteerträge und Profitabilität Landnutzungsentscheidungen beeinflussen, und wo sich in Nordost-Madagaskar Chancen für den Naturschutz bieten. Damit ist die Arbeit ein Beitrag zum noch jungen Forschungsfeld der Landnutzungsforschung in Madagaskar. Dass dieses Thema noch wenig untersucht wurde, zeigt sich auch darin, dass bis anhin fast nichts über Artenvielfalt und Ökosystemdienstleistungen in Vanille-Agroforsten bekannt ist.

Um die verschiedenen Formen der Landnutzung vergleichen zu können, haben wir 80 Flächen in zehn Dörfern und im Marojejy Nationalpark ausgewählt. Auf diesen Flächen haben wir den Großteil der Daten zu Biodiversität und Ökosystemdienstleistungen gesammelt, die als Grundlage für diese Arbeit dienen. Im Fokus standen sieben Landnutzungstypen: Primärwald, Waldfragment, Vanille-Agroforst mit Waldursprung, Vanille-Agroforst mit Brachlandursprung, krautige Brache, holzige Brache, und Naßreis. Um genauere Daten über 
Baumdynamik und Ernten in Vanille-Agroforsten zu sammeln, habe wir zusätzlich eine Chronosequenz mit 209 Vanille-Agroforsten erforscht. Ferner enthält diese Dissertation einen Review zur Landnutzungsgeschichte in Agroforstsystemen (Kapitel 2).

Die Resultate zeigen unter anderem, dass sich Artengemeinschaften von Vögeln (Kapitel 3 \& 4), Reptilien, und Amphibien (Kapitel 5) stark zwischen verschiedenen Landnutzungstypen unterscheiden und dass Primärwald unersetzlich für viele Arten ist, insbesondere die endemischen. Vanille-Agroforstsysteme bieten Chancen für den Naturschutz, insbesondere wenn diese auf Brachland und nicht im Wald etabliert werden (Kapitel 3 - 9). Zudem sind Vanilleernten in Agroforstsystemen unabhängig vom Beschattungsgrad. Der Anbau von Vanille in baumreichen Agroforsten ist demnach ohne Ernteverlust realisierbar (Kapitel 7 \& 8) und hat Vorteile für Biodiversität und Ökosystemdienstleistungen.

Die vorliegende Dissertation führt zu einer wesentlichen Verbesserung unseres Verständnisses bezüglich des Wandels der Artenvielfalt und der Ökosystemleistungen in der kleinbäuerlich geprägten Agrarlandschaft des nordöstlichen Madagaskars. Sie gibt auch erste Einblicke in den Einfluss von Landnutzungsgeschichte, Schattenbäumen und Bewirtschaftungspraktiken auf Vanilleernten. Das Herausheben der Bedeutung der Landnutzungsgeschichte für Biodiversität und Ökosystemleistungen in tropischen Agroforstsystemen stellt zudem eine konzeptionelle Weiterentwicklung des Forschungsfeldes dar. 


\section{Preface}

I start my thesis with an introduction followed by seven research chapters. I led four of these chapters myself (Chapters 2, 3, 6 \& 8), while the other three were led by one of my colleagues (Chapters 5 \& 7) or a MSc student I advised (Chapter 4). In chapter 9, I list abstracts of additional manuscripts to which I have contributed. I finish the thesis with a synthesis chapter (Chapter 10). Additionally, I included boxes in the introduction and synthesis chapters to give a different perspective on my $\mathrm{PhD}$ - a bit away from the science, I highlight six aspects of this four-year journey.

Chapter 1, the introduction, sets the frame, by highlighting land-use change as a key driver of biodiversity loss and outlines ways for more biodiversity-friendly farming. To provide important context about the field studies, I then continue with a section on the natural history of Madagascar and the pressing land-use and conservation challenges the country faces. I finish the chapter with a detailed overview of our study design.

Chapter 2, published in Conservation Letters, conceptualizes land-use history of tropical agroforestry systems and reviews ecosystem services and conservation value of agroforests of contrasting land-use history. While of broad relevance for agroforestry research in general, the chapter also provides the key conceptual framework for chapters 4 to 10 which are based on field data.

Chapter 3, published in Biotropica, investigates how bird diversity and composition changes along a land-use gradient in north-eastern Madagascar. The chapter thus provides first insights into the response of biodiversity to land-use change in the region.

Chapter 4, led by MSc student Saskia Dröge and published in Ecological Indicators, uses sound recording data to show how a variety of sound diversity indices vary across the land- 
use gradient. The chapter further links these indices with bird data from chapter 4 to investigate how sound diversity may work as a proxy for biodiversity.

Chapter 5, led by my PhD colleague Thio Rosin Fulgence, uses an extensive dataset of amphibian and reptile abundances across the land-use gradient to show how species richness, composition and abundance is strongly influenced by land use.

Chapter 6, published in Ecosystems, investigates how canopy cover, agroforest age and planting density influence vanilla yields across 209 vanilla agroforests and how tree rehabilitation on the plot-scale may translate to the landscape-scale

Chapter 7, led by my PhD colleague Annemarie Wurz, investigates drivers of vanilla yields in more depth and elucidates how it is possible to combine high vanilla yields with high levels of biodiversity.

Chapter 8, the 'crown' of this thesis, describes re-occurring conservation opportunities along the land-use trajectory, thereby synthesizing data from across the empirical chapters. The chapter further includes data from other research from within the project, namely from the papers that have their abstracts included in chapter 9.

In Chapter 9, I list seven abstracts of manuscripts led by my colleagues from across the $\mathrm{Di}$ versity Turn project to which I contributed as a co-author. Two manuscripts highlight how additional taxonomic groups (Trees, 9.1; herbaceous plants, 9.2) are affected by land-use change in north-eastern Madagascar. These are followed by five additional manuscripts: first, a natural history note (9.3) describes how spiders build traps to catch frogs. Second, a manuscript (9.4) that investigates how predation rate, a key ecosystem service, changes across the land-use gradient. Third, a manuscript highlighting carbon sequestration opportunities through fallow-derived vanilla agroforestry (9.5). Fourth, a study investigating ecosystem services of various land-use types 9.6). Fifth, a socio-economic baseline study (9.7) that provided some foundational work for village- and plot selection.

In Chapter 10, the synthesis of this thesis, I jointly discuss the findings of chapter 2 to 9. I conclude on the value of various land-use types for ecosystem services and biodiversity. I further discuss outcomes of different land-use trajectories in relation to possible alternatives. Lastly, I relate the findings of this thesis to the broader context within Madagascar and the wider land-use literature. 


\section{Table of contents}

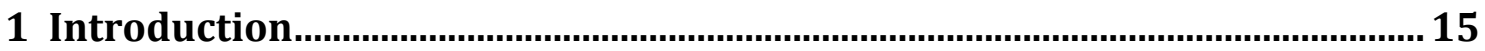

1.1 Land-use change as a key diver of biodiversity loss ................................................15

Box 1: My PhD journey - Interdisciplinarity and diversity........................................... 18

1.2 Trade-offs between biodiversity, ecosystem services, and yields in tropical smallholder agriculture, with a focus on agroforests .....................................................19

Box 2: My PhD journey - Transdisciplinarity ............................................................ 22

1.3 Natural history, land-use change, and conservation in Madagascar ...........................23

Box 3: My PhD journey - Field work in Madagascar..................................................... 28

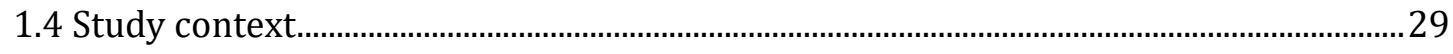

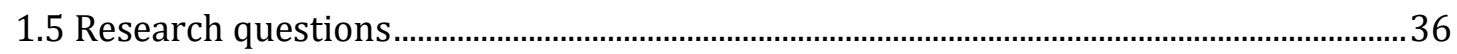

2 Land-use history determines ecosystem services and conservation value in

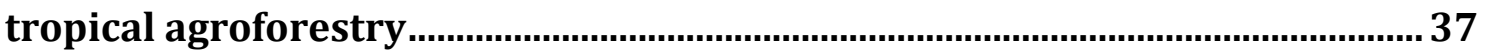

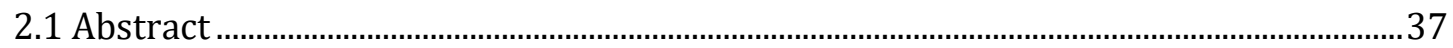

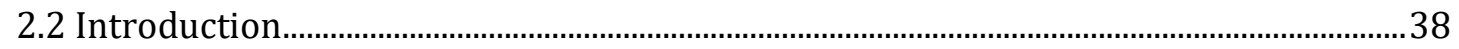

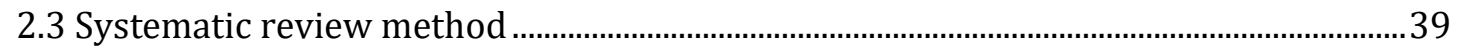

2.4 The importance of land-use history in tropical agroforestry ............................................40

2.5 Suitability of open vs. forest land for agroforest establishment......................................44

2.6 Land-use history affects ecosystem functions and services..............................................4

BOX: The case of vanilla agroforestry in Madagascar................................................................4

2.7 Land-use history shapes vegetation structure and biodiversity ......................................46

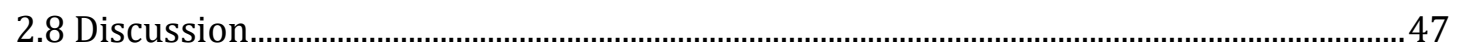

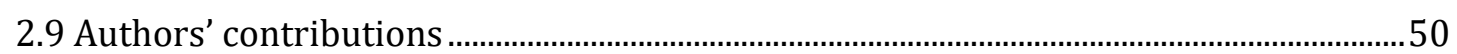


3 Bird diversity and endemism along a land-use gradient in Madagascar: the

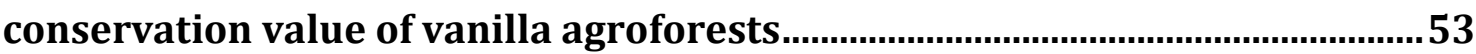

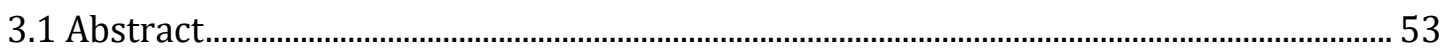

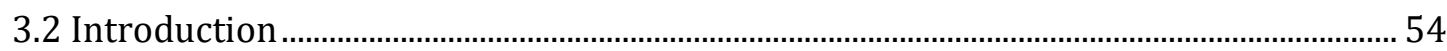

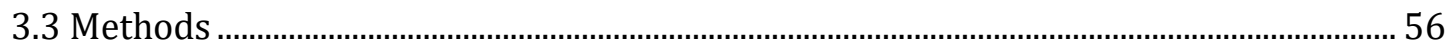

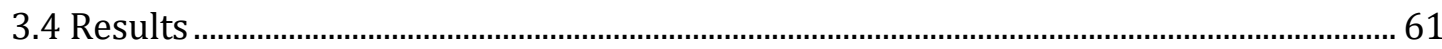

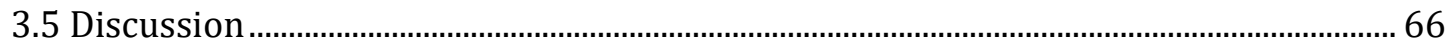

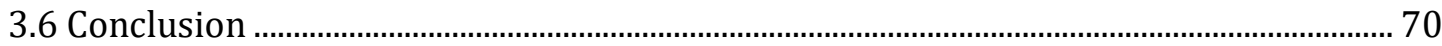

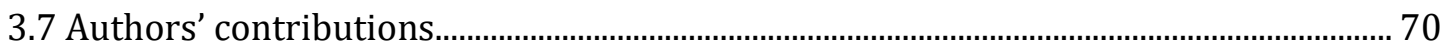

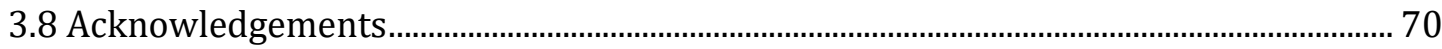

3.9 Conflict of interest .............................................................................................................. 71

3.10 Data accessibility.................................................................................................................. 71

4 Listening to a changing landscape: acoustic indices reflect bird species richness and plot-scale vegetation structure across different land-use types

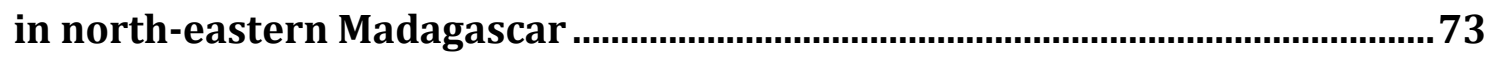

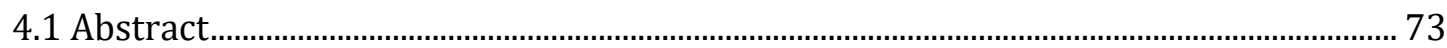

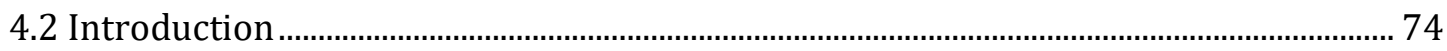

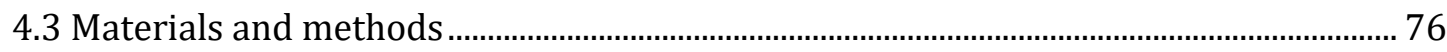

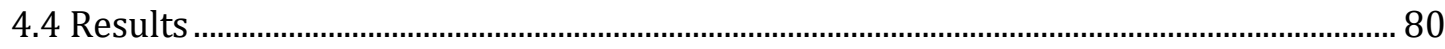

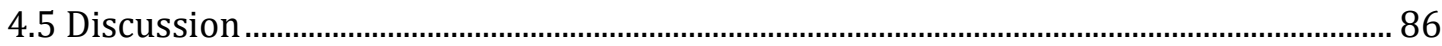

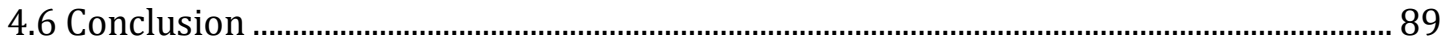

4.7 Author's contributions........................................................................................................ 89

4.8 Acknowledgements............................................................................................................ 90

4.9 Data availability statement .................................................................................................... 90

5 Differential responses of amphibians and reptiles to land-use change in the biodiversity hotspot of north-eastern Madagascar ...........................................91

5.1 Abstract................................................................................................................................... 91

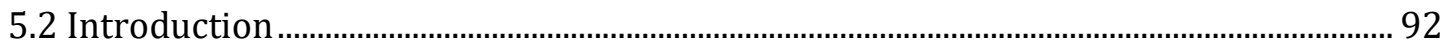

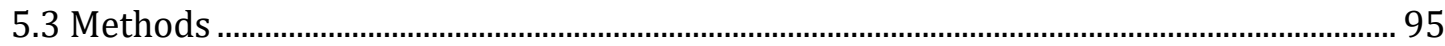

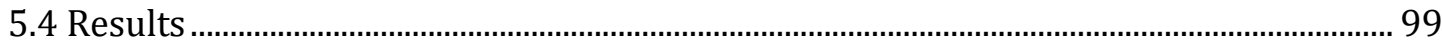

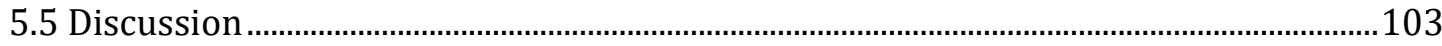

5.6 Author's contributions.......................................................................................................109 
6 Shade-tree rehabilitation in vanilla agroforests is yield neutral and may translate into landscape-scale canopy cover gains ........................................... 111

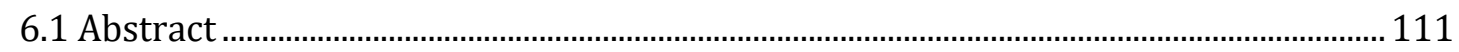

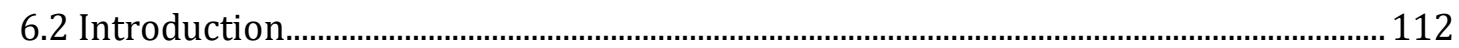

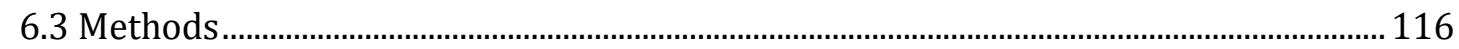

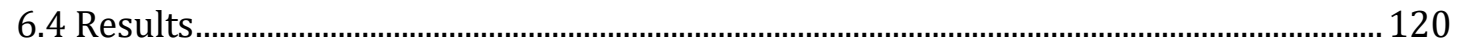

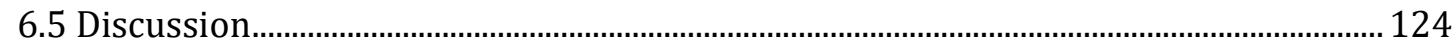

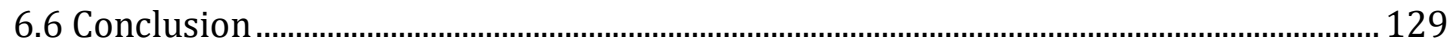

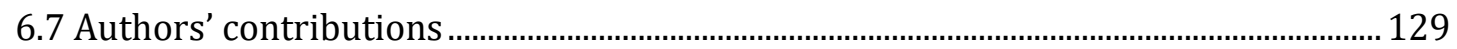

6.8 Acknowledgements ........................................................................................................ 129

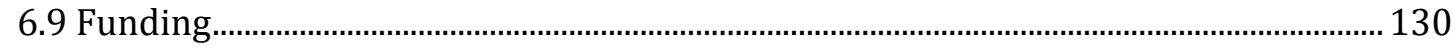

6.10 Data availability statement.................................................................................................. 130

7 High crop yields without biodiversity losses in tropical agroforestry ..... 131

7.1 Abstract ............................................................................................................................... 131

7.2 Introduction ..................................................................................................................... 132

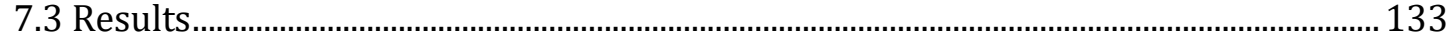

7.4 Discussion............................................................................................................................ 139

7.5 Methods ............................................................................................................................ 142

7.6 Acknowledgements ........................................................................................................ 154

8 Uncovering conservation opportunities in a global biodiversity hotspot155

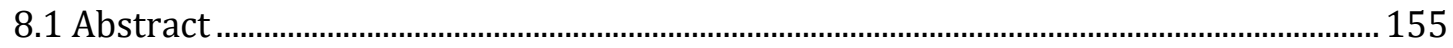

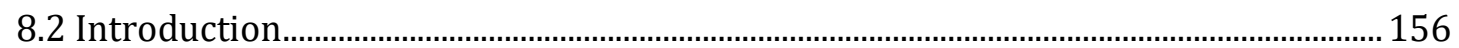

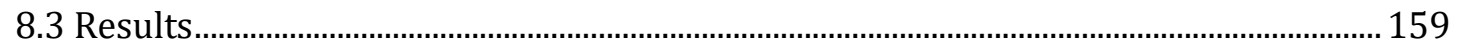

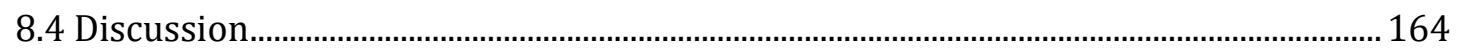

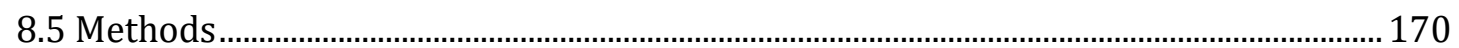

8.6 Acknowledgements ............................................................................................................ 180

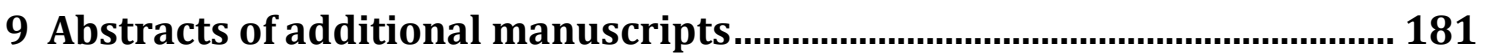

9.1 Land-use history determines habitat structure and tree diversity in tropical agroforestry

9.2 Land-use intensification increases richness of native and exotic herbaceous plants, but not endemics, in Malagasy vanilla landscapes. 
9.4 Decreasing predation rates and shifting predator compositions along a land-use gradient in Madagascar's vanilla landscapes.

9.5 Aboveground biomass carbon in Madagascar's vanilla production landscape -

exploring rehabilitation by agroforestry in the light of land-use history.

9.6 Fallow lands and forest fragments are essential for plant use and ecosystem service provisioning in a tropical agricultural landscape.

9.7 Socio-economic, land use and value chain perspectives on vanilla farming in the SAVA region (north-eastern Madagascar): the Diversity Turn Baseline Study (DTBS) 193

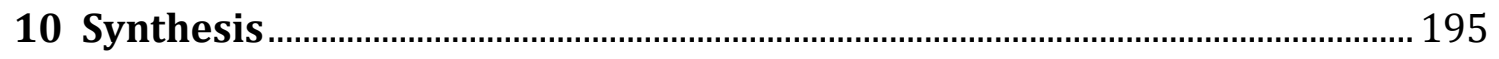

10.1 How to farm vanilla in ways that benefits nature and people alike? ......................196

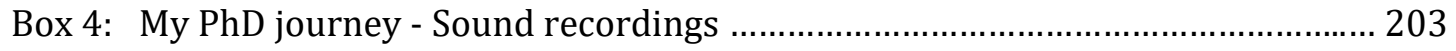

10.2 How to design policies that enable a sustainable land-use transformation in north-

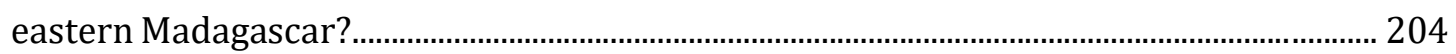

Box 5: My PhD journey - Writing, data analysis, and science communication ............ 212

10.3 Ideas for future land-use research in north-eastern Madagascar............................213

Box 6: My PhD journey - DAAD Grant 'Partnerships for Biodiversity' .......................... 214

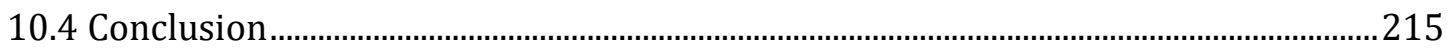

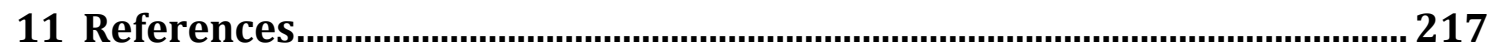

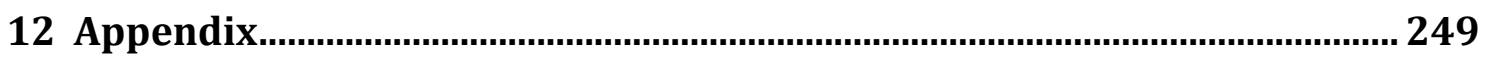

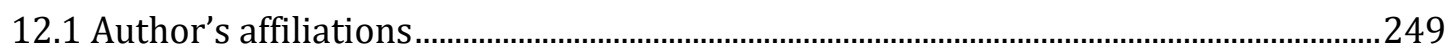

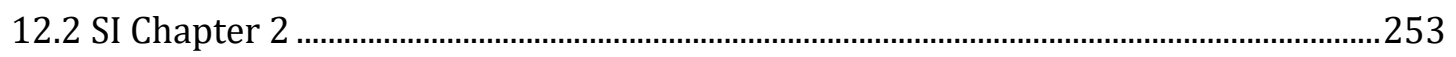

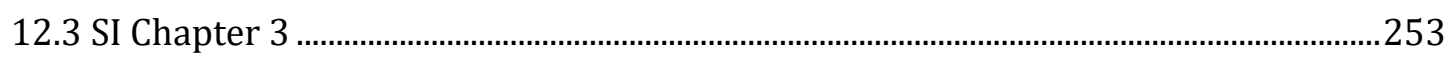

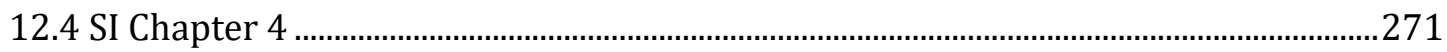

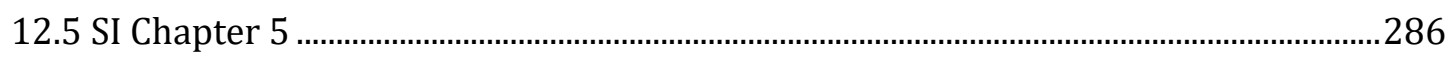

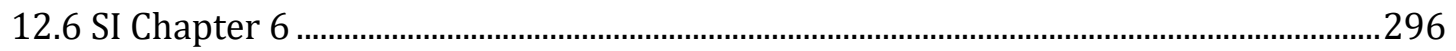

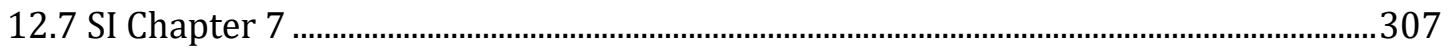

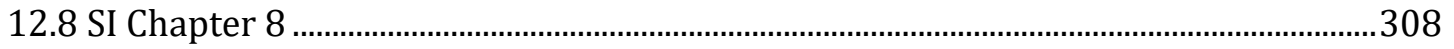

12.9 Curriculum vitae Dominic A. Martin .....................................................................................311

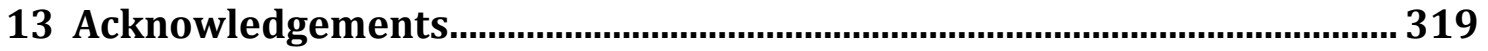




\section{Figures}

Figure 1.1: Land cover (A) and elevation (B) in Madagascar..................................................................24

Figure 1.2: Maps of the study region

Figure 1.3: Possible transformation pathways from old-growth forest into different land-uses in north-eastern Madagascar.

Figure 1.4: Study area in north-eastern Madagascar.

Figure 1.5: Semi-blocked study design with replicated land-use types across 10 villages and two

old-growth forest sites where we collected data for chapters 3-5, 7, and 8.

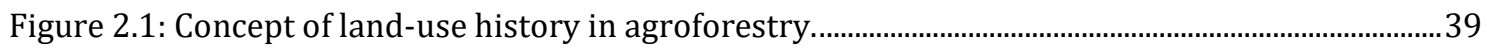

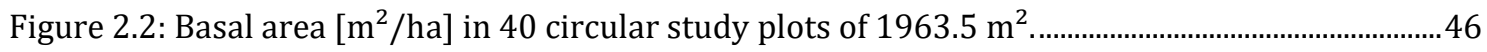

Figure 2.3: Conceptual framework of land-use history for tropical agroforests including possible

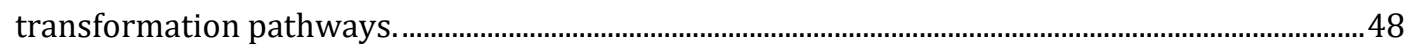

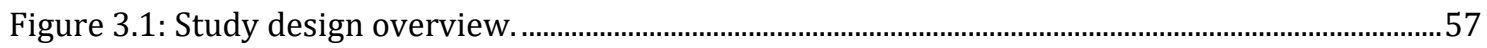

Figure 3.2: Plot-level bird species richness in seven prevalent land-use types in north-eastern Madagascar. .62

Figure 3.3: Total number of bird species (gamma-diversity) and number of species per endemism level across all plots $(\mathrm{N}=80)$ and in each land-use type. . .63

Figure 3.4: Bird species composition across seven land-use types in north-eastern Madagascar.....65

Figure 4.1: Study area, study design and land-use types. . .76

Figure 4.2: Temporal variation of the Acoustic Complexity Index (ACI), the Acoustic Diversity Index (ADI), the inverse Acoustic Evenness Index (1-AEI) and Acoustic Entropy $(\mathrm{H})$ for the different land-use types. . .82 
Figure 4.3: Variation of the Acoustic Complexity Index (ACI), the Acoustic Diversity Index (ADI), the inverse Acoustic Evenness Index (1-AEI) and Acoustic Entropy (H)

Figure 4.4: Correlation between bird species richness and the Acoustic Complexity Index (ACI), the Acoustic Diversity Index (ADI), the inverse Acoustic Evenness Index (1-AEI) and Acoustic Entropy $(\mathrm{H})$ for the different land-use types.

Figure 4.5: Relative variable importance explaining differences in Acoustic Complexity Index (ACI), the Acoustic Diversity Index (ADI), the inverse Acoustic Evenness Index (1-AEI) and Acoustic Entropy (H) 85

Figure 5.1: Study design overview. .95

Figure 5.2: Plot-level amphibian and reptile species richness across seven land-use types. 100

Figure 5.3: Encounter-based accumulation curves for amphibians and reptiles. 101

Figure 5.4: Species composition across seven land-use types. 103

Figure 6.1: Photos of forest- and fallow-derived vanilla agroforests. 115

Figure 6.2: Results of a linear mixed effect model explaining green vanilla yield [kg ha-1 $\left.\mathrm{yr}^{-1}\right]$ across 209 agroforests.

Figure 6.3: Results of two linear mixed effect models explaining canopy cover [\%] and canopy height [m] across 209 vanilla agroforests.

Figure 6.4: Canopy cover dynamics in the agricultural landscape in a $2 \mathrm{~km}$ circle around centres of 60 focal villages

Figure 7.1: Species richness across land-use types (boxplots) and with increasing vanilla yield (scatterplots) in a Malagasy agricultural landscape. 134

Figure 7.2: Endemic species richness across land-use types (boxplots) and with increasing vanilla yield (scatterplots) in a Malagasy agricultural landscape. 136

Figure 8.1: Hypothesized transformation outcomes for ecosystem functions and biodiversity along the predominant land-uses trajectory in north-eastern Madagascar. 158

Figure 8.2: Parallel coordinate plots displaying key characteristics of one focal land-use type in relation to the other six predominant land-use types in north-eastern Madagascar.. 160

Figure 8.3: Multidiversity, endemic multidiversity and multifunctionality at stages along a land-use trajectory in north-eastern Madagascar. 161

Figure 8.4: Comparison of biodiversity, endemic biodiversity, ecosystem functions, and agricultural productivity along a land-use trajectory in north-eastern Madagascar. 163

Figure 10.1: Overview of findings concerning biodiversity and ecosystem services across the seven predominant land-use types in north-eastern Madagascar. 206 


\section{Tables}

Table 2.1: Characteristics of forest-derived and open-land-derived agroforests with a comparison between the two.

Table 3.1: General linear models (GLMs) explaining non-endemic species richness and endemic species richness.

Table 5.1: Amphibian and reptile species diversity for all land-use types and separated per land-use type showing the observed and extrapolated species diversity.. 102

Table 7.1: Management and environmental determinants of vanilla yield/ha.. 137

Table 7.2: Overview of effects of environmental and management variables on yield and species richness across 7 taxa. 


\section{Introduction}

\subsection{Land-use change as a key driver of biodiversity loss}

Life on earth is threatened by human activities, namely land-use change, climate change, pollution, and invasive species (IPBES 2019). Importantly, these stressors are not independent but often have cumulative effects on our environment (Hof et al., 2011). On top of this, responses of the environment to the stressors may not be linear (Schneider, 2004). Instead, we might face non-reversable regime shifts (Cooper et al., 2020; Trisos et al., 2020) and collapses of complete ecosystems, if tipping points are passed (Lovejoy \& Nobre, 2018). Land-use change may also lead to 'ecosystem decay', a process where species decline faster than would be expected by habitat loss alone (Chase et al., 2020). This highlights the case for coordinated action in addressing various stressors to safe biodiversity.

The Sustainable Development Goals have been designed and approved by the United Nations to halt negative impacts on the environment and to improve the well-being of humankind (United Nations, 2015). The seventeen goals aim to ensure the welfare of humans as well as the environment, with the two goals Life below water and Life on land directly referring to biodiversity (United Nations, 2015). Importantly, the goals cannot be reached independently and should be approached in an integrated way (Blanc, 2015).

However, key knowledge gaps to achieve the Sustainable Development Goals remain, particularly concerning the effectiveness of policies to promote desired socio-ecological change, and relating to the feedbacks between social and ecological systems (Mastrángelo et al., 2019). These knowledge gaps are also relevant to land-use change, the largest driver of the global biodiversity crisis (IPBES 2019). 


\subsubsection{Drivers of land-use change}

Land-use change can be divided into two principal processes: Land cover conversion, i.e. the transformation of one land cover type into another, and land-cover modifications, i.e. changes within one land-cover type, such as agricultural intensification within arable land (Lambin et al., 2003). In historically forested landscapes, the first land cover conversion signifies an abrupt and massive change: at so-called agricultural frontiers (or forest frontiers), forest is converted into agricultural land. Importantly, most agricultural frontiers are nowadays in the tropics (Meyfroidt \& Lambin, 2011) where forest transformation happens through two principal processes: large-scale deforestation for commodity production and shifting cultivation (Curtis et al., 2018).

Large-scale deforestation for agricultural commodities such as oil palm and soy is responsible for $27 \%$ of global forest loss (Curtis et al., 2018). This figure does, however, vary geographically, and in Southeast Asia and Latin America, more than $60 \%$ of forest loss is attributed to large-scale deforestation. In Africa, in contrast, only $2 \%$ of forest loss can be attributed to this driver (Curtis et al., 2018).

The second principal process is shifting cultivation, which is globally responsible for $24 \%$ of forest loss (Curtis et al., 2018). Again, regional figures are hugely variable: in Africa, shifting cultivation is responsible for $93 \%$ of deforestation, whereas in Southeast Asia and Latin America, shifting cultivation is accountable for only around $20 \%$ of forest loss (Curtis et al., 2018). Shifting cultivation has become less important over time and is expected to continue to decrease in extent, yet 280 million hectares remain under shifting cultivation today (Heinimann et al., 2017), with the largest share in Africa.

Shifting cultivation is often portrayed as destructive, inefficient, and irrational, and policies promoting alternatives to shifting cultivation have been pushed by UN organisations (Mertz et al., 2009). Studies have shown, however, that shifting cultivation may well be a rational decision for tropical smallholder farmers (Mertz et al., 2009; van Vliet et al., 2012). Their actions are driven by responses to economic opportunities that are created through global forces (Lambin et al., 2001). Policies that aim to reduce forest loss through shifting cultivation thus need to put people at the centre and understand how their actions are embedded in the local, national and global context. 


\subsubsection{Mitigating the negative effects of land-use change on habitats, species and eco- system services}

One of the longest-standing mitigation approaches to the negative effects of land-use change has been the implementation of protected areas (Watson et al., 2014). Protected areas have lower rates of land-use change than surrounding habitats (Andam et al., 2008) and biodiversity therein is higher than outside (Gray et al., 2016). Protected areas are, however, not without pressures. Degradation of habitat within protected areas is common (Watson et al., 2014), particularly in regions with weak governance (Geldmann et al., 2019), questioning their value in the long run. Additionally, it is questionable for how long relatively small and isolated 'high-value habitat' inside protected areas can sustain biodiversity, given the lack of connectivity between protected areas (Newmark, 2008).

It is thus unsurprising, that conservationists and landscape ecologists have advocated for biodiversity friendly human-dominated landscapes. While running under different names, various concepts (e.g. countryside biogeography (Daily, 1997), wildlife-friendly farming (Tscharntke et al., 2012), conservation biogeography (Whittaker et al., 2005); critically reviewed in Driscoll et al., 2019) advocate for a reconciliation of farming with biodiversity and aim to study how to do so best. Their common aim is to create knowledge on how to maintain or create habitat for species that can live in human-dominated landscapes and also to improve connectivity between high-value habitats respectively protected areas. At the same time, such landscapes should also provide resilient livelihoods to people (Daily, 1997).

Tightly linked to these concepts is the land sharing vs. land sparing debate (Phalan et al., 2011); one of the most intensive debates landscape ecologists have ever fought. Advocates of land sparing effectively postulate that intensive farming on little land combined with the sparing of high-value habitat is better for biodiversity than farming the same amount of food less intensively on more land in a biodiversity-friendly way (Edwards et al., 2015). Advocates of land sharing, on the other hand, postulate the opposite (Fischer et al., 2011). Modelling approaches typically find land-sparing to be superior to land-sharing (Edwards et al., 2015; Finch et al., 2020), particularly in the tropics (Lee et al., 2014). Yet land-sparing commonly fails as the increasing yields may not necessarily spare land for nature, but rather drive the expansion of profitable high yield farming (Ewers et al., 2009), threatening the habitat that should have been spared. Over the last years, it has, however, become clear that researchers may have discussed a false dichotomy: Large protected zones of primary vegetation as well as diverse agricultural landscapes may be necessary to sustain biodiversity (Grass et al., 2019; Kremen, 2015). Furthermore, various local factors should be considered 
in policies (Baudron \& Giller, 2014), among them land-use history (von Wehrden et al., 2014) and governance (Ceddia et al., 2014). As noted by Bennett (2017), addressing an 'artificial choice' between one and the other is likely resulting in an 'artificial solution' that will not be to the benefit of society.

\section{Box 1: My PhD journey - Interdisciplinarity and diversity}

Six boxes in the introduction and synthesis parts of this thesis give a different perspective on my PhD - a bit away from the science, I describe selected aspects of this four-year journey.

Investigating the topic of vanilla cultivation and land-use change in north-eastern Madagascar from within one discipline is doomed to fail - too manifold and interlinked are the challenges and possible approaches to improve the situation locally. A broader perspective is hence needed. Within the Diversity Turn in Land Use Science project, we worked together in an international interdisciplinary team ranging from Ecology over Agricultural Economics to Sociology - thus incorporating many disciplines. This enabled me to collaborate, learn and work with a group of thirteen PhD students, two Postdocs and various MSc students. As one might imagine, the large team and interdisciplinary approach offered opportunities and challenges alike. The largest opportunity to me was to learn from each other. I recall my colleague Viviana who now uses 'ecologists vocabulary' as an economist, and us ecologists learning about choice experiments and behavioural economics. This led to a broader understanding of the vanilla value chain and the land-use dynamics in the study region.

It did, however, also lead to challenges. Sometimes the way different disciplines 'work' led to discussions and conflicts about how to approach our research, a phenomenon that is not uncommon in interdisciplinary team (Kluger \& Bartzke, 2020). Discussions emerged, for example, about the selection of study villages or the compensation (respectively the lack thereof) of study participants. Over time we grew together as a team and managed to find solutions to almost all of these problems, but the process also showed how difficult this can be.

The interdisciplinary approach was further amended and facilitated by the large diversity of backgrounds we were from. Nonetheless, the different 
working conditions we did find ourselves in caused some challenges and inequalities: the salaries paid to those employed by the University of Goettingen included social benefits and security, while the working agreement with the Malagasy colleagues was informal and only included a basic salary. The different working conditions also meant that we lived on very different budgets during fieldwork, making it sometimes difficult to find compromises that worked for everyone. Overall, the diversity of backgrounds did, however, contribute to the success of the project. Everyone had strengths and weaknesses in different areas, leading to a team which grew together by helping each other out.

To put it short, the interdisciplinarity and diversity of our team led to a successful completion of the project and was a pre-requisite for the transdisciplinary approach we took (see Box 2).

\subsection{Trade-offs between biodiversity, ecosystem services, and yields in tropical smallholder agriculture, with a focus on agroforests}

\subsubsection{Importance of tropical smallholder agriculture}

Smallholder agriculture produces $70 \%$ of food calories in the developing world, despite only accounting for $30 \%$ of agricultural land (Samberg et al., 2016). The dependence on smallholders to produce key internationally traded commodities is also high: $80 \%$ of coffee (Fairtrade International, 2020) and cacao (Duguma et al., 2001) are produced by smallholder farmers. Smallholder agriculture is, however, underrepresented in agroecological research: Steward et al. (2014) found in a meta-review that only $12 \%$ of studies on pollination and biological control have been conducted in smallholder agriculture. This seems particularly problematic given that smallholder farmers are more likely to be negatively impacted by climate change (Cohn et al., 2017), making research into adaption strategies necessary.

Smallholder agriculture in the tropics typically results in diverse mosaic landscapes. These have been postulated as a way to maintain biodiversity and ecosystem functions (Frishkoff et al., 2019; Mendenhall et al., 2011; Ranganathan et al., 2008). Over the past twenty years, a considerable amount of research has gone into investigating biodiversity (reviewed in Perfecto \& Vandermeer, 2008) and ecosystem services (reviewed in Rasmussen et al. 
(2018) and Thorn et al. (2016)) in such landscapes. However, the long-term stability of tropical mosaic landscapes has been questioned because inherent intensification incentives may drive land-use change and land-use intensification (Tscharntke et al., 2012). Additionally, questions of extinction debts (Kuussaari et al., 2009) in 'young' tropical landscapes remain largely unresolved (but see Hylander \& Nemomissa (2017) for an exception), further questioning whether current day patterns of biodiversity are stable in the long run. A combination of the two factors may drive the long-term decline of biodiversity in tropical agricultural landscapes (Şekercioğlu et al., 2019; Socolar et al., 2019).

\subsubsection{Trade-offs between yields, ecosystem services and biodiversity in tropical ag- riculture}

Diverse smallholder-dominated landscapes are under intensification pressure, threatening the provisioning of ecosystem services and habitat for biodiversity (Bommarco et al., 2013; Tscharntke et al., 2005). This effect is typically caused by trade-offs between yields respectively profit on the one hand, and ecosystem services and biodiversity on the other.

Such trade-offs exist between land-use types, driving land-use change towards more profitable but less biodiverse and less multifunctional land-use types. For example in Sumatra, Indonesia, profitable oil palm plantations are replacing less profitable rubber plantations, at the expense of certain ecosystem services and species (Grass et al., 2020). However, trade-offs also exist within land-use types, driving intensification within fields (Rasmussen et al., 2018). For example in cacao agroforest, higher yields under low to medium shade typically drive a reduction in shade cover, to the detriment of ecosystem services and biodiversity (Jha et al., 2014).

If aiming for a land-sharing approach, i.e. combining agricultural production with biodiversity on the same land, mitigating trade-offs between yield and biodiversity is necessary to avoid agricultural intensification. One approach is sustainability certification, where farmers receive price premium under the obligation of following rules that should benefit the environment (Tayleur et al., 2017; Tscharntke et al., 2014). Evidence on the success of such schemes is mixed: according to a global synthesis of 24 studies (DeFries et al., 2017), 34\% of response variables showed positive outcomes, 58\% showed no significant differences, and $8 \%$ showed negative outcomes. One main criticism of sustainability certification is that it may promote business-as-usual (Bose et al., 2016). This is so partly due to selection bias: farmers who already follow rules pre-certification have little costs in joining but will naturally not change their management due to certification rules, limiting their positive impact 
(Blackman \& Rivera, 2011). Alternatively, selection bias may also stem from cooperatives or exporters, who can maximise their profits by certifying farmers who already have large produce, thereby excluding the smallest producers from benefits (Blackman \& Rivera, 2011; Blum et al., in prep.).

Alternatively, finding ways to farm crops without the here-discussed trade-offs - i.e. achieving high yields, high levels of ecosystem service provisioning, and high biodiversity on the same land - would offer opportunities for sustainable land-use without targeted incentives such as sustainability certification. Examples of such win-win situations are rare, but may be found in agroforestry systems (Clough et al., 2011).

\subsubsection{Tropical agroforestry as a chance for people and nature?}

Tropical agroforestry has been described as an opportunity for biodiversity-friendly farming (Bhagwat et al., 2008; Schroth, 2004). At the same time, agroforests may provide a bundle of ecosystem services (Jose, 2009) and may also be profitable for farmers (Garrity, 2004).

Traditionally, ecologists have compared structurally simple with structurally diverse agroforests (Moguel \& Toledo, 1999) and have found biodiversity and non-yield ecosystem services to generally increase with structural complexity of the shade-tree canopy (De Beenhouwer et al., 2013). However, agroforests change over time: many agroforests lose structural complexity over time, as farmers cut shade trees to increase yields (Beer et al., 1998; Jha et al., 2014; Tscharntke et al., 2011). Indeed, coffee (Perfecto et al., 2005) and cacao yields often increase when more sunlight is available (Blaser et al., 2018). On the long term, however, shaded agroforests may produce yields more reliably and for a longer period of time (Clough et al., 2009). Furthermore, studies have shown, that shade-grown coffee may be of higher quality (Muschler, 2001; Vaast et al., 2006), offering opportunities for farmers serving a premium market.

Despite these opportunities, intensification and specifically tree-cutting incentives prevail. To overcome these incentives, sustainability certifications have been designed to compensate farmers for lower yields and/or higher labour input in structurally complex agroforests (Perfecto et al., 2005; Tscharntke et al., 2014). Today, products that can be farmed in agroforestry systems are the agricultural commodities with the largest share of sustainability certification, reaching $24 \%$ for coffee, $14 \%$ for cocoa, and $12 \%$ for tea (Tayleur et al., 2017). Nonetheless, many agroforests are established inside forest, threatening forest-dependent tropical biodiversity (Ruf, 2001). Alternatively, agroforests may be established on 
historically forested open land, offering the opportunity to restore ecosystem services and biodiversity (Jagoret et al., 2012). A separation of agroforests based on their land-use history has, however, rarely been considered in agroforestry research and policy, despite its relevance (Chapter 2). Explicitly incorporating land-use history into agroforestry research thus represents a major research gap, as identified in chapter 2 and 'filled' in chapters 3-5 and 6-9.

In sum, the value of tropical agroforests for biodiversity is highly context specific and likely changing over time, making case studies across regions and crops necessary to understand emerging dynamics (Miller et al., 2020). Such knowledge may enable policy interventions that can contribute to a more sustainable management of tropical agroforests for people and nature alike.

\section{Box 2: My PhD journey - Transdisciplinarity}

The Diversity Turn in Land Use Science project was designed in a transdisciplinary way. Transdisciplinarity is defined as a critical and self-reflexive research approach that relates societal with scientific problems and which produces new knowledge by integrating different scientific and extra-scientific insights (Jahn et al., 2012). Putting this into practice was always a high aim and - while we tried our best - we did not always achieve our aims.

We kicked off our fieldwork in 2016 with a 'naïve' transdisciplinary phase: we had not the aim to collect data but to get a first grasp of the local context by talking to other researchers, local NGOs, vanilla exporters, and vanilla farmers. We did so as an interdisciplinary team of PhD students and Postdocs. This approach worked well to establish a common understanding of basic social, economic and ecological dynamics in the region. We ecologists new about price fluctuations of vanilla, and the economists knew about conservation challenges in the region.

Deriving concrete research questions from this common understanding has, however, proved more difficult. For example, one key question of farmers was 'How can we stop vanilla theft?'. Given the complexity of this question and its tight links to national governance questions, we soon realized, that we would not be able to answer the question. Similarly, farmers wanted us to investigate how they could handle Fusarium-induced root and stem rot in their vanilla agroforests. A question, we could not address, as no one in our group was a plant pathologist. Furthermore, 
many research questions and approaches were already pre-defined in the research proposal, limiting our flexibility.

Furthermore, the transdisciplinary approach also led to continuous exchange with farmers and stakeholders throughout the project. At annual stakeholder meetings, we communicated first results and discussed them with NGO exponents, vanilla exporters, and local government officials. At meetings with farmers in our focal villages, we presented the most important findings and engaged in interesting discussions on vanilla farming practices with the cultivators; a process that enhanced our understanding of the system as well.

In conclusion, our attempt to work truly transdisciplinary struggled because research goals and research questions were limited by what was possible to achieve, by the expertise of $\mathrm{PhD}$ researchers and supervisors, and by the frame of the research grant. I believe, however, that the approach still had value and strongly contributed to our research questions and study design. The process also enabled us to embrace standards for ethical research in Madagascar (Wilmé et al., 2016).

\subsection{Natural history, land-use change, and conservation in Madagascar}

Through my PhD, I addressed research questions on drivers and impacts of land-use change in north-eastern Madagascar. To embed this research in the wider literature and local context, I describe key aspects of the natural history, past and present land-use change and ongoing conservation action in Madagascar.

\subsubsection{Natural history}

Whether Madagascar can be truly described as an island remains contested as one could argue that Madagascar qualifies as a 'mini continent' (de Wit, 2003). In favour of this argument, one can list 300'000 years of isolation from Africa and Asia (de Wit, 2003), the diversity of climatic zones (Donque, 1972), the variety of habitats (Du Puy \& Moat, 1996) on small scale (Figure 1.1), and the biogeographic origin of the Malagasy flora and fauna, which is partly autochthone, partly roots in Africa, and partly immigrated from Asia (Wilmé et al., 2006).

This manifold of origins and the long isolation has led to an exceptional biodiversity in Madagascar. While the total species richness lacks behind other tropical areas (Mammals, amphibians and birds: Grenyer et al., 2006; Plants: Kreft \& Jetz, 2007), the Indian island 
nation counts as a biodiversity hotspot (Myers et al., 2000), due to the high levels of endemism and threat. Unparalleled is also the micro-endemism, i.e. the endemism within a very restricted area (Wilmé et al., 2006). Endemism reaches 92 - 100\% for terrestrial vertebrates and $52 \%$ and $60 \%$, respectively, for birds and bats (Goodman \& Benstead, 2005). Invertebrates and plants also show high levels of endemism (Goodman \& Benstead, 2005).

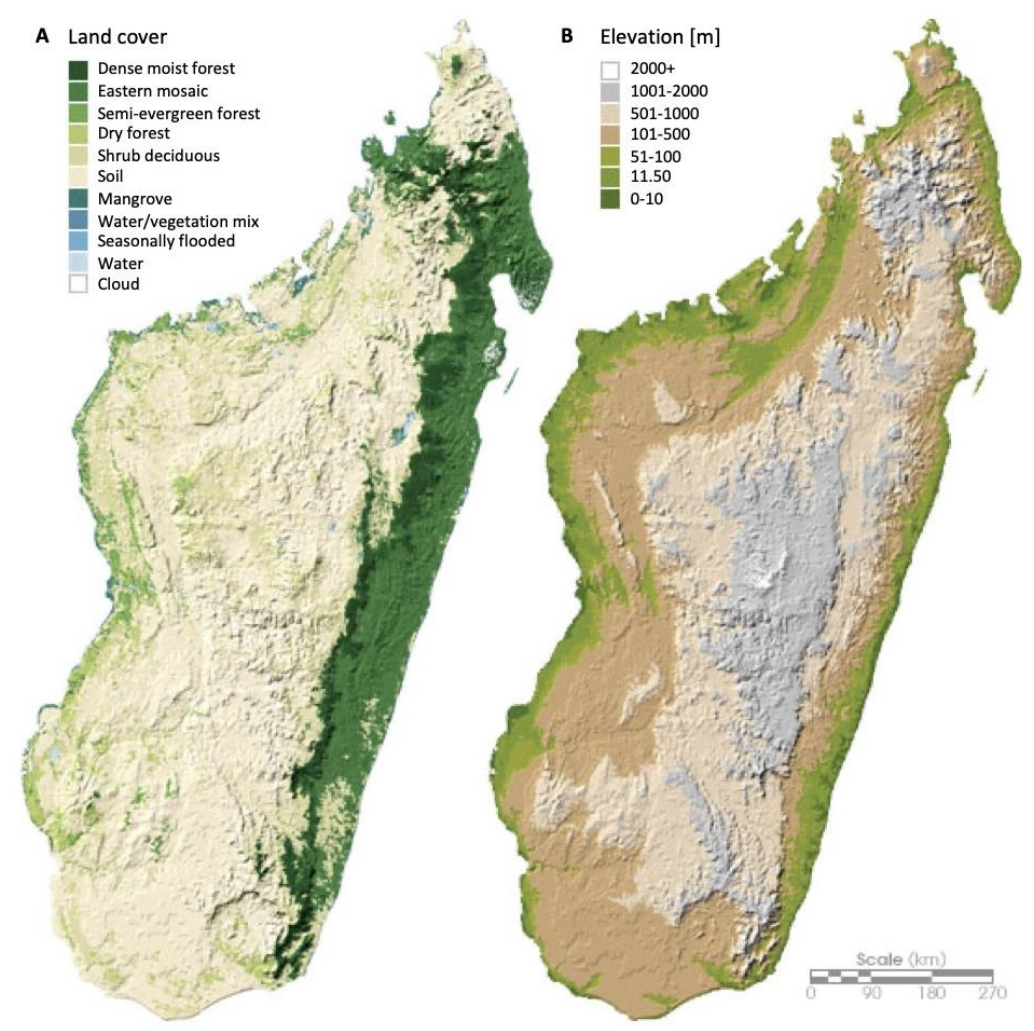

Figure 1.1: Land cover (A) and elevation (B) in Madagascar. A: The central highland of Madagascar is largely deforested and covered with grassland on the hills and rice paddies in the valleys (McConnell et al., 2015). Towards the west, savannas, of at least partially natural origin (Bond et al., 2008; Solofondranohatra et al., 2020; Vorontsova et al., 2016), occupy extensive areas. Western Madagascar is dominated by a mosaic of deciduous dry forest, agriculture, fallow land, and wetlands (Scales, 2011). Southern Madagascar is home to deciduous thorny shrubland (Du Puy \& Moat, 1996). The eastern part of the island is characterized by rainforest which is now limited to isolated blocks within an agricultural landscape (Vieilledent et al., 2018). The north of Madagascar is a mosaic of savannah, agriculture, deciduous dry forest, and rainforest (Quemere et al., 2012). These patterns are largely shaped by elevation (B), geology, rainfall, and hundreds of years of human influence (Du Puy \& Moat, 1996). Source: NASA, 2004.

\subsubsection{Early human presence and influence on forests and fauna}

The first traces of humans on Madagascar date back at least 2000 years before present (Douglass et al., 2019), but much debate surrounds the date of earliest human arrival to the 
island (Hansford et al., 2018). The impacts of humans on the forests and animals that occupied much of the land remained, however, rather limited until circa 1300 years before present (Burns et al., 2016). Subsequently, much of Madagascar's megafauna was lost within 200 years, most likely due to a combination of habitat loss and hunting (Godfrey et al., 2019). Over much of the time to follow, Malagasy people mainly settled in the central highlands and along the coasts (Randrianja \& Ellis, 2009). The transformation of the landscape in the central highlands and around coastal settlements was consequently most profound, while large areas of deciduous forest in the west, of spiny thicket in the south, and of humid rainforest on the eastern escarpment stayed intact until the late $19^{\text {th }}$ century (Jarosz, 1993).

\subsubsection{Agricultural expansion under French colonial rule}

In the late $19^{\text {th }}$ century, Madagascar was a nationally united kingdom under the rule of the central-highland Merina people (Randrianja \& Ellis, 2009). French colonial power seized control in 1896 (Randrianja \& Ellis, 2009), with the aim to exploit the resources the country had to offer. Thereafter, the exploitation of natural resources such as timber, gemstones, and minerals took its course while the production of export crops was intensified (Jarosz, 1993). To do so, each administrative region of the country was to focus on a specific crop (Correll, 1953): cocoa in north-western Madagascar, coffee in the central eastern region, clove in the Analanjirofo region - which even bears the Malagasy word for clove, i.e. 'jirofo', in its name - and vanilla in the north-eastern SAVA region (more on vanilla in section 1.4.2).

This exploitation of resources and the expansion of export-oriented agriculture had profound effects on the environment. The use of the most fertile land for export crops pushed farmers into shifting cultivation in eastern Madagascar (Jarosz, 1993), while state-orchestrated cash crop booms drove forest loss in the west (Scales, 2011). By 1953, towards the end of colonial times, Madagascar's forests only covered 27\% of the country (Vieilledent et al., 2018).

\subsubsection{Forest loss narratives}

Triggered by the sight of forest fires, erosion gullies, and silt-rich river runoff, environmentalists and researchers have often described Madagascar as a textbook example for environmental degradation (Bond et al., 2008; Kull, 2000). Tightly linked with this narrative is the notion that Madagascar was once occupied by a single contiguous forest - a myth that has recently been busted based on genetic data from lemurs (Quemere et al., 2012) and the natural history of Malagasy grassland (Bond et al., 2008; Solofondranohatra et al., 2020; Vorontsova et al., 2016). In short, deforestation and erosion are certainly a problem in 
Madagascar, but the long-standing notion of ' $90 \%$ forest loss' in Madagascar is certainly wrong (Scales, 2014b).

\subsubsection{Current day environmental threats}

Deforestation and land-use change are the most important drivers of biodiversity decline in Madagascar (Allnutt et al., 2008). Unlike in other tropical regions, secondary forest regeneration in Madagascar is extremely slow (Brown \& Gurevitch, 2004), adding to the urgency to halt old-growth forest loss.

Forest loss in Madagascar is mainly driven by smallholder agriculture, in line with trends across Africa but in contrast to other tropical regions (Curtis et al., 2018; Sy et al., 2019). In dry western and southern Madagascar, forest is typically burned to grow maize or peanuts (Vieilledent et al., 2020). After only a few years of cultivation, weed prevalence and dropping soil fertility lead to dwindling yields which prompt farmers to cut additional forest (Gay-des-Combes et al., 2017; Raharimalala et al., 2010). In humid eastern Madagascar, hill rice cultivation is the main driver of forest conversion (Styger et al., 2007; Zaehringer et al., 2015). Here, the shifting cultivation system responsible for much of the forest loss is called tavy (more on the system in 1.4.3).

Beside habitat loss, climate change is also predicted to negatively affect biodiversity in Madagascar, especially micro-endemic taxa (Hannah et al., 2008). However, land-use and climate change are not independent of each other but are interacting, magnifying the impact on flora and fauna (Morelli et al., 2020). Furthermore, climate change will also profoundly impact people's livelihoods (Harvey et al., 2014), possibly resulting in adaptation and migration, which could further threaten habitats and species.

Other key environmental threats in Madagascar are fuel wood extraction (Minten et al., 2013), selective logging of timber and precious woods (Patel, 2007; Rakotomanana et al., 2013), invasive species (Kull et al., 2014) and overexploitation and hunting (Razafimanahaka et al., 2012).

Underlying many of these direct threats is the difficult socio-economic situation many Malagasy people find themselves in. With a human development index of 0.52, Madagascar is on rank 162 of 189 countries evaluated (United Nations Development Programme, 2019), exemplifying the need to improve living conditions. Particularly in rural areas, where $63 \%$ of people live (Worldbank, 2020), the lack of economic alternatives often makes the exploitation of natural resource the only viable livelihood option (Minten \& Barrett, 2008). 
Blaming poor smallholder farmers as the sole responsible of environmental degradation is thus problematic. Numerous studies (Jarosz, 1993; Kull, 2000; Scales, 2011; Vieilledent et al., 2020) show that state policies, international market forces and urban elites have had a profound impact on rural land-use change in Madagascar, often actively promoting destructive activities. Furthermore, corruption jeopardizes many efforts that aim at improving the living conditions of Malagasy people and conserving the country's biodiversity (Gore et al., 2013). To have a long-lasting impact, interventions that address the above-described environmental threats thus need to take the socio-economic situation of people into account, while also tackling governance issues.

\subsubsection{Terrestrial conservation action in Madagascar}

Conservation in Madagascar has largely been reliant on a protected area approach (Rakotomanana et al., 2013; Waeber et al., 2020). The first protected areas were established in the early $20^{\text {th }}$ century under French colonial rule (Waeber et al., 2020), with a steady increase in protected areas thereafter. Back in 2003, Madagascar's then president Marc Ravalomanana pledged to triple the countries' protected areas by 2008 (Gardner et al., 2018). Together with a surge of international conservation funding and a spark in eco-tourism, the commitment led to considerable optimism about the conservation of Madagascar's fauna and flora at the time (Norris, 2006). Consequently, annual deforestation rates fell to $0.4 \%$ by 2005 (Vieilledent et al., 2018). However, a political coup in 2009, which washed Ravalomanana away from power, led to years of instability. This instability led to an increase of rosewood logging (Schuurman \& Lowry II, 2009) and was also associated with an increase in deforestation (Vieilledent et al., 2018). Nowadays, much of the hope conservationists have expressed in the 2000s has vanished (Jones et al., 2019b; Waeber et al., 2016).

The focus on protected areas as the main conservation approach has further downsides: protected areas have often been designed and delimited in a top down approach (Gardner et al., 2018; Kremen et al., 2008) without consulting local communities, leading to non-compliance with newly established rules (Ormsby \& Kaplin, 2005). More broadly speaking, costs of protected area establishment to people living at the forest frontier have been largely neglected (Ward et al., 2018) and are not or insufficiently compensated for (Poudyal et al., 2018; Sommerville et al., 2010). Unsurprisingly, people who depend on the forest as a future land resource as well as for their daily needs will feel excluded and may continue their practices despite the changed legal status of the land. 
To overcome these challenges, a community-focused conservation approach is slowly gaining ground in Madagascar (Gardner et al., 2013). Results of Reduced Emission from Deforestation and Degradation (REDD+) schemes and of community forest management are, however, mixed (Rasolofoson et al., 2015; Toillier et al., 2011).

Today, Madagascar is at a cross road: leading experts on conservation in Madagascar have declared the current term of President Andry Rajoelina as 'the last chance for Madagascar's biodiversity' (Jones et al., 2019c). To seek this chance, they suggest five ways forward: firstly, improving the rule of law to counteract manifold negative consequences of crime for people and nature (Jones et al., 2019b). Secondly, investment in Madagascar's protected areas to warrant the safeguarding of biodiversity therein. Thirdly, ensuring that major infrastructure developments limit impacts on biodiversity. Fourthly, strengthening tenure over natural resources, such as forests, for people. And lastly, addressing the mounting fuel wood crisis, which threatens forests across the country (Jones et al., 2019c).

\section{Box 3: My PhD journey - Field work in Madagascar}

I spent roughly one fourth of my $\mathrm{PhD}$ time in Madagascar - overall a bit more than a year. The experiences I made in this country will profoundly influence me for a long time to come.

I was lucky enough to spend time in Madagascar before my PhD started. Back in 2014, I had the opportunity to attend a field course organized by the Tropical Biology Association in Kirindy Forest, western Madagascar. During the four weeks, I not only learned about tropical ecology and Malagasy wildlife but also saw how fieldwork in the country could be like. During the PhD two years later, I learned however, that working on a field station in a forest is very different to working in villages.

The challenges were manifold. Travels from our base in the provincial capital, Sambava, to the villages took often half a day on bumpy roads, already requiring much energy. On arrival, we would try to meet all involved farmers before any activity could start. This process, walking around in the villages and knocking on doors, was tedious but necessary to cultivate the relationships with all involved landowners. After having met everyone, we often had dinner with our host family in the village, before going to bed in the hosts' home. 
Early the next day, we would leave for the first point counts, often wading through muddy paths, fast flowing streams, or brown rivers, with the aim to reach our plots; some an hour away. This combination - maintaining relationships with landowners and data collection in difficult-to-access plots - would go on for the week before we returned to Sambava, where we unpacked our stuff, charged batteries, wrote emails, packed again, and, occasionally, would have time for a swim in the nearby Indian Ocean.

The openness of farmers and the way we were welcomed as outsiders in the village was, however, remarkable. Farmers let us visit their agroforests, let us measure vanilla yields, and patiently answered our questions. And on departure, they would fill the car (or canoe!) with fresh avocado, litchi, or coconut.

Nonetheless, maintaining such a field work pace over weeks was only possible thanks to my Diversity Turn colleagues from around the world. Thank you!

\subsection{Study context}

\subsubsection{Natural history and conservation in north-eastern Madagascar}

North-eastern Madagascar forms part of the eastern escarpment of Madagascar which is biogeographically characterized by humid rainforest (Du Puy \& Moat, 1996). The region is, even for Malagasy standards, particularly biodiverse (Brown et al., 2014; Carrasco et al., 2020) and a global hotspot of threatened species richness (Grenyer et al., 2006). Conservationists aim to protect this outstanding biodiversity through several large protected areas that cover the region. These are namely Masoala National Park, Marojejy National Park, Makira Natural Park, Anjanaharibe-Sud special reserve, and the COMATSA corridor, linking the latter three (UNEP-WCMC and IUCN, 2020). Masoala and Marojejy National Park form furthermore part of a World Heritage site (UNEP-WCMC and IUCN, 2020). Both parks' interiors are also scored as forests with high ecosystem integrity (Grantham et al., 2020). Interestingly, the north east has retained more forest cover than the remaining eastern escarpment (Vieilledent et al., 2018). However, in the north-eastern SAVA region, 52\% of forest cover was lost between 1953 and 2014 as shown in a MSc thesis I supervised (Ferreira Arruda, 2018). The data also shows that between 2010 and 2014 the region lost $0.95 \%$ of forest cover per year. Importantly, this loss is driven predominantly by smallholder shifting cultivation resulting in highest deforestation rates in difficult-to-access areas around remote 
villages (Ferreira Arruda, 2018). This land-use transition has resulted in a smallholder mosaic landscape characterized by shifting cultivation, rice paddies, and agroforestry (Llopis et al., 2019).

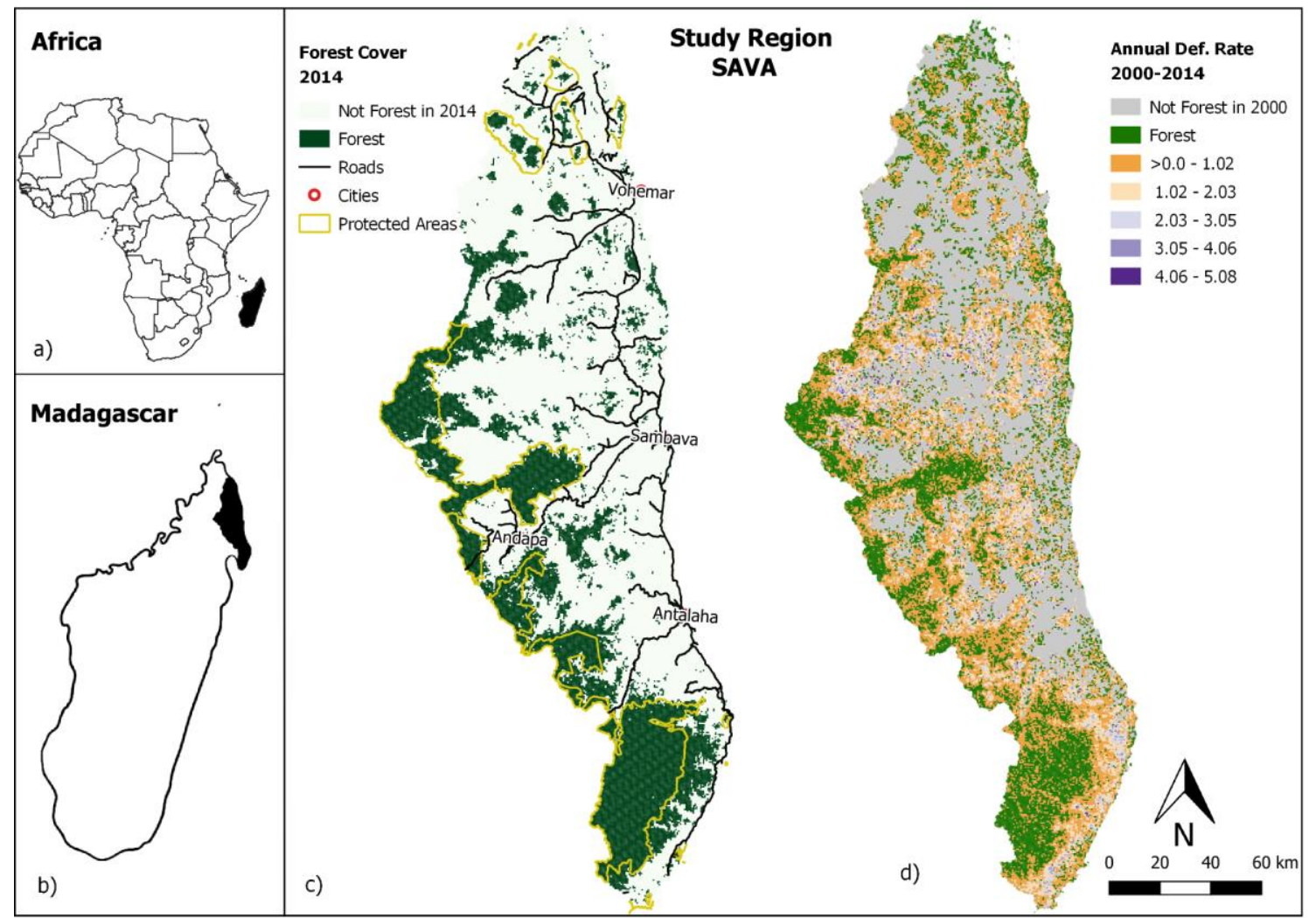

Figure 1.2: Maps of the study region from Ferreira Arruda (2018) based on data of (Vieilledent et al., 2018) aggregated into $600 \mathrm{~m} \times 600 \mathrm{~m}$ grid cells. a) The island of Madagascar off East Africa. b) SAVA region located in north-eastern Madagascar. c) Forest cover of the SAVA region in 2014. Note the concentration of remaining forest inside of protected areas. d) Annual deforestation rates from 2000 to 2014 inside each grid cell. Green grid cells were forested in 2000 and 2014 and did not experience any deforestation. Deforestations also occurred in the periphery of the protected areas.

\subsubsection{Vanilla and its importance in north-eastern Madagascar}

Vanilla planifolia is the only one of more than 20'000 species of orchids that is farmed commercially for its fruits (Havkin-Frenkel \& Belanger, 2018). In its native Central American range, the hemi-epiphytic orchid climbs up rainforest trees to flower in the canopy (Correll, 1953). After being pollinated by solitary bees of the Eulaema genus (Lubinsky et al., 2006), vanilla flowers develop into a single green fruit which splits open from the bottom end to spread the tiny seeds roughly nine months after pollination (Van Dyk et al., 2014). Vanilla seeds are then dependent on mycorrhiza fungi which enable germination and growth (Alomia et al., 2017). 
Looking after a plant up in the canopy would, however, be unhandy for farmers. They have thus come up with a way to grow long vanilla vines closer to the ground. By looping the vine up and down a support tree or an artificial support structure (Fouché \& Jouve, 1999), vanilla vines can reach dozens of meters in length, without being out of reach for humans (Correll, 1953). This farming technique facilitates care, pollination, and harvest.

A critical step in vanilla farming is hand pollination. Discovered most likely more than once (Arditti et al., 2009), hand pollination is necessary in the native and introduced ranges of Vanilla planifolia, to achieve economically viable yields (Borbolla-Pérez et al., 2017; Correll, 1953). The easiest way to achieve pollination is to press anthers and stigma of the same flower together (Arditti et al., 2009), thereby self-pollinating each flower. The resulting fruits are harvested green and require curing to enable storage and export. During the curing process, the green fruits are dipped in hot water and thereafter sun-dried for several weeks (Havkin-Frenkel \& Belanger, 2018), allowing them to develop their characteristic black colour and the aroma they are praised for.

As vanilla naturally grows in forests, it comes as no surprise that the orchid requires a certain level of shade to thrive. Optimum shade levels for vanilla farming are largely unknown, but intermediate shade levels of 50-60\% have been advocated (Havkin-Frenkel \& Belanger, 2018). Shade may be either provided by shade nets, that are spanned across the vanilla plantations (Shade-houses; Barrera-Rodríguez et al., 2009), or by combining vanilla vines with trees in agroforestry systems (Barrera-Rodríguez et al., 2009; Correll, 1953; Hending et al., 2018). Artificially-shaded and tree-shaded systems parallelly occur in many vanilla cultivation countries, but agroforestry systems seem overall more common (BarreraRodríguez et al., 2009; Havkin-Frenkel \& Belanger, 2018), SI Chapter 6).

With roughly $40 \%$ of global produce, Madagascar is the largest producer of vanilla in the world (FAO, 2020) and has been so since colonial times (Correll, 1953). Specifically, the north-eastern SAVA region has been designated as the vanilla region by French colonial power (Correll, 1953), and the region maintains its role as the 'vanilla region' to the current day (Hänke et al., 2018). Here, vanilla is farmed almost exclusively by smallholder farmers in small agroforests of typically less than one hectare and without the use of pesticides or fertilizers (Chapter 6). Farmers work the agroforest with family labour (Hänke et al., 2018) and an average rural household in the region sells around $50 \mathrm{~kg}$ of green vanilla per annum (Hänke et al., 2018). The trade is organised by a complex network of middlemen, traders, preparators, and exporters who trade both green and cured black vanilla (Hänke et al., 2018; Neimark et al., 2019). 
Vanilla is also traded under sustainability standards (Brownell, 2010), which aim at making vanilla farming more environmentally friendly and/or at ensuring adequate prices for farmers (International Trade Centre, 2019). In practice, the enforcement of sustainability standards requires vertically integrated value chains, as the convoluted non-vertically integrated trade with many middleman and traders makes source tracing of produce impossible (Blum et al., in prep.). However, farmers who have little vanilla produce do not normally get integrated, excluding the most vulnerable farmers from the benefits the sustainability standards may provide (Blum et al., in prep.; Hänke et al., 2018).

A price boom from 2012 to 2019 on the international vanilla market (Aust \& Hachmann (Canada) Ltd, 2020; Hänke et al., 2018) has resulted in the extension of vanilla farming in the region (Andriatsitohaina et al., 2020; Llopis et al., 2019), raising questions on the sustainability of the practice. The high prices have also benefitted smallholder farmers, who managed to increase their assets (Hänke et al., 2018; Osterhoudt, 2020; Zhu, 2018). On the downside, the high vanilla prices have led to a spark of vanilla theft (Neimark et al., 2019) and accompanying mob justice, killing hundreds of alleged thieves (Osterhoudt, 2020). Beside pivotal importance as a cash crop, vanilla also serves as a source of pride to people in north-eastern Madagascar (Osterhoudt, 2014).

\subsubsection{Land-use trajectories in north-eastern Madagascar.}

We identified seven prevalent land-use types in the study region. Old-growth forest are the last large contiguous parts of rainforest that formerly covered the study area. We decided to term those as old-growth forest, rather than primary forest, as some level of disturbance, like hunting and selective logging, occurs in parts of these forests (Patel, 2007). Forest fragments lie scattered throughout the study area and have resulted from old-growth forest fragmentation. Forest fragments are heavily used for timber and firewood extraction and other natural products. Few large trees remain. Herbaceous fallows, in Malagasy called 'matrangy', are part of the shifting cultivation cycle for hill rice production. Within two years, first woody plants emerge on herbaceous fallows and without further intervention, this succession on herbaceous fallows results in woody fallows, or 'savoka' in Malagasy. These are characterized by a mix of herbaceous plants, shrubs, small trees and occasionally bamboo. We further identified irrigated rice paddies, or 'horoka' in Malagasy, as an important land-use type. These are mostly situated in floodplains or along rivers.

Vanilla agroforests are another key land-use type in the area. Importantly, vanilla agroforests differ in land-use history. They are either established on fallow land, which was used 
for shifting hill rice cultivation. We termed those agroforests fallow-derived vanilla agroforests. The fallow-derived agroforests are established on historically forested open land and are thus 'open-land-derived' following the concept presented in Chapter 2. Alternatively, vanilla agroforests may be directly established inside forest fragments. We termed those forest-derived vanilla agroforests, following the land-use history concept presented in Chapter 2 .

Six of these seven land-use types are interlinked among each other along a distinct land-use trajectory (Figure 1.3). The exception to this is rice paddy, which is typically established in wetlands and alongside rivers, thus not forming part of the main trajectory.

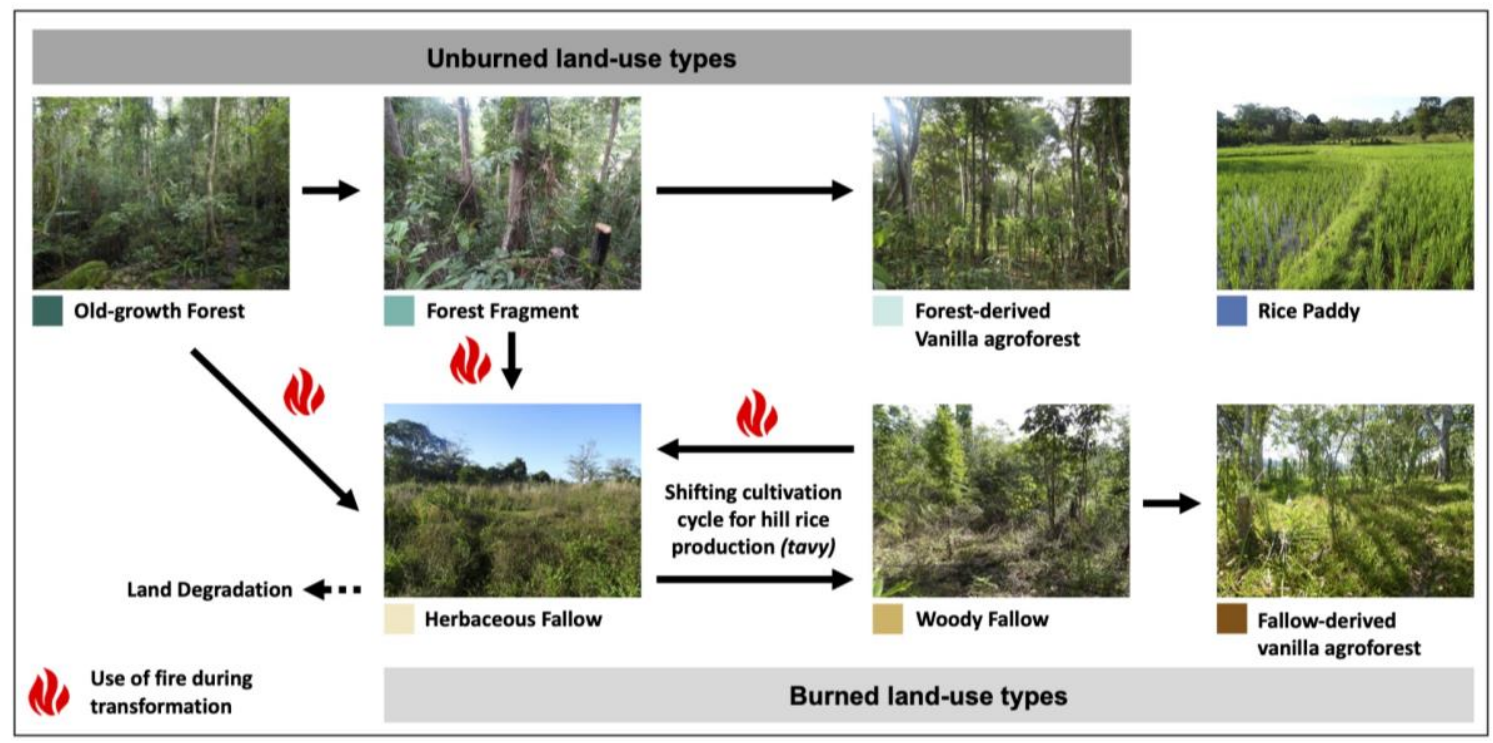

Figure 1.3: Possible transformation pathways from old-growth forest into different land-uses in north-eastern Madagascar. Old-growth forest is either fragmented into forest fragments or burned for shifting hill rice cultivation. Hill rice fields turn into herbaceous fallows after harvest. Over relatively short time, shrubs and small trees establish on herbaceous fallows resulting in woody fallows. Woody fallows may be burned again resulting in herbaceous fallows or, alternatively, may be converted into vanilla agroforests established on fallow land, termed fallow-derived vanilla agroforests. However, vanilla agroforests are also established inside forest fragments, resulting in forest-derived vanilla agroforests. Lastly, we studied rice paddies, representing a potential alternative to shifting rice cultivation.

The here-described trajectory offers an excellent framework to investigate and discuss land-use change in the region (Chapter 8.18). Importantly, most land in the study area can be attributed to one of these predominant land-use types; secondary forest, pastures, and non-vanilla agroforests (e.g. clove, coffee, and cacao) are rare in the study area. 


\subsubsection{Study region and study design}

The Diversity Turn in Land Use Science project chose the central part of the SAVA region for as the study area. The annual rainfall is $2223 \mathrm{~mm}$ with a mean annual temperature of 24.0 ${ }^{\circ} \mathrm{C}$ (mean across 80 focal plots; data extracted from the CHELSA climatology (Karger et al., 2017). The potential natural vegetation is tropical rainforest (Du Puy \& Moat, 1996), but only 35\% of forest cover remains (Ferreira Arruda, 2018).

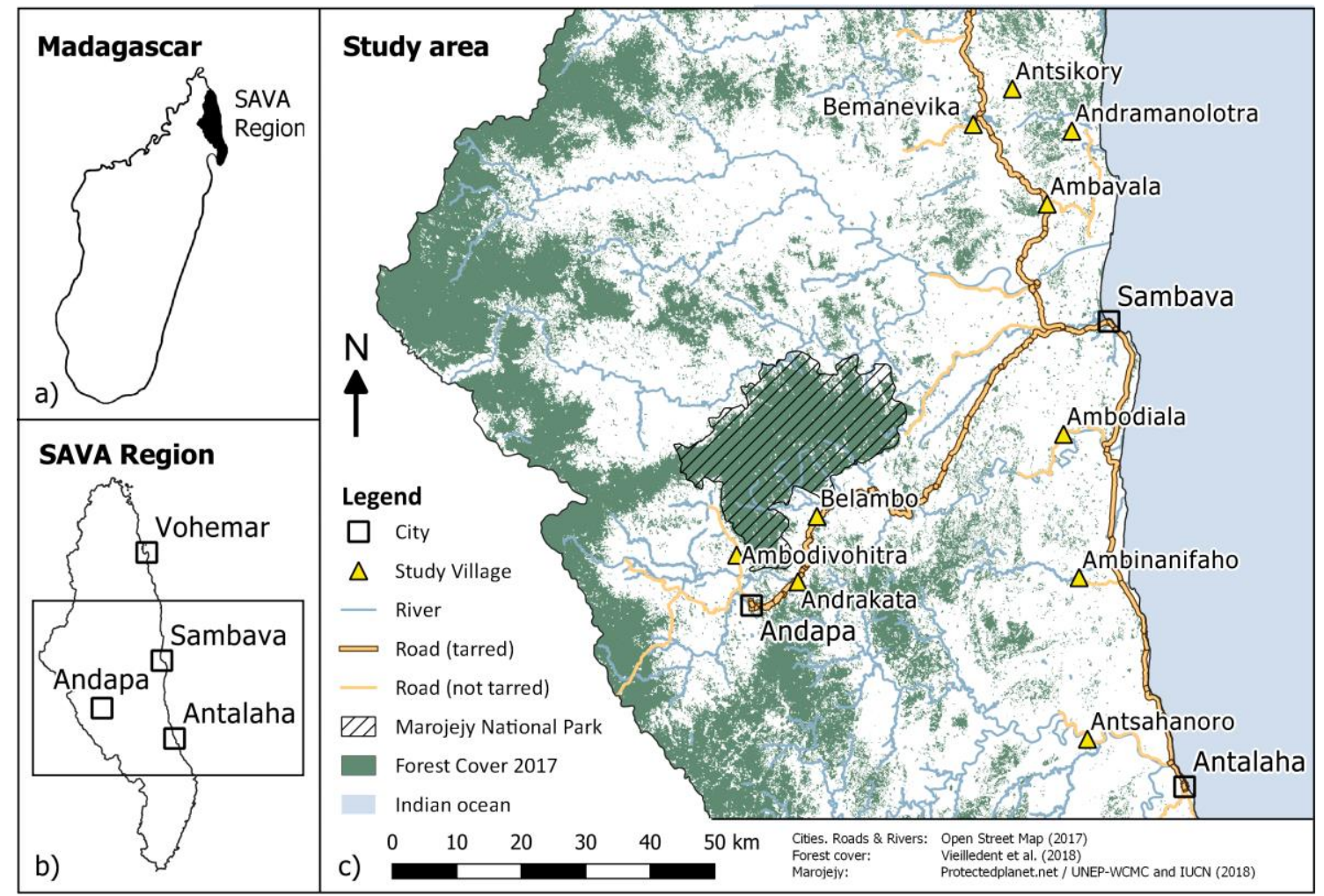

Figure 1.4: Study area in north-eastern Madagascar. a) The island of Madagascar off East Africa with the SAVA region. b) SAVA (Sambava-Antalaha-Vohémar-Andapa) region. c) Study area with forest cover 2017 (Vieilledent et al., 2018), roads, rivers and the three major cities Sambava, Antalaha and Andapa as well as the 10 study villages and Marojejy National Park where we collected data for chapters $3-5,7$, and 8 .

We first selected 60 villages in a stratified-random way from an initial sample of 323 villages that were within $10 \mathrm{~km}$ of roads within the study area (see Hänke et al., 2018 for details). For the majority of our data collection (Chapters 3-5, 7, \& 8), we chose 10 villages out of the 60. We did so using Google Earth, via which we selected villages that did not have coconut plantations, that had less than $40 \%$ water (sea, lake, or river), and that had forest fragments and shifting cultivation within a $2 \mathrm{~km}$ radius buffer around the village. This produced a list of 17 villages. If two of those 17 villages had overlapping $2 \mathrm{~km}$ buffers, we selected one of 
them randomly resulting in 14 remaining villages. We then visited those villages in random order to select plots. In one village, we did not find the land-use types for our study, and in one village people were not willing to cooperate with us. We thus visited 12 of the 14 villages and chose plots in 10 villages. We did not visit the remaining 2 of the 14 villages because we could already establish suitable plots in 10 villages, which was the targeted number of study villages a priori. See Figure 1.2 for a map of all ten villages.

We collected data for chapters 3-5, 7, and 8, in a space-for-time design (De Palma et al., 2018). This widespread design has the advantage to enable data collection in a comparatively short time window but relies on the assumption that space (i.e. different plots at the same time) are adequate to study changes over time (i.e. same plot after land-use transformation), an assumption that may be problematic (De Palma et al., 2018). Before-after-control-impact (BACI) designs or time series are more robust in detecting temporal changes (De Palma et al., 2018), but an implementation was not possible under given constraints. We did, nevertheless, collect data for Chapter 6 on different plots along a chronosequence, covering agroforests spanning from 0 to 88 years in age, elucidating some of the temporal dynamics we may have missed in the main study design.

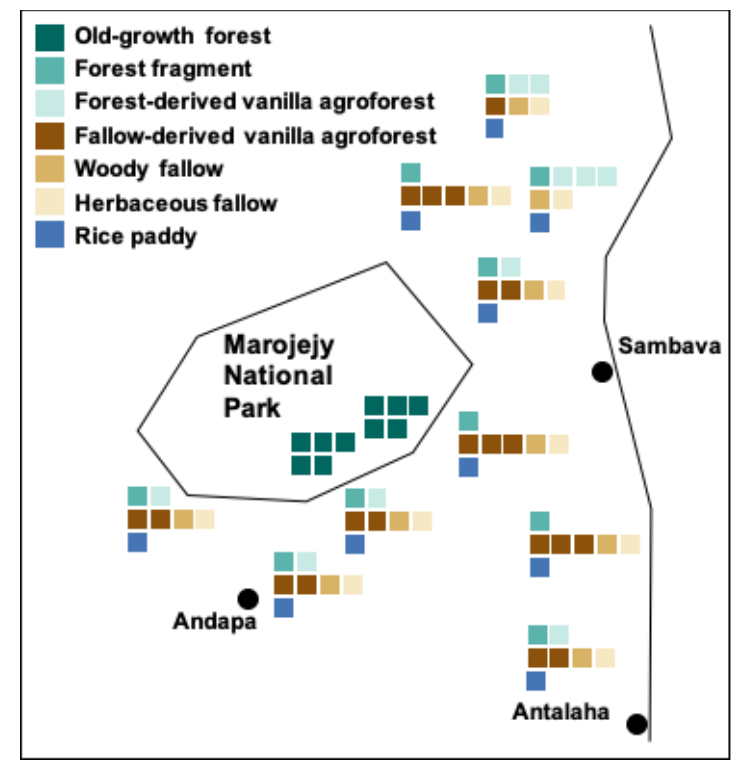

Figure 1.5: Semi-blocked study design with replicated land-use types across 10 villages and two oldgrowth forest sites where we collected data for chapters 3-5, 7, and 8. Each square represents one plot, squares are arranged in 12 blocks according to the site respectively village of the plot.

To control for spatial effects, we aimed to 'block' our plots by village. Specifically, we aimed at replicating each land-use type (except old-growth forest) in each of 10 focal villages (Figure 1.4), so that unknown village-level effect would affect all land-use types similarly 
(Figure 1.5). Due to the unbalanced occurrence of forest-derived and fallow-derived agroforests, we could not fully realize this design for vanilla agroforests, which we had initially chosen along a canopy cover gradient (SI Chapter 3). Furthermore, old-growth forest did not exist in the villages, prompting us to select two sites of five plots each within Marojejy National Park. The design for Chapters 3-5, 7, and 8 can thus be described as a semi-blocked space-for-time design following De Palma et al. (2018).

\subsection{Research questions}

In this PhD thesis, I aim to address eight specific research questions:

- What are the implications of land-use history of tropical agroforests for biodiversity and ecosystem services? (Chapter 2)

- What are the implications of land-use history of vanilla agroforests in north-eastern Madagascar for biodiversity? (Chapter 3-5, 7 \& 8)

- What are the drivers of vanilla yields? (Chapter $6 \& 7$ )

- How are shade-trees influenced by vanilla agroforest age? (Chapter 6)

- What are the differences between the seven predominant land-use types of the study area in terms of biodiversity? (Chapter 3-5, \& 8)

- How can a land-use trajectory approach help to identify trade-offs and opportunities for sustainable land-use in Madagascar's vanilla landscape? (Chapter 8)

Those specific questions can be organised under two overarching questions:

- How to farm vanilla in a way that benefits nature and people alike?

- How to design policies that enable a sustainable land-use transformation in northeastern Madagascar?

Consequently, I have organised the synthesis of this thesis (Chapter 10) along these overarching questions. 


\section{Land-use history determines ecosystem services and conservation value in tropical agroforestry}

Dominic Andreas Martin, Kristina Osen, Ingo Grass, Dirk Hölscher, Teja Tscharntke, Annemarie Wurz, \& Holger Kreft

Contribution: Conceptualization, Data curation, Formal analysis, Investigation, Project administration, Validation, Visualization, Writing - original draft

Status: Published in Conservation Letters; https://doi.org/10.1111/conl.12740.

\subsection{Abstract}

Agroforestry is widely promoted as a potential solution to address multiple UN Sustainable Development Goals, including zero hunger, responsible consumption and production, climate action and life on land. Nonetheless, agroforests in the tropics often result from direct forest conversions, displacing rapidly vanishing and highly biodiverse forests with large carbon stocks, causing undesirable trade-offs. Scientists thus debate whether the promotion of agroforestry in tropical landscapes is a sensible policy. So far, this debate typically fails to consider land-use history, that is, whether an agroforest is derived from forest or from open land. Indeed, 57\% of papers which we systematically reviewed did not describe the land-use history of focal agroforestry systems. We further find that forest-derived agroforestry supports higher biodiversity than open-land-derived agroforestry but essentially represents a degradation of forest, whereas open-land-derived agroforestry rehabilitates formerly forested open land. Based on a conceptual framework, we recommend to 1) 
promote agroforestry on suitable open land, 2) maintain tree cover in existing forest-derived agroforests and 3) conserve remaining forests. Land-use history should be incorporated into land-use policy to avoid incentivizing forest degradation and to harness the potential of agroforestry for ecosystem services and biodiversity.

Key words: biodiversity, cacao, carbon stocks, coffee, ecosystem services, forest-derived agroforestry, land-use history, open-land-derived agroforestry, rehabilitation, restoration

\subsection{Introduction}

Agroforestry is often promoted in global initiatives as a way to simultaneously address multiple UN Sustainable Development Goals (van Noordwijk et al., 2018). Among them zero hunger (goal 2), responsible consumption and production (goal 12), climate action (goal 13) and life on land (goal 15). Embedded it this context, the UN Decade on Ecosystem Restoration (2021-2030) emphasizes the opportunity to plant trees in agroforestry systems as a way to reverse land degradation and restore ecosystems, thereby contributing to climate change mitigation. However, the concept of agroforestry as an association of trees with crops or livestock on the same land (FAO, 2017) embraces a broad range of systems under different management schemes: many important perennial agroforestry crops, such as cacao or coffee, can be farmed underneath shade trees. Such agroforests may be established on open land or inside forest (Moguel \& Toledo, 1999), but in the latter case, they may contribute to the loss of highly diverse forests (Lewis et al., 2015; Schroth, 2004). This drawback stimulates debate over the conservation value of tropical agroforests and whether their promotion is indeed a sensible policy (Philpott \& Dietsch, 2003; Tejeda-Cruz et al., 2010).

Surprisingly, tropical agroforestry research has made few attempts to investigate how ecosystem functions and services as well as biodiversity differ among agroforests of contrasting land-use history, i.e. between forest- and open-land-derived agroforests. Instead, researchers have commonly compared structurally simple with structurally diverse agroforests (Moguel \& Toledo, 1999) and have found biodiversity and non-yield ecosystem services to generally increase with structural complexity (De Beenhouwer et al., 2013).

Here, we collate published information on socio-economic implications as well as ecosystem services and biodiversity in forest- and open-land-derived agroforestry and identify knowledge gaps. We find that forest-derived agroforests can be best described as a form of forest degradation while open-land-derived agroforests rehabilitate formerly forested open land (sensu Chazdon et al., 2016). We then argue that emphasizing land-use history in 
tropical agroforestry research and policy may foster biodiversity conservation and contribute to the safeguarding of ecosystem functions and services in tropical landscapes.

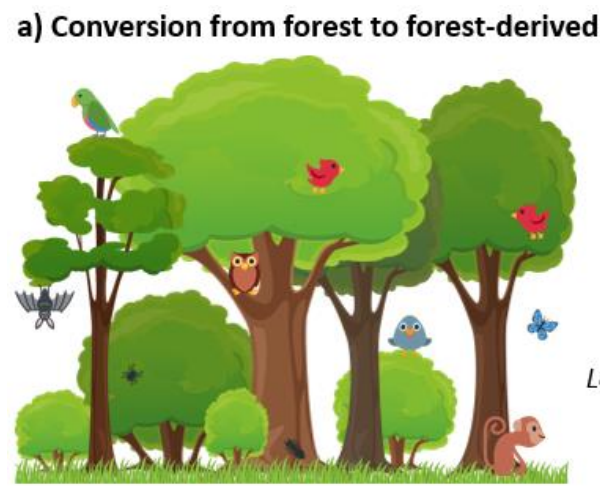

Tropical forest

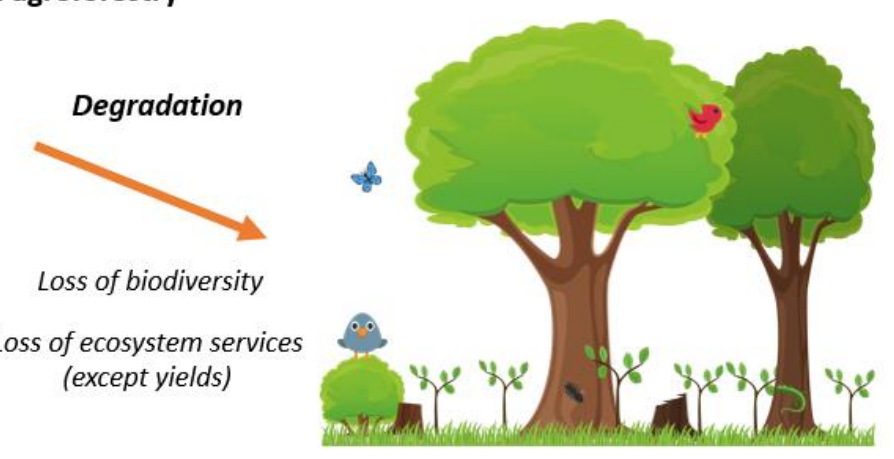

Forest-derived agroforestry

b) Conversion from open land to open-land-derived agroforestry

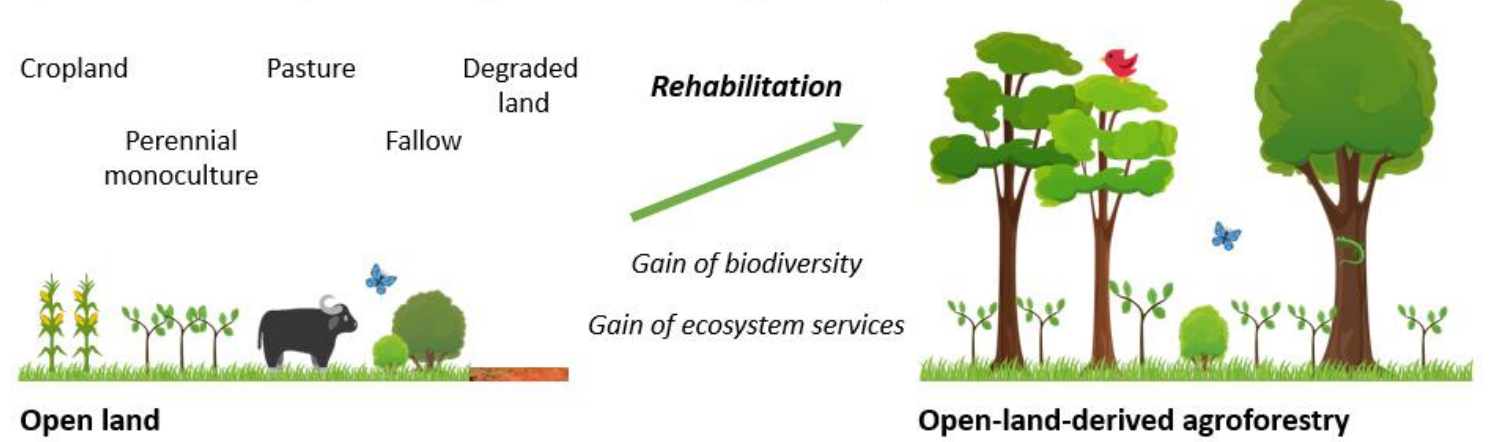

Figure 2.1: Concept of land-use history in agroforestry. a) Forest-derived agroforests are established by thinning the forest and replacing the understory with shade-tolerant agroforestry crops such as coffee, cacao, rubber, or vanilla, thereby representing a degradation of forest with overall losses of biodiversity and ecosystem services (except for yields). b) Open-land-derived agroforests are established by planting agroforestry crops alongside planted or naturally regenerating shade trees on suitable open land. Open-land-derived agroforestry consequently has the potential to rehabilitate cropland, perennial monocultures, pastures, fallow or degraded land, leading to gains in biodiversity and ecosystem services.

\subsection{Systematic review method}

We relied upon a recently published evidence and gap map (Miller et al., 2020), which systematically assessed the available literature on impacts of agroforestry on agricultural productivity, ecosystem services, and human well-being. We used their data extraction record (sup-0001) and filtered the results for the practice type 'Trees integrated with plantation crops' and 'Tropical' OR 'Multiple' ecoregions to match the scope of our paper. We subsequently excluded 23 studies that were either not in English (1 study), unavailable (2 
studies), situated outside the tropics (5 studies), or that investigated combinations of trees with annual crops (15 studies). We then systematically reviewed the remaining 98 papers and assessed whether authors had 1) described land-use history of all agroforestry types studied, 2) directly compared between forest- and open-land-derived agroforests, 3) directly compared agroforests and their former land-use (forest/open land), and 4) discussed the topic. We provide a table with extracted data as Supporting Information (SI Chapter 2).

\subsection{The importance of land-use history in tropical agroforestry}

Relatively few crops are shade-tolerant and may be planted directly inside forests (Figure 2.1). These crops include coffee, cacao, pepper, rubber or vanilla - all crops that can also be planted on open land, but that may partly require specific varieties or temporary artificial or natural shade. In our systematic review, $57 \%$ of studies did not describe the land-use history of focal agroforests and only $5 \%$ directly compared agroforests of contrasting landuse history. Of those studies which described land-use history, 50\% investigated forest-derived agroforests, while 38\% investigated open-land-derived agroforests and 12\% compared the two, emphasizing the importance of both kinds. Forest- and open-land-derived agroforests are commonly found alongside each other in mosaic landscapes across the tropics. In Sulawesi, Indonesia, 50\% of cacao plantations are forest-derived while the other half was established on open land (Rice \& Greenberg, 2000). In north-eastern Madagascar, 70\% of vanilla agroforests are open-land-derived, while 30\% are forest-derived (Hänke et al., 2018; more on vanilla agroforests in Box). The possibility to plant the same crops inside forest and on open land highlights the relevance of land-use history when studying such agroforestry systems. Furthermore, these crops are frequently farmed within forest landscapes in tropical biodiversity hotspots, accentuating the importance of biodiversityfriendly farming practices. 
Table 2.1: Characteristics of forest-derived and open-land-derived agroforests with a comparison between the two. Characteristics are separated into suitability of land for agroforest establishment, ecosystem functions and services, and vegetation structure and biodiversity. References are reviews where available. If no studies were available, we formulated hypothesis that are formatted in italics.

\begin{tabular}{|c|c|c|c|c|c|}
\hline \multicolumn{2}{|c|}{ Characteristic } & $\begin{array}{l}\text { Characteristics of forest-derived agro- } \\
\text { forests }\end{array}$ & $\begin{array}{l}\text { Characteristics of open-land-derived } \\
\text { agroforests }\end{array}$ & $\begin{array}{l}\text { Comparison between forest-derived } \\
\text { and open-land-derived agroforests }\end{array}$ & References \\
\hline \multicolumn{6}{|c|}{ Suitability of land for agroforest establishment } \\
\hline \multicolumn{2}{|c|}{ Land availability } & $\begin{array}{l}\text { Forest land may be the only land available } \\
\text { to farmers, particularly if their means to } \\
\text { purchase land are limited. }\end{array}$ & $\begin{array}{l}\text { Open land may be the only land available } \\
\text { at places without forest or where remain- } \\
\text { ing forests are protected or otherwise in- } \\
\text { accessible. }\end{array}$ & $\begin{array}{l}\text { Advantages and disadvantages of either } \\
\text { type depend on local and individual con- } \\
\text { text. }\end{array}$ & $\begin{array}{l}\text { Meyfroidt et al., } \\
\text { 2014; Ruf, } 2001\end{array}$ \\
\hline \multicolumn{2}{|c|}{$\begin{array}{l}\text { Land tenure \& } \\
\text { rights }\end{array}$} & $\begin{array}{l}\text { Agroforest establishment inside forest } \\
\text { may represent a land claim. Land rights } \\
\text { determine land availability. Forests may } \\
\text { be protected, preventing forest-derived } \\
\text { agroforestry. }\end{array}$ & $\begin{array}{l}\text { Land must already be claimed before ag- } \\
\text { roforest establishment. Land tenure inse- } \\
\text { curity discourages agroforestry establish- } \\
\text { ment. }\end{array}$ & $\begin{array}{l}\text { No direct comparison available, strong } \\
\text { land rights will facilitate open-land-de- } \\
\text { rived agroforestry whereas strict forest } \\
\text { protection may hamper forest-derived ag- } \\
\text { roforestry. }\end{array}$ & $\begin{array}{l}\text { Meyfroidt et al., } \\
\text { 2014; Ruf, } 2001\end{array}$ \\
\hline \multicolumn{2}{|c|}{$\begin{array}{l}\text { Competition with } \\
\text { previous land use }\end{array}$} & $\begin{array}{l}\text { Direct land-use competition limited, but } \\
\text { loss of forest-generated ecosystem func- } \\
\text { tions and services. }\end{array}$ & $\begin{array}{l}\text { Competition with services and yields de- } \\
\text { rived from cropland, perennial monocul- } \\
\text { ture, pasture or fallow. Less problematic } \\
\text { on degraded land. }\end{array}$ & $\begin{array}{l}\text { No direct comparison available, trade-offs } \\
\text { exist for both types. Advantages and disad- } \\
\text { vantages depend on local context. }\end{array}$ & Meyfroidt et al., 2014 \\
\hline \multicolumn{2}{|c|}{ Production costs } & NA & NA & $\begin{array}{l}\text { Production costs are higher in open-land- } \\
\text { derived agroforestry compared to forest- } \\
\text { derived agroforestry. }\end{array}$ & Ruf, 2001 \\
\hline \multicolumn{6}{|c|}{ Ecosystem functions and services } \\
\hline 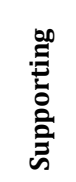 & $\begin{array}{l}\text { Soil fertil- } \\
\text { ity }\end{array}$ & $\begin{array}{l}\text { Nutrient acquisition incl. } \mathrm{N} \text { fixation } \\
\text { through forest remnant or planted (leg- } \\
\text { ume) trees; litter fall maintains soil fertil- } \\
\text { ity. }\end{array}$ & $\begin{array}{l}\text { Nutrient acquisition incl. } \mathrm{N} \text { fixation } \\
\text { through planted (legume) trees; particu- } \\
\text { larly useful if resource needs of chosen } \\
\text { trees and agroforestry crop are }\end{array}$ & $\begin{array}{l}\text { No direct comparison available, possibly } \\
\text { higher soil fertility in forest-derived agro- } \\
\text { forestry but potential for carry-over effects }\end{array}$ & $\begin{array}{l}\text { Cannell et al., 1996; } \\
\text { Tscharntke et al., } \\
2011\end{array}$ \\
\hline
\end{tabular}




\begin{tabular}{|c|c|c|c|c|c|}
\hline & & & $\begin{array}{l}\text { complementary. May also depend on for- } \\
\text { mer use of open land. }\end{array}$ & $\begin{array}{l}\text { from previous land-use in open-land-de- } \\
\text { rived agroforestry. May change over time. }\end{array}$ & \\
\hline & $\begin{array}{l}\text { Water reg- } \\
\text { ulation \& } \\
\text { supply }\end{array}$ & $\begin{array}{l}\text { Integrity of water cycle with high evapo- } \\
\text { transpiration and low surface run-off may } \\
\text { be retained. }\end{array}$ & $\begin{array}{l}\text { Improved integrity of the water cycle } \\
\text { with enhanced evapotranspiration and } \\
\text { reduced surface run-off. }\end{array}$ & $\begin{array}{l}\text { No direct comparison available, possibly } \\
\text { higher integrity of water cycle in forest-de- } \\
\text { rived agroforestry. }\end{array}$ & $\begin{array}{l}\text { Abdulai et al., 2018; } \\
\text { Blaser et al., 2018; } \\
\text { Wanger et al., } 2018\end{array}$ \\
\hline \multirow[b]{4}{*}{ 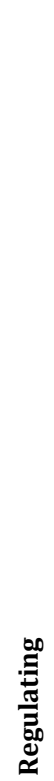 } & $\begin{array}{l}\text { Climate } \\
\text { regulation }\end{array}$ & $\begin{array}{l}\text { Above-ground carbon stocks are lower } \\
\text { than in forests. Within forest-derived ag- } \\
\text { roforests, biomass is often times reduced } \\
\text { over time as trees are cut. Soil organic car- } \\
\text { bon can be maintained if trees are kept. }\end{array}$ & $\begin{array}{l}\text { Above-ground carbon stocks are initially } \\
\text { low, but can be elevated to medium levels } \\
\text { with time. Soil organic carbon is initially } \\
\text { low but may rebound over time. }\end{array}$ & $\begin{array}{l}\text { No direct comparison available, open- } \\
\text { land-derived agroforestry typically have } \\
\text { lower carbon stocks compared to forest- } \\
\text { derived agroforestry. }\end{array}$ & $\begin{array}{l}\text { De Beenhouwer et } \\
\text { al., 2016; Hombe- } \\
\text { gowda et al., 2016; } \\
\text { Nair et al., } 2009\end{array}$ \\
\hline & $\begin{array}{l}\text { Climate } \\
\text { change } \\
\text { adapta- } \\
\text { tion }\end{array}$ & $\begin{array}{l}\text { Possibly dependent on tree cover; studies } \\
\text { report mixed results about the direction } \\
\text { of the effect for cacao. }\end{array}$ & $\begin{array}{l}\text { Possibly dependent on tree cover; given } \\
\text { that trees are often actively planted, tree } \\
\text { species adapted to climate change could be } \\
\text { chosen. }\end{array}$ & $\begin{array}{l}\text { No direct comparison available, more ac- } \\
\text { tive choice of tree species in open-land-de- } \\
\text { rived agroforests could be an opportunity } \\
\text { for climate change adaptation. }\end{array}$ & $\begin{array}{l}\text { Abdulai et al., 2018; } \\
\text { Blaser et al., 2018; } \\
\text { Wanger et al., } 2018\end{array}$ \\
\hline & $\begin{array}{l}\text { Erosion } \\
\text { preven- } \\
\text { tion }\end{array}$ & $\begin{array}{l}\text { Little change compared to forest if trees } \\
\text { are maintained. }\end{array}$ & Improvement over open land. & $\begin{array}{l}\text { No direct comparison available, possibly } \\
\text { better in forest-derived agroforests which } \\
\text { have not experienced clear cuts or fire. }\end{array}$ & Labrière et al., 2015 \\
\hline & $\begin{array}{l}\text { Biological } \\
\text { control }\end{array}$ & $\begin{array}{l}\text { Pest control services and disease preva- } \\
\text { lence (in coffee and cacao) both increase } \\
\text { with tree cover, leading to potential } \\
\text { trade-offs between the two. }\end{array}$ & $\begin{array}{l}\text { Pest control services and disease preva- } \\
\text { lence may increase with tree cover recov- } \\
\text { ery. }\end{array}$ & $\begin{array}{l}\text { No direct comparison available, pests and } \\
\text { disease may differentially affect forest- and } \\
\text { open-land-derived agroforests. }\end{array}$ & $\begin{array}{l}\text { Blaser et al., 2018; } \\
\text { Clough et al., } 2009\end{array}$ \\
\hline \multirow{2}{*}{ 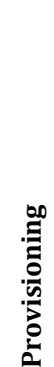 } & $\begin{array}{l}\text { Primary } \\
\text { crop yield }\end{array}$ & $\begin{array}{l}\text { Yield gains in coffee and cacao are com- } \\
\text { mon when shade tree cover is reduced } \\
\text { from high to medium shade, but long- } \\
\text { term yields may suffer under low shade } \\
\text { conditions. }\end{array}$ & $\begin{array}{l}\text { Possible yield reduction in coffee and cacao } \\
\text { agroforests where shade tree regeneration } \\
\text { leads to higher canopy cover. }\end{array}$ & $\begin{array}{l}\text { No difference in cacao yield between for- } \\
\text { est- and open-land-derived agroforestry } \\
\text { (but only one study available). }\end{array}$ & $\begin{array}{l}\text { Clough et al., 2009; } \\
\text { Nijmeijer et al., } 2019\end{array}$ \\
\hline & $\begin{array}{l}\text { Secondary } \\
\text { crop yield }\end{array}$ & $\begin{array}{l}\text { Products may be harvested if useful } \\
\text { plants and trees are kept, promoted or } \\
\text { planted. Trees can be cut and used. }\end{array}$ & $\begin{array}{l}\text { Useful plants/trees can be planted during } \\
\text { agroforest establishment but might take }\end{array}$ & $\begin{array}{l}\text { No direct comparison available, the more } \\
\text { active choice of tree species in open-land- }\end{array}$ & $\begin{array}{l}\text { Tscharntke et al., } \\
2011\end{array}$ \\
\hline
\end{tabular}




\begin{tabular}{|c|c|c|c|c|}
\hline $\begin{array}{l}\text { \& raw ma- } \\
\text { terials }\end{array}$ & & $\begin{array}{l}\text { time until first harvest; dependent on } \\
\text { product. }\end{array}$ & $\begin{array}{l}\text { derived agroforestry predicts higher sec- } \\
\text { ondary crop yields in such systems. }\end{array}$ & \\
\hline \multicolumn{5}{|c|}{ Vegetation structure and biodiversity } \\
\hline $\begin{array}{l}\text { Tree cover \& } \\
\text { structure }\end{array}$ & $\begin{array}{l}\text { Initially high tree cover and structure may } \\
\text { be reduced with time if trees are ex- } \\
\text { tracted. }\end{array}$ & $\begin{array}{l}\text { Initially low tree cover and structure, may } \\
\text { be elevated to medium levels with time } \\
\text { through tree growth. }\end{array}$ & $\begin{array}{l}\text { Typically lower tree cover and simplified } \\
\text { structure in open-land-derived agrofor- } \\
\text { estry than in forest-derived agroforestry } \\
\text { (See also Box). }\end{array}$ & $\begin{array}{l}\text { Nijmeijer et al., 2019; } \\
\text { Ruf, 2001; } \\
\text { Tscharntke et al., } \\
2011\end{array}$ \\
\hline Tree diversity & $\begin{array}{l}\text { Selective cutting of trees reduces diver- } \\
\text { sity compared to forest. More useful trees } \\
\text { (see above) are more likely to be kept. }\end{array}$ & $\begin{array}{l}\text { Diversity is highly managed as trees are } \\
\text { planted or selected by farmers. Species } \\
\text { are typically chosen based on their useful- } \\
\text { ness, suitability and availability. }\end{array}$ & $\begin{array}{l}\text { Normally lower in open-land-derived ag- } \\
\text { roforestry than in forest-derived agrofor- } \\
\text { estry. }\end{array}$ & $\begin{array}{l}\text { Nijmeijer et al., 2019; } \\
\text { Tscharntke et al., } \\
\text { 2011; Valencia et al., } \\
2016\end{array}$ \\
\hline Biodiversity & $\begin{array}{l}\text { Generally lower than in forest. May be } \\
\text { taxon-specific and/or on the level of spe- } \\
\text { cies composition rather than species rich- } \\
\text { ness. Effects will be strongest for forest- } \\
\text { dependent species. }\end{array}$ & $\begin{array}{l}\text { Generally higher than in open land. Ef- } \\
\text { fects may be taxon specific and/or on the } \\
\text { level of species composition rather than } \\
\text { species richness. Open-land species may } \\
\text { decrease following agroforest establish- } \\
\text { ment. }\end{array}$ & $\begin{array}{l}\text { Overall lower in open-land-derived agro- } \\
\text { forestry than in forest-derived agrofor- } \\
\text { ests, but open-land and generalist species } \\
\text { may be more common in open-land-de- } \\
\text { rived agroforests. }\end{array}$ & $\begin{array}{l}\text { De Beenhouwer et } \\
\text { al., 2013; Hoehn et } \\
\text { al., 2010; Perfecto et } \\
\text { al., 1996; Philpott et } \\
\text { al., } 2008\end{array}$ \\
\hline Legacy effects & $\begin{array}{l}\text { Extinction debts are likely to exist, sug- } \\
\text { gesting a loss in species over time even } \\
\text { under stable tree cover. }\end{array}$ & $\begin{array}{l}\text { Immigration credit is likely to exist, sug- } \\
\text { gesting a gain in species over time under } \\
\text { stable management regime. }\end{array}$ & $\begin{array}{l}\text { No direct comparison available, realizing } \\
\text { legacy effects would lead to reduced differ- } \\
\text { ences between forest- and open-land-de- } \\
\text { rived agroforests in terms of biodiversity. }\end{array}$ & $\begin{array}{l}\text { Hylander and Ne- } \\
\text { momissa, 2017; Jack- } \\
\text { son and Sax, 2010; } \\
\text { Shumi et al., } 2018\end{array}$ \\
\hline
\end{tabular}




\subsection{Suitability of open vs. forest land for agroforest establishment}

Land accessibility and availability influence whether agroforests are established inside forests or on open land (Meyfroidt et al., 2014, Table 2.1). Establishing forest-derived agroforests is only possible where forests are available, typically at deforestation frontiers or where forest fragments are scattered in a landscape. As forests are vanishing across the tropics (Lewis et al., 2015), many farmers live far away from available forests, making openland-derived agroforestry the only option.

Other factors are also shaping agroforestry expansion (Table 2.1). For example, planting crops inside forest may represent a form of land claim (Meyfroidt et al., 2014), incentivizing forest-derived agroforestry. On open-land, land tenure must already be secured, given the significant investments needed to establish an agroforest (Ruf, 2001). Opportunity costs may apply in either case: for forests, those are likely limited to the loss of forest-specific ecosystem functions and services, while on open land, the costs for losing perennial monocultures, arable crop land or pastures will be considerable. Fallows may offer an opportunity for open-land-derived agroforestry, given their abundance in many tropical regions (Chazdon et al., 2009). Degraded land, typically of low value to people and nature (Lamb et al., 2005), could also be suitable for open-land-derived agroforestry, but only if costs, for example associated with management of invasive species or erosion control, are manageable. The price tag might also be a more general disadvantage of open-land-derived agroforestry; cacao production costs are for instance 30 - 50\% higher in open-land-derived agroforests compared to forest-derived agroforests due to costs for fertilizers and maintenance (Ruf, 2001). Additionally, planting trees on open-land may be expensive (Ruf, 2001), while making space for forest-derived agroforestry may be attractive in itself if felled forest trees can be used or sold (Tscharntke et al., 2011).

\subsection{Land-use history affects ecosystem functions and services}

Establishing an agroforest on open land that was formerly forested can be regarded as a form of rehabilitation (Chazdon et al., 2016), leading to an overall increase of tree cover and associated ecosystem functions and services (Table 2.1). Tropical open-land-derived agroforests thus have a large carbon sequestration potential (Hombegowda et al., 2016; Nair et al., 2009; Nijmeijer et al., 2019). Forest-derived agroforests, on the other hand, typically store less carbon than forests (De Beenhouwer et al., 2016; Nair et al., 2009). For example, 
forest-derived coffee agroforests in Ethiopia lose $47 \%$ of their carbon stocks along an intensification gradient compared to forests (De Beenhouwer et al., 2016). For tree basal area, we find the same pattern in vanilla agroforests, where open-land-derived agroforests have three times more basal area than open fallow land. Forest-derived vanilla agroforests, on the other hand, have 59\% less basal area than forest (Box).

Whether forest- and open-land-derived agroforestry differ in yields remains poorly understood. A single study in cacao shows no differences (Nijmeijer et al., 2019), but research has mainly focused on how tree cover is correlated with yields. In coffee, yields are typically higher under low- or medium-shade conditions (Perfecto et al., 1996). In cacao, yields generally increase when shade is reduced (Blaser et al., 2018), but low-shade systems may fail to maintain yields in the long run (Clough et al., 2009). Yields may also be influenced by pest control services in agroforestry systems, but whether land-use history per se influences pest control is unknown. Similarly, it remains unclear whether land-use history affects how agroforests cope with elevated temperatures and droughts. Elucidating the interplay between land-use history, tree cover, pest control and yields under climate change will thus help to improve agroforest management to the benefit of farmers as well as ecosystem services and biodiversity.

\section{BOX: The case of vanilla agroforestry in Madagascar}

Vanilla agroforests along with hill- and paddy rice, fallows and forest fragments form a mosaic landscape in north-eastern Madagascar which arose through rainforest conversion. High vanilla prices have led to an expansion of vanilla agroforestry at the cost of both forest and open land. Forest-derived vanilla agroforests, which make up around 30\% of all vanilla agroforest (Hänke et al., 2018), are established by understory clearance and tree thinning. This conversion maintains some tree cover but basal area in forest-derived vanilla agroforests is less than half compared to forest (Figure 2.2). In contrast, 70\% of vanilla agroforests originate from abundant open land that lays fallow as part of the slash-and-burn hill rice cultivation cycle (Hänke et al., 2018). The cessation of fire, that comes with the establishment of permanent open-land-derived vanilla agroforests, enables tree recovery, resulting in a threefold higher basal area compared to open land (Figure 2.2). When compared directly, forest-derived vanilla agroforests have almost twice the basal area of open-land- 
derived vanilla agroforests. This highlights the role of agroforests of contrasting land-use history for maintaining trees and their associated functions and services.
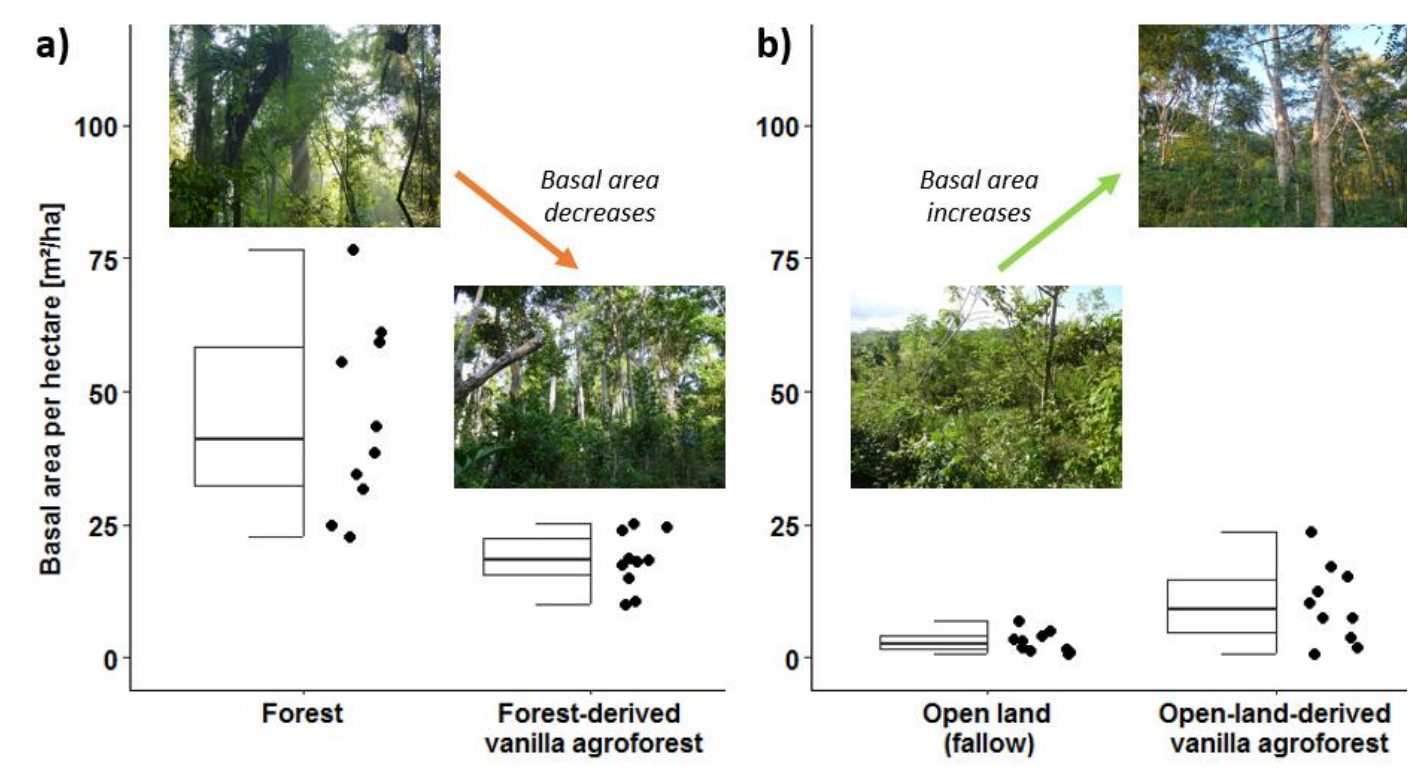

Figure 2.2: Basal area $\left[\mathrm{m}^{2} / \mathrm{ha}\right]$ in 40 circular study plots of $1963.5 \mathrm{~m}^{2}$. Measurements include all living trees, palms and herbs with a diameter at breast height $\geq 8 \mathrm{~cm}$. a) Basal area in forest-derived vanilla agroforests is $59 \%$ lower than in forests $(\mathrm{p}<0.001)$. b) Basal area in open-land-derived vanilla agroforests is three times higher than in open lands $(238 \%$ increase; $p=0.011)$. Open-land-derived vanilla agroforests have $45 \%$ less $(p=0.009)$ basal area than forest-derived vanilla agroforests. Test results are based on Wilcoxon signed-rank tests.

\subsection{Land-use history shapes vegetation structure and biodiversity}

Planting crops inside forest and the accompanying simplification of vegetation structure leads to a loss of biodiversity (De Beenhouwer et al., 2013; Tscharntke et al., 2011). While immigrating generalist or open-land specialist species may compensate for some of the losses in species richness, forest specialists (De Beenhouwer et al., 2013; Perfecto et al., 1996) and threatened species (Schroth, 2004) are particularly affected. This species turnover exacerbates conservation concerns of forest-derived agroforestry. Nevertheless, forestderived agroforests surpass alternative forms of forest conversion, such as slash-and-burn practices (Perfecto et al., 1996; Schroth, 2004). Planting agroforests on open land should, in contrast, enhance structural complexity and increase resource diversity, thereby bolstering biodiversity of forest-associated taxa (Figure 2.1). However, few studies compare open- 
land-derived agroforests with their respective baselines (Rice and Greenberg, 2000). This is also reflected in our systematic review, where only two studies compared biodiversity of open-land-derived agroforestry with open land while 14 studies compared forest-derived agroforestry with forest (see also Table 2.1 and SI Chapter 2). Direct comparisons between forest-derived and open-land-derived agroforests are scarce, but published studies show a more forest-like species composition (Hoehn et al., 2010; Valencia et al., 2016), fewer invasive species (Bos et al., 2008), and higher species diversity (Nijmeijer et al., 2019; Siebert, 2002) in forest-derived agroforests.

However, the differences between agroforests of contrasting land-use history might diminish over time. Oftentimes, forest-derived agroforests lose tree cover due to logging of existing trees, natural mortality and limited recruitment (De Beenhouwer et al., 2016; Shumi et al., 2018; Valencia et al., 2016), typically resulting in a reduction of biodiversity (Philpott et al., 2008; Tscharntke et al., 2011). Contrastingly, open-land-derived agroforests gain tree cover over time and could thereby enter into a positive biodiversity trajectory (Perfecto et al., 1996). In this context, contrasting trajectories in forest- and open-land-derived cacao agroforests in Cameroon have equalized tree diversity after $\sim 25$ years (Nijmeijer et al., 2019).

Furthermore, legacy effects could reduce the gap in biodiversity between forest- and openland-derived agroforests over time. Extinction debts suggest a continuing loss of biodiversity as populations that are not viable under new conditions go extinct (Jackson \& Sax, 2010).

Evidence for extinction debts comes from forest-derived agroforests in Ethiopia, where epiphytes are less likely to occur in long-converted agroforests further away from the historic forest edge (Hylander \& Nemomissa, 2017). Conversely, open-land-derived agroforests may enjoy an immigration credit (Jackson \& Sax, 2010; Shumi et al., 2018), implying that species have not yet immigrated into newly established agroforests, despite suitable habitat. 'Paying out' extinction debts and immigration credits would thus reduce differences in species richness between forest- and open-land-derived agroforests.

\subsection{Discussion}

Agroforestry is often seen as an economically viable land-use option that benefits people and nature alike (Schroth, 2004), thereby contributing to reaching the UN Sustainable Development Goals. To what extent will depend on whether an agroforest is established on 
open land or at the cost of biodiverse tropical forest. Nonetheless, forest-derived agroforestry represents a limited loss of ecosystem functions and biodiversity compared to more destructive conversion methods such as slash-and-burn or a combination of intensive logging and grazing (Figure 2.3). Conversely, agroforestry on formerly forested open land will typically have a positive effect on ecosystem services and biodiversity: the land gains vertical habitat complexity through the restoration of shade trees and crops on open land, which in turn increases biodiversity and ecosystem functions and services. In short, open-landderived agroforestry will often perform worse than forest-derived agroforestry in absolute terms but forest-derived agroforestry degrades forest whereas open-land-derived agroforestry rehabilitates open land that was once forested (BOX: The case of vanilla agroforestry in Madagascar, Figure 2.3).

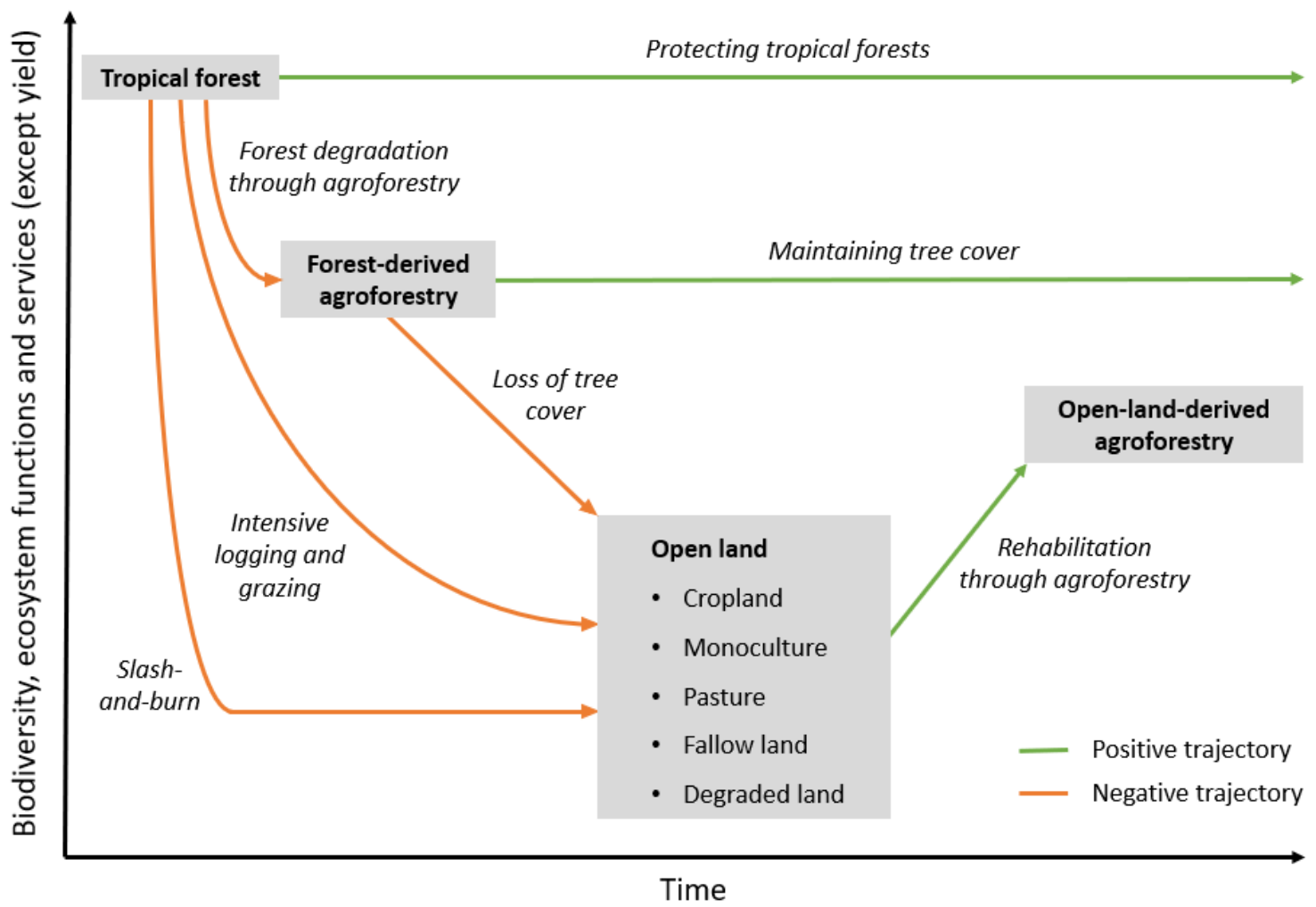

Figure 2.3: Conceptual framework of land-use history for tropical agroforests including possible transformation pathways. Forest-derived agroforestry represents a decline of biodiversity, ecosystem functions and services compared to forest (except crop yields). Conversely, open-land-derived agroforestry represents an improvement over previous land use. In direct comparison, forest-derived agroforestry outperforms open-land-derived agroforestry if tree cover is maintained. Importantly, the framework only applies to formerly forested land in the tropics and is not applicable to naturally open land, such as savannahs. Note that both axes are not absolute, i.e. processes may 
happen faster or slower ( $\mathrm{x}$-axis) and losses and gains could be stronger or weaker (y-axis), depending on environmental and socio-economic context.

\subsubsection{Incentivizing positive land-use trajectories}

Maintaining tree cover in forest-derived agroforestry (Figure 2.3) might be associated with lower yields (Blaser et al., 2018; Perfecto et al., 1996) and establishing open-land-derived agroforests instead of forest-derived ones might come at extra direct costs (Ruf, 2001; Tscharntke et al., 2011). Incentives such as sustainability certification schemes could, however, make both economically viable (Philpott \& Dietsch, 2003; Tscharntke et al., 2014). Analogously, farmers could profit from payments for ecosystem services aimed at carbon sequestration in their open-land-derived agroforests (Salzman et al., 2018). Interestingly, many sustainability standards prohibit 'forest conversion into production land' (e.g. Rainforest Alliance, Organic, Fair Trade (International Trade Centre, 2019)), effectively excluding forest-derived agroforests. But in practice, many certified agroforests are forest-derived (e.g. vanilla: Hänke et al., 2018; coffee: Philpott and Dietsch, 2003). This is not per se problematic if sustainability certification ensures that ecosystem functions and services as well as biodiversity are maintained in long-established agroforests (Tscharntke et al., 2014). To avoid incentivizing forest degradation, the certification of recently converted forest-derived agroforests should nonetheless be avoided. On the other hand, open-land-derived agroforests might struggle to meet certification criteria, despite the improvement over previous land use. For instance, Rainforest Alliance requires 'diverse native shade canopies for shade-tolerant crops' (International Trade Centre, 2019) - a criterion that will typically be harder to meet in open-land-derived agroforestry (Rice \& Greenberg, 2000). In this case, rules could be adapted so that open-land-derived agroforests with a lower proportion of native trees still qualify for sustainability standards. In sum, sustainability standards and payments for ecosystem services should be sensitive to land-use history in order to avoid adverse outcomes.

\subsubsection{Key research questions on land-use history of tropical agroforests}

First, we encourage studies that investigate the time scale of described processes. In forestderived agroforestry, we hypothesize a rapid loss of biodiversity and ecosystem functions and services during the initial transformation from forest and a somewhat slower decline thereafter. In open-land-derived agroforestry, recovery time will again depend on the focal variable, but may be only a few years for certain ecosystem functions (Nijmeijer et al., 2019). In this context, time series will be particularly interesting. Second, research quantifying the 
extent of biodiversity and ecosystem functioning gain and loss during transformation is equally important. Third, elucidating how forest- and open-land-derived agroforestry could be utilized to restore land-sharing/sparing connectivity landscapes would be highly interesting (Grass et al., 2019). For example, one could imagine landscapes with forest-derived agroforests as buffers around protected areas and corridors of open-land-derived agroforestry connecting forest fragments - thereby reaping the advantages of both types.

\subsubsection{Policy implications}

Agroforestry is widely promoted to address multiple UN Sustainable Development Goals, but policy often does not distinguish between forest- and open-land-derived agroforests. Here, we find that ecosystem functions and services as well as biodiversity are strongly influenced by land-use history in agroforests; suggesting a high relevance of land-use history for policy. Policies aiming to conserve biodiversity and ecosystem services should 1) prioritize forest protection over forest-derived agroforestry, 2) promote forest-derived agroforestry as an alternative to deforestation, 3) incentivise tree cover maintenance in existing forest-derived agroforests, 4) encourage open-land-derived agroforestry on suitable open land, particularly on fallow and degraded land, and 5) stimulate applied research on landuse history.

Our framework is relevant to numerous policy tools. Those include payments for ecosystem services and sustainability certification, but can be extended to agricultural subsidy schemes, zero-deforestation commitments and governmental land-use policy, among others. Notably, all approaches will need to be highly adapted to local context as environmental and socio-economic factors influence whether and where the promotion of forest- respectively open-land-derived agroforestry is a sensible policy.

\subsection{Authors' contributions}

All authors conceived ideas and planned the paper; DAM conducted the systematic review, produced Figure 2.1 and Figure 2.3, and led the writing of the manuscript; KO collected basal area data and created Figure 2.2. All authors contributed to the writing and gave final approval. 


\subsection{Acknowledgements and data}

We thank the 'Diversity Turn in Land Use Science' team for inspiring discussions. We are grateful to Marie Rolande Soazafy and research assistants who contributed to basal area data. We thank two anonymous reviewers and the editor for their helpful feedback. This study was financially supported by the Niedersächsisches Vorab of Volkswagen Foundation (Grant number 11-76251-99-35/13 (ZN3119)). Basal area data is available upon request. 


\section{Bird diversity and endemism along a land- use gradient in Madagascar: the conserva- tion value of vanilla agroforests}

Dominic Andreas Martin, Rouvah Andriafanomezantsoa, Saskia Dröge, Kristina Osen, Eric Rakotomalala, Annemarie Wurz, Aristide Andrianarimisa, Holger Kreft

Contribution: Conceptualization, Data curation, Formal analysis, Investigation, Project administration, Validation, Visualization, Writing - original draft

Status: Published in Biotropica; https://doi.org/10.1111/btp.12859.

\subsection{Abstract}

Land-use change is the most important driver of biodiversity loss worldwide and particularly so in the tropics, where natural habitats are transformed into large-scale monocultures or heterogeneous landscape mosaics of largely unknown conservation value. Using birds as an indicator taxon, we evaluated the conservation value of a landscape mosaic in northeastern Madagascar, a biodiversity hotspot and the center of global vanilla production. We assessed bird species richness and composition by conducting point counts across seven prevalent land-use types (forest- and fallow-derived vanilla agroforests, woody and herbaceous fallow that are part of a shifting cultivation system, rice paddy, forest fragment and contiguous old-growth forest). We find that old-growth forest had the highest species richness, driven by a high share of endemics. Species richness and community composition in forest-derived vanilla agroforest was similar to forest fragment, whereas fallow-derived vanilla agroforest was most comparable to woody fallow. The open land-use types herbaceous 
fallow and rice paddy had fewest species. Across forest fragment, vanilla agroforests and woody fallow, endemic bird species richness was positively correlated to landscape-scale forest cover. We conclude that both fallow- and forest-derived vanilla agroforests play an important but contrasting role for bird conservation: fallow-derived agroforests are less valuable but take fallow land out of the shifting cultivation cycle, possibly preventing further degradation. Conversely, forest-derived agroforests contribute to forest degradation but may avoid total loss of tree cover from forest fragments. Considering the land-use history of agroforests may thus be a promising avenue for future research beyond the case of vanilla.

Keywords: agroecology, agroforestry, biodiversity, land-use history, land-use change, ornithology, shifting cultivation, SAVA region

\subsection{Introduction}

While intact forests within protected areas are indispensable to protect biodiversity (Gibson et al., 2011; Gray et al., 2016), heterogeneous landscapes with a mosaic of smallscale agriculture, agroforestry and forest remnants also have the potential to sustain high levels of biodiversity in the tropics (Bhagwat et al., 2008; Melo et al., 2013; Schroth, 2004). Similarly, such landscapes can provide ecosystem services that offer resilient livelihood options for rural people (Gordon et al., 2007). However, optimizing landscapes for the benefit of biodiversity and humans alike remains a major challenge; partly so due to a strong context dependency caused by dissimilar abiotic, biological and socio-economic conditions in different parts of the world (Frishkoff et al., 2019).

In Madagascar, high levels of endemism (Goodman \& Benstead, 2005) coincide with high rates of habitat loss (Rakotomanana et al., 2013), making the island one of the hottest biodiversity hotspots (Myers et al., 2000). Over the past 50 years, Madagascar lost approximately half of its forest cover (Vieilledent et al., 2018), illustrating the need for forest preservation while highlighting the potentially increasing role of the resulting human-dominated landscape for conservation. However, the distribution of species in agricultural landscapes of Madagascar has rarely been assessed (exceptions are Martin et al., 2012, Ndriantsoa et al., 2017 and Rocha et al., 2015), as most research focuses on forested protected areas (Irwin et al., 2010). In our study region in north-eastern Madagascar, ongoing land-use change has resulted in a small-scale landscape mosaic encompassing agroforests, shifting cultivation, forest fragments and rice paddies, resembling landscapes found throughout eastern Madagascar (Zaehringer et al., 2017). At the national scale, north-eastern 
Madagascar holds the highest percentage of forest cover (Vieilledent et al., 2018) and counts among the most biodiverse regions of the country (Brown et al., 2016), emphasizing the need for a sustainable land-use transformation.

Concurrently, north-eastern Madagascar is the global center of vanilla production, where smallholders produce roughly $40 \%$ of the world's vanilla in agroforestry systems (FAO, 2020), making vanilla the country's top export commodity (Comtrade, 2017). The current expansion of vanilla agroforests, which is instigated by record-high prices (Hänke et al., 2018; Llopis et al., 2019), raises questions on the impacts of vanilla cultivation on biodiversity. Indeed, very little is known about the factors influencing biodiversity in vanilla agroforests and how they could be managed in a biodiversity-friendly way; contra to other agroforestry commodities like coffee or cacao (Schroth, 2004; Tscharntke et al., 2011). Furthermore, important linkages between vanilla cash-cropping and alternative forms of land use, such as the land-intensive and potentially unsustainable shifting cultivation (locally referred to as tavy, Styger et al., 2007), remain largely unstudied (Llopis et al., 2019).

Malagasy vanilla agroforests are strikingly heterogeneous due to differences in land-use history. In north-eastern Madagascar, around 30\% of agroforests are directly derived from forest (Hänke et al., 2018) by thinning of trees, cleaning of the understory and planting vanilla under remaining trees (Martin et al., 2020b). Roughly 70\% of agroforests originate from fallow land (Hänke et al., 2018) that had once burned within the shifting cultivation cycle for hill rice cultivation (Styger et al., 2007). The transformation of these frequently burned plots into agroforestry systems and the cessation of fires allows the regeneration of trees. Interestingly, land-use history is largely neglected in the literature on biodiversity and ecosystem services in tropical agroforestry systems (Martin et al., 2020b). Given the rapid expansion of vanilla agroforests in north-eastern Madagascar in recent years (Llopis et al., 2019), further insights are needed to elucidate the conservation potential of vanilla agroforests in this biodiversity hotspot.

Here, we use birds as a model group to study the conservation value of vanilla agroforests and other prevalent land-use types in north-eastern Madagascar, as well as old-growth forests as a baseline. We compare bird species richness, composition and endemism between land-use types and focus on vanilla agroforests of different land-use history. We also focus on endemism, because endemic species are emblematic of Malagasy biodiversity (Goodman \& Benstead, 2005) and because endemic species have been shown to be more susceptible to land-use change (de Lima et al., 2013; Fordham \& Brook, 2010) and may thus serve as a proxy for conservation value (Waltert et al., 2011). We firstly investigate how total and 
endemic bird species richness differs among land-use types. Secondly, we study how and why bird communities differ in species composition across land uses. Thirdly, we use this knowledge to derive management advice for vanilla agroforests that might optimize their value for bird conservation. Ultimately, we show that the differentiation of agroforests based on land-use history is a meaningful approach with applications beyond the case of vanilla.

\subsection{Methods}

\subsubsection{Study region and study design}

We conducted our study in the SAVA region in north-eastern Madagascar (Figure 3.1). The annual rainfall is $2223 \mathrm{~mm}$ with a mean annual temperature of $24.0^{\circ} \mathrm{C}$ (mean across 80 plots; data extracted from the CHELSA climatology (Karger et al., 2017). The potential natural vegetation is tropical rainforest, but only $35 \%$ of forest cover remains (Ferreira Arruda, 2018).

We collected data in 10 villages covering all prevalent land-use types as well as old-growth forest. In each village, we selected one rice paddy, one herbaceous fallow, one woody fallow and one forest fragment plus three vanilla agroforests summing up to 70 plots within 10 villages. Not in all villages were fallow- and forest-derived vanilla agroforests available, leading to an unbalanced design for vanilla agroforests (Figure 3.1). Additionally, we studied 10 old-growth forest plots at two sites inside Marojejy National Park, the only place with contiguous low-altitude old-growth forest persisting in our study area. We chose the two old-growth forest sites within the same park as a compromise between low-altitude, maximum distance between the two sites and accessibility. See SI Chapter 3 for choice of villages and old-growth forest sites.

\subsubsection{Sampled land-use types}

One of the old-growth forest sites had experienced selective logging in the past but is now well protected while the other site is still subjected to selective logging (personal communication Jean-Chrysostome Bevao; see SI Chapter 3 for details on old-growth forest). Forest fragments lie scattered throughout the study region. All 10 fragments were unburned but used for extraction of timber, firewood and other natural products with few large trees remaining. 
Herbaceous fallows (Malagasy: matrangy) are part of the shifting cultivation cycle for hill rice production (tavy). All 10 herbaceous fallows have been burned repeatedly and last burned at the end of 2016, about one year before the first data collection in 2017, followed by hill rice cultivation. Thereafter, the land was left fallow until the end of data collection in December 2018. By late 2018, first woody plants had emerged on certain herbaceous fallows. Without further intervention, this succession on herbaceous fallows results in woody fallows (savoka), which are characterized by a mix of herbaceous plants, shrubs, small trees and occasionally bamboo. The 10 woody fallows chosen for our study had last burned 4 16 years prior to data collection. Lastly, we studied 10 irrigated rice paddies (horoka), mostly situated in floodplains. See Figure 3.1 for a schematic overview.

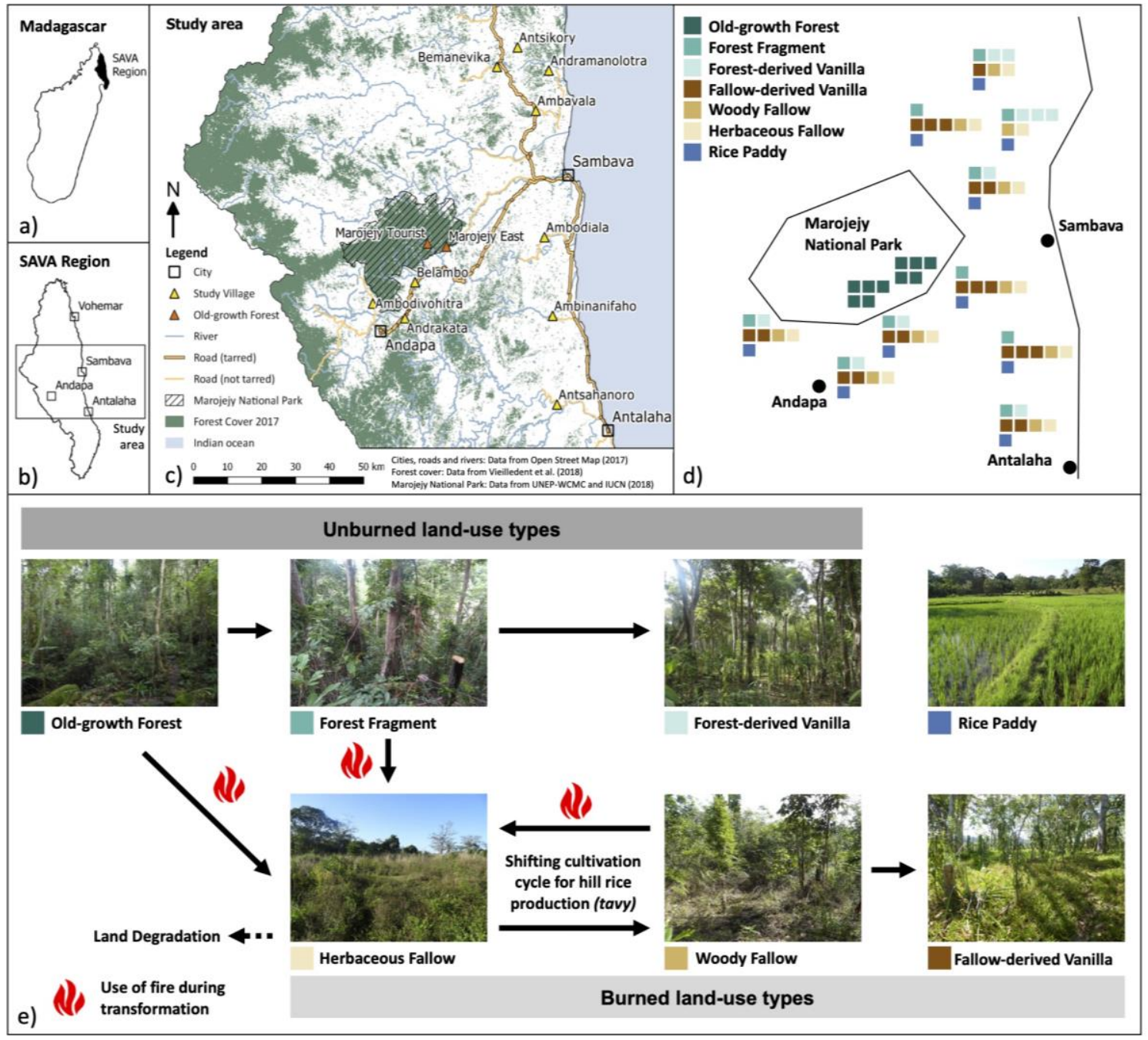

Figure 3.1: Study design overview. a) The island of Madagascar off East Africa with the SAVA region. b) SAVA region c) Study area with forest cover 2017 (Vieilledent et al., 2018), roads, rivers and the three major cities Sambava, Antalaha and Andapa as well as the 10 study villages, Marojejy National Park and the two sampling sites therein. d) A schematic overview of the study area, depicting which 
land-use types were sampled in each of the 10 villages and the two sampling sites inside Marojejy National Park. e) Possible transformation pathways from old-growth forest into different land-use types that we assessed in this study. Rice paddies are usually established on floodplains and are thus not part of the displayed transformation pathways.

Vanilla planifolia is a climbing orchid native to Mexico, which is locally farmed in agroforestry systems using small trees as a support, while a variety of taller trees form the canopy above (Havkin-Frenkel \& Belanger, 2018). We selected 20 vanilla agroforests that were established on fallow land, formerly part of the shifting cultivation cycle ('Fallow-derived vanilla'). Those agroforests are established on formerly forested open land and are thus 'openland-derived' following the concept of Martin et al. (2020b). We selected 10 additional vanilla agroforests which were directly established inside forest fragments and thus 'forestderived' (Martin et al., 2020b). See Supporting Information for details.

\subsubsection{Plot design}

We collected all data within circular $25 \mathrm{~m}$ radius plots. Adjacent land is often used differently, which is reflected in the small mean sizes of each land unit in which we established the plots (SI Chapter 3, Table 12.1). The mean minimum distance from one plot to the closest neighboring plot was $719 \mathrm{~m}(S D \pm 438 \mathrm{~m})$ with a minimum of $260 \mathrm{~m}$. Plot elevation spanned from 7 to 819 m.a.s.l. (mean $=192 \mathrm{~m}, S D \pm 207 \mathrm{~m}$ ).

\subsubsection{Point counts}

On all 80 plots, two observers jointly conducted two 40 minutes fixed-radius point counts (Bibby et al., 2000) before 8:15 AM during the breeding season (late August-December). We thus sampled all plots with the same effort of 80 minutes. We completed the first round of point counts on all plots, except in old-growth forest, in 2017 and the second round in 2018, reversing the order between years. We sampled in old-growth forest in 2018 only but waited 11 weeks between point counts on the same plot. Point-count times and observers are listed in SI Chapter 3 Table 12.2. Lesser Vasa Parrot (Coracopsis nigra) and Greater Vasa Parrot (C. vasa) were difficult to distinguish in the field (Hawkins et al., 2015) and consequently counted as one species. We excluded all species only seen in flight and outside the plot and worked with presence / absence data only for further analysis. See SI Chapter 3 for details. 


\subsubsection{Basal area, canopy closure and landscape-scale forest cover data}

Within each plot, we measured the diameter at breast height ( $\mathrm{dbh}$ ) of all living trees, palms and herbs with a dbh $\geq 8 \mathrm{~cm}$ following (Condit, 2008). We then calculated the basal area per tree and summed up basal area of all trees per plot. From the tree dataset, we also derived the number of large trees, defined as the number of trees on each plot which had a basal area and height within the upper quartile basal area and height of all trees across the landuse types. Information for basal area and the number of large trees is missing for two plots due to denied plot access.

We obtained mean canopy closure values from five hemispherical images per plot, using a Nikon D5100 camera equipped with a Sigma Circular Fisheye $4.5 \mathrm{~mm} \mathrm{1:2.8} \mathrm{lens} \mathrm{mounted}$ on a tripod at $2.4 \mathrm{~m}$ height. We determined exposure following the histogram-exposure protocol of Beckschäfer et al. (2013), and extracted canopy closure values by applying a minimum thresholding algorithm.

We assessed proportion of forest cover in a 250-m-radius buffer around plot-centers using the raster R-package (Hijmans et al., 2019) and 2017 binary forest cover data with $30 \mathrm{~m}$ resolution (Vieilledent et al., 2018). We henceforth call this variable 'landscape-scale forest cover'.

\subsubsection{Endemism level, nativeness and IUCN red-list status}

We assigned all species to one of five different levels of endemism i.e. 1) non-endemic, 2) species level endemic, 3) genus level endemic, 4) subfamily level endemic and 5) family level endemic. We based this categorization on the BirdLife species factsheet data (BirdLife International, 2018), where species only occurring in Madagascar are listed as country-endemics. We then checked for each endemic species whether there are other species of the same genus / subfamily / family occurring outside Madagascar and attributed each species to the according endemism level. We assigned three bird species breeding only in Madagascar but migrating outside the country to non-endemic. We treated the two very similar Vasa Parrot species as one species and categorized it as non-endemic as one of them (C. vasa) also occurs outside Madagascar. We supplemented the data with native / non-native status (BirdLife International, 2018) and the threat category from the red list (IUCN, 2018). See SI Chapter 3 Table 12.3 . 


\subsubsection{Statistical analysis}

To assess the representativeness of our sample, we computed species accumulation curves and sample completeness per land-use type with raw incidence data in the R-package iNext (Hsieh et al., 2016), using each plot as one incidence. We used an analysis of variance (ANOVA) and pairwise Tukey's honest significance tests to assess differences in plot-level species richness between land-use types. To test for differences in endemic species richness, we used weighted regression with Bonferroni correction because a Levene-test showed heteroscedasticity in the variances between land-use types. For both tests, we applied a significance level of $\mathrm{p}<0.05$.

To derive the total number of species (gamma diversity) per endemism level for each landuse type, we subsampled the fallow-derived vanilla plots as we had 20 plots thereof (compared to 10 for all other land-use types). To do so, we randomly selected one fallow-derived vanilla plot within each village and a $10^{\text {th }}$ randomly from the remaining fallow-derived vanilla plots (as one village did not have a fallow-derived vanilla, see Figure $3.1 \mathrm{~d}$ )). We tested whether the observed number of species per endemism level differed from random expectation by creating null models of species richness per endemism level for each land-use type. For each land-use type and each endemism level, we drew 1000 times the realized number of species from the total species pool (57 species) without substitution to estimate expected means and standard deviation $(S D)$. We calculated the means and $S D$ for the sum of endemism levels equal or below each level for all endemic levels, e.g. the estimate for endemic genera represents the sum of family, sub-family and genus level endemics which can be expected under random conditions based on the land-use-type-specific null model. The nonendemic estimate was the null estimate for non-endemic species only, plus the effectively realized number of endemic species for each land-use type. We then tested whether the number of species per endemism level found in each land-use type was within one or two $S D$.

To visualize the co-occurrence of species across land-use types, we used UpsetR (Conway et al., 2017). To investigate differences in species composition between land-use types, we used the metaMDS function of the R-package vegan (Oksanen et al., 2019) with two dimensions and standard settings. We tested for differences between land-use types using the adonis function of vegan and the pairwise.adonis function with Bonferroni correction to test for pairwise differences between land-use types. We then displayed the correlation of three environmental variables (basal area, landscape-scale forest cover and elevation; for two 
plots with missing basal area data, we used mean basal area data for the land-use type) with the site scores to the NMDS plot using the envfit function of vegan.

To analyze the drivers of non-endemic and endemic species richness across land-use types with tree presence outside old-growth forest (forest fragment, forest- and fallow-derived vanilla, woody fallow), we generated two generalized linear models (GLMs) with a Poisson error structure in the lme4 package (Bates, 2014). We fitted basal area, altitude, landscapescale forest cover and land-use type as predictor variables. Two additional predictor variables, canopy closure and number of large trees, were strongly correlated with basal area (Spearman rank correlation: 0.770 for canopy closure and 0.829 for large trees; SI Chapter 3, Figure 12.3), which is why we a priori included only basal area in the models. For both models, we scaled numeric variables to facilitate interpretability of the model outputs. We excluded data from two fallow-derived vanilla plots for the GLMs due to missing basal area data. Lastly, we extracted Nagelkerke's R2 for all GLMs (Nagelkerke, 1991). We analyzed data using R version 3.5.3 (R Core Team, 2019).

\subsection{Results}

We detected 2,506 birds belonging to 57 species, of which 31 were endemic and four redlisted by the IUCN. Species accumulation curves indicated still increasing species numbers after 10 plots per land-use type. However, sample coverage was $>80 \%$ for all land-use types except rice paddy, suggesting an adequate sampling of the bird communities (SI Chapter 3, Figure 12.1). At plot level, old-growth forest had on average 12.3 species, which was twice the average of all other land-use types (6.1 species). Rice paddy, in contrast, had only 2.9 species on average, which was significantly less than other land-use types except herbaceous fallow which had 5.6 species. Considering endemic species only, rice paddy had fewer species than the unburned land-use types old-growth forest, forest fragment and forest-derived vanilla, but not significantly fewer species than fallow-derived vanilla, woody fallow and herbaceous fallow (Figure 3.2; test results SI Chapter 3, Table 12.4 and Table 12.5).

We encountered two non-native species: Common Myna (Acridotheres tristis) occurred on 12 burned plots and Helmeted Guineafowl (Numida meleagris) on one forest-derived vanilla plot. Four detected species are IUCN listed, all of which are endemic: we found Dusky Tetraka (Crossleyia tenebrosa) and Helmet Vanga (Euryceros prevostii), listed as 'vulnerable', in old-growth forest, Madagascar Sparrowhawk (Accipiter madagascariensis), listed as 'near threatened', in one forest fragment and Madagascar Rail (Rallus madagascariensis), listed as 'vulnerable', in a rice paddy plot (SI Chapter 3, Table 12.3). Gamma diversity 
across ten plots per land-use type was 34 species ( 25 endemic) in old-growth forest, 23 (11 endemic) in forest fragments, 25 (14 endemic) in forest-derived vanilla, 19 (8 endemic) in fallow-derived vanilla, 22 (8 endemic) in woody fallow, 16 (7 endemic) in herbaceous fallow, and 15 ( 2 endemic) in rice paddy (Figure 3.3). Endemic species were overrepresented in old-growth forest and underrepresented in the burned land-use types and rice paddy when compared to the land-use-type-specific null models. Conversely, the bird communities in forest fragments and forest-derived vanilla depicted a relatively representative subset of the overall community (Figure 3.3).

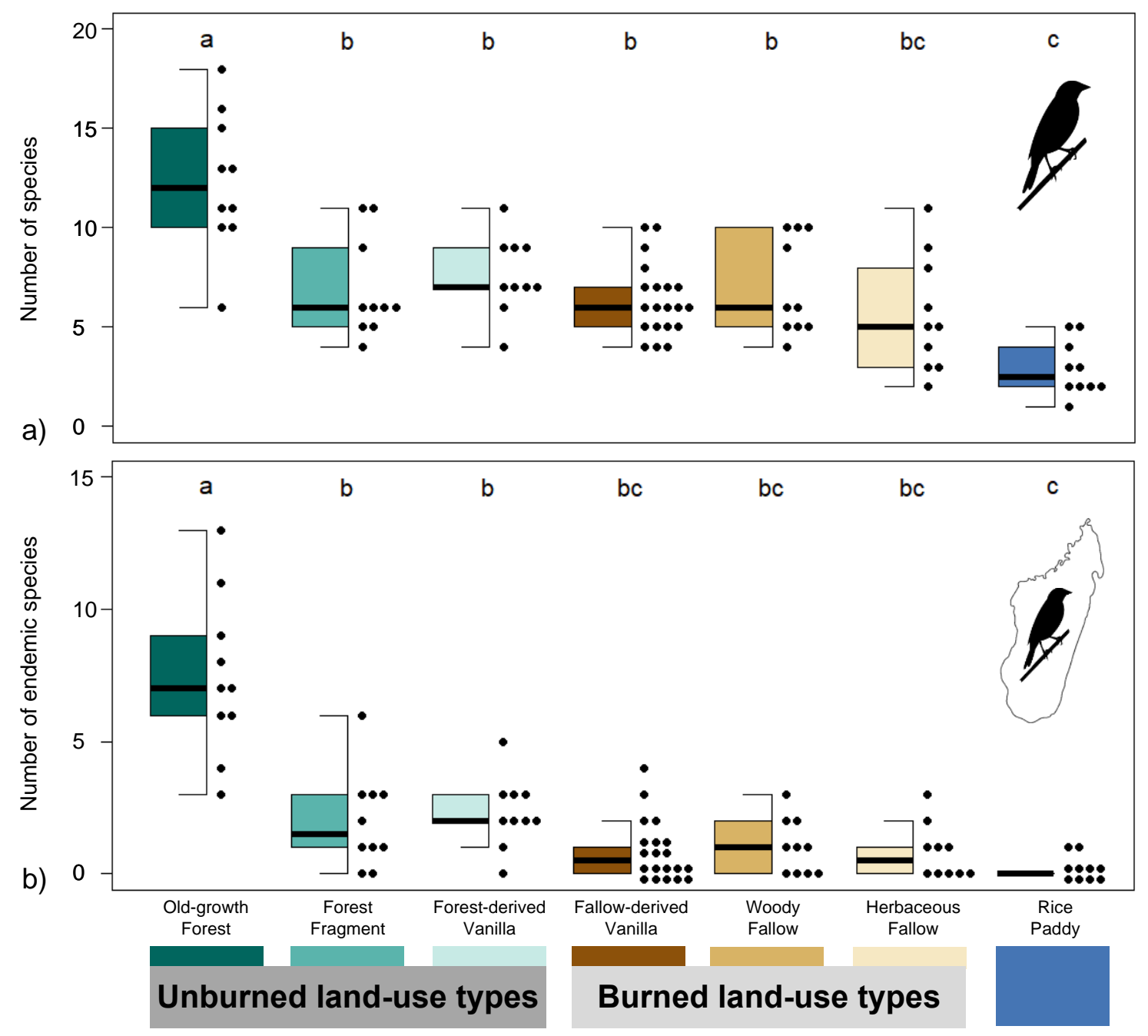

Figure 3.2: Plot-level bird species richness in seven prevalent land-use types in north-eastern Madagascar ( $N=10$, except fallow-derived vanilla $N=20)$ for $\mathbf{a}$ ) all species and $\mathbf{b})$ endemic species only. The black horizontal line represents the median for each land-use type, the lower and upper hinges of each box correspond to the first and third quartiles. The upper whiskers extend to the largest value whereas the lower whiskers extend to the smallest value, no further than $1.5 \mathrm{x}$ the inter-quartile range from the hinges of the box. Letters indicate significant differences between land-use types 
based on pairwise Tukey's honest significance tests for a) and a weighted regression for b) because a Levene-test showed heteroscedasticity in the variances for species richness between land-use types for the latter (Numeric test results in SI Chapter 3, Table 12.4 and Table 12.5).

Species composition (Figure 3.4 b)) differed significantly between land-use types (Multivariate ANOVA based on dissimilarities: $\mathrm{R}^{2}=0.35, \mathrm{p}<0.001, \mathrm{DF}=6$ ). Pairwise comparisons revealed significant differences between old-growth forest and all other land-use types as well as significant differences between pairs of burned and unburned land-use types (SI Chapter 3, Table 12.6). Pairs within the burned respectively unburned land-use types were usually not significantly different (SI Chapter 3 , Table 12.6). These patterns were driven by 13 mainly endemic species occurring exclusively in old-growth forest and another twelve species being confined to unburned land-use types. Burned land-use types, on the other hand, only harbored four exclusive species while rice paddies had six thereof. 22 species occurred in both burned and unburned land-use types (Figure $3.4 \mathrm{a}$ )). Basal area, landscapescale forest cover and elevation structured bird community composition (Figure 3.4 b)).

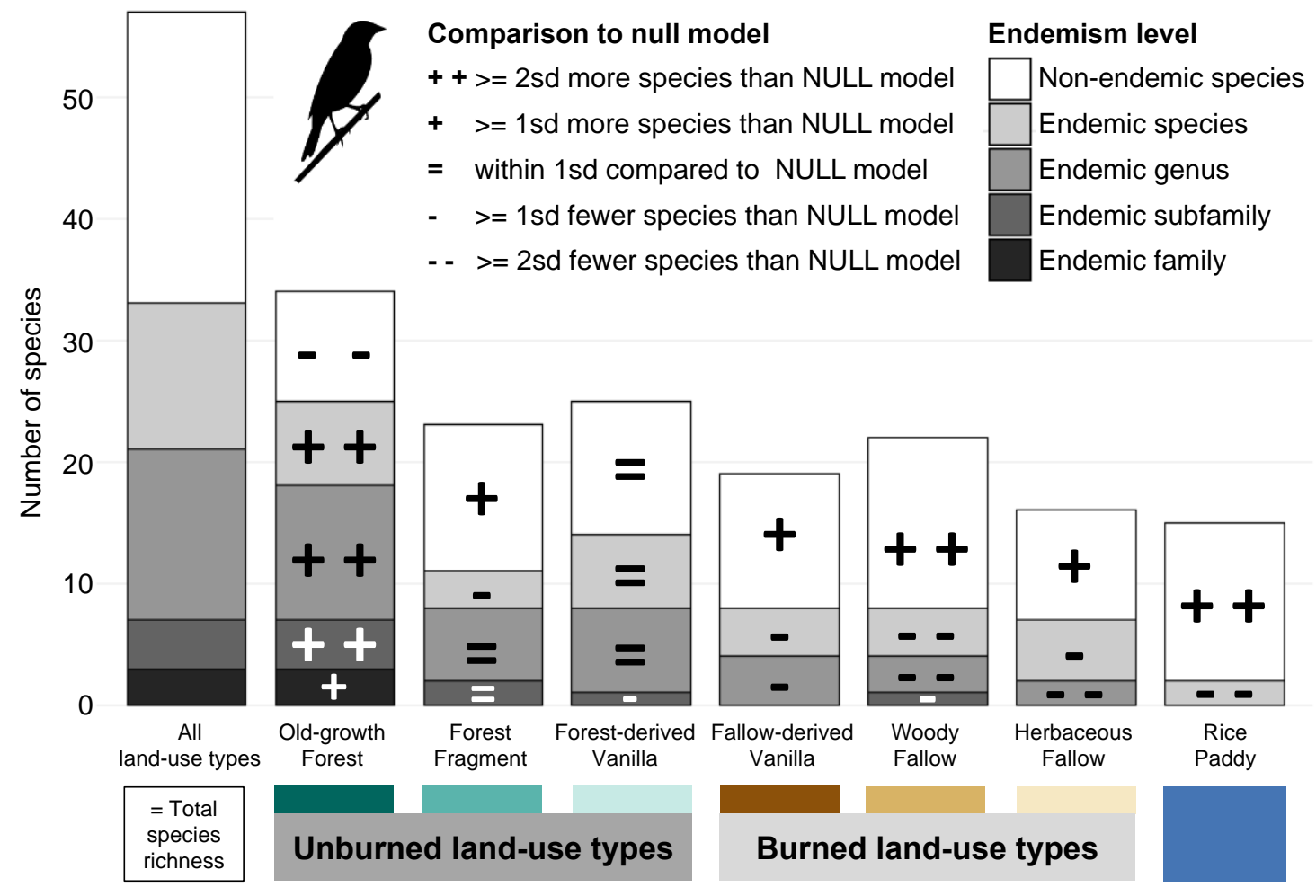

Figure 3.3: Total number of bird species (gamma-diversity) and number of species per endemism level across all plots $(\mathrm{N}=80)$ and in each land-use type $(\mathrm{N}=10$ plots per land-use type; $10 / 20$ subsampled for fallow-derived vanilla). Endemics made up a larger proportion than expected from a null model in old-growth forests. The unburned land-use types forest fragment and forest-derived vanilla came closest to the null model, while non-endemic species were heavily overrepresented in burned 
land-use types and rice paddies. Species endemic on family level did only occur in old-growth forest. SI Chapter 3 Figure 12.2 shows all null model estimates and one respectively two standard deviations including those for endemism levels without observations.

On land-use types with tree presence outside old-growth forest (forest fragment, forestderived vanilla, fallow-derived vanilla and woody fallow), the plot-level parameters basal area and elevation had weak and non-significant associations with non-endemic and endemic species richness (Table 3.1). In contrast, landscape-scale forest cover was strongly and significantly associated with endemic species richness: where landscape-scale forest cover was high, we found $43 \%$ more endemic bird species than in plots with low landscapescale forest cover (Table 3.1). Overall, the model explaining endemic species richness performed well (Nagelkerke's $\mathrm{R}^{2}=0.47$ ) while the model explaining non-endemic species richness performed poorly (Nagelkerke's $\mathrm{R}^{2}=0.13$ ).

Table 3.1: General linear models (GLMs) explaining non-endemic species richness and endemic species richness in land-use types with tree presence outside old-growth forest (Forest fragment, forestderived vanilla, fallow-derived vanilla and woody fallow, 48 plots, 2 plots excluded due to missing basal area data).

\begin{tabular}{|c|c|c|c|c|c|c|c|c|}
\hline \multirow{2}{*}{$\begin{array}{l}\text { Response } \\
\text { Predictors }\end{array}$} & \multicolumn{4}{|c|}{ Number of non-endemic species } & \multicolumn{4}{|c|}{ Number of endemic species } \\
\hline & Estimate & $\begin{array}{r}\text { Standard } \\
\text { Error } \\
\end{array}$ & Z-value & $P$-Value & Estimate & $\begin{array}{r}\text { Standard } \\
\text { Error } \\
\end{array}$ & Z-value & $P$-Value \\
\hline Intercept & 1.56 & 0.17 & 9.37 & $<0.001$ & 0.56 & 0.26 & 1.95 & 0.052 \\
\hline Basal Area & -0.02 & 0.10 & -0.17 & 0.868 & -0.08 & 0.20 & -0.38 & 0.705 \\
\hline Elevation & -0.03 & 0.07 & -0.49 & 0.622 & 0.08 & 0.11 & 0.73 & 0.465 \\
\hline $\begin{array}{l}\text { Landscape-scale } \\
\text { forest cover }\end{array}$ & 0.06 & 0.07 & 0.88 & 0.382 & 0.35 & 0.12 & 2.85 & $<0.001$ \\
\hline $\begin{array}{l}\text { Forest-derived } \\
\text { vanilla }\end{array}$ & 0.03 & 0.20 & 0.14 & 0.891 & -0.04 & 0.31 & -0.12 & 0.90 \\
\hline $\begin{array}{l}\text { Fallow-derived } \\
\text { vanilla }\end{array}$ & 0.16 & 0.21 & 0.75 & 0.45 & -0.55 & 0.42 & -1.31 & 0.190 \\
\hline Woody fallow & 0.21 & 0.27 & 0.75 & 0.45 & -0.59 & 0.54 & -1.08 & 0.278 \\
\hline Observations & & & & 48 & & & & 48 \\
\hline Nagelkerke's R² & & & & 0.125 & & & & 0.466 \\
\hline
\end{tabular}



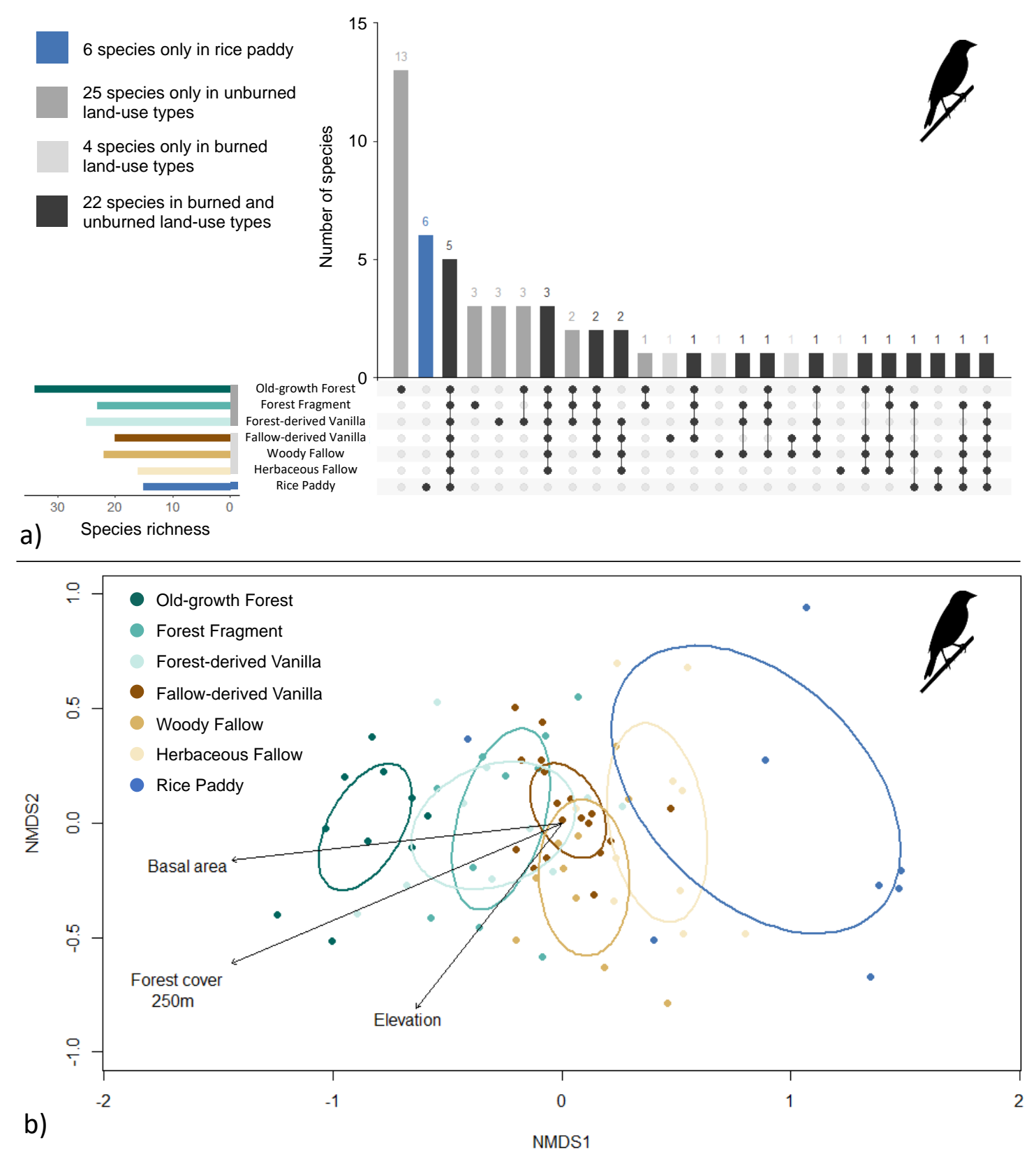

Figure 3.4: Bird species composition across seven land-use types in north-eastern Madagascar. a) Distribution of species by land-use type. Vertical bars show the number of species occurring in each of the unique combinations of land-use types depicted with the connected points. The color of the vertical bars corresponds to species occurring in any combination of unburned (dark grey), burned (light grey), or unburned and burned land-use types (black). The vertical bar representing species occurring exclusively in rice paddy is in blue. The horizontal bars depict the gamma diversity per land-use type. b) Species composition across land-use types from nonmetric-multidimensional-scaling (stress value $=0.174$ ). Colors depict the different land-use types and ellipsoids indicate standard error of the weighted average of scores for each land-use type. Pairwise comparison between landuse types are displayed in SI Chapter 3 Table 12.6. Basal area, landscape-scale forest cover and elevation are plotted as environmental variables. 


\subsection{Discussion}

We assessed the value of a smallholder landscape mosaic in north-eastern Madagascar for bird conservation by comparing six land-use types with old-growth forest. Alpha and gamma diversity were highest in old-growth forest and lowest in rice paddy. Conversely, alpha diversity did not differ significantly between other land-use types and between the two kind of vanilla agroforests. Here, the number of endemic species, species composition and gamma diversity revealed differences. Furthermore, endemic species were overrepresented in old-growth forest, representatively occurring in forest fragment and forest-derived vanilla and underrepresented in fallow-derived vanilla, woody fallow, herbaceous fallow and rice paddy. Across plots outside old-growth forest with tree presence, landscapescale forest cover was strongly positively associated with endemic species richness, but not with non-endemic species richness. Overall, these results highlight the value of old-growth forest for birds and the important role of forest-derived vanilla agroforests for endemic birds.

\subsubsection{High value of old-growth forests for bird conservation}

We present compelling evidence for the importance of old-growth forests for bird conservation, corroborating findings from Madagascar (Irwin et al., 2010; Rocha et al., 2015) and other tropical regions (Gibson et al., 2011). Firstly, old-growth forest had the highest alpha and gamma diversity of all land-use types studied. Secondly, bird communities in oldgrowth forest had many unique species and distinct community assemblages. Thirdly, endemic species were overrepresented in old-growth forest and species endemic on family level only occurred therein. These results are in line with other studies across tropical landuse gradients, which suggest that endemic species are often better suited for assessing the conservation value of a habitat than total species richness (de Lima et al., 2013; Waltert et al., 2011). Fourthly, we encountered threatened and near-threatened species most frequently in old-growth forest. Similarly, the only two other studies comparing bird diversity between forest sites and agricultural sites in eastern Madagascar found a strong turnover of species between forest and the agricultural mosaic (Martin et al., 2012; Rocha et al., 2015). The uniqueness of bird communities found in old-growth forests thus underlines the importance of well-governed protected areas and forest conservation policies in Madagascar to preserve its highly endemic biodiversity (Rakotomanana et al., 2013). 


\subsubsection{Rice paddies harbor few but specialized birds}

Although rice paddies had the lowest species richness, they might play an important role for certain specialized wetland species, as a total of six species were exclusively found in them; one of which was the endemic and red-listed Madagascar rail (Rallus madagascariensis). However, many other species typically found in wetlands did not occur in rice paddy, emphasizing the conservation needs for wetlands in Madagascar (Kull, 2012).

\subsubsection{Vanilla agroforests as a conservation opportunity?}

Vanilla agroforests are an important land-use in the study area, but little is known about the value of vanilla agroforest for biodiversity. The lack of ecological research in vanilla agroforests is surprising given our knowledge on the contributions of other agroforests to biodiversity conservation (Bhagwat et al., 2008). The only studies available for vanilla are from a recent rapid biodiversity assessment: Hending et al. $(2018,2019)$ reported fewer lemur sightings in vanilla agroforests than in forests and a diverse plant community in traditionally, less intensively managed vanilla agroforests in proximity to forests. Similarly, we find vanilla agroforests to host fewer bird species than old-growth forest and show that landscape-scale forest cover is essential for endemic birds. The conservation value of vanilla agroforestry can, however, only be assessed relative to other land uses and, most importantly, in comparison to the land-use the agroforest was derived from. This distinction lacks in previous studies (Hending et al., 2018, 2019).

The conversion of existing forest fragments into forest-derived vanilla agroforests causes, perhaps surprisingly, little change for birds. We explain this by the small size, the high level of wood extraction, and abundant disturbances in studied forest fragments, which has already caused losses in bird diversity compared to the contiguous old-growth forest. This pattern is typical for tropical rainforest fragments, which are sensitive to disturbance and fragmentation (Turner, 1996).

As an alternative to forest-derived vanilla agroforestry, a forest fragment could also be burned and used for hill rice production, which would convert the land into an herbaceous fallow in the short run and a woody fallow thereafter. According to our results, this conversion leads to a loss of higher-level-endemic species, making vanilla farming a more birdfriendly land-use option in comparison to burning for shifting hill rice cultivation. Another open question is how forest-derived agroforests are able to sustain tree cover in the long run: agroforests often loose shade-trees over time, as shown for cacao (Tscharntke et al., 2011) and coffee (Geeraert et al., 2019). In contrast, a first study in Malagasy vanilla 
agroforest shows stable canopy cover along a chronosequence, suggesting that the loss of shade-trees may be less pronounced in vanilla agroforestry (Martin et al., 2020c).

Fallow-derived vanilla had a lower conservation value than forest-derived vanilla and was most similar to woody fallow, which is the land-use type these agroforests were derived from. However, concluding a low conservation value of fallow-derived vanilla for biodiversity would be short-sighted. Instead of establishing a vanilla agroforest, a woody fallow owner may also continue the shifting cultivation cycle. Ultimately, the land under shifting cultivation might enter a degradation cycle with disastrous effects for biodiversity, ecosystem services and rice production (Styger et al., 2007), making vanilla farming, respectively the transformation from shifting cultivation to permanent agroforestry, a more biodiversity-friendly land-use option.

Conversely, planting vanilla inside old-growth forest would lead to a marked loss in bird species, with higher-level endemics being more likely to be lost. This underpins the limits of agroforests and heavily used forest fragments for bird conservation, while stressing the importance of old-growth forest conservation (see above). In spite of this, we have little evidence of large-scale encroachment of vanilla agroforests into old-growth forest at places we have visited. At least in Marojejy National Park, fast-paying activities like illegal logging of precious wood (Patel, 2007) seem to threaten biodiversity at a greater extent than vanilla cultivation.

Besides direct effects, vanilla cultivation could also indirectly influence biodiversity in our study region by generating income as a high-value cash crop. High vanilla prices could enable farmers to reduce the land-intensive shifting cultivation for staple crop production and purchase imported rice instead, thus reducing the pressures on remaining forests. Yet this option is impeded by fluctuating vanilla prices and the great risk of vanilla theft in the region (Laney \& Turner, 2015), which both make an exclusive focus on vanilla cultivation a risky option for farmers. Vanilla cultivation could also negatively affect biodiversity, because farmers often invest their return from vanilla sales into house construction (Hänke et al., 2018), which might lead to an increase in demand for local timber. This, in turn, might drive selective logging in forests (Zaehringer et al., 2017), with potentially negative effects for biodiversity (Irwin et al., 2010).

We conclude that while fallow-derived agroforests are less valuable for birds than forestderived agroforests, they may take fallow land out of the shifting cultivation cycle, possibly preventing further ecological degradation. Conversely, forest-derived agroforests may degrade forest, but the change compared to already-disturbed forest fragments is limited. 
Additionally, forest-derived agroforests may avoid the loss of tree cover from forest fragments by offering an income from vanilla farming.

\subsubsection{Bird-friendly vanilla agroforest management}

Landscape-scale forest cover benefits endemic bird species richness and is maintained by old-growth forest, forest fragments and forest-derived vanilla agroforest. Keeping trees in forest-derived agroforests may, however, be directly and indirectly disadvantageous for farmers, leading to possible conservation trade-offs. Directly, since trees cannot be used for timber and fuelwood (Zaehringer et al., 2017), and indirectly, because trade-offs could exist between yields and canopy closure. However, a recent study has shown no trade-offs between yields and canopy cover under current farming practices (Martin et al., 2020c). Nonetheless, given these potential economic losses for farmers, sustainability standards could provide incentives to keep trees producing 'high-shade vanilla', following examples from coffee and cacao (Perfecto et al., 2005; Tscharntke et al., 2014). Importantly, sustainability standards should encourage tree recovery in fallow-derived agroforests and tree maintenance in forest-derived agroforests but avoid incentivizing the establishment of new forestderived agroforests (Martin et al., 2020b). Sustainability standards should thus be sensible to land-use history, leading to an agricultural landscape with optimized benefits for people and nature.

\subsubsection{Landscape forest cover as a predictor of bird diversity outside old-growth for- est}

Landscape-scale forest cover had a positive effect on endemic species richness in vanilla agroforests, forest fragments and woody fallows and also affected community composition. Non-endemic bird species richness was, however, not affected (Table 3.1). Consistent with findings from Afro-tropical agroforestry (Waltert et al., 2011), this suggests that endemic bird species need a minimum amount of forest cover on a landscape-scale to survive. This threshold is likely species-specific (Ocampo-Ariza et al., 2019) and currently unknown for our study area. Forest cover in the agricultural landscape is maintained by forest fragments and forest-derived vanilla agroforests. This highlights the importance of landscape-scale action in conserving old-growth forest as well as tree cover within agroforests and forest fragments (Perfecto et al., 2005; Tscharntke et al., 2014). Given the recent loss of forest cover, some bird species in the region might show an extinction debt, since present day forest cover might not provide enough habitat for their current populations to persist in the long run (Kuussaari et al., 2009). This might potentially confound our results, but our study 
design is not aimed at investigating extinction debts. However, evidence suggests that extinction debts are highest for long-lived species (Kuussaari et al., 2009) and since most species in our study are relatively small and short-lived, we suggest a minor role of extinction debts on the results of our study.

\subsection{Conclusion}

Old-growth forests are indispensable for many endemic bird species. However, vanilla agroforestry may provide an important habitat for birds within the agricultural landscape mosaic, but their conservation value fundamentally depends on land-use history: forest-derived agroforests are most similar to small and selectively logged forest fragments, whereas fallow-derived agroforests are most similar to fallow land. Importantly, forest-derived vanilla agroforest may avoid the loss of forest fragments, while fallow-derived vanilla agroforest may reduce land degradation through shifting cultivation, by providing a more attractive alternative land-use. The stark contrasts between fallow-derived and forest-derived vanilla agroforests further suggest that a differentiation based on land-use history represents a promising avenue for future research and applications in tropical agroforestry systems beyond vanilla.

\subsection{Authors' contributions}

DAM, KO, AW, AA and HK conceived the ideas and designed methodology; DAM, RA, SD and ER collected bird data; KO collected and processed tree and canopy closure data; DAM analyzed the data; DAM led the writing of the manuscript. All authors contributed to the manuscript and gave final approval for publication.

\subsection{Acknowledgements}

We thank all chef de fokontany, landowners and Madagascar National Parks for granting us access to sites and information. We are grateful to Marie Rolande Soazafy and all research assistants involved in data collection and to two reviewers who provided valuable feedback. We collected data under research permits $\mathrm{N}^{\circ} 100 / 17 / M E E F / S G / D G F / D S A P / S C B . R e$, N¹63/17/MEEF/SG/DGF/DSAP/SCB.Re, N¹8/18/MEEF/SG/DGF/DSAP/SCB.Re and №254/18/MEEF/ SG/DGF/DSAP/SCB.Re granted by the Ministry of Environment and Sustainable Development, Antananarivo. This study was financially supported by the Niedersächsisches Vorab of Volkswagen Foundation as part of the research project 'Diversity Turn in Land Use Science' (Grant number 11-76251-99-35/13 (ZN3119)). 


\subsection{Conflict of interest}

The corresponding author confirms on behalf of all authors that there have been no involvements that might raise the question of bias in the work reported or in the conclusions, implications, or opinions stated.

\subsection{Data accessibility}

The data that support the findings of this study are available on Data Dryad: Martin, D. A., Andriafanomezantsoa, R., Dröge, S., Osen, K., Rakotomalala, E., Wurz, A., Andrianarimisa, A., \& Kreft, H. (2020), Data from: Bird diversity and endemism along a land-use gradient in Madagascar: the conservation value of vanilla agroforests. Data Dryad, https://doi.org/10.5061/dryad.83bk3j9nm 


\section{Listening to a changing landscape: acoustic indices reflect bird species richness and plot-scale vegetation structure across dif- ferent land-use types in north-eastern Mad- agascar}

Saskia Dröge, Dominic Andreas Martin, Rouvah Andriafanomezantsoa, Zuzana Burivalova, Thio Rosin Fulgence, Kristina Osen, Eric Rakotomalala, Dominik Schwab, Annemarie Wurz, Torsten Richter, \& Holger Kreft

Contribution: Conceptualization, Data curation, Investigation, Project administration, Supervision, Validation, Writing - review \& editing

Status: Published in Ecological Indicators; https://doi.org/10.1016/i.ecolind.2020.106929.

\subsection{Abstract}

New technologies like ecoacoustic surveys promise time and cost efficiency for biodiversity assessments, serve as a basis for effective conservation policies, and are particularly appealing for remote and highly diverse tropical areas. Acoustic indices facilitate the analysis of large acoustic datasets but no consensus on their performance has been reached yet. We evaluated the efficacy of four acoustic indices (Acoustic Complexity Index, Acoustic Diversity Index, Acoustic Evenness Index, Acoustic Entropy) for sound data analysis and biodiversity assessments inside a national park and the agricultural mosaic landscape of northeastern Madagascar, a global biodiversity hotspot. We used self-built sound recorders to 
continuously record soundscapes on 80 plots across seven land-use types (old-growth forest, forest fragment, forest-derived and fallow-derived vanilla agroforest, herbaceous and woody fallow, rice paddy) and compared index values between land-use types, assessed the correlation with bird species richness as measured by point counts, and related the acoustic indices to plot- and landscape-scale parameters. The Acoustic Diversity Index, Acoustic Evenness Index (inverse) and Acoustic Entropy were highest in old-growth forest and lowest for rice paddies and fallow land. Index values for structurally similar land-use types did not differ significantly from each other. The correlation of the three acoustic indices with bird species richness was strongest during daytime $\left(R^{2} \geq 0.30\right)$. Differences in the index values were best explained by land-use type and vegetation density. Our results showed that all investigated indices except the Acoustic Complexity Index were suitable biodiversity indicators for a tropical, agricultural landscape. Soundscape diversity was positively affected by plot-scale vegetation structure, emphasizing the importance of forests and particularly old-growth forest for conservation. We demonstrated that acoustic indices and sound recordings are a useful tool for assessing biodiversity in tropical agricultural mosaic landscapes. To realize the full potential of ecoacoustics in conservation, sampling guidelines and user-friendly analysis packages will be key to facilitate a wider implementation.

Keywords: Acoustic indices, rapid biodiversity assessment, conservation, ecoacoustics, land-use change, Madagascar

\subsection{Introduction}

The anthropogenic alteration and overexploitation of the planet's ecosystems lead to global biodiversity loss at an unprecedented rate (Jantz et al., 2015; Newbold et al., 2015). Despite ambitious global targets to reduce biodiversity loss (Tittensor et al., 2014), pressure on biodiversity has increased notably over the past four decades (Butchart et al., 2010). Currently, agricultural expansion and intensification are the main drivers of the biodiversity crisis (IPBES 2019).

Detailed accounts of the state and trends of biodiversity at a local scale are thus needed to inform effective conservation policies and environmental management practices (IPBES 2019). However, field surveys, especially in remote tropical areas with high species diversity, can be time-consuming as well as logistically and taxonomically challenging (Digby et al., 2013; Gardner et al., 2008). Ecoacoustic surveys are a promising tool to overcome these limitations by reducing survey costs substantially through the use of open-source acoustic hardware and software (Hill et al., 2018; Whytock \& Christie, 2017). 
Ecoacoustic surveys rely on the Acoustic Niche Hypothesis which posits that each environment has a soundscape (Pijanowski et al., 2011; Schafer, 1993). The partitioning of the soundscape in time and frequency range results into a limited number of acoustic niches (Krause, 1993). The occupancy of acoustic niches by vocalizing species is regarded as an indicator for ecological integrity (Servick, 2014) and the number of species in a habitat is expected to increase the variety and complexity of acoustic signals (Sueur et al., 2008). In this context, it is important to note that vocalizing communities are not limited to the audible range and surveys may also include infra- and ultrasonic sounds.

Continuing developments in data storage capacities allow ecologists to gather large acoustic datasets in short time, but manual analysis of full datasets remains time-consuming. One alternative to a manual or species-focused sound data analysis is to assess the complete soundscape by computing various acoustic indices that determine, for example, the amplitude and frequency variation within a recording (Buxton et al., 2018; Sueur et al., 2008).

Rapid biodiversity assessment tools are particularly helpful in highly diverse tropical regions such as Madagascar. The country is a global biodiversity hotspot with an exceptional endemism (Myers et al., 2000), which has lost $44 \%$ of its forest cover over the last six decades (Vieilledent et al., 2018). In north-eastern Madagascar, shifting cultivation of hill rice is the main driver of deforestation (Zaehringer et al., 2015). Successional stages within the shifting cultivation cycle and permanent small-scale vanilla agroforestry lead to a diverse landscape mosaic. The potential of vanilla agroforests for conservation is still poorly studied but likely depends on land-use history, that is whether an agroforest is established inside forest or on formerly forested open fallow land (Martin et al., 2020b).

The aim of this study was to investigate the efficacy of acoustic indices as a biodiversity indicator in the tropical, agricultural landscapes of north-eastern Madagascar. Specifically, we tested (i) if acoustic indices vary systematically across 80 plots covering the seven predominant land-use types of the study region (old-growth forest, forest fragments, forestderived vanilla agroforests, fallow-derived vanilla agroforests, woody fallow, herbaceous fallow, rice paddy); (ii) if acoustic indices serve as a reliable proxy for biodiversity; and (iii) which environmental parameters co-vary with acoustic indices. 


\subsection{Materials and methods}

\subsubsection{Study area and design}

We conducted this study in the SAVA region in north-east Madagascar (Figure 4.1). The climate is tropical-humid with a mean annual temperature of $24^{\circ} \mathrm{C}$ and annual rainfall of 2220 mm. The rainy season lasts from November to April (Tattersall \& Sussman, 1975).

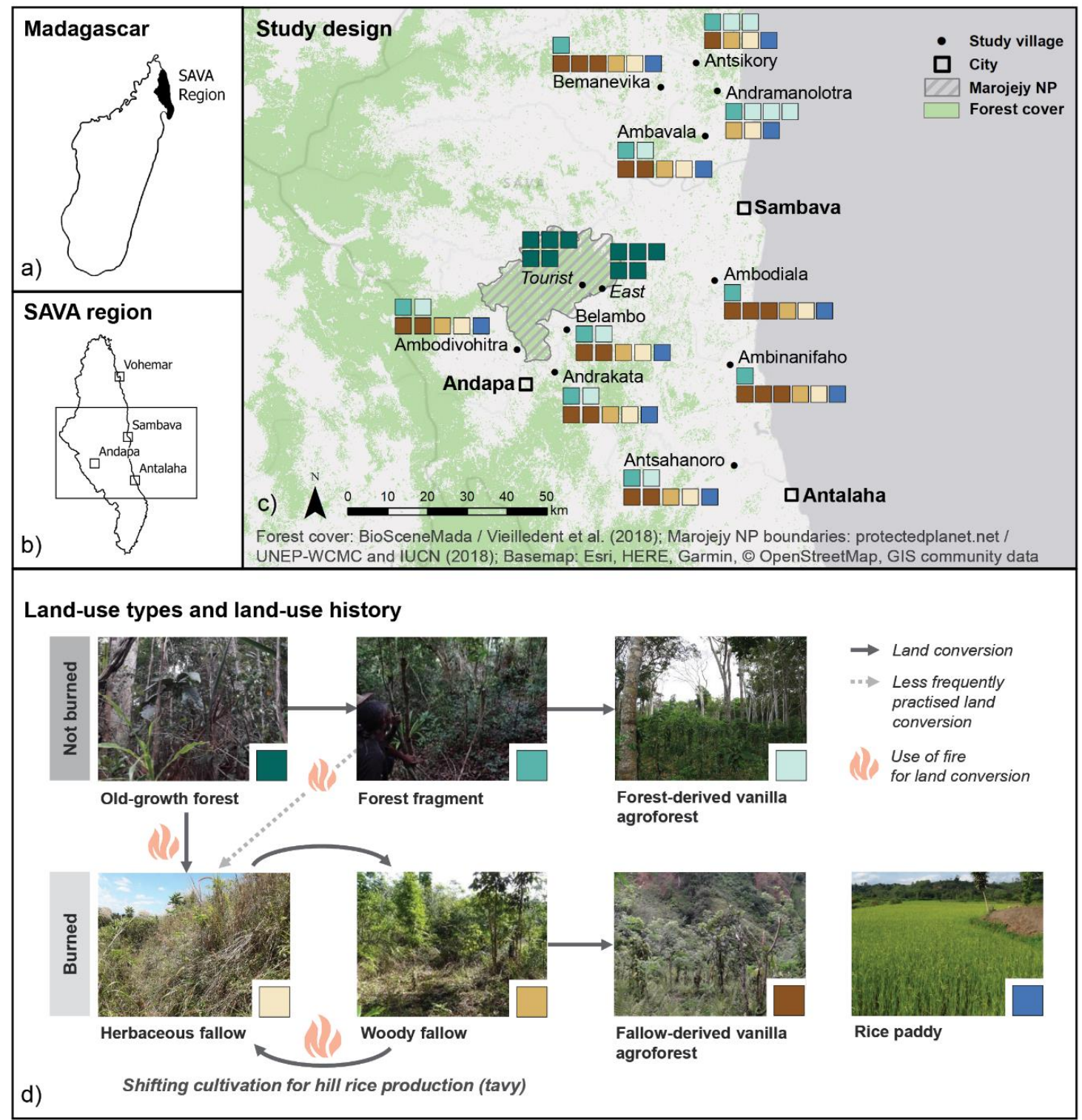

Figure 4.1: Study area, study design and land-use types. a) Location of SAVA region in north-eastern

Madagascar and b) study region therein. c) Distribution of 80 plots across 10 different villages and Marojejy National Park in the SAVA region. d) Overview of studied land-use types and typical transformation pathways. 
In our study area, there are seven prevalent land-use types (Figure 4.1): i) old-growth forests, which represent lowland tropical rainforests, the natural vegetation in the region; ii) forest fragments, which are small remnants of old-growth forest, typically used for timber extraction by private landowners. Furthermore, we included two types of vanilla agroforests: iii) forest-derived vanilla agroforests, established inside of remaining forests, and iv) fallow-derived vanilla agroforests, established by conversion of fallow land that was formerly part of the shifting cultivation cycle. In forest-derived vanilla agroforests, the forest understory is thinned or cleared but native trees usually remain as shade trees and smaller trees are kept or additionally planted as support structures for the vanilla vines. In fallowderived vanilla agroforests, in turn, shade and support trees either represent secondary regrowth or were subsequently planted. Additionally, we distinguished v) herbaceous and vi) woody fallows as successional stages within the shifting cultivation cycle of rainfed upland rice farming (tavy), different from vii) irrigated rice paddies. Herbaceous fallows last burned $\sim 1$ year before the start of our study in late 2017, while woody fallows last burned 4-16 years before.

For studying the seven land-use types, we selected 80 plots of 25 m radius, with 10 replicates for each land-use type (20 replicates for fallow-derived vanilla agroforests). The oldgrowth forest plots were at two sites within Marojejy National Park (241 to $701 \mathrm{~m}$ above sea level). The plots in the remaining land-use types were in 10 villages ( 7 to $819 \mathrm{~m}$ above sea level), placed using a nested design with one plot per land-use type per village, except for the two types of vanilla agroforest, which could not be equally distributed across villages (see Figure 4.1). The mean minimum distance from one plot to the closest neighbouring plot, regardless of land-use type, was $719 \mathrm{~m}(S D \pm 438 \mathrm{~m})$ with a minimum of $260 \mathrm{~m}$.

\subsubsection{Plot characteristics}

To quantify the structural complexity of the focal plots, we assessed basal area and vegetation density. Firstly, we calculated the basal area of all living trees with a diameter at breast height $\geq 8 \mathrm{~cm}$. Secondly, we estimated the overall vegetation density including non-woody vegetation. To this end, we established vegetation density profiles (adapted from Van Der Maarel (1970)) based on photographs taken in cardinal directions from the plot centre. From the photos, we estimated the vegetation density of six 0.5 m-layers between 0 and 3 $m$ above ground in $\%$ and used all layers to calculate the average vegetation density for each plot. We further extracted the elevation above sea level of all plots from the digital elevation model AW3D30 (Japan Aerospace Exploration Agency, 2018). To assess landscape-level 
effects of forest on acoustic indices, we calculated the forest cover within a $250 \mathrm{~m}$ radius around the plot centre using 2017 binary forest cover data (Vieilledent et al., 2018).

\subsubsection{Bird point counts}

We conducted one point count per plot between October and December 2017 and one point count per plot between August and December 2018 based on Bibby et al. (2000); SI Chapter 4 , Table 12.10. We reversed the sequence of plots in the second year to avoid possible biases due to seasonal changes. In the old-growth forest, we did point counts only in 2018 but repeated them at the beginning and end of the field season (August/September; December) to cover similar seasonal conditions as in the other land-use types. We call the two sampling periods 'year' in the rest of the manuscript.

Each point count lasted 40 minutes and was done by two observers starting around sunrise and finishing before 8:15 AM (SI Chapter 4, Table 12.10). For identification of bird species, we followed the field guide of Hawkins et al. (2015) and BirdLife nomenclature (Handbook of the Birds of the World and BirdLife International, 2018). We combined the 2017- and 2018-point count data to calculate the cumulative bird species richness for each plot, including only detections within the $25 \mathrm{~m}$ plot radius and excluding detections of species only seen in flight. Further details of bird point counts are described in Martin et al. (2020a).

\subsubsection{Sound recordings}

We used self-built, autonomous Solo audio recorders (Whytock \& Christie, 2017) with two omnidirectional microphones (SI Chapter 4, Figure 12.4; SI Chapter 4, Table 12.7 - Table 12.8) and deployed them in the plot centre at $130 \mathrm{~cm}$ height for at least 72 hours (continuous recording). We did the sound recordings during the same field work as point counts (October - December 2017; August - December 2018) and followed the same sampling sequence as for point counts (SI Chapter 4, Table 12.10).

\subsubsection{Acoustic indices}

We randomly selected one continuous recording section (24 hours, starting at 12 AM) per year per plot (SI Chapter 4, Table 12.10). We visually inspected spectrograms of the chosen recording section and selected a different 24-hour section of that recording if precipitation or anthropogenic noise was high. We could not use one corrupted 2017 recording, resulting in a total of 3,816 recording hours used for index calculation.

We used R version 3.5.0 (R Core Team, 2019) and the multiple_sounds function of the package soundecology (Villanueva-Rivera \& Pijanowski, 2018) to calculate four acoustic indices: 
the Acoustic Complexity Index ACI (Pieretti et al., 2011), the Acoustic Diversity Index ADI (Villanueva-Rivera et al., 2011), the Acoustic Evenness Index AEI (Villanueva-Rivera et al., 2011) and Acoustic Entropy $\mathbf{H}$ (Sueur et al., 2008). We selected the four acoustic indices based on their frequent use in recent ecoacoustic studies. To limit computation time, we used the setting of a maximum frequency $(12 \mathrm{kHz})$ available for the ACI, ADI and AEI. To exclude low frequency background noise, we used the setting of a minimum frequency 0.2 $\mathrm{kHz})$ available for the ACI and a dB threshold ( $-40 \mathrm{~dB})$ available for the ADI and AEI. We provide an overview of all computational settings for index calculation in Table I in SI Chapter 4.

We calculated the acoustic indices on 1-min-basis, resulting into 1,440 index values per continuous recording. To receive a final value per plot, we calculated the median of the full 24-hour-recording duration using the 1-min-based values of the 2017 and 2018 recording per plot. We did the same for shorter time intervals, specifically the night-time (12 AM - 5 $\mathrm{AM}$; $6 \mathrm{PM}$ - $12 \mathrm{AM}$ ), dawn chorus (5 AM - $8 \mathrm{AM}$ ) and daytime interval (5 AM - $6 \mathrm{PM})$. Because high AEI values represent high evenness within a recording (few or no signals), and to facilitate comparability, we present the results of this index inverse (1-AEI).

\subsubsection{Statistical analysis}

We performed all statistical analysis in R version 3.5.0 (R Core Team, 2019). We used the Shapiro-Wilk test to assess whether the acoustic index values (medians) are normally distributed. To determine differences in acoustic indices between the land-use types and because of non-normal distribution of the data, we performed a Kruskal-Wallis test and a pairwise Wilcoxon rank-sum test including Bonferroni correction. To test for a correlation between observed bird species richness and acoustic indices, we fitted linear and second-order polynomial models and selected the most parsimonious model based on the Akaike Information Criterion (AIC) (Akaike, 1998). We used the polynomial model only if its AIC value was at least two units lower as models with AIC values less than two units apart are equivalent and do not justify the use of higher complexity to describe a relationship (Burnham \& Anderson, 1998).

We followed the approach of Burivalova et al. (2018) to investigate differences in the acoustic index values between land-use types and over time. We used the lmer function of the package lme4 (Bates, 2014) to build linear mixed-effect models for every minute of the day: we included basal area, elevation, forest area within $250 \mathrm{~m}$ radius around plot centres, landuse type and vegetation density of plots as fixed effects (Table 12.9). We included the 10 
study villages and the two old-growth forest sites as a random effect. We rescaled the fixed continuous variables between zero and one and excluded two fallow-derived vanilla agroforests due to missing basal area data.

We used the dredgeDS function of the package MuMIn (Bartoń, 2020) that produces models with all possible combinations of the five explanatory variables, resulting in $2^{5}(=32)$ models. We then sorted all 32 models for each acoustic index and each minute of the day according to AIC (Akaike, 1998; Burnham \& Anderson, 1998). Subsequently, we calculated the relative variable importance for each fixed effect by summing up the Akaike weights over all models in which the effect appears. We did this separately based on how the fixed effect was considered within the model (positive; negative).

\subsection{Results}

Three of the acoustic indices (ADI, 1-AEI, H) varied systematically between the seven land-use types in north-eastern Madagascar (Figure 4.2). Values for these acoustic indices were highest for old-growth forest and forest fragments (Figure 4.3) and showed a strong correlation with bird species richness (Figure 4.4). The plot-level vegetation density explained the differences in acoustic indices among the land-use types best (Figure 4.5).

\subsubsection{Temporal variation of acoustic indices}

The ADI, 1-AEI and $\mathrm{H}$ showed a distinct temporal pattern (Figure 4.2): index values were high during night-time for all land-use types. After sunrise, we observed a strong decrease of the three acoustic indices in rice paddies and herbaceous fallows and values were lowest between $11 \mathrm{AM}$ and $3 \mathrm{PM}$. Index values for woody fallows, fallow-derived and forest-derived vanilla agroforests decreased moderately after sunrise. The old-growth forest and forest fragments had high values throughout the day. The ACI showed no distinctive pattern for the different land-use types.

\subsubsection{Differences in acoustic indices among land-use types}

The ADI, the 1-AEI and $\mathrm{H}$ showed strongest differences in index values between land-use types during daytime, between 5 AM and 6 PM (Figure 4.3). Differences were less substantial but still apparent during the full recording and the dawn chorus and became indistinct during night-time. These three acoustic indices showed highest values for old-growth forest and lowest values for rice paddy. During daytime, the index values for rice paddies, herbaceous and woody fallows, and fallow-derived vanilla agroforests were significantly lower 
$(\mathrm{p}<0.05)$ compared to old-growth forest and forest fragments, with the $\mathrm{H}$ in woody fallow being the only exception (SI Chapter 4, Table 12.11 - Table 12.13). The ACI showed the lowest values for the old-growth forest and the highest values for the herbaceous fallow.

\subsubsection{Correlation of acoustic indices with bird species richness}

There was a significant positive correlation between bird species richness and ADI, 1-AEI and $\mathrm{H}$, respectively, for all time intervals (except 1-AEI during dawn chorus) (Figure 4.4). The strongest correlation between bird species richness and the ADI (adj. $\mathrm{R}^{2}=0.38$ ), the 1-AEI (adj. $\left.\mathrm{R}^{2}=0.30\right)$ and $\mathrm{H}\left(\mathrm{adj} . \mathrm{R}^{2}=0.39\right)$ occurred between $5 \mathrm{AM}$ and $6 \mathrm{PM}$ (daytime interval). The second order polynomial model outperformed the linear model during this time interval. During night and dawn chorus, adjusted $\mathrm{R}^{2}$ values were low and the linear model performed better (SI Chapter 4, Table 12.14). For the ACI, the correlation with bird species richness was significantly negative. However, adjusted $\mathrm{R}^{2}$ values were very low (adj. $\mathrm{R}^{2}<0.09$ ), indicating only a weak correlation.

\subsubsection{Structural parameters of plots driving acoustic indices}

The most parsimonious models explaining differences in ADI, 1-AEI and $\mathrm{H}$ values among plots included most frequently the variables vegetation density (during the whole day) and land-use type (especially during daytime; Figure 4.5). Furthermore, the basal area was a positive determinant for the 1-AEI. For the ACI, the best models most frequently included basal area and land-use type as variables. A higher basal area was negatively associated with ACI values and the elevation and vegetation density played only a minor role. The forested area in $250 \mathrm{~m}$ radius around plot centres was of low relevance to all four acoustic indices. 

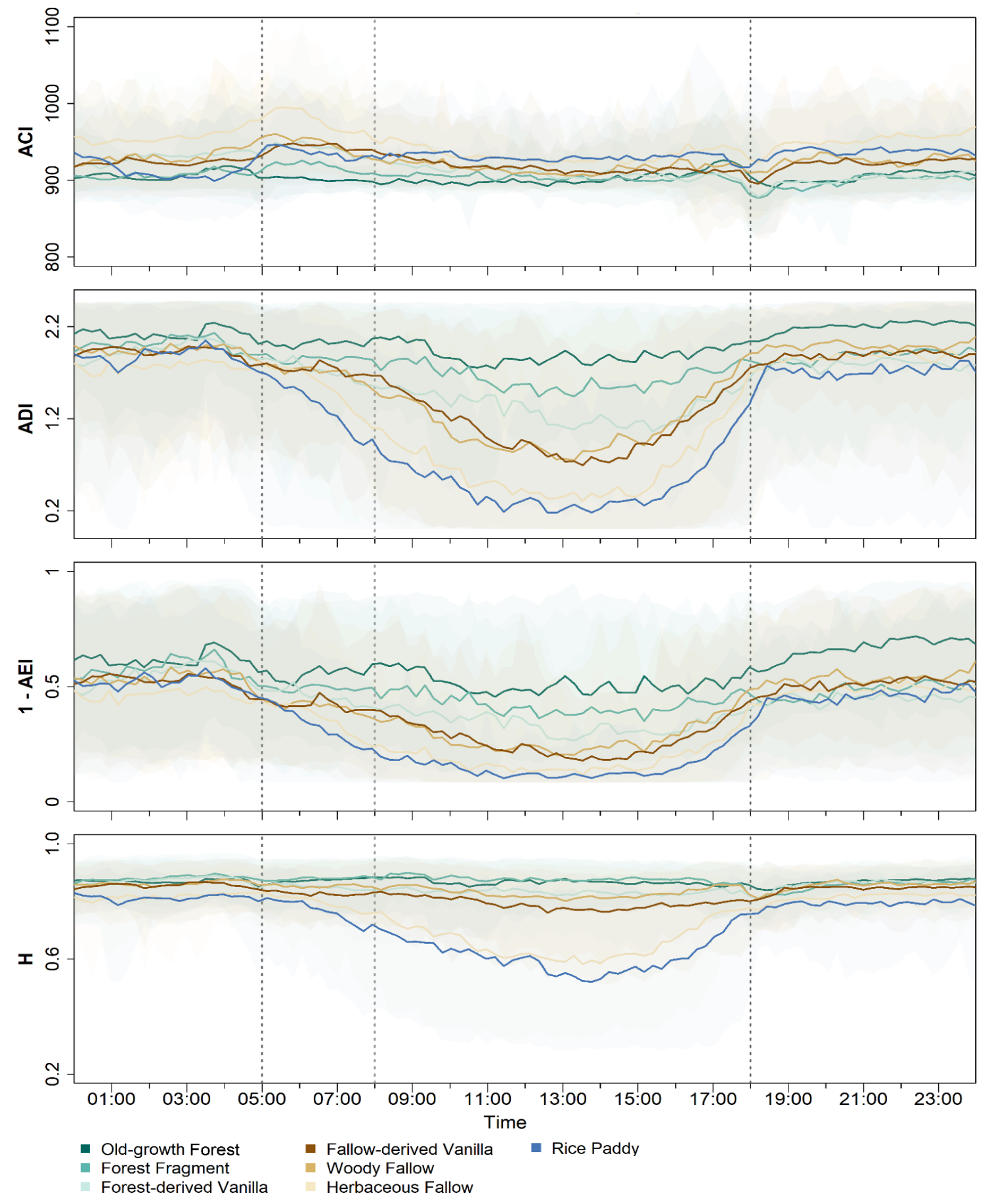

Figure 4.2: Temporal variation of the Acoustic Complexity Index (ACI), the Acoustic Diversity Index (ADI), the inverse Acoustic Evenness Index (1-AEI) and Acoustic Entropy (H) for the different land-use types. We used one continuous recording of 24 hours of each year $(2017 ; 2018)$ per plot and calculated the acoustic indices on 1-min-basis. Based on 10 replicates per land-use type $(20$ replicates for fallow-derived vanilla), we show the median (line) and 95\%-confidence interval (background colour) for each land-use type. To facilitate interpretation and visualization, we applied locally weighted polynomial regression (LOWESS) on the medians and confidence intervals. Dotted lines mark sunrise (equivalent to start time of point counts), end time of point counts, and sunset. 

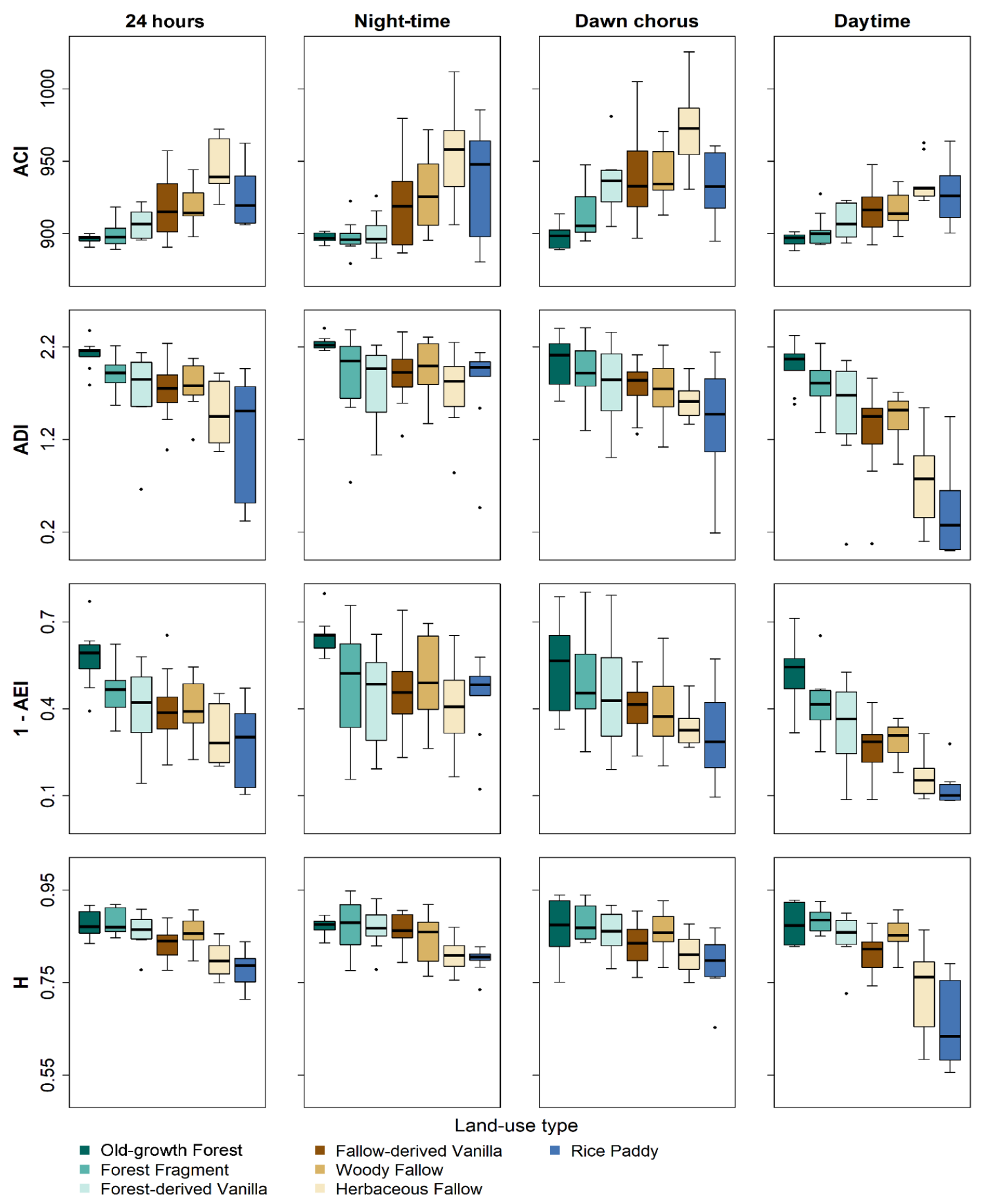

Figure 4.3: Variation of the Acoustic Complexity Index (ACI), the Acoustic Diversity Index (ADI), the inverse Acoustic Evenness Index (1-AEI) and Acoustic Entropy $(\mathrm{H})$ for 10 plots per land-use type (20 plots for fallow-derived vanilla). We used one continuous recording per recording seasons per plot $(2017 ; 2018)$ and calculated the acoustic indices on 1 -min basis. To receive a final value per plot, we used the 1-min-based values to calculate the median for the continuous 24 hours recording, the night-time (12 AM - 5 AM; 6 PM - 12 AM), dawn chorus (5 AM - 8 AM) and daytime (5 AM - 6 PM). Box-and-whiskers represent lower extreme, lower quartile, median, upper quartile, upper extreme and outliers outside double interquartile range for each land-use type based on the plot medians. 

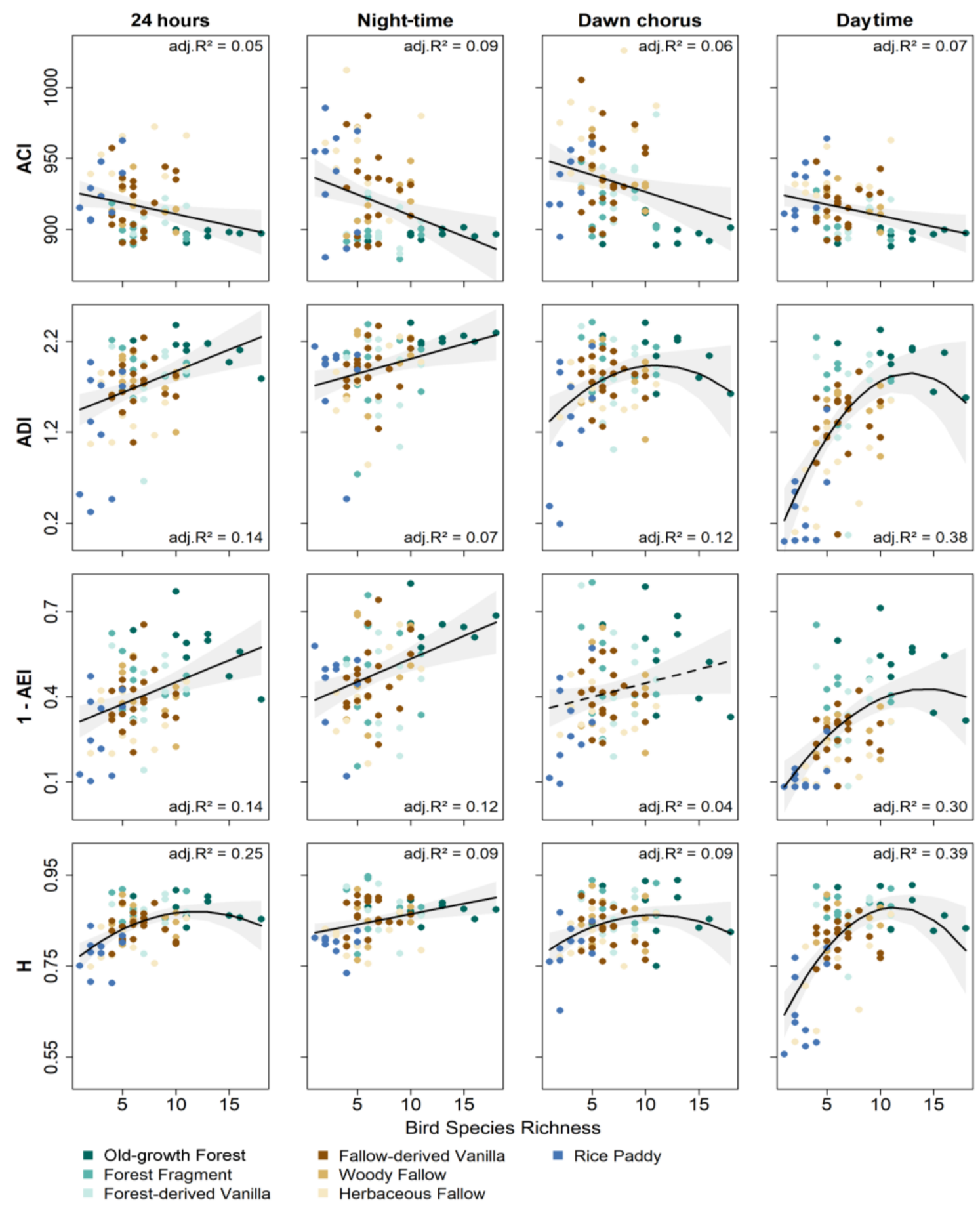

Figure 4.4: Correlation between bird species richness and the Acoustic Complexity Index (ACI), the Acoustic Diversity Index (ADI), the inverse Acoustic Evenness Index (1-AEI) and Acoustic Entropy $\mathrm{H}$ ) for the different land-use types during the full 24 hours recording duration, the night-time before $5 \mathrm{AM}$ and after $6 \mathrm{PM}$, the morning chorus between 5 and $8 \mathrm{AM}$ and the day-time between $5 \mathrm{AM}$ and 6 PM. We tested a linear and a second-order polynomial model to describe the correlation. We display the simple linear model by default and only show the polynomial model if $\Delta$ AIC $\geq 2$. The correlations are significant for all time intervals except one (dashed line). Grey ribbons indicate $95 \%$-confidence intervals for each estimate. 


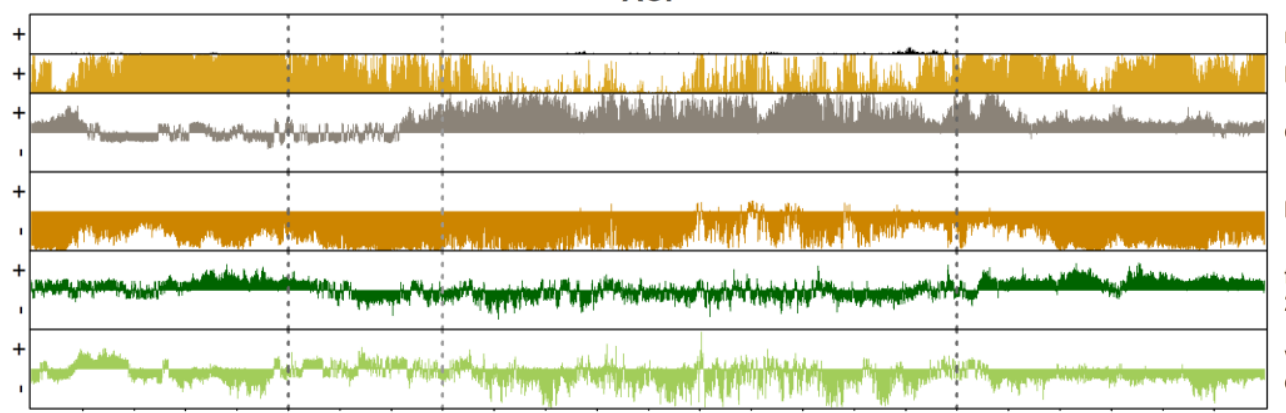

ADI

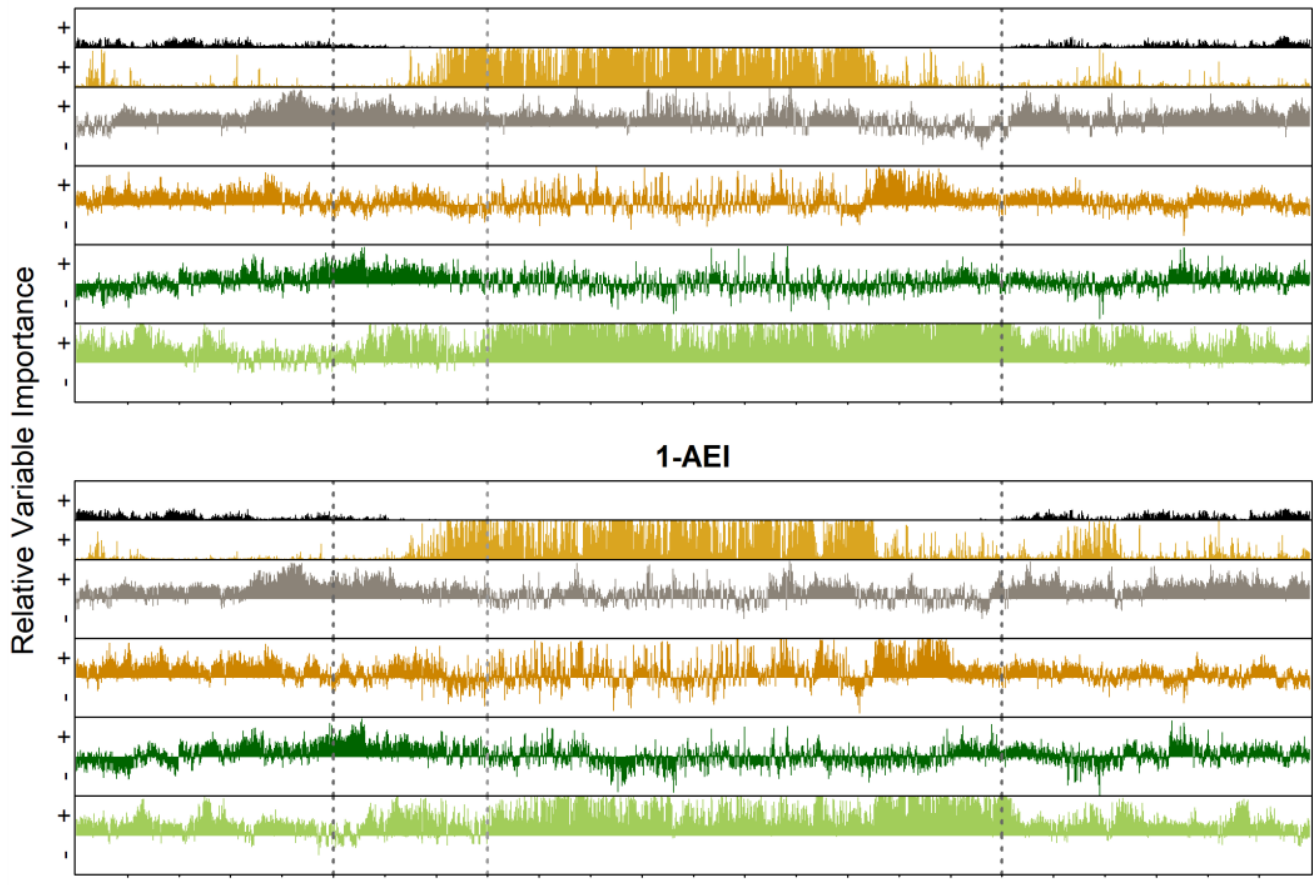

H

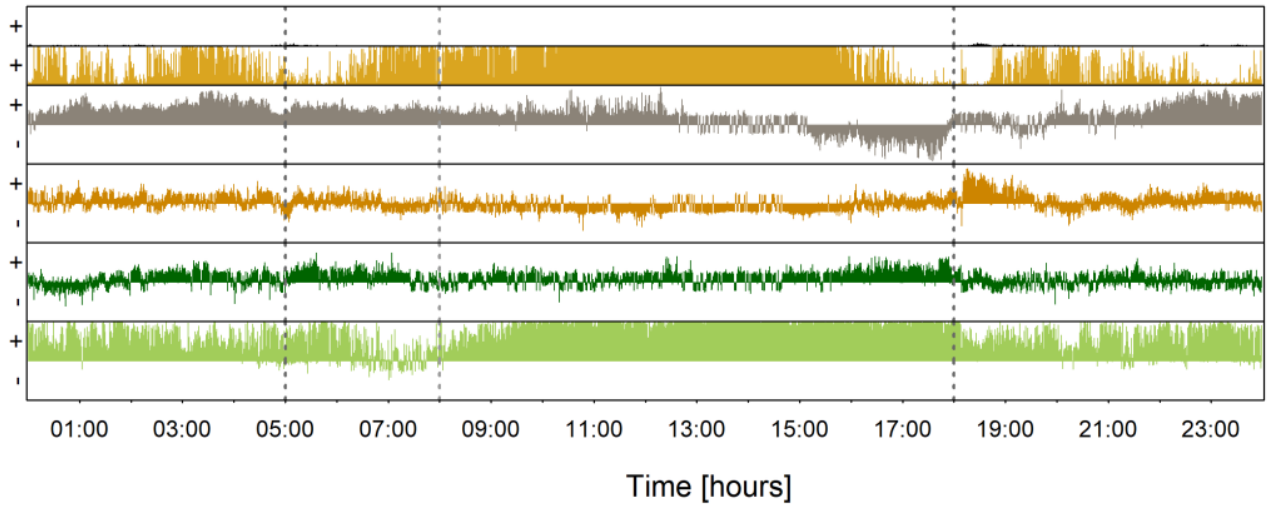

Figure 4.5: Relative variable importance explaining differences in Acoustic Complexity Index (ACI), the Acoustic Diversity Index (ADI), the inverse Acoustic Evenness Index (1-AEI) and Acoustic Entropy $(\mathrm{H})$. Model variables included land-use type, elevation, basal area, forested area within a 250 $\mathrm{m}$ radius around plot centre and vegetation density. Black colour represents the Akaike weight of the null model during that time of the day. 


\subsection{Discussion}

We tested the performance of sound recordings and acoustic indices to assess and monitor the biodiversity in old-growth-forest, forest fragments and agricultural land-use systems in north-eastern Madagascar. Evaluating the efficacy of this emerging rapid biodiversity assessment method, we found three acoustic indices to be useful proxies for biodiversity.

\subsubsection{Systematic variation of acoustic indices among land-use types}

We found that three acoustic indices varied systematically across the seven land-use types in north-eastern Madagascar (Figure 4.3). The ADI, the 1-AEI and H showed the lowest index values for irrigated rice paddies and fallow land within the hill rice shifting cultivation cycle, typically facing highest land-use intensity and therefore indicating a lower value for biodiversity due to less suitable habitat. Acoustic index values for forest fragments and oldgrowth forest in particular were consistently high, emphasizing their importance for conservation, in line with results of previous studies relying on conventional methods (Gardner et al., 2016; Rocha et al., 2015).

As the ACI should theoretically be high in habitats with higher variability in biotic sound intensity (Pieretti et al., 2011), our results were contrary to our expectations and opposite to the other three indices studied: ACI values were highest in herbaceous fallows and rice paddies and lowest in old-growth forest (Figure 4.3). This might be because irrigated rice paddies can be dominated by a single distinct signal, like the vocalizations of amphibians during night-time, therefore having a high variation in sound intensity. Additionally, boundaries of vocalizations of different species in a diverse habitat like an old-growth forest may overlap, ultimately leading to a lower variation in sound intensity over time and thus lower ACI values. Therefore, the ACI might not be a useful biodiversity indicator in a tropical, agricultural landscape.

\subsubsection{Acoustic indices as a proxy for biodiversity}

We found that the ADI, 1-AEI and $\mathrm{H}$ were correlated with bird species richness, a standard biodiversity indicator. This correlation was particularly strong during daytime. Our results are thus in line with a case study from South China, which reports the same three acoustic indices to be correlated with bird species richness (Mammides et al., 2017). Similarly, a case study from the Brazilian Cerrado showed a correlation of bird species richness and the ADI (Machado et al., 2017) and in the Brazilian Atlantic Rainforest, AEI was correlated with species richness (Jorge et al., 2018). The higher support for the polynomial models during 
daytime indicates a saturation in the soundscape as index values do not differ between species-rich plots (Figure 4.4). Hence, losses in species richness within species-rich plots may not be reflected by acoustic indices, limiting the efficacy of these particular indices in hyperdiverse tropical forests. This limitation could be overcome by a multiple analysis approach including machine learning, as well as new variations of indices.

Contrary to our expectations, the ACI showed a negative and only weak correlation with bird species richness. Izaguirre and Ramírez-Alán (2018) reported the ACI to be useful to monitor bird abundance in a tropical dry forest in Costa Rica. Towsey et al. (2014) confirmed the viability of the index for species diversity for bushland in eastern Australia. However, our results do not provide evidence for the ACI being a good proxy for bird species richness in north-eastern Madagascar.

\subsubsection{Plot-scale vegetational structure related to soundscape diversity}

The three acoustic indices describing the soundscape diversity of the study plots were mainly related to the plot-specific vegetation structure. Vegetation density, and to a lesser extend basal area, were positively associated with higher index values. Our findings indicate that maintaining vegetation structure in the agricultural landscape and preventing forest degradation is key to preserve a high soundscape diversity.

The soundscape of natural environments is composed by vocalisations of birds, amphibians and insects. Therefore, we would not expect a perfect correlation of the four acoustic indices with bird species richness, as this is only one taxon representing a part of the acoustic fingerprint of a habitat. Furthermore, the contribution of understory-dependent amphibians and insects to the recorded soundscapes may explain why the plot-scale vegetational structure was of highest relevance for the soundscape diversity within our study. Supporting this theory, it has been observed that insects and frogs can dominate dusk and dawn chorus in tropical biomes (Farina \& Gage, 2017). It also points out to the potential of ecoacoustics to assess biodiversity holistically through regarding the full soundscape instead of focusing on single indicator taxa, which may respond to land-use change very differently (Barlow et al., 2007).

\subsubsection{Implications for the use of acoustic indices for biodiversity assessments}

Three acoustic indices (ADI, 1-AEI, H) showed strongest differences in the soundscape of the different land-use types in north-eastern Madagascar during noon and afternoon (Figure 4.2). Only few ecoacoustic studies have described similar patterns of high soundscape 
diversity during night-time and a decline during daytime (Fuller et al., 2015; Gasc et al., 2013). As realized within our study, only continuous recordings are able to reveal such fine temporal patterns, yet many studies rely on a reduced sampling scheme, e.g. recording 1 min every 10 min (Gómez et al., 2018) or only dawn and dusk chorus (Depraetere et al., 2012), due to data storage capacities and battery power. Continuous sampling for several days in a row is desirable to capture the complete soundscape and diurnal trends. Moreover, it is the basis for the comparability of ecoacoustic surveys across different biomes, as advocated by Bradfer-Lawrence et al. (2019).

Currently, a limiting factor for conservation practitioners to use acoustic indices for rapid biodiversity assessments is the challenging nature of sound data analysis. Due to the variability of habitats and lack of standard protocols, the settings for index computation (e.g. frequency thresholds and dB-thresholds) are mainly set by trial and error. More research and case studies are needed to provide firm guidelines for ecoacoustic surveys, including, for example, user-friendly and open-source analyses packages.

The acoustic indices used in our study captured substantial differences between land-use types but were not suitable to detect the more subtle differences in the soundscape of structurally similar land-use types, particularly in species rich habitats. Furthermore, some acoustic indices rely on the same coefficients (Shannon-Index; ADI and H) or similar equations (ADI and AEI) used for computation. Some acoustic indices are hence correlated and thus provide partly complementary information. An alternative might be a combination of analyses, including e.g. automated classification and machine learning, which currently focus on the identification of a single or few species (Aide et al., 2013). However, the latter approaches would require advanced knowledge in signal processing, large training data sets and available software may not be open source (Priyadarshani et al., 2018).

\subsubsection{Implications on the potential of vanilla agroforests for biodiversity conserva- tion}

We found that forest-derived vanilla agroforests had similar acoustic index values as forest fragments, suggesting the maintenance of biodiversity after conversion of forest fragments into forest-derived vanilla agroforests (Figure 4.3). Fallow-derived agroforests, on the other hand, had index values similar to woody fallows, the land-use type on which such agroforests are typically established. These results highlight the importance of land-use history when assessing the conservation value of agroforests (Martin et al., 2020b). Agroforests can increase landscape connectivity (Bhagwat et al., 2008) and previous studies in Madagascar 
showed that the agricultural landscapes can support a high number of the endemic birds if forest fragments remain within a landscape mosaic (Martin et al., 2012). Currently, expanding vanilla agroforestry could thus be biodiversity-friendly 1) if forest-derived agroforests contribute to tree maintenance by avoiding complete forest fragment loss and 2) if the establishment of fallow-derived agroforests on woody fallows leads to a cessation of the shifting cultivation cycle on this land. The potential of vanilla agroforests to complement and enhance the landscape mosaic will, however, need further research.

\subsection{Conclusion}

Autonomous sound recordings and acoustic indices are regarded as time-efficient assessment tools in the biodiversity conservation context. Based on an exceptionally large acoustic dataset, our study contributes to a better understanding of the relationship between acoustic indices and bird species richness as well as between acoustic indices and plot- and landscape-scale characteristics. We found that the Acoustic Diversity Index, the Acoustic Evenness Index, and the Acoustic Entropy are informative metrics to analyse sound data and estimate soundscape diversity in a biodiverse tropical landscape. Acoustic index values were highest for the old-growth forests, highlighting their importance for conservation, however, forest fragments also retained relatively high index values. Our results emphasize the potential of vanilla agroforests to contribute to the maintenance of biodiversity in the agricultural landscape. Nonetheless, the acoustic indices alone did not allow us to distinguish structurally similar land-use types due to high variations in soundscapes within landuse types. The Acoustic Complexity Index emerged as not useful in our study region. Using a multiple analysis approach, e.g. including machine learning, could overcome methodological limitations. Together with user-friendly analysis packages and firm guidelines this will facilitate a wider implementation of ecoacoustics in applied ecology and conservation.

\subsection{Author's contributions}

SD, DAM and HK designed the study. SD, DAM, RA, ER and TRF collected sound and bird data; KO collected basal area data and DS collected vegetation density data. DAM prepared the point count data; SD analysed the sound data and wrote the first manuscript draft. ZB contributed to the mixed effect modelling. All authors contributed to the manuscript and gave final approval for publication. 


\subsection{Acknowledgements}

We thank all Malagasy farmers and chef de fokontany involved as well as Madagascar National Parks for their cooperation. We thank Marie Rolande Soazafy contributing substantially to a successful data collection. We collected data under research permits Nº100/17/MEEF/SG/DGF/DSAP/SCB.Re, N163/17/MEEF/SG/DGF/DSAP/SCB.Re, N¹8/ 18/MEEF/SG/DGF/DSAP/SCB.Re and N²54/18/MEEF/ SG/DGF/DSAP/SCB.Re granted by the Ministry of Environment and Sustainable Development, Antananarivo, Madagascar. This study was financially supported by the 'Niedersächsisches Vorab' of 'Volkswagen Foundation' as part of the research project 'Diversity Turn in Land Use Science' (Grant number 11-76251-99-35/13 (ZN3119)). The Centre for Biodiversity and Sustainable Land Use (CBL) financially supported SD for fieldwork.

\subsection{Data availability statement}

Data (plot parameters, acoustic index minute-based values, acoustic index median values, bird-species richness) are available via Mendeley Data (Dröge et al., 2020) https://doi.org/10.17632/fxxnwtmynv.1 


\section{Differential responses of amphibians and reptiles to land-use change in the biodiver- sity hotspot of north-eastern Madagascar}

Thio Rosin Fulgence, Dominic Andreas Martin, Romual Randriamanantena, Ronick Botra, Erosiniot Befidimanana, Kristina Osen, Annemarie Wurz, Holger Kreft, Aristide Andrianarimisa, \& Fanomezana Mihaja Ratsoavina

Contribution: Conceptualization, Formal analysis, Project administration, Funding acquisition, Validation, Writing - original draft, Writing - review \& editing

Status: In preparation.

\subsection{Abstract}

Background: Large expanses of tropical rainforest have been converted into smallholderdominated agricultural landscapes. This is also the case in north-eastern Madagascar, a region where significant proportions of forest cover remain despite shifting hill rice cultivation and vanilla agroforestry. The region is also a global hotspot for amphibian and reptile diversity, but how this diversity is affected by land-use change remains largely unknown.

Aim: To derive conservation advice, we compare species diversity and composition across seven prevalent land-use types (old-growth forest inside a national park, forest fragment, forest-derived vanilla, and in burned land uses including, fallow-derived vanilla, woody fallow, herbaceous fallow and rice paddy) with at least ten replicates each.

Location: North-eastern Madagascar. 
Time period: September 2017-April 2019.

\section{Major taxa studied: Amphibians and reptiles}

Methods: Time-standardized transects in a space-for-time study design covering the predominant land-use types of the study region.

Results: At plot level, amphibian species richness was highest in old-growth forest and significantly lower in all other land-use types, with the lowest values in rice paddy. Plot-level reptile species richness was significantly higher in unburned land-use types. For both amphibians and reptiles, the less-disturbed land-use types showed more uneven communities, particularly old-growth forest. Old-growth forest also harboured species compositions significantly different to all other land-use types. Amphibians showed a higher level of forest dependency and showed stronger species turnover after forest conversion than reptiles.

Conclusion: We document an outstanding diversity of amphibians and reptiles in the biodiversity hotspot of north-eastern Madagascar, but the two groups react differently to landuse change: the small-scale agricultural landscape has relatively low value for amphibian conservation. For reptiles, losses in species richness were less pronounced and unburned agricultural habitats were relatively important, suggesting that reptiles are less affected by land-use change than amphibians. Old-growth forest harboured a unique diversity of reptiles and amphibians, highlighting its high conservation value. In sum, amphibian and reptile conservation in north-eastern Madagascar should focus on the conservation of oldgrowth forest in protected areas and forest fragments within the agricultural landscape.

Key words: Amphibian, reptile, conservation, agroforestry, human-dominated landscape, land-use change, vanilla, Madagascar.

\subsection{Introduction}

Demand for agricultural goods is still on the rise due to a growing world population and a change in diets (Tilman et al., 2011) leading to both an expansion of croplands into natural areas and an intensification of existing production systems (Tscharntke et al., 2012). Most agricultural expansion in the tropics happens at the expense of forest and leads to an increase of forest fragmentation (Gibbs et al., 2010; Hansen et al., 2020). Land-use change is thus the main driver of biodiversity decline globally (Powers \& Jetz, 2019), and this is particularly pronounced in the tropics (Foley, 2005; Laurance et al., 2014) where high land use pressure and biodiversity coincide. 
However, tropical agricultural landscapes also provide opportunities for nature conservation (Perfecto \& Vandermeer, 2010). This might be particularly the case where agricultural landscapes are not dominated by large-scale monocultures but rather consist of a diverse mosaic of forest fragments, agroforestry systems and more intensively farmed annual crop fields (Bhagwat et al., 2008; Mendenhall et al., 2016). Beside the value for biodiversity, small scale land-use mosaics can also provide essential ecosystem services and livelihoods for rural people, making landscapes work for humans and nature (Kremen \& Merenlender, 2018). However, most research investigating the value of tropical agricultural landscapes for biodiversity and humans was conducted in the Neotropics (see for example: Mendenhall et al., 2016; Philpott et al., 2008) while the conservation value of Afrotropical agricultural landscapes is less well understood (Waltert et al., 2011).

Madagascar is country with particular importance for global conservation. The country has lost around $44 \%$ of forest cover since the 1950s, mainly due to transformation to agricultural lands (Vieilledent et al., 2018). This is threatening many species (Jones et al., 2019c), and in concert with unsustainable extraction rates (Borgerson et al., 2019), leads to more than half of evaluated Malagasy species being at risk of extinction (IUCN, 2018). Madagascar also has outstanding levels of endemism (Brown et al., 2016; Goodman \& Benstead, 2005) and ongoing threats, thus qualifying Madagascar as a global biodiversity hotspot (Myers et al., 2000). While the forests and protected areas of the island are increasingly well surveyed for biodiversity, the biodiversity in the agricultural landscapes has largely been neglected (reviewed in Irwin et al., 2010 and exemplified in Hending et al., 2018; Martin et al., 2020a; Martin et al., 2012; and Ndriantsoa et al., 2017).

The amphibians and reptiles of Madagascar are characterised by high species richness and a high percentage of endemic species. The number of Malagasy amphibian species is currently estimated at around 369 (AmphibiaWeb, 2020) and that of reptiles at around 440 species (Reptile Database, 2020). Nevertheless, many species still await discovery and/or description, suggesting that total species richness will increase further by continuous discovery (Vieites et al., 2009). Furthermore, almost all native amphibian species and $91 \%$ of reptile species of Madagascar are endemic (Goodman \& Benstead, 2005). However, from other regions we known that the herpetofauna is very sensitive to various anthropogenic threats including chytrid fungi (Hof et al., 2011; O’Hanlon et al., 2018), environmental pollution (Hof et al., 2011), collection for pet trade (Marshall et al., 2020), climate change (Hof et al., 2011; Raxworthy et al., 2008) and conversion of forest habitat into agricultural lands (Doherty et al., 2020; Hof et al., 2011; Palacios et al., 2013). 
North-eastern Madagascar is the most densely forested region of Madagascar (Vieilledent et al., 2018) and global priority area for amphibian research (Nori et al., 2018). Besides being known for its remarkable biodiversity, north-eastern Madagascar is also known for vanilla cultivation (Hänke et al., 2018). The price boom of the spice over the last four years has triggered an expansion of vanilla agroforests (Llopis et al., 2019), and nowadays roughly $80 \%$ of rural households in the study region farm vanilla (Hänke et al., 2018). Vanilla is thus the main cash crop in the region. Importantly, vanilla agroforests differ in land-use history: They are either established directly inside forest via cutting of forest understory, which is replaced by the planting of vanilla vines and their support trees, i.e. forest-derived vanilla or on historically forested open land, i.e. fallow-derived vanilla (Martin et al., 2020b). Besides farming vanilla, the rural population also practices shifting cultivation for hill rice production. Valleys and plains in the study region are commonly occupied by irrigated rice paddies, forming the backbone of the staple crop supply. The remoteness and difficult logistic conditions of the region might explain why few researchers are conducting fieldwork in north-eastern Madagascar (Gehring et al., 2010). Furthermore, the completed research in this area has, like in the rest of the country, focused on protected forest areas (Irwin et al., 2010). This is resulting in a lack of studies concerning biodiversity associated with the agricultural landscape outside protected areas, despite that this landscape actually occupies more land than the remaining primary forest (Vieilledent et al., 2018). To understand how the agricultural landscape can contribute to amphibian and reptile diversity, it is imperative to collect data outside the protected areas of north-eastern Madagascar.

In this study, we assessed amphibian and reptile diversity of the small-scale agricultural landscape mosaic outside the protected areas and study the role of different land-use types in conserving amphibian and reptile diversity in north-eastern Madagascar. In particular, we compare diversity and community composition of amphibians and reptiles across six land-use types within the smallholder-dominated agricultural landscape and within oldgrowth forests inside a national park. We specifically studied vanilla agroforests of contrasting land-use history (forest- and fallow-derived vanilla), herbaceous fallow, woody fallow, rice paddy, forest fragment and old-growth forest inside Marojejy National Park with ten to twenty replicates each. We hypothesize higher species richness in lower intensity land-use types and a unique community composition for old-growth forest. 


\subsection{Methods}

\subsubsection{Study region and study design}

We conducted our study in the SAVA region in north-eastern Madagascar (Figure 5.1 A \& B). The climate is tropical-humid with an average annual temperature of $24{ }^{\circ} \mathrm{C}$ and rainfall of $2223 \mathrm{~mm}$ (mean across 80 plots, according to (Karger et al., 2017)). The landscape was formerly covered with humid evergreen forest (Du Puy \& Moat, 1996), but forests are nowadays highly fragmented or restricted to National Parks (Vieilledent et al., 2018).

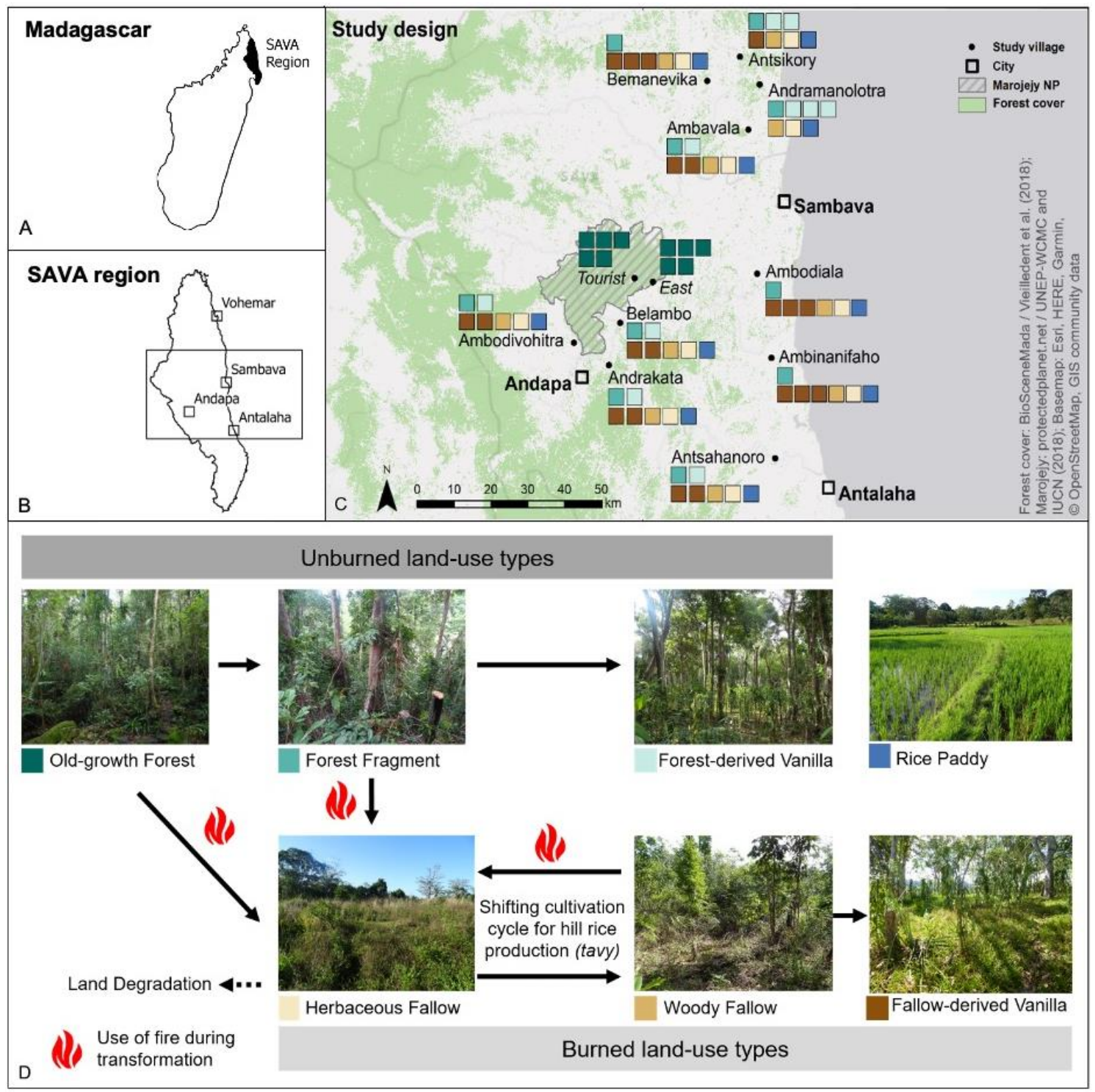

Figure 5.1: Study design overview. A: SAVA region in north-eastern Madagascar; B: study area within SAVA region; C: study design showing the distribution of 80 plots in ten villages and in two sites inside Marojejy National Park; D: overview of studied land-use types and typical land-use 
transformation trajectory from old-growth forest to forest fragments and agricultural land-uses. Rice paddy is not part of the main land-use trajectory.

We collected data at low to mid-altitude, 7-819 $\mathrm{m}$ above sea level (mean $=192 \mathrm{~m} \pm 207 \mathrm{~m}$ ). surrounding ten villages and in a protected area (63.75\% of the plot less than $200 \mathrm{~m}, 22.5 \%$ between $200-500 \mathrm{~m}$ and $13.75 \%$ higher than $500 \mathrm{~m}$ ). In each village, we chose seven plots: Three vanilla agroforests (forest-derived vanilla and/or fallow-derived vanilla), one forest fragment, one herbaceous fallow, one woody fallow, and one rice paddy. Additionally, we chose ten plots at two sites (5 plots each) inside Marojejy National Park in low altitude oldgrowth forest. The fallow-derived vanilla was replicated twenty times while all other landuse types were replicated ten times. The minimum average distance between one plot and the next closest plot was $719 \mathrm{~m} \pm 438 \mathrm{~m}$, while the smallest distance between two plots was $260 \mathrm{~m}$. Overall, we surveyed 80 plots of seven land-use types (Figure 5.1 C \& D).

\subsubsection{Sampled land-use types}

We selected 10 old-growth forest plots at two sites with 5 plots each. One of the sites has experienced some selective logging in the past but is now well protected (touristic zone in Manantenina valley), the other one still suffers from occasional selective logging and trapping (Bangoabe), but we chose plots that did not show signs of recent disturbance. The oldgrowth forest plots are a minimum of $300 \mathrm{~m}$ from the National Park boundary.

In the study region, forest fragments occur dispersed around villages and are remnants of the continuous forest cover that existed in the region until large scale deforestation began in the early 20th century. The 10 fragments have not burnt but are all heavily used for construction wood, firewood and other natural products. Few large trees remain in those fragments.

Herbaceous fallows occur after shifting hill rice cultivation (locally referred to as tavy) and are sometimes grazed by cows. Those herbaceous fallow plots selected for this study had last burned at the end of 2016, one year before the onset of data collection in 2017.

Woody fallows are following the succession form herbaceous fallows, containing shrubs and small trees. Woody fallows also are occasionally grazed by cows. Those woody fallows in our study had last burnt 4-16 years before the onset of data collection in 2017.

Vanilla is the main cash crop in north-eastern Madagascar and widely planted throughout the study region. Vanilla is farmed in agroforestry systems with distinct land-use histories (following Martin et al., 2020b): in the first type of agroforest, vanilla is directly planted into 
the forest after removing understory trees and shrubs while some tall trees are kept for shade. We thus call these agroforests 'forest-derived'. In the second type, vanilla is planted on fallow land which resulted from shifting cultivation. In these 'fallow-derived' vanilla agroforests, farmers leave small trees to regenerate or plant trees as support trees for vanilla vines or for shade. In the 10 villages, we initially selected 30 vanilla agroforests along a canopy cover gradient. After consultation with the agroforest owner and a visual confirmation on the plot, we found that 20 agroforests were fallow-derived while 10 agroforests were forest-derived. This approach allows us to understand the response of amphibians and reptiles to land-use history of vanilla agroforests.

Lastly, we studied irrigated rice paddies that occur throughout the whole study region and are often situated in valley bottoms and plains. Rice is planted and harvested between one to three times per year. The rice paddies chosen for our study had wider-than-average banks to facilitate movement within the plots.

\subsubsection{Sampling and data collection}

To collect data in the villages, we organized two sampling campaigns during the driest period of the year (October to December 2017 and late August to December 2018) and one campaign during the wettest period (Mid-January to early April 2018). To collect data in Marojejy National Park, we organized two sampling campaigns during the driest period of the year (late August - early September 2018 and December 2018) and one during the wettest period (February 2019). During each campaign, we visited each plot once during the day (08:00 - 17:00) and once at night (18:30-23:00). Overall, we thus visited each plot six times, three times during the day and three times at night; four times during the driest period of the year and two times during the wettest period of the year.

We collected data on the amphibian and reptile community during time-standardized search (Kadlec et al., 2012). During the walk search, we systematically searched the complete circular plot of $25 \mathrm{~m}$ radius in a zig-zag pattern (Kadlec et al., 2012).

Each walk search was standardized to 45 minutes of searching time by two observers. With three nocturnal and three diurnal visits, we thus conducted 270 minutes of searching time by two people on each plot, summing up to 408 hours of searching time over all plots. To detect individuals hiding under rocks, in leaf axils, tree barks, tree holes, leaf litter or dead wood, we actively checked those microhabitats and lifted removable rocks and deadwood to check underneath. 
Upon encountering an individual, we stopped our stopwatch to halt the searching time. We then identified all individuals to species level using morphological characteristics following the field guide to Amphibians and Reptiles of Madagascar (Glaw \& Vences, 2007) and additional literature (Rakotoarison et al., 2017; Ratsoavina et al., 2019). For those individuals for which we could not identify in the field, we extracted tissue samples for DNA analysis and/or collected the specimen. We released all individuals which we did not collect as a specimen at the place where we captured them. We then resumed the searching time so that the searching time was independent of the abundance and diversity of amphibians and reptiles during a given transect. Throughout this manuscript, we refer to each encountered individual as an 'encounter' rather than an individual as we cannot exclude the possibility of having encountered the same individual at more than one sampling event.

\subsubsection{Species identification with DNA samples}

We collected muscle or toe clips as tissue samples of individuals in those cases where the identification based on morphological characteristics was not possible or in cases we had doubts. We collected 498 tissue samples for DNA barcoding, conserved in 90\% ethanol, stored and analysed at the Evolutionary Biology laboratory (Group Vences). We used DNA barcoding based on fragments of the mitochondrial 16S and COI genes for PCR with primers 16SAL/16SBH and the COI reptile primers. Obtained sequences were compared with data on GenBank. We collected voucher specimens, euthanized, preserved in ethanol $70 \%$ for amphibians and $90 \%$ for reptiles, and stored at Regional University Centre of SAVA region (CURSA).

\subsubsection{Data analysis and visualization: species richness and abundance}

To analyse the mean of variance of plot-level species richness across land-use types, we applied an ANOVA using the aov function and Tukey HSD test to evaluate the multiple pairwise-comparison using the glht function in the R-package 'multcomp' (Hothorn, 2020).

We used encounter data to compute species accumulation curves using sample-size-based rarefaction and extrapolation (Hsieh et al., 2016) in the iNEXT package to assess the diversity (species richness, Shannon and Simpson diversity) across land-use types using the Hill number framework (Chao et al., 2014).

To display the total species diversity in each land-use type we subsampled 10 plots within 20 plots of fallow-derived vanilla. To do so, we firstly randomly selected one fallow-derived vanilla plot from each village. As one of the villages lacks fallow-derived vanilla plots 
(Andramanolotra, see Figure 5.1), this resulted in 9 plots. To facilitate the comparison to the other six land-use types, with 10 replicates, we proceed to select one additional plot from the remaining fallow-derived vanilla plots, enabling a fair comparison of total species diversity across 10 plots of each land-use type.

\subsubsection{Data analysis and visualization: species composition}

To evaluate the differences in species composition across land-use types, we used the metaMDS (with 1000 permutation) function and computed the pairwise difference using the Adonis function of the R-package 'vegan'. We used non-metric dimensional scaling to visualize the dissimilarity of species composition. We plotted the proportion of encounters for each species across land-use types to visualize forest dependency. We conducted all statistical analyses and prepared all figures in R version 3.5.1 (R Core Team, 2019).

\subsection{Results}

\subsubsection{Encounters and species richness}

In total, we made 6215 encounters and found 119 species of amphibians and reptiles. The 3694 amphibian encounters resulted in 58 species. The most species-rich genera were Boophis (11 species) and Gephyromantis (10 species). The 2521 reptile encounters resulte in 61 species of reptiles of 5 families and 28 genera (SI Chapter 5, Table 12.15). We could not identify 9 species and recognized 12 new candidate species (SI Chapter 5, Table 12.15). 16 reptile and 6 amphibian species encountered are near-threatened or threatened according to the red list (IUCN, 2018; SI Chapter 5, Table 12.15); 11 and 5 of them, respectively, only occurred in old-growth forest.

Plot-level amphibian species richness (Figure 5.2 A; SI Chapter 5, Table 12.16) differed significantly among land-use types ( $\mathrm{f}(6.73)=19.59$, p-value $<.001)$. A Tukey post-hoc test revealed significant pairwise differences between some land-use types: Old-growth forest plots have the highest average species richness and rice paddy plots the lowest. Forest-derived vanilla, fallow-derived vanilla, woody fallow, and herbaceous fallow show no significant differences. Old-growth forests had a significantly higher species richness than any other land-use type (SI Chapter 5, Table 12.16).

Concerning reptiles (Figure 5.2 B; SI Chapter 5, Table 12.17), we found a statistically significant difference in mean species richness between land-use types $(f(6.73)=18.55$, $p$-value $<.001$ ). Tukey post-hoc test revealed non-significant pairwise difference between old- 
growth forest and forest fragment ( $\mathrm{p}$-value $=0.88$ ) and between old-growth forest and forest-derived vanilla ( $\mathrm{p}$-value $=0.77$ ), and they presented the highest mean species richness between land-use types. Rice paddy presents the lowest species richness but the difference between herbaceous fallow and rice paddy was not significant ( $p$-value $=0.19$ ). Forest-derived and fallow-derived vanilla showed a significant difference ( $\mathrm{p}$-value $=0.01$; Figure 5.2 B; SI Chapter 5, Table 12.17).

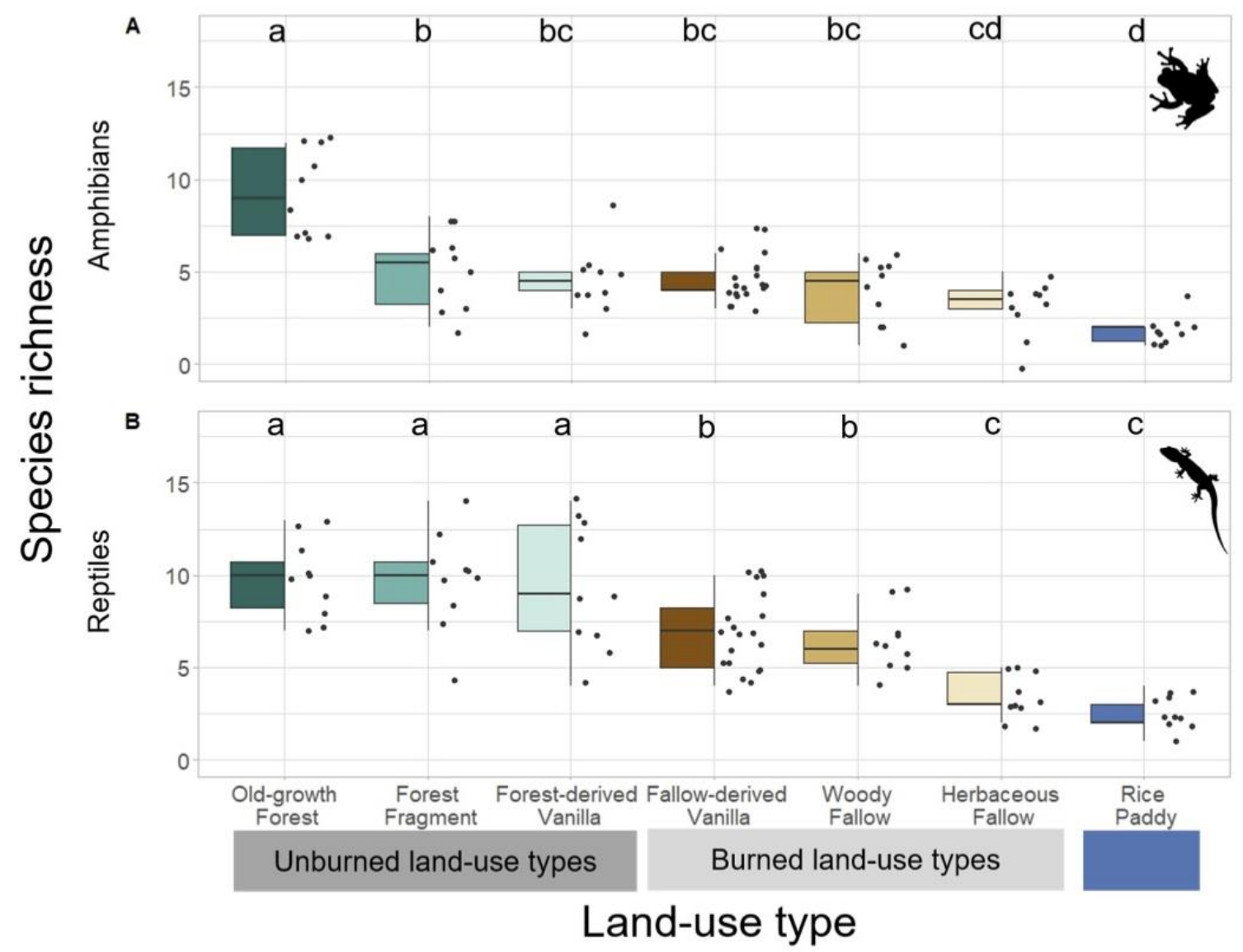

Figure 5.2: Plot-level amphibian (A) and reptile (B) species richness across seven land-use types (replicated 10 times each except fallow-derived vanilla, which is replicated 20 times). The dots represent the species richness per plot in each land use. The black horizontal line in the box shows the median. Land use types with letters in common did not differ significantly based on pairwise comparisons that controlled for inflated false positive errors using the Tukey HSD approach (Numeric results in SI Chapter 5: amphibians Table 12.16 \& reptiles Table 12.17).

\subsubsection{Accumulated species diversity}

Encounter-based accumulation curves revealed the highest species diversity in old-growth forest (for amphibians and reptiles) and the lowest in rice paddy for amphibians but in herbaceous fallow for reptiles (Table 5.1 \& Figure 5.3). The overlap of the $95 \%$ confidence 
interval of extrapolated amphibian richness for old-growth forest and forest fragment in (Figure $5.3 \mathrm{~A}$ ) indicates no differences in species richness. We found no overlap of extrapolated amphibian richness between burned and unburned land-use types (Figure 5.3 B). Accumulated amphibian diversity of old-growth forest was significant different to all other land-use types for the Hill numbers $q=1$ (Shannon diversity) and $q=2$ (Simpson diversity). Accumulated amphibian diversity of forest fragment and forest-derived vanilla agroforest did not differ significantly to burned land uses, except to rice paddy for both $\mathrm{q}=1$ and $\mathrm{q}=$ 2. We found no difference in extrapolated reptile richness among unburned and burned land-use types respectively (Figure 5.3 C \& D) but for $\mathrm{q}=1$ and $\mathrm{q}=2$. The species diversity drops stronger in amphibian than reptiles from ${ }^{0} \mathrm{D}$ (species richness) to ${ }^{1} \mathrm{D}$ (Shannon diversity) and 2D (Simpson diversity; Figure 5.3; SI Chapter 5, Table 12.18 \& Table 12.19), highlighting that amphibian communities were more uneven than reptile communities.

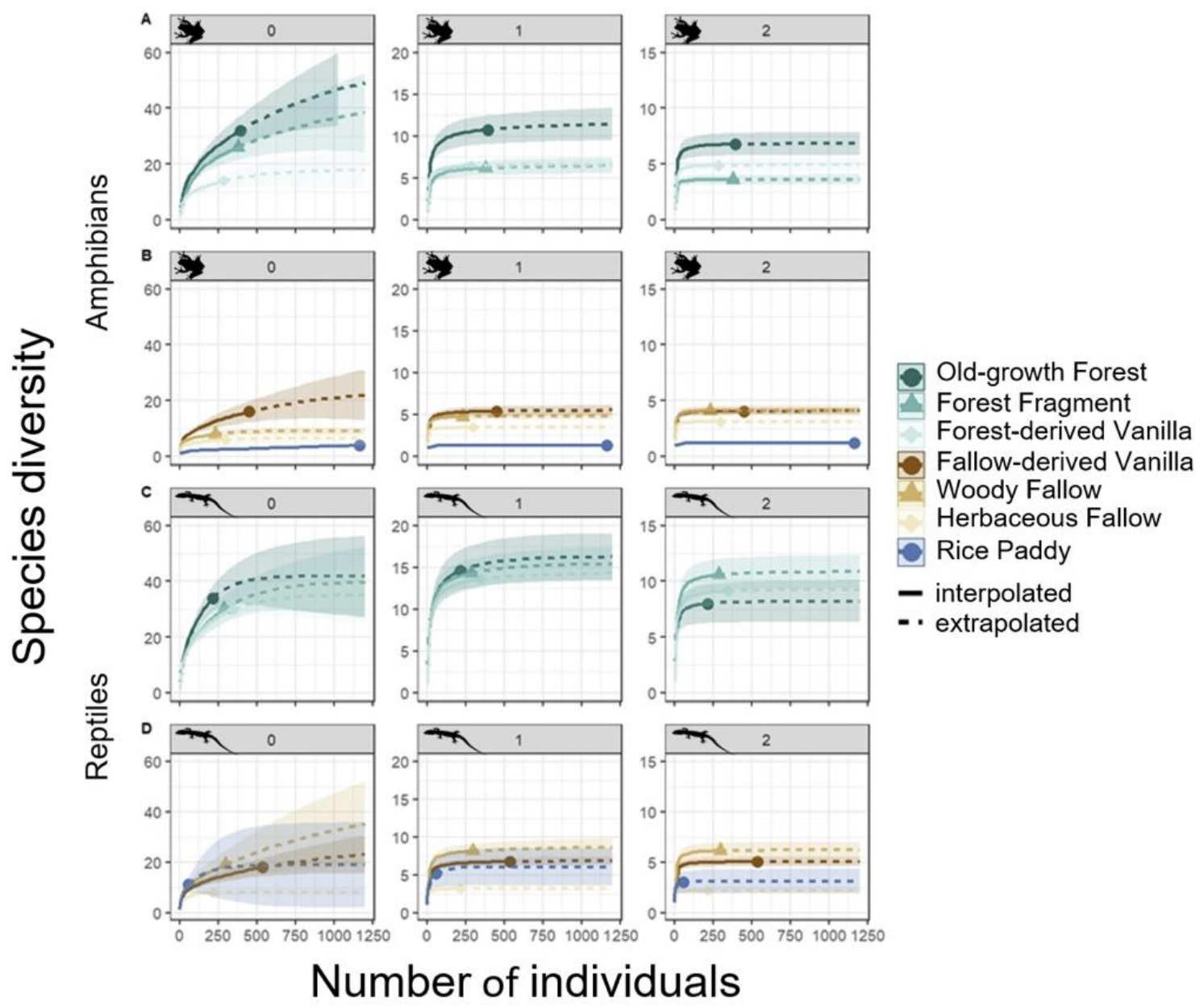

Figure 5.3: Encounter-based accumulation curves showing interpolation (solid line) and extrapolation (dotted line) for amphibians (A, B) and reptiles (C, D). Unburned (A, C) and burned (B, D) landuse types are separated. The species richness represented by $q=0$ (left panel), Shannon diversity, q=1 (middle panel) and Simpson diversity q = 2 (right panel) with 95\% confidence intervals (shaded 
areas) for the amphibian and the reptile data at seven land-use types. The solid dots, triangles and diamonds represent the reference samples, i.e. the number of encounters and species richness.

Table 5.1: Amphibian and reptile species diversity $(\mathrm{q}=0)$ for all land-use types and separated per land-use type showing the observed and extrapolated species diversity. Each land-use type is represented by 10 plots; for fallow-derived vanilla, the 10 plots are down-sampled from 20 plots. Extrapolated species diversity is based on 5000 encounters and includes the lower and upper $95 \%$ confidence interval in italics below. See SI Chapter 5 for results of $q=1$ and $q=2$ (amphibians: Table 12.18; reptiles: Table 12.19).

\begin{tabular}{|c|c|c|c|c|c|c|c|c|}
\hline $\begin{array}{l}\begin{array}{r}\text { Land-use } \\
\text { type }\end{array} \\
\text { Species } \\
\text { Group } \\
\text { (measure) }\end{array}$ & $\begin{array}{l}\frac{5}{0} \\
0 \\
0 \\
0 \\
0 \\
0 \\
0 \\
0 \\
0 \\
\overline{0} \\
\bar{z}\end{array}$ & 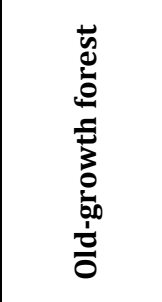 & 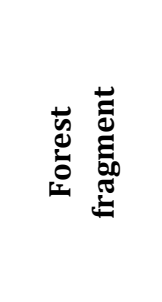 & 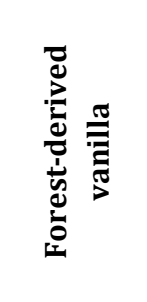 & 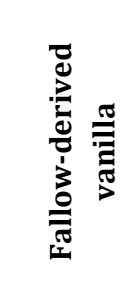 & $\begin{array}{l}3 \\
0 \\
\frac{3}{\pi} \\
\frac{\pi}{0} \\
\frac{0}{0} \\
3\end{array}$ & 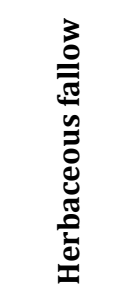 & $\begin{array}{l}\frac{\partial}{\sigma} \\
\tilde{\sigma} \\
\frac{0}{0} \\
\frac{0}{x}\end{array}$ \\
\hline $\begin{array}{l}\text { Amphibian } \\
\text { (observed) }\end{array}$ & 58 & 32 & 26 & 14 & 16 & 8 & 6 & 4 \\
\hline $\begin{array}{l}\text { Amphibian } \\
\text { (extrapolated) }\end{array}$ & NA & $\begin{array}{l}60.0 \\
20.4-99.6\end{array}$ & $\begin{array}{l}46.1 \\
12.4-79.8\end{array}$ & $\begin{array}{l}18.0 \\
9.1-26.9\end{array}$ & $\begin{array}{l}25.0 \\
7.0-42.9\end{array}$ & $\begin{array}{l}9.0 \\
7.4-10.6\end{array}$ & $\begin{array}{l}6.5 \\
3.9-9.1\end{array}$ & $\begin{array}{l}5.0 \\
4.3-5.6\end{array}$ \\
\hline $\begin{array}{l}\text { Reptile } \\
\text { (observed) }\end{array}$ & 61 & 34 & 30 & 30 & 18 & 19 & 8 & 11 \\
\hline $\begin{array}{l}\text { Reptile } \\
\text { (extrapolated) }\end{array}$ & NA & $\begin{array}{l}42.0 \\
20.4-63.5\end{array}$ & $\begin{array}{l}40.1 \\
10.2-69.9\end{array}$ & $\begin{array}{l}35.1 \\
18.2-52.4\end{array}$ & $\begin{array}{l}26.9 \\
8.2-45.7\end{array}$ & $\begin{array}{l}46.6 \\
11.5-81.7\end{array}$ & $\begin{array}{l}8.0 \\
6.8-9.2\end{array}$ & $\begin{array}{l}18.9 \\
4.3-33.4\end{array}$ \\
\hline $\begin{array}{l}\text { Total } \\
\text { (observed) }\end{array}$ & 119 & 66 & 56 & 44 & 34 & 27 & 14 & 15 \\
\hline
\end{tabular}

\subsubsection{Species composition and forest dependency}

The species composition showed significant differences between land-use types in the NMDS ordination $\left(\mathrm{R}_{2}=0.50\right.$, $\mathrm{p}$-value $\left.<.001, \mathrm{Df}=6\right)$. The dissimilarity in species composition between all land-use types was larger in the amphibian community than in the reptile community. Old-growth forest communities were significantly different to all other land-use types in both species groups. For amphibians, the species community in rice paddy was also significantly different from other land uses. For both amphibians and reptiles, the overlap of ordihull-graphs represent a similar species community in forest fragment, forest-derived vanilla, fallow-derived vanilla, woody fallow and herbaceous fallow (Figure $5.4 \mathrm{~A} \& \mathrm{C}$ ). Calculated forest dependency of all species showed that 38\% of amphibians and $26 \%$ of reptiles occurred exclusively in old-growth forest (Figure 5.4 B \& D). Amphibians are thus more dependent on old-growth forest than reptiles. 


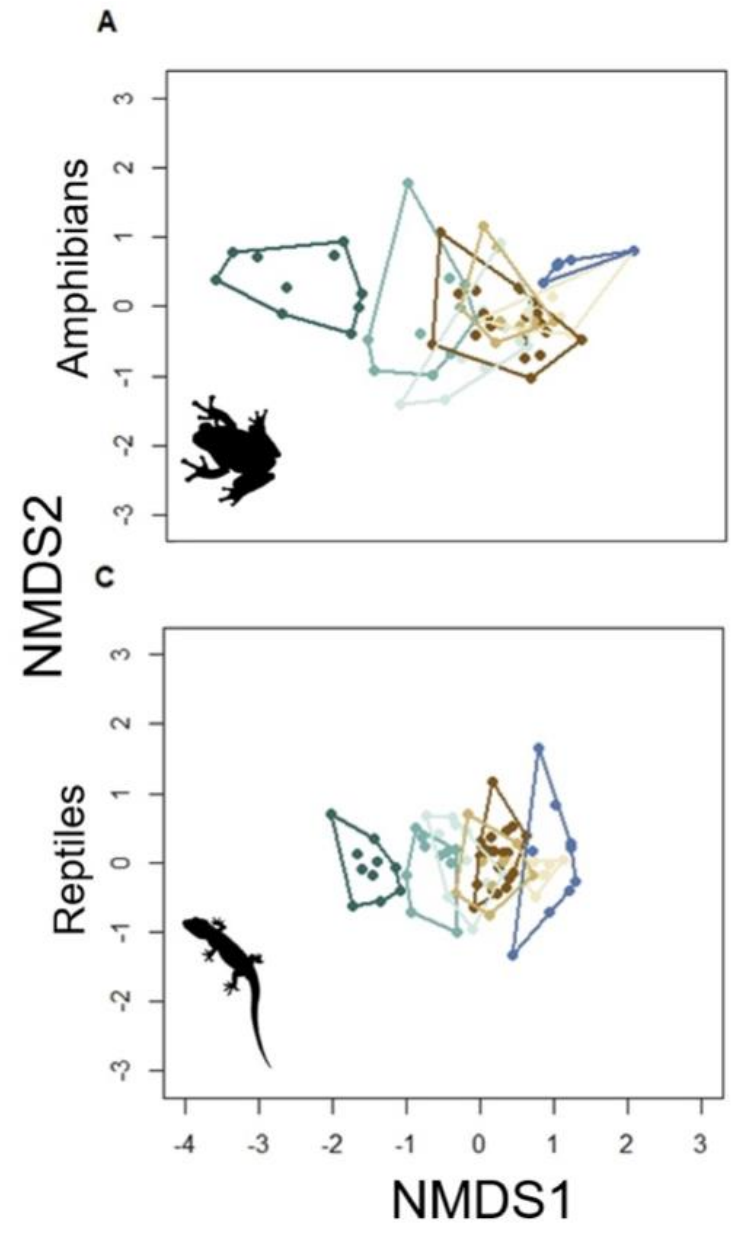

Old-growth Forest

Fallow-derived Vanilla

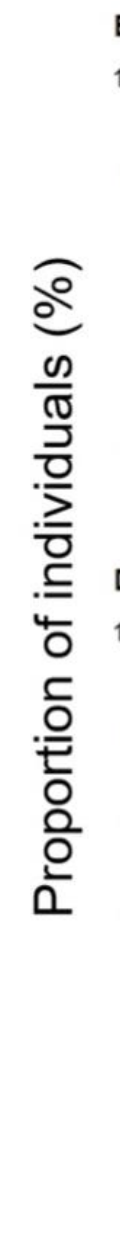

B
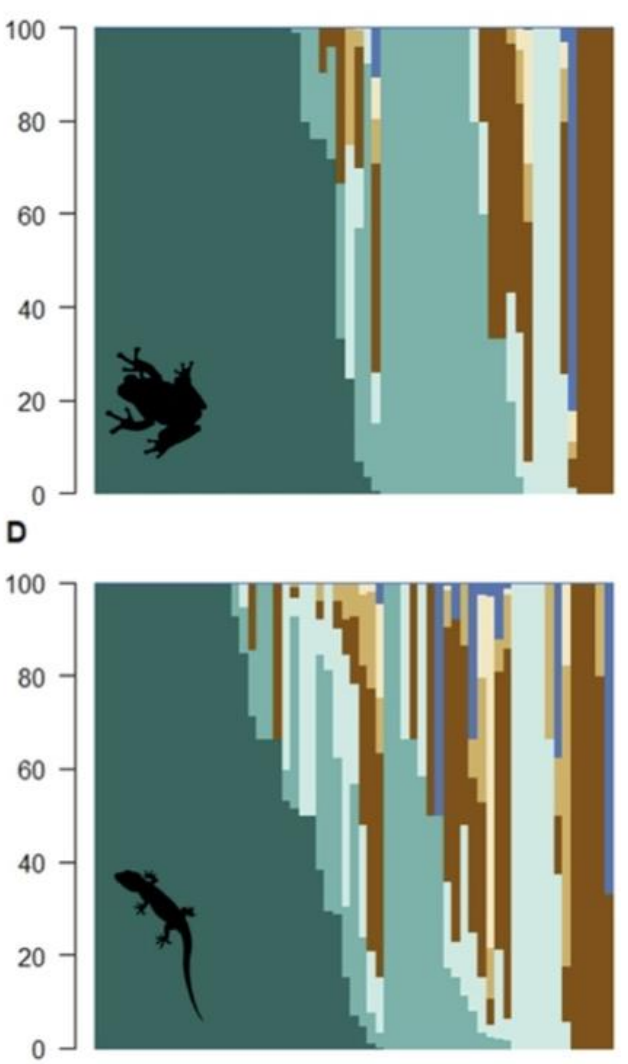

Species by forest dependency rank

Figure 5.4: Species composition across seven land-use types. Non-metric dimensional scaling (NMDS) showing community dissimilarity of amphibian (A) and reptile communities (C). All 58 amphibian species with 3694 encounters (B) and all 61 reptile species (D) with 2521 encounters by forest dependency rank. $38 \%$ of amphibian species and $26 \%$ of reptile species exclusively occurred in old-growth forest, despite only accounting for $12.5 \%$ of the plots.

\subsection{Discussion}

This study represents the first comprehensive assessment of the response of amphibian and reptile diversity to land-use change in the biodiversity hotspot of north-eastern Madagascar. We found a very high species richness of both amphibians and reptiles, with up to 12 and 14 species, respectively, on a plot-level, and 58 and 61 species, respectively, across all plots. Old-growth forest showed significant differences to all other land-use types in terms of total species richness and community composition. Rice paddy and herbaceous fallow 
harboured the lowest species richness. Significant differences in species richness per plot between forest-derived and fallow-derived vanilla agroforests existed only for reptiles. Woody fallow, herbaceous fallow and rice paddy do not harbour unique species. Importantly, we found that amphibians and reptiles responded differently to land-use history. After any kind of forest conversion, amphibian species communities were drastically smaller and showed high species turnover compared to forest. In reptile communities, the forest conversion through slash-and-burn showed a strong species loss as well, but losses were less pronounced under conversion to forest fragment or forest-derived vanilla agroforest, which refrain from using slash-and-burn.

\subsubsection{Outstanding diversity of amphibians and reptiles in Madagascar's north-east}

The diversity of amphibians and reptiles documented here is outstanding, both within Madagascar and compared to other tropical biodiversity hotspots. On the plot level, we found up to 12 amphibian and 13 reptile species within a 25 m radius, summing up to 119 species overall (58 amphibian and 51 reptile species). Other studies investigating the response of amphibian communities to land-use change in Madagascar (Ndriantsoa et al., 2017; Vallan, 2000) found lower overall values, with 62 and 28 species, respectively; and Andreone et al. (2000) found 42 amphibian and 23 reptile species in a rainforest in north-eastern Madagascar. The only study coming close to the diversity documented here is also from northeastern Madagascar, obtaining records for 80 amphibian 52 reptile species (Rabearivony et al., 2015) in a forest corridor. This highlights that the north-east of Madagascar is the most species rich region for the two groups within Madagascar, as suggested in previous biogeographic analysis (Brown et al., 2016). The documented diversity also exceeds values found in other tropical biodiversity hotspots - for example Gillespie et al. (2012) found 31 amphibian species in forest fragments of Borneo, Mendenhall et al. (2014) found 67 species of amphibians and reptiles along a land-use gradient in Costa Rica, Kurz et al. (2014) found 25 amphibian and 20 reptile species, also in Costa Rica, while Wanger et al. (2010) documented 8 amphibian and 12 reptile species across 31 plots in Sulawesi, Indonesia. Lastly, Paoletti et al. (2018) located 29 amphibian and 15 reptiles species across various land-use types in Sumatra, Indonesia.

Firstly, these results reflect the extraordinary species diversity of amphibians (Vieites et al., 2009) and reptiles (Brown et al., 2016) in Madagascar; indeed the diversity of both taxa alone exceeds, for example, the number of bird species (57) found within the same 80 plots (Martin et al., 2020a). Secondly, the high species diversity is also driven by an extensive sampling effort, in terms of plots (80), land-use types (7), and search effort (total of $270 \mathrm{~min}$ 
searching time by two observers per plot), and is also enhanced by the use of DNA sample for species identification. Thirdly, the recorded species richness underlines the importance to study (Nori et al., 2018) and conserve (Jenkins et al., 2014) this extraordinary diversity in Madagascar.

\subsubsection{Response of amphibian diversity to land-use change}

We found a strong negative response of amphibian species richness to any form of oldgrowth forest conversion. Old-growth forest had a significantly higher species richness than all other land-use types, a unique species composition, and 38\% of species exclusively occurred in old-growth forest. Also, 5 of the 6 near-threatened or threatened amphibian species found occurred exclusively in old-growth forest. Only forest fragments could rival oldgrowth forests in terms of accumulated species richness $(q=0)$, but values for Shannon diversity $(\mathrm{q}=1)$ and Simpson diversity $(\mathrm{q}=2)$ were significantly lower in forest fragments, demonstrating that old-growth forest plots were more uneven due to many rare species. In sum, we found that amphibians are extremely sensitive to habitat change in north-eastern Madagascar; more so than reptiles (see 5.5.3) or birds (Martin et al., 2020a) along the same land-use gradient. This result is in line with findings from the only other study on amphibian communities in disturbed habitats of eastern Madagascar: Ndriantsoa et al. (2017) show strongly impoverished frog communities in secondary vegetation and rice fields compared to forests. Importantly, forest fragments were the only other land-use type that is of greater relevance for amphibians, as highlighted by the high accumulated species diversity, which has non-overlapping confidence intervals with all other land-use types within the agricultural landscape, the significant number of unique species, and the species composition most similar to old-growth forest. The importance of forest fragments for Malagasy amphibians is also recognised by others (Riemann et al., 2015; Vallan, 2000), who also conclude that forest fragments cannot substitute continuous old-growth forest but that they are important in maintaining amphibian diversity within the agricultural landscape. Similarly, small forest elements within the agricultural landscape strongly contributed to the available habitat of forest-dependent amphibians and reptiles in Costa Rica (Mendenhall et al., 2014). There are various factors that could explain the strong negative response of amphibians to forest fragmentation and deforestation. Many amphibian species rely on moist environments to avoid dehydration (Clarke, 1997), especially those living in moist evergreen rainforest habitat (Hof et al., 2011). Given the severe changes in microclimate that come with selective logging, forest fragmentation, and deforestation (Ewers \& Banks-Leite, 2013), many species may struggle to cope. Furthermore, amphibians rely on a plethora on different 
microhabitats, depending on the species (Hof et al., 2011). Such microhabitats are being lost in concert with the forest structure, making new habitats unsuitable. The loss of microhabitats could also be the reason for the loss of accumulated species richness $(q=0)$ and shifts in species composition under the transformation of forest fragments to forest-derived vanilla agroforestry.

The role of the other land-use types (fallows that form part of the shifting cultivation cycle, vanilla agroforests, and rice paddies) are of minor importance for amphibian and reptile conservation, given the low diversity and abundance of common species. Nonetheless, amphibians could play an important functional role in these habitats: abundance of amphibians is high throughout, reflected by high number of encounters, particularly in rice paddies. Indeed, they may be an important food source for other taxa or could provide pest control services (Hocking \& Babbitt, 2014).

\subsubsection{Response of reptile diversity to land-use change}

We found a strong effect of land-use history on reptile diversity: Non-burned land-use types (old-growth forest, forest fragments, and forest-derived vanilla agroforests) had significantly higher plot-level species richness, a higher accumulated species richness, more uneven communities, more unique species, and largely distinct species composition compared to burned land-uses (herbaceous fallow, woody fallow, fallow-derived vanilla agroforest) and rice paddy. Within the non-burned land-use types, old-growth forest stood out with a unique species composition and $26 \%$ of species detected only occurring therein (while accounting for $12.5 \%$ of sampling effort). Furthermore, 11 out of 16 near-threatened and threatened reptile species exclusively occurred in old-growth forest. This is, to our knowledge, the first study shedding light on the response of reptiles to land-use change in the humid eastern Madagascar. Studies from the drier south of the country (Gardner et al., 2016; Nopper et al., 2018; Scott et al., 2006) show that Malagasy reptile species react less strongly to habitat change than other taxa (Scott et al., 2006), especially if diurnal (Nopper et al., 2018). Similarly, we find that amphibians (see 5.5.2), birds (Martin et al., 2020a) and trees (Osen et al., in review) react more strongly under the conversion of old-growth forest to forest fragments and forest-derived vanilla agroforests. However, also reptile diversity was greatest in least disturbed habitats in southern Madagascar (Gardner et al., 2016) and old-growth forests harboured a unique species composition in this study. These findings underpin the need for the conservation of the least disturbed habitats for reptiles; a key finding of a meta-analysis (Doherty et al., 2020). Importantly, Doherty et al. (2020) also 
demonstrate that small-ranged species are more sensitive to habitat modification, possibly highlighting a thread for micro-endemic reptile species (Brown et al., 2014).

Importantly, we demonstrate how slash-and-burn of non-burned land-use types, usually old-growth forest and forest fragments, for shifting hill rice cultivation will decimate reptile diversity. Also, the rehabilitation of trees on resulting fallow land through fallow-derived agroforestry (Martin et al., 2020b) can only restore the land in part (more on agroforests in 5.5.4). This may be as burning destroys multiple micro-habitats on which reptiles rely, such as leaf litter or dead wood (Urbina-Cardona et al., 2006). This theory is further supported as habitat conversion without the use of fire, i.e. the establishment of forest-derived vanilla agroforests, comes with little change for reptiles.

Interestingly, the stronger effects of land-use change on amphibians than reptiles in tropical landscapes has also been demonstrated by others (Kurz et al., 2014; Paoletti et al., 2018; Wanger et al., 2010) and was found in a review by Palacios et al. (2013). This may be due to the high thermotolerance of reptiles, which may be advantageous in more open, hotter and drier environments (Doherty et al., 2020). However, the review of Palacios et al. (2013) identifies a negative change in reptile abundance under the conversion of forests into agroforests/plantations, something that we could not find.

\subsubsection{Land-use history of vanilla agroforests matters for reptiles but not amphibi- ans}

Vanilla agroforests are an important land-use type in the study region and provide income for smallholder farmers (Hänke et al., 2018). Assessing their conservation value for amphibians and reptiles is thus an important undertaking which has not been done previously, in contrast to other agroforestry systems (Palacios et al., 2013). Importantly, we differentiated between those vanilla agroforests that are established inside forests, i.e. forest-derived vanilla agroforests, and those that are established on fallow land, i.e. fallow-derived vanilla agroforests, thereby explicitly accounting for land-use history (Martin et al., 2020b). For amphibians, we found no differences between the two kind across metrics. Instead, reptile communities in forest-derived vanilla agroforests were significantly more species rich on the plot level, more species rich overall, more uneven, and compositionally different. Reptile communities in forest-derived vanilla agroforests were thus more similar to communities found in forest fragments and old-growth forests, whereas those communities in fallowderived vanilla agroforests were most similar to fallow land, thereby resembling the landuse types agroforests were derived from. Importantly, we also show an increase in 
accumulated species richness for fallow-derived vanilla agroforest over fallow land, highlighting a rehabilitation opportunity of fallow land through agroforestry.

These finding align, firstly, with predictions from a recent review concerning the land-use history of agroforestry systems (Martin et al., 2020b), and, secondly, with a review that shows a decrease of amphibian richness when forests are compared to agroforests and plantations (Palacios et al., 2013). We further hypothesize, that the strong importance of forest-derived vanilla agroforests for reptiles may be in part driven by leaf-litter depth. Indeed, leaf litter is deeper in forest-derived agroforests (mean: $5.18 \mathrm{~cm}, S D \pm 3.40 \mathrm{~cm}$ ) than in fallow-derived agroforests (mean: $0.819 \mathrm{~cm}, S D \pm 1.42 \mathrm{~cm}$ ), and leaf litter depth is known to positively influence reptile diversity and abundance (Urbina-Cardona et al., 2006). However, the same study also showed positive effects of leaf litter depth and cover on amphibians and can thus not explain, why there are no differences between the two kind of agroforests for amphibians. However, other factors such as canopy cover and stem density differ between agroforests in our study (Osen et al., in review), calling for further investigation combining habitat characteristics with species traits (Oliveira et al., 2017) to elucidate the drivers of change in both species groups.

\subsubsection{Conservation implications}

The strong response of amphibians to old-growth forest modification, of any form, calls for the protection of remaining old-growth forests. Additionally, conserving forest fragments within the agricultural landscape will be important to many reptile and amphibian species that are absent from many of the other land-use types. This is particularly important given widespread micro-endemism for both species groups (Brown et al., 2014), suggesting that forest needs to be protected everywhere as certain, possibly undescribed (Vieites et al., 2009), taxa may only occur in few fragments. The protection of forests of all sizes throughout the region is also important under a warming climate (Hof et al., 2011; Raxworthy et al., 2008) and in light of emerging threats, such as the chytrid fungi (Kolby \& Skerratt, 2015; O'Hanlon et al., 2018) and the recent uncontrolled spread of the invasive Asian common toad (Duttaphrynus melanostictus) that will threaten amphibians in the future (Pearson, 2015). We further show, that while diverse agroforestry systems play a limited role for rare amphibians, they may be more important for reptile species who prefer forest-derived vanilla agroforests over shifting cultivation and fallow-derived agroforests. Supporting the maintenance of forest-derived vanilla agroforests while avoiding the establishment of new forest-derived vanilla agroforests, which represent a degradation of forests (Martin et al., 2020b), should thus be a priority. These conservation needs are further underscored by the 
exceptional diversity of reptiles and amphibians in north-eastern Madagascar as well as by the high proportion of endemic species.

\subsection{Author's contributions}

TRF, DAM, KO, AW, HK, AA, and FMR designed the study. TRF, EB, RB, and RR collected amphibian and reptile data under the lead of TRF. TRF and DAM analysed the data. TRF and DAM wrote the first manuscript draft. All authors revised the manuscript.

\subsection{Acknowledgements}

We are grateful to all chef de fokontany, landowners, and Madagascar National Parks for granting us access to sites and information. We thank Prof. Miguel Vences for assistance with the DNA barcoding and Saskia Dröge for preparing panel C of Figure 5.1. We collected data under research permits $\mathrm{N}^{\circ} 100 / 17 / \mathrm{MEEF} / \mathrm{SG} / \mathrm{DGF} / \mathrm{DSAP} / \mathrm{SCB} \cdot \mathrm{Re}, \mathrm{N}^{\circ} 163 / 17 / \mathrm{MEEF} /$ SG/DGF/DSAP/SCB.Re, N¹8/18/MEEF/SG/DGF/DSAP/SCB.Re and N²54/18/MEEF/SG/ DGF/DSAP/SCB.Re granted by the Ministry of Environment and Sustainable Development, Antananarivo. We transported DNA samples domestically under the transport permit $\mathrm{N}^{\circ}$ 34/17-MEEF/SG/DREEF/SAVA/SRF granted by the Regional Office of the Ministry of Environment and Sustainable Development, Sambava. We exported the samples from Madagascar under CITES permits $\mathrm{N}^{\circ} 323 \mathrm{C}-\mathrm{EA05} / \mathrm{MG18}$ and $\mathrm{N}^{\circ} 180 \mathrm{C}-\mathrm{EA03/MG19}$ granted by the Ministry of Environment and Sustainable Development, Antananarivo, and imported the samples to Germany under CITES permits DE-E-03377/18, DE-E-03378/18, DE-E02422/19, DE-E-02423/19, DE-E-02424/19, and DE-E-02425/19 granted by the Ministry for Conservation, Bonn. This study was financially supported by the Niedersächsisches Vorab of Volkswagen Foundation as part of the research project 'Diversity Turn in Land Use Science' (Grant number 11-76251-99-35/13 (ZN3119)) and by the German Academic Exchange Service (DAAD) within the 'Partnerships for Supporting Biodiversity in Developing Countries' initiative (Project Nr. 57449386). The authors have no conflict of interest to declare. 



\section{Shade-tree rehabilitation in vanilla agrofor- ests is yield neutral and may translate into landscape-scale canopy cover gains}

Dominic Andreas Martin, Annemarie Wurz, Kristina Osen, Ingo Grass, Dirk Hölscher, Thorien Rabemanantsoa, Teja Tscharntke, \& Holger Kreft

Contribution: Conceptualization, Data curation, Formal analysis, Investigation, Project administration, Validation, Visualization, Writing - original draft

Status: Published in Ecosystems, https://doi.org/10.1007/s10021-020-00586-5

\subsection{Abstract}

Agroforestry can contribute to an increase in tree cover in historically forested tropical landscapes with associated gains in biodiversity and ecosystem functioning, but only if established on open land instead of underneath a forest canopy. However, declines in yields with increasing shade are common across agroforestry crops, driving shade-tree removal in forest-derived agroforests and hindering tree regrowth in open-land-derived agroforests. To understand trajectories of change in tree cover in forest- and open-land-derived agroforests, and the impacts of tree cover on vanilla yields, we studied 209 vanilla agroforests along an 88-year chronosequence in Madagascar. Additionally, we used remotelysensed canopy cover data to investigate tree cover change in the agricultural landscape. We found yields to vary widely but independently of canopy cover and land-use history (forestvs. open-land-derived), averaging at $154.6 \mathrm{~kg} \mathrm{ha}^{-1} \mathrm{yr}^{-1}(S D \pm 186.9)$. Furthermore, we found that forest- and open-land-derived vanilla agroforests gained canopy cover over time, but 
that only open-land-derived agroforests gained canopy height. Canopy cover increased also at the landscape scale: areas in the agricultural landscape with medium initial canopy cover gained 6.4\% canopy cover over 10 years, but canopy cover decreased in areas with high initial canopy cover. These opposing trends suggest tree cover rehabilitation across areas covered by vanilla agroforests, whereas remnant forest fragments in the agricultural landscape were transformed or degraded. Our results indicate that yield-neutral tree rehabilitation through open-land-derived agroforestry could, if coupled with effective forest protection, provide benefits for both ecosystem functions and agricultural production in a smallholder-dominated agricultural landscape.

Keywords: agroecology, agroforestry, canopy cover, ecosystem services, land-use history, Madagascar, rehabilitation, restoration, vanilla, yield

\subsection{Introduction}

Rehabilitation of historically forested open land is widely advocated to re-establish connectivity and increase ecosystem functions in tropical rainforest landscapes (Bastin et al., 2019; Chazdon, 2003). To date, governments and institutions have pledged to restore 140 million hectares of land in the tropics (Brancalion et al., 2019). However, realizing those pledges could jeopardize food security if tree cover restoration replaces cropland, casting doubt on their feasibility (Eitelberg et al., 2016) and desirability (Holl \& Brancalion, 2020). In this light, agroforests may provide an opportunity to combine trees with agricultural production on the same land (De Beenhouwer et al., 2016; FAO, 2017). Agroforests that are established on historically forested open-land hold a particularly large potential, because open-landderived agroforests rehabilitate selected ecosystem functions like erosion control or carbon storage on open land (Martin et al., 2020b). To describe this process, we specifically use the word 'tree rehabilitation' based on Chazdon et al. (2016), as the focus lies on the rehabilitation of ecosystem functions, without necessarily restoring ecological integrity. In contrast to this, agroforests planted under the canopy of existing forests typically contribute to forest degradation (Martin et al., 2020b), thus hampering ecosystem functioning and ecological integrity (Coe et al., 2013; McDowell et al., 2020).

Nonetheless, trade-offs between shade cover and yields are common across many key agroforestry crops (Tscharntke et al., 2011), limiting the potential of these agroforestry systems to contribute to tree rehabilitation in tropical rainforest landscapes. Such shade-yield trade-offs are exemplified in coffee and cacao agroforests (Blaser et al., 2018; SteffanDewenter et al., 2007), where felling trees is typically beneficial to farmers aiming at 
optimizing yields. Finding a balance between ecosystem services, biodiversity and profitability thus requires targeted incentives. In their absence, a decrease in canopy cover and tree height over time commonly occurs (Tscharntke et al., 2014), but time series or chronosequences, which are necessary to identify trends, are rare (see Nijmeijer et al. (2019) for an exception). Finding farming techniques or crops where such trade-offs do not inherently occur would, on the other hand, offers an opportunity to profitably farm crops in high-shade agroforestry systems without the need for further incentives.

One candidate crop where shade-yield trade-offs are currently unknown is the spice vanilla. When farmed in agroforestry systems, the vanilla orchid (Vanilla planifolia) is typically grown on support trees which act as a climbing structure for the non-woody vine (Correll, 1953). Vanilla flowers are then hand pollinated and green pods are harvested nine months later. The green pods are subsequently cured, thereby developing their distinct flavour and black colouration while losing roughly $80 \%$ of their weight (Havkin-Frenkel \& Belanger, 2018). The resulting black vanilla has strongly increased in price from 2012 to 2019, triggering the expansion of vanilla farming in Madagascar (Hänke et al., 2018; Llopis et al., 2019; SI Chapter 6, Figure 12.5).

In north-eastern Madagascar, vanilla is the main cash crop for smallholder farmers (Hänke et al., 2018) who farm the bulk of Madagascar's 40\% share on the world market (FAO, 2020). Here, vanilla is almost exclusively produced in rather extensively managed agroforestry systems without the application of fertilizers, herbicides and pesticides. This is partly in contrast to other production areas, such as La Réunion or Mexico, where artificial shade houses are common (Havkin-Frenkel \& Belanger, 2018). These extensively managed vanilla agroforests also have value for biodiversity: various endemic lemur species live in diverse agroforests (Hending et al., 2018) and vanilla agroforests have a more diverse avifauna than open land uses (Martin et al., 2020a). Other prominent land uses in the Malagasy vanilla region include remnant forest fragments, irrigated rice paddies and hill rice fields with the associated herbaceous and woody fallows, that form part of the shifting cultivation cycle, locally known as tavy (Martin et al., 2020a; Styger et al., 2007). The first cycle of shifting cultivation, where fire is used to convert forest into hill rice fields, is the main reason for forest loss in the region (Schüßler et al., 2020; Zaehringer et al., 2015). This dynamic is consistent with trends across most of Africa, but contrasts with trends in the remaining tropics (Curtis et al., 2018; van Vliet et al., 2012).

Vanilla agroforests may be established inside forest fragments or on open fallow land, thereby differing in land-use history (Martin et al., 2020b). Forest-derived vanilla 
agroforests degrade the forest they are established in but will typically outperform shifting cultivation, i.e. the replacement of forest with hill rice cultivation, for ecosystem functions and biodiversity (Martin et al., 2020b). Open-land-derived agroforests may instead restore land formerly under hill rice cultivation by rehabilitating tree cover and preventing the reoccurring fires which characterize the shifting hill rice cultivation system (Holloway, 2004; Styger et al., 2007). In north-eastern Madagascar, $30 \%$ of vanilla agroforests are forest-derived while 70\% are open-land-derived (Hänke et al., 2018), further underlining the rehabilitation opportunity offered by open-land-derived agroforestry. The high potential for tree rehabilitation and habitat restoration in Madagascar is also recognized in a recent study by Brancalion et al. (2019), who attribute the $4^{\text {th }}$ largest restoration opportunity area (in terms of benefits and feasibility) of lowland tropical rainforest to Madagascar. Simultaneously, the country is characterized by high levels of endemism (Goodman \& Benstead, 2005) and high deforestation rates (Harper et al., 2007; Vieilledent et al., 2018) and qualifies as a biodiversity hotspot (Myers et al., 2000). This exacerbates the need for both effective biodiversity conservation within the existing protected areas as well as restoration within the agricultural landscape.

In this study, we 1) examined how land-use history, canopy cover, agroforest age, planting density and precipitation influence vanilla yields, 2) assessed tree rehabilitation dynamics across vanilla agroforests of different age and of contrasting land-use history, and 3) investigated how tree rehabilitation within vanilla agroforests may transform the landscape as a whole. To this end, we assessed vanilla yields, canopy cover and canopy height in 209 vanilla agroforests of contrasting land-use history and of different age ( 0 - 88 years), thus representing an 88-year chronosequence. Subsequently, we used remotely sensed canopy cover data to study canopy cover change from 2000-2010 on the landscape-scale. Based on previous studies from cocoa and coffee agroforests (Blaser et al., 2018; Jezeer et al., 2017; Perfecto et al., 2005), we expected vanilla yields to decline with increasing canopy cover. We further anticipated canopy cover and canopy height to decline with increasing age of forest-derived agroforests, but expected both variables to increase with age in open-landderived agroforests, in line with the predictions by Martin et al. (2020b). At the landscapescale, we presumed that the ongoing transformation of open fallow land into open-landderived agroforests may positively influence canopy cover around the villages. 


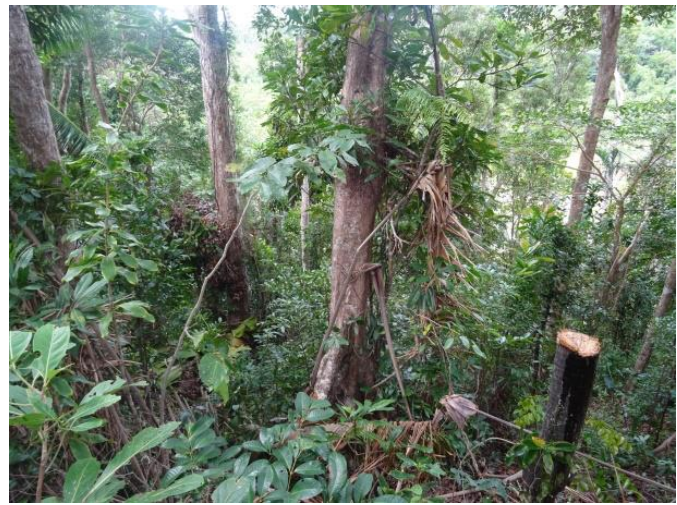

Tropical forest fragment

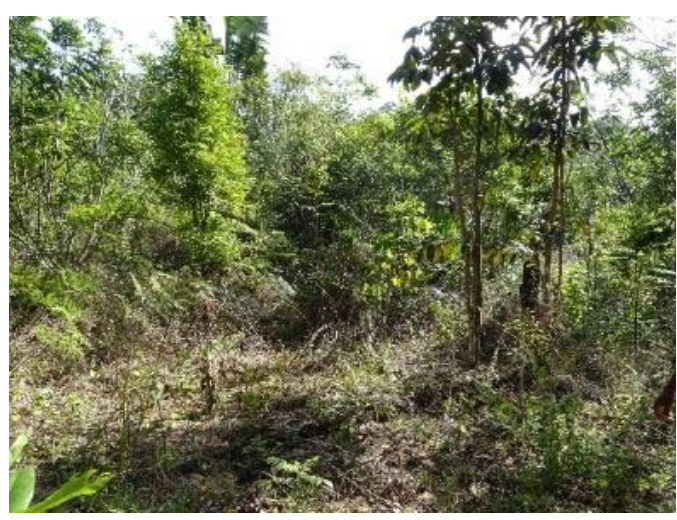

Open land (Woody fallow)

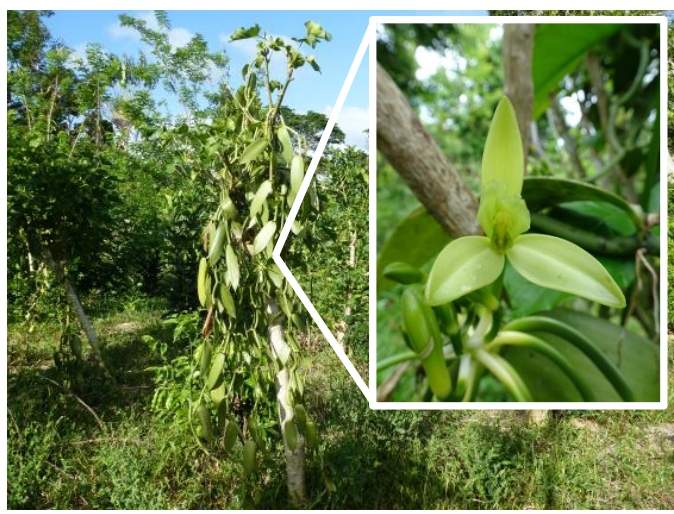

Vanilla pied (unit of vanilla vine and support tree), flower and green pods

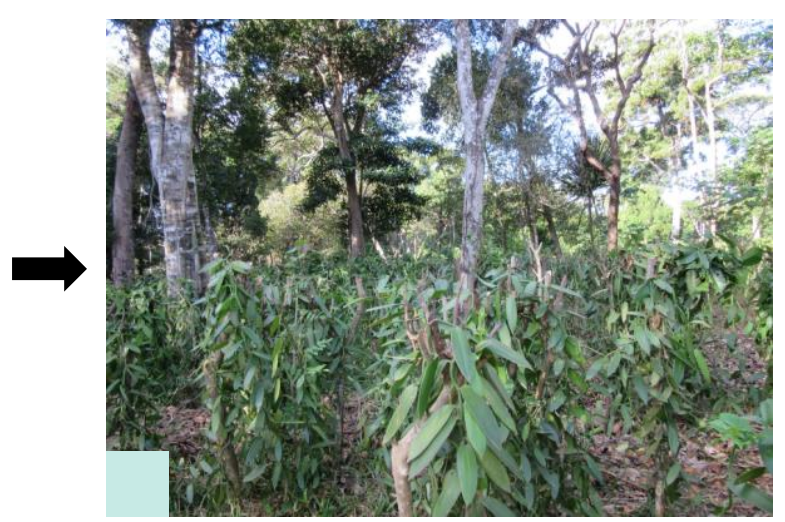

Forest-derived vanilla agroforest

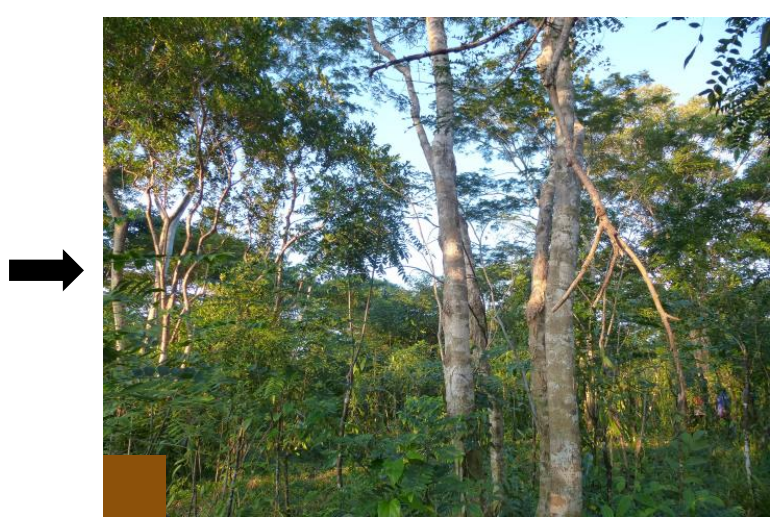

Open-land-derived vanilla agroforest

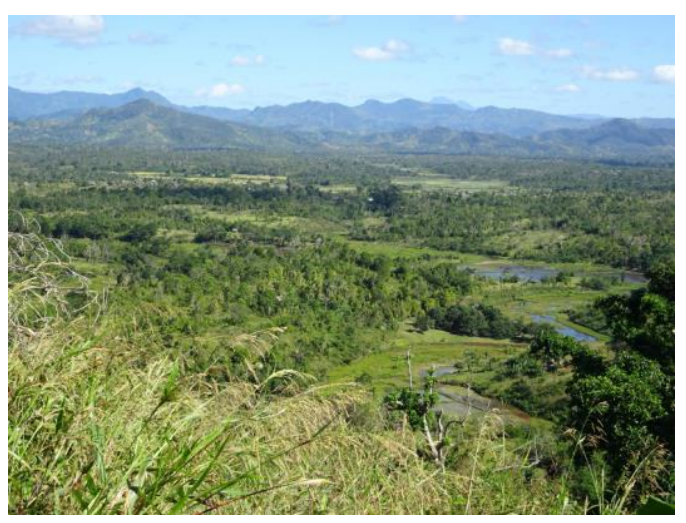

Agricultural landscape in northeastern Madagascar

Figure 6.1: Top row: Forest-derived vanilla agroforests are directly established inside forest. Middle row: Open-land-derived vanilla agroforests are established on open land, typically woody fallow. Bottom row: Vanilla pied (unit of vanilla vine and support tree) and agricultural landscape in northeastern Madagascar where the study took place. Colour labels indicate contrasting land-use history of vanilla agroforests and are used throughout the manuscript. All photos by the authors. 


\subsection{Methods}

\subsubsection{Study region}

The SAVA region (25 $518 \mathrm{~km}^{2}$ / Latitude: $14^{\circ} 16^{\prime} \mathrm{S}$, Longitude: $50^{\circ} 10^{\prime} \mathrm{E}$ ) of north-eastern Madagascar is the historic (Correll, 1953) and current (Hänke et al., 2018) center of global vanilla production and a biodiversity hotspot (Myers et al., 2000). Mean annual temperature is $23.7^{\circ} \mathrm{C}$ and annual rainfall averages at $2238 \mathrm{~mm}$ (Mean across 209 focal agroforests; data from CHELSA climatologies (Karger et al., 2017)). In the southern part of the SAVA region, where we collected the data (SI Chapter 6, Figure 12.6), the natural vegetation is tropical rainforest (Vieilledent et al., 2018), but only 35\% forest cover remains across the SAVA region (Ferreira Arruda, 2018).

\subsubsection{Selection of vanilla agroforests}

We first selected 60 villages in a stratified-random way for a previous study (Hänke et al., 2018). From those 60 , we selected 10 villages in a nested stratified-random way that controlled for village size. Specifically, we randomly selected two villages per village size category (0-1000 people, 1001-2000 people, 2001-3000 people, 3000-4000 people, $>4000$ people). Within each village, we chose 14 households randomly from the 30 households included in Hänke et al. (2018); however, 20 households opted out, leaving us with 120 households.

We then visited accessible ( $<4 \mathrm{~h}$ walking return) vanilla agroforests; 33 households did not own any accessible vanilla agroforests and 27 had more than one agroforest, resulting in a sample of 123 agroforests owned by 87 households. After collecting data from those agroforests, but before doing any data analysis, we checked the number of forest- and openland-derived agroforests in the sample and realised that the number was uneven (36 vs. 87).

We thus decided to include four additional villages from the stratified random sample of 60 villages. For those villages, we knew based on Hänke et al. (2018) that their proportion of forest-derived vanilla agroforests would be high, resulting in roughly even numbers of forest- and open-land-derived agroforests in the final sample. In those four villages, we visited 65 households included in Hänke et al. (2018). Those households owned 86 additional accessible agroforests (7 open-land-derived, 79 forest-derived). This led to a total sample of 115 forest-derived and 94 open-land-derived agroforests (209 in total) owned by 152 
households across 14 villages. SI Chapter 6, Figure 12.6 shows all 14 villages with field data and the 60 villages from the initial sample.

\subsubsection{Data collection in agroforests}

We collected field data between July and October 2018 after the 2018 vanilla harvest.

During visits to the agroforests, we asked vanilla agroforest owners in Malagasy about 1) the realized yield of green vanilla in 2017 and 2018 [kg agroforest-1], 2) estimated green vanilla theft from the agroforest before harvest in 2017 and 2018 [kg agroforest ${ }^{-1}$ ], 3) the number of pieds (combination of vanilla vine and support tree; Figure 6.1) in the agroforest, 4) the year in which the agroforest was established, and 5) whether the agroforest was forest- or open-land-derived (sensu Martin et al. (2020b). Vanilla yields are commonly reported as the weight of green rather than black pods, since green pod weight is independent of the curing technique (Havkin-Frenkel \& Belanger, 2018). We subsequently added estimated theft to the realized yields as we were interested in the productivity of the agroforests rather than the farmers' income. We measured agroforest size during perimeter walks using handheld GPS devices and applied a slope correction (based on the digital surface model 'ALOS World 3D' (Japan Aerospace Exploration Agency, 2018)) to account for different steepness of the terrain. By combining yield data and the slope-corrected agroforest size, we calculated mean green vanilla yield per hectare $\left[\mathrm{kg} \mathrm{ha}^{-1}\right.$ year-1] across the two years for further analysis. Based on slope-corrected agroforest size and number of pieds, we calculated planting density [pieds ha-1].

We used tablets to assess canopy cover, as photos from mobile devices have been found to be an adequate, cheap and fast technique to assess canopy cover (Bianchi et al., 2017; Tichý, 2016). Observers held the tablet (Lenovo YT3-850F) above their head (circa $190 \mathrm{~cm}$ ) and used the built-in camera (Lenovo 5C28C02840) with the standard lens and auto-exposure to take a photo in azimuthal direction. We repeated this procedure at nine locations per plot (SI Chapter 6), resulting in 1881 photos from 209 agroforests. We then classified all photos into vegetation/sky using the R-Package caiman (Diaz \& Lencinas, 2015; more details on canopy cover classification in SI Chapter 6) and calculated mean canopy cover across all 9 photos to derive one value per agroforest. Additionally, the observer estimated the highest point of vegetation above each camera position, enabling us to calculate the mean canopy height across 9 locations for each agroforest.

Some farmers did not know the number of pieds and/or the year of establishment of their agroforest, leading to missing data for planting density and agroforest age in 8 and 3 cases, 
respectively (out of 209). We imputed this data for the linear mixed effect models using the mean of each respective variable.

\subsubsection{Data extraction from raster layers}

To investigate how precipitation and temperature influenced vanilla yields, we extracted annual mean temperature and annual precipitation for each agroforest from the CHELSA climatologies with a resolution of 30 arc sec (Karger et al., 2017) using the plot center as a reference point. Due to the strong correlation of annual mean temperature and annual precipitation (-0.76, Pearson correlation coefficient), we only used elevation and annual precipitation for the analysis on vanilla yields. Analogously, we obtained the elevation of each agroforest from the digital surface model 'ALOS World 3D' (Japan Aerospace Exploration Agency, 2018). Lastly, we extracted the percentage landscape forest cover in a radius of 250 $\mathrm{m}$ around plot centres using published binary forest cover data for the year 2017 (Vieilledent et al., 2018).

\subsubsection{Analysis of vanilla yields, canopy cover and canopy height}

We used three linear mixed-effects models to analyse variation in vanilla yields, canopy cover and canopy height, with 'household' (owner of agroforest, $\mathrm{N}=152$ ) and 'village' ( $\mathrm{N}=$ 14) as random effects in all models. We fitted all models using the R-Package Ime4 version 1.1.21 (Bates, 2014) and scaled all explanatory and response variables to zero mean and unit variance, allowing for direct comparison of effect sizes within and across models (Harrison et al., 2018). We used an alpha level of 0.05 and calculated marginal and conditional $\mathrm{R}^{2}$-values for all models (Nakagawa \& Schielzeth, 2013). We used QQ-plots to assess normality of model residuals and tested for variable inflation; none of the models had significant deviations in the QQ-plots or variable inflation values above 1.5 .

In a first model, we assessed the variation in the response variable green vanilla yield [kg ha-1] in relation to the explanatory variables land-use history (forest vs. open-land-derived; coded as 1 vs. 0 ), canopy cover, age of agroforest, planting density and annual precipitation. To reach normality of model residuals, we applied a Box-Cox transformation to the response variable (Box \& Cox, 1964). We determined a lambda of 0.25 to be suitable for the transformation using the boxcox function of the R-package mass version 7.3.51.4 (Ripley et al., 2013). Due to the highly right-skewed nature of the age and planting density data, we square root transformed these two variables. We additionally included interactions between landuse history and all explanatory variables to test whether responses would differ between forest- and open-land-derived agroforests. 
In a second and third model, we assessed factors influencing the response variables canopy cover (untransformed) and canopy height (Box-Cox-transformed with lambda 0.35), respectively. We used land-use history, age of agroforest, elevation, landscape forest cover and planting density as explanatory variables. Again, we square root transformed the age and planting density data and included interactions between land-use history and all explanatory variables.

In the yield and canopy cover model, none of the interactions were significant, prompting us to present the reduced model without interactions. In the canopy height model, only the interaction between age and land-use history was significant at the $p<0.05$ level. We thus only kept this interaction in the reduced model. All models are presented in full and reduced (i.e. final) form in the Supporting Information (SI Chapter 6, Table 12.20 - Table 12.22).

To visualize the models, we calculated estimated marginal means and their $95 \%$ confidence intervals using the R-Package emmeans version 1.4.5 (Length et al., 2018). We further backtransformed the estimated marginal means to the original distributions to facilitate the interpretation of model results.

\subsubsection{Analysis of canopy cover dynamics in the agricultural andscape}

We used remotely sensed canopy cover data to explore how observed tree rehabilitation within agroforests translated to the landscape scale. We obtained canopy cover data for the year 2000 and 2010 from a Landsat-derived product of continuous canopy cover values with 30 m resolution (Hansen et al., 2013). Using the raster R-package version 3.0.12 (Hijmans et al., 2019), we subtracted the 2000 layer from the 2010 layer to obtain a new raster layer with tree cover gains and losses, respectively (change of canopy cover between 2000 and 2010 [\%]). We restricted both layers to an area of $2 \mathrm{~km}$ around the centers of 60 focal villages (excluding any offshore areas), for which we knew that vanilla farming was common and from which we selected the villages for the plot-based part of this study (Village selection described in Hänke et al. (2018). We chose $2 \mathrm{~km}$ because agroforests in this range will typically belong to the focal village (personal observation). We then fitted a generalized additive mixed model (GAMM) using the R-package mgcv version 1.8-28 (Wood, 2012) to evaluate how the dependent variable 'initial canopy cover in the year 2000' determined the independent variable 'change in canopy cover from 2000 to 2010'. We included 'village' as a random effect and also included longitude and latitude of each raster cell as random effects to control for spatial autocorrelation. Therefore, the model read: change in canopy cover $\sim$ initial canopy cover $+(1 \mid$ village $)+(1 \mid$ longitude $)+(1 \mid$ latitude $)$. We 
further ran the model on the basic dimension $\mathrm{k}=8$. We checked model assumptions using the gam.check function of the mcgv R-package which demonstrated $\mathrm{k}=8$ to be adequate and a near-normal distribution of residuals.

We analysed all data in R version 3.6.0 (R Core Team, 2019). The underlying data and Rcode are publicly available (see data availability statement).

\subsection{Results}

\subsubsection{Determinants of vanilla yields}

Green vanilla yield per pied varied strongly and ranged from $0-860$ g pied $^{-1}$ year-1 $^{-1}$ with an average of 69.9 g pied $^{-1}$ year-1 $^{-1}(S D \pm 112.3 ; \mathrm{N}=209$ agroforests; mean from 2017 and 2018). Note that this estimate includes pieds without any yield as it is calculated by dividing the total yield by the number of pieds in each agroforest. Similarly, green vanilla yields differed strongly across agroforests, ranging from 0 - $932.7 \mathrm{~kg} \mathrm{ha}^{-1}$ year-1 with an average of 154.6 $\mathrm{kg} \mathrm{ha}^{-1}$ year-1 $^{-1} S D \pm 186.9 ; \mathrm{N}=209$ agroforests; mean of 2017 and 2018). Using farmgate vanilla prices for the year 2017 (Hänke et al., 2018), this average yield translates into mean gross earnings of $4684 €$ ha-1 $^{-1}$. However, a household in this dataset only farmed 0.46 ha (SD $\pm 0.42 ; \mathrm{N}=152$ ) of accessible vanilla agroforests in average. The difference in green vanilla yield per ha between the two years was small (2017: $158.8 \mathrm{~kg} \mathrm{ha}^{-1}(S D \pm 200.1)$; 2018: 150.2 $\left.\mathrm{kg} \mathrm{ha}^{-1}(S D \pm 202.6)\right)$ and a Wilcoxon rank sum test revealed no significant differences between years ( $\mathrm{W}=21267, \mathrm{p}=0.642, \mathrm{~N}=209$ agroforests). Farmers reported green vanilla theft in 26 agroforests (12.4\%) for 2017 and in 25 agroforests (12.0\%) for 2018. Farmers who reported theft, stated that they lost on average $9.15 \mathrm{~kg}(S D \pm 15.3)$ green vanilla per agroforest in 2017 and $8.72 \mathrm{~kg}(S D \pm 8.7)$ per agroforest in 2018.

Our yield model (Figure 6.2; SI Chapter 6, Table 12.20) revealed that vanilla yields varied independently of land-use history, i.e. whether an agroforest was forest- or open-land-derived. Yields were furthermore not significantly related to canopy cover and annual precipitation. Yields rose with increasing agroforest age and planting density. Overall, the marginal $\mathrm{R}^{2}$-value of the model was 0.216 while the conditional $\mathrm{R}^{2}$-value was 0.450 . The difference between the two values was mainly driven by the random intercept variance for the random effect 'household' $\left(\tau_{00}=0.26\right)$; the random intercept variance for the random effect 'village' was negligible $\left(\tau_{00}=0.03\right)$ 

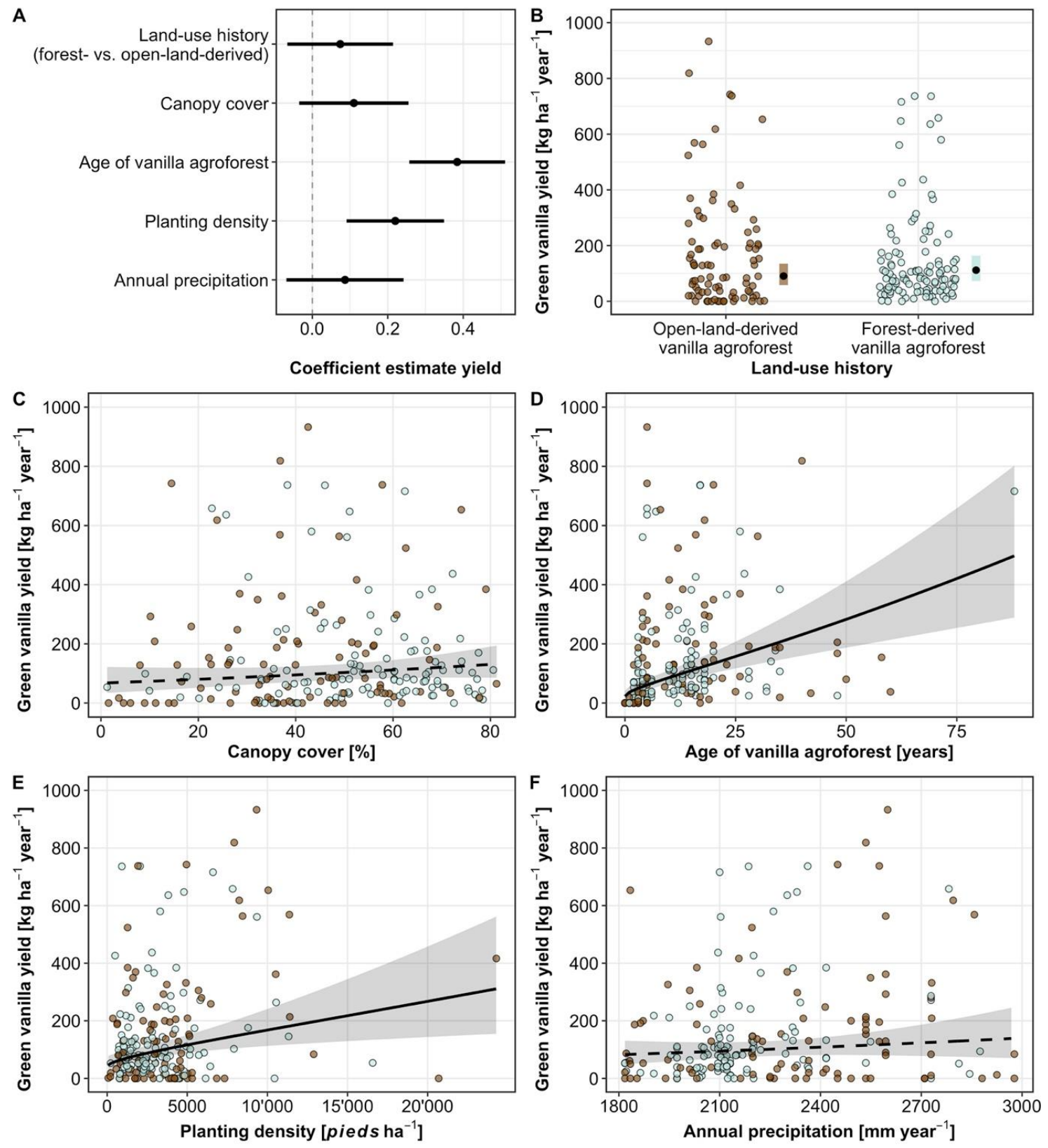

Figure 6.2: Results of a linear mixed effect model explaining green vanilla yield [ $\left.\mathrm{kg} \mathrm{ha}^{-1} \mathrm{yr}^{-1}\right]$ across 209 agroforests. A: Scaled effect plot of the reduced yield model for all five predictors. B-F: Green vanilla yields as a function of land-use history (B), canopy cover [\%] (C), age of vanilla agroforest [years] (D), planting density [pieds ha-1 ${ }^{-1}$ (E) and annual precipitation [mm year $\left.{ }^{-1}\right]$ (F). Green vanilla yields were independent of land-use history and positively associated with all four continuous variables, but the relationships between canopy cover and yields as well as annual precipitation and yields were not significant. Lines and black dots respectively show back-transformed estimated marginal means based on the linear mixed-effect model and shaded areas depict $95 \%$ confidence intervals. Points are raw data separated in forest-derived (blue) and open-land-derived (brown) agroforests. A table with model results can be found in the Supporting Information (SI Chapter 6, Table 12.20). 


\subsubsection{Determinants of canopy cover and canopy height}

Canopy cover was $12.8 \%$ (estimated marginal means 6.3\%) higher in forest-derived vanilla agroforests (mean $=52.9 \%, S D \pm 17.2$ ) compared to open-land-derived agroforests (mean $=40.1 \%, S D \pm 19.0$; Figure 6.3; SI Chapter 6, Table 12.21 and Table 12.22). The age of the agroforests differed along the chronosequence between 1 and 88 years in forest-derived agroforests and between 0 and 60 years in open-land-derived agroforests. Age positively related to canopy cover, in both forest- and open-land derived agroforestry: canopy cover increased by $39.5 \%$ (CI $34.5-44.6 \%$ ) over 88 years.
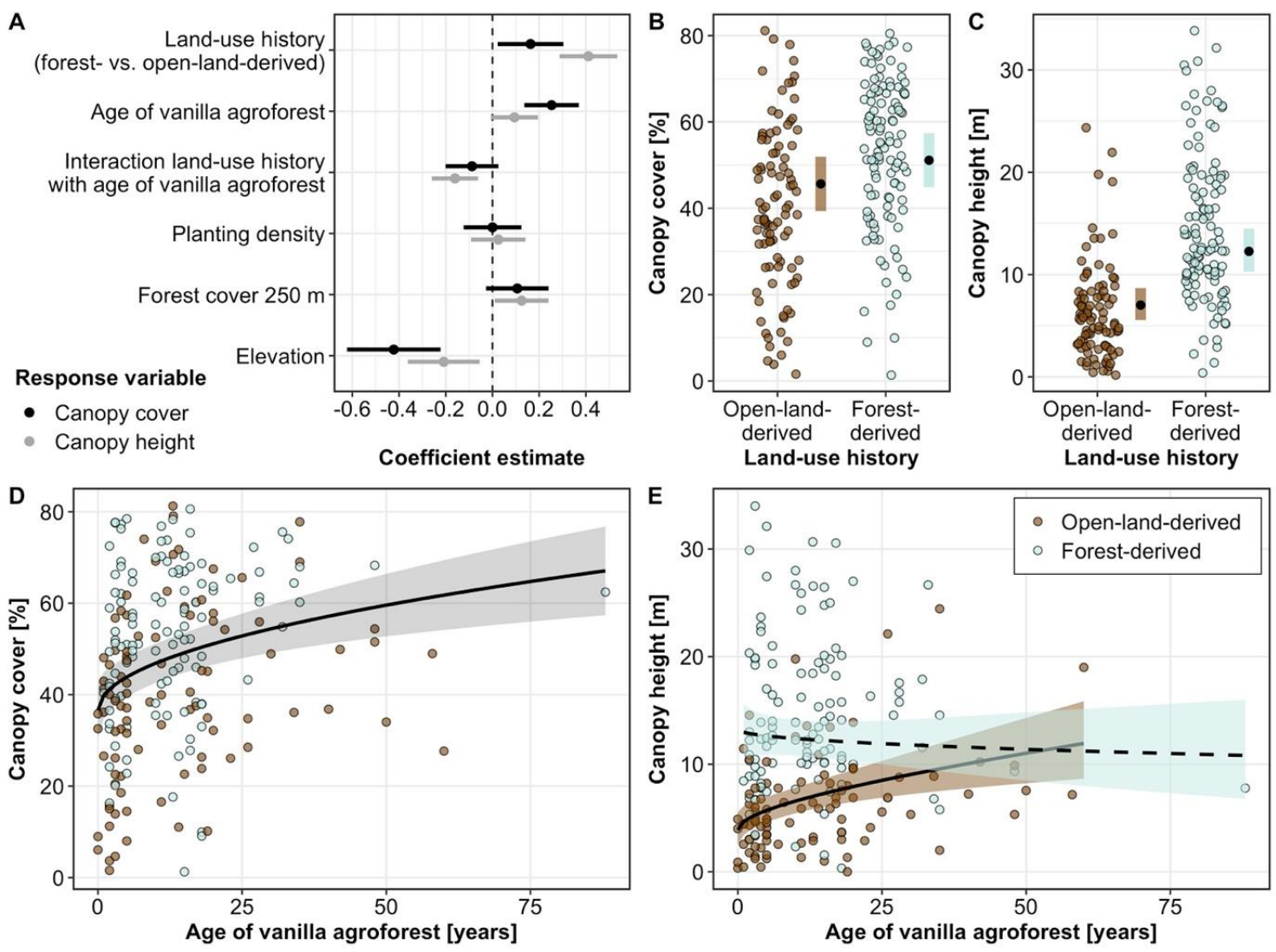

Figure 6.3: Results of two linear mixed effect models explaining canopy cover [\%] and canopy height [m] across 209 vanilla agroforests. A: Scaled effect plot of the reduced canopy cover model (black) and the reduced canopy height model (grey) for all five predictors, including the interaction between land-use history and age [years] in the canopy height model. B \& C: Forest-derived agroforests (blue) had both higher canopy height and higher canopy cover compared to open-land-derived agroforests (brown). D: Older forest- and open-land-derived agroforests had higher canopy cover. E: Older agroforests also had higher canopies, but only if open-land-derived. Lines and black dots respectively show back-transformed estimated marginal means based on linear mixed-effect models and shaded areas depict 95\% confidence intervals. Points are raw data separated in forest-derived (blue) and 
open-land-derived (brown) agroforests. Tables with the results of both models can be found in the Supporting Information (SI Chapter 6, Table 12.21 and Table 12.22).

Similarly, canopy height was $8.2 \mathrm{~m}$ (estimated marginal means $5.2 \mathrm{~m}$ ) higher in forest-derived agroforests (mean $=14.5 \mathrm{~m}, S D \pm 7.3$ ) compared to open-land-derived agroforests (mean $=6.3 \mathrm{~m}, S D \pm 4.6$; Figure 6.3; SI Chapter 6, Table 12.22). The age of the agroforest positively affected canopy height in open-land-derived agroforests where canopy height increased on average by $8 \mathrm{~m}$ (CI $6.1-10.3 \mathrm{~m}$ ) over 60 years. Canopy height in forest-derived agroforests was relatively stable (mean decrease of 1.7 m (CI -2.7 - -0.4) over 60 years and a mean decrease of $2.1 \mathrm{~m}$ (CI $-3.9-+0.4$ ) over 88 years).

Vanilla planting density did not correlate with canopy cover or height (Figure 6.3; SI Chapter 6, Table 12.21 and Table 12.22). Furthermore, agroforests with more surrounding forest cover had taller trees and greater canopy cover, but confidence intervals overlapped zero for the latter (Figure 6.3 A). Elevation was negatively associated with both tree height and canopy cover (Figure 6.3 A). The canopy cover model (Figure 6.3; SI Chapter 6, Table 12.21) had a marginal $\mathrm{R}^{2}$-value of 0.34 and a conditional $\mathrm{R}^{2}$-value of 0.56 , while the canopy height (Figure 6.3; SI Chapter 6, Table 12.22) model had a marginal $\mathrm{R}^{2}$-value of 0.35 and a conditional $\mathrm{R}^{2}$-value of 0.74 . The substantial difference between conditional and marginal $\mathrm{R}^{2}$-values stemmed from the strong explanatory power of the random effect 'household' (canopy cover model: $\tau_{00}=0.16$ / canopy height model: $\tau_{00}=0.37$ ); the random intercept variance for the random effect 'village' was small (canopy cover model: $\tau_{00}=0.07$ / canopy height model: $\tau_{00}=0.02$ ).

\subsubsection{Canopy cover dynamics in the agricultural landscape}

Areas within the agricultural landscape around villages that had low initial canopy cover in the year 2000 experienced little change from 2000 to 2010 (Figure 6.4 C; SI Chapter 6, Table 12.23). Areas with medium to high initial canopy cover experienced an increase in canopy cover, reaching the maximum increase of $6.4 \%$ at $68.3 \%$ initial canopy cover (Figure $6.4 \mathrm{~A}$ ). Areas with very high initial canopy cover lost in average $4.4 \%$ of canopy cover (Figure 6.4 B \& D). Overall, canopy cover increased by $2.7 \%$. The general additive model explained $8.0 \%$ of the variation in the data. 


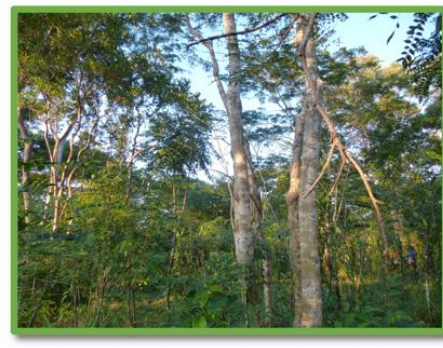

A: Rehabilitation of fallow land, formerly part of the shifting cultivation cycle for hill rice production, through open-landderived vanilla agroforestry is associated with an increase in canopy cover.

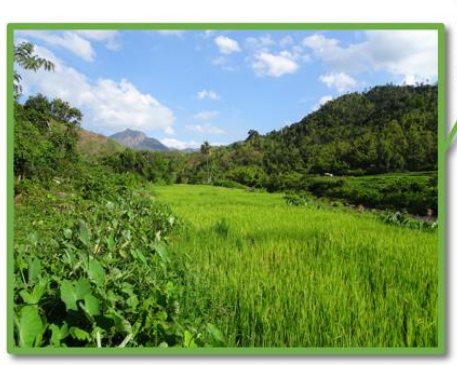

C: No change of land use in productive and valuable rice paddies.

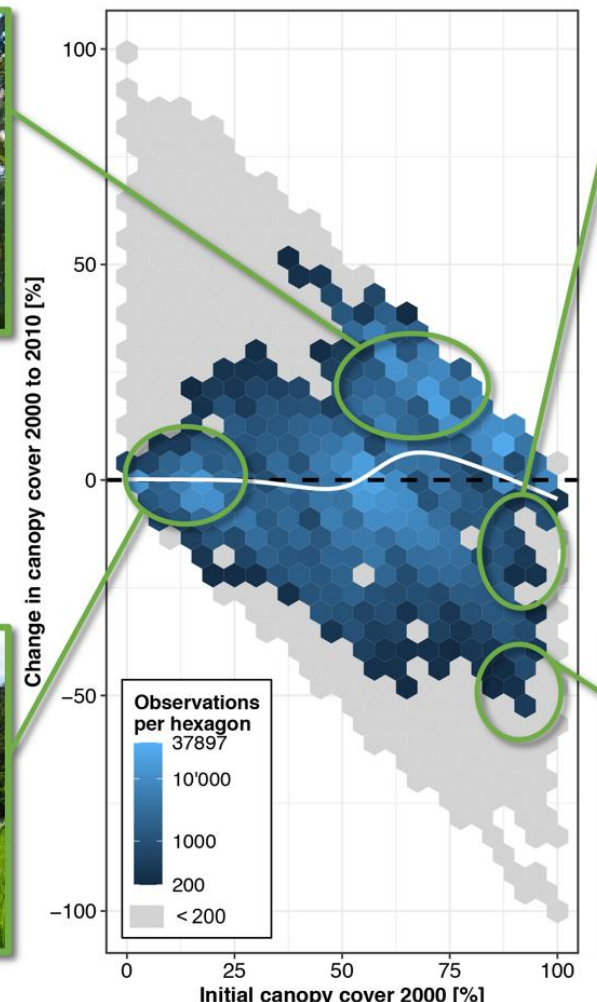

Initial canopy cover 2000 [\%]

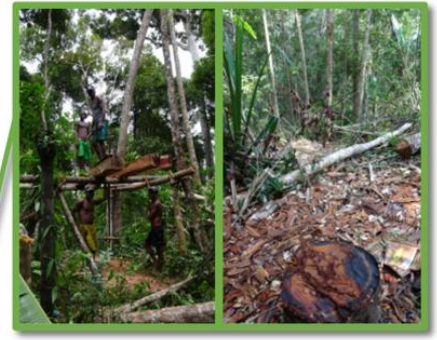

B: Degradation of remaining forest fragments through selective logging and the establishment of new forestderived vanilla agroforests is associated with moderate losses of canopy cover.

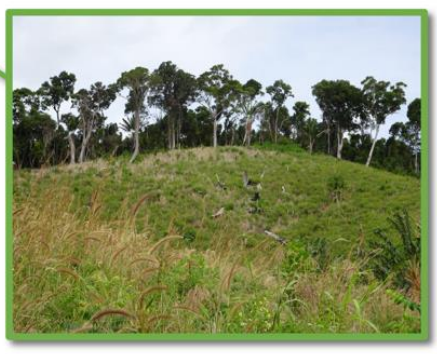

D: Loss of remaining forest fragments through shifting cultivation for hill rice production.

Figure 6.4: Canopy cover dynamics in the agricultural landscape in a $2 \mathrm{~km}$ circle around centres of 60 focal villages between 2000 and 2010 using canopy cover raster data with 30 m resolution (Hansen and others, 2013). Canopy cover increased overall by $2.7 \%$, driven by canopy cover increase in areas with medium to high initial canopy cover (e.g. vanilla agroforests; A). Canopy cover did, however, decrease in areas with very high initial canopy cover (e.g. forest; B, D) and was stable in areas with little initial canopy cover (e.g. rice paddies; C). The central plot shows hexagon bins of bin-width $5 \%$ which are coloured according to the number of $30 \times 30 \mathrm{~m}$ raster cells (i.e. observations) within each hexagon bin. Hexagon bins with less than 200 observations are grey. The white line depicts predicted outcomes of a general additive model explaining change in canopy cover (SI Chapter 6, Table 12.23). All photos by the authors.

\subsection{Discussion}

Across an 88-year chronosequence of 209 agroforests in the SAVA region of north-eastern Madagascar, we found vanilla yields to vary widely and to be positively affected by planting density and agroforest age, while land-use history, canopy cover, and precipitation had no effects on yields. Older vanilla agroforests had higher canopy cover, and, if open-land-derived, also greater canopy height. On the landscape-scale, areas within the agricultural landscape with medium canopy cover gained canopy cover between the years 2000 and 2010. 


\subsubsection{Determinants of vanilla yields}

We found vanilla yields to be hugely variable across agroforests, ranging from $0-932.7 \mathrm{~kg}$ green vanilla per hectare. This variability was driven by variable yields per pied (unit of support tree and vanilla vine) and planting densities. Such variability is typical for smallholder agroforests in tropical countries (Clough et al., 2011) and points towards large yield gaps caused by sub-optimal management practices (Lobell et al., 2009). This also suggests a large intensification potential in existing agroforests and opportunities for sustainable intensification (Tilman et al., 2011). Our mean yield estimate of $154.6 \mathrm{~kg} \mathrm{ha}^{-1}$ is lower than most vanilla yield estimates, but published studies cover a large range of rather intensive systems in other growing regions, including plantations with artificial shade (SI Chapter 6, Table 12.24), potentially explaining lower yields in rather extensively managed Malagasy agroforests. Our mean yield estimate of $154.6 \mathrm{~kg} \mathrm{ha}^{-1}$ translates into gross earnings of annually $4684 € \mathrm{ha}^{-1}$, exhibiting the exceptional income opportunity vanilla provides under the high prices of the year 2017 (Hänke et al., 2018). However, an average rural household in the study region only sells $51.6 \mathrm{~kg}$ of green vanilla per year (Hänke et al. (2018); also including households which did not sell any vanilla) and labour demands for the crop are high (Correll, 1953). Furthermore, high vanilla prices have led to a surge in local living costs, which are estimated at $5751 €$ per household and year (Hänke \& Fairtrade International, 2019), and vanilla theft is commonplace (Neimark et al., 2019), further impairing the situation for farmers.

In contrast to other studies (Havkin-Frenkel \& Belanger, 2018; Santosa et al., 2005), we do not see yield declines after a certain plantation age (Figure 6.2, SI Chapter 6, Table 12.20). The explanation for this is twofold: farmers constantly establish new pieds, resulting in old agroforests that still contain vanilla vines of young and medium age (DAM personal observation). Furthermore, constant 'looping' of vines on the same pied is common: hereby, vanilla vines are guided back down to the soil where new roots establish (Fouché \& Jouve, 1999). The originally-planted part of the vine may die at some point, but the vanilla plant can survive due to the water and soil access that the additional roots provide. Given that new pieds are also propagated by vine-cuttings (Fouché \& Jouve, 1999; Havkin-Frenkel \& Belanger, 2018), planting of new pieds and looping of vines are comparable processes. In combination with the relatively short time to first produce (circa three years; Havkin-Frenkel \& Belanger, 2018), the looping of vanilla vines may lead to stable yields over time and could thus avoid boom and bust cycles. Such cycles are a common occurrence in other agroforestry crops like cacao (Clough et al., 2009) and refer to farmers realising short-term 
increases in yields through shade tree removal at the expense of associated biodiversity and ecosystem functions (Tscharntke et al., 2011). The resulting yield increase may be followed by a decrease, caused by elevated pest pressure and dwindling soil fertility (Clough et al., 2009). Falling yields prompt the abandoning of plantations and further forest conversion to agroforestry elsewhere (Clough et al., 2009). The likely absence of these busts in vanilla agroforests does hence point towards the long-term sustainability of these agroforestry systems. We also found no link between precipitation and vanilla yields using down-scaled climate data (Figure 6.2; SI Chapter 6, Table 12.20), suggesting that all villages where this data was collected have generally-suitable growing conditions. Nonetheless, the data is not yearor season-specific and can thus only represent general differences in precipitation between sites, possibly hiding effects caused by exceptionally dry or wet years or seasons.

\subsubsection{Increasing vanilla yields without impairing canopy cover}

We show that vanilla yields vary independently of canopy cover suggesting that no tradeoffs exist between yields and maintaining or restoring trees (Figure 6.2; SI Chapter 6, Table 12.20 ), much in contrast to comparable crops, where yields typically decline above $40 \%$ canopy cover, for example in cacao (Blaser et al., 2018; Clough et al., 2011) or coffee (Jezeer et al., 2017; Perfecto et al., 2005). The here-shown independence of yields and canopy cover enables farmers to maintain remnant forest trees, which are highly beneficial for ecosystem services and biodiversity (Tscharntke et al., 2011) in forest-derived vanilla agroforests, at no direct cost. Furthermore, tree and canopy cover rehabilitation in open-land-derived vanilla agroforests is also possible without compromising on yields. The independence of vanilla yields and shade is supported by plant-physiological experiments which show that vanilla performs well under various light regimes (Díez et al., 2017).

Interestingly, vanilla planting density was independent of canopy cover and canopy height (Figure 6.3; SI Chapter 6, Table 12.21 and Table 12.22). This suggests that closing yield gaps is possible by planting vanilla pieds more densely and that doing so does not per se impair canopy cover or height within the currently existing planting density range. Maintaining or promoting trees will likely have positive effects on biodiversity and ecosystem functions (Leakey, 2014; Tscharntke et al., 2011). For example, predation rates rise with increasing stem density in vanilla agroforests of north-eastern Madagascar (Schwab et al., 2020), indicating that trees promote pest control. In sum, the possibility to plant vanilla more densely without impairing canopy cover further strengthens the case for sustainable intensification opportunities in vanilla agroforestry. 


\subsubsection{Limitations of yield data}

Despite methodological improvements over many previous studies (SI Chapter 6, Table 12.24), this study lacks detail on various potential drivers of vanilla yields. This is highlighted by the strong random intercept variance. The random effect 'household' might reflect differences in management practices between households (Hänke et al., 2018), while 'village' might represent biotic or abiotic village-level effects, such as different soil properties. We also acknowledge that the estimation of the weight of stolen vanilla pods, which we had to factor in for $\sim 12 \%$ of agroforests, brings in additional uncertainty. Lastly, our study cannot draw conclusions beyond the range of the data examined, for example the effects of shade on vanilla yields in highly intensified systems. We thus call for more research on vanilla yield determinants that may generate more applicable management advice for farmers.

\subsubsection{Increasing canopy cover and tree height over time}

Tree rehabilitation in agroforestry systems is a global priority (FAO, 2017). However, many tropical agroforests of key cash crops like cacao or coffee are forest-derived, thus typically contributing to forest degradation rather than tree rehabilitation (Martin et al., 2020b). Open-land derived agroforests, on the other hand, may contribute to tree rehabilitation, but empirical chronosequences that document tree recovery in open-land derived agroforests are rare (but see Nijmeijer et al. (2019)). Here we show that canopy cover is higher in older forest- and open-land-derived agroforests than in younger ones (Figure 6.3; SI Chapter 6, Table 12.21). Furthermore, trees were taller in older open-land-derived agroforests, but not in older forest-derived agroforest (Figure 6.3; SI Chapter 6, Table 12.22). This suggests that open-land-derived agroforests can play a key role in tree rehabilitation, given that these agroforests originate from open fallow land. They could thus contribute to increased carbon storage (Nair et al., 2009) and the restoration of other ecosystem services (De Beenhouwer et al., 2013) while providing new habitat for tree-dependent taxa (Clough et al., 2011). To what extent this will be the case also depends on the tree species that farmers allow to regenerate or plant. Here, native trees will be necessary for many biodiversity benefits while introduced fruit and timber trees could provide benefits to farmers (Tscharntke et al., 2011).

In contrast to open-land-derived agroforests, canopy cover in forest-derived agroforests will likely only recover after an initial drop at the time of establishment (Martin et al., $2020 \mathrm{~b}$ ), which is not covered here as our chronosequence does not include forest 
fragments. The stable tree height is in line with this interpretation, as the removal of single trees at time of establishment may not reduce mean tree height at the plot level. Alternatively, the resulting chronosequence could also stem from a change of practices over time, resulting in recently established forest-derived agroforests with low canopy cover in the chronosequence.

Taken together, our results show that forest-derived vanilla agroforests may have relatively stable canopy cover over time and highlight the potential of open-land-derived agroforests to restore ecosystem functions in cultivated landscapes. The transformation of land under shifting cultivation into cash cropping systems is furthermore in line with regional (Andriatsitohaina et al., 2020) and global trends (van Vliet et al., 2012).

\subsubsection{Canopy cover dynamics in the agricultural landscape}

We used remotely sensed canopy cover data to explore how observed plot-scale tree rehabilitation translates to the landscape-scale. Comparing canopy cover changes between 2000 and 2010, we found that areas with lowest initial canopy cover, probably mostly rice paddies, had stable canopy cover (Figure 6.4 C; SI Chapter 6, Table 12.23). This is to be expected, given the high productivity of irrigated rice and its local importance for food security (Hänke et al., 2018; Laney \& Turner, 2015), which make a conversion of rice paddies to other land uses unlikely. Areas with very high canopy cover, i.e. forest fragments around villages, lost canopy cover over time. Here, small losses may represent forest degradation through selective logging for timber or through the establishment of new forest-derived vanilla agroforests. Some of these areas also showed large losses, likely reflecting shifting cultivation, where forest is cut and burned for hill rice cultivation (Figure 6.4).

Areas with medium to high initial canopy cover showed increases in canopy cover, most likely representing fallows that were transformed to open-land-derived vanilla agroforests. Here, the cessation of repeated burning for shifting cultivation, that comes with the establishment of permanent agroforestry, may have enabled tree rehabilitation at the landscape scale, as observed inside the plots.

Overall, these dynamics resulted in a net increase in canopy cover on the landscape scale, as observed for agricultural landscapes across Madagascar (Zomer et al., 2016). The combination of canopy cover gains and losses may be positive for ecosystem services that can be provided by areas with medium canopy cover, such as the provision of fruit or firewood, and for species that can handle habitats with medium canopy cover. Forest-dependent species and ecosystem services that depend on high canopy cover, as found in forests, will 
suffer. Conservation of remaining forests is thus necessary to conserve the large share of Malagasy biodiversity that cannot persist outside forest (Irwin et al., 2010). Furthermore, the forests of north-eastern Madagascar have some of the highest carbon stocks of all Malagasy forests (Vieilledent et al., 2016), underlining the importance of forest conservation also in light of climate change mitigation.

Importantly, these findings are limited to the agricultural landscape around 60 focal villages that are predominantly not at the deforestation frontier. Canopy cover dynamics might be different around villages closer to large connecting forest blocks, where an overall increase in canopy cover seems unlikely, given the ongoing deforestation trend in north-eastern Madagascar (Harper et al., 2007; Vieilledent et al., 2018). Further research elucidating the differences in canopy cover dynamics between villages close and far away from the forest frontier will hence be highly relevant.

\subsection{Conclusion}

Our main finding, that yields and canopy cover in vanilla agroforests of north-eastern Madagascar varied independently, suggests the possibility to combine high vanilla yields with a high tree cover. This has potential benefits for ecosystem services and biodiversity in a globally important biodiversity hotspot. Our finding contrasts with other agroforestry crops for which higher canopy cover typically impairs yields. Furthermore, the higher canopy cover in older compared to younger vanilla agroforests suggests opportunities to rehabilitate landscapes by enhancing tree cover in open-land-derived agroforests. If coupled with effective protection of remaining forests, yield-neutral tree recovery in agroforestry systems could contribute to a multifunctional and biodiversity-friendly agricultural landscape.

\subsection{Authors' contributions}

All authors conceived ideas and planned data collection and analysis. DAM, AW, and KO coordinated the data collection; TR led the field team; DAM analysed and visualized the data; DAM led the writing of the manuscript. All authors contributed to the writing and gave final approval for publication.

\subsection{Acknowledgements}

We are grateful to the research assistants Marie Berthine Maminirina, Grimo Jaona Sedric and Jacqueline Estenie Soa for their help with data collection. We thank all chef de fokontany 
and farmers for access to sites and information. We collected data under the research per-

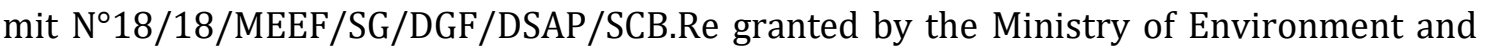
Sustainable Development, Antananarivo, Madagascar. We thank Gastón Mauro Díaz who wrote the R-script for canopy photo thresholding, Hendrik Hänke who collected the data from 60 focal villages, Fanilo Andrianisaina who curated household data, Nathaly Guerrero Ramirez and Patrick Weigelt who helped during data analysis, and two reviewers and the editor who gave detailed and constructive feedback. The authors have no conflict of interest to declare.

\subsection{Funding}

This study was financially supported by the 'Niedersächsisches Vorab' of 'Volkswagen Foundation' as part of the research project 'Diversity Turn in Land Use Science' (Grant Number 11-76251-99-35/13 (ZN3119)). Open access funding enabled and organized by 'Projekt DEAL'.

\subsection{Data availability statement}

Data and R-Code are available within the Open Science Framework (OSF): Martin, D. A., Wurz, A., Osen, K., Grass, I., Hölscher, D., Rabemanantsoa, T., Tscharntke, T., Kreft, H. (2020). Shade-tree rehabilitation in vanilla agroforests is yield neutral and may translate into landscape-scale canopy cover gains. OSF. https://doi.org/10.17605/OSF.IO/J64M8 


\section{High crop yields without biodiversity losses in tropical agroforestry}

Annemarie Wurz, Teja Tscharntke, Dominic Andreas Martin, Kristina Osen, Estelle Raveloaritiana, Rouvah Andriafanomezantsoa, Fanilo Andrianisaina,, Thio Rosin Fulgence, Saskia Dröge, Anjaharinony A. N. A. Rakotomalala, Romual Randriamanantena, Marie Rolande Soazafy, Aristide Andrianarimisa, Fenohaja Soavita Babarezoto, Jan Barkmann, Hendrik Hänke, Dirk Hölscher, Holger Kreft, Bakolimalala Rakouth, Nathaly GuerreroRamirez, Hery Lisy Tiana Ranarijaona, Fanomezana Mihaja Ratsoavina, Lala Harivelo Raveloson, \& Ingo Grass

Contribution: Conceptualization, Data curation, Investigation, Project administration, Validation, Writing - review \& editing

Status: In preparation.

\subsection{Abstract}

Solutions to ecological-economic trade-offs from agricultural productivity gains at the cost of biodiversity losses are urgently needed. Here, we focused on smallholder vanilla agroforests in Madagascar, a global biodiversity hotspot. Agroforests established in forests supported 30\% (48\%) less whole-ecosystem (endemic) diversity as compared to old-growth forest, but 26\% (131\%) more when established on degraded fallow land. Vanilla yields varied by more than two orders of magnitude, with no correlation to richness of trees, herbs, birds, amphibians, reptiles, and ants. While yields increased with greater vanilla planting density and longer vanilla vines, non-yield-related management variables such as canopy 
cover and landscape forest cover largely determined biodiversity of agroforests. Land-use history mattered as forest-derived agroforests supported higher diversity of endemics than fallow-derived ones. Our findings highlight the great restoration potential of agroforests for degraded tropical land. For vanilla, high yields can be achieved without further compromising biodiversity. However, well-designed policies are needed to promote restoration of degraded land and to halt loss of primary forest.

Keywords: agroforest, endemic, land-use history, Madagascar, trade-offs, vanilla, cash crop, deforestation

\subsection{Introduction}

Agricultural expansion and intensification are the main drivers of today's biodiversity crisis (Maxwell et al., 2016). Increases in agricultural productivity are typically achieved at the cost of biodiversity, particularly in the tropics (Grass et al., 2020). Solutions to the resulting ecological-economic trade-offs are urgently needed, especially in tropical landscapes that undergo rapid transformation (Macchi et al., 2020). Agroforestry is often seen as a profitable land use maintaining more tropical biodiversity than structurally less complex cropland types such as monocultures (Schroth, 2004; Tschora \& Cherubini, 2020; Udawatta et al., 2019). With respect to the upcoming UN Decade on Ecosystem Restoration (2021-2030), agroforestry also opens up promising opportunities for restoration of degraded land that makes up large shares of tropical landscapes characterized by shifting cultivation, or slashand-burn agriculture (Santos et al., 2019). However, agroforests may also result in biodiversity losses if established at the expense of forests. Whether tropical agroforests contribute to halting deforestation or accelerate biodiversity declines thus depends on their landuse history, meaning whether they are established on degraded land or by thinning forest (Martin et al., 2020b; Warren-Thomas et al., 2020). Surprisingly, despite decades of research, land-use history is usually not considered in most studies on tropical agroforestry (Martin et al., 2020b). Consequently, the value of tropical agroforestry for biodiversity conservation, ecosystem restoration, and sustainable intensification of agricultural production remains inconclusive.

Here, we focus on vanilla agroforestry in Madagascar. Madagascar has exceptional high rates of endemism but faces great challenges aligning conservation to sustainable development (Jones et al., 2019a; Scales, 2014a). Madagascar is globally the biggest producer of vanilla, with a majority produced by smallholders (FAO, 2020; Hänke et al., 2018). The high world market price of vanilla brings socio-economic benefits for livelihoods of Malagasy 
smallholders, incentivizing the expansion of vanilla cultivation (Hänke et al., 2018; Llopis et al., 2019). The hemi-epiphytic vanilla orchid is typically grown in agroforests on support trees in combination with shade trees (Havkin-Frenkel \& Belanger, 2018). Vanilla is farmed either by conversion of forest to agroforests or by establishment on fallow land, an aspect that is so far not considered by most studies (Martin et al., 2020b), but very important in light of on-going degradation of tropical landscapes, with large impacts on human livelihoods and ecosystem functioning (Hooper et al., 2012; Newbold et al., 2015). In contrast to the degradation of forest by forest-derived vanilla agroforestry, the conversion of fallow land to vanilla agroforests can rehabilitate important ecosystem functions (Chowdhury et al., 2020; Schwab et al., 2020). To identify yield-biodiversity trade-offs, we used data on trees, herbaceous plants, birds, amphibians, reptiles, butterflies, and ants and used yield data from 30 vanilla agroforests. We assessed the biodiversity value of forest- and fallowderived vanilla agroforest and compared the species richness with old-growth forest and fallow land. To identify biodiversity-friendly and profitable strategies of vanilla cultivation, we assessed environmental and management parameters driving high yields and high species richness.

\subsection{Results}

\subsubsection{Biodiversity and vanilla yield}

We found that increasing vanilla yield/ha did not reduce species richness of trees, herbaceous plants, birds, amphibians, and reptiles, and ants (Figure 7.1). Butterflies were the only taxa that decreased in species richness with increasing yield/ha (Figure 7.1 G)). Amphibian richness even increased with increasing yield/ha (Figure 7.1 E). Species richness of trees and reptiles was higher in forest-derived than in fallow-derived vanilla agroforests (Figure 7.1 B \& F). Looking at endemics, increasing vanilla yield/ha did not reduce endemic species richness of trees, herbaceous plants, birds, amphibians, butterflies and ants (Figure 7.2). Increasing vanilla yield/ha reduced endemic reptile richness in fallow-derived vanilla agroforests but increased endemic reptile richness in forest-derived vanilla agroforests (Figure 7.2 F). Endemic species richness of trees, herbaceous plants, birds and ants was higher in forest-derived vanilla agroforests compared to fallow-derived. In line with the results for species richness of single taxa, whole-ecosystem diversity (i.e., multidiversity) was not related to vanilla yield/ha. Furthermore, increasing vanilla yield/ha did not reduce endemic whole-ecosystem diversity, but endemic whole-ecosystem diversity was higher in forestderived vanilla agroforests (Figure 7.1 A \& Figure 7.2 A). 

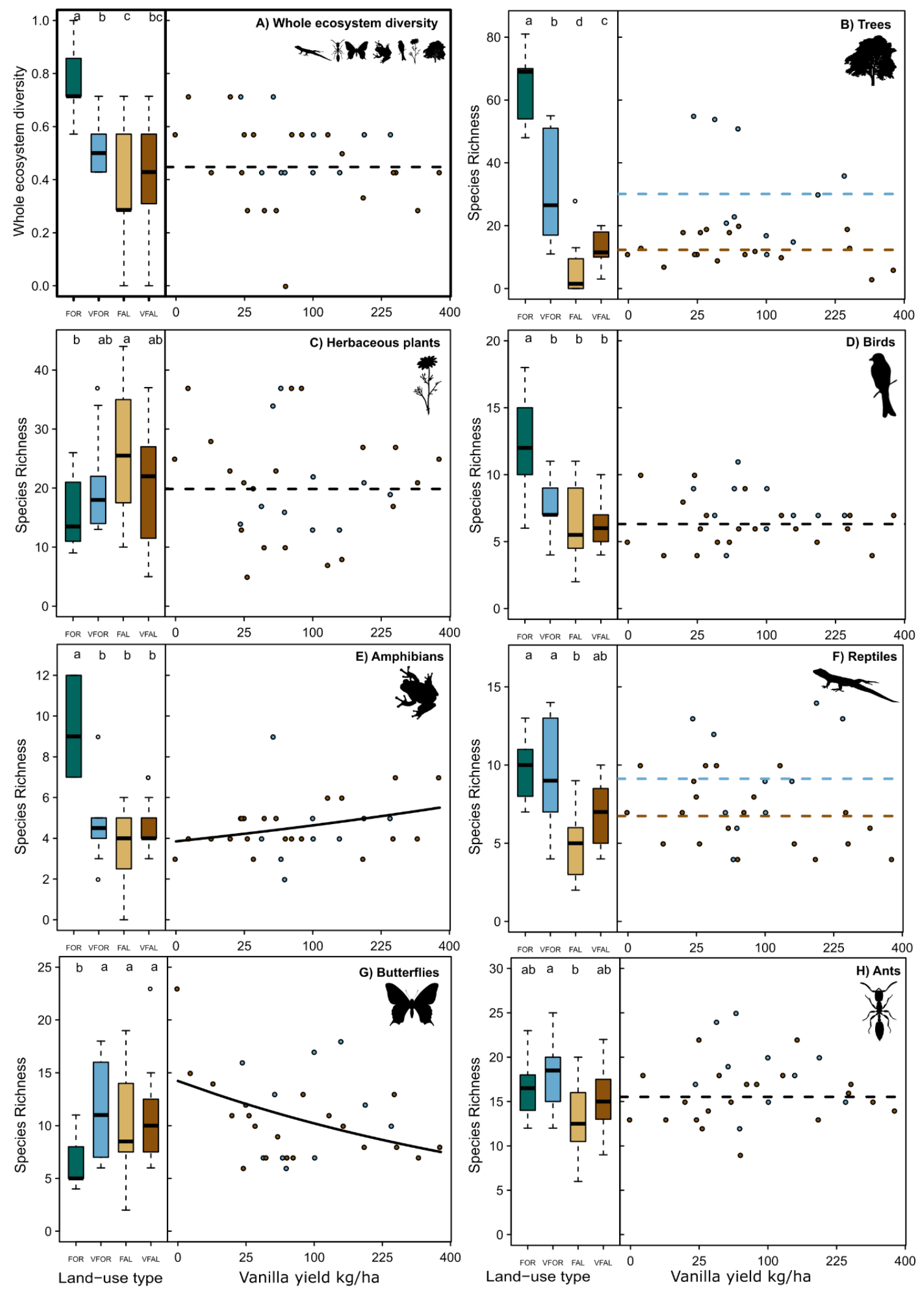

o Forest-derived vanilla agroforest (VFOR) o Fallow-derived vanilla agroforest (VFAL)

Old-growth forest (FOR) Fallow (FAL)

Figure 7.1: Species richness across land-use types (boxplots) and with increasing vanilla yield (scatterplots) in a Malagasy agricultural landscape. Shown are boxplots of plot-level whole ecosystem 
diversity (i.e., multidiversity) (A) and species richness of seven taxa individually (B-H) ( $\mathrm{N}=10$ for FOR, VFOR and N = 20 for FAL and VFAL) of old-growth forest (FOR), forest-derived vanilla agroforest (VFOR), fallow (FAL) and fallow-derived vanilla agroforest (VFAL). The line inside the boxplot represents the median of each land-use type, the lower and upper hinges of each boxplot correspond to the first and third quartiles and the whiskers represent the lowest and highest values within the 1.5 interquartile range (IQR). Outliers are shown as dots. Letters indicate significant differences between land-use types based on pairwise Tukey's honest significance tests. Groups which do not share a letter are significantly different. Scatterplots show the relationship between plot-level whole ecosystem diversity (i.e., multidiversity) (A) and plot-level species richness of seven taxa individually (B-H) and vanilla yield with estimated regression line from fitted model. Dashed lines are interceptonly linear models. If land-use history as additive effect is significant, intercept of both forest- and fallow-derived is displayed. Species richness: $\mathrm{N}=60$ for herbaceous plants, birds, amphibians, reptiles, butterflies and ants; $\mathrm{N}=58$ for trees; $\mathrm{N}=30$ for vanilla yield. Scale of vanilla yield $/ \mathrm{kg}$ is backtransformed from sqrt.

\subsubsection{Effects of land-use history on biodiversity in agroforests}

Average losses in species richness from forests (FOR) to forest-derived vanilla agroforests (VFST) were most pronounced for trees (-51\%), birds (-38\%), and amphibians $(-51 \%)$, whereas herbaceous plants, reptiles, butterflies and ants showed no significant difference in species richness (Figure 7.1). Gains in species richness from fallows (FLW) to fallow-derived vanilla agroforests (VFLW) were only significant for trees (+149\%; Figure 7.1 B). For endemics, we found strong losses from forest to forest-derived vanilla agroforests in endemic birds (-69\%) and endemic amphibians (-57\%; Figure 7.2). Endemic species richness of reptiles $(+38 \%)$ and ants $(+130 \%)$ was significantly higher in fallow-derived vanilla agroforests than in fallows (Figure 7.2). A significant amount of whole-ecosystem diversity ($30 \%$ ) was lost in forest-derived vanilla agroforests compared to old-growth forests, with a greater loss in species when looking at endemics only (-48\%; Figure 7.1 A \& Figure 7.2 A)). Whole-ecosystem diversity of fallow-derived vanilla agroforests did not differ to fallows (Figure 7.1 A). In contrast, whole-ecosystem endemic diversity was higher in fallow-derived vanilla agroforest $(+131 \%$ ) compared to fallows (Figure $7.2 \mathrm{~A}$ ). 

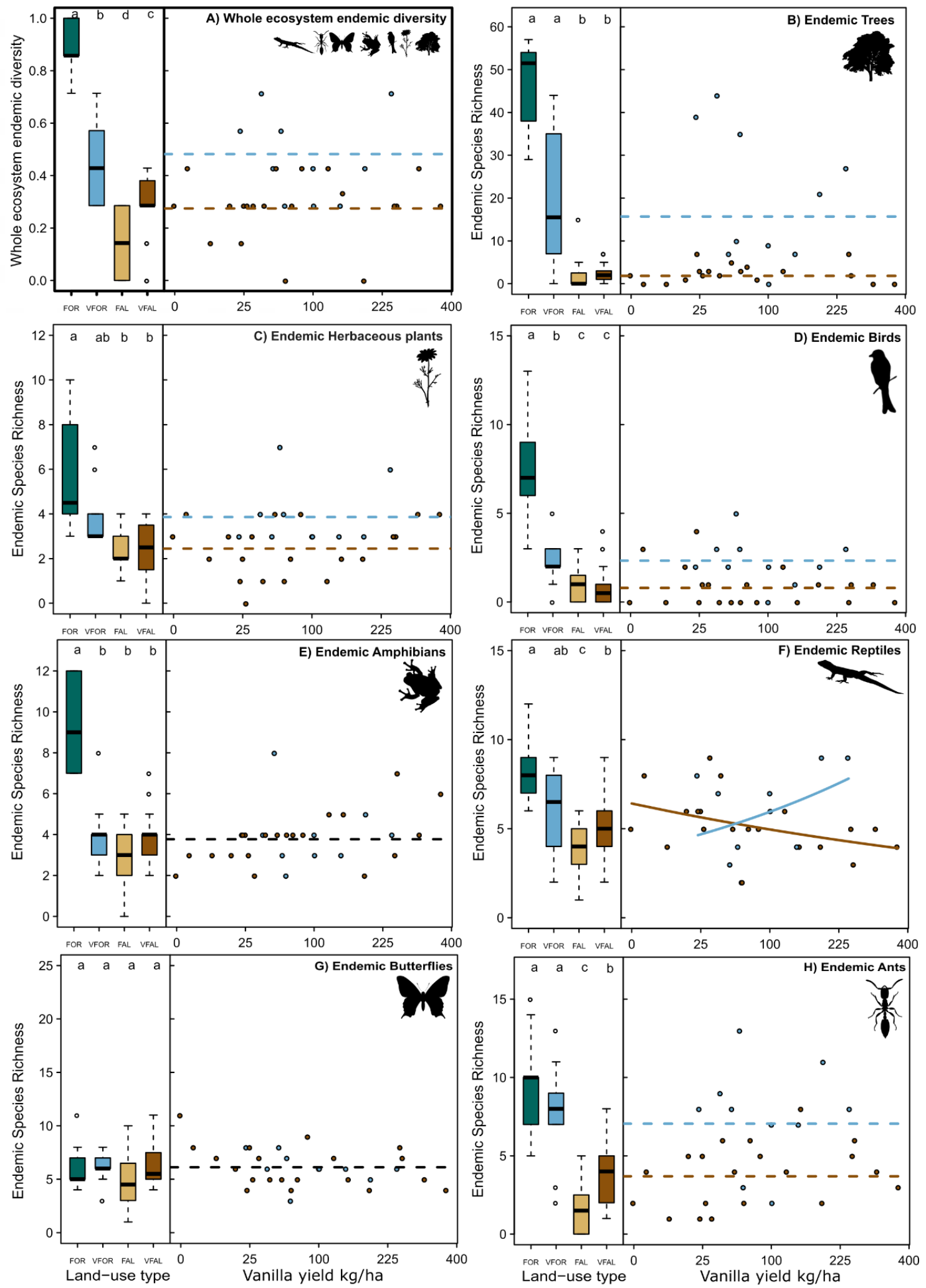

o Forest-derived vanilla agroforest (VFOR) o Fallow-derived vanilla agroforest (VFAL)

Old-growth forest (FOR) Fallow (FAL)

Figure 7.2: Endemic species richness across land-use types (boxplots) and with increasing vanilla yield (scatterplots) in a Malagasy agricultural landscape. Shown are boxplots of plot-level whole 
ecosystem endemic diversity (i.e., endemic multidiversity) (A) of all taxa combined and plot-level endemic species richness of seven taxa individually (B-H) (N = 10 for FOR, VFOR and N = 20 for FAL and VFAL) of old-growth forest (FOR), forest-derived vanilla agroforest (VFOR), fallow (FAL) and fallow-derived vanilla agroforest (VFAL). The line inside the boxplot represents the median of each land-use type, the lower and upper hinges of each boxplot correspond to the first and third quartiles and the whiskers represent the lowest and highest values within the 1.5 interquartile range (IQR). Outliers are shown as dots. Letters indicate significant differences between land-use types based on pairwise Tukey's honest significance tests. Groups which do not share a letter are significantly different. Scatterplots show the relationship between plot-level whole ecosystem endemic diversity (i.e., endemic multidiversity) (A) of all taxa combined or and plot-level endemic species richness of seven taxa individually (B-H) and vanilla yield with estimated regression line from fitted model if relationship significant (solid lines, regression line is back-transformed with the exponential function). If land-use history as additive effect is significant, intercept of both forest- and fallow-derived is displayed. Dashed lines are intercept-only linear models. Endemic species richness: $\mathrm{N}=60$ for herbaceous plants, birds, amphibians, reptiles, butterflies and ants; $\mathrm{N}=58$ for trees; $\mathrm{N}=30$ for vanilla yield. Scale of vanilla yield per kg is back-transformed from sqrt.

\subsubsection{Effects of environmental and management parameters on yield}

Vanilla yield (kg/ha) was positively associated to planting density and vanilla vine length (Table 7.1). Our findings indicate that while low vanilla planting density (3000-4000 vanilla plants/ha) resulted in only low to moderate yield outcomes (71 -109 kg/ha), doubling vanilla planting density to $6000-8000$ vanilla plants/ha led to yield increases ranging from $208-339 \mathrm{~kg} / \mathrm{ha}$ (66-68\% more). In addition, low to medium vanilla vine length $(400-600 \mathrm{~cm})$ resulted in only low to moderate yield outcomes (38-65 kg/ha), doubling liana length to $800-1200 \mathrm{~cm}$ led to yield increases ranging from $100-191 \mathrm{~kg} / \mathrm{ha}(62-66 \%$ more). Vanilla yield (kg/ha) was only marginally positively associated to pollination labour input. Importantly, vanilla yield was not related to canopy closure, slope, landscape forest cover, lower vegetation cover or elevation, suggesting high intensification potential without shade or vegetation removal in any location. Furthermore, vanilla plant age did not influence vanilla yield, neither did percentage leaf damage of vanilla plants. Vanilla yields did not differ between fallow- and forest-derived vanilla agroforests (Tukey post-hoc test: $\beta=0.77, \mathrm{SE}=$ $1.94, \mathrm{p}=0.691$ ).

Table 7.1: Management and environmental determinants of vanilla yield/ha (sqrt-transformed) in 30 vanilla agroforests. The mean value of all 30 agroforests was used for three missing values of pollination work input (hrs/ha). All predictor variables are scaled. Estimates, standard error and p- 
value are extracted from the best linear mixed effect model. Model selection was performed by single term deletion using the anova function from the R stats package with all terms significant at $<0.05$.

\begin{tabular}{lllr}
\hline Predictor & Estimate & SE & p-value \\
\hline Intercept & 9.005 & 0.803 & $<\mathbf{0 . 0 0 1}$ \\
\hline Planting density (no/ha) & 2.878 & 0.415 & $<\mathbf{0 . 0 0 1}$ \\
\hline Pollination (hrs/ha) & 0.943 & 0.473 & 0.058 \\
\hline Vanilla vine length (cm) & 2.630 & 0.391 & $<\mathbf{0 . 0 0 1}$ \\
\hline Soil characteristics (PC1) & - & - & - \\
\hline Vanilla plant age (yrs) & - & - & - \\
\hline Canopy closure (\%) & - & - & - \\
\hline Slope $\left({ }^{\circ}\right)$ & - & - & - \\
\hline Landscape forest cover (\%) & - & - & - \\
\hline Lower vegetation cover (\%) & - & - & - \\
\hline Elevation (m) & - & - & - \\
\hline Leaf damage (\%) & - & - & - \\
\hline
\end{tabular}

\subsubsection{Effects of environmental and management parameters on biodiversity}

Species richness was mostly associated to environmental and management parameter unrelated to higher vanilla yields (Table 7.2). High canopy closure, a structural parameter which farmers can actively alter was positively associated with higher species richness of trees, endemic herbs, (endemic) reptiles and endemic ants; on top of elevation, slope, and soil fertility,

Table 7.2: Overview of effects of environmental and management variables on yield and species richness across 7 taxa (trees, herbaceous plants, birds, amphibians, reptiles, butterflies and ants). Effects are based on direction of estimates ( + or - ) and displayed if p-value $<0.05$. Effects in parentheses were marginally significant $(0.05 \leq \mathrm{p}<0.10)$.

\begin{tabular}{|c|c|c|}
\hline Predictor & Yield & Species richness \\
\hline Planting density (no/ha) & + & - Trees + Endemic Herbs \\
\hline Vanilla vine length $(\mathrm{cm})$ & + & - Trees - Endemic Trees - Reptiles (- Endemic Reptiles) \\
\hline Pollination labour input (hrs/ha) & + & - Butterflies - Endemic Butterflies \\
\hline \multirow[t]{2}{*}{ Soil characteristics (PC1) } & $(-)$ & - Endemic Trees (+ Herbs) - Birds + Endemic Reptiles \\
\hline & & + Butterflies + Endemic Butterflies \\
\hline \multicolumn{3}{|l|}{ Vanilla plant age (yrs) } \\
\hline Canopy closure $(\%)$ & & $\begin{array}{l}\text { + Tree + Endemic Herbs + Reptiles + Endemic Reptiles } \\
\text { + Endemic Ants }\end{array}$ \\
\hline Slope $\left({ }^{\circ}\right)$ & & - Endemic Trees - Amphibians - Endemic Amphibians \\
\hline Landscape forest cover (\%) & & $\begin{array}{l}\text { + Tree + Endemic Trees + Endemic Herbs (-Amphibians) } \\
\text { + Endemic Ants }\end{array}$ \\
\hline Lower vegetation cover $(\%)$ & & + Birds (- Butterflies) - Endemic Butterflies \\
\hline Elevation (m) & & + Herbs (+ Endemic Herbs) (+ Endemic Butterflies) \\
\hline
\end{tabular}


Additionally, higher vegetation cover (below $2 \mathrm{~m}$ ) was positively related to bird species richness but negatively to endemic butterflies. Landscape forest cover, mainly shaped by remaining forest fragments in the agricultural matrix, was important for (endemic) trees, endemic herbs, and endemic ants. Conflicting with higher yields, less trees were found in vanilla agroforests with a higher density of vanilla plants. Furthermore, longer vanilla vines were negatively associated to (endemic) trees and reptiles.

\subsection{Discussion}

Here, we focused on smallholder vanilla agroforests in Madagascar, a global biodiversity hotspot, with big pressure on remaining primary forest and major sustainability challenges (Scales, 2014a). Madagascar has high levels of poverty, with most people continuing to depend on natural resources (Molotoks et al., 2017), but inefficient land management and weak law enforcement are major challenges to biodiversity conservation (Rakotomanana et al., 2013). With Madagascar's biodiversity being indispensable to the countries sustainable development (Jones et al., 2019c), multidisciplinary approaches are needed to address Madagascar's problems before it is too late.

In contrast to common expectations of economic-ecological trade-offs, we show that higher yields did not decrease whole-ecosystem (endemic) diversity and species richness of (endemic) trees, (endemic) herbs, (endemic) birds, (endemic) amphibians, reptiles, endemic butterflies, and (endemic) ants in vanilla agroforestry in Madagascar. Importantly, land-use history of vanilla agroforests mattered for endemics, as agroforestry established on fallows was poorer in whole-ecosystem endemic diversity (-60\%) than that based on thinned forest. We show agroforests established in forests supported 30\% (48\%) less whole-ecosystem (endemic) diversity than old-growth forest, but fallow-derived agroforest had 26\% (131\%) higher whole-ecosystem diversity than fallow land, highlighting its great restoration potential in tropical landscapes. While yields increased with greater vanilla planting density and longer vanilla vines, non-yield-related management variables such as canopy closure and landscape forest cover largely determined biodiversity of agroforests. Important for the conservation of endemic species, higher landscape forest cover and higher canopy closure was related to more endemics of trees, herbs, reptiles, and ants in vanilla agroforests. However, (endemic) trees and reptiles were negatively associated to higher pied density or longer vanilla vines.

Our findings are in line with other studies in cacao agroforestry which found no relationship between cacao yield and tree, bird, amphibian, butterfly, and ant richness in Indonesia 
(Clough et al., 2011) and between yield and butterfly richness in Peru (Jezeer et al., 2019). In contrast, a study on Cameroonian cacao agroforests found a negative relationship between ant richness and cocoa yield suggesting trade-offs with biodiversity at high yield levels if shade vegetation was removed (Bisseleua et al., 2009).

Loss of species richness through forest conversion has been documented by several studies. A systematic review on biodiversity in small-scale agroforests showed that in almost $80 \%$ of the cases species richness in agroforests was lower than in forests (Scales \& Marsden, 2008). In line with our findings for trees, studies have highlighted that in particularly plants are negatively affected by forest conversion compared to mobile taxa like insects (Bhagwat et al., 2008; Steffan-Dewenter et al., 2007). Nevertheless agroforests can also have similar species richness as forests, if the transformation to agroforestry occurred recently and management remained extensive (Beukema et al., 2007; Harvey \& González Villalobos, 2007). Vanilla agroforests, in contrast to coffee and cacao agroforestry systems, are generally extensively managed with a global yield averaging around $500 \mathrm{~kg}$ green vanilla per hectare (Odoux \& Grisoni, 2010). Malagasy vanilla is manually managed without the use of fertilizers or pesticides (personal observation). The extensive management of vanilla as well as the setting in a diverse mosaic landscape can explain the maintenance of richness levels in vanilla agroforests compared to forest for some of the species groups (e.g. butterflies and ants).

Our findings confirm that land-use history is an important aspect in agroforestry, affecting species richness of several taxa, particularly endemic species. The increase in (particularly endemic) whole ecosystem biodiversity by vanilla agroforestry established on fallows, presents conservation opportunities in line with the goals of the UN Decade on Ecosystem Restoration (2021-2030; recover ecosystem from degradation) in an area identified as global priority for restoration (Strassburg et al., 2020). Furthermore, the IPBES report highlights restoration of fallow land as an important tool to combat species extinction (IPBES 2019). Nevertheless, our results show that whole-ecosystem diversity in old-growth forest is without equal, making those forests a conservation priority.

In contrast to our biodiversity results, land-use history did not matter for vanilla yields indicating equal opportunities for profitable agroforestry on fallow land without further forest loss. These results are in line with findings from 209 vanilla agroforests with no significant difference in vanilla yields in forest- to fallow-derived vanilla agroforests (Martin et al., 2020c). In addition, unlike in cacao and coffee agroforests (Tscharntke et al., 2011), our vanilla agroforests did not yield higher or lower depending on canopy closure. However, 
(endemic) trees suffered from an increase of both planting density and vine length in vanilla agroforests, presenting a clear conflict between cash crop production and tree conservation. In addition, fewer reptiles were related to longer vines. This is surprising since high yields were neither related to fewer trees or fewer reptiles. Diverse studies suggest that a high tree richness is indispensable for the maintenance of a diverse plant and animal community (Bhagwat et al., 2008; Moguel \& Toledo, 1999). Furthermore, the loss of trees as a 'keystone structure' which other species depend on, can cause time-lagged responses of vertebrate and invertebrate taxa (Tews et al., 2004), and thus trees require high conservation attention. When looking at the effects of intensification, doubling from 3000 to 6000 vanilla plants/ha or $300-600 \mathrm{~cm}$ vine length, corresponded to a decrease in tree richness by $27 \%$ or $23 \%$, respectively. However, high income benefits for farmers were associated to this intermediate intensification, with a $>280 \%$ yield increase (71 kg to $200 \mathrm{~kg}$ ) translating into a yearly gross income of $6160 € /$ ha for green vanilla at high vanilla prices of 2016 (Bouriquet, 1946; Hänke et al., 2018). By contrast, almost tripling planting densities to 8500 plants/ha or quadrupling to $1200 \mathrm{~cm}$ vine length lowered tree species richness by $>55 \%$ and $52 \%$, respectively. Intermediate increases of planting density and vanilla vine length can thus represent a compromise for tree conservation and vanilla production.

Global biodiversity loss through the expansion of agriculture is a pressing environmental concern (Kehoe et al., 2015; Laurance et al., 2014). Our study provides evidence that high crop yields can be combined with biodiversity benefits. Notably, vanilla yields varied by more than two orders of magnitude, with no correlation to richness of trees, herbs, birds, amphibians, reptiles, and ants. Here, vanilla agroforests established on fallows allow an improvement of productivity and biodiversity alike, without further expansion into intact forest habitat. We found a high potential for intensification of vanilla agroforests by increasing planting density and increasing vanilla vine length. Furthermore, canopy closure and landscape forest cover largely determined biodiversity with no negative effect on yield.

Simultaneously, sustainability standards (e.g. Fair Trade, Rainforest Alliance) are needed to preserve key parameters such as canopy closure in vanilla agroforests. Furthermore, farmer cooperatives must be supported, to provide a stable income for vanilla farmers de-incentivizing further encroachment into remaining forests. This stresses that careful land planning is needed to guide this ecological intensification process - a problem in Madagascar, where illegal logging and poor governance is still widespread. However, the protection of remaining natural habitats is imperative for the preservation of Madagascar's unique biodiversity but hinging on functional governance which needs to put effective restrictions in place. 


\subsection{Methods}

\subsubsection{Study area}

All plots were situated in north-eastern Madagascar in the SAVA region around the main cities of Sambava, Antalaha, Vohémar and Andapa. The natural vegetation is tropical lowland rainforest, but deforestation rates are high (Vieilledent et al., 2018). The region is a global but also national biodiversity hotspot with high levels of endemism (Brown et al., 2014; Myers et al., 2000). Forest loss is mainly driven by slash-and-burn agriculture for hill rice cultivation (Zaehringer et al., 2015). The region is characterized by a warm and humid climate with an annual rainfall of $2223 \mathrm{~mm}$ and a mean annual temperature of $24^{\circ} \mathrm{C}$ (mean value of 80 plots extracted from CHELSA climatology; Karger et al., 2017). The hot season with more rain last between October to April (Tattersall \& Sussman, 1975). Vanilla is the main cash crop in the SAVA region, making Madagascar the main vanilla producer globally (FAO, 2020; Hänke et al., 2018). Vanilla prices have shown strong dynamics in the past year, with a price boom in 2017 triggering an expansion of vanilla agroforestry in the region (Hänke et al., 2018; Llopis et al., 2019).

\subsubsection{Study design}

We selected 10 villages based on the 60 villages selected within the Diversity Turn in Land Use Science project (Hänke et al., 2018). Among the 60 villages, we chose 17 villages without coconut plantations, with less than $40 \%$ covered by water (river, sea and lakes) and with forest fragment and shifting cultivation present within a $2 \mathrm{~km}$ radius around the village. Two of these 17 villages overlapped within the $2 \mathrm{~km}$ radius of the villages, thus we selected randomly one of the overlapping villages, resulting in 14 village left. We visited these 14 villages in a randomized order. Two villages were excluded because in one not all land-use types were present and in the other the village didn't want to participate in the study. We visited 12 out of the 14 villages and stopped because we found 10 villages which were happy to participate and had all required land-uses. In each of the 10 villages we selected three vanilla agroforests and two fallows. Overall, we studied 50 plots across 10 villages and 10 plots in one protected forest (Marojejy National Park).

\subsubsection{Plot selection}

In each of our 10 villages, we selected three vanilla agroforests with low, medium and high canopy closure by sight covering a within village gradient of canopy cover gradient. After plot selection, differences in vegetation structure depending on land-use history became 
clear to us. Thus, we used interviews with the plot owners to categorize all vanilla agroforests based on land-use history into fallow- and forest-derived agroforests according to (Martin et al., 2020b). Forest-derived vanilla agroforests are established within forest fragments, which have been manually thinned of dense understory vegetation. Fallow-derived vanilla agroforests are established on formerly slash-and burned plots, where vegetation has been cut and burned for hill rice production. Out of our 30 vanilla agroforests, 20 vanilla agroforests were fallow-derived and 10 vanilla agroforests were forest-derived, matching with the proportion of fallow- and forest-derived vanilla agroforests across the study region (70\% are fallow-derived vanilla agroforests, $27 \%$ are forest-derived vanilla agroforests and $3 \%$ of unknown origin, Hänke et al., 2018).

In addition to vanilla agroforests, we selected in each of the 10 study villages one herbaceous and one woody fallow. Both fallow types derive from slash-and-burn agriculture for hill rice production and have been left fallow following crop production. Herbaceous fallows have been slash-and burned multiple times with the last slash-and-burning and subsequent hill rice cultivation at the end of 2016, one year prior to the first species data collection in 2017. After hill rice production, herbaceous fallows grew through fallowing and the emergence of herbaceous plants and later in 2018 some woody plants. The continuous fallowing of herbaceous fallows turns them over time into woody fallows with a domination of woody plants including shrubs, trees and sometimes bamboo. Our 10 woody fallows have last burned 4-16 years before data collection. In this study, we categorized both herbaceous and woody fallow as fallows.

We also studied 10 plots at two sites of Marojejy National Park, the only remaining oldgrowth forest in our area. We chose both sites for data collection within the same park because Marojejy National Park provided the only sites of old-growth forest which are continuous, mostly intact and at low-altitude in the study region. We chose old-growth forest sides with a maximum distance of $260 \mathrm{~m}$ to each other, with a minimum distance of $250 \mathrm{~m}$ from the forest edge and with feasible accessibility. Five of the 10 old-growth forest plots were located in Manantenina Valley (known as Marojejy Tourist), the other five old-growth forest plots were situated at the eastern part of Marojejy National Park, called Boangabe area (known as Marojejy East). Illegal selective logging has occurred at some parts of the park (Patel, 2007). During our plot selection, we avoided sites with traces of selective logging. 


\subsubsection{Plot design}

Species data was collected on plots with a radius of $25 \mathrm{~m}$. We chose this size as a compromise between plot size and survey time needed for all taxa studied. We established our circle plots in a homogeneous area of the land-use type or forest. Adjacent land-uses were usually different because farmers generally own small-scale land with a mean size of 0.66 ha. All plots had a minimum distance of $260 \mathrm{~m}$ to the closest neighbouring plot and a mean minimum distance of $794 \mathrm{~m}(\mathrm{SD} \pm 468 \mathrm{~m}$ ) to each other. Plot elevation ranged between 10 to 819 m.a.s.l. (mean $=205 \mathrm{~m}, \pm 213 \mathrm{~m})$.

\subsubsection{Vegetation structure of vanilla agroforests}

Vanilla agroforests are diverse in structure and species composition. They are characterized by a medium high vegetation layer of vanilla plants growing on support trees (height of vanilla-support-tree unit is not higher than an average person to facilitate hand pollination and harvest) and shade trees (vanilla agroforests without shade trees exist). In total, we recorded 229 tree species across the 30 vanilla agroforests (trees $\geqslant 8 \mathrm{~cm} \mathrm{DBH).} \mathrm{Support}$ trees are either planted or naturally growing. Overall, we found 122 tree species used as support tree, with a mean of 20.2 support tree species in forest-derived and 4.7 support tree species in fallow-derived vanilla agroforests. A majority of support trees are introduced species such as the fast-growing tree species Jatropha curcas L., Clausena excavate Burm f., Pachira glabra, the legimonous tree species Gliricidia sepium (Jacq.) Kunth ex Walp. and the food tree species Coffea canephora Pierre ex A. Froehner. But also native or endemic support tree species occur, such as the food plant Parinari curatellifolia Planch. Ex Benth. or Streblus dimepate (Bureau) C.C. Berg. Common shade trees in fallow-derived vanilla agroforests are the native species Albizia adianthifolia or the introduced species Clausena excavate, Jatropha curcas, Musa paradisiaca. Common shade trees in forest-derived vanilla agroforests are the introduced species Artocarpus heterophyllus, the endemic species of Protium madagascariense and Anthostema madagascariense and the native species of Harungana madagascariensis. Fruit trees such as papaya Carica papaya, diverse Citrus species and avocado Persea Americana as well as other cash crops such as coffee Coffea canephora and ylang ylang Cananga odorata or ornamental trees of Ravenala madagascariensis are commonplace. 


\subsubsection{Management variables}

\section{$\underline{\text { Pied selection and pied density assessment }}$}

Vanilla plant data (yield, vine length etc.) was assessed on 36 vanilla-support-tree-units of each circle plot. 36 vanilla-support-tree-units were evenly selected across the circle plot using reference lines in the shape of a square with two central diagonal lines. We chose vanilla-support-tree-units independent of age, length or health condition. We defined one vanilla-support-tree-unit as the combination of a vanilla vine and support tree. A vanillasupport-tree-unit can consist of more than one support tree, if the distance between the support tree does not exceed $30 \mathrm{~cm}$. We marked the 36 selected vanilla-support-tree-units with a unique barcode to assess leaf damage (in 2017) and vanilla yield (in 2018) on the same vanilla-support-tree-unit. We assessed leaf damage on 20 vanilla-support-tree-units (a subset of the 36 vanilla-support-tree-units). However, for 37 vanilla-support-tree-units (out of a total of 1080 vanilla-support-tree-units), the barcodes were lost or unreadable and we selected a new plant closest to the original position (independent of age, length or condition) and marked it with a new unique barcode.

\section{Yield assessment}

We measured yield on 30 vanilla plantations ( 10 forest-derived vanilla plantations and 20 fallow-derived vanilla plantations) in each of our 10 study villages. We measured vanilla yield on a total of 36 vanilla-support-tree-units (SI Chapter 7, Figure 12.10) per plantation in March-April 2018 prior to harvest. We assessed the vanilla yield prior to harvest to ensure an accurate yield assessment due to two reasons: Firstly, vanilla beans are commonly harvested successively due to their differing pollination date and maturity requiring multiple visits throughout several weeks. Secondly, theft of vanilla beans is commonplace around harvest time. We therefore estimated the weight of the on-plant-hanging vanilla bean by a length by width formula. Vanilla beans do not change their size in the last months of their ripening, allowing our pre-harvest yield assessment (Van Dyk et al., 2014).

Our yield assessment consisted of one interview part with the plot owner and one measurement part. The interview questions were aimed at finding out whether beans had already been removed from the plantation at the time of the yield assessment. We therefore asked: Has there been any theft on this plantation in this season? Have you already harvested any beans on this plantation in this season? During the measurement part we assessed the number, width and length of all vanilla beans per bean bundle/inflorescence. We measured vanilla bean length with a ruler starting at the junction of stem and bean until the tip of the bean without considering the bending of the bean. We measured width at the widest part of 
the bean using a calliper. Additionally, we counted the number of empty bases on the inflorescence, i.e. the number of aborted, already harvested or stolen beans or flowers.

To calculate the weight of each vanilla bean, we firstly calculated bean volume based on the standard cylinder formula using the measured width $(\mathrm{mm})$ and length $(\mathrm{cm})$. To calculate the weight ( $g$ ) of each bean we used the linear regression equation $\left(y=a+b^{*} x\right)$ of a weightvolume correlation of 114 vanilla beans. We assessed the weight, length and width of these 114 vanilla beans post-harvest in 2017. No vanilla beans were stolen or already harvested on our 36 vanilla-support-tree-units and hence we didn't need to account for it in our vanilla yield calculation.

\section{Planting density}

We counted each vanilla-support-tree-unit (combination of vanilla plant and support tree) on each $25 \mathrm{~m}$ circle plot by dividing the plot in four quarter segments by ropes for orientation. We calculated the area of each 25 m radius plot including slope correction. Planting density (vanilla-support-tree-units per hectare) was calculated by dividing the number of vanilla-support-tree-units by the slope corrected circle plot area.

\section{$\underline{\text { Size of vanilla agroforest }}$}

We measured the size of the vanilla agroforest by walking with the plot owner and a handheld GPS device the perimeter of the plot. We used the size of the vanilla agroforest to calculate the number of vanilla-support-tree-units per agroforest by multiplying the planting density based on the $25 \mathrm{~m}$ radius plot estimation by the (slope corrected) size of the agroforest in hectare.

Vanilla vine length

We assessed vanilla vine length for all 36 vanilla-support-tree units (same vanilla-supporttree units as used for the leaf damage and yield assessment) by measuring the total length of the vine from the lowest to the highest part with a measuring stick. If the vanilla vine was looped on the support tree (= vanilla vine is hanging in multiple loops on the support tree), we measured from the top height of the looping of the vanilla vine until the lowest height of the vine. At the medium height of the vanilla vine, we counted the number of times the vanilla vine passed through. We calculated the total length of the liana by multiplying the maximum height of the vanilla vine by the number of times the vine passed through the middle. In some cases, the vanilla vine looped at two different heights, we thus considered the middle between the two looping heights as top height. If the vine tissue was partially dead, we measured the length until the alive vine tissue ended. If the support tree, including the 
vanilla vine, was bending in 'half-moon-shape' towards the ground and the vanilla vine entered the soil on both sides of the support tree, we measured the top height at the middle of the plant. If vanilla vines grew on two different support trees, we considered them as one vanilla-support-tree-unit if support trees were $<30 \mathrm{~cm}$ apart. If the distance between both support trees exceeded $30 \mathrm{~cm}$, we considered only the support tree with most vines for the measurement.

\section{Pollination labour input}

We performed a longitudinal survey with the plot owners of our 30 vanilla agroforests from October 2017 to October 2018. Each plot owner had to fill out a questionnaire with pictograms bi-weekly over one year giving us information on total (family) labor invested in pollination. We measured the actual size of each vanilla agroforest with a GPS device. We calculated pollination labor input per hectare by summarizing all working hours within one year and dividing it by the (slope corrected) plot size.

\section{Vanilla plant age}

We assessed vanilla plant age by asking the farmer for each of the 36 vanilla-support-tree units 'How many years ago was the liana at this plant planted?'. Here the age referred to the vanilla vine but not the support tree.

\subsubsection{Environmental variables}

\section{Canopy closure}

We measured mean canopy closure at five subplots of our circular plots by taking hemispherical images through a Sigma Circular Fisheye $\left(180^{\circ}\right) 4.5 \mathrm{~mm} \mathrm{1:2.8} \mathrm{lens} \mathrm{with} \mathrm{a} \mathrm{Nikon}$ D5100 camera. The camera was fixed on a tripod at $2.4 \mathrm{~m}$ height above vanilla support trees and understory vegetation. We selected the images with the best contrast of sky and vegetation using the histogram-exposure protocol of Beckschäfer et al. (2013) and calculated canopy closure using a minimum thresholding algorithm by Beckschäfer (2015).

\section{Slope and elevation}

We used the 30 m-resolution digital surface model ALOS World 3D (Japan Aerospace Exploration Agency, 2018) to assess the mean slope and the mean elevation of each plot. For all values we applied slope correction.

\section{Landscape forest cover}

We calculated forest cover in a $250 \mathrm{~m}$ radius around each plot centre based on binary forest cover data from 2017 with a 30 m resolution (Vieilledent et al., 2018) and the R-package 
raster (Hijmans et al., 2019). We waypoint averaged each plot centers with a hand-held GPS device to improve accuracy. We chose this size of radius as a compromise between mobile and immobile taxa.

\section{Lower vegetation cover}

We estimated the vegetation percentage cover (woody and herbaceous) visually below two meter for five subplots (located in the center and at $16.6 \mathrm{~m}$ from the center in each cardinal direction) on each plot and calculated the mean. Vanilla-support-tree units were not considered in the estimation of vegetation cover.

\section{Leaf damage}

We assessed leaf damage on all 30 vanilla agroforests between October and December 2017 on 20 vanilla-support-tree-units (a subset of the 36 vanilla-support-tree-units used for the yield assessment). We recorded the vanilla-support-tree-identity with a unique barcode. On each selected vanilla-support-tree-unit we assessed missing leaf tissue, leaf necrosis and leaf rotting. On each of the 20 plants we selected 24 leaves randomly independent of age and health constitution. We selected 6 leaves on each of the four main cardinal directions (N, E, S and W) of the plant. For random selection we divided the total length of the vine by 6 and choose one leaf randomly on each of the 6 height levels. We marked each leaf with a peg until the damage assessment was completed. We assessed three different types of leaf damage (SI Chapter 7, Figure 12.11). We defined missing leaf tissue as the amount of irregular or regular removed leaf tissue per leaf. Leaf necrosis was defined as dead plant tissue visible by darkening or discoloration of the green leaf. If plant tissue decomposed, shown as dry or soft rot, we defined it as leaf rotting. The area of missing, rotting or necrotic leaf tissue was estimated per leaf in percentage and summed up to total leaf damage.

\section{$\underline{\text { Soil characteristics }}$}

We took soil samples with a MacFadyen soil corer ( $5 \mathrm{~cm}$ diameter, $295 \mathrm{ml}, 0-15 \mathrm{~cm}$ depth). We took two mixed samples on each plot from four subplots respectively, one at $16.6 \mathrm{~m}$ from plot center in all four cardinal directions and the second at $8.3 \mathrm{~m}$ from plot center in all four inter-cardinal directions. We stored each soil sample in a zip-lock bag until laboratory analysis. In the lab, we measured $\mathrm{pH}\left(\mathrm{H}_{2} \mathrm{O}\right)$ with the fresh soil samples using 1:10 humus/water suspension after $24 \mathrm{~h}$ of equilibration. We measured $\mathrm{pH}(\mathrm{KCl})$ by adding $1.86 \mathrm{~g} \mathrm{KCl}$. We calculated the mean $\mathrm{pH}$ values of the two mixed samples by firstly backtransforming (delogarithmise), then averaging and lastly logarithmise the mean value. We dried the leftover soil at $70{ }^{\circ} \mathrm{C}$ and ground it. We measured total organic carbon (C) and nitrogen (N) 
concentrations (mg/gTB; mmol/gTB)) by using the C/N elemental analyser (Vario EL III, elementar, Hanau, Germany). Additionally, we measured the concentrations ( $\mu$ molc/gTB) of phosphorus (P), potassium (K), magnesium $(\mathrm{Mg})$, calcium $(\mathrm{Ca})$, iron $(\mathrm{Fe})$, manganese $(\mathrm{Mn})$, and aluminium (Al) with the ICP-OES technique (inductively coupled plasma optical emission spectrometry, Optima 3000 XL, Perkin Elmer, USA) subsequently to the digestion of the soil material with $65 \% \mathrm{HNO}_{3}$ at $195{ }^{\circ} \mathrm{C}$ for $8 \mathrm{~h}$.

To identify most influential soil parameters, we performed a principal component analysis using the R package ggbiplot ( $\mathrm{Vu}, 2011$ ) and factorextra (Kassambara \& Mundt, 2020). The mean values of the following 17 nutrient values of each plot were included: $\mathrm{pH}(\mathrm{KCl})$, carbon (C) (mmol/gTB), nitrogen (N) (mmol/gTB), organic carbon (mmol/gTB), organic carbonnitrogen ratio (mol/mol), phosphorus resin (P resin) ( $\mu$ molP/gTB), the total effective cation exchange capacity ( $\mu \mathrm{molP} / \mathrm{gTB}$ ), the total base saturation $(\%)$ and the effective cation exchange capacity in $\mu \mathrm{molP} / \mathrm{gTB}$ of aluminum (Al), calcium (Ca), iron (Fe), potassium $(\mathrm{K})$, magnesium (Mg), manganese (Mn), hydrogen $(\mathrm{H})$ and in mol/l of $\mathrm{pH}$ percolate and $\mathrm{HBaCl}$. We performed spearman correlation using the function cor.test from the ggpubr R package (Kassambara, 2020) to test for correlation among all included variables using the spearman rank correlation method. We found high correlations ( $>0.65$ ) of effective cation exchange capacity of $\mathrm{Ca}, \mathrm{Mg}$ and $\mathrm{K}$ with total mean effective cation exchange capacity but low to medium correlations for effective cation exchange capacity of $\mathrm{Al}, \mathrm{H}, \mathrm{Fe}$ and $\mathrm{Mn}$. Therefore, we excluded total mean effective cation exchange capacity from further analysis. We found high correlation $(>0.8)$ between total base saturation and effective cation exchange capacity of $\mathrm{Ca}, \mathrm{Mg}, \mathrm{Al}, \mathrm{H}$ and $\mathrm{pH}$ percolate but low to medium correlations for effective cation exchange capacity of K and Mn. Therefore, we excluded total base saturation from further analysis. Carbon was highly correlated with organic carbon. Hence, we excluded carbon from the analysis, since organic carbon is more biological active. Effective cation exchange capacity of $\mathrm{pH}$ percolate was highly correlated with effective cation exchange capacity of $\mathrm{H}$. We excluded the effective cation exchange capacity of $\mathrm{pH}$ percolate from further analysis. Mean effective cation exchange capacity of $\mathrm{HBaCl}$ showed laboratory measuring mistakes and was therefore excluded from analysis.

We repeated the PCA including the following 12 parameters: $\mathrm{pH}(\mathrm{KCl})$, nitrogen (mmol/gTB), organic carbon (mmol/gTB), organic carbon-nitrogen ratio ( $\mathrm{mol} / \mathrm{mol}$ ), phosphorus resin ( $\mu \mathrm{molP} / \mathrm{gTB})$, the effective cation exchange capacity ( $\mu \mathrm{molP} / \mathrm{gTB})$ of $\mathrm{Al}, \mathrm{Ca}, \mathrm{Fe}$, $\mathrm{K}, \mathrm{Mg}, \mathrm{Mn}$ and $\mathrm{H}$. We computed the eigenvalues/factor loadings for each parameter in PC 14. We performed a correlation matrix using spearman rank test of all remaining variables. 
If variables were highly correlated $(>0.6)$ we kept the variables with higher factor loading in PC 1 or if both variables are important plant nutrients we kept both parameters in the analysis. We performed a PCA with the following remaining variables: effective cation exchange capacity ( $\mu \mathrm{molP} / \mathrm{gTB}$ ) of $\mathrm{Ca}, \mathrm{K}, \mathrm{Al}$ and $\mathrm{Mn}$ as well as $\mathrm{pH}(\mathrm{KCl})$, nitrogen (mmol/gTB), $\mathrm{P}(\mathrm{resin})(\mu \mathrm{molP} / \mathrm{gTB})$ and the organic carbon-nitrogen ratio $(\mathrm{mol} / \mathrm{mol})$. We extracted the coordinates of PC1 and included them as soil fertility variable as explanatory variable in our yield and biodiversity analysis (PC1 45.2\% explained variation; PC2 20.9\% explained variation).

\subsubsection{Statistical analysis}

\section{Multidiversity}

To unify the species richness of various taxa, we calculated multidiversity (Manning et al., 2018). Multidiversity is an index that calculates a plot-level diversity across taxonomic groups based on a threshold approach (Lefcheck et al., 2015). The threshold approach generates multidiversity with the number of taxa which have passed a certain threshold in relation to the maximum species richness found across all plots, not only a specific land-use type. We defined the maximum species richness for each taxa as the mean of the five highest numbers of species richness to minimize the effect of outliers (Allan et al., 2015). We used a threshold of $50 \%$ as a compromise between rigorosity and mildness. With this threshold we state that a certain loss of species within vanilla agroforests or fallows is acceptable but if species numbers fall below a 50\% threshold the loss is 'penalized' by a reduction in multidiversity. We calculated multidiversity and endemic multidiversity across the whole threshold range (1\%-99\%) to track changes in multidiversity.

\section{Biodiversity depending on yield}

We investigated the relationship of species richness with vanilla yield in 30 vanilla agroforests using glmmTMB models with species richness as response variable, vanilla yield (sqrttransformed) in interaction with land-use history (fallow vs. forest-derived) as explanatory variable and village as a random effect. We scaled and sqrt-transformed vanilla yield due to few high-yielding plots inflating the data distribution. We assumed poisson distribution for the models with species richness. We used simulation plots from the DHARMa package to validate our model fit (Hartig, 2020). If our models were under-dispersed or over-dispersed, we changed the model family to compois and negative binominal (nbinom2), respectively. We assumed normal distribution for the model with multidiversity as a response and used a linear mixed effect model instead. 


\section{Biodiversity depending on environmental parameters}

We assessed the environmental and management drivers of species richness with a glmmTMB model (M. E. Brooks et al., 2017) using species richness as a dependent variable and canopy closure, soil fertility, slope, landscape forest cover, vegetation cover, elevation, planting density, pollination labour input, vanilla vine length, leaf damage, vanilla plant age as explanatory variables. We added village as a random effect and scaled all explanatory variables. For all models, all explanatory variables were initially included (full model). We selected the explanatory variables for the final model by performing a Chi-square test with the anova function comparing the full model with models excluding each explanatory variable one by one (single term deletion). The final model included all explanatory variables with a residual deviance (chi-squared value) $<0.05$ in the model comparison with the full model. After model simplification, we used simulation plots from the DHARMa package to validate the model fit (Hartig, 2020). If our models were under-dispersed or over-dispersed, we changed the model family to compois and negative binominal (nbinom2), respectively. To assess marginal and conditional R2 we used the delta method using the rsquaredGLMM function of the package MuMIn (Bartoń, 2020).

\section{Yield depending on environmental variables}

We investigated the drivers of vanilla yield using a linear mixed effect model with yield (sqrt-transformed) as response variable and the same dependent variables as for the analysis of biodiversity drivers including village as a random effect. All explanatory variables were scaled. We used the same model simplification approach as for the model identifying the drivers of species richness and validated model fit with DHARMa package (Hartig, 2020).

\section{Biodiversity comparison}

We assessed differences in species richness between forest, forest-derived vanilla agroforests, fallow-derived vanilla agroforest and fallows by fitting a glmmTMB model (M. E. Brooks et al., 2017) with species richness as a response variable and land-use type as explanatory variable with village as random effect. For multidiversity we used a linear mixed effect model to model the effect of land-use type. We used the glht function from the multcomp package (Hothorn et al., 2008) applying a Tukey's all-pair comparisons with Bonferroni correction to assess differences in species richness between land-use types. We assumed normal distribution for the model explaining multidiversity but poisson distribution for all other models explaining individual taxa richness and changed to compois or negative 
binominal (nbinom2) family if models were under- or over-dispersed. We used simulation plots from the DHARMa package to validate our model fit (Hartig, 2020).

\subsubsection{Biodiversity assessment}

\section{Trees}

We sampled trees between September 2018 and January 2019 on all land-use types with tree except herbaceous fallow. We received access to 48 plots (all except two fallow-derived vanilla agroforest). We did a full inventory of all trees with free-standing stems of $\geq 8 \mathrm{~cm}$ diameter at breast height in each plot. This included trees, arborescent palms, herbs, and tree ferns but excluded lianas. We identified tree individuals with the help of a local and a taxonomic expert from Missouri Botanical Garden (Antananarivo). We derived information on origin and endemism for each species from the Tropicos Madagascar Catalogue (Missouri Botanical Garden, 2019). See Osen et al. (in review) for more details.

$\underline{\text { Herbaceous plants }}$

We sampled herbaceous plants in eight subplots of $4 \mathrm{~m}^{2}$ each ( $32 \mathrm{~m}^{2}$ overall). In each subplot, we assessed vascular plant species that without apparent wood at maturity. We determined each species' endemism status from the Tropicos Madagascar Catalogue (Missouri Botanical Garden, 2019). See Raveloaritiana et al. (in review) for more details.

\section{$\underline{\text { Birds }}$}

We sampled birds during two 40 min point counts per plot. We conducted one point count in 2017 (September-December) and a second one between August and December 2018. In old-growth forest plots, we did all point counts in 2018 (August 2018 and December 2018). We disregarded observations in flight and outside the plot. We defined species only occurring in Madagascar according to BirdLife species fact sheets as endemic. See Martin et al. (2020a) for more details.

\section{Amphibians and reptiles}

We sampled amphibians and reptiles using repeated time-standardized search walks by two observers. We visited each plot three times during the day and three times at night. We did so during the driest (One nocturnal and one diurnal search between October - December 2017; one nocturnal and one diurnal search between August-December 2018) and wettest period (One nocturnal and one diurnal search between January - April 2018 or in February 2019). We systematically walked the plot in zig-zag pattern. We actively checked microhabitats to detect individuals hiding therein. When encountering an individual, we 
stopped the standardized search time and identified the individual following Glaw \& Vences (2007). We took DNA samples to determine the species for those individuals that proved difficult to identify using morphological characteristics only. More information in Fulgence et al. (in prep.).

\section{$\underline{\text { Butterflies }}$}

We sampled butterflies with fruit traps and sweep nets between August and December 2018. We baited fruit traps with fermented banana and deployed the cylindrical nets for 24 hours. Prior to deployment, we fermented bananas for 48 hours in an air-tight container. On each plot, we installed a total of 8 fruit traps. We deployed four fruit traps at $16.6 \mathrm{~m}$ distance from the plot center in the four main cardinal directions and the other four fruit traps at $20 \mathrm{~m}$ distance from the center in the four inter-cardinal directions. During the 30 minutes time-standardized sweep netting, we caught butterflies within an imaginary $2 \mathrm{~m}$ wide box to each side of the sweep-net while walking at slow and steady speed in a zigzag to equally cover the plot area. We performed the time-standardized netting in dry and lowwind conditions only, either in the morning ( $8 \mathrm{am}-12 \mathrm{pm}$ ) or in the afternoon (1-5 pm). We then collected and dried all captured butterflies and identified them to species level in the laboratory (moths excluded).

$\underline{\text { Ants }}$

We sampled ground-foraging ants using bait and pitfall traps. We conducted the sampling in the villages between October and December 2017, and in the old-growth forest in August and December 2018. We established five sampling stations per plot: one at the plot center, and four at $16 \mathrm{~m}$ distance from the plot center; one in each cardinal direction. We then set bait and pitfall traps $10 \mathrm{~m}$ apart at each sampling station. We baited the bait traps using sardine and sugar on two white flat plastic plates with a diameter of $13 \mathrm{~cm}$ and placed the two plates about $5 \mathrm{~cm}$ apart. We left the baited traps for 30 minutes before collecting ants

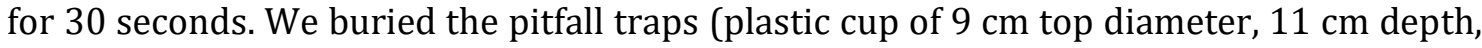
and $6 \mathrm{~cm}$ bottom diameter) in the soil and filled them one-third with 70-\%-alcohol and a few drops of soapy water. We emptied the pitfall traps after 48 hours and identified ants to species/morphospecies level in the laboratory. We defined endemic ant species as those species only present in the country of Madagascar. 


\subsection{Acknowledgements}

We wish to thank all village chiefs, village facilitators, local and regional authorities who supported, communicated and permitted our research. Special thanks go to all plot owners and their family members who allowed us to work on their fields and committed their time to facilitate our research. We are grateful for their continuous trust and their openness to share their knowledge and views on their farming practices. We thank Madagascar National Parks and the Ministry of environment and sustainable development to grant us access to sites and allow the export of samples. We express our appreciation to Rainer Marggraf and Andrea Bührmann. Thank you to Theudy Alexis, Patrice Antilahimena, Evrard Benasoavina, Claudine Bemamy, Jean Chrysostome Bevao, Ronik Botra, Adriane März, Johannes Osewold, Thorien Rabemanantsoa, Julien Randriampenomanana, Cédric Randrianantenaina, Eric Rakotomalala, Gatien Rasolofonirina, Joel Razafinantenaina and Guillaume Velotody who were indispensable to our data collection. We are also grateful for the sample processing and identification work done by Maria S. Vorontsova and Nantenaina Herizo Rakotomalala from Kew as well as David Lees from NHM, Sáfián Szabolcs, Jean Chrysostome Bevao and Patrice Antilahimena from MBG, Miguel Vences from TU Braunschweig and Dietrich Hertel from the University of Goettingen. We collected data under research permits $\mathrm{N}^{\circ} 100 / 17 / \mathrm{MEEF} /$ SG/DGF/DSAP/SCB.Re, Nº163/17/MEEF/SG/DGF/DSAP/SCB.Re, N18/18/MEEF/SG/ DGF/DSAP/SCB.Re, and $N^{\circ} 254 / 18 / \mathrm{MEEF} / \mathrm{SG} / \mathrm{DGF} / \mathrm{DSAP} / \mathrm{SCB}$. Re granted by the Ministry for Environment and Sustainable Development, Antananarivo. This study was financially supported by the Niedersächsisches Vorab of Volkswagen Foundation as part of the research project 'Diversity Turn in Land Use Science' (Grant number 11-76251-99-35/13 (ZN3119)) and German Academic Exchange Service (DAAD) within the 'Partnerships for Supporting Biodiversity in Developing Countries' initiative (Project Nr. 57449386). 


\section{Uncovering conservation opportunities in a global biodiversity hotspot}

Dominic Andreas Martin, Fanilo Andrianisaina, Thio Rosin Fulgence, Kristina Osen, Anjaharinony Andry Ny Aina Rakotomalala, Estelle Raveloaritiana, Marie Rolande Soazafy, Annemarie Wurz, Rouvah Andriafanomezantsoa, Harilala Andriamaniraka, Aristide Andrianarimisa, Jan Barkmann, Saskia Dröge, Ingo Grass, Nathaly Guerrero-Ramirez, Hendrik Hänke, Dirk Hölscher, Bakolimalala Rakouth, Hery Lisy Tiana Ranarijaona, Romual Randriamanantena, Fanomezana Mihaja Ratsoavina, Lala Harivelo Ravaomanarivo Raveloson, Dominik Schwab, Teja Tscharntke, Delphine Clara Zemp, \& Holger Kreft

Contribution: Conceptualization, Data curation, Formal analysis, Investigation, Project administration, Validation, Visualization, Writing - original draft

Status: In preparation.

\subsection{Abstract}

Effective policies to preserve rainforest and diverse agricultural mosaic landscapes in the tropics are urgently needed. However, land-use options presented to people are dependent on prior decisions made in the past, implying path-dependency. We illustrate the strength of explicitly incorporating path-dependency into land-use science by using a trajectory approach to land-use changes in the biodiversity hotspot of north-eastern Madagascar. Here, smallholder agriculture has resulted in a mosaic landscape with contiguous old-growth forests, forest fragments, vanilla agroforestry, and shifting cultivation. On the land-use trajectory, we identify three conservation opportunities. We then assess trade-offs and win-win situations at each opportunity, using data from seven taxa, five ecosystem functions, and 
four measures of agricultural productivity. At one of the three opportunities, we identify a win-win situation through multifunctional and profitable vanilla agroforestry established on former fallow land, while trade-offs dominate under forest transformation. In sum, incorporating path-dependency along a land-use trajectory enables us to derive relevant policy recommendations for land-use issues in Madagascar, highlighting a rapidly closing 'window of opportunity' for conservation action in this biodiversity hotspot.

Key words: agroforestry, conservation, land-use change, land-use history, land-use policy, land-use trajectory, Madagascar, path-dependency, shifting cultivation, vanilla

\subsection{Introduction}

Unique tropical ecosystems face multiple pressures (Bowler et al., 2020), putting species (Brooks et al., 2002) and ecosystem functions (DeFries et al., 2004) at risk. A key pressure is deforestation (Rosa et al., 2016), which may result in monocultures or heterogeneous mosaic landscapes, depending on the drivers of forest loss (Curtis et al., 2018). If driven by smallholder activities, resulting tropical mosaic landscapes may host a plethora of different land uses. Thanks to the diversity of the various mosaic pieces, such landscapes may be a balanced ecosystem that delivers for biodiversity, ecosystem functions, and people (Tscharntke et al., 2012). Policies may thus be concerned with avoiding undesired changes within these mosaics or with enhancing mosaic landscapes through targeted interventions (Prudhomme et al., 2020). This seems particularly important, given the interacting effects of land-use and climate change on biodiversity in tropical mosaic landscapes (Hendershot et al., 2020; Williams \& Newbold, 2020) and the frequent loss of regulating ecosystem services over time (Pereira et al., 2020).

These dynamics suggest that conservation opportunities exist at deforestation frontiers, where old-growth can be conserved, as well as within the mosaic landscapes. However, some of these opportunities may be closing, thereby limiting future land-use options: for example, conserving old-growth forests in landscapes with no such forest left, will prove impossible (Hedges et al., 2018). Similarly, conserving biodiversity in tree-rich agroforests will only be possible as long as such agroforests exist (Geeraert et al., 2019). These examples highlight that future land-use options may be limited, as they are dependent on today's decisions, as well as that current options may be limited by past decisions, a concept termed 'path-dependency' (Jepsen et al., 2015; Wilson, 2007). To operationalize this approach, we can conceptualize a landscape along a land-use trajectory, which describes a landscape along several distinct stages that may be converted into each other following the trajectory 
(Geist et al., 2006; Wilson, 2007), thereby accounting for the inherent path-dependency. Importantly, the different stages differ in their divergence from the historical land cover (e.g. old-growth forest) but may all occur simultaneously in space.

Here, we propose that the identification of conservation opportunities along land-use trajectories may help to identify intervention points for policy in complex mosaic landscapes. At each conservation opportunity, research may identify co-benefits and trade-offs in terms of biodiversity, ecosystem functions, and agricultural productivity, which can be directly compared and weighed against each other. This approach may help, for example, to calculate economic losses for land users that should be compensated for, if a conservation opportunity is to be realised (Neudert et al., 2017). Furthermore, research may identify which intervention points along the land-use trajectory offer the most co-benefits, thus representing a promising conservation opportunity. Lastly, path dependency also suggests the possibility of closing 'windows of opportunity', as current decisions may limit the conservation opportunities which will exist in the future.

We apply our framework of land-use trajectories and conservation opportunities to the case of Madagascar - a biodiversity hotspot, where the once continuous old-growth forest has been largely converted into agricultural land uses over the past century (44\% forest loss from 1953-2014; Vieilledent et al., 2018). Smallholder agriculture, predominantly through shifting cultivation, remains the main driver of forest loss in the north-eastern part of the country (Zaehringer et al., 2015), which is in line with deforestation dynamics in Sub-Saharan Africa (Curtis et al., 2018; van Vliet et al., 2012). North-eastern Madagascar is also the most important vanilla growing region globally, with vanilla providing a livelihood for an estimated 70-80'000 households (SVI, 2020). Here, smallholders farm the vanilla orchid (Vanilla planifolia) in agroforestry systems, largely relying on family labour (Hänke et al., 2018). Yet, vanilla agroforests differ in their land-use history: forest-derived agroforests are established inside remaining forests, while fallow-derived agroforests are established on fallow land, previously forming part of the shifting hill rice cultivation cycle (Martin et al., 2020b). Vanilla, therefore, plays a role at two distinct points along the land-use trajectory: if forest-derived, vanilla agroforestry contributes to forest degradation; if fallow-derived, vanilla agroforestry has the potential to rehabilitate fallow land (Martin et al., 2020c).

To date, conservation policies in Madagascar have largely focused on old-growth forest conservation, paying little attention to land-use change and intensification within mosaic landscapes (Rakotomanana et al., 2013). However, research has shown an ongoing loss of forest fragments (Schüßler et al., 2020) and a structural simplification of mosaic landscapes in te 
country (Zaehringer et al., 2015). This change may be associated with the loss of biodiversity and ecosystem functions on the one hand, and with a gain in agricultural productivity on the other. A comprehensive assessment for north-eastern Madagascar is, however, missing.

To identify conservation opportunities for a sustainable land-use transformation, we conceptualized the landscape of north-eastern Madagascar along the predominant land-use trajectory, thereby explicitly accounting for path dependency. Old-growth forest (Stage 0; historic baseline, see Figure 8.1) can be burned for shifting hill rice cultivation (Stage 1).

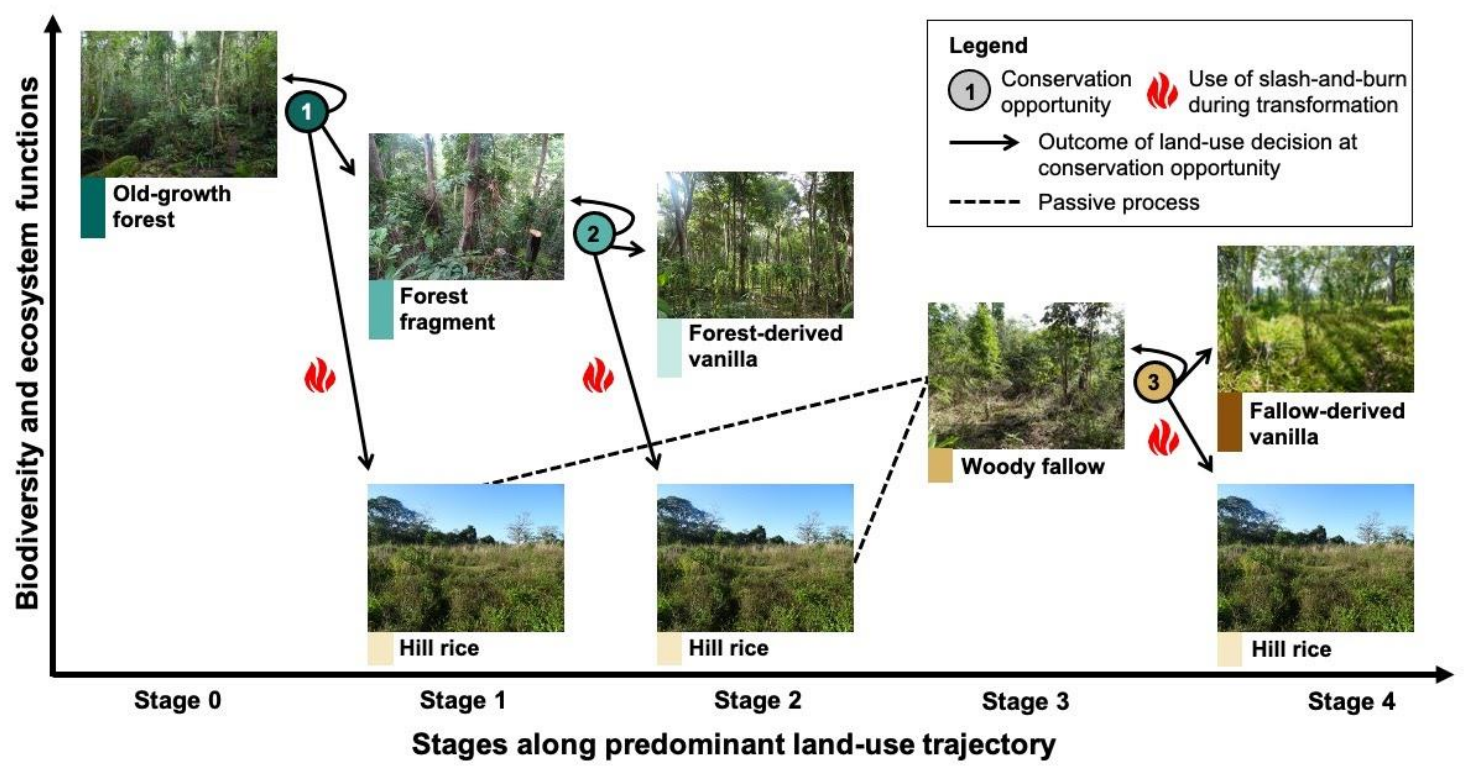

Figure 8.1: Hypothesized transformation outcomes for ecosystem functions and biodiversity along the predominant land-uses trajectory in north-eastern Madagascar with conservation opportunities 1-3. At each conservation opportunity, the current land-use could be preserved or alternatively converted into one of two alternatives. These alternatives can then be evaluated against the current stage and against each other concerning ecosystem functions, biodiversity, and agricultural productivity. The relative position on the y-axis for each land-use type represents hypothesized outcomes for ecosystem functions and biodiversity.

Alternatively, an old-growth forest may be fragmented and heavily used for timber extraction, resulting in forest fragments (Stage 1). These fragments can, in turn, be transformed into shifting hill rice cultivation or into forest-derived vanilla agroforests (Stage 2). Irrespective of their previous use, hill rice fields are left fallow and usually develop into woody fallows within a few years (Stage 3). Such woody fallows can again be transformed, currently either through an additional cycle of shifting hill rice cultivation or through the establishment of a fallow-derived vanilla agroforest (Stage 4). Rice paddies are another prevalent land-use type in the region but are not part of the main trajectory as they are typically 
established in floodplains and wetlands. Given the here-described trajectory, we hypothesize possible outcomes for biodiversity, ecosystem functions, and agricultural productivity. As indicated in Figure 8.1, we expect ecosystem functions and biodiversity to decline through conversion of old-growth forest (Carrasco et al., 2017; Newbold et al., 2015), particularly if transformed through slash-and-burn rather than forest use and fragmentation (Klanderud et al., 2010). Similarly, we hypothesize a loss of ecosystem functions and biodiversity under forest fragment conversion (Carrasco et al., 2017; Newbold et al., 2015), again more pronounced if under the use of slash-and-burn for shifting cultivation (Klanderud et al., 2010). We also hypothesize a gain of ecosystem functions and biodiversity under fallow regrowth (to stage 3), and a further rehabilitation through fallow-derived agroforestry (Martin et al., 2020b). Again, we hypothesize a loss of ecosystem functions and biodiversity under hill rice cultivation.

\subsection{Results}

To test these hypotheses, we collected data on seven taxa (trees, herbaceous plants, birds, amphibians, reptiles, butterflies, and ants), five ecosystem functions and services (above ground carbon, soil organic carbon, predation rate, natural product provisioning and water regulation; thus excluding yields; hereafter ecosystem functions), and three parameters of agricultural productivity (profit per unit labour, profit per unit area, and yield) across the seven predominant land-use types of north-eastern Madagascar. None of the land-use types scores highly in all three domains (biodiversity, ecosystem functions, and agricultural productivity; Figure 8.2), suggesting trade-offs between biodiversity and ecosystem functions on the one hand, and agricultural productivity on the other. This is also apparent when comparing land-use types along the dominant land-use trajectory of the region (Figure 8.3), but important conservation opportunities (Figure 8.4) exist through vanilla agroforestry that combine medium levels of biodiversity and ecosystem functions with high profits from vanilla farming.

\subsubsection{Multidiversity, multifunctionality and agricultural productivity differs be- tween land-use types}

We collected the data for seven taxa and three ecosystem functions on 80 plots of all six land-use types that form part of the trajectory, as well as on rice paddy (10 plots per landuse type, except 20 plots for fallow-derived vanilla). Additionally, we interviewed people about the ecosystem services (water regulation and natural product provisioning) they 
profit from. We combine these data by calculating endemic multidiversity, multidiversity, and multifunctionality. These combined measures enable us to summarize the ability of each land-use type to simultaneously host a suite of (endemic) taxa and to provide multiple ecosystem functions and services into only three measures. We display (endemic) multidiversity and multifunctionality at a 50\% threshold, i.e. as a proportion of species/functions that surpass $50 \%$ of the mean value of the top five plot for that species/function on any land-use type. Additionally, we compare three parameters of agricultural productivity (harvest per unit area, net income per unit area, and net income per unit labour; collected through a longitudinal study) across all seven land-use types (Figure 8.2).

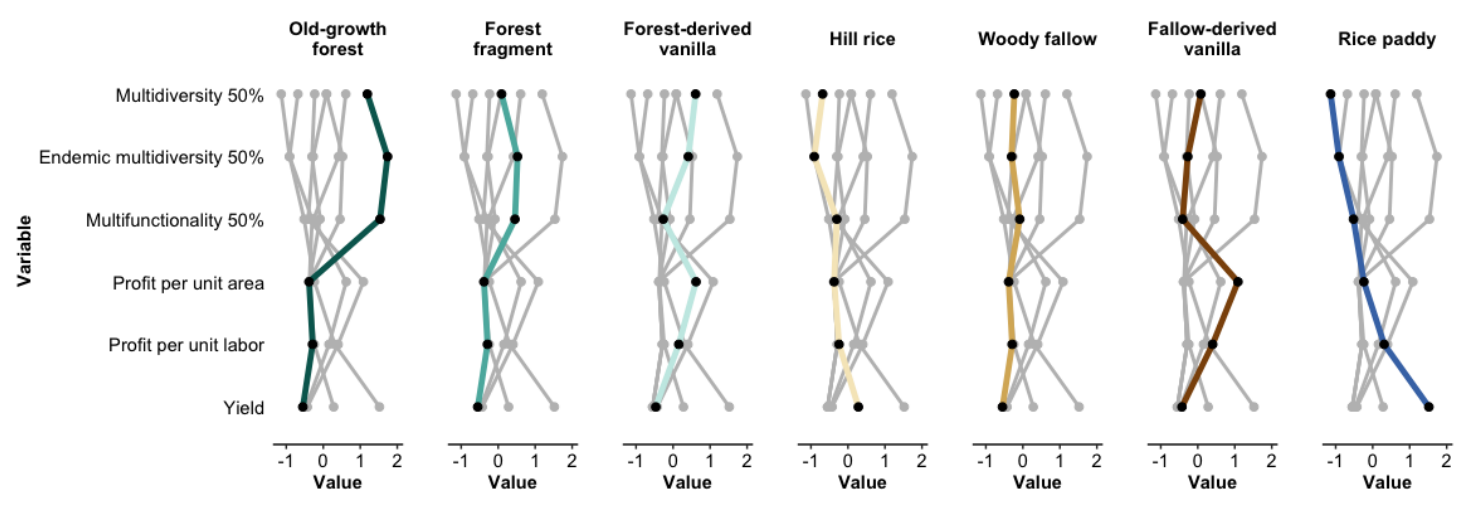

Figure 8.2: Parallel coordinate plots displaying key characteristics of one focal land-use type (colour) in relation to the other six predominant land-use types (grey) in north-eastern Madagascar. Variables displayed are multidiversity, endemic multidiversity, multifunctionality (each at the $50 \%$ threshold), profit per unit labour, profit per unit area, and yield. To make values across various scales comparable, we subtracted underlying values from the mean and divided by the standard deviation within each variable. We then plotted the mean of the standardized value for each land-use type and variable.

Old-growth forest performs best for multidiversity and, even to a greater extent, for multidiversity of endemic species (Figure 8.2). Old-growth forests also play a key role for ecosystem functions but have no agricultural productivity. Forest fragments also emerge as important reservoirs for biodiversity and most ecosystem functions, but likewise provide no agricultural productivity. In contrast, forest-derived vanilla agroforests, that are established directly inside forests, are highly profitable per unit labour and per unit area and provide habitat for more species than forest fragment yet have fewer endemics. Hill rice and woody fallows, which form part of the shifting cultivation cycle, perform relatively poorly in terms of biodiversity and ecosystem functions and rice yields are lower than those from rice paddy. Furthermore, hill rice farming is not profitable. Fallow-derived vanilla, that is, vanilla agroforests established on fallow land, performs similarly to woody fallow in terms of 
biodiversity and ecosystem functions but is highly profitable per unit area and per unit labour. Rice paddies provide high yields and profits but perform badly in terms of biodiversity and ecosystem functions.

\subsubsection{Multidiversity and multifunctionality dynamics along the land-use trajectory}

Along the land-use trajectory, changes in biodiversity are strongest under old-growth forest transformation (Stage 0 to stage 1, Conservation opportunity 1; Figure 8.3 A, B). Losses under transformation to hill rice farming strongly exceed losses under transformation to forest fragment. Losses in both cases are particularly pronounced for endemic species which reacted stronger than the community as a whole. Importantly, a second major drop in biodiversity happens when forest fragments are transformed to hill rice farming, again more pronounced for endemics (Stage 1 to stage 2, Conservation opportunity 2; Figure 8.3 A, B). Transforming forest fragments to forest-derived vanilla agroforests, on the other hand, limits losses of endemic species and increases multidiversity of all species (Figure 8.3). However, hill rice fields developing into woody fallows regain some multidiversity and endemic multidiversity, but pre-burning levels cannot be reached (Stage 1 / 2 to stage 3 ).
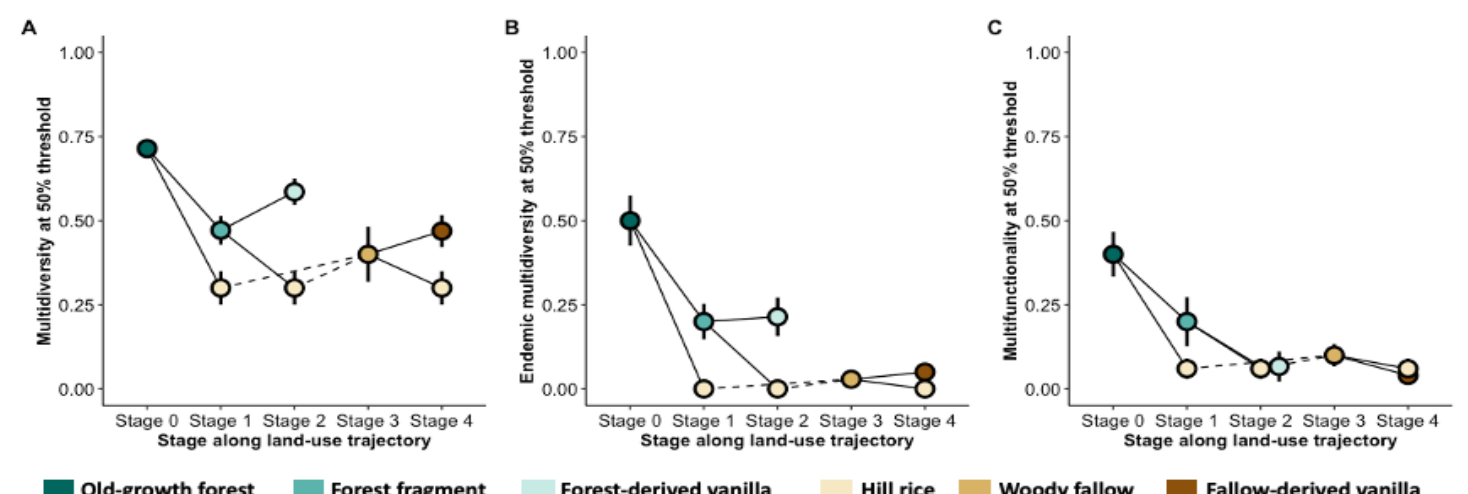

Figure 8.3: Multidiversity, endemic multidiversity and multifunctionality at stages along a land-use trajectory in north-eastern Madagascar. Losses of multidiversity (A), and to a greater extent endemic multidiversity (B), happen after old-growth forest conversion, particularly if land enters shifting hill rice cultivation. Differences at later transitions within the land-use trajectory (Conservation opportunities 2 and 3) are less strong. However, retaining non-burned forest fragment and forest-derived vanilla agroforestry is generally superior to the conversion to previously burned land-uses (shifting cultivation, fallow-derived agroforestry). Multifunctionality (C) shows less pronounced differences between land-use types, but again old-growth forest and forest fragments stand out. Points coloured according to the land-use type represent the mean value for each land-use type while error bars represent standard errors. Multidiversity, endemic multidiversity, and multifunctionality values for all 
land-use types are shown here for a 50\% threshold; $20 \%$ and $80 \%$ thresholds are displayed in SI Chapter 8, Figure 12.14.

Multifunctionality generally differs less strongly between land-use types (Figure 8.3). However, multifunctionality is highest in old-growth forests and, in parallel to multidiversity, declines stronger under conversion to hill rice cultivation than if converted to forest fragments. However, differences between all other human-dominated land-use types are negligible at the $50 \%$ threshold. These trends are qualitatively similar at the $20 \%$ and $80 \%$ threshold (SI Chapter 8, Figure 12.14). However, differences between land-use types are largest at the $50 \%$ threshold for multidiversity and endemic multidiversity but largest at the $20 \%$ threshold for multifunctionality (SI Chapter 8, Figure 12.14).

\subsubsection{Trade-offs and win-win outcomes at conservation opportunities}

To explicitly analyse possible trade-offs and co-benefits between variables at each conservation opportunity, we contrast gains and losses of all available variables under both plausible land-use conversions to the current stage at each conservation opportunity (Figure 8.4). To make data comparable across variables, we standardize all values by subtracting the mean of the variable and dividing through the standard deviation, allowing us to calculate a standardized change compared to the current stage.

Trade-offs between biodiversity conservation and ecosystem functions on the one hand, and agricultural productivity on the other hand, are evident at conservation opportunity 1 , where old-growth forest is at risk of conversion into hill rice cultivation. A conversion to forest fragments has largely similar trade-offs, but to a lesser extent. At conservation opportunity 2 , forest fragments may be converted to hill rice fields or forest-derived vanilla agroforests. Again, trade-offs prevail under conversion to hill rice cultivation. Converting forest fragments to forest-derived vanilla agroforests, on the other hand, offers mutually beneficial outcomes between agricultural productivity and biodiversity conservation and ecosystem functions, respectively. At conservation opportunity 3, land-users face the option of continuing shifting cultivation or establishing a fallow-derived agroforest on the same land. At this opportunity, farming profits can be raised by more than $3500 €$ per hectare without consistently negative effects for biodiversity and ecosystem functions, as land under shifting cultivation is converted into permanent vanilla agroforestry. 


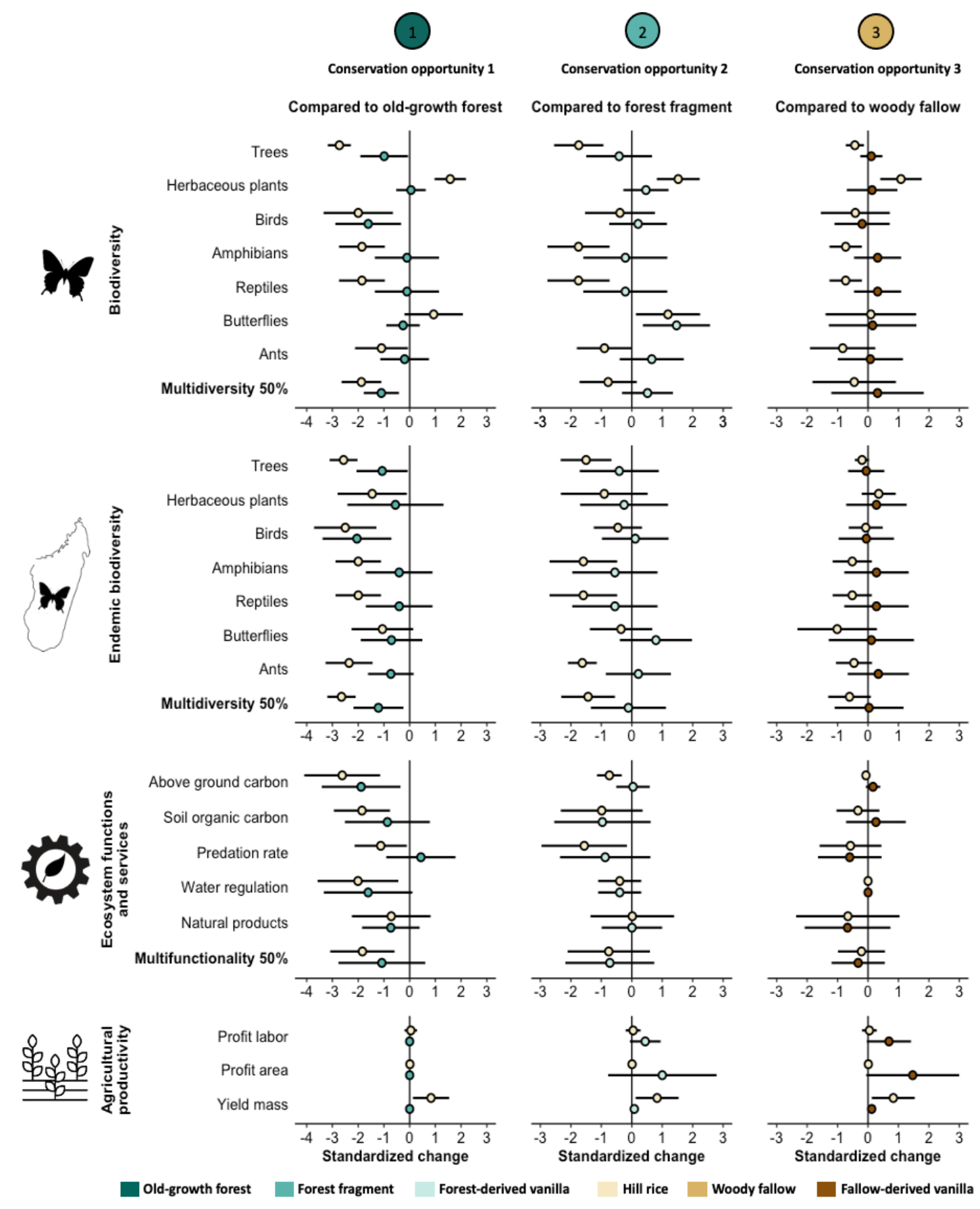

Figure 8.4: Comparison of biodiversity, endemic biodiversity, ecosystem functions, and agricultural productivity at conservation opportunities 1-3 along a land-use trajectory in north-eastern Madagascar. Conservation opportunity 1: Conserving old-growth forest is necessary to retain many endemic taxa and high levels of ecosystem functions. Conversion to shifting hill rice cultivation has overall stronger effects than conversion to forest fragments. Conservation opportunity 2: Conserving forest fragments is important to retain biodiversity and ecosystem functions, but the lack of agricultural productivity encourages their conversion. In case of forest fragment conversion, forestderived agroforests outperform shifting hill rice cultivation across variables. Conservation opportunity 3: Mutually beneficial outcomes are possible under conversion of fallow land to fallow- 
derived vanilla agroforestry, given stable multidiversity and multifunctionality and a strong increase in profitability. Values are standardized to enable comparison; dots represent mean changes compared to the previous stage, and errorbars represent standard deviations of mean changes, thereby representing the variability across plots and households, respectively.

\subsection{Discussion}

In this study, we combine data on seven taxa, five ecosystem functions, and three measures of agricultural productivity to assess three conservation opportunities along a land-use trajectory in north-eastern Madagascar, thereby explicitly accounting for path dependency in land-use decisions. We find co-benefits between ecosystem functions and biodiversity on the one hand, and agricultural productivity on the other hand, under conversion of fallow land into fallow-derived vanilla agroforestry. Trade-offs nonetheless prevail under forest conversion into shifting hill rice cultivation and vanilla agroforestry, suggesting that a targeted policy, that compensates for opportunity costs of land-users, may help to realize the two conservation opportunities that do not offer co-benefits. Finally, we argue that the approach of conservation opportunities along land-use trajectories may be a viable tool for land-use science and policy elsewhere.

\subsubsection{Conservation opportunity 1: Trade-offs in old-growth forest conservation}

Our results indicate that the loss of old-growth forest in north-eastern Madagascar is associated with a loss of species richness and an even stronger loss of endemic species richness across taxa. The stronger losses for endemic species supports the view that these species are more affected by land-use change than non-endemic species (Waltert et al., 2011; Wilmé, 1996). Furthermore, it also underlines the importance of conserving the remaining old-growth forests in Madagascar (Rakotomanana et al., 2013).

These losses are particularly strong when old-growth forests enter the shifting cultivation cycle for hill rice production - i.e. when they are cleared under the use of slash-and-burn. The fragmentation into forest fragments and the extraction of timber and other natural products also results in a loss of (endemic) species, but to a lesser extent. However, our assessment of conservation opportunity 1 also shows the considerable benefits land users gain from old-growth forest conversion. Hill rice cultivation results in rice yields that are mainly used for subsistence as poorer households own little or no paddy rice (Hänke et al., 2018), thus contributing to food security (Andriamparany et al., in review). Furthermore, forest fragments and fallow land is used for natural product extraction. 
Given these benefits of old-growth conversion, land-users need clear economic alternatives to forest conversion or alternatively need to be compensated for losses they experience. For example in eastern Madagascar, opportunity costs for forest use and forest conversion restrictions are estimated at $27-84 \%$ of total annual income for median-income households (Poudyal et al., 2018). Compensation could be achieved through various approaches, but current REDD+ (Reducing Emissions from Deforestation and Forest Degradation) programs in Madagascar undercompensate real costs (Neudert et al., 2017; Poudyal et al., 2018). Furthermore, unrolling such an approach in the remote study landscape at a large scale would remain an additional hurdle.

\subsubsection{Conservation opportunity 2: Maintaining forest fragments and favouring for- est-derived agroforestry over shifting cultivation}

Conservation opportunity 2 shows that maintaining forest fragments benefits endemic biodiversity and ecosystem functions and services, exceeding both the conversion into forestderived vanilla agroforests as well as the conversion into shifting hill rice cultivation. This result underpins past research (Ricketts et al., 2004; Şekercioğlu et al., 2007) on the high value of rapidly vanishing tropical forest fragments (Hansen et al., 2020) for biodiversity and ecosystem services. However, the conversion of forest fragments into forest-derived vanilla agroforestry, where understory shrubs are used as support trees for the vanilla vines, while most of the canopy stays intact, maintains much of the biodiversity and ecosystem functions of forest fragments. Indeed, overall species richness even increases mostly due to non-endemic herbaceous plants, birds, butterflies, and ants that are slightly more species-rich in the more open forest-derived agroforests. Interestingly, a chronosequence within vanilla agroforest shows stable canopy cover in forest-derived vanilla agroforests over time, suggesting that forest-derived agroforests may sustain trees over many years (Martin et al., 2020c). This may be due to the absence of a response of vanilla yields to light - meaning that the maintenance of trees in vanilla agroforests does not lead to decreasing yields (Martin et al., 2020c). In contrast, positive yield responses to light often incentivize the reduction of canopy cover in other agroforestry crops such as coffee or cacao (Tscharntke et al., 2011), setting vanilla apart.

The profitability of vanilla farming, both per unit labour and unit land, strongly incentivises the conversion of forest-fragments into forest-derived vanilla agroforests, particularly under high vanilla prices as between 2012 and 2019. Given the limited trade-offs in forestderived vanilla agroforestry, it may be advantageous to focus efforts on old-growth forest conservation, while conserving trees from forest fragments through forest-derived 
agroforestry. In sum, forest-derived agroforestry established inside forest fragments is justifiable as an alternative to shifting cultivation in terms of biodiversity, ecosystem functions, and agricultural productivity.

\subsubsection{Conservation opportunity 3: Possible win-win opportunity in the rehabilita- tion of fallow land through fallow-derived agroforests}

The last conservation opportunity along the trajectory occurs on fallow land. Fallows form an integral part of the shifting cultivation cycle (Styger et al., 2007), following the cultivation of crops. Land users who own fallow land in north-eastern Madagascar essentially face three options: first, land users may keep the land under shifting cultivation by initiating another rice cultivation cycle through slash-and-burn. This transformation would be associated with a short-term loss of biodiversity but an increase in yield. Importantly, the land should stay fallow for several years prior to the conversion to ensure the sustainability of the technique (Styger et al., 2007). Otherwise, the land may enter land degradation associated with non-native plants and a loss of fertility (Laney, 2002; Styger et al., 2007). A shortening of fallow periods can, however, be observed in eastern Madagascar as land becomes scarce (Laney, 2002) and degraded land does occur in our study region (Styger et al., 2007). This further questions the sustainability of the technique and shows the importance of longenough fallow periods and/or alternative land use such as fallow-derived agroforestry, the second option at this conservation opportunity.

Under this second option, land users may establish a fallow-derived vanilla agroforest. Here we show that the conversion of fallow land into fallow-derived vanilla agroforest is associated with strong gains in profitability and stable or slightly increasing biodiversity indicators, including endemic multidiversity. Similarly, fallow-derived agroforests also show ecosystem functioning and ecosystem functions at par with fallow land. We therewith identify the fallow-derived vanilla agroforests as a win-win-win opportunity between biodiversity, ecosystem functions, and agricultural productivity. This opportunity will also avoid land degradation through unsustainable shifting cultivation (Labrière et al., 2015; Styger et al., 2007), thus providing an additional benefit.

Nonetheless, various factors may prohibit land users from converting their fallow land into fallow-derived vanilla agroforests. On the one hand, labour input for vanilla is high (Hänke et al., 2018). Expanding vanilla cultivation may thus necessitate to lessen other farming activities (Laney \& Turner, 2015), such as rice cultivation, or to hire labour. Additionally, vanilla yields only after three years (Havkin-Frenkel \& Belanger, 2018), thereby creating a 
time lag between resource investment and the first pay-off. Another factor that may hinder fallow-derived vanilla agroforest expansion is that sustainability certification schemes (e.g. Rainforest Alliance, Organic) require diverse and native shade-tree cover (International Trade Centre, 2019), a criterion that may be more difficult to meet in fallow-derived agroforestry compared to forest-derived agroforestry (see Martin et al. (2020b) for an extended discussion of the topic).

The third possible option, allowing secondary forest regeneration on woody fallow, is extremely rare. Indeed, secondary forests barely occur in eastern Madagascar (Klanderud et al., 2010). This may be due to land scarcity, prompting farmers to keep land inside the shifting cultivation system. Additionally, accidental fire escapes from neighbouring land may reach into mature woody fallows (Kull, 2002; Styger et al., 2007), thereby halting secondary forest regeneration. Lastly, repeated burning depletes the soil seedbank of native trees and promotes invasive shrubs (Styger et al., 2007), thus limiting the potential for secondary forest regeneration.

In sum, land-use policies targeted towards reduced land degradation should aim at increasing access to fallow-derived agroforestry for land users that struggle to establish agroforests without support. For example, a guaranteed food aid for the three years until the first vanilla yield could act as an accelerator for farmers who struggle to establish vanilla agroforestry due to the competing labour demand with rice farming. Additionally, vanilla sustainability certification should incorporate land-use history in their criteria, facilitating the certification of fallow-derived vanilla agroforests (Martin et al., 2020b).

\subsubsection{Conceptualizing the landscape along a land-use trajectory: advantages and limitations}

Our study reveals how the conceptualization of the study landscape along a land-use trajectory may help to identify conservation opportunities and trade-offs respectively win-wins associated with these opportunities. The here-identified land-use trajectory incorporates all predominant land-use types of the study region, thereby exemplifying real-world landuse dynamics.

The approach also shows that ignoring the land-use history of agroforests, and thereby path-dependency, would lead to a wrong assessment of their value for biodiversity and ecosystem services. Indeed, incorporating the land-use history of vanilla agroforests in this study made it possible to 1 ) identify that forest-derived agroforests degrade forests while fallow-derived agroforests rehabilitate formerly forested fallow land, 2) missed the 
difference in endemic biodiversity between forest- and fallow-derived agroforests. These findings are in line with a recent review of land-use history in agroforests (Martin et al., $2020 \mathrm{~b}$ ) which shows that the incorporation of land-use history is key to properly assess the conservation value and ecosystem service provisioning of agroforestry systems.

The observed early- to medium-stage forest transition in eastern Madagascar is particularly worrying, given that forest regeneration - which tempts to dominate later stages of forest transition - is particularly slow in Madagascar and rarely occur in the study region (see above). Secondary forests are thus not part of the here-described land-use trajectory in the region, nor are other currently rare land-use types such as pastures, degraded land, or nonvanilla agroforests.

As new actors, new infrastructure, or new market opportunities arrive, new land-use trajectories may emerge. Examples from south-east Asia show that the arrival of new market opportunities with new cash crops can transform landscapes in a matter of years (Vongvisouk et al., 2014), thus also resulting in new land-use options and trajectories. Such a new option along the trajectory could create new or altered conservation opportunities in the future which cannot be evaluated here. Nonetheless, vanilla farming has a long tradition in north-eastern Madagascar (Correll, 1953) and farmers stick to farming this crop even during low price phases (FAO, 2020). This is possibly due to weak market development for other crops (Hänke et al., 2018), low diversification of smallholder farms (Hänke et al., 2018), a strong historical focus on vanilla (Correll, 1953), and the remoteness and the lack of reliable transport infrastructure in the region (Weiss et al., 2018) which may hamper the export of more bulky cash crops such as palm oil or rubber that are more difficult to transport. This suggests that the here-studied trajectory may be relatively stable over time and can thus provide policy guidance for years to come.

Similarly to land-use change, land-use intensification within a given land-use type may also erode biodiversity and ecosystem functions, while benefiting yields and profits (Grass et al., 2020; Meyfroidt et al., 2018) - a dynamic not covered here. Our research from more than 200 vanilla agroforests in the region does, however, show stable or increasing canopy cover over time, indicating limited that vanilla agroforests are not intensified at the cost of trees (Martin et al., 2020c). Furthermore, farmers use neither pesticides nor fertilizers in the vanilla agroforests (Hänke et al., 2018; Havkin-Frenkel \& Belanger, 2018), suggesting that land-use change is currently a more important driver of biodiversity decline than land-use intensification. 


\subsubsection{Policy recommendations informed by conservation opportunities}

We derive four key policy recommendations from the analysis of conservation opportunities along the predominant land-use trajectory in north-eastern Madagascar. Firstly, remaining old-growth forests have to be conserved, but opportunity costs for local land users need to be entirely and efficiently compensated for (Poudyal et al., 2018). Likewise, local livelihoods need to be taken into account, otherwise conservation efforts are unlikely to be successful in Madagascar (Andriamihaja et al., 2021; Cullman, 2015). Secondly, fallow-derived vanilla agroforestry should be favoured over forest-derived agroforestry (Martin et al., 2020b), given win-win situations for ecosystem functions and biodiversity on the one hand, and agricultural productivity on the other. Thirdly, forest-derived agroforestry should only be encouraged as an alternative to deforestation of forest fragments and should play no role in old-growth forest degradation (Martin et al., 2020b). Fourthly, while shifting cultivation hill rice cultivation may not be economically profitable at first sight, its contribution to food security (Andriamparany et al., in review) and natural product provisioning (Raveloaritiana et al., in prep.) is considerable. This is mainly because hill-rice farming households are in average poorer and own no or little land for paddy rice cultivation (Hänke et al., 2018), illustrating the need for shifting cultivation despite low yields (Andrianisaina et al., in prep.).

Policies should thus encourage the sustainable continuation of existing shifting cultivation with long-enough fallow periods and other measures that support yields in the long term, rather than calling for their abandonment (Mertz, 2002). Sustainable shifting cultivation may, however, only be possible with enhanced access to rice paddies (e.g. through investment in irrigation) for typically disadvantaged households that are currently heavily dependent on shifting hill rice cultivation and thus forced to apply short fallow periods. Rice paddies have higher yields and higher profits than shifting hill rice cultivation but have limited value for ecosystem functions and biodiversity (Figure 8.2). Alternatively, short-term rice aid could support farmers in transitioning from shifting hill rice cultivation to permanent vanilla agroforestry on parts of their land to bridge the three years from investment to first yield in vanilla cropping. Importantly, all of these policies will rely on the empowerment of various global and local actors in their ability to jointly implement necessary steps (Andriamihaja et al., 2021). 


\subsubsection{Broader applications: land-use trajectories as a tool to evaluate land-use sys- tems for land-use policy}

The conceptualization of landscapes along trajectories, and the incorporation of path dependency that comes with it, offers the opportunity to identify multiple conservation opportunities. These can then be evaluated in terms of biodiversity, ecosystem functions, and agricultural productivity (Clough et al., 2016). Our approach may be particularly beneficial in diverse tropical mosaic landscapes where valuable habitat is lost to land-use change and intensification (Hendershot et al., 2020; Steffan-Dewenter et al., 2007). In such landscapes, forest loss and forest rehabilitation co-occur, enabling interventions on the conservation as well as the restoration side: for example, reforestation happened amidst ongoing deforestation at an agricultural frontier in Panama (Sloan, 2008). To first identify plausible conservation opportunities before contrasting different land-use options further avoids the evaluation of theoretical contrasts between land-use options that do not exist anymore due to path-dependency, thereby avoiding inapplicable policy recommendations.

Importantly, path-dependency also implies closing 'windows of opportunity' as conservation opportunities are lost due to prior decisions limiting the scope of interventions in the future. For example in north-eastern Madagascar, secondary forests are largely absent. This suggests that attempting to restore ecologically intact forests on land once used for shifting cultivation is extremely hard and unlikely to have a good cost-to-benefit ratio. Avoiding ongoing deforestation is thus even more important but the 'window of opportunity' is closing fast (Morelli et al., 2020). However, by simultaneously reducing further primary habitat loss and promoting habitat rehabilitation at key conservation opportunities, land-use policies informed by land-use trajectories can contribute to 'bending the curve' for terrestrial biodiversity (Leclère et al., 2020).

\subsection{Methods}

\subsubsection{Study region}

We collected data in the central part of the SAVA region in north-eastern Madagascar (see Figure 12.12 in SI Chapter 8 for a map). The area is a global biodiversity hotspot (Myers et al., 2000) and even for Malagasy standards particularly biodiverse (Brown et al., 2016). The area has retained more forest than other parts of the eastern Madagascar rainforest biome but suffers ongoing forest loss (Vieilledent et al., 2018). Most of the forest loss in northeastern Madagascar can be attributed to shifting hill rice cultivation (Zaehringer et al., 
2015) that is practised by smallholders. The SAVA region is also the historic (Correll, 1953) and current (Hänke et al., 2018) global centre of vanilla production, producing the majority of Madagascar's 40\% share on the world market (FAO, 2020). A recent price boom for vanilla (Hänke et al., 2018) has led to the expansion of vanilla agroforestry (Llopis et al., 2019). Prices have, however, dropped considerably in 2020, potentially putting a halt to this expansion.

\subsubsection{Sampled land-use types biodiversity and ecosystem functions}

We sampled the seven predominant land-use types of north-eastern Madagascar. Large connecting old-growth forest, our historic baseline, once covered the study region but is now restricted to protected areas. Forest fragments result from fragmentation and degradation of old-growth forest and exist scattered throughout most of the region. Forest-derived vanilla agroforests are established inside forest fragments via thinning of understory shrubs and planting of vanilla (Martin et al., 2020c). However, forests in the region are also cut and burned, thereby entering the shifting hill rice cultivation cycle. The system, referred to as 'tavy' in Malagasy, involves the use of fire directly before rice can be planted at the beginning of the rainy season and rice can be harvested at the end of the rainy season. When sampled for biodiversity and ecosystem functions 6-21 months after harvest, these hill rice fields had already turned into herbaceous follows (Malagasy: 'Matrangy') that are characterized by herbaceous plants. Thereafter, shrubs and small trees establish, resulting in woody fallow (Malagasy: 'Savoka'). The sampled woody fallows had last burned 4-16 years prior to the onset of our data collection in September 2017. Lastly, we sampled irrigated rice paddies situated on riverbanks and plains. This land-use type is usually not directly converted from or converted to one of the other studied land-use types and thus stands outside the trajectory. See Martin et al. (2020a) for more details on each land-use type and Figure 8.1 for example photos.

\subsubsection{Study design biodiversity and ecosystem functions}

We selected 10 villages based on several criteria (Martin et al., 2020a) from a previous sample of 60 villages (Hänke et al., 2018). Additionally, we chose two old-growth forest sites within Marojejy National park. See Figure 12.12 in SI Chapter 8 for a map of the study region, the old-growth forest sites and the villages.

At each old-growth forest site, we chose 5 plots, leading to 10 replicates. At the village level, we chose plots in a semi-blocked design, meaning that we chose one plot each per land-use type (forest fragment, hill rice, woody fallow, rice paddy). It was, however, not possible to 
find suitable forest- and fallow-derived agroforests in each village - leading to one village without fallow-derived vanilla agroforest and three villages without forest-derived agroforest (see SI Chapter 8 Figure 12.13 for a schematic overview that shows which land-use types were represented in which village). Furthermore, fallow-derived vanilla was replicated 20 times, resulting in 80 plots (70 in villages and 10 old-growth forests) overall. These 80 plots form the sampling design for all (endemic) biodiversity, above-ground carbon, soil $\mathrm{pH}$, soil organic carbon, and predation rate. Each plot was of circular shape with a $25 \mathrm{~m}$ radius $\left(1963.5 \mathrm{~m}^{2}\right)$. More information on the spatial arrangement of the land-use types is published in Martin et al. (2020a).

\subsubsection{Trees}

We sampled trees between September 2018 and January 2019 on all land-use types with tree presence (old-growth forest, forest fragment, forest- and fallow-derived vanilla agroforest, and woody fallow) and received access to 58 plots overall (all except two fallowderived vanilla agroforest). In each plot, we did a full inventory of all trees with free-standing stems with $\geq 8 \mathrm{~cm}$ of diameter at breast height, also including arborescent palms, herbs and tree ferns but excluding lianas. We identified all living tree individuals with the help of one local expert and one taxonomic expert from Missouri Botanical Garden in Antananarivo and derived information on origin and endemism for each species according to the Tropicos Madagascar Catalogue (Missouri Botanical Garden, 2019). We recorded a total of 5484 single or multi-stemmed tree individuals, belonging to 455 (morpho-) species of which 279 (61\%) were endemic. Mean plot level species richness ranged from 10.2 species in woody fallows to 64.5 species in old-growth forest. For more details on habitat structure, tree diversity and community composition, see Osen et al. (in review).

\subsubsection{Herbaceous plants}

We sampled herbaceous plants within eight subplots of $4 \mathrm{~m}^{2}$ each (32 $\mathrm{m}^{2}$ overall). In each subplot, we assessed all vascular plant species that did not have apparent wood at maturity. For each assessed species we determined the species endemism using the Tropicos Madagascar Catalogue (Missouri Botanical Garden, 2019). In total, we recorded 44248 plants belonging to 355 (morpho-) species of which 60 were endemic. We detected the lowest plotlevel mean species richness in forest fragments $(14.1 \pm 6.6)$ and the highest in rice paddies (49.4 \pm 7.6$)$. For more details on sampling methods and herbaceous plants communities see Raveloaritiana et al. (in review). 


\subsubsection{Birds}

We sampled birds during two 40 min point counts per plot. We conducted one point count during the main breeding season in 2017 (September-December) and a second one between August and December 2018, resulting in an observation time of 80 min per plot. In the oldgrowth forest plots, we conducted all point counts with the same method in 2018 but left at least 11 weeks between two point counts in the same plot (August 2018 and December 2018). We excluded observations in flight and outside the plot. We defined bird endemism as species only occurring in the country of Madagascar according to BirdLife species fact sheets. Within the plots, we detected 2506 birds belonging to 57 species of which 31 were endemic. Mean plot-level species richness per land-use type ranged from $2.9( \pm \mathrm{SE})$ species in rice paddy to $12.3( \pm \mathrm{SE})$ species in old-growth forest. More details about sampling methods and bird communities in Martin et al. (2020a).

\subsubsection{Amphibians and reptiles}

We sampled amphibians and reptiles using repeated time-standardized search walks of 45 min each by two observers in each plot during the driest (October - December 2017; AugustDecember 2018) and wettest period (January - April 2018 and February 2019). During the walk, we systematically searched the complete plot in zig-zag pattern. We visited each plot three times during the day and three times at night. The diurnal visits were between 08:00 and 17:00; the nocturnal visits were between 18:30 and 23:00. We actively checked microhabitats (e.g rocks, leaf axils, tree barks, tree holes, leaf litter, or dead wood) to detect individuals hiding therein. Upon encountering an individual, we stopped the standardized search time and identified the individual to species level following Glaw \& Vences (2007). For individuals where a morphological identification proved difficult, we took DNA samples that we used to determine the species. Overall, we detected 58 species of amphibians and 61 species of reptiles. More information in Fulgence et al. (in prep.).

\subsubsection{Butterflies}

We sampled butterflies with fruit trapping and time-standardized netting between August and December 2018. We baited fruit traps (cylindrical nets) with fermented bananas and deployed them for 24 hours. Bananas were fermented for 48 hours prior to deployment in an air-tight container. On each plot, we installed eight fruit traps. We deployed four fruit traps $16.6 \mathrm{~m}$ from the center in the four cardinal directions from the plot center and an additional four fruit traps at $20 \mathrm{~m}$ from the center in the four intercardinal directions. During the time-standardized netting, we caught butterflies for 30 minutes while walking at 
slow and steady speed in a zigzag line from plot edge to plot center to cover the plot area equally and interrupted the 30 minutes search-time when handling butterflies. We only performed time-standardized netting in dry and non-windy conditions either in the morning (8 am-12 pm) or afternoon (1-5 pm). We caught butterflies only within an imaginary $2 \mathrm{~m}$ box on each side of the sweep-net. Irrespective of the sampling method, we collected all captured butterflies, dried them and took them to the lab for identification (moths excluded). We defined butterfly endemism as species/morphospecies only occurring in the country of Madagascar according to Lees et al. (2003), including manual updates by David Lees. We identified butterflies to species level in the laboratory. We defined endemic butterflies as butterfly species that are only present in the country of Madagascar. With both methods combined, we collected 2643 individual butterflies belonging to 88 (morpho-) species of which 46 species were endemic. Mean plot-level species richness per land-use type ranged from 5.1 (in forest fragment) to 11.3 (in forest-derived vanilla) species.

\subsubsection{Ants}

We sampled ants on all plots except the old-growth forest plots between October and December 2017, and in the old-growth forest in August and December 2018. We sampled ground-foraging ants using bait and pitfall traps. In each plot, we established five sampling stations: one at the plot center, and four at $16 \mathrm{~m}$ away from the plot center in each cardinal direction. At each sampling station, we set bait and pitfall traps $10 \mathrm{~m}$ apart. For bait traps, we put sardine and sugar as bait on two different white flat plastic plates (diameter of 13 $\mathrm{cm}$ ) about $5 \mathrm{~cm}$ apart. We set bait traps for 30 minutes and collected ants thereafter for 30 seconds. For pitfall traps, we buried a plastic cup $(9 \mathrm{~cm}$ top diameter, $11 \mathrm{~cm}$ deep, $6 \mathrm{~cm}$ bottom diameter), one-third filled with 70-\%-alcohol and a few drops of soapy water in the soil. We set pitfall traps for 48 hours. We preserved ant specimens in a tube with $70-\%$ alcohol. We identified ants to species/morphospecies level in the laboratory. We defined endemic ants as ant species that are only present in the country of Madagascar. With both methods combined, we collected 128 (morpho-)species of which 58 were endemic. Mean plot-level species richness per land-use type ranged from 0.3 to 9.6 species.

\subsubsection{Above-ground carbon}

We estimated aboveground carbon stocks (in $\mathrm{MgC} / \mathrm{ha}$ ) based on above ground biomass values derived from the tree inventory data (see tree section). To calculate these, we used the pantropical allometric model by Chave et al. (2014) with 'diameter at breast height' (DBH; at $1.3 \mathrm{~m}$ ), tree height and wood density as input data. Therefore, we measured the DBH and 
height for each tree individual, following a standardized protocol (Condit, 2008). Additionally, we derived wood density data for all trees, using either a Pilodyn wood tester, or retrieved wood density values from the global wood density database (Chave et al., 2009). For palms, tree ferns, bananas (Musa sp.) and traveller palms (Ravenala madagascariensis) we used different allometric equations to estimate aboveground plant biomass, based on literature (for further details, see Soazafy \& Osen et al in prep). We obtained aboveground carbon stocks by multiplying the estimated aboveground plant biomass by 0.5 , based on the assumption that plant biomass is $50 \%$ carbon (Chave et al., 2005). Mean plot level aboveground carbon stocks ranged from $5 \mathrm{Mg} / \mathrm{ha}$ in woody fallows to $178 \mathrm{Mg} / \mathrm{ha}$ in old-growth forest. For more details on sampling methods and aboveground carbon analysis, see Soazafy et al. (in prep.).

\subsubsection{Soil organic carbon}

We took soil samples with a MacFadyen soil corer ( $5 \mathrm{~cm}$ diameter, 0-15 cm depth, $295 \mathrm{ml}$ volume) between October and December 2017 in 10 villages and between August and September 2018 in Marojejy National Park. We took two mixed samples on each plot. Each mixed sample stemmed from four soil cores from four locations; the first mixed sample from four locations at $16.6 \mathrm{~m}$ from the plot center in all four cardinal directions and the second mixed sample from four locations at $8.3 \mathrm{~m}$ from the plot center in all four intercardinal directions. We stored each soil sample in a zip-lock bag until laboratory analysis.

Given that an overall 'simple' soil indicator is often not very meaningful (Bünemann et al., 2018), we decided to focus on soil organic carbon as a widely applied soil property (Bünemann et al., 2018) for comparison. Soil organic carbon is a proxy for soil matter turnover and soil physical properties (Bünemann et al., 2018). Here, we defined plots with a higher soil organic carbon content to provide higher ecosystem functions.

We processed soil samples in the laboratory to acquire soil organic carbon values of all 160 mixed samples. We dried the soil at $70^{\circ} \mathrm{C}$ and grounded it. We assessed the total organic carbon (C) concentrations (mmol/gTB) using a C/N elemental analyser (Vario EL III, elementar, Hanau, Germany) and calculated the mean of the two mixed samples per plot. Lab methods followed Hertel (2011).

\subsubsection{Predation rate}

We assessed predation rates using artificial caterpillars made from plasticine. The standardised design of the caterpillars allows for the measurement and comparison of relative 
predation rates across land-use types (Howe et al., 2009). In this experiment, we deployed the dummy caterpillars in the plots for 48 hours and calculated predation rates for each plot based on the ratio of dummies that were attacked by predators to the number of dummies that remained untouched. Mean predation rates ranged from $21.2 \% \pm 6.0 \%$ (mean $\pm S E$ ) in rice paddies to $47.6 \% \pm 6.0 \%$ in forest fragments. Ants were main drivers of predation across land-use types with orthoptera contributing considerably to total predation in forested land-use types. The contribution of Vertebrates like birds or rodents to the total predation remained low throughout this experiment. More details are published in Schwab et al. (2020).

\subsubsection{Ecosystem services: natural products and water regulation}

We interviewed 322 households in 10 villages to quantify ecosystem services. We collected data in the same 10 villages where the plots were situated (SI Chapter 8, Figure 12.12) and interviewed mainly randomly-selected households that participated in our baseline study (233 of 322; Hänke et al., 2018). The remaining 89 households were not randomly selected and did not take part in the baseline study.

We first asked the head of each household if they had access to each land-use type (same land-use types as for plots, except for vanilla which we did not separate into fallow- and forest-derived for these interviews). For old-growth forest, forest fragment, and each landuse type that the household had access, we asked the respondent to name all the benefits they get. From their responses, we defined natural products as the following responses: charcoal, firewood, plants for construction, weaving materials, lianas for string making, livestock fodder, wild food, honey, and medicinal plants. These responses constitute nonfarmed goods, thereby representing a provisioning ecosystem service. We also considered all responses related to water: water retention, water infiltration, and interception of precipitation (except provisioning of clean water).

We then derived a single measure for all-natural products and water-related responses because many of the products were only rarely cited. To do so, we summed up all products derived from each land-use type in each village and divided the figure with the number of households that had access to that land-use type. This resulted in one access-corrected value per land-use type per village. Similarly as for the natural products, we divided the number of people who cited they derived water regulation services from each land-use type by the number of households that had access to that land-use type in that village. Again, this 
resulted in one access-corrected value per land-use type per village. For data analysis, we treated the two ecosystem services as functions for simplicity.

\subsubsection{Agricultural productivity: profitability and yields}

We used data of 109 households dispersed in 10 villages, from a previous sample of 1,800 households in 60 villages (Hänke et al., 2018). We collected data from three stages: i) baseline survey in 2017 (Hänke et al., 2018); ii) longitudinal survey from October 2017 to October 2018; iii) field-plot measurements and recall survey between October 2018 and March 2019.

For the longitudinal survey, we transformed our questionnaires into pictograms that the household head filled in bi-weekly over one year. This provided information on total family labour, expenses and revenues of vanilla and rice farming, thus not covering profits generated from non-agricultural activities like forest use.

As farmers tend to overestimate their land area (Hänke et al., 2018), we measured the actual size of each plot of vanilla, paddy rice and hill rice that the 109 households farm on in-situ, by using a GPS device. While walking around the perimeter of each plot with the field owner, we also asked questions about the plot's history and agricultural production. Moreover, we conducted a cross-sectional survey to get information about farming inputs and outputs during last cultivation.

We calculated three parameters of agricultural productivity: harvest per unit of area, net income per unit of area and net income per unit of labour. Net income is the difference between gross income and total costs. Gross income is the harvest multiplied by the median price surveyed $\left(165,000 \mathrm{MGA} \mathrm{kg}^{-1}\right.$ for green vanilla beans and 1,300 $\mathrm{MGA} \mathrm{kg}^{-1}$ for brown rice). Costs include values of seeds, fertilizers and pesticides used, hired labour wages, inkind costs for labour, other cash costs directly related to production, and depreciation of materials. We didn't value non-paid labour (family labour and exchange labour) as costs. However, we calculated net income per person-day by dividing net income to non-paid labour. We further considered one person-day to be equivalent to eight working hours and converted working hours into adult male equivalents (McConnell et al., 1997).

\subsubsection{Calculation of multidiversity and multifunctionality}

We calculated multidiversity and multifunctionality to unify multiple indicators for biodiversity, endemic biodiversity, and ecosystem functions into a single value (Manning et al., 2018). We computed multidiversity and endemic multidiversity for each land-use type 
based on plot-level species richness data of seven taxonomic groups (trees, herbaceous plants, birds, amphibians, reptiles, butterflies, and ants) covering plants, vertebrates, and invertebrates. For all species groups, we defined 'endemic' as occurring in the country of Madagascar (more details on the definition and sources for the endemic-classification for each species group can be found in the respective sections). Analogously to multidiversity, we calculated multifunctionality for each land-use type from three ecosystem functions (above ground carbon, soil organic carbon, and predation rate) measured on the plot level and two ecosystem services (natural product provisioning and water regulation) assessed through interviews. Thereby we combined measures for ecosystem function multifunctionality and ecosystem service multifunctionality (sensu Manning et al., 2018) into a single measure: multifunctionality. We opted for this approach because, firstly, we had limited data available for either ecosystem function multifunctionality or ecosystem service multifunctionality alone, which would have led to potentially biased measures (Garland et al., 2020). Secondly, we refrained from deriving to indicators from the same dataset (e.g. two soil variables) to keep indicators as independent as possible (Garland et al., 2020), except for natural product provisioning and water regulation which are derived from the same interviews.

Multidiversity and multifunctionality is commonly calculated using a thresholding approach (Manning et al., 2018). The basic idea behind this approach is that to fulfil a function or service, a taxa or services needs to occur in a sufficient extent to provide that service. Multidiversity or multifunctionality is then expressed as the proportion of functions or taxonomic groups that exceed an a priori defined threshold, as compared with the maximum reached performance level (Manning et al., 2018). To circumvent the definition of an arbitrary threshold, researchers often use a multi-threshold approach, running the analysis for each threshold between 0-100\% (Manning et al., 2018). Here we have computed multidiversity and multifunctionality with all thresholds but chose to display the $50 \%$ threshold result in the main text (Figure 8.3) while results for $20 \%$ and $80 \%$ thresholds are only displayed in the Supporting Information (SI Chapter 8, Figure 12.14). We chose to most prominently display the $50 \%$ threshold as diversity effects on ecosystem functioning peak at the $50 \%$ threshold (Lefcheck et al., 2015), but we display the results at a $20 \%$ and $80 \%$ threshold in the Supporting Information (SI Chapter 8, Figure 12.14).

To operationalize this approach, we first calculated the maximum reached performance level as the average of the five highest recorded values across all 80 plots, allowing us to reduce the influence of potential outliers. Importantly, the five highest recorded values are 
not limited to a single land-use type, so the average of the five highest recorded values may stem from three old-growth forest plots and two forest fragment plots. We then calculated how many evaluated taxa / ecosystem functions reached the threshold on each plot, resulting in a single value per plot. For example, in a plot that reached a multidiversity value of 0.75 at the $50 \%$ threshold, $75 \%$ of all evaluated taxa reached a minimum of $50 \%$ of species richness compared to the average of the 5 plots of any land-use type with most species of that taxa. This approach follows (Grass et al., 2020).

To visualize multidiversity, endemic multidiversity, multifunctionality, and individual measures of agricultural productivity per land-use type, we standardized all variables to a common scale according to the following formula: $\mathrm{STD}=\left(X-X_{\text {mean }}\right) /\left(X_{\text {sD }}\right)$. We then calculated the mean for each variable for each land-use type (Figure 8.2) to provide an overview across the seven land-use types. To visualize multidiversity, endemic multidiversity and multifunctionality along the land-use trajectory (Figure 8.3), we calculated mean and standard error for each variable at each stage on the land-use trajectory.

\subsubsection{Assessment of conservation opportunities}

We defined conservation opportunities as distinct stages along a land-use trajectory where land-users face alternative land-use options with potentially contrary outcomes. Importantly, different conservation opportunities exist at the same point in time due to various current land-use types that are placed at different stages along the trajectory. In the case of north-eastern Madagascar, each conservation opportunity has three possible outcomes: conservation of the present state and two contrasting land-use transformations. Therefore, each conservation opportunity has distinct trade-offs and opportunities, depending on land-use decisions. The frequency at which each conservation opportunity occurs may vary through time: as old-growth forest vanishes, conservation opportunity 1 , where old-growth forest is at risk of being transformed, will become less common, signifying a closing window of opportunity.

We investigated multiple taxa, ecosystem functions and services, and agricultural productivity at each conservation opportunity to comprehensively assess trade-offs and win-wins between them (Figure 8.4). For each taxon, ecosystem service, and farming outcome (see above for study design and data collection), we considered the difference to the current land-use as the outcome of a decision. We visualized the standardized data by calculating the difference in the mean of each variable to the mean of that variable at the current stage in the land-use trajectory. Similarly, we calculated the error bars in Figure 8.4 as the square- 
root of the sum of the squared standard deviation of the variable under the current stage and the squared standard deviation of the variable under the alternative stage.

We processed and visualized all data in R version 3.6.2 (R Core Team, 2019).

\subsection{Acknowledgements}

General: We thank members of the Diversity Turn in Land Use Science project for discussions and feedback, all involved farmers and chef de fokontany for their support, and the Ministry of Environment and Sustainable Development for research permits (Nº100/17/MEEF/ SG/DGF/DSAP/SCB.Re, N¹63/17/MEEF/SG/DGF/DSAP/SCB.Re, Nº18/18/MEEF/SG/DGF/DSAP/SCB.Re, \& N²54/18/MEEF/ SG/DGF/DSAP/SCB.Re). We are grateful to Theudy Alexis, Patrice Antilahimena, Evrard Benasoavina, Claudine Bemamy, Jean Chrysostome Bevao, Ronik Botra, Dietrich Hertel, David Lees, Marie Berthine Maminirina, Thorien Rabemanantsoa, Julien Randriampenomanana, Cédric Randrianantenaina, Nantenaina Herizo Rakotomalala, Eric Rakotomalala, Gatien Rasolofonirina, Joel Razafinantenaina, Grimo Jaona Sedric, Jacqueline Estenie Soa, Sáfián Szabolcs, Guillaume Velotody, Miguel Vences, and Maria S. Vorontsova who contributed to data collection, sample identification, or sample processing, and to our logistics manager Soavita Fenohaja Babarezoto. Funding: Niedersächsisches Vorab of Volkswagen Foundation (Grant number 1176251-99-35/13 (ZN3119)) and German Academic Exchange Service (DAAD) within the 'Partnerships for Supporting Biodiversity in Developing Countries' initiative (Project Nr. 57449386). NG-R thanks the Dorothea Schlözer Postdoctoral Programme of the University of Goettingen for their support. Author contributions: DAM, IG, DH, KO, TT, AW, \& HK conceived the plot design. FA, HA, JB, \& HH designed the farming surveys. DAM, TRF, KO, MRS, \& AW selected plots. DAM, RA, FA, SD, TRF, HH, KO, AANAR, RR, ER, DS, MRS, \& AW collected and processed data. All authors designed methods. DAM devised the initial concept of the paper. DAM analysed the data with input by IG, NG-R, DCZ, \& HK. DAM wrote the initial draft of the manuscript. All authors revised the draft. Competing interests: The authors have no competing interests to declare. 


\title{
9 Abstracts of additional manuscripts
}

During the course of my PhD, I contributed to seven further manuscripts led by colleagues within the Diversity Turn project. Some of these manuscripts have been published already, some are under revision, and others are still in the process of being compiled. I list all abstracts of these manuscripts in this chapter as I also discuss findings from these manuscripts in the synthesis (Chapter 10).

\subsection{Land-use history determines habitat structure and tree diversity in tropical agroforestry}

Kristina Osen, Marie Rolande Soazafy, Dominic Andreas Martin, Annemarie Wurz, Adriane März, Hery Lisy Tiana Ranarijaona, Dirk Hölscher

Contribution: Conceptualization, Validation, Writing - review \& editing

Status: Revised manuscript under review in Applied Vegetation Science.

\begin{abstract}
:
Question: In human-modified tropical landscapes, agroforestry is considered a promising land use to reconcile biodiversity conservation with production goals. The role of agroforests in regard to conservation may strongly be influenced by land-use history, however few studies have explicitly investigated this. We thus tested the importance of land-use history for habitat structure and tree diversity in vanilla agroforests situated in a human-modified tropical landscape.

Location: Marojejy National Park and smallholder mosaic landscape of north-eastern Madagascar.
\end{abstract}


Methods: We studied tree stand structure, diversity and composition in vanilla agroforests of contrasting land-use history, old-growth forests, forest fragments and woody fallows after slash-and-burn agriculture, which all contribute to the smallholder mosaic landscape of north-eastern Madagascar. The vanilla agroforests were either derived directly from forest or otherwise from woody fallows after slash-and-burn agriculture.

Results: Land-use history strongly influenced tree species diversity and composition in vanilla agroforests and also affected stand structure. Forest-derived agroforests maintained high levels of tree species diversity and differed in community composition compared to fallow-derived agroforests, which sustained relatively low levels of tree diversity. Additionally, forest-derived vanilla agroforests harboured a significantly higher percentage of endemic species than fallow-derived agroforests, and shared many species with old-growth forests and forest fragments. Fallow-derived vanilla agroforests harboured a lower percentage of endemic species than woody fallows.

Conclusion: Considering the land-use history of agroforests is important to unfold their full potential as elements in a multifunctional human-modified landscape. Forest-derived agroforests are an alternative to forest conversion through slash-and-burn agriculture and have the potential to sustain high levels of species diversity and important habitat structures. In contrast, fallow-derived agroforests regain stand structure on degraded formerly forested land and thereby have the potential to increase canopy cover and connectivity at the landscape scale.

Keywords: land-use history, conservation, old-growth forest, human-modified landscape, endemism, forest fragments, Madagascar, vanilla agroforestry, stand structure, tree diversity 


\subsection{Land-use intensification increases richness of native and exotic her- baceous plants, but not endemics, in Malagasy vanilla landscapes}

Estelle Raveloaritiana, Annemarie Wurz, Ingo Grass, Kristina Osen, Marie Rolande Soazafy, Dominic Andreas Martin, Lucien Faliniaina, Nantenaina H. Rakotomalala, Maria S. Vorontsova, Teja Tscharntke, Bakolimalala Rakouth

Contribution: Conceptualization, Funding acquisition, Project administration, Validation, Writing - review \& editing

Status: Under revision for Diversity and Distributions.

\section{Abstract:}

Aim: North-eastern Madagascar is a hotspot of plant diversity, where vanilla and rice farming are driving land-use change, the latter including slash-and-burn management. However, it remains unknown how land-use change and land-use history affect richness and composition of endemic, native and exotic herbaceous plant species.

Location: North-eastern Madagascar

Methods: We assessed herbaceous plants along a land-use intensification gradient ranging from unburned land-use types (i.e. old-growth forest, forest fragment and forest-derived vanilla agroforest) to burned land-use types (i.e. fallow-derived vanilla agroforest, woody fallow and herbaceous fallow) and rice paddy. We compared land-use types and analysed the effects of land-use history, canopy closure and landscape forest cover on species richness. Additionally, we analysed species compositional changes across land-use types.

Results: Across 80 plots, we found 355 plant species (180 native non-endemics, 57 exotics, 60 endemics and 58 species of unknown origin). Native and exotic species richness increased with increasing land-use intensity, whereas endemics decreased. Unburned landuse types had higher endemic species richness ( $4.28 \pm 0.37$ [mean \pm SE]) than burned ones (2.4 \pm 0.21$)$. Exotic and native species richness, but not endemics, decreased with increasing canopy closure. Landscape forest cover reduced exotic, but not native or endemic richness. Species composition of old-growth forests was unique compared to all other land-uses and only forest-derived, not fallow-derived vanilla agroforests, had a similar endemic species composition to forest fragments.

Main conclusions: Our results indicate that old-growth forests and forest fragments are indispensable for maintaining endemic herbaceous plants. We further show that the land-use 
history of agroforests should be considered in conservation policy. In forest-derived vanilla agroforests, management incentives are needed to halt loss of canopy closure. In conclusion, considering species origin (endemic, native and exotic) and composition is essential for the identification of suitable management practices to avoid irreversible species loss.

Keywords: Herbaceous plants, land-use history, Madagascar, slash-and-burn, species origin, vanilla agroforest 


\title{
9.3 Spider traps amphibian in north-eastern Madagascar
}

Thio Rosin Fulgence, Dominic Andreas Martin, Holger Kreft, Fanomezana M. Ratsoavina, Aristide Andrianarimisa

Contribution: Conceptualization, Funding acquisition, Project administration, Investigation, Validation, Writing - review \& editing

Status: Published in Ecology and Evolution; https://doi.org/10.1002/ece3.7102

\begin{abstract}
:
Predation can take unexpected turns. For instance, various invertebrate species - most commonly spiders - may prey on vertebrates. Here, we report one observation of a spider (Sparassidae, Damastes sp.) feeding on an amphibian (Hyperoliidae, Heterixalus andrakata) inside a retreat in north-eastern Madagascar. To our knowledge, this is the second report of vertebrate predation by spiders in Madagascar. Three additional observations of retreats built by the same spider species show that the spiders built similar retreats and were hiding at the rear end of the retreat. The retreats were built by weaving two green leaves together which were still attached to the tree. We speculate from the observations that the retreat serves as a targeted trap that deceives frogs seeking shelter during daytime.
\end{abstract}

Key words: Heterixalus andrakata, Amphibian, Spider, Predation, Behavior, Madagascar 


\subsection{Decreasing predation rates and shifting predator compositions along a land-use gradient in Madagascar's vanilla landscapes}

Dominik Schwab, Annemarie Wurz, Ingo Grass, Anjaharinony A. N. A. Rakotomalala, Kristina Osen, Marie Rolande Soazafy, Dominic Andreas Martin, \& Teja Tscharntke

Contribution: Conceptualization, Project administration, Validation, Writing - review \& editing

Status: Published in Journal of Applied Ecology; https://10.1111/1365-2664.13766.

Abstract:

1. Land-use change is the main driver of deforestation and land degradation resulting in the loss of biodiversity and ecosystem functioning in north-eastern Madagascar. Vanilla, the region's main cash crop, is grown in agroforestry systems and may provide an opportunity for the conservation of biodiversity and ecosystem functioning.

2. We used dummy caterpillars to assess predation rates and predator communities along a land-use gradient including unburned old-growth and forest fragments, herbaceous and woody fallows after shifting cultivation with fire usage, as well as rice paddies. The studied vanilla agroforests were either forest-derived or fallow-derived. Besides landuse type, we considered the effects of land-use history (unburned/burned), plot-level parameters and the landscape composition to conclude on management recommendations.

3. Old-growth forest and forest fragments exhibited highest predation rates, which decreased with land-use intensity. Overall, predation was higher in unburned land-use types than in more open, previously burned habitats, and rice paddies. High stem and vegetation densities were positively related to predation rates, but decreased with landuse intensity. High forest cover in the surrounding landscape led to higher predation rates, while local structural parameters remained more important.

4. The predator community was arthropod-dominated across all land-use types with ants responsible for between $33 \%$ and $69 \%$ of all predation events. Overall predator composition in old-growth and forest fragments differed from all other land-use types. Predation by Gryllacrididae (Orthoptera) was lower in all land-use types, including forestderived vanilla, than in old-growth forest and forest fragments, where they were important contributors to total predation. Vertebrate predation was low throughout. 
5. Synthesis and applications. Forested habitats feature higher predation rates and different predator compositions than other land-use systems. Maintaining or restoring treeand understory-rich vanilla agroforestry represents a viable tool in landscape conservation programmes as it has the potential to contribute to the conservation of predation as an important ecosystem function in both forest- and fallow-derived agroforests. However, vanilla agroforestry has limited value in conserving forest-specialised predator communities. While the establishment of tree-rich agroforests on former fallow land is favourable for conservation ecosystem functioning, further forest transformation should be avoided.

Keywords: conservation, ecosystem functioning, dummy caterpillars, land-use history, Madagascar, predation, shifting cultivation, vanilla agroforestry 


\subsection{Aboveground biomass carbon in Madagascar's vanilla production landscape - exploring rehabilitation by agroforestry in the light of land-use history}

Marie Rolande Soazafy*, Kristina Osen*, Dominic Andreas Martin, Annemarie Wurz, Hery Lisy Tiana Ranarijaona \& Dirk Hölscher

* These authors contributed equally to this work.

Contribution: Conceptualization, Project administration, Validation

Status: In preparation.

Abstract:

Forests and tree-dominated land uses produce large quantities of aboveground plant biomass and therefore play an important role in the global carbon cycle. Especially in tropical landscapes, aboveground biomass carbon stocks are strongly influenced by land cover and land-use changes. Agroforestry has the potential to maintain or restore carbon in plant biomass but the amount will be influenced by various factors that may include land-use history, biodiversity and canopy cover. However, few studies explicitly address these factors and their role in the carbon context. With our study we aim (a) to assess aboveground biomass carbon stocks and its components across different tropical land-use types, and (b) to disentangle direct and indirect influences of land-use history, stand structure and tree diversity on aboveground carbon stocks in agroforestry systems. The study was implemented in the mosaic landscape of north-eastern Madagascar in old-growth forest, forest fragments, woody fallows and vanilla agroforests. The agroforests differed in land-use history and were either derived directly from forest or derived from woody fallows after slash-andburn agriculture. Aboveground carbon stocks were highest in old-growth forest and lowest in woody fallows. Aboveground carbon stocks in vanilla agroforests were highly variable whereas fallow-derived agroforests stored significantly less carbon than forest-derived agroforests. Within the agroforests, the effect of land-use history on aboveground carbon was mainly mediated by tree basal area, which was also the main direct factor to control aboveground carbon, whereas tree diversity and canopy closure played a minor role. However, the local and biological importance of taxonomic and functional tree diversity calls for strategies that safeguard habitat, biodiversity and ecosystem services. In conclusion, forest-derived agroforests support higher carbon stocks than fallow-derived agroforests and have the potential to maintain a relatively high carbon stocks in the landscape, whereas fallow- 
derived agroforests contribute to take degraded land out of the slash-and burn cycle and restore carbon stocks. 


\subsection{Fallow lands and forest fragments are essential for plant use and ecosystem service provisioning in a tropical agricultural land- scape}

Estelle Raveloaritiana, Annemarie Wurz, Ingo Grass, Kristina Osen, Dominic Andreas Martin, Marie Rolande Soazafy, Claudine Bemamy, Hery Lisy Tiana Ranarijaona, Holger Kreft, Dirk Hölscher, Bakolimalala Rakouth, Teja Tscharntke

Contribution: Conceptualization, Project administration, Validation, Writing - review \& editing

Status: In preparation.

\section{Abstract:}

Tropical forests have been modified into agricultural land in many countries through sifting cultivation and this threaten both biodiversity and ecosystem services. Shifting cultivation often results in fallow lands which are usually considered as wasteland or useless. Here we investigate the ecosystems services provided by shifting cultivations lands incorporated into other prevalent land-use types which are old-growth forest, forest fragment, vanilla agroforest, woody fallow, herbaceous fallow and rice paddy within the vanilla production landscapes of north-eastern Madagascar. We interviewed 322 households across 10 villages in north-eastern Madagascar and we asked the ecosystem services (benefits) provided by land-use types to each household (excluding the main crop yield). We also asked names of plant species used and harvest location for seven use categories: medicine, food, construction, firewood, charcoal, forage and weaving. We analysed the importance of land-use types in terms of ecosystem service based on the benefits mentioned, the harvest location of plant used for all categories and the diversity of species harvested. We found that old-growth forest and forest fragment were important for regulating while all other land-use types were mainly important for provisioning services. Woody fallow was named most for the collection of plants and also showed the highest multi-use since it provided plants for all categories. In terms of species used, woody fallows and forest fragments had the highest number of species used per village. We also found that the proportion of endemic species harvested from forest fragment was the higher than in all other land-use types. Rice paddy and herbaceous fallow were used to collect most cited herbs species, forest for most cited woody plants and woody fallow for both herbs and woody plants. Based on these results, woody fallows with forest fragments are essential for households on providing plants for multiple 
uses and ecosystem services despite its little value for crop production. Thus, most products are derived from the agricultural landscapes' matrices while old-growth forests are only valuable for non-material services as it is illegal to collect plant products from protected areas. This highlights that woody fallows need to be included in ecosystem service and land management schemes since local people continue to depend on an extensive and diverse set of plant species for living.

Key words: human-modified landscape, woody fallow, ecosystem services, plant uses, plant diversity 


\subsection{Socio-economic, land use and value chain perspectives on vanilla farming in the SAVA region (north-eastern Madagascar): the Diver- sity Turn Baseline Study (DTBS)}

Hendrik Hänke, Jan Barkmann, Lloyd Blum, Yvonne Franke, Dominic Andreas Martin, Janna Niens, Kristina Osen, Viviana Uruena, S. Annette Witherspoon, \& Annemarie Wurz

Contribution: Conceptualization, Validation, Writing - review \& editing

Status: Published in DARE Diskussionsbeiträge, http://hdl.handle.net/10419/183584.

Abstract:

The SAVA region in north-eastern Madagascar is the global centre of vanilla production. Here, around 70,000 farmers are estimated to produce $70-80 \%$ of all global bourbon vanilla. Yet, little is known about the farming population, their livelihoods, and the impact of vanilla cultivation on biodiversity.

This publication presents the results of the Diversity Turn Baseline Survey (DTBS) that was conducted in 2017. The survey provides baseline data on the socio-economic characteristics and living conditions of the local population, and farming of vanilla as well as the most important other crops ( $\mathrm{N}=1,800$ households). As international demand for natural vanilla has increased considerably, special emphasis is placed on the vertical integration of vanilla farmers into the global vanilla value chain. This integration is increasingly accomplished through contract farming arrangements between vanilla farmers, collectors and exporters. After a first rise in vanilla prices in 2015, the current vanilla boom took off in 2016 and was still in full swing in 2017. Consequently, the start of the price boom coincides with this survey and its retrospective questions often address the situation in 2016. The large majority of the surveyed households (HHs) in the study region practice vanilla farming (83\%). Of these, only $15 \%$ conclude formal contracts while the majority of farmers (63\%) sell their vanilla in informal spot markets often depending on several middlemen. Our data show that the socio-economic situation of smallholder vanilla farmers has recently improved when considering vanilla prices received, education, access to electricity and ownership of assets. However, under the high vanilla prices, theft and crime are now key constraints for vanilla farmers.

In addition to descriptive statistics, this publication compares selected data between maleand female-headed HHs, poor and non-poor HHs, and HHs with- and without contracts. 
Members of female-headed HHs have significantly lower education, lower labour availability, smaller fields and lower vanilla harvests than male-headed HHs. HHs with contracts possess more assets, are better educated, have higher labour availability, larger vanilla plots, and larger vanilla harvests than HHs without contracts.

The DTBS confirms a number of benefits for smallholders who conclude contracts with vanilla exporters or collectors. Among these benefits are the significantly higher vanilla prices even during market peaks. However, the distribution of HHs with or without contracts is skewed indicating entry barriers for certain groups of smallholders. For example, femaleheaded HHs were significantly less likely to have a contract than male-headed HHs, and it appears that HHs with a contract had already been less poor than HHs without a contract prior to entering contract arrangements. 


\section{Synthesis}

Considerable efforts have been undertaken to study biodiversity, ecosystem services, and yields in tropical agroforestry systems, particularly so in coffee and cacao (reviewed in: De Beenhouwer et al., 2013; Miller et al., 2020; Niether et al., 2020; Tscharntke et al., 2011). For vanilla, however, next to nothing has been published to date. For instance, a search on Google Scholar for the term 'vanilla agroforest OR vanilla agroforestry' yielded only 15 results (Including six results that form part of this thesis; search on $25^{\text {th }}$ of November 2020), while the same search with 'coffee' and 'cocoa' had 3720 and 1890 results, respectively. This is despite the importance of vanilla agroforestry as a land use and as an income source in the biodiversity hotspots of north-eastern Madagascar (FAO, 2020; Hänke et al., 2018; SVI, 2020) and in other tropical biodiversity hotspots, such as Mexico (Borbolla-Pérez et al., 2017). With this thesis, I shed first light on this topic, but many open questions remain.

Additionally, I compare vanilla agroforestry to five other land-use types, namely old-growth forest, forest fragment, herbaceous fallow, woody fallow, and rice paddy. By doing so, I highlight the relative value of vanilla agroforestry compared to other prevalent land uses, which is key to determine their conservation value. Importantly, these land-uses are best understood along a land-use trajectory, with strong path-dependency (Chapter 8). This has important implications for conservation policy in the biodiversity hotspot of north-eastern Madagascar. However, the here-demonstrated trajectory approach is also applicable to ongoing land-use change elsewhere, thereby providing a conceptual advancement in the field. In this synthesis chapter, I firstly bring together the findings on biodiversity, ecosystem services, and yields in vanilla agroforests and give recommendations on how to farm vanilla in ways that benefit nature and people alike. In a second step, I zoom out to a landscape-scale 
and collate ideas on how to design policies that enable a sustainable land-use transformation in north-eastern Madagascar; a section ending with my personal vision for a sustainable future of the region. I then finish this synthesis chapter with a section on future research directions, before concluding on more than four years of research that has culminated in this thesis.

\subsection{How to farm vanilla in ways that benefits nature and people alike?}

Here, I firstly summarise findings of chapter 2,6 , and 7, showing how vanilla yields can be optimized without negative impacts for trees, which have been widely recognised to provide key ecosystem functions in agroforestry systems (Tscharntke et al., 2011). I then summarise our findings on the conservation value of vanilla agroforests, drawing on all chapters of this thesis. Taking those two sections together, I describe management and policy recommendation for vanilla agroforestry systems. Lastly, I outline how various policies could make the vanilla trade more equitable, which could itself contribute to more sustainable land-use in north-eastern Madagascar.

\subsubsection{Optimizing vanilla yields without impairing trees}

Across various agroforestry crops, research has commonly shown trade-offs between yields and canopy cover (Beer et al., 1998; Blaser et al., 2018), driving shade tree loss in agroforests across the tropics (Jha et al., 2014). Whether this is also the case for vanilla was so far unclear. Here we show that there are no trade-offs between shade-trees and yields in vanilla agroforests. We show this using a well replicated, but rather undetailed dataset from 209 vanilla agroforests (Chapter 6), as well as a detailed, but less replicated dataset from 30 vanilla agroforests (Chapter 7).

Why may this be so? Firstly, plant physiological experiments have shown that vanilla responds weakly to light (Díez et al., 2017), as may be expected for an orchid growing naturally in humid forests of Central America (Correll, 1953). Secondly, yield responses to shade are not universal in other agroforestry crops either, as yields are not only dependent on light availability but are also influenced by factors that may profit from shade trees, such as pest control (Asare et al., 2019; Escobar-Ramírez et al., 2019) or soil fertility (Sauvadet et al., 2020; Tscharntke et al., 2011). This suggest a complex interplay of shade trees, light availability, pest control, soil fertility, and other factors in determining yields in agroforestry systems (Niether et al., 2020; Perfecto et al., 2014; Tscharntke et al., 2011). Depending on the circumstances, the response of yields to shade (i.e. canopy cover) may thus go either 
way, highlighting the importance of local context in assessing the potential of various farming practices. Thirdly, our results only describe yield responses to shade under the current range of growing regimes and may not be suitable to conclude on effects in more intensified systems, such as shade houses (Havkin-Frenkel \& Belanger, 2018), or in vanilla agroforests relying on inputs, such as fertilisers or pesticides.

Yields could, however, be optimized by planting vanilla pieds, the unit of support tree and vanilla vine, more densely (Chapter 6 and 7). Additionally, managing vanilla agroforests continuously, irrespective of price fluctuations, would be beneficial, as old (Chapter 6) and long (Chapter 7) vanilla vines yield well. Importantly, there is also no correlation between vanilla planting density and canopy cover (Chapter 6), and across taxa, only tree diversity is negatively associated with planting density in vanilla agroforests (Chapter 7). As a result, multidiversity of seven taxa is not negatively associated with yields (Chapter 7). It is thus possible to optimise yields in vanilla agroforests without impairing biodiversity, suggesting that commonly encountered trade-offs between biodiversity and yields (Phalan et al., 2014) or between biodiversity and profit (Grass et al., 2020) do not exist (more on biodiversity in 10.2).

Importantly, we also find that vanilla yields are independent of land-use history (Chapter 6 \& 7), in line with published results from cocoa agroforests in Cameroon (Nijmeijer et al., 2019). However, to what degree those results from Cameroon hold in other regions remains unknown, and no data is available for other agroforestry crops, such as coffee (Chapter 2). Taken together, these early results demonstrate that there is no inherent incentive to grow agroforestry crops like cocoa or vanilla in either forest- or open-land-derived agroforests. This is positive from a conservationist's perspective, as farmers who have both open-land and forest available for cultivation, are not incentivised to establish forest-derived agroforests, which degrade forests (Chapter 2), instead of open-land-derived agroforests. On the other hand, the finding that land-use history does not influence yields also does not drive farmers away from forest-derived agroforestry. Incentives may hence still be necessary to promote open-land-derived agroforests and to discourage the establishment of new forestderived agroforests to the benefit of biodiversity and ecosystem services (Chapter 2). Indeed, these incentives may be needed as establishing open-land-derived agroforests may be more expensive than establishing open-land-derived agroforests, at least for cocoa, where establishment costs were twice as high in open-land derived agroforests (Ruf, 2001). This questions whether agroforests may go from a deforestation agent in the $20^{\text {th }}$ century to a reforestation agent in the $21^{\text {st }}$ century, as hypothesized by the same author (Ruf, 2001). 
Importantly, our research on vanilla yields also has caveats. For instance, it is primarily applicable to the current range of management practices (rather extensive agroforests; no pesticide or fertilizers applied) and is thus not suited to derive management advice for highly intensified vanilla cultivation, such as shade houses (Havkin-Frenkel \& Belanger, 2018). Given the short-term nature of our data (two harvests in Chapter 6; one harvest in Chapter 7), we were not able to study the effects of precipitation and temperature on vanilla yields, and we could therefore not assess how yields in agroforests may respond to a changing climate. Indeed, climate smart agroforestry may provide a promising option for smallholder farmers to adapt to the impacts of climate change (Blaser et al., 2018; Vaast et al., 2016). In this context, I also hypothesize that water competition between shade-trees and crop trees in coffee and cocoa (Abdulai et al., 2018; Blaser et al., 2018), which may be amplified by climate change (Schroth et al., 2016), should be less of an issue for vanilla, as the orchid roots shallowly (Havkin-Frenkel \& Belanger, 2018). Given these limitations, more research is needed to elucidate the interplay between shade trees, management, climate change, and land-use history in driving vanilla yields in agroforestry systems and in more intensive plantations (see section 10.3 on ideas for future research).

In sum, our finding of the independence of yield and canopy cover is encouraging, as it suggests that there are no inherent trade-offs between yields, which are important for farmers, and trees, which are important for biodiversity and key ecosystem services.

\subsubsection{Conservation value of vanilla agroforestry}

The work in my $\mathrm{PhD}$ is some of the first shedding light on the conservation value of vanilla agroforests, thereby testing whether promised conservation benefits of agroforestry systems materialise (Bhagwat et al., 2008). Indeed, I am only aware of two other studies on the topic, both published recently (Hending et al., 2018, 2019). Firstly, the team around Hending showed that vanilla agroforests in the northern part of the SAVA region, in northeastern Madagascar, can be home to various lemur species, especially so if agroforests are close to natural forest (Hending et al., 2018). Secondly, the team showed, that traditionally managed vanilla agroforests retain some of the plant species richness found in adjacent forests (Hending et al., 2019). However, it remains unclear, whether the studied agroforests were forest- or fallow-derived (i.e. open-land-derived; Chapter 2), which represents an important distinction in Malagasy vanilla agroforestry in terms of conservation value (Chapters 2 - 5, \& 7-8). Hending et al. are not the only ones missing this important distinction: indeed only $43 \%$ of studies on tropical agroforestry systems described the land-use history 
of focal agroforests, and only $5 \%$ of assessed studies directly compared agroforests of contrasting land-use history (Chapter 2).

Through this thesis, I show that any policies aiming at making vanilla agroforestry in Madagascar more biodiversity-friendly should be sensitive to land-use history, to avoid adverse outcomes. This is because forest-derived agroforests typically represent a degradation of forest, whereas fallow-derived agroforests represent a rehabilitation opportunity (Chapter 2 ). The importance of land-use history is also reflected in data on various taxa (Trees, Abstract 9.1; herbaceous plants, Abstract 9.2; birds, Chapter 3; amphibians, Chapter 5; reptiles, Chapter 5; \& butterflies, Chapter 7) that me and my colleagues collected across 30 forestand fallow-derived agroforests. Across taxa, forest-derived vanilla agroforests are in average more species rich than fallow-derived agroforests (all above-mentioned taxa, except herbaceous plants and butterflies), but differences are not significant, except for trees and reptiles. In contrast, endemic species richness is significantly higher in forest-derived agroforests for four out of seven taxa, including endemic multidiversity. Amphibians, reptiles, and butterflies are the exceptions (Chapter 7). The difference between forest- and fallowderived agroforests also becomes apparent when assessing species composition: forest-derived agroforests did, for instance host a bird community most similar to forest fragments (Chapter 3). Similarly, amphibian and reptile communities in forest-derived vanilla agroforests are placed between forest fragments and fallow-derived agroforests on a NMDS-Plot (Chapter 5), underlining the important role of these agroforests in maintaining biodiversity in the agricultural mosaic landscape. These results are in line with one of the few other studies that collected biodiversity data in agroforests of contrasting land-use history: Nijmeijer et al. (2019) found species composition of perennial plant species to resemble the previous land-use of cocoa agroforests in Cameroon, either savanna or forest.

In a second step, we also analysed how plot-level species richness was correlated to various variable across agroforests, including yields. We found no correlation between vanilla yields and species richness across taxa, including multidiversity (except amphibians which exhibited a positive relationship, and butterflies, which exhibited a negative one; Chapter 7). Interestingly, the independence of yields and species richness also holds for endemic species and endemic multidiversity (except for reptiles; Chapter 7). These finding are in line with cocoa agroforests in Sulawesi, Indonesia, where species richness was also largely independent of yields (Clough et al., 2011), but in contrast to most other cases, where an increase in yields (Phalan et al., 2014) or profit (Grass et al., 2020) is associated with a decrease in biodiversity. 
In sum, the results presented in this thesis suggest that vanilla agroforest represent a prime opportunity for land sharing (Phalan et al., 2011) in north-eastern Madagascar: they are currently the most profitable land-use option in the region, both per unit labour and per unit area (Andrianisaina et al., in prep. \& Chapter 7), yet perform also well in terms of biodiversity and non-yield ecosystem services compared to other agricultural land-uses (more on this in 10.2.1). Additionally, the absence of a negative correlation between yields and biodiversity suggests that trade-offs are also limited within vanilla agroforestry, underlining the conservation opportunities offered by such smallholder agroforests.

\subsubsection{Management and policy recommendations for vanilla agroforestry systems}

From the findings in this thesis, I can derive four principal management recommendations for vanilla agroforests: firstly, the establishment of new forest-derived vanilla agroforests should be avoided. Especially if established inside old-growth forest, a strong loss of (endemic) biodiversity would result (e.g. Chapters $3 \& 5$ ). Losses of endemic biodiversity and ecosystem services also occur if vanilla agroforests established inside forest fragments (Chapters 3, Abstracts 9.1-9.4). Nonetheless, there might be cases where landowners face the choice between converting a forest fragment to a forest-derived vanilla agroforest and using the forest for shifting hill rice cultivation. In this case, the forest-derived vanilla agroforest would be the better choice in terms of ecosystem services (Abstracts $9.4-9.6$ ) and biodiversity (Chapters 2 - 5, \& 7-8).

Secondly, in those forest-derived vanilla agroforests that are already established, maintaining shade trees would be a sensible option. This would benefit endemic birds (Chapter 3) and endemic plants (Abstract 9.2) without impairing yields (Chapter 6 and 7). However, despite no direct yield costs, farmers may wish to remove trees for timber or other uses. Encouraging tree maintenance could thus be achieved through sustainability certification schemes requiring a minimum amount of shade trees (Tscharntke et al., 2014).

Thirdly, the establishment of new fallow-derived vanilla agroforestry should be promoted (Chapter 2). One key argument for fallow-derived vanilla agroforestry is the cessation of fire that comes with the establishment of a permanent vanilla agroforest (Chapter 3 ) on land under shifting cultivation (Styger et al., 2007). The stop of regular burning enables tree rehabilitation (Chapter 6). In the long run, fallow-derived vanilla agroforests may also be able to halt land degradation, if the fallow land would have entered a cycle of falling soil fertility, increased weed pressure, and falling yields (Styger et al., 2007) that may have ultimately lead to land abandonment. Land degradation could, in turn, motivate farmers to 
convert additional forest to shifting cultivation, so avoiding this trajectory, through the establishment of fallow-derived vanilla agroforests may be beneficial. It is, however, also important to recognise the importance of fallow land for food security and provisioning ecosystem services (Abstract 9.6). A complete halt of ongoing shifting cultivation on already burned land or a complete conversion of the land to fallow-derived vanilla agroforestry would thus not be recommendable. This is also an unlikely scenario, given that current average fallow land assets per household (Andrianisaina et al., in prep.) exceed the amount of land that a single household can realistically farm as a vanilla agroforest (usually $<1$ ha, more usually only if vanilla is planted at low density or with paid labour), given labour constraints (Andrianisaina et al., in prep.; Laney \& Turner, 2015).

Fourthly, promoting tree rehabilitation in existing fallow-derived vanilla agroforests can further contribute to ecosystem service provisioning (e.g. above ground carbon storage, Abstract 9.5) and biodiversity conservation without impairing yields (Chapter $6 \& 7$ ). Thereby, vanilla agroforests may contribute to the global tree planting potential (Bastin et al., 2019), without competing for land with agriculture (Meyfroidt et al., 2014). Depending on the choice of tree species, farmers may also generate additional income from shade trees through the sale of fruits or the harvesting of timber (Abstract 9.6). Furthermore, carbon credits could compensate farmers for the carbon dioxide sequestration the trees provide (Nair et al., 2009).

To implement these recommendations, I see four ways forward: firstly, there is a need for better governance of protected areas to stop the establishment of new forest-derived vanilla agroforests in old-growth forests. Secondly, it is important to raise awareness on differences between forest- and fallow-derived agroforests in the vanilla industry, in sustainability certification, NGOs, and farmer groups. This should include the finding that forest- and fallow-derived agroforests do not systematically differ in yields (Chapter 6 \& 7). Thirdly, and in concert with the previous point, it would be important to increase knowledge exchange between farmers, NGOs and researchers about possibilities to increase vanilla yields without impairing shade trees; for example, through the roundtable on nature conservation established under the umbrella of our DAAD project 'Transnational Partnership for Biodiversity' (see Box 6). Fourthly, sustainability certification should specify rules to forest- and fallow-derived agroforests, as current rules, for example for the Rainforest Alliance seal (International Trade Centre, 2019), are easier to meet in forest-derived agroforests (see Chapter 2 for more). Certification of newly forest-derived vanilla agroforests should be 
avoided, which could be achieved through a cut-off date before which the agroforests must have been established.

\subsubsection{Policies to make the vanilla trade more equitable}

A major problem of the recent vanilla boom in north-eastern Madagascar is the inequality it procreates (Neimark et al., 2019). Despite north-eastern Madagascar being the centre of global vanilla production (FAO, 2020; Hänke et al., 2018), not everyone is involved in vanilla farming, processing, or trade (Hänke et al., 2018). Nonetheless, costs of living are raising (Hänke \& Fairtrade International, 2019), making life more difficult for those who cannot profit from the vanilla boom. In the countryside, these are mainly farming families who have little or poor land: because of a lack of paddy rice available to them, they are forced to farm hill rice on their own or on rented land in order to produce enough rice (Laney \& Turner, 2015). Given that hill rice production is more labour intensive than paddy rice production, time to invest into vanilla cash-cropping may be lacking, even when suitable land for a small vanilla agroforest is available (Andrianisaina et al., in prep.; Laney \& Turner, 2015).

Furthermore, getting additional benefits through sustainability certification may be particularly difficult for the smallest producers. This is because larger vanilla farmers are more likely to receive certification, demonstrating a selection bias on the side of the vanilla exporters (Blum et al., in prep.; Hänke et al., 2018), a problem also common in sustainability certification of other commodities (Blackman \& Rivera, 2011; DeFries et al., 2017). So instead of making rural communities more equal, sustainability certification may actually propagate inequality by supporting people that are already better off.

Policies aiming at an inclusion of more people into the vanilla value chain should thus be a priority. This could be done via programs that support farmers during the first three years of vanilla cultivation with no yield, thereby bridging the 'profit gap' between subsistencefocused farming and mixed subsistence-cash-crop farming. Additionally, vanilla exporters that aim for sustainability certification should be forced to certify a certain percentage of 'small smallholders' to include the more vulnerable people into their schemes.

To increase the negotiating power of farmers, self-organised farmers' groups or cooperatives may be a way forward. As of today, many of the existing farmers' groups in the region are organised in a 'top-down-way' by vanilla exporters (Blum et al., in prep.), fulfilling requirements of sustainability certification schemes (International Trade Centre, 2019). If, instead, such groups would be self-supporting, they could enable exchange of farming 
knowledge between farmers and could enable a higher share of the added value to stay with smallholders (Grashuis \& Su, 2019) rather than vanilla traders or exporters.

A further looming risk for every vanilla farmer is a crash in vanilla prices. Indeed, vanilla prices fluctuate stronger than prices of other agricultural commodities (De Melo et al., 2000). Just this year (2020), vanilla prices have fallen roughly 50\% (Aust \& Hachmann (Canada) Ltd, 2020) but a total crash, as feared by many farmers, did not materialize. Here, having an international minimum price for vanilla might be a way forward, but its implementation seems challenging. A national minimum export price, as imposed by the government of Madagascar (Cadot et al., 2009), does not benefit farmers (De Melo et al., 2000) and is making Malagasy vanilla unattractive on the world market (Aust \& Hachmann (Canada) Ltd, 2020).

\section{Box 4: My PhD journey - Sound recordings}

In January 2017, we discussed among the Diversity Turn ecologists who would collect which kind of data. Given my long experience as a bird watcher and my knowledge of the Malagasy avifauna, we decided that I would focus on birds. To complement bird point count data, we soon decided to also conduct sound recordings, given their advantages over point counts (Darras et al., 2019). I thus spent February 2017 to search for a suitable recorder for the field conditions in northeastern Madagascar. We figured that the self-built open-source recorder 'SOLO' would work best (Whytock \& Christie, 2017). From March to June 2017, I invested a lot of time and resources into building eight customised 'SOLO' recorders (see Chapter 4 for details on sound recorders).

The sound recorders did an excellent job at recording the soundscape across the land-use gradient, despite heavy rain and hot temperatures. Furthermore, none of our recorders was stolen or damaged. In total, we could thus collect 7.8 terabyte of sound recordings over the two field seasons of 2017 and 2018. But what to do with that much data?

My plan was to collaborate with Malagasy ornithologists who have excellent knowledge of bird vocalizations. They would listen to a subset of the recordings from each plot, identify birds, and estimate the distance between sound recorder and bird (Darras, Furnas, et al., 2018) using the BioSounds platform developed by colleagues at the University of Goettingen (Darras et al., 2020). I met two skilful 
ornithologists who were willing to take up the job. After several meetings it turned out that both were unfortunately too busy and could not make time for the identification, leaving me with no 'real', i.e. species-level, data.

I hence decided to work on a first manuscript using point count data only (Chapter 3), which is now published in Biotropica (Martin et al., 2020a). To my luck, I had the chance to supervise the MSc thesis of Saskia Dröge, who compared four different sound diversity indices across the land-use gradient (Chapter 4). By now, her thesis has morphed into a manuscript published in Ecological Indicators (Dröge et al., 2021) - something I'm proud of as her (unofficial) supervisor.

I derive two lessons from this: firstly, relying exclusively on technology-heavy data collection is risky, despite advantages over more traditional methods (Darras et al., 2019). Having a low-tech backup, such as the point counts, is thus crucial. Secondly, one can make the best out of a difficult situation: despite the described difficulties, we managed to publish two bird-focused manuscripts over the course of my $\mathrm{PhD}$. Lastly, the sound recording data is not lost. Ecological sound data analysis technology is evolving fast (Sugai et al., 2019), suggesting that me, another PhD student, or anyone else can analyse the recordings in the future using newly emerging software. This also encompasses the possibility to revisit the same plots in the future to assess changes in sound diversity or species composition over time.

\subsection{How to design policies that enable a sustainable land-use transfor- mation in north-eastern Madagascar?}

Here, I firstly summarise findings from across the thesis that contrast biodiversity, ecosystem services, and agricultural productivity of vanilla agroforests to other land uses (oldgrowth forest, forest fragment, herbaceous fallow, woody fallow, and rice paddy) thereby leaving the within-vanilla differences (synthesized in 10.1) behind. I then discuss policy implications of our findings, trying to find ways of how to address the 'wicked problem' of sustainable development in the region. I end this section on a positive note, by envisioning a thriving and sustainable future scenario for north-eastern Madagascar. 


\subsubsection{Biodiversity and ecosystem services across the predominant land-use types of north-eastern Madagascar}

Importantly, our research within the Diversity Turn in Land Use Science project not only focuses on vanilla agroforestry but also investigates biodiversity, ecosystem services, and yields across other important land-use types in north-eastern Madagascar. This research enables us to quantify the relative contribution of vanilla agroforestry to biodiversity conservation and ecosystem service provisioning, thus assessing the land systems as a whole. This then makes it possible to derive management and policy recommendations that go beyond vanilla agroforestry, having the whole landscape as well as peoples' livelihoods in mind. Here, I sum up key findings from across the thesis and put them in context to the literature on biodiversity conservation and ecosystem services in tropical mosaic landscapes. I also provide a short visual summary (Figure 10.1).

We show that preserving remaining old-growth forest is of utmost importance to conserve the unique biodiversity of the region (Chapters $3 \& 5$, Abstracts $9.1 \& 9.2$ ). This finding is in line with findings from elsewhere in Madagascar (reviewed in Irwin et al., 2010) and beyond (Barlow et al., 2007; Gibson et al., 2011), highlighting the irreplaceable value of primary forests for the conservation of tropical biodiversity. Importantly, the dependence on old-growth forests differs between taxa: we find 38\% of amphibian species to exclusively occur in old-growth forest plots (Chapter 5 ), while this figure was only $26 \%$ for trees (Abstract 9.1), 26\% for reptiles (Chapter 5), 22\% for birds (Chapter 3), and $9 \%$ for herbaceous plants (Abstract 9.2). These differences likely highlight that amphibians are particularly affected by land-use change, confirming findings from elsewhere (Hof et al., 2011). Additionally, old-growth forest dependency was higher for endemic trees, endemic herbaceous plants, and endemic birds, than for their non-endemic counterparts. For the birds in particular, I show that a higher endemism level, i.e. whether a species is non-endemic, endemic on species level, endemic on genera level, or endemic on (sub-)family level, is a strong predictor of the vulnerability of a species to land-use change. This finding corroborates a longstanding but largely untested hypothesis by Wilmé (1996), which links endemism level to forest disturbance vulnerability in the Malagasy avifauna. Testing whether this relationship is merely explained by range size (Sykes et al., 2020) or whether Malagasy endemics are actually 'special' concerning their response to land-use change remains an open question. This goes of course not only for birds, but also for other taxa as highlighted above. 


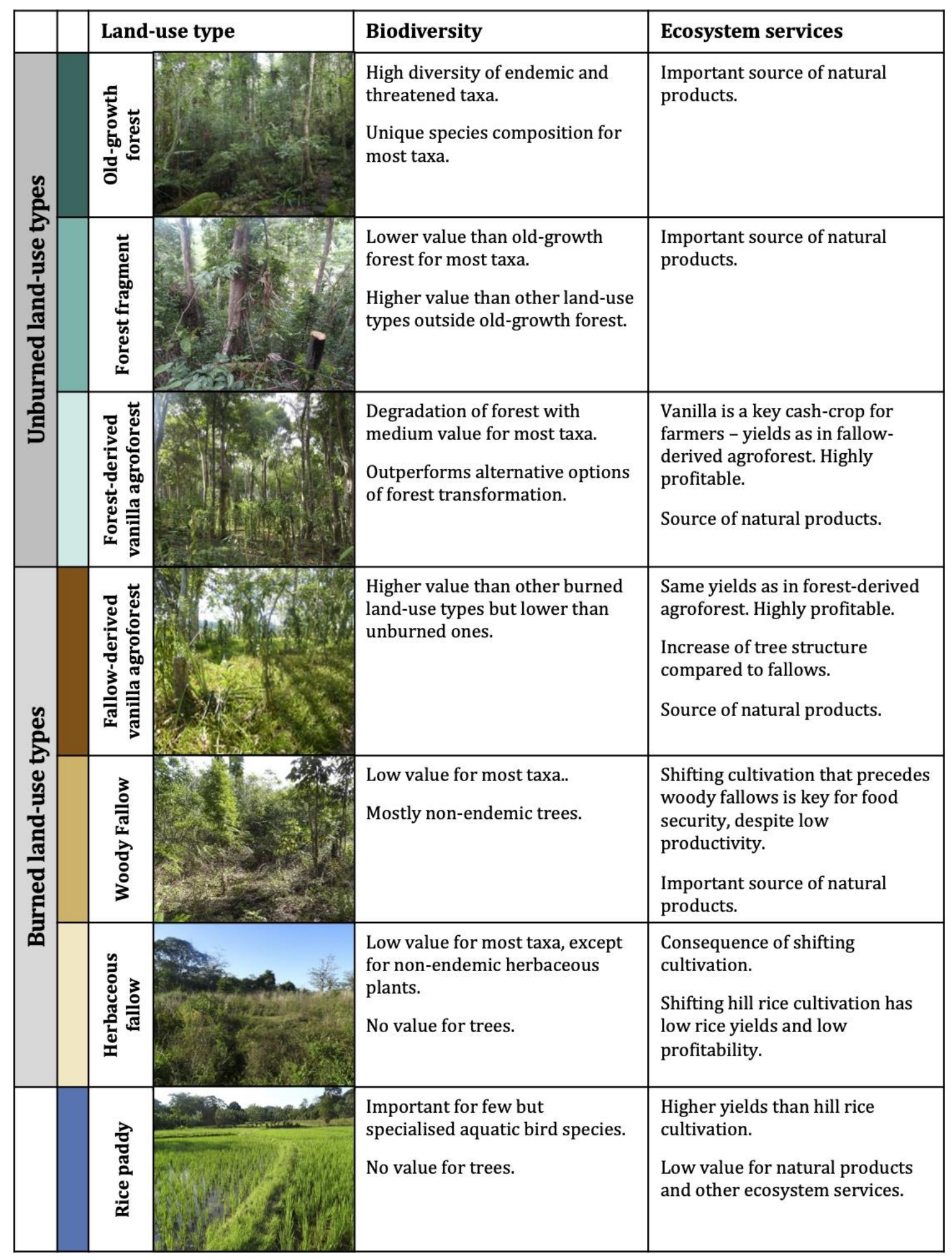

Figure 10.1: Overview of key findings concerning biodiversity and ecosystem services across the seven predominant land-use types in north-eastern Madagascar, separated in biodiversity and ecosystem services (including yields). 
Crucially, old-growth forests in north-eastern Madagascar also provide important ecosystem services. Across all investigated land-use types, old-growth forests have the largest carbon storage (Abstract 9.5), the second highest predation rate (after forest fragments; Abstract 9.4), the highest soil organic carbon content (Chapter 8), and the highest importance for water regulation (Chapter 8, Abstract 9.6). They consequently have a high multifunctionality (Chapter 8). These findings are reflecting what has been shown for old-growth forests elsewhere in Madagascar (Dave et al., 2017; Vieilledent et al., 2013) and across the tropics (DeFries et al., 2004; Don et al., 2011). Furthermore, old-growth forests are used by people for the collection of natural products (Abstract 9.6), despite forest-use restrictions in protected areas. Other research from north-eastern Madagascar also highlights the important role of old-growth forests as a source of bushmeat which is crucial for child nutrition in certain villages (Golden et al., 2011). In sum, protecting remaining old-growth forests in north-eastern Madagascar from the most pressing issues they face today, shifting hill rice cultivation (Zaehringer et al., 2015) and overexploitation (Patel, 2007; Razafimanahaka et al., 2012), is key to maintain biodiversity and ecosystem services in this biodiversity hotspot. Particularly so, as further loss of old-growth forest would risk further 'ecosystem decay' where species are lost faster than would be expected by forest loss alone (Chase et al., 2020). The need to conserve remaining old-growth forest is further underscored by that secondary forest regeneration in the rainforest biome of eastern Madagascar appears to be much slower than elsewhere (Brown \& Gurevitch, 2004; Klanderud et al., 2010).

Our research also highlights the important role of forest fragments in safeguarding biodiversity providing ecosystem services. These unburned but heavily used fragments of the once continuous old-growth forest can be found throughout much of the agriculture landscape. They are more common close to the deforestation frontiers (Vieilledent et al., 2018), highlighting that these forest fragments are being lost with time (Schüßler et al., 2018), a trend also observed in other tropical regions (Hansen et al., 2020). The loss of forest fragments puts biodiversity at risk: we find a higher level of species richness compared to other land-use types within the agricultural landscape for various taxa (trees, Abstract 9.1; amphibians and reptiles, Chapter 5). For other taxa, levels of endemism are elevated (birds, Chapter 3; trees, Abstract 9.1; herbaceous plants, Abstract 9.2). The single observation of a near-threatened bird species, the Madagascar Sparrowhawk, also stems from a forest fragment (Chapter 3). Taken together, this underlines the value of forest fragment to provide a refuge for various species within the agricultural mosaic landscape. However, the biodiversity in forest fragments documented by us may be in decline, even if the fragments can be 
conserved. Extinction debts (Kuussaari et al., 2009) are likely to occur as the isolation of the forest fragment is relatively recent. If such losses over time would materialise, the forest fragments of north-eastern Madagascar would align with other tropical rainforest fragments that, in average, show negative trends in biodiversity indicators (Turner, 1996). Forest fragments are also important for the provisioning of ecosystem services. Indeed, people value their contribution to water regulation and collect various natural products (Chapter 8, Abstract 9.6). Furthermore, forest fragments represent important carbon stocks, both above and below ground (Abstract 9.5, Chapter 8), and have the highest predation rates across all studied land uses (Abstract 9.4). In sum, these factors contribute to multifunctionality, which is higher in forest fragments than in any other land-use type within the agricultural landscape (Chapter 8). This important role of forest for ecosystem service provisioning in north-eastern Madagascar has been recognised previously (e.g. Zaehringer et al., 2017) underlining the need to stop the disappearance of forest fragments for biodiversity and ecosystem services.

In north-eastern Madagascar, shifting cultivation represents the most important land-use on the hills in terms of area. Given how dynamic this system is (Styger et al., 2007), we studied two stages of the shifting cultivation cycle: herbaceous fallows, as found roughly half a year after rice harvest, and woody fallows - as found 4-16 years post rice harvest (see Introduction 1.4.3). We show that herbaceous fallows host low levels of species richness across taxa and some recovery in terms of species richness under the transformation to woody fallow. However, assemblages are typically dominated by non-endemic species (e.g. birds, Chapter 3). The exception are herbaceous plants, that are species rich in both stages, but again, assemblages are dominated by non-endemic species (Abstract 9.2). When combined, we see comparatively low values of multidiversity and even lower values for endemic multidiversity in fallow lands (Chapter 8). These results are in line with plant-focused studies from other areas in eastern Madagascar (e.g. Klanderud et al., 2010) that show a plateauing recovery of plant structure and diversity in fallows. This indicates that secondary forest recovery in the region is slow. Furthermore, the recovery is typically stopped by intentional fires, necessary for an additional cycle of hill rice cultivation, or by fire escapes, which frequently burn fallow lands (Kull, 2002; Styger et al., 2007). In terms of ecosystem functions and services, we find similar patterns of limited recovery from herbaceous to woody fallow: above-ground carbon (Abstract 9.5), soil organic carbon (Chapter 8), and predation rates (Abstract 9.4) are higher in woody than in herbaceous fallows; nonetheless, all indicators are lower than what we find in old-growth forest, forest fragment, and forest- 
derived vanilla agroforestry. The shifting cultivation cycle does, however, provide rice yields, especially for households with little or no vanilla agroforestry or rice paddy (Andrianisaina et al., in prep.), highlighting the importance for food security (Andriamparany et al., in review). Furthermore, woody fallows in particular are an important source of natural products (Abstract 9.6).

We further demonstrate that separating vanilla agroforests based on their land-use history (forest- vs. fallow-derived) is essential to assess their conservation value and their contribution to the provisioning of ecosystem services (all Chapters). We confirm that, overall, forest-derived vanilla agroforests degrade forests whereas fallow-derived vanilla agroforests rehabilitate historically forested open fallow land, as suggested in Chapter 2. I here refrain from further discussion of our results on biodiversity and ecosystem services in vanilla agroforests, as an in-depth discussion of the topic can be found in Section 10.1.2.

Rice paddies are of relatively low conservation value, except for certain endemic water birds (Chapter 3). They are also the most species-rich land-use type in terms of herbaceous plants (Abstract 9.2), but most of these species are exotics. Rice paddies perform also poorly in terms of multidiversity and multifunctionality (Chapter 8). Nonetheless, rice yields in rice paddies are substantial and the land use represents a profitable land-use option for smallholder farmers, both per unit area and per unit labour (Chapter 8). They are thus important for food security (Andriamparany et al., in review). However, rice paddies in Madagascar yield less than in other countries with similar bio-physical conditions (Stoop et al., 2002). A sustainable intensification approach (Stoop et al., 2002) may thus offer an opportunity to close yield gaps on existing paddies, potentially sparing forest land from shifting cultivation or enabling longer fallow periods on land already under shifting cultivation. Nonetheless, these potential benefits may not materialise, as many of the households engaging heavily in shifting cultivation own little or no rice paddy (Andrianisaina et al., in prep.). Sustainable rice intensification (Stoop et al., 2002) may thus be insufficient to take conversion pressure off surrounding hills. Furthermore, the most suitable places for paddy rice in our study villages are already farmed as such, making the establishment of new rice paddies more difficult (Llopis et al., 2019).

To best understand dynamics between these land-use types, I conceptualised the landscape of north-eastern Madagascar along the prevailing land-use trajectory (Chapter 8). This trajectory than allows to identify conservation opportunities. The approach reveals distinct trade-offs between ecosystem functions and biodiversity on the one hand, and agricultural productivity on the other, at two out of three opportunities under forest conversion. Co- 
benefits between agricultural productivity and biodiversity and ecosystem functions exist for fallow-derived agroforestry.

\subsubsection{Land-use change and forest conservation in north-eastern Madagascar - a ‘wicked problem’?}

A policy brief by colleagues (Zaehringer et al., 2018), who work on land-use change issues further south on Madagascar's east coast, frames the conflict between the needs of smallholder farmers and forest conservation as a 'wicked problem'. On the one hand, deforestation rates in eastern Madagascar remain high (Vieilledent et al., 2018), symptomatically showing that there has been little progress in improving forest governance. Nonetheless, living standards of the rural poor have largely been stagnating as Sustainable Development Goal (SDG) targets have not been met (Waeber et al., 2016). This highlights that there is no increase of living standards as forests are converted to agricultural lands, as can (at least in part) be observed elsewhere, for example in oil palm landscapes (Qaim et al., 2020; Santika et al., 2019).

Such wicked problems are not uncommon in environmental management and represent governance problems where no clear-cut solution exists (DeFries \& Nagendra, 2017). However, the fact that a problem is difficult to solve should not be stopping us from developing approaches, even if they only address certain aspects of the issue (Zaehringer et al., 2018). For example, the proliferation of sustainable and well-yielding vanilla agroforestry practices (see 10.1) may increase cash crop income of small holder farmers, the transformation of fallow land into fallow-derived vanilla agroforests could rehabilitate land (10.1), and a more equitable vanilla trade (10.1.4) may increase the share of vanilla profits going to farmers and could also lead to more stable prices. However, policies will need to go beyond vanilla. Firstly, because not everyone profits from vanilla farming (Hänke et al., 2018), and, secondly, because sustainable land-use cannot be achieved with vanilla agroforestry alone (Laney \& Turner, 2015). Instead, policies need to focus on other land uses as well. This may include sustainable paddy rice intensification (Stoop et al., 2002), more sustainable shifting cultivation (Mertz, 2002; Messerli, 2000), and an optimised livestock keeping (Kunz et al., 2020). Policies will also need to be focused on the remaining old-growth forest: the longestablished Marojejy National Park would profit from better policing of existing rules in the short- and midterm; other forest blocks in the region may profit from secured forest tenure and community forest management (Rasolofoson et al., 2015; Robinson et al., 2014). In sum, interventions at various stages along the land-use trajectory (Chapter 8) will be necessary to maintain unique forest habitat and to maintain, and in places restore, the agriculture 
mosaic landscape of north-eastern Madagascar. To implement some of the options suggested above, identifying people or institutions that may apply new policies and initiate innovative approaches (i.e. agents of change, Andriamihaja et al., 2021) may provide a first starting point. Importantly, any attempts to address the issues locally also need to go in concert with improvement of country-wide governance, as they otherwise risk to be jeopardized (Vieilledent et al., 2020; Waeber et al., 2016).

In sum, saving the unique biodiversity of north-eastern Madagascar and enabling a fulfilled life for people in the region is not one or the other. Instead, both are necessarily connected and must be achieved in concert, without playing one side against the other. That being said, regulations will be needed to safeguard remaining old-growth forests in National Parks in the short- and mid-term. At the same time, measures enabling livelihoods that do not rely on deforestation, must be stepped up.

\subsubsection{My thriving vision for north-eastern Madagascar}

In the long-term, I envision a diverse smallholder-dominated agricultural landscape in north-eastern Madagascar, whic exemplifies land sharing. Diverse and well-yielding vanilla, clove, coffee, and cocoa agroforests established on fallow land (Chapter 2) would cover the hills, productive rice paddies would be situated in valleys and on terraced slopes, and remnant forest fragments would proudly stand in between. Existing forest-derived agroforests would be maintained, and targeted sustainability certification schemes would encourage the regeneration of native trees in these agroforests (Chapter $2 \& 6$ ), as would the local pride in these traditional agroforestry systems. Reforestation projects run by local people would restore the missing connection between protected areas, thereby also providing additional income through payments for ecosystem services (PES) schemes and timber sales. A thriving eco-tourism sector would provide unique nature experiences for the growing urban Malagasy middle class, who would crave to visit the countries' forests. Adequate roads, safe buses, and fast boat links would connect rural centers to the regions' four main cities, providing possibilities for teachers, nurses, technicians, and everyone else to travel to and from the countryside. Sambava, Antalaha, Vohémar, and Andapa, the regions' four main cities, would become trade hubs for the agricultural commodities the region has to offer. Small workshops would process cocoa beans into premium chocolate and brew vanilla essence for the export market, thereby adding more value locally. A train link would connect Antalaha and Sambava to the port of Vohémar and the capital Antananarivo, offering transport for goods and people, and views on the solar farms, palm plantations, and littoral forest restoration projects that would characterize the littoral zone along the Indian Ocean. 


\section{Box 5: My PhD journey - Writing, data analysis and science communication}

Pursuing a PhD is often described as a difficult and long journey with a multitude of challenges. In my case starting with data collection in north-eastern Madagascar (discussed in 'My PhD journey - Field work in Madagascar'), followed by data curation, data analysis, write-up and communication.

I'm personally in the position that I enjoy scientific writing, which typically poses a major challenge to many PhD students (Cotterall, 2011; RamírezCastañeda, 2020). This is also the reason why I could complete the review chapter on land-use history of tropical agroforests (Chapter 2) - which involved hardly any data analysis - in a short period of time. The fact that I enjoy the writing process has also to do with the great mentorship I got during my Masters (shout out to Alfredo Sánchez-Tójar and Julia Schroeder!) and during my PhD through supervisors and co-authors.

Data analysis, on the other hand, posed a challenge to me. While I always enjoyed coming up with possible ways to analyse and, in particular, visualize the data, I struggled on the statistical side of it. Even after reading for hours, I always had the impression that there is more to read and more statistical premises to test for, raising concerns on whether the chosen approach would be valid. I figured at some point that it is also necessary to be pragmatic: trying the best in being rigorous and open about the methods applied (by publishing the R-scripts), but also recognising that one is an ecologist and not a statistician.

Coming back to a topic I enjoyed a lot: science communication. I see the communication of scientific results to the public as a core task for us scientist, given the public funds we receive. Interestingly, science communication can also enhance the citations and thus the proliferation of a paper (Peoples et al., 2016). From the beginning, I co-ran the Diversity Turn Twitter account (@Diversity Turn) and also tweeted through my personal account (@Dominic Mart), reaching thousands of people every month. However, most people seeing our tweets were scientists themselves, so communicating our research through traditional media also seemed important. Over the course of the project, I had several opportunities to talk to Journalist, leading to media coverage on the British television station Channel 5 and on German Deutschlandfunk radio. Additionally, a media release to my Conservation 
Letters paper (Chapter 2) prompted coverage on various outlets. My Diversity Turn colleagues also communicated our findings through interviews with the magazine Positive News, the German radio DetektorFM, and the Malagasy radio stations Radio Vanille and Radio MFK.

\subsection{Ideas for future land-use research in north-eastern Madagascar}

In this section, I discuss potential future land-use research in north-eastern Madagascar, going beyond what we could achieve within the Diversity Turn in Land Use Science project; both on the plot- and landscape scale, as well as concerning land-use policy.

On a plot scale, I believe that we need additional insights into drivers of vanilla yields. In this context, I find it particularly interesting to study how shade-tree management and landuse history interact in influencing vanilla yields under increasingly difficult growing conditions expected under climate change (Harvey et al., 2014). This could be achieved through drought experiments in vanilla agroforests, as pioneered in cocoa (Schwendenmann et al., 2010). Furthermore, exclusion experiments (Maas et al., 2019) could show if shade-tree management and land-use history influence pest control in vanilla agroforestry.

Further research on the plot-scale would be necessary to elucidate the impacts of vanilla management practices and other land-use decisions on biodiversity and ecosystem services, especially in the long run. Indeed, our data can only provide a snapshot of the state of biodiversity and ecosystem functions in 2017 and 2018, the two years we collected data. Given the importance of time series data in detecting biodiversity change (Dornelas et al., 2014) and limitations of the space-for-time approach we applied (De Palma et al., 2018), collecting more long-term data, or at least data at a second instance in the future, would be highly interesting. Especially so, as biodiversity loss in tropical agricultural landscapes may otherwise be overlooked (Maas et al., 2009; Socolar et al., 2019). Such a comparison over time might be facilitated by the audio recordings I collected across our study design (Chapter 4): they may enable an accurate comparison of biodiversity variables across time steps, as the same analysis methods may be applied, without problems of observer bias (Darras, Batáry, et al., 2018; Sugai et al., 2019). Comparison of biodiversity changes over time will also be facilitated by archiving our existing data and by describing methods and metadata as a data paper, a step that I have in mind for next year. These records, in concert with longterm data collection and environmental monitoring, would enable researchers to assess the stability of biodiversity and ecosystem functions in north-eastern Madagascar over time. 
For example, this may help to identify extinction debts (Kuussaari et al., 2009) in landscapes where forest cover has been lost in recent years, or possible immigration credits (Jackson \& Sax, 2010) in fallow-derived agroforests that rehabilitate land previously under shifting cultivation (more in Chapter 2).

On a landscape scale, I would be highly interested to see research on the impacts of proposed land-use policies (see 10.2) on deforestation, land-use practices, and livelihoods. To do so, a randomized control trials (RCT), where an intervention is rolled out in a randomly selected subsample of experimental units, would offer a unique opportunity to study the effect of an intervention in depth (Pynegar et al., 2020). Such research could show whether and how a policy is working for the environment and for people. However, designing a randomized control trial is non-trivial and requires a well-developed intervention that can be evaluated (Pynegar et al., 2020). Consequently, a RCT may only be possible after more indepth research on possible interventions.

This research could be delivered through various approaches. One interesting and applied approach to shed light on possible futures for the vanilla landscapes in north-eastern Madagascar is participatory scenario planning (Oteros-Rozas et al., 2015). The tool allows researchers to evaluate alternative futures of social-ecological systems, thereby incorporating the ideas and concerns of people living in the landscapes of question. Importantly, this would allow to conceptualise future outcomes, rather than disparaging about the past (Oteros-Rozas et al., 2015). For example, a recent study has highlighted alternative futures for coffee landscapes in south-western Ethiopia (Jiren et al., 2020). The research finds that agroecological development pathways may generate synergies between food security and biodiversity conservation, whereas production-focused pathways entail degradation of natural capital and social inequity.

\section{Box 6: My PhD journey - DAAD Grant 'Partnerships for Biodiversity'}

In early 2018, we came to the conclusion that the funding available for the Malagasy PhD students involved in the Diversity Turn in Land Use Science project was insufficient to make our collaboration a success. The budget of the project was not intended to fund $\mathrm{PhD}$ students based in Madagascar in the first place, and while a basic salary could be funded, little was possible beyond that. Particularly so, as we felt that multi-month research stays of the Malagasy PhD students at the University 
of Goettingen would greatly profit our common research goals and the personal development of everyone involved.

We thus started to look for funding options and came across the DAAD Partnerships for Biodiversity in Developing Countries. Given the approaching deadline, we only had one month to design a four-year 200 '000 Euro project and to complete a full grant. With this time pressure, we put all our effort together and wrote the grant collaboratively between Kristina Osen, Annemarie Wurz, Holger Kreft, and me.

Much to our own surprise, we managed to submit in time and were very excited to learn about the success of the grant in autumn 2018. Since then, the funding has enabled a workshop in Sambava, a conservation roundtable for the SAVA region, and nine multi-months research stays at the University of Goettingen for my Malagasy colleagues. The program has made it possible to work more closely together, advance collaborative publications, and grow together as a team. For the next two years to come, we have planned two more conservation roundtables, teaching exchanges, and an excursion for students of three partner Universities.

Writing a relatively large grant proposal during my $\mathrm{PhD}$ has taught me a lot for my future career and was an experience I would not want to have missed. Particularly so since we succeeded in securing the funding and could already see the fruits of the work over the past two years.

Thanks to the German Academic Exchange Service (DAAD) for the funding!

\subsection{Conclusion}

The central aim of my thesis is to elucidate drivers and impacts of land-use change in northeastern Madagascar, a global biodiversity hotspot. I was able to provide knowledge on negative impacts of land-use change on biodiversity (Chapters 3-5 \& 7-9) and ecosystem services (Chapter 8, Abstracts 9.4-9.6). I further generated knowledge on how vanilla agroforests can be managed for people and nature (Chapters $6 \& 7$ ), and how important it is to consider land-use history of (vanilla) agroforests (Chapter 2).

In sum, land-use change is driven by economic opportunities for farmers aiming at expanding their land to make a living. In the case of shifting hill rice cultivation, which is responsible for the majority of forest loss in the region (Zaehringer et al., 2015), these opportunities are a need to fulfil subsistence requirements (Laney \& Turner, 2015; Llopis et al., 2020). In 
the case of vanilla agroforestry, these economic opportunities are strongly driven by high but hugely fluctuating world market prices for vanilla (Hänke et al., 2018). Nonetheless, different land-uses have varying impact on biodiversity and ecosystem services. Old-growth forest conversion inevitably leads to a loss of biodiversity, particularly of endemic biodiversity, highlighting the importance of old-growth forest conservation. Similarly, some key ecosystem services are lost. Thereafter, however, land-use types outside old-growth forest that are established without the use of fire (forest fragments and forest-derived vanilla) generally outperform land-use types that were established under the use of fire, namely herbaceous and woody fallow, as well as fallow-derived vanilla agroforestry, in terms of ecosystem services and biodiversity. These findings call for a consideration of land-use history respectively the conceptualisation of landscapes along land-use trajectories to derive meaningful advice for policy makers - both in the case of north-eastern Madagascar and beyond. Within vanilla agroforests, vanilla yields are independent of canopy cover and are not correlated to biodiversity metrics, suggesting opportunities for sustainable intensification of existing vanilla agroforests to optimise yields. Nonetheless, enabling the rejuvenation of native trees in forest-derived vanilla agroforests and facilitating the ongoing tree rehabilitation in fallow-derived agroforests will be necessary to safeguard those mutually beneficial production systems into the future.

However, the data presented in this thesis have their limitations. Particularly, they can only provide a snapshot of the state of biodiversity and ecosystem services at the time of data collection and cannot be conclusive about long-term trends. The findings are also based on correlational analyses, calling for more experimental approaches in future research. Importantly, the here-generated advice is furthermore in need for refinement through more applied and policy-focused approaches to avoid an implementation gap.

With this thesis, I provide a major advancement of our knowledge concerning biodiversity, ecosystem services, and yields in vanilla agroforestry systems. Furthermore, I illustrate the importance of understanding vanilla agroforestry in a land-use context that is sensible to land-use history; a subject that I have put on the agenda for agroforestry research. Finally, I anticipate that my research will pave the way for more policy-relevant research which will be necessary to achieve a sustainable land-use transformation in the biodiversity hotspot of north-eastern Madagascar, contributing to the wellbeing of people and nature alike. 


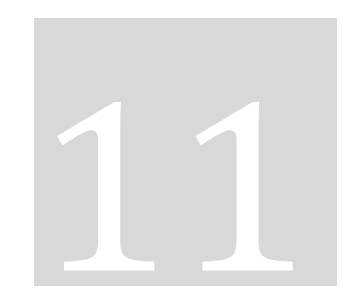

\section{References}

Abdulai, I., Vaast, P., Hoffmann, M. P., Asare, R., Jassogne, L., Asten, P. V., Rötter, R. P., \& Graefe, S. (2018). Cocoa agroforestry is less resilient to sub-optimal and extreme climate than cocoa in full sun. Global Change Biology, 24(1), 273-286. https://doi.org/10.1111/gcb.13885

Aide, T. M., Corrada-Bravo, C., Campos-Cerqueira, M., Milan, C., Vega, G., \& Alvarez, R. (2013). Realtime bioacoustics monitoring and automated species identification. PeerJ, 1, e103. https://doi.org/10.7717/peerj.103

Akaike, H. (1998). Information Theory and an Extension of the Maximum Likelihood Principle. In E. Parzen, K. Tanabe, \& G. Kitagawa (Eds.), Selected Papers of Hirotugu Akaike (pp. 199-213). Springer. https://doi.org/10.1007/978-1-4612-1694-0_15

Allan, E., Manning, P., Alt, F., Binkenstein, J., Blaser, S., Blüthgen, N., Böhm, S., Grassein, F., Hölzel, N., Klaus, V. H., Kleinebecker, T., Morris, E. K., Oelmann, Y., Prati, D., Renner, S. C., Rillig, M. C., Schaefer, M., Schloter, M., Schmitt, B., ... Fischer, M. (2015). Land use intensification alters ecosystem multifunctionality via loss of biodiversity and changes to functional composition. Ecology Letters, 18(8), 834-843. https://doi.org/10.1111/ele.12469

Allnutt, T. F., Ferrier, S., Manion, G., Powell, G. V. N., Ricketts, T. H., Fisher, B. L., Harper, G. J., Irwin, M. E., Kremen, C., Labat, J.-N., Lees, D. C., Pearce, T. A., \& Rakotondrainibe, F. (2008). A method for quantifying biodiversity loss and its application to a 50-year record of deforestation across Madagascar: Extinction estimates in Madagascar from deforestation. Conservation Letters, 1(4), 173-181. https://doi.org/10.1111/j.1755-263X.2008.00027.x

Alomia, Y. A., Mosquera-Espinosa, A. T., Flanagan, N. S., \& Otero, J. T. (2017). Seed Viability and Symbiotic Seed Germination in Vanilla spp. (Orchidaceae). Research Journal of Seed Science, 10(2), 43-52. https://doi.org/10.3923/rjss.2017.43.52

AmphibiaWeb. (2020). AmphibiaWeb Database. https://amphibiaweb.org/

Andam, K. S., Ferraro, P. J., Pfaff, A., Sanchez-Azofeifa, G. A., \& Robalino, J. A. (2008). Measuring the effectiveness of protected area networks in reducing deforestation. Proceedings of the National Academy of Sciences, 105(42), 16089-16094. https://doi.org/10.1073/pnas.0800437105

Andreone, F., Randrianirina, J. E., Jenkins, P. D., \& Aprea, G. (2000). Species diversity of Amphibia, Reptilia and Lipotyphla (Mammalia) at Ambolokopatrika, a rainforest between the Anjanaharibe-Sud and Marojejy massifs, NE Madagascar. Biodiversity \& Conservation, 9(12), 1587-1622. https://doi.org/10.1023/A:1026559728808

Andriamihaja, O. R., Metz, F., Zaehringer, J. G., Fischer, M., \& Messerli, P. (2021). Identifying agents of change for sustainable land governance. Land Use Policy, 100, 104882. https://doi.org/10.1016/j.landusepol.2020.104882 
Andriamparany, J., Hänke, H., \& Schlecht, E. (in review). Food security and food quality among vanilla farmers in Madagascar: The role of contract farming and livestock keeping.

Andrianisaina, F., Hänke, H., \& Barkmann, J. (in prep.). Longitudinal survey among vanilla farmers in the Sava Region of northeastern Madagascar (2017-2018).

Andriatsitohaina, R. N. N., Celio, E., Llopis, J. C., Rabemananjara, Z. H., Ramamonjisoa, B. S., \& GrêtRegamey, A. (2020). Participatory Bayesian network modeling to understand driving factors of land-use change decisions: Insights from two case studies in northeast Madagascar. Journal of Land Use Science, 15(1), 1-22. https://doi.org/10.1080/1747423X.2020.1742810

Arditti, J., Rao, A. N., \& Nair, H. (2009). Hand-Pollination of Vanilla: How Many Discoverers? In T. Kull, J. Arditti, \& S. M. Wong (Eds.), Orchid Biology: Reviews and Perspectives. Springer Science \& Business Media.

Asare, R., Markussen, B., Asare, R. A., Anim-Kwapong, G., \& Ræbild, A. (2019). On-farm cocoa yields increase with canopy cover of shade trees in two agro-ecological zones in Ghana. Climate and Development, 11(5), 435-445. https://doi.org/10.1080/17565529.2018.1442805

Aust \& Hachmann (Canada) Ltd. (2020). Vanilla Market Update-November 2020. Aust \& Hachmann Vanilla Market Updates. http://www.austhachcanada.com/november-2020/

Barlow, J., Gardner, T. A., Araujo, I. S., Avila-Pires, T. C., Bonaldo, A. B., Costa, J. E., Esposito, M. C., Ferreira, L. V., Hawes, J., Hernandez, M. I. M., Hoogmoed, M. S., Leite, R. N., Lo-Man-Hung, N. F., Malcolm, J. R., Martins, M. B., Mestre, L. A. M., Miranda-Santos, R., Nunes-Gutjahr, A. L., Overal, W. L., ... Peres, C. A. (2007). Quantifying the biodiversity value of tropical primary, secondary, and plantation forests. Proceedings of the National Academy of Sciences, 104(47), 18555-18560. https://doi.org/10.1073/pnas.0703333104

Barrera-Rodríguez, A. I., Herrera-Cabrera, B. E., Jaramillo-Villanueva, J. L., Escobedo-Garrido, J. S., \& Bustamante-González, Á. (2009). Characterization of vanilla production systems (Vanilla planifolia A.) on orange tree and mesh shade in the Totonacapan Region. Tropical and Subtropical Agroecosystems, 10, 199-212.

Bartoń, K. (2020). MuMIn: Multi-model inference [R-package].

Bastin, J.-F., Finegold, Y., Garcia, C., Mollicone, D., Rezende, M., Routh, D., Zohner, C. M., \& Crowther, T. W. (2019). The global tree restoration potential. Science, 365(6448), 76-79. https://doi.org/10.1126/science.aax0848

Bates, D. M. (2014). Ime4: Mixed-effects modeling with R (1.1-21) [R-Package].

Baudron, F., \& Giller, K. E. (2014). Agriculture and nature: Trouble and strife? Biological Conservation, 170, 232-245. https://doi.org/10.1016/j.biocon.2013.12.009

Beckschäfer, P. (2015). Hemispherical_2. 0-Batch Processing Hemispherical and Canopy Photographs With ImageJ-User Manual. 1-6. GeorgAugust-Universität Göttingen Germany.

Beckschäfer, P., Seidel, D., Kleinn, C., \& Xu, J. (2013). On the exposure of hemispherical photographs in forests. IForest - Biogeosciences and Forestry, 6(4), 228-237. https://doi.org/10.3832/ifor0957-006

Beer, J., Muschler, R., Kass, D., \& Somarriba, E. (1998). Shade management in coffee and cacao plantations. Directions in Tropical Agroforestry Research, 53, 139-164. https://doi.org/10.1007/978-94-015-9008-2_6

Bennett, E. M. (2017). Changing the agriculture and environment conversation. Nature Ecology \& Evolution, 1(1), 1-2. https://doi.org/10.1038/s41559-016-0018

Beukema, H., Danielsen, F., Vincent, G., Hardiwinoto, S., \& van Andel, J. (2007). Plant and bird diversity in rubber agroforests in the lowlands of Sumatra, Indonesia. Agroforestry Systems, 70(3), 217-242. https://doi.org/10.1007/s10457-007-9037-x

Bhagwat, S. A., Willis, K. J., Birks, H. J. B., \& Whittaker, R. J. (2008). Agroforestry: A refuge for tropical biodiversity? Trends in Ecology \& Evolution, 23(5), 261-267. https://doi.org/10.1016/j.tree.2008.01.005 
Bianchi, S., Cahalan, C., Hale, S., \& Gibbons, J. M. (2017). Rapid assessment of forest canopy and light regime using smartphone hemispherical photography. Ecology and Evolution, 7(24), 10556-10566. https://doi.org/10.1002/ece3.3567

Bibby, C. J., Burgess, N. D., Hill, D. A., \& Mustoe, S. (2000). Bird Census Techniques. Elsevier.

BirdLife International. (2018). BirdLife International: Data Zone. http://datazone.birdlife.org/home

Bisseleua, D. H. B., Missoup, A. D., \& Vidal, S. (2009). Biodiversity Conservation, Ecosystem Functioning, and Economic Incentives under Cocoa Agroforestry Intensification. Conservation Biology, 23(5), 1176-1184. https://doi.org/10.1111/j.1523-1739.2009.01220.x

Blackman, A., \& Rivera, J. (2011). Producer-Level Benefits of Sustainability Certification. Conservation Biology, 25(6), 1176-1185. https://doi.org/10.1111/j.1523-1739.2011.01774.x

Blanc, D. L. (2015). Towards Integration at Last? The Sustainable Development Goals as a Network of Targets. Sustainable Development, 23(3), 176-187. https://doi.org/10.1002/sd.1582

Blaser, W. J., Oppong, J., Hart, S. P., Landolt, J., Yeboah, E., \& Six, J. (2018). Climate-smart sustainable agriculture in low-to-intermediate shade agroforests. Nature Sustainability, 1(5), 234-239. https://doi.org/10.1038/s41893-018-0062-8

Blum, L., Hänke, H., \& Barkmann, J. (in prep.). Private voluntary sustainability standards in the booming vanilla business of Madagascar: A smallholder's perspective.

Bommarco, R., Kleijn, D., \& Potts, S. G. (2013). Ecological intensification: Harnessing ecosystem services for food security. Trends in Ecology \& Evolution, 28(4), 230-238. https://doi.org/10.1016/j.tree.2012.10.012

Bond, W. J., Jr, J. A. S., Ranaivonasy, J., \& Ratsirarson, J. (2008). The antiquity of Madagascar's grasslands and the rise of C4 grassy biomes. Journal of Biogeography, 35(10), 1743-1758. https://doi.org/10.1111/j.1365-2699.2008.01923.x

Borbolla-Pérez, V., Iglesias-Andreu, L. G., Luna-Rodríguez, M., \& Octavio-Aguilar, P. (2017). Perceptions regarding the challenges and constraints faced by smallholder farmers of vanilla in Mexico. Environment, Development and Sustainability, 19(6), 2421-2441. https://doi.org/10.1007/s10668-016-9863-y

Borgerson, C., Razafindrapaoly, B., Rajaona, D., Rasolofoniaina, B. J. R., \& Golden, C. D. (2019). Food Insecurity and the Unsustainable Hunting of Wildlife in a UNESCO World Heritage Site. Frontiers in Sustainable Food Systems, 3, 99. https://doi.org/10.3389/fsufs.2019.00099

Bos, M. M., Tylianakis, J. M., Steffan-Dewenter, I., \& Tscharntke, T. (2008). The invasive Yellow Crazy Ant and the decline of forest ant diversity in Indonesian cacao agroforests. Biological Invasions, 10(8), 1399-1409. https://doi.org/10.1007/s10530-008-9215-4

Bose, A., Vira, B., \& Garcia, C. (2016). Does environmental certification in coffee promote "business as usual"? A case study from the Western Ghats, India. Ambio, 45(8), 946-955. https://doi.org/10.1007/s13280-016-0796-3

Bouriquet, G. (1946). Le Vanillier et la Vanille à Madagascar. Journal d'agriculture Traditionnelle et de Botanique Appliquée, 26(286), 398-404.

Bowler, D. E., Bjorkman, A. D., Dornelas, M., Myers-Smith, I. H., Navarro, L. M., Niamir, A., Supp, S. R., Waldock, C., Winter, M., Vellend, M., Blowes, S. A., Böhning-Gaese, K., Bruelheide, H., Elahi, R., Antão, L. H., Hines, J., Isbell, F., Jones, H. P., Magurran, A. E., ... Bates, A. E. (2020). Mapping human pressures on biodiversity across the planet uncovers anthropogenic threat complexes. People and Nature, 2(2), 380-394. https://doi.org/10.1002/pan3.10071

Box, G. E., \& Cox, D. R. (1964). An analysis of transformations. Journal of the Royal Statistical Society: Series B (Methodological), 26(2), 211-243. https://doi.org/10.1111/j.25176161.1964.tb00553.x

Bradfer-Lawrence, T., Gardner, N., Bunnefeld, L., Bunnefeld, N., Willis, S. G., \& Dent, D. H. (2019). Guidelines for the use of acoustic indices in environmental research. Methods in Ecology and Evolution, 10(10), 1796-1807. https://doi.org/10.1111/2041-210X.13254

Brancalion, P. H. S., Niamir, A., Broadbent, E., Crouzeilles, R., Barros, F. S. M., Zambrano, A. M. A., Baccini, A., Aronson, J., Goetz, S., Reid, J. L., Strassburg, B. B. N., Wilson, S., \& Chazdon, R. L. 
(2019). Global restoration opportunities in tropical rainforest landscapes. Science Advances, 5(7), eaav3223. https://doi.org/10.1126/sciadv.aav3223

Brooks, M. E., Kristensen, K., van Benthem, K. J., Magnusson, A., Berg, C. W., Nielsen, A., Skaug, H. J., Machler, M., \& Bolker, B. M. (2017). GlmmTMB balances speed and flexibility among packages for zero-inflated generalized linear mixed modeling. The R Journal, 9(2), 378-400. https://doi.org/10.3929/ethz-b-000240890

Brooks, T. M., Mittermeier, R. A., Mittermeier, C. G., Fonseca, G. A. B. D., Rylands, A. B., Konstant, W. R., Flick, P., Pilgrim, J., Oldfield, S., Magin, G., \& Hilton-Taylor, C. (2002). Habitat Loss and Extinction in the Hotspots of Biodiversity. Conservation Biology, 16(4), 909-923. https://doi.org/10.1046/j.1523-1739.2002.00530.x

Brown, J. L., Cameron, A., Yoder, A. D., \& Vences, M. (2014). A necessarily complex model to explain the biogeography of the amphibians and reptiles of Madagascar. Nature Communications, 5(1). https://doi.org/10.1038/ncomms6046

Brown, J. L., Sillero, N., Glaw, F., Bora, P., Vieites, D. R., \& Vences, M. (2016). Spatial Biodiversity Patterns of Madagascar's Amphibians and Reptiles. PLOS ONE,11(1), e0144076. https://doi.org/10.1371/journal.pone.0144076

Brown, K. A., \& Gurevitch, J. (2004). Long-term impacts of logging on forest diversity in Madagascar. Proceedings of the National Academy of Sciences, 101(16), 6045-6049. https://doi.org/10.1073/pnas.0401456101

Brownell, R. J. (2010). Fair Trade-The Future of Vanilla? In D. Havkin-Frenkel \& F. C. Belanger (Eds.), Handbook of vanilla science and technology (Second Edition). Wiley.

Bünemann, E. K., Bongiorno, G., Bai, Z., Creamer, R. E., De Deyn, G., de Goede, R., Fleskens, L., Geissen, V., Kuyper, T. W., Mäder, P., Pulleman, M., Sukkel, W., van Groenigen, J. W., \& Brussaard, L. (2018). Soil quality - A critical review. Soil Biology and Biochemistry, 120, 105-125. https://doi.org/10.1016/j.soilbio.2018.01.030

Burivalova, Z., Towsey, M., Boucher, T., Truskinger, A., Apelis, C., Roe, P., \& Game, E. T. (2018). Using soundscapes to detect variable degrees of human influence on tropical forests in Papua New Guinea: Tropical-Forest Soundscapes. Conservation Biology, 32(1), 205-215. https://doi.org/10.1111/cobi.12968

Burnham, K. P., \& Anderson, D. R. (1998). Practical Use of the Information-Theoretic Approach. In K. P. Burnham \& D. R. Anderson (Eds.), Model Selection and Inference: A Practical InformationTheoretic Approach (pp. 75-117). Springer. https://doi.org/10.1007/978-1-4757-29177_3

Burns, S. J., Godfrey, L. R., Faina, P., McGee, D., Hardt, B., Ranivoharimanana, L., \& Randrianasy, J. (2016). Rapid human-induced landscape transformation in Madagascar at the end of the first millennium of the Common Era. Quaternary Science Reviews, 134, 92-99. https://doi.org/10.1016/j.quascirev.2016.01.007

Butchart, S. H. M., Walpole, M., Collen, B., Strien, A. van, Scharlemann, J. P. W., Almond, R. E. A., Baillie, J. E. M., Bomhard, B., Brown, C., Bruno, J., Carpenter, K. E., Carr, G. M., Chanson, J., Chenery, A. M., Csirke, J., Davidson, N. C., Dentener, F., Foster, M., Galli, A., ... Watson, R. (2010). Global Biodiversity: Indicators of Recent Declines. Science, 328(5982), 1164-1168. https://doi.org/10.1126/science.1187512

Buxton, R. T., McKenna, M. F., Clapp, M., Meyer, E., Stabenau, E., Angeloni, L. M., Crooks, K., \& Wittemyer, G. (2018). Efficacy of extracting indices from large-scale acoustic recordings to monitor biodiversity: Acoustical Monitoring. Conservation Biology, 32(5), 1174-1184. https://doi.org/10.1111/cobi.13119

Cadot, O., Dutoit, L., \& de Melo, J. (2009). The Elimination of Madagascar's Vanilla Marketing Board, 10 Years on. Journal of African Economies, 18(3), 388-430. https://doi.org/10.1093/jae/ejn025

Cannell, M. G. R., Van Noordwijk, M., \& Ong, C. K. (1996). The central agroforestry hypothesis: The trees must acquire resources that the crop would not otherwise acquire. Agroforestry Systems, 34(1), 27-31. https://doi.org/10.1007/BF00129630 
Carrasco, J., Price, V., Tulloch, V., \& Mills, M. (2020). Selecting priority areas for the conservation of endemic trees species and their ecosystems in Madagascar considering both conservation value and vulnerability to human pressure. Biodiversity and Conservation, 29, 1841-1854. https://doi.org/10.1007/s10531-020-01947-1

Carrasco, L. R., Webb, E. L., Symes, W. S., Koh, L. P., \& Sodhi, N. S. (2017). Global economic trade-offs between wild nature and tropical agriculture. PLOS Biology, 15(7), e2001657. https://doi.org/10.1371/journal.pbio.2001657

Ceddia, M. G., Bardsley, N. O., Gomez-y-Paloma, S., \& Sedlacek, S. (2014). Governance, agricultural intensification, and land sparing in tropical South America. Proceedings of the National Academy of Sciences, 111(20), 7242-7247. https://doi.org/10.1073/pnas.1317967111

Chao, A., Gotelli, N. J., Hsieh, T. C., Sander, E. L., Ma, K. H., Colwell, R. K., \& Ellison, A. M. (2014). Rarefaction and extrapolation with Hill numbers: A framework for sampling and estimation in species diversity studies. Ecological Monographs, 84(1), 45-67. https://doi.org/10.1890/13-0133.1

Chase, J. M., Blowes, S. A., Knight, T. M., Gerstner, K., \& May, F. (2020). Ecosystem decay exacerbates biodiversity loss with habitat loss. Nature, 584(7820), 238-243. https://doi.org/10.1038/s41586-020-2531-2

Chave, J., Andalo, C., Brown, S., Cairns, M. A., Chambers, J. Q., Eamus, D., Fölster, H., Fromard, F., Higuchi, N., Kira, T., Lescure, J.-P., Nelson, B. W., Ogawa, H., Puig, H., Riéra, B., \& Yamakura, T. (2005). Tree allometry and improved estimation of carbon stocks and balance in tropical forests. Oecologia, 145(1), 87-99. https://doi.org/10.1007/s00442-005-0100-x

Chave, J., Coomes, D., Jansen, S., Lewis, S. L., Swenson, N. G., \& Zanne, A. E. (2009). Towards a worldwide wood economics spectrum. Ecology Letters, 12(4), 351-366. https://doi.org/10.1111/j.1461-0248.2009.01285.x

Chave, J., Réjou-Méchain, M., Búrquez, A., Chidumayo, E., Colgan, M. S., Delitti, W. B. C., Duque, A., Eid, T., Fearnside, P. M., Goodman, R. C., Henry, M., Martínez-Yrízar, A., Mugasha, W. A., MullerLandau, H. C., Mencuccini, M., Nelson, B. W., Ngomanda, A., Nogueira, E. M., Ortiz-Malavassi, E., ... Vieilledent, G. (2014). Improved allometric models to estimate the aboveground biomass of tropical trees. Global Change Biology, 20(10), 3177-3190. https://doi.org/10.1111/gcb.12629

Chazdon, R. L. (2003). Tropical forest recovery: Legacies of human impact and natural disturbances. Perspectives in Plant Ecology, Evolution and Systematics, 6(1), 51-71. https://doi.org/10.1078/1433-8319-00042

Chazdon, R. L., Brancalion, P. H. S., Laestadius, L., Bennett-Curry, A., Buckingham, K., Kumar, C., MollRocek, J., Vieira, I. C. G., \& Wilson, S. J. (2016). When is a forest a forest? Forest concepts and definitions in the era of forest and landscape restoration. Ambio, 45(5), 538-550. https://doi.org/10.1007/s13280-016-0772-y

Chazdon, R. L., Peres, C. A., Dent, D., Sheil, D., Lugo, A. E., Lamb, D., Stork, N. E., \& Miller, S. E. (2009). The Potential for Species Conservation in Tropical Secondary Forests. Conservation Biology, 23(6), 1406-1417. https://doi.org/10.1111/j.1523-1739.2009.01338.x

Chowdhury, F. I., Barua, I., Chowdhury, A. I., Dios, V. R. de, \& Alam, M. S. (2020). Agroforestry shows higher potential than reforestation for soil restoration after slash-and-burn: A case study from Bangladesh. Geology, Ecology, and Landscapes, 0(0), 1-7. https://doi.org/10.1080/24749508.2020.1743528

Clarke, B. T. (1997). The Natural History of Amphibian Skin Secretions, Their Normal Functioning and Potential Medical Applications. Biological Reviews, 72(3), 365-379. https://doi.org/10.1111/j.1469-185X.1997.tb00018.x

Clough, Y., Barkmann, J., Juhrbandt, J., Kessler, M., Wanger, T. C., Anshary, A., Buchori, D., Cicuzza, D., Darras, K., Putra, D. D., Erasmi, S., Pitopang, R., Schmidt, C., Schulze, C. H., Seidel, D., SteffanDewenter, I., Stenchly, K., Vidal, S., Weist, M., ... Tscharntke, T. (2011). Combining high biodiversity with high yields in tropical agroforests. Proceedings of the National Academy of Sciences, 108(20), 8311-8316. https://doi.org/10.1073/pnas.1016799108 
Clough, Y., Faust, H., \& Tscharntke, T. (2009). Cacao boom and bust: Sustainability of agroforests and opportunities for biodiversity conservation. Conservation Letters, 2(5), 197-205. https://doi.org/10.1111/j.1755-263X.2009.00072.x

Clough, Y., Krishna, V. V., Corre, M. D., Darras, K., Denmead, L. H., Meijide, A., Moser, S., Musshoff, O., Steinebach, S., Veldkamp, E., Allen, K., Barnes, A. D., Breidenbach, N., Brose, U., Buchori, D., Daniel, R., Finkeldey, R., Harahap, I., Hertel, D., ... Scheu, S. (2016). Land-use choices follow profitability at the expense of ecological functions in Indonesian smallholder landscapes. Nature Communications, 7, 13137. https://doi.org/10.1038/ncomms13137

Coe, M. T., Marthews, T. R., Costa, M. H., Galbraith, D. R., Greenglass, N. L., Imbuzeiro, H. M. A., Levine, N. M., Malhi, Y., Moorcroft, P. R., Muza, M. N., Powell, T. L., Saleska, S. R., Solorzano, L. A., \& Wang, J. (2013). Deforestation and climate feedbacks threaten the ecological integrity of south-southeastern Amazonia. Philosophical Transactions of the Royal Society B: Biological Sciences, 368(1619), 20120155. https://doi.org/10.1098/rstb.2012.0155

Cohn, A. S., Newton, P., Gil, J. D. B., Kuhl, L., Samberg, L., Ricciardi, V., Manly, J. R., \& Northrop, S. (2017). Smallholder Agriculture and Climate Change. Annual Review of Environment and Resources, 42(1), 347-375. https://doi.org/10.1146/annurev-environ-102016-060946

Comtrade (2017). United Nations. https://comtrade.un.org

Condit, R. (2008). Methods for estimating aboveground biomass of forest and replacement vegetation in the tropics. Center for Tropical Forest Science Research Manual, 73, 1-73.

Conway, J. R., Lex, A., \& Gehlenborg, N. (2017). UpSetR: An R package for the visualization of intersecting sets and their properties. Bioinformatics, 33(18), 2938-2940. https://doi.org/10.1093/bioinformatics/btx364

Cooper, G. S., Willcock, S., \& Dearing, J. A. (2020). Regime shifts occur disproportionately faster in larger ecosystems. Nature Communications, 11(1), 1-10. https://doi.org/10.1038/s41467020-15029-x

Correll, D. S. (1953). Vanilla-its botany, history, cultivation and economic import. Economic Botany, 7(4), 291-358. https://doi.org/10.1007/BF02930810

Cotterall, S. (2011). Doctoral students writing: Where's the pedagogy? Teaching in Higher Education, 16(4), 413-425. https://doi.org/10.1080/13562517.2011.560381

Cullman, G. (2015). Community Forest Management as Virtualism in Northeastern Madagascar. Human Ecology, 43(1), 29-41. https://doi.org/10.1007/s10745-015-9725-5

Curtis, P. G., Slay, C. M., Harris, N. L., Tyukavina, A., \& Hansen, M. C. (2018). Classifying drivers of global forest loss. Science, 361(6407), 1108-1111. https://doi.org/10.1126/science.aau3445

Daily, G. C. (1997). Countryside Biogeography and the Provision of Ecosystem Services. In P. H. Raven (Ed.), Nature and Human Society: The Quest for a Sustainable World. National Academy Press.

Darras, K., Batáry, P., Furnas, B., Celis-Murillo, A., Van Wilgenburg, S. L., Mulyani, Y. A., \& Tscharntke, T. (2018). Comparing the sampling performance of sound recorders versus point counts in bird surveys: A meta-analysis. Journal of Applied Ecology, 55(6), 2575-2586. https://doi.org/10.1111/1365-2664.13229

Darras, K., Batáry, P., Furnas, B. J., Grass, I., Mulyani, Y. A., \& Tscharntke, T. (2019). Autonomous sound recording outperforms human observation for sampling birds: A systematic map and user guide. Ecological Applications, 29(6), e01954. https://doi.org/10.1002/eap.1954

Darras, K., Furnas, B., Fitriawan, I., Mulyani, Y., \& Tscharntke, T. (2018). Estimating bird detection distances in sound recordings for standardizing detection ranges and distance sampling. Methods in Ecology and Evolution, 9(9), 1928-1938. https://doi.org/10.1111/2041210X.13031

Darras, K., Pérez, N., Mauladi, \& Hanf-Dressler, T. (2020). BioSounds: An open-source, online platform for ecoacoustics. F1000Research, 9, 1224. https://doi.org/10.12688/f1000research.26369.1 
Dave, R., Tompkins, E. L., \& Schreckenberg, K. (2017). Forest ecosystem services derived by smallholder farmers in northwestern Madagascar: Storm hazard mitigation and participation in forest management. Forest Policy and Economics, 84, 72-82. https://doi.org/10.1016/j.forpol.2016.09.002

De Beenhouwer, M., Aerts, R., \& Honnay, O. (2013). A global meta-analysis of the biodiversity and ecosystem service benefits of coffee and cacao agroforestry. Agriculture, Ecosystems \& Environment, 175, 1-7. https://doi.org/10.1016/j.agee.2013.05.003

De Beenhouwer, M., Geeraert, L., Mertens, J., Van Geel, M., Aerts, R., Vanderhaegen, K., \& Honnay, 0. (2016). Biodiversity and carbon storage co-benefits of coffee agroforestry across a gradient of increasing management intensity in the SW Ethiopian highlands. Agriculture, Ecosystems \& Environment, 222,193-199. https://doi.org/10.1016/j.agee.2016.02.017

De La Cruz Medina, J., Rodriguez Jiménes, G. C., \& García, H. S. (2009). Vanilla Post-harvest Operations (INPhO - Post-Harvest Compendium).

De Lima, R. F., Dallimer, M., Atkinson, P. W., \& Barlow, J. (2013). Biodiversity and land-use change: Understanding the complex responses of an endemic-rich bird assemblage. Diversity and Distributions, 19(4), 411-422. https://doi.org/10.1111/ddi.12015

De Melo, J., Olarreaga, M., \& Takacs, W. (2000). Pricing Policy Under Double Market Power: Madagascar and the International Vanilla Market. Review of Development Economics, 4(1), 1-20. https://doi.org/10.1111/1467-9361.00075

De Palma, A., Sanchez-Ortiz, K., Martin, P. A., Chadwick, A., Gilbert, G., Bates, A. E., Börger, L., Contu, S., Hill, S. L. L., \& Purvis, A. (2018). Challenges With Inferring How Land-Use Affects Terrestrial Biodiversity: Study Design, Time, Space and Synthesis. In Advances in Ecological Research (Vol. 58, pp. 163-199). Elsevier. https://doi.org/10.1016/bs.aecr.2017.12.004

De Wit, M. J. (2003). Madagascar: Heads It's a Continent, Tails It's an Island. Annual Review of Earth and Planetary Sciences, 31(1), 213-248. https://doi.org/10.1146/annurev.earth.31.100901.141337

DeFries, R., Fanzo, J., Mondal, P., Remans, R., \& Wood, S. A. (2017). Is voluntary certification of tropical agricultural commodities achieving sustainability goals for small-scale producers? A review of the evidence. Environmental Research Letters, 12(3), 033001. https://doi.org/10.1088/1748-9326/aa625e

DeFries, R., Foley, J. A., \& Asner, G. P. (2004). Land-use choices: Balancing human needs and ecosystem function. Frontiers in Ecology and the Environment, 2(5), 249-257. https://doi.org/10.1890/1540-9295(2004)002[0249:LCBHNA]2.0.CO;2

DeFries, R., \& Nagendra, H. (2017). Ecosystem management as a wicked problem. Science, 356(6335), 265-270. https://doi.org/10.1126/science.aal1950

Depraetere, M., Pavoine, S., Jiguet, F., Gasc, A., Duvail, S., \& Sueur, J. (2012). Monitoring animal diversity using acoustic indices: Implementation in a temperate woodland. Ecological Indicators, 13(1), 46-54. https://doi.org/10.1016/j.ecolind.2011.05.006

Diaz, G. M., \& Lencinas, J. D. (2015). Enhanced Gap Fraction Extraction From Hemispherical Photography. IEEE Geoscience and Remote Sensing Letters, 12(8), 1785-1789. https://doi.org/10.1109/LGRS.2015.2425931

Díez, M. C., Moreno, F., \& Gantiva, E. (2017). Effects of light intensity on the morphology and CAM photosynthesis of Vanilla planifolia Andrews. Revista Facultad Nacional de Agronomía, 70(1), 8023-8033. https://doi.org/10.15446/rfna.v70n1.61736

Díez, M. C., Osorio, N. W., \& Moreno, F. (2016). Effect of dose and type of fertilizer on flowering and fruiting of vanilla plants. Journal of Plant Nutrition, 39(9), 1297-1310. https://doi.org/10.1080/01904167.2015.1098673

Digby, A., Towsey, M., Bell, B. D., \& Teal, P. D. (2013). A practical comparison of manual and autonomous methods for acoustic monitoring. Methods in Ecology and Evolution, 4(7), 675-683. https://doi.org/10.1111/2041-210X.12060 
Doherty, T. S., Balouch, S., Bell, K., Burns, T. J., Feldman, A., Fist, C., Garvey, T. F., Jessop, T. S., Meiri, S., \& Driscoll, D. A. (2020). Reptile responses to anthropogenic habitat modification: A global meta-analysis. Global Ecology and Biogeography, 29(7), 1265-1279. https://doi.org/10.1111/geb.13091

Don, A., Schumacher, J., \& Freibauer, A. (2011). Impact of tropical land-use change on soil organic carbon stocks - a meta-analysis. Global Change Biology, 17(4), 1658-1670. https://doi.org/10.1111/j.1365-2486.2010.02336.x

Donque, G. (1972). The Climatology of Madagascar. In R. Battistini \& G. Richard-Vindard (Eds.), Biogeography and Ecology in Madagascar (pp. 87-144). Springer Netherlands. https://doi.org/10.1007/978-94-015-7159-3_3

Dornelas, M., Gotelli, N. J., McGill, B., Shimadzu, H., Moyes, F., Sievers, C., \& Magurran, A. E. (2014). Assemblage Time Series Reveal Biodiversity Change but Not Systematic Loss. Science, 344(6181), 296-299. https://doi.org/10.1126/science.1248484

Douglass, K., Hixon, S., Wright, H. T., Godfrey, L. R., Crowley, B. E., Manjakahery, B., Rasolondrainy, T., Crossland, Z., \& Radimilahy, C. (2019). A critical review of radiocarbon dates clarifies the human settlement of Madagascar. Quaternary Science Reviews, 221, 105878. https://doi.org/10.1016/j.quascirev.2019.105878

Driscoll, D. A., Balouch, S., Burns, T. J., Garvey, T. F., Wevill, T., Yokochi, K., \& Doherty, T. S. (2019). A critique of 'countryside biogeography' as a guide to research in human-dominated landscapes. Journal of Biogeography, 46(12), 2850-2859. https://doi.org/10.1111/jbi.13712

Dröge, S., Martin, D. A., Andriafanomezantsoa, R., Burivalova, Z., Fulgence, T. R., Osen, K., Rakotomalala, E., Schwab, D., Wurz, A., Richter, T., \& Kreft, H. (2020). Dataset to: Listening to a changing landscape: Acoustic indices reflect bird species richness and plot-scale vegetation structure across different land-use types in north-eastern Madagascar. https://doi.org/10.17632/fxxnwtmynv.1

Dröge, S., Martin, D. A., Andriafanomezantsoa, R., Burivalova, Z., Fulgence, T. R., Osen, K., Rakotomalala, E., Schwab, D., Wurz, A., Richter, T., \& Kreft, H. (2021). Listening to a changing landscape: Acoustic indices reflect bird species richness and site-scale vegetation structure in the biodiversity hotspot of north-eastern Madagascar. Ecological Indicators, 120, 106929. https://doi.org/10.1016/j.ecolind.2020.106929

Du Puy, D. J., \& Moat, J. (1996). A refined classification of the primary vegetation of Madagascar based on the underlying geology: Using GIS to map its distribution and to assess its conservation status. In Proceedings of the International Symposium on the 'Biogeography de Madagascar', Paris, September 1995 (Editions de l’ORSTOM, pp. 205-218). W.R. Lourenço.

Duguma, B., Gockowski, J., \& Bakala, J. (2001). Smallholder Cacao (Theobroma cacao Linn.) cultivation in agroforestry systems of West and Central Africa: Challenges and opportunities. Agroforestry Systems, 51(3), 177-188. https://doi.org/10.1023/A:1010747224249

Edwards, D. P., Gilroy, J. J., Thomas, G. H., Uribe, C. A. M., \& Haugaasen, T. (2015). Land-Sparing Agriculture Best Protects Avian Phylogenetic Diversity. Current Biology, 25(18), 2384-2391. https://doi.org/10.1016/j.cub.2015.07.063

Eitelberg, D. A., van Vliet, J., Doelman, J. C., Stehfest, E., \& Verburg, P. H. (2016). Demand for biodiversity protection and carbon storage as drivers of global land change scenarios. Global Environmental Change, 40, 101-111. https://doi.org/10.1016/j.gloenvcha.2016.06.014

Escobar-Ramírez, S., Grass, I., Armbrecht, I., \& Tscharntke, T. (2019). Biological control of the coffee berry borer: Main natural enemies, control success, and landscape influence. Biological Control, 136, 103992. https://doi.org/10.1016/j.biocontrol.2019.05.011

Ewers, R. M., \& Banks-Leite, C. (2013). Fragmentation Impairs the Microclimate Buffering Effect of Tropical Forests. PLOS ONE, 8(3), e58093. https://doi.org/10.1371/journal.pone.0058093

Ewers, R. M., Scharlemann, J. P. W., Balmford, A., \& Green, R. E. (2009). Do increases in agricultural yield spare land for nature? Global Change Biology, 15(7), 1716-1726. https://doi.org/10.1111/j.1365-2486.2009.01849.x 
Fairtrade International. (2020). Coffee farmers. https://www.fairtrade.org.uk/Farmers-and-Workers/Coffee

FAO (2017). Agroforestry for landscape restoration-Exploring the potential of agroforestry to enhance the sustainability and resilience of degraded landscapes (p. 28). http://www.fao.org/3/b-i7374e.pdf

FAO (2020). FAOSTAT. Food and Agriculture Organisation of the United Nations. http://www.fao.org/faostat/en/\#home

Farina, A., \& Gage, S. H. (Eds.). (2017). Ecoacoustics: The ecological role of sounds. Wiley.

Ferreira Arruda, T. (2018). Spatial-temporal patterns of deforestation in Northeast Madagascar [MSc Thesis]. University of Goettingen.

Finch, T., Day, B. H., Massimino, D., Redhead, J. W., Field, R. H., Balmford, A., Green, R. E., \& Peach, W. J. (2020). Evaluating spatially explicit sharing-sparing scenarios for multiple environmental outcomes. Journal of Applied Ecology. https://doi.org/10.1111/1365-2664.13785

Fischer, J., Batary, P., Bawa, K. S., Brussaard, L., Chappell, M. J., Clough, Y., Daily, G. C., Dorrough, J., Hartel, T., Jackson, L. E., Klein, A. M., Kremen, C., Kuemmerle, T., Lindenmayer, D. B., Mooney, H. A., Perfecto, I., Philpott, S. M., Tscharntke, T., Vandermeer, J., ... Von Wehrden, H. (2011). Conservation: Limits of Land Sparing. Science, 334(6056), 593-593. https://doi.org/10.1126/science.334.6056.593-a

Foley, J. A. (2005). Global Consequences of Land Use. Science, 309(5734), 570-574. https://doi.org/10.1126/science.1111772

Fordham, D. A., \& Brook, B. W. (2010). Why tropical island endemics are acutely susceptible to global change. Biodiversity and Conservation, 19(2), 329-342. https://doi.org/10.1007/s10531-008-9529-7

Fouché, J. G., \& Jouve, L. (1999). Vanilla planifolia: History, botany and culture in Reunion island. Agronomie, 19(8), 689-703. https://doi.org/10.1051/agro:19990804

Frishkoff, L. O., Ke, A., Martins, I. S., Olimpi, E. M., \& Karp, D. S. (2019). Countryside Biogeography: The Controls of Species Distributions in Human-Dominated Landscapes. Current Landscape Ecology Reports. https://doi.org/10.1007/s40823-019-00037-5

Fulgence, T. R., Martin, D. A., Befidimanana, E., Botra, R., Osen, K., Randriamanantena, R., Wurz, A., Kreft, H., Andrianarimisa, A., \& Ratsoavina, F. M. (in prep.). Differential responses of amphibians and reptiles to land-use change in the biodiversity hotspot of north-eastern Madagascar.

Fuller, S., Axel, A. C., Tucker, D., \& Gage, S. H. (2015). Connecting soundscape to landscape: Which acoustic index best describes landscape configuration? Ecological Indicators, 58, 207-215. https://doi.org/10.1016/j.ecolind.2015.05.057

Gardner, C. J., Jasper, L. D., Eonintsoa, C., Duchene, J.-J., \& Davies, Z. G. (2016). The impact of natural resource use on bird and reptile communities within multiple-use protected areas: Evidence from sub-arid Southern Madagascar. Biodiversity and Conservation, 25(9), 17731793. https://doi.org/10.1007/s10531-016-1160-4

Gardner, C. J., Nicoll, M. E., Birkinshaw, C., Harris, A., Lewis, R. E., Rakotomalala, D., \& Ratsifandrihamanana, A. N. (2018). The rapid expansion of Madagascar's protected area system. Biological Conservation, 220, 29-36. https://doi.org/10.1016/j.biocon.2018.02.011

Gardner, C. J., Nicoll, M. E., Mbohoahy, T., Oleson, K. L. L., Ratsifandrihamanana, A. N., Ratsirarson, J., de Roland, L.-A. R., Virah-Sawmy, M., Zafindrasilivonona, B., \& Davies, Z. G. (2013). Protected areas for conservation and poverty alleviation: Experiences from Madagascar. Journal of Applied Ecology, 50(6), 1289-1294.

Gardner, T. A., Barlow, J., Araujo, I. S., Ávila-Pires, T. C., Bonaldo, A. B., Costa, J. E., Esposito, M. C., Ferreira, L. V., Hawes, J., Hernandez, M. I. M., Hoogmoed, M. S., Leite, R. N., Lo-Man-Hung, N. F., Malcolm, J. R., Martins, M. B., Mestre, L. A. M., Miranda-Santos, R., Overal, W. L., Parry, L., ... Peres, C. A. (2008). The cost-effectiveness of biodiversity surveys in tropical forests: Costeffectiveness of biodiversity surveys. Ecology Letters, 11(2), 139-150.

https://doi.org/10.1111/j.1461-0248.2007.01133.x 
Garland, G., Banerjee, S., Edlinger, A., Oliveira, E. M., Herzog, C., Wittwer, R., Philippot, L., Maestre, F. T., \& Heijden, M. G. A. van der. (2020). A closer look at the functions behind ecosystem multifunctionality: A review. Journal of Ecology. https://doi.org/10.1111/1365-2745.13511

Garrity, D. P. (2004). Agroforestry and the achievement of the Millennium Development Goals. $\mathrm{Ag}$ roforestry Systems, 61(1), 5-17. https://doi.org/10.1023/B:AGF0.0000028986.37502.7c

Gasc, A., Sueur, J., Pavoine, S., Pellens, R., \& Grandcolas, P. (2013). Biodiversity Sampling Using a Global Acoustic Approach: Contrasting Sites with Microendemics in New Caledonia. PLOS ONE, 8(5), e65311. https://doi.org/10.1371/journal.pone.0065311

Gay-des-Combes, J. M., Robroek, B. J. M., Hervé, D., Guillaume, T., Pistocchi, C., Mills, R. T. E., \& Buttler, A. (2017). Slash-and-burn agriculture and tropical cyclone activity in Madagascar: Implication for soil fertility dynamics and corn performance. Agriculture, Ecosystems \& Environment, 239, 207-218. https://doi.org/10.1016/j.agee.2017.01.010

Geeraert, L., Hulsmans, E., Helsen, K., Berecha, G., Aerts, R., \& Honnay, O. (2019). Rapid diversity and structure degradation over time through continued coffee cultivation in remnant Ethiopian Afromontane forests. Biological Conservation, 236, 8-16. https://doi.org/10.1016/j.biocon.2019.05.014

Gehring, P.-S., Ratsoavina, F. M., \& Vences, M. (2010). Filling the gaps - amphibian and reptile records from lowland rainforests in eastern Madagascar. Salamandra, 46(4), 214-234.

Geist, H., McConnell, W., Lambin, E. F., Moran, E., Alves, D., \& Rudel, T. (2006). Causes and Trajectories of Land-Use/Cover Change. In E. F. Lambin \& H. Geist (Eds.), Land-Use and Land-Cover Change: Local Processes and Global Impacts (pp. 41-70). Springer. https://doi.org/10.1007/3-540-32202-7_3

Geldmann, J., Manica, A., Burgess, N. D., Coad, L., \& Balmford, A. (2019). A global-level assessment of the effectiveness of protected areas at resisting anthropogenic pressures. Proceedings of the National Academy of Sciences, 117(41), 23209-23215. https://doi.org/10.1073/pnas.1908221116

Gibbs, H. K., Ruesch, A. S., Achard, F., Clayton, M. K., Holmgren, P., Ramankutty, N., \& Foley, J. A. (2010). Tropical forests were the primary sources of new agricultural land in the 1980s and 1990s. Proceedings of the National Academy of Sciences, 107(38), 16732-16737. https://doi.org/10.1073/pnas.0910275107

Gibson, L., Lee, T. M., Koh, L. P., Brook, B. W., Gardner, T. A., Barlow, J., Peres, C. A., Bradshaw, C. J. A., Laurance, W. F., Lovejoy, T. E., \& Sodhi, N. S. (2011). Primary forests are irreplaceable for sustaining tropical biodiversity. Nature, 478(7369), 378-381. https://doi.org/10.1038/nature 10425

Gillespie, G. R., Ahmad, E., Elahan, B., Evans, A., Ancrenaz, M., Goossens, B., \& Scroggie, M. P. (2012). Conservation of amphibians in Borneo: Relative value of secondary tropical forest and nonforest habitats. Biological Conservation, 152, 136-144. https://doi.org/10.1016/j.biocon.2012.03.023

Glaw, F., \& Vences, M. (2007). A field guide to the amphibians and reptiles of Madagascar (3rd ed.). Vences \& Glaw Verlag.

Godfrey, L. R., Scroxton, N., Crowley, B. E., Burns, S. J., Sutherland, M. R., Pérez, V. R., Faina, P., McGee, D., \& Ranivoharimanana, L. (2019). A new interpretation of Madagascar's megafaunal decline: The "Subsistence Shift Hypothesis". Journal of Human Evolution, 130, 126-140. https://doi.org/10.1016/j.jhevol.2019.03.002

Golden, C. D., Fernald, L. C. H., Brashares, J. S., Rasolofoniaina, B. J. R., \& Kremen, C. (2011). Benefits of wildlife consumption to child nutrition in a biodiversity hotspot. Proceedings of the National Academy of Sciences, 108(49), 19653-19656. https://doi.org/10.1073/pnas.1112586108

Gómez, W. E., Isaza, C. V., \& Daza, J. M. (2018). Identifying disturbed habitats: A new method from acoustic indices. Ecological Informatics, 45, 16-25. https://doi.org/10.1016/j.ecoinf.2018.03.001 
Goodman, S. M., \& Benstead, J. P. (2005). Updated estimates of biotic diversity and endemism for Madagascar. Oryx, 39(01). https://doi.org/10.1017/S0030605305000128

Gordon, C., Manson, R., Sundberg, J., \& Cruz-Angón, A. (2007). Biodiversity, profitability, and vegetation structure in a Mexican coffee agroecosystem. Agriculture, Ecosystems \& Environment, 118(1), 256-266. https://doi.org/10.1016/j.agee.2006.05.023

Gore, M. L., Ratsimbazafy, J., \& Lute, M. L. (2013). Rethinking Corruption in Conservation Crime: Insights from Madagascar. Conservation Letters, 6(6), 430-438. https://doi.org/10.1111/conl.12032

Grantham, H. S., Duncan, A., Evans, T. D., Jones, K., Beyer, H., Schuster, R., Walston, J., Ray, J., Robinson, J., Callow, M., Clements, T., Costa, H. M., DeGemmis, A., Elsen, P. R., Ervin, J., Franco, P., Goldman, E., Goetz, S., Hansen, A., ... Watson, J. E. M. (2020). Modification of forests by people means only $40 \%$ of remaining forests have high ecosystem integrity. BioRxiv. https://doi.org/10.1101/2020.03.05.978858

Grashuis, J., \& Su, Y. (2019). A Review of the Empirical Literature on Farmer Cooperatives: Performance, Ownership and Governance, Finance, and Member Attitude. Annals of Public and Cooperative Economics, 90(1), 77-102. https://doi.org/10.1111/apce.12205

Grass, I., Kubitza, C., Krishna, V. V., Corre, M. D., Mußhoff, O., Pütz, P., Drescher, J., Rembold, K., Ariyanti, E. S., Barnes, A. D., Brinkmann, N., Brose, U., Brümmer, B., Buchori, D., Daniel, R., Darras, K. F. A., Faust, H., Fehrmann, L., Hein, J., ... Wollni, M. (2020). Trade-offs between multifunctionality and profit in tropical smallholder landscapes. Nature Communications, 11(1), 1-13. https://doi.org/10.1038/s41467-020-15013-5

Grass, I., Loos, J., Baensch, S., Batáry, P., Librán-Embid, F., Ficiciyan, A., Klaus, F., Riechers, M., Rosa, J., Tiede, J., Udy, K., Westphal, C., Wurz, A., \& Tscharntke, T. (2019). Land-sharing/-sparing connectivity landscapes for ecosystem services and biodiversity conservation. People and Nature, 1(2), 262-272. https://doi.org/10.1002/pan3.21

Gray, C. L., Hill, S. L. L., Newbold, T., Hudson, L. N., Börger, L., Contu, S., Hoskins, A. J., Ferrier, S., Purvis, A., \& Scharlemann, J. P. W. (2016). Local biodiversity is higher inside than outside terrestrial protected areas worldwide. Nature Communications, 7, 12306. https://doi.org/10.1038/ncomms12306

Grenyer, R., Orme, C. D. L., Jackson, S. F., Thomas, G. H., Davies, R. G., Davies, T. J., Jones, K. E., Olson, V. A., Ridgely, R. S., Rasmussen, P. C., Ding, T.-S., Bennett, P. M., Blackburn, T. M., Gaston, K. J., Gittleman, J. L., \& Owens, I. P. F. (2006). Global distribution and conservation of rare and threatened vertebrates. Nature, 444(7115), 93-96. https://doi.org/10.1038/nature05237

Handbook of the Birds of the World and BirdLife International. (2018). Handbook of the Birds of theWorld and BirdLife International digital checklist of the birds of the world. Version 3. http://datazone.birdlife.org/userfiles/file/Species/Taxonomy/HBW-BirdLife_Checklist_v3_Nov18.zip

Hänke, H., Barkmann, J., Blum, L., Franke, Y., Martin, D. A., Niens, J., Osen, K., Uruena, V., Witherspoon, S. A., \& Wurz, A. (2018). Socio-economic, land use and value chain perspectives on vanilla farming in the SAVA Region (north-eastern Madagascar): The Diversity Turn Baseline Study (DTBS). July 2019 Edition. https://doi.org/10.13140/RG.2.2.22059.80163

Hänke, H., \& Fairtrade International. (2019). Living Income Reference Price for Vanilla from Uganda and Madagascar. Fairtrade International.

Hannah, L., Dave, R., Lowry, P. P., Andelman, S., Andrianarisata, M., Andriamaro, L., Cameron, A., Hijmans, R., Kremen, C., MacKinnon, J., Randrianasolo, H. H., Andriambololonera, S., Razafimpahanana, A., Randriamahazo, H., Randrianarisoa, J., Razafinjatovo, P., Raxworthy, C., Schatz, G. E., Tadross, M., \& Wilmé, L. (2008). Climate change adaptation for conservation in Madagascar. Biology Letters, 4(5), 590-594. https://doi.org/10.1098/rsbl.2008.0270

Hansen, M. C., Potapov, P. V., Moore, R., Hancher, M., Turubanova, S. A., Tyukavina, A., Thau, D., Stehman, S. V., Goetz, S. J., Loveland, T. R., \& others. (2013). High-resolution global maps of 21stcentury forest cover change. Science, 342(6160), 850-853. https://doi.org/10.1126/science. 1244693 
Hansen, M. C., Wang, L., Song, X.-P., Tyukavina, A., Turubanova, S., Potapov, P. V., \& Stehman, S. V. (2020). The fate of tropical forest fragments. Science Advances, 6(11), eaax8574. https://doi.org/10.1126/sciadv.aax8574

Hansford, J., Wright, P. C., Rasoamiaramanana, A., Pérez, V. R., Godfrey, L. R., Errickson, D., Thompson, T., \& Turvey, S. T. (2018). Early Holocene human presence in Madagascar evidenced by exploitation of avian megafauna. Science Advances, 4(9), eaat6925. https://doi.org/10.1126/sciadv.aat6925

Harper, G. J., Steininger, M. K., Tucker, C. J., Juhn, D., \& Hawkins, F. (2007). Fifty years of deforestation and forest fragmentation in Madagascar. Environmental Conservation, 34(4), 325-333. https://doi.org/10.1017/S0376892907004262

Harrison, X. A., Donaldson, L., Correa-Cano, M. E., Evans, J., Fisher, D. N., Goodwin, C. E. D., Robinson, B. S., Hodgson, D. J., \& Inger, R. (2018). A brief introduction to mixed effects modelling and multi-model inference in ecology. PeerJ, 6, e4794. https://doi.org/10.7717/peerj.4794

Hartig, F. (2020). DHARMa: Residual diagnostics for hierarchical (multi-level/mixed) regression models. R package. http://florianhartig.github.io/DHARMa/

Harvey, C. A., \& González Villalobos, J. A. (2007). Agroforestry systems conserve species-rich but modified assemblages of tropical birds and bats. Biodiversity and Conservation, 16(8), 2257-2292. https://doi.org/10.1007/s10531-007-9194-2

Harvey, C. A., Rakotobe, Z. L., Rao, N. S., Dave, R., Razafimahatratra, H., Rabarijohn, R. H., Rajaofara, H., \& MacKinnon, J. L. (2014). Extreme vulnerability of smallholder farmers to agricultural risks and climate change in Madagascar. Philosophical Transactions of the Royal Society B: Biological Sciences, 369(1639), 20130089. https://doi.org/10.1098/rstb.2013.0089

Havkin-Frenkel, D., \& Belanger, F. C. (Eds.). (2018). Handbook of vanilla science and technology (Second edition). Wiley.

Hawkins, A. F. A., Safford, R., \& Skerrett, A. (2015). Birds of Madagascar and the Indian Ocean Islands. London, UK: Christopher Helm.

Hedges, S. B., Cohen, W. B., Timyan, J., \& Yang, Z. (2018). Haiti's biodiversity threatened by nearly complete loss of primary forest. Proceedings of the National Academy of Sciences, 115(46), 11850-11855. https://doi.org/10.1073/pnas.1809753115

Heinimann, A., Mertz, O., Frolking, S., Egelund Christensen, A., Hurni, K., Sedano, F., Parsons Chini, L., Sahajpal, R., Hansen, M., \& Hurtt, G. (2017). A global view of shifting cultivation: Recent, current, and future extent. PLoS ONE, 12(9). https://doi.org/10.1371/journal.pone.0184479

Hendershot, J. N., Smith, J. R., Anderson, C. B., Letten, A. D., Frishkoff, L. O., Zook, J. R., Fukami, T., \& Daily, G. C. (2020). Intensive farming drives long-term shifts in avian community composition. Nature, 579(7799), 393-396. https://doi.org/10.1038/s41586-020-2090-6

Hending, D., Andrianiaina, A., Maxfield, P., Rakotomalala, Z., \& Cotton, S. (2019). Floral species richness, structural diversity and conservation value of vanilla agroecosystems in Madagascar. African Journal of Ecology, 58(1), 100-111. https://doi.org/10.1111/aje.12682

Hending, D., Andrianiaina, A., Rakotomalala, Z., \& Cotton, S. (2018). The Use of Vanilla Plantations by Lemurs: Encouraging Findings for both Lemur Conservation and Sustainable Agroforestry in the Sava Region, Northeast Madagascar. International Journal of Primatology, 39(1), 141-153. https://doi.org/10.1007/s10764-018-0022-1

Hernández, J. V., \& Héctor Guillermo, G. V. (2014). Producción de Vanilla en Tres Sistemas de Producción en la Sierra Huasteca Potosina. Instituto Nacional de Investigaciones Forestales, Agrícolas y Pecuarias.

Hertel, D. (2011). Tree roots in canopy soils of old European beech trees-An ecological reassessment of a forgotten phenomenon. Pedobiologia, 54(2), 119-125. https://doi.org/10.1016/j.pedobi.2010.11.003

Hijmans, R. J., van Etten, J., Cheng, J., Mattiuzzi, M., Sumner, M., Greenberg, J. A., Lamigueiro, O. P., Bevan, A., Racine, E. B., \& Shortridge, A. (2019). Package 'raster' (3.0-7) [R-Package]. 
Hill, A. P., Prince, P., Piña Covarrubias, E., Doncaster, C. P., Snaddon, J. L., \& Rogers, A. (2018). AudioMoth: Evaluation of a smart open acoustic device for monitoring biodiversity and the environment. Methods in Ecology and Evolution, 9(5), 1199-1211. https://doi.org/10.1111/2041-210X.12955

Hocking, D. J., \& Babbitt, K. J. (2014). Amphibian contributions to ecosystem services. Herpetological Conservation and Biology, 9(1), 1-17.

Hoehn, P., Steffan-Dewenter, I., \& Tscharntke, T. (2010). Relative contribution of agroforestry, rainforest and openland to local and regional bee diversity. Biodiversity and Conservation, 19(8), 2189-2200. https://doi.org/10.1007/s10531-010-9831-z

Hof, C., Araújo, M. B., Jetz, W., \& Rahbek, C. (2011). Additive threats from pathogens, climate and land-use change for global amphibian diversity. Nature, 480(7378), 516-519. https://doi.org/10.1038/nature10650

Holl, K. D., \& Brancalion, P. H. S. (2020). Tree planting is not a simple solution. Science, 368(6491), 580-581. https://doi.org/10.1126/science.aba8232

Holloway, L. (2004). Ecosystem Restoration and Rehabilitation in Madagascar. Ecological Restoration, 22(2), 113-119. https://doi.org/10.3368/er.22.2.113

Hombegowda, H. C., van Straaten, O., Köhler, M., \& Hölscher, D. (2016). On the rebound: Soil organic carbon stocks can bounce back to near forest levels when agroforests replace agriculture in southern India. SOIL, 2(1), 13-23. https://doi.org/10.5194/soil-2-13-2016

Hooper, D. U., Adair, E. C., Cardinale, B. J., Byrnes, J. E. K., Hungate, B. A., Matulich, K. L., Gonzalez, A., Duffy, J. E., Gamfeldt, L., \& O'Connor, M. I. (2012). A global synthesis reveals biodiversity loss as a major driver of ecosystem change. Nature, 486(7401), 105-108. https://doi.org/10.1038/nature11118

Hothorn, T. (2020). multcomp: Simultaneous Inference in General Parametric Models [R-Package].

Hothorn, T., Bretz, F., \& Westfall, P. (2008). Simultaneous Inference in General Parametric Models. Biometrical Journal, 50(3), 346-363. https://doi.org/10.1002/bimj.200810425

Howe, A., Lövei, G. L., \& Nachman, G. (2009). Dummy caterpillars as a simple method to assess predation rates on invertebrates in a tropical agroecosystem. Entomologia Experimentalis et Applicata, 131(3), 325-329. https://doi.org/10.1111/j.1570-7458.2009.00860.x

Hsieh, T. C., Ma, K. H., \& Chao, A. (2016). iNEXT: An R package for rarefaction and extrapolation of species diversity (Hill numbers). Methods in Ecology and Evolution, 7(12), 1451-1456. https://doi.org/10.1111/2041-210X.12613

Hylander, K., \& Nemomissa, S. (2017). Waiving the extinction debt: Can shade from coffee prevent extinctions of epiphytic plants from isolated trees? Diversity and Distributions, 23(8), 888897. https://doi.org/10.1111/ddi.12579

International Trade Centre. (2019). Sustainability Map. https://www.sustainabilitymap.org

IPBES (2019). Summary for policymakers of the global assessment report on biodiversity and ecosystem services of the Intergovernmental Science-Policy Platform on Biodiversity and Ecosystem Services. https://uwe-repository.worktribe.com/output/1493508

Irwin, M. T., Wright, P. C., Birkinshaw, C., Fisher, B. L., Gardner, C. J., Glos, J., Goodman, S. M., Loiselle, P., Rabeson, P., Raharison, J.-L., Raherilalao, M. J., Rakotondravony, D., Raselimanana, A., Ratsimbazafy, J., Sparks, J. S., Wilmé, L., \& Ganzhorn, J. U. (2010). Patterns of species change in anthropogenically disturbed forests of Madagascar. Biological Conservation, 143(10), 2351-2362. https://doi.org/10.1016/j.biocon.2010.01.023

IUCN. (2018). The IUCN Red List of Threatened Species (Version 2018-2). http://www.iucnredlist.org.

Izaguirre, M. I. R., \& Ramírez-Alán, O. (2018). Acoustic indices applied to biodiversity monitoring in a Costa Rica dry tropical forest. JEA, 2(1), 1-1. https://doi.org/10.22261/jea.tnw2np

Jackson, S. T., \& Sax, D. F. (2010). Balancing biodiversity in a changing environment: Extinction debt, immigration credit and species turnover. Trends in Ecology \& Evolution, 25(3), 153160. https://doi.org/10.1016/j.tree.2009.10.001 
Jagoret, P., Michel-Dounias, I., Snoeck, D., Ngnogué, H. T., \& Malézieux, E. (2012). Afforestation of savannah with cocoa agroforestry systems: A small-farmer innovation in central Cameroon. Agroforestry Systems, 86(3), 493-504. https://doi.org/10.1007/s10457-012-9513-9

Jahn, T., Bergmann, M., \& Keil, F. (2012). Transdisciplinarity: Between mainstreaming and marginalization. Ecological Economics, 79, 1-10. https://doi.org/10.1016/j.ecolecon.2012.04.017

Jantz, S. M., Barker, B., Brooks, T. M., Chini, L. P., Huang, Q., Moore, R. M., Noel, J., \& Hurtt, G. C. (2015). Future habitat loss and extinctions driven by land-use change in biodiversity hotspots under four scenarios of climate-change mitigation. Conservation Biology, 29(4), 1122-1131. https://doi.org/10.1111/cobi.12549

Japan Aerospace Exploration Agency. (2018). ALOS Global Digital Surface Model «ALOS World 3D 30m (AW3D30). http://www.eorc.jaxa.jp/ALOS/en/aw3d30/

Jarosz, L. (1993). Defining and Explaining Tropical Deforestation: Shifting Cultivation and Population Growth in Colonial Madagascar (1896-1940). Economic Geography, 69(4), 366. https://doi.org/10.2307/143595

Jenkins, R. K. B., Tognelli, M. F., Bowles, P., Cox, N., Brown, J. L., Chan, L., Andreone, F., Andriamazava, A., Andriantsimanarilafy, R. R., Anjeriniaina, M., Bora, P., Brady, L. D., Hantalalaina, E. F., Glaw, F., Griffiths, R. A., Hilton-Taylor, C., Hoffmann, M., Katariya, V., Rabibisoa, N. H., ... Vences, M. (2014). Extinction Risks and the Conservation of Madagascar's Reptiles. PLOS ONE, 9(8), e100173. https://doi.org/10.1371/journal.pone.0100173

Jepsen, M. R., Kuemmerle, T., Müller, D., Erb, K., Verburg, P. H., Haberl, H., Vesterager, J. P., Andrič, M., Antrop, M., Austrheim, G., Björn, I., Bondeau, A., Bürgi, M., Bryson, J., Caspar, G., Cassar, L. F., Conrad, E., Chromý, P., Daugirdas, V., ... Reenberg, A. (2015). Transitions in European land-management regimes between 1800 and 2010. Land Use Policy, 49, 53-64. https://doi.org/10.1016/j.landusepol.2015.07.003

Jezeer, R. E., Santos, M. J., Verweij, P. A., Boot, R. G. A., \& Clough, Y. (2019). Benefits for multiple ecosystem services in Peruvian coffee agroforestry systems without reducing yield. Ecosystem Services, 40, 101033. https://doi.org/10.1016/j.ecoser.2019.101033

Jezeer, R. E., Verweij, P. A., Santos, M. J., \& Boot, R. G. A. (2017). Shaded Coffee and Cocoa - Double Dividend for Biodiversity and Small-scale Farmers. Ecological Economics, 140, 136-145. https://doi.org/10.1016/j.ecolecon.2017.04.019

Jha, S., Bacon, C. M., Philpott, S. M., Ernesto Méndez, V., Läderach, P., \& Rice, R. A. (2014). Shade Coffee: Update on a Disappearing Refuge for Biodiversity. BioScience, 64(5), 416-428. https://doi.org/10.1093/biosci/biu038

Jiren, T. S., Hanspach, J., Schultner, J., Fischer, J., Bergsten, A., Senbeta, F., Hylander, K., \& Dorresteijn, I. (2020). Reconciling food security and biodiversity conservation: Participatory scenario planning in southwestern Ethiopia. Ecology and Society, 25(3). https://doi.org/10.5751/ES-11681-250324

Jones, J. P. G., Ratsimbazafy, J., Ratsifandrihamanana, A. N., Watson, J. E. M., Andrianandrasana, H. T., Cabeza, M., Cinner, J. E., Goodman, S. M., Hawkins, F., Mittermeier, R. A., Rabearisoa, A. L., Rakotonarivo, O. S., Razafimanahaka, J. H., Razafimpahanana, A. R., Wilmé, L., \& Wright, P. C. (2019a). Last chance for Madagascar's biodiversity. Nature Sustainability, 2018, 9-11. https://doi.org/10.1038/s41893-019-0288-0

Jones, J. P. G., Ratsimbazafy, J., Ratsifandrihamanana, A. N., Watson, J. E. M., Andrianandrasana, H. T., Cabeza, M., Cinner, J. E., Goodman, S. M., Hawkins, F., Mittermeier, R. A., Rabearisoa, A. L., Rakotonarivo, O. S., Razafimanahaka, J. H., Razafimpahanana, A. R., Wilmé, L., \& Wright, P. C. (2019b). Madagascar: Crime threatens biodiversity. Science, 363(6429), 825-825. https://doi.org/10.1126/science.aaw6402

Jones, J. P. G., Ratsimbazafy, J., Ratsifandrihamanana, A. N., Watson, J. E. M., Andrianandrasana, H. T., Cabeza, M., Cinner, J. E., Goodman, S. M., Hawkins, F., Mittermeier, R. A., Rabearisoa, A. L., Rakotonarivo, O. S., Razafimanahaka, J. H., Razafimpahanana, A. R., Wilmé, L., \& Wright, P. C. (2019c). Last chance for Madagascar's biodiversity. Nature Sustainability, 2(5), 350-352. https://doi.org/10.1038/s41893-019-0288-0 
Jorge, F. C., Machado, C. G., da Cunha Nogueira, S. S., \& Nogueira-Filho, S. L. G. (2018). The effectiveness of acoustic indices for forest monitoring in Atlantic rainforest fragments. Ecological Indicators, 91, 71-76. https://doi.org/10.1016/j.ecolind.2018.04.001

Jose, S. (2009). Agroforestry for ecosystem services and environmental benefits: An overview. Agroforestry Systems, 76(1), 1-10. https://doi.org/10.1007/s10457-009-9229-7

Kadlec, T., Tropek, R., \& Konvicka, M. (2012). Timed surveys and transect walks as comparable methods for monitoring butterflies in small plots. Journal of Insect Conservation, 16(2), 275-280. https://doi.org/10.1007/s10841-011-9414-7

Karger, D. N., Conrad, O., Böhner, J., Kawohl, T., Kreft, H., Soria-Auza, R. W., Zimmermann, N. E., Linder, H. P., \& Kessler, M. (2017). Climatologies at high resolution for the earth's land surface areas. Scientific Data, 4(1), 1-20. https://doi.org/10.1038/sdata.2017.122

Kassambara, A. (2020). ggpubr: "Ggplot2" based publication ready plots [R-Package].

Kassambara, A., \& Mundt, F. (2020). Factorextra: Extract and visualize the results of multivariate data analyses [R-Package].

Kehoe, L., Kuemmerle, T., Meyer, C., Levers, C., Václavík, T., \& Kreft, H. (2015). Global patterns of agricultural land-use intensity and vertebrate diversity. Diversity and Distributions, 21(11), 1308-1318.

Klanderud, K., Mbolatiana, H. Z. H., Vololomboahangy, M. N., Radimbison, M. A., Roger, E., Totland, $\emptyset$., \& Rajeriarison, C. (2010). Recovery of plant species richness and composition after slash-and-burn agriculture in a tropical rainforest in Madagascar. Biodiversity and Conservation, 19(1), 187-204. https://doi.org/10.1007/s10531-009-9714-3

Kluger, M. O., \& Bartzke, G. (2020). A practical guideline how to tackle interdisciplinarity-A synthesis from a post-graduate group project. Humanities and Social Sciences Communications, 7(1), 1-11. https://doi.org/10.1057/s41599-020-00540-9

Kolby, J. E., \& Skerratt, L. F. (2015). Amphibian Chytrid Fungus in Madagascar neither Shows Widespread Presence nor Signs of Certain Establishment. PLOS ONE, 10(10), e0139172. https://doi.org/10.1371/journal.pone.0139172

Komarek, A. M. (2010). Crop diversification decisions: The case of vanilla in Uganda. Quarterly Journal of International Agriculture, 49(3), 227-242. https://doi.org/10.22004/ag.econ.155551

Krause, B. L. (1993). The niche hypothesis: A virtual symphony of animal sounds, the origins of musical expression and the health of habitats. The Soundscape Newsletter, 6, 6-10.

Kreft, H., \& Jetz, W. (2007). Global patterns and determinants of vascular plant diversity. Proceedings of the National Academy of Sciences, 104(14), 5925-5930.

Kremen, C. (2015). Reframing the land-sparing/land-sharing debate for biodiversity conservation. Annals of the New York Academy of Sciences, 1355(1), 52-76. https://doi.org/10.1111/nyas.12845

Kremen, C., Cameron, A., Moilanen, A., Phillips, S. J., Thomas, C. D., Beentje, H., Dransfield, J., Fisher, B. L., Glaw, F., Good, T. C., Harper, G. J., Hijmans, R. J., Lees, D. C., Louis, E., Nussbaum, R. A., Raxworthy, C. J., Razafimpahanana, A., Schatz, G. E., Vences, M., ... Zjhra, M. L. (2008). Aligning Conservation Priorities Across Taxa in Madagascar with High-Resolution Planning Tools. Science, 320(5873), 222-226. https://doi.org/10.1126/science.1155193

Kremen, C., \& Merenlender, A. M. (2018). Landscapes that work for biodiversity and people. Science, 362(6412), eaau6020. https://doi.org/10.1126/science.aau6020

Krishnamurthy, P. K., \& Reddiar, K. L. (2011). Agrobiodiversity for Livelihood Security: A Case Study of Agroforestry Technologies in Mexico. Journal of Life Sciences, 5(2), 108-119.

Kull, C. A. (2000). Deforestation, Erosion, and Fire: Degradation Myths in the Environmental History of Madagascar. Environment and History, 6(4), 423-450. JSTOR.

Kull, C. A. (2002). Madagascar aflame: Landscape burning as peasant protest, resistance, or a resource management tool? Political Geography, 21(7), 927-953. https://doi.org/10.1016/S0962-6298(02)00054-9 
Kull, C. A. (2012). Air photo evidence of historical land cover change in the highlands: Wetlands and grasslands give way to crops and woodlots. Madagascar Conservation \& Development, 7(3), 144-152-152. https://doi.org/10.4314/mcd.v7i3.7

Kull, C. A., Tassin, J., \& Carriere, S. M. (2014). Approaching invasive species in Madagascar. Madagascar Conservation \& Development, 9(2), 60-70. https://doi.org/10.4314/mcd.v9i2.2

Kunz, S., Hänke, H., \& Schlecht, E. (2020). Income Diversification trough Animal Husbandry for Smallholder Vanilla Farmers in Madagascar. Journal of Agriculture and Rural Development in the Tropics and Subtropics, 121(1), 63-75. https://doi.org/10.17170/kobra202004061143

Kurz, D. J., Nowakowski, A. J., Tingley, M. W., Donnelly, M. A., \& Wilcove, D. S. (2014). Forest-land use complementarity modifies community structure of a tropical herpetofauna. Biological Conservation, 170, 246-255. https://doi.org/10.1016/j.biocon.2013.12.027

Kuussaari, M., Bommarco, R., Heikkinen, R. K., Helm, A., Krauss, J., Lindborg, R., Öckinger, E., Pärtel, M., Pino, J., Rodà, F., Stefanescu, C., Teder, T., Zobel, M., \& Steffan-Dewenter, I. (2009). Extinction debt: A challenge for biodiversity conservation. Trends in Ecology \& Evolution, 24(10), 564-571. https://doi.org/10.1016/j.tree.2009.04.011

Labrière, N., Locatelli, B., Laumonier, Y., Freycon, V., \& Bernoux, M. (2015). Soil erosion in the humid tropics: A systematic quantitative review. Agriculture, Ecosystems \& Environment, 203, 127-139. https://doi.org/10.1016/j.agee.2015.01.027

Lamb, D., Erskine, P. D., \& Parrotta, J. A. (2005). Restoration of Degraded Tropical Forest Landscapes. Science, 310(5754), 1628-1632. https://doi.org/10.1126/science.1111773

Lambin, E. F., Geist, H. J., \& Lepers, E. (2003). Dynamics of land-use and land-cover change in tropical regions. Annual Review of Environment and Resources, 28(1), 205-241. https://doi.org/10.1146/annurev.energy.28.050302.105459

Lambin, E. F., Turner, B. L., Geist, H. J., Agbola, S. B., Angelsen, A., Bruce, J. W., Coomes, O. T., Dirzo, R., Fischer, G., Folke, C., George, P. S., Homewood, K., Imbernon, J., Leemans, R., Li, X., Moran, E. F., Mortimore, M., Ramakrishnan, P. S., Richards, J. F., ... Xu, J. (2001). The causes of land-use and land-cover change: Moving beyond the myths. Global Environmental Change, 11(4), 261-269. https://doi.org/10.1016/S0959-3780(01)00007-3

Laney, R. M. (2002). Disaggregating Induced Intensification for Land-Change Analysis: A Case Study from Madagascar. Annals of the Association of American Geographers, 92(4), 702-726. https://doi.org/10.1111/1467-8306.00312

Laney, R. M., \& Turner, B. L. (2015). The Persistence of Self-Provisioning Among Smallholder Farmers in Northeast Madagascar. Human Ecology, 43(6), 811-826. https://doi.org/10.1007/s10745-015-9791-8

Laurance, W. F., Sayer, J., \& Cassman, K. G. (2014). Agricultural expansion and its impacts on tropical nature. Trends in Ecology \& Evolution, 29(2), 107-116. https://doi.org/10.1016/j.tree.2013.12.001

Leakey, R. R. B. (2014). The Role of Trees in Agroecology and Sustainable Agriculture in the Tropics. Annual Review of Phytopathology, 52(1), 113-133. https://doi.org/10.1146/annurevphyto-102313-045838

Leclère, D., Obersteiner, M., Barrett, M., Butchart, S. H. M., Chaudhary, A., De Palma, A., DeClerck, F. A. J., Di Marco, M., Doelman, J. C., Dürauer, M., Freeman, R., Harfoot, M., Hasegawa, T., Hellweg, S., Hilbers, J. P., Hill, S. L. L., Humpenöder, F., Jennings, N., Krisztin, T., ... Young, L. (2020). Bending the curve of terrestrial biodiversity needs an integrated strategy. Nature, 1-6. https://doi.org/10.1038/s41586-020-2705-y

Lee, J. S. H., Garcia-Ulloa, J., Ghazoul, J., Obidzinski, K., \& Koh, L. P. (2014). Modelling environmental and socio-economic trade-offs associated with land-sparing and land-sharing approaches to oil palm expansion. Journal of Applied Ecology, 51(5), 1366-1377.

https://doi.org/10.1111/1365-2664.12286 
Lees, D. C., Kremen, C., Raharitsimba, T., Goodman, S. M., \& Benstead, J. P. (2003). Classification, diversity, and endemism of the butterflies (Papilionoidea and Hesperioidea): A revised species checklist. Chicago University Press.

Lefcheck, J. S., Byrnes, J. E. K., Isbell, F., Gamfeldt, L., Griffin, J. N., Eisenhauer, N., Hensel, M. J. S., Hector, A., Cardinale, B. J., \& Duffy, J. E. (2015). Biodiversity enhances ecosystem multifunctionality across trophic levels and habitats. Nature Communications, 6(1), 6936. https://doi.org/10.1038/ncomms7936

Length, R., Singmann, H., \& Love, J. (2018). Emmeans: Estimated marginal means, aka least-squares means (1.4.5) [R-Package].

Lewis, S. L., Edwards, D. P., \& Galbraith, D. (2015). Increasing human dominance of tropical forests. Science, 349(6250), 827-832. https://doi.org/10.1126/science.aaa9932

Llopis, J. C., Diebold, C. L., Schneider, F., Harimalala, P. C., Patrick, L., Messerli, P., \& Zaehringer, J. G. (2020). Capabilities Under Telecoupling: Human Well-Being Between Cash Crops and Protected Areas in North-Eastern Madagascar. Frontiers in Sustainable Food Systems, 3. https://doi.org/10.3389/fsufs.2019.00126

Llopis, J. C., Harimalala, P. C., Bär, R., Heinimann, A., Rabemananjara, Z. H., \& Zaehringer, J. G. (2019). Effects of protected area establishment and cash crop price dynamics on land use transitions 1990-2017 in north-eastern Madagascar. Journal of Land Use Science, 14(1), 1-29. https://doi.org/10.1080/1747423X.2019.1625979

Lobell, D. B., Cassman, K. G., \& Field, C. B. (2009). Crop Yield Gaps: Their Importance, Magnitudes, and Causes. Annual Review of Environment and Resources, 34(1), 179-204. https://doi.org/10.1146/annurev.environ.041008.093740

Lovejoy, T. E., \& Nobre, C. (2018). Amazon Tipping Point. Science Advances, 4(2), eaat2340. https://doi.org/10.1126/sciadv.aat2340

Lubinsky, P., Van Dam, M., \& Van Dam, A. (2006). Pollination of vanilla and the evolution in the orchidaceae. American Orchid Society Bulletin, 32, 525-554.

Maas, B., Heath, S., Grass, I., Cassano, C., Classen, A., Faria, D., Gras, P., Williams-Guillén, K., Johnson, M., Karp, D. S., Linden, V., Martínez-Salinas, A., Schmack, J. M., \& Kross, S. (2019). Experimental field exclosure of birds and bats in agricultural systems-Methodological insights, potential improvements, and cost-benefit trade-offs. Basic and Applied Ecology, 35, 1-12. https://doi.org/10.1016/j.baae.2018.12.002

Maas, B., Putra, D. D., Waltert, M., Clough, Y., Tscharntke, T., \& Schulze, C. H. (2009). Six years of habitat modification in a tropical rainforest margin of Indonesia do not affect bird diversity but endemic forest species. Biological Conservation, 142(11), 2665-2671. https://doi.org/10.1016/j.biocon.2009.06.018

Macchi, L., Decarre, J., Goijman, A. P., Mastrangelo, M., Blendinger, P. G., Gavier-Pizarro, G. I., Murray, F., Piquer-Rodriguez, M., Semper-Pascual, A., \& Kuemmerle, T. (2020). Trade-offs between biodiversity and agriculture are moving targets in dynamic landscapes. Journal of Applied Ecology, 57(10), 2054-2063.

Machado, R. B., Aguiar, L., \& Jones, G. (2017). Do acoustic indices reflect the characteristics of bird communities in the savannas of Central Brazil? Landscape and Urban Planning, 162, 36-43. https://doi.org/10.1016/j.landurbplan.2017.01.014

Mammides, C., Goodale, E., Dayananda, S. K., Kang, L., \& Chen, J. (2017). Do acoustic indices correlate with bird diversity? Insights from two biodiverse regions in Yunnan Province, south China. Ecological Indicators, 82, 470-477. https://doi.org/10.1016/j.ecolind.2017.07.017

Manning, P., van der Plas, F., Soliveres, S., Allan, E., Maestre, F. T., Mace, G., Whittingham, M. J., \& Fischer, M. (2018). Redefining ecosystem multifunctionality. Nature Ecology \& Evolution, 2(3), 427-436. https://doi.org/10.1038/s41559-017-0461-7

Marshall, B. M., Strine, C., \& Hughes, A. C. (2020). Thousands of reptile species threatened by underregulated global trade. Nature Communications, 11(1), 4738. https://doi.org/10.1038/s41467-020-18523-4 
Martin, D. A., Andriafanomezantsoa, R., Dröge, S., Osen, K., Rakotomalala, E., Wurz, A., Andrianarimisa, A., \& Kreft, H. (2020a). Bird diversity and endemism along a land-use gradient in Madagascar: The conservation value of vanilla agroforests. Biotropica, 53(1). https://doi.org/10.1111/BTP.12859

Martin, D. A., Osen, K., Grass, I., Hölscher, D., Tscharntke, T., Wurz, A., \& Kreft, H. (2020b). Land-use history determines ecosystem services and conservation value in tropical agroforestry. Conservation Letters, 13(5), e12740. https://doi.org/10.1111/conl.12740

Martin, D. A., Wurz, A., Osen, K., Grass, I., Hölscher, D., Rabemanantsoa, T., Tscharntke, T., \& Kreft, H. (2020c). Shade-tree rehabilitation in vanilla agroforests is yield neutral and may translate into landscape-scale canopy cover gains. Ecosystems. https://doi.org/10.1007/s10021020-00586-5

Martin, E. A., Viano, M., Ratsimisetra, L., Laloë, F., \& Carrière, S. M. (2012). Maintenance of bird functional diversity in a traditional agroecosystem of Madagascar. Agriculture, Ecosystems \& Environment, 149, 1-9. https://doi.org/10.1016/j.agee.2011.12.005

Mastrángelo, M. E., Pérez-Harguindeguy, N., Enrico, L., Bennett, E., Lavorel, S., Cumming, G. S., Abeygunawardane, D., Amarilla, L. D., Burkhard, B., Egoh, B. N., Frishkoff, L., Galetto, L., Huber, S., Karp, D. S., Ke, A., Kowaljow, E., Kronenburg-García, A., Locatelli, B., Martín-López, B., ... Zoeller, K. (2019). Key knowledge gaps to achieve global sustainability goals. Nature Sustainability, 1-7. https://doi.org/10.1038/s41893-019-0412-1

Maxwell, S. L., Fuller, R. A., Brooks, T. M., \& Watson, J. E. M. (2016). Biodiversity: The ravages of guns, nets and bulldozers. Nature News, 536(7615), 143. https://doi.org/10.1038/536143a

McConnell, D. J., MacConnell, D. J., \& Dillon, J. L. (1997). Farm management for Asia: A systems approach. Food \& Agriculture Org.

McConnell, W., Viña, A., Kull, C., \& Batko, C. (2015). Forest Transition in Madagascar's Highlands: Initial Evidence and Implications. Land, 4(4), 1155-1181. https://doi.org/10.3390/land4041155

McDowell, N. G., Allen, C. D., Anderson-Teixeira, K., Aukema, B. H., Bond-Lamberty, B., Chini, L., Clark, J. S., Dietze, M., Grossiord, C., Hanbury-Brown, A., Hurtt, G. C., Jackson, R. B., Johnson, D. J., Kueppers, L., Lichstein, J. W., Ogle, K., Poulter, B., Pugh, T. A. M., Seidl, R., ... Xu, C. (2020). Pervasive shifts in forest dynamics in a changing world. Science, 368(6494), eaaz9463. https://doi.org/10.1126/science.aaz9463

Melo, F. P. L., Arroyo-Rodríguez, V., Fahrig, L., Martínez-Ramos, M., \& Tabarelli, M. (2013). On the hope for biodiversity-friendly tropical landscapes. Trends in Ecology \& Evolution, 28(8), 462-468. https://doi.org/10.1016/j.tree.2013.01.001

Mendenhall, C. D., Frishkoff, L. O., Santos-Barrera, G., Pacheco, J., Mesfun, E., Quijano, F. M., Ehrlich, P. R., Ceballos, G., Daily, G. C., \& Pringle, R. M. (2014). Countryside biogeography of Neotropical reptiles and amphibians. Ecology, 95(4), 856-870. https://doi.org/10.1890/122017.1

Mendenhall, C. D., Sekercioglu, C. H., Brenes, F. O., Ehrlich, P. R., \& Daily, G. C. (2011). Predictive model for sustaining biodiversity in tropical countryside. Proceedings of the National Academy of Sciences, 108(39), 16313-16316. https://doi.org/10.1073/pnas.1111687108

Mendenhall, C. D., Shields-Estrada, A., Krishnaswami, A. J., \& Daily, G. C. (2016). Quantifying and sustaining biodiversity in tropical agricultural landscapes. Proceedings of the National Academy of Sciences, 113(51), 14544-14551. https://doi.org/10.1073/pnas.1604981113

Mertz, 0. (2002). The relationship between length of fallow and crop yields in shifting cultivation: A rethinking. Agroforestry Systems, 55(2), 149-159. https://doi.org/10.1023/A:1020507631848

Mertz, O., Padoch, C., Fox, J., Cramb, R. A., Leisz, S. J., Lam, N. T., \& Vien, T. D. (2009). Swidden Change in Southeast Asia: Understanding Causes and Consequences. Human Ecology, 37(3), 259264. https://doi.org/10.1007/s10745-009-9245-2 
Messerli, P. (2000). Use of Sensitivity Analysis to Evaluate Key Factors for Improving Slash-andBurn Cultivation Systems on the Eastern Escarpment of Madagascar. Mountain Research and Development, 20(1), 32-41. https://doi.org/10.1659/02764741(2000)020[0032:UOSATE]2.0.CO;2

Meyfroidt, P., Carlson, K. M., Fagan, M. E., Gutiérrez-Vélez, V. H., Macedo, M. N., Curran, L. M., DeFries, R. S., Dyer, G. A., Gibbs, H. K., Lambin, E. F., Morton, D. C., \& Robiglio, V. (2014). Multiple pathways of commodity crop expansion in tropical forest landscapes. Environmental Research Letters, 9(7), 074012. https://doi.org/10.1088/1748-9326/9/7/074012

Meyfroidt, P., \& Lambin, E. F. (2011). Global Forest Transition: Prospects for an End to Deforestation. Annual Review of Environment and Resources, 36(1), 343-371. https://doi.org/10.1146/annurev-environ-090710-143732

Meyfroidt, P., Roy Chowdhury, R., de Bremond, A., Ellis, E. C., Erb, K.-H., Filatova, T., Garrett, R. D., Grove, J. M., Heinimann, A., Kuemmerle, T., Kull, C. A., Lambin, E. F., Landon, Y., le Polain de Waroux, Y., Messerli, P., Müller, D., Nielsen, J. Ø., Peterson, G. D., Rodriguez García, V., ... Verburg, P. H. (2018). Middle-range theories of land system change. Global Environmental Change, 53, 52-67. https://doi.org/10.1016/j.gloenvcha.2018.08.006

Miller, D. C., Ordoñez, P. J., Brown, S. E., Forrest, S., Nava, N. J., Hughes, K., \& Baylis, K. (2020). The impacts of agroforestry on agricultural productivity, ecosystem services, and human wellbeing in low-and middle-income countries: An evidence and gap map. Campbell Systematic Reviews, 16(1), e1066. https://doi.org/10.1002/cl2.1066

Minten, B., \& Barrett, C. B. (2008). Agricultural Technology, Productivity, and Poverty in Madagascar. World Development, 36(5), 797-822. https://doi.org/10.1016/j.worlddev.2007.05.004

Minten, B., Sander, K., \& Stifel, D. (2013). Forest management and economic rents: Evidence from the charcoal trade in Madagascar. Energy for Sustainable Development, 17(2), 106-115. https://doi.org/10.1016/j.esd.2012.08.004

Missouri Botanical Garden. (2019). Catalogue of the Plants of Madagascar. Missouri Botanical Garden, St. Louis; Antananarivo Madagascar. http://legacy.tropicos.org/Project/Madagascar

Moguel, P., \& Toledo, V. M. (1999). Biodiversity Conservation in Traditional Coffee Systems of Mexico. Conservation Biology, 13(1), 11-21. https://doi.org/10.1046/j.15231739.1999.97153.x

Molotoks, A., Kuhnert, M., Dawson, T. P., \& Smith, P. (2017). Global Hotspots of Conflict Risk between Food Security and Biodiversity Conservation. Land, 6(4), 67. https://doi.org/10.3390/land6040067

Morelli, T. L., Smith, A. B., Mancini, A. N., Balko, E. A., Borgerson, C., Dolch, R., Farris, Z., Federman, S., Golden, C. D., Holmes, S. M., Irwin, M., Jacobs, R. L., Johnson, S., King, T., Lehman, S. M., Louis, E. E., Murphy, A., Randriahaingo, H. N. T., Randrianarimanana, H. L. L., ... Baden, A. L. (2020). The fate of Madagascar's rainforest habitat. Nature Climate Change, 10(1), 89-96. https://doi.org/10.1038/s41558-019-0647-x

Muschler, R. G. (2001). Shade improves coffee quality in a sub-optimal coffee-zone of Costa Rica. Agroforestry Systems, 51(2), 131-139. https://doi.org/10.1023/A:1010603320653

Myers, N., Mittermeier, R. A., Mittermeier, C. G., da Fonseca, G. A. B., \& Kent, J. (2000). Biodiversity hotspots for conservation priorities. Nature, 403(6772), 853-858. https://doi.org/10.1038/35002501

Nagelkerke, N. J. D. (1991). A note on a general definition of the coefficient of determination. Biometrika, 78(3), 691-692. https://doi.org/10.2307/2337038

Nair, P. K. R., Kumar, B. M., \& Nair, V. D. (2009). Agroforestry as a strategy for carbon sequestration. Journal of Plant Nutrition and Soil Science, 172(1), 10-23. https://doi.org/10.1002/jpln.200800030

Nakagawa, S., \& Schielzeth, H. (2013). A general and simple method for obtaining $R^{2}$ from generalized linear mixed-effects models. Methods in Ecology and Evolution, 4(2), 133-142. https://doi.org/10.1111/j.2041-210x.2012.00261.x 
NASA. (2004). Madagascar Topography and Vegetation. accessed via https://commons.wikimedia.org/wiki/File:Madagascar_topo.jpg.

Ndriantsoa, S. H., Riemann, J. C., Raminosoa, N., Rödel, M.-O., \& Glos, J. S. (2017). Amphibian Diversity in the Matrix of a Fragmented Landscape Around Ranomafana in Madagascar Depends on Matrix Quality. Tropical Conservation Science, 10, 1-16. https://doi.org/10.1177/1940082916686065

Neimark, B., Osterhoudt, S., Blum, L., \& Healy, T. (2019). Mob justice and 'The civilized commodity'. The Journal of Peasant Studies, 1-20. https://doi.org/10.1080/03066150.2019.1680543

Neudert, R., Ganzhorn, J. U., \& Wätzold, F. (2017). Global benefits and local costs - The dilemma of tropical forest conservation: A review of the situation in Madagascar. Environmental Conservation, 44(01), 82-96. https://doi.org/10.1017/S0376892916000552

Newbold, T., Hudson, L. N., Hill, S. L. L., Contu, S., Lysenko, I., Senior, R. A., Börger, L., Bennett, D. J., Choimes, A., Collen, B., Day, J., De Palma, A., Díaz, S., Echeverria-Londoño, S., Edgar, M. J., Feldman, A., Garon, M., Harrison, M. L. K., Alhusseini, T., ... Purvis, A. (2015). Global effects of land use on local terrestrial biodiversity. Nature, 520(7545), 45-50. https://doi.org/10.1038/nature14324

Newmark, W. D. (2008). Isolation of African protected areas. Frontiers in Ecology and the Environment, 6(6), 321-328. https://doi.org/10.1890/070003

Niether, W., Jacobi, J., Blaser, W. J., Andres, C., \& Armengot, L. (2020). Cocoa agroforestry systems versus monocultures: A multi-dimensional meta-analysis. Environmental Research Letters, 15(10), 104085. https://doi.org/10.1088/1748-9326/abb053

Nijmeijer, A., Lauri, P.-E., Harmand, J.-M., Freschet, G. T., Essobo Nieboukaho, J.-D., Fogang, P. K., Enock, S., \& Saj, S. (2019). Long-term dynamics of cocoa agroforestry systems established on lands previously occupied by savannah or forests. Agriculture, Ecosystems \& Environment, 275, 100-111. https://doi.org/10.1016/j.agee.2019.02.004

Nopper, J., Riemann, J. C., Brinkmann, K., Rödel, M.-O., \& Ganzhorn, J. U. (2018). Differences in land cover - biodiversity relationships complicate the assignment of conservation values in human-used landscapes. Ecological Indicators, 90, 112-119. https://doi.org/10.1016/j.ecolind.2018.02.004

Nori, J., Villalobos, F., \& Loyola, R. (2018). Global priority areas for amphibian research. Journal of Biogeography, 45(11), 2588-2594. https://doi.org/10.1111/jbi.13435

Norris, S. (2006). Madagascar Defiant. BioScience, 56(12), 960-965. https://doi.org/10.1641/00063568(2006)56[960:MD]2.0.C0;2

Ocampo-Ariza, C., Denis, K., Njie Motombi, F., Bobo, K. S., Kreft, H., \& Waltert, M. (2019). Extinction thresholds and negative responses of Afrotropical ant-following birds to forest cover loss in oil palm and agroforestry landscapes. Basic and Applied Ecology, 39, 26-37.

https://doi.org/10.1016/j.baae.2019.06.008

Odoux, E., \& Grisoni, M. (Eds.). (2010). Vanilla. CRC Press.

O’Hanlon, S. J., Rieux, A., Farrer, R. A., Rosa, G. M., Waldman, B., Bataille, A., Kosch, T. A., Murray, K. A., Brankovics, B., Fumagalli, M., Martin, M. D., Wales, N., Alvarado-Rybak, M., Bates, K. A., Berger, L., Böll, S., Brookes, L., Clare, F., Courtois, E. A., ... Fisher, M. C. (2018). Recent Asian origin of chytrid fungi causing global amphibian declines. Science, 360(6389), 621-627. https://doi.org/10.1126/science.aar1965

Oksanen, J., Blanchet, F. G., Friendly, M., Kindt, R., Legendre, P., McGlinn, D., Minchin, P. R., O’Hara, R. B., Simpson, G. L., Solymos, P., Stevens, M. H. H., Szoecs, E., \& Wagner, H. (2019). vegan: Community Ecology Package (2.5-4) [Computer software]. https://CRAN.R-project.org/package=vegan

Oliveira, B. F., São-Pedro, V. A., Santos-Barrera, G., Penone, C., \& Costa, G. C. (2017). AmphiBIO, a global database for amphibian ecological traits. Scientific Data, 4, 170123. https://doi.org/10.1038/sdata.2017.123 
Ormsby, A., \& Kaplin, B. A. (2005). A framework for understanding community resident perceptions of Masoala National Park, Madagascar. Environmental Conservation, 32(2), 156-164. https://doi.org/10.1017/S0376892905002146

Osen, K., Soazafy, M. R., Martin, D. A., Wurz, A., März, A., Ranarijaona, H. L. T., \& Hölscher, D. (2021). Land-use history controls habitat structure and tree diversity in tropical agroforestry. Applied Vegetation Science, 24(1). https://doi.org/10.1111/avsc.12563

Osterhoudt, S. R. (2014). The Forest in the Field: The Cultural Dimensions of Agroforestry Landscapes in Madagascar. https://search.proquest.com/openview/56e0bd1d0f9874e3ea967 cbf22e0bbde/1?pq-origsite=gscholar\&cbl=18750\&diss=y

Osterhoudt, S. R. (2020). “Nobody wants to kill”. American Ethnologist, 47(3), 249-263. https://doi.org/10.1111/amet.12911

Oteros-Rozas, E., Martín-López, B., Daw, T. M., Bohensky, E. L., Butler, J. R. A., Hill, R., Martin-Ortega, J., Quinlan, A., Ravera, F., Ruiz-Mallén, I., Thyresson, M., Mistry, J., Palomo, I., Peterson, G. D., Plieninger, T., Waylen, K. A., Beach, D. M., Bohnet, I. C., Hamann, M., ... Vilardy, S. P. (2015). Participatory scenario planning in place-based social-ecological research: Insights and experiences from 23 case studies. Ecology and Society, 20(4), :32. http://dx.doi.org/10.5751/ES-07985-200432

Palacios, C. P., Agüero, B., \& Simonetti, J. A. (2013). Agroforestry systems as habitat for herpetofauna: Is there supporting evidence? Agroforestry Systems, 87(3), 517-523. https://doi.org/10.1007/s10457-012-9571-z

Paoletti, A., Darras, K., Jayanto, H., Grass, I., Kusrini, M., \& Tscharntke, T. (2018). Amphibian and reptile communities of upland and riparian sites across Indonesian oil palm, rubber and forest. Global Ecology and Conservation, 16, e00492. https://doi.org/10.1016/j.gecco.2018.e00492

Patel, E. R. (2007). Logging of Rare Rosewood and Palisandre (Dalbergia spp.) within Marojejy National Park, Madagascar. Madagascar Conservation \& Development, 2(1), 11-16. https://doi.org/10.4314/mcd.v2i1.44124

Pearson, R. G. (2015). Asian common toads in Madagascar: An urgent effort to inform surveys and eradication efforts. Global Change Biology, 21(1), 9-9. https://doi.org/10.1111/gcb.12693

Peoples, B. K., Midway, S. R., Sackett, D., Lynch, A., \& Cooney, P. B. (2016). Twitter Predicts Citation Rates of Ecological Research. PLOS ONE, 11(11). https://doi.org/10.1371/journal.pone. 0166570

Pereira, H. M., Rosa, I. M. D., Martins, I. S., Kim, H., Leadley, P., Popp, A., Vuuren, D. P. van, Hurtt, G., Anthoni, P., Arneth, A., Baisero, D., Chaplin-Kramer, R., Chini, L., Fulvio, F. D., Marco, M. D., Ferrier, S., Fujimori, S., Guerra, C. A., Harfoot, M., ... Alkemade, R. (2020). Global trends in biodiversity and ecosystem services from 1900 to 2050. BioRxiv. https://doi.org/10.1101/2020.04.14.031716

Perfecto, I., Rice, R. A., Greenberg, R., \& van der Voort, M. E. (1996). Shade Coffee: A Disappearing Refuge for Biodiversity. BioScience, 46(8), 598-608. https://doi.org/10.2307/1312989

Perfecto, I., \& Vandermeer, J. (2008). Biodiversity Conservation in Tropical Agroecosystems. Annals of the New York Academy of Sciences, 1134(1), 173-200. https://doi.org/10.1196/annals.1439.011

Perfecto, I., \& Vandermeer, J. (2010). The agroecological matrix as alternative to the land-sparing/agriculture intensification model. Proceedings of the National Academy of Sciences, 107(13), 5786-5791. https://doi.org/10.1073/pnas.0905455107

Perfecto, I., Vandermeer, J., Mas, A., \& Pinto, L. S. (2005). Biodiversity, yield, and shade coffee certification. Ecological Economics, 54(4), 435-446. https://doi.org/10.1016/j.ecolecon.2004.10.009

Perfecto, I., Vandermeer, J., \& Philpott, S. M. (2014). Complex Ecological Interactions in the Coffee Agroecosystem. Annual Review of Ecology, Evolution, and Systematics, 45(1), 137-158. https://doi.org/10.1146/annurev-ecolsys-120213-091923 
Phalan, B., Green, R., \& Balmford, A. (2014). Closing yield gaps: Perils and possibilities for biodiversity conservation. Philosophical Transactions of the Royal Society B: Biological Sciences, 369(1639), 20120285. https://doi.org/10.1098/rstb.2012.0285

Phalan, B., Onial, M., Balmford, A., \& Green, R. E. (2011). Reconciling Food Production and Biodiversity Conservation: Land Sharing and Land Sparing Compared. Science, 333(6047), 12891291. https://doi.org/10.1126/science.1208742

Philpott, S. M., Arendt, W. J., Armbrecht, I., Bichier, P., Diestch, T. V., Gordon, C., Greenberg, R., Perfecto, I., Reynoso-Santos, R., Soto-Pinto, L., Tejeda-Cruz, C., Williams-Linera, G., Valenzuela, J., \& Zolotoff, J. M. (2008). Biodiversity Loss in Latin American Coffee Landscapes: Review of the Evidence on Ants, Birds, and Trees. Conservation Biology, 22(5), 1093-1105. https://doi.org/10.1111/j.1523-1739.2008.01029.x

Philpott, S. M., \& Dietsch, T. (2003). Coffee and Conservation: A Global Context and the Value of Farmer Involvement. Conservation Biology, 17(6), 1844-1846. https://doi.org/10.1111/j.1523-1739.2003.00150.x

Pieretti, N., Farina, A., \& Morri, D. (2011). A new methodology to infer the singing activity of an avian community: The Acoustic Complexity Index (ACI). Ecological Indicators, 11(3), 868873. https://doi.org/10.1016/j.ecolind.2010.11.005

Pijanowski, B. C., Villanueva-Rivera, L. J., Dumyahn, S. L., Farina, A., Krause, B. L., Napoletano, B. M., Gage, S. H., \& Pieretti, N. (2011). Soundscape Ecology: The Science of Sound in the Landscape. BioScience, 61(3), 203-216. https://doi.org/10.1525/bio.2011.61.3.6

Poudyal, M., Jones, J. P. G., Rakotonarivo, O. S., Hockley, N., Gibbons, J. M., Mandimbiniaina, R., Rasoamanana, A., Andrianantenaina, N. S., \& Ramamonjisoa, B. S. (2018). Who bears the cost of forest conservation? PeerJ, 6, e5106. https://doi.org/10.7717/peerj.5106

Powers, R. P., \& Jetz, W. (2019). Global habitat loss and extinction risk of terrestrial vertebrates under future land-use-change scenarios. Nature Climate Change, 9(4), 323-329. https://doi.org/10.1038/s41558-019-0406-z

Priyadarshani, N., Marsland, S., \& Castro, I. (2018). Automated birdsong recognition in complex acoustic environments: A review. Journal of Avian Biology, 49(5). https://doi.org/10.1111/jav.01447

Prudhomme, R., Palma, A. D., Dumas, P., Gonzalez, R., Leadley, P., Levrel, H., Purvis, A., \& Brunelle, T. (2020). Combining mitigation strategies to increase co-benefits for biodiversity and food security. Environmental Research Letters, 15(11), 114005. https://doi.org/10.1088/17489326/abb10a

Pynegar, E. L., Gibbons, J. M., Asquith, N. M., \& Jones, J. P. G. (2020). What role should randomized control trials play in providing the evidence base for conservation? Oryx, 1-10. https://doi.org/10.1017/S0030605319000188

Qaim, M., Sibhatu, K. T., Siregar, H., \& Grass, I. (2020). Environmental, Economic, and Social Consequences of the Oil Palm Boom. Annual Review of Resource Economics, 12(1), 321-344. https://doi.org/10.1146/annurev-resource-110119-024922

Quemere, E., Amelot, X., Pierson, J., Crouau-Roy, B., \& Chikhi, L. (2012). Genetic data suggest a natural prehuman origin of open habitats in northern Madagascar and question the deforestation narrative in this region. Proceedings of the National Academy of Sciences, 109(32), 13028-13033. https://doi.org/10.1073/pnas.1200153109

$R$ Core Team. (2019). $R$ : A language and environment for statistical computing (3.6.0) [R].

Rabearivony, J., Rasamoelina, M., Raveloson, J., Rakotomanana, H., Raselimanana, A., Raminosoa, N., \& Zaonarivelo, J. (2015). Roles of a forest corridor between Marojejy, Anjanaharibe- Sud and Tsaratanana protected areas, northern Madagascar, in maintaining endemic and threatened Malagasy taxa. Madagascar Conservation \& Development, 10(2), 85. https://doi.org/10.4314/mcd.v10i2.7

Raharimalala, O., Buttler, A., Dirac Ramohavelo, C., Razanaka, S., Sorg, J.-P., \& Gobat, J.-M. (2010). Soil-vegetation patterns in secondary slash and burn successions in Central Menabe, 
Madagascar. Agriculture, Ecosystems \& Environment, 139(1), 150-158.

https://doi.org/10.1016/j.agee.2010.07.013

Rakotoarison, A., Scherz, M. D., Glaw, F., Köhler, J., Andreone, F., Franzen, M., Glos, J., Hawlitschek, O., Jono, T., Mori, A., Ndriantsoa, S. H., \& Rasoamam, N. (2017). Describing the smaller majority: Integrative taxonomy reveals twenty-six new species of tiny microhylid frogs (genus Stumpffia) from Madagascar. VERTEBRATE ZOOLOGY, 67(3), 271-398.

Rakotomanana, H., Jenkins, R. K. B., \& Ratsimbazafy, J. (2013). Conservation Challenges for Madagascar in the Next Decade. In P. H. Raven, N. S. Sodhi, \& L. Gibson (Eds.), Conservation Biology: Voices from the Tropics (pp. 33-39). John Wiley \& Sons, Ltd. https://doi.org/10.1002/9781118679838.ch5

Ramírez-Castañeda, V. (2020). Disadvantages in preparing and publishing scientific papers caused by the dominance of the English language in science: The case of Colombian researchers in biological sciences. PLOS ONE, 15(9), e0238372. https://doi.org/10.1371/journal.pone. 0238372

Randrianja, S., \& Ellis, S. (2009). Madagascar: A short history. Hurst.

Ranganathan, J., Daniels, R. J. R., Chandran, M. D. S., Ehrlich, P. R., \& Daily, G. C. (2008). Sustaining biodiversity in ancient tropical countryside. Proceedings of the National Academy of Sciences, 105(46), 17852-17854. https://doi.org/10.1073/pnas.0808874105

Rasmussen, L. V., Coolsaet, B., Martin, A., Mertz, O., Pascual, U., Corbera, E., Dawson, N., Fisher, J. A., Franks, P., \& Ryan, C. M. (2018). Social-ecological outcomes of agricultural intensification. Nature Sustainability, 1(6), 275. https://doi.org/10.1038/s41893-018-0070-8

Rasolofoson, R. A., Ferraro, P. J., Jenkins, C. N., \& Jones, J. P. G. (2015). Effectiveness of Community Forest Management at reducing deforestation in Madagascar. Biological Conservation, 184, 271-277. https://doi.org/10.1016/j.biocon.2015.01.027

Ratsoavina, F. M., Raselimanana, A. P., Scherz, M. D., Rakotoarison, A., Razafindraibe, J. H., Glaw, F., \& Vences, M. (2019). Finaritra! A splendid new leaf-tailed gecko (Uroplatus) species from Marojejy National Park in north-eastern Madagascar. Zootaxa, 4545(4), 563-577. https://doi.org/10.11646/zootaxa.4545.4.7

Raveloaritiana, E., Wurz, A., Grass, I., Osen, K., Soazafy, M. R., Martin, D. A., Faliniaina, L., Rakotomalala, N. H., Vorontsova, M. S., Tscharntke, T., \& Bakolimalala, R. (2021). Land-use intensification increases richness of native and exotic herbs, but not endemics, in Malagasy vanilla landscapes. Diversity and Distributions. https://doi.org/10.1111/ddi.13226

Raveloaritiana, E., Wurz, A., Soazafy, M. R., Osen, K., Martin, D. A., Bemamy, C., Ranarijaona, H. L. T., Borgerson, C., Kreft, H., Hölscher, D., Grass, I., Rakouth, B., \& Tscharntke, T. (in prep.). Fallow lands and forest fragments are essential for plant use and ecosystem service provisioning in a tropical agricultural landscape.

Raxworthy, C. J., Pearson, R. G., Rabibisoa, N., Rakotondrazafy, A. M., Ramanamanjato, J.-B., Raselimanana, A. P., Wu, S., Nussbaum, R. A., \& Stone, D. A. (2008). Extinction vulnerability of tropical montane endemism from warming and upslope displacement: A preliminary appraisal for the highest massif in Madagascar. Global Change Biology, 14(8), 1703-1720. https://doi.org/10.1111/j.1365-2486.2008.01596.x

Razafimanahaka, J. H., Jenkins, R. K. B., Andriafidison, D., Randrianandrianina, F., Rakotomboavonjy, V., Keane, A., \& Jones, J. P. G. (2012). Novel approach for quantifying illegal bushmeat consumption reveals high consumption of protected species in Madagascar. Oryx, 46(04), 584592. https://doi.org/10.1017/S0030605312000579

Reptile Database. (2020). http://www.reptile-database.org/data/

Rice, R. A., \& Greenberg, R. (2000). Cacao Cultivation and the Conservation of Biological Diversity. Ambio, 29(3), 167-173. https://doi.org/10.1579/0044-7447-29.3.167

Ricketts, T. H., Daily, G. C., Ehrlich, P. R., \& Michener, C. D. (2004). Economic value of tropical forest to coffee production. Proceedings of the National Academy of Sciences, 101(34), 1257912582. https://doi.org/10.1073/pnas.0405147101 
Riemann, J. C., Ndriantsoa, S. H., Raminosoa, N. R., Rödel, M.-O., \& Glos, J. (2015). The value of forest fragments for maintaining amphibian diversity in Madagascar. Biological Conservation, 191, 707-715. https://doi.org/10.1016/j.biocon.2015.08.020

Ripley, B., Venables, B., Bates, D. M., Hornik, K., Gebhardt, A., Firth, D., \& Ripley, M. B. (2013). Package 'mass' (7.3.51.4) [R-Package].

Robinson, B. E., Holland, M. B., \& Naughton-Treves, L. (2014). Does secure land tenure save forests? A meta-analysis of the relationship between land tenure and tropical deforestation. Global Environmental Change, 29, 281-293. https://doi.org/10.1016/j.gloenvcha.2013.05.012

Rocha, R., Virtanen, T., \& Cabeza, M. (2015). Bird Assemblages in a Malagasy Forest-Agricultural Frontier: Effects of Habitat Structure and Forest Cover. Tropical Conservation Science, 8(3), 681-710. https://doi.org/10.1177/194008291500800307

Rosa, I. M. D., Smith, M. J., Wearn, O. R., Purves, D., \& Ewers, R. M. (2016). The Environmental Legacy of Modern Tropical Deforestation. Current Biology, 26(16), 2161-2166. https://doi.org/10.1016/j.cub.2016.06.013

Ruf, F. (2001). Tree crops as deforestation and reforestation agents: The case of cocoa in Côte d'Ivoire and Sulawesi. In A. Angelsen \& D. Kaimowitz (Eds.), Agricultural technologies and tropical deforestation. CABI Publishing. https://doi.org/10.1079/9780851994512.0291

Salzman, J., Bennett, G., Carroll, N., Goldstein, A., \& Jenkins, M. (2018). The global status and trends of Payments for Ecosystem Services. Nature Sustainability, 1(3), 136-144. https://doi.org/10.1038/s41893-018-0033-0

Samberg, L. H., Gerber, J. S., Ramankutty, N., Herrero, M., \& West, P. C. (2016). Subnational distribution of average farm size and smallholder contributions to global food production. Environmental Research Letters, 11(12), 124010. https://doi.org/10.1088/17489326/11/12/124010

Santika, T., Wilson, K. A., Budiharta, S., Law, E. A., Poh, T. M., Ancrenaz, M., Struebig, M. J., \& Meijaard, E. (2019). Does oil palm agriculture help alleviate poverty? A multidimensional counterfactual assessment of oil palm development in Indonesia. World Development, 120, 105-117. https://doi.org/10.1016/j.worlddev.2019.04.012

Santos, P. Z. F., Crouzeilles, R., \& Sansevero, J. B. B. (2019). Can agroforestry systems enhance biodiversity and ecosystem service provision in agricultural landscapes? A meta-analysis for the Brazilian Atlantic Forest. Forest Ecology and Management, 433, 140-145. https://doi.org/10.1016/j.foreco.2018.10.064

Santosa, E., Sugiyama, N., Nakata, M., \& Kawabata, S. (2005). Profitability of Vanilla Intercropping in Pine Forests in West Java, Indonesia. Japanese Journal of Tropical Agriculture, 49(3), 207214. https://doi.org/10.11248/jsta1957.49.207

Sauvadet, M., Saj, S., Freschet, G. T., Essobo, J.-D., Enock, S., Becquer, T., Tixier, P., \& Harmand, J.-M. (2020). Cocoa agroforest multifunctionality and soil fertility explained by shade tree litter traits. Journal of Applied Ecology, 57(3), 476-487. https://doi.org/10.1111/13652664.13560

Scales, B. R., \& Marsden, S. J. (2008). Biodiversity in small-scale tropical agroforests: A review of species richness and abundance shifts and the factors influencing them. Environmental Conservation, 35(2), 160-172. https://doi.org/10.1017/S0376892908004840

Scales, I. R. (2011). Farming at the Forest Frontier: Land Use and Landscape Change in Western Madagascar, 1896-2005. Environment and History, 17(4), 499-524. https://doi.org/10.3197/096734011X13150366551481

Scales, I. R. (Ed.). (2014a). Conservation and environmental management in Madagascar. Routledge. https://doi.org/10.4324/9780203118313

Scales, I. R. (2014b). The drivers of deforestation and the complexity of land use in Madagascar. In Conservation and environmental management in Madagascar (p. 23). Routledge.

Schafer, R. M. (1993). The soundscape: Our sonic environment and the tuning of the world. Destiny Books. 
Schneider, S. H. (2004). Abrupt non-linear climate change, irreversibility and surprise. Global Environmental Change, 14(3), 245-258. https://doi.org/10.1016/j.gloenvcha.2004.04.008

Schroth, G. (Ed.). (2004). Agroforestry and biodiversity conservation in tropical landscapes. Island Press.

Schroth, G., Läderach, P., Martinez-Valle, A. I., Bunn, C., \& Jassogne, L. (2016). Vulnerability to climate change of cocoa in West Africa: Patterns, opportunities and limits to adaptation. Science of The Total Environment, 556, 231-241. https://doi.org/10.1016/j.scitotenv.2016.03.024

Schüßler, D., Mantilla-Contreras, J., Stadtmann, R., Ratsimbazafy, J. H., \& Radespiel, U. (2020). Identification of crucial stepping stone habitats for biodiversity conservation in northeastern Madagascar using remote sensing and comparative predictive modeling. Biodiversity and Conservation, 29, 2161-2184. https://doi.org/10.1007/s10531-020-01965-z

Schüßler, D., Radespiel, U., Ratsimbazafy, J. H., \& Mantilla-Contreras, J. (2018). Lemurs in a dying forest: Factors influencing lemur diversity and distribution in forest remnants of northeastern Madagascar. Biological Conservation, 228, 17-26. https://doi.org/10.1016/j.biocon.2018.10.008

Schuurman, D., \& Lowry II, P. (2009). The Madagascar rosewood massacre. Madagascar Conservation \& Development, 4(2). https://doi.org/10.4314/mcd.v4i2.48649

Schwab, D., Wurz, A., Grass, I., Rakotomalala, A. A. N. A., Osen, K., Soazafy, M. R., Martin, D. A., \& Tscharntke, T. (2020). Decreasing predation rates and shifting predator compositions along a land-use gradient in Madagascar's vanilla landscapes. Journal of Applied Ecology, 58(2). https://doi.org/10.1111/1365-2664.13766

Schwendenmann, L., Veldkamp, E., Moser, G., Hölscher, D., Köhler, M., Clough, Y., Anas, I., Djajakirana, G., Erasmi, S., Hertel, D., Leitner, D., Leuschner, C., Michalzik, B., Propastin, P., Tjoa, A., Tscharntke, T., \& Straaten, O. V. (2010). Effects of an experimental drought on the functioning of a cacao agroforestry system, Sulawesi, Indonesia. Global Change Biology, 16(5), 1515-1530. https://doi.org/10.1111/j.1365-2486.2009.02034.x

Scott, D. M., Brown, D., Mahood, S., Denton, B., Silburn, A., \& Rakotondraparany, F. (2006). The impacts of forest clearance on lizard, small mammal and bird communities in the arid spiny forest, southern Madagascar. Biological Conservation, 127(1), 72-87. https://doi.org/10.1016/j.biocon.2005.07.014

Şekercioğlu, C.. H., Loarie, S. R., Oviedo Brenes, F., Ehrlich, P. R., \& Daily, G. C. (2007). Persistence of Forest Birds in the Costa Rican Agricultural Countryside. Conservation Biology, 21(2), 482494. https://doi.org/10.1111/j.1523-1739.2007.00655.x

Şekercioğlu, C.. H., Mendenhall, C. D., Oviedo-Brenes, F., Horns, J. J., Ehrlich, P. R., \& Daily, G. C. (2019). Long-term declines in bird populations in tropical agricultural countryside. Proceedings of the National Academy of Sciences, 116(20), 9903-9912. https://doi.org/10.1073/pnas.1802732116

Servick, K. (2014). Eavesdropping on Ecosystems. Science, 343(6173), 834-837. https://doi.org/10.1126/science.343.6173.834

Shumi, G., Schultner, J., Dorresteijn, I., Rodrigues, P., Hanspach, J., Hylander, K., Senbeta, F., \& Fischer, J. (2018). Land use legacy effects on woody vegetation in agricultural landscapes of south-western Ethiopia. Diversity and Distributions, 24(8), 1136-1148. https://doi.org/10.1111/ddi.12754

Siebert, S. F. (2002). From shade- to sun-grown perennial crops in Sulawesi, Indonesia: Implications for biodiversity conservation and soil fertility. Biodiversity \& Conservation, 11(11), 1889-1902. https://doi.org/10.1023/A:1020804611740

Sloan, S. (2008). Reforestation amidst deforestation: Simultaneity and succession. Global Environmental Change, 18(3), 425-441. https://doi.org/10.1016/j.gloenvcha.2008.04.009

Soazafy, M. R., Osen, K., Martin, D. A., Wurz, A., Ranarijaona, H. L. T., \& Hölscher, D. (in prep.). Carbon storage along a land-use gradient in Madagascar. 
Socolar, J. B., Sandoval, E. H. V., \& Wilcove, D. S. (2019). Overlooked biodiversity loss in tropical smallholder agriculture. Conservation Biology, 33(6), 1338-1349.

https://doi.org/10.1111/cobi.13344

Solofondranohatra, C. L., Vorontsova, M. S., Hempson, G. P., Hackel, J., Cable, S., Vololoniaina, J., \& Lehmann, C. E. R. (2020). Fire and grazing determined grasslands of central Madagascar represent ancient assemblages. Proceedings of the Royal Society B: Biological Sciences, 287(1927). https://doi.org/10.1098/rspb.2020.0598

Sommerville, M., Jones, J. P. G., Rahajaharison, M., \& Milner-Gulland, E. J. (2010). The role of fairness and benefit distribution in community-based Payment for Environmental Services interventions: A case study from Menabe, Madagascar. Ecological Economics, 69(6), 1262-1271. https://doi.org/10.1016/j.ecolecon.2009.11.005

Steffan-Dewenter, I., Kessler, M., Barkmann, J., Bos, M. M., Buchori, D., Erasmi, S., Faust, H., Gerold, G., Glenk, K., Gradstein, S. R., Guhardja, E., Harteveld, M., Hertel, D., Hohn, P., Kappas, M., Kohler, S., Leuschner, C., Maertens, M., Marggraf, R., ... Tscharntke, T. (2007). Tradeoffs between income, biodiversity, and ecosystem functioning during tropical rainforest conversion and agroforestry intensification. Proceedings of the National Academy of Sciences, 104(12), 4973-4978. https://doi.org/10.1073/pnas.0608409104

Steward, P. R., Shackelford, G., Carvalheiro, L. G., Benton, T. G., Garibaldi, L. A., \& Sait, S. M. (2014). Pollination and biological control research: Are we neglecting two billion smallholders. $\mathrm{Ag}$ riculture \& Food Security, 3(1), 5. https://doi.org/10.1186/2048-7010-3-5

Stoop, W. A., Uphoff, N., \& Kassam, A. (2002). A review of agricultural research issues raised by the system of rice intensification (SRI) from Madagascar: Opportunities for improving farming systems for resource-poor farmers. Agricultural Systems, 71(3), 249-274. https://doi.org/10.1016/S0308-521X(01)00070-1

Strassburg, B. B. N., Iribarrem, A., Beyer, H. L., Cordeiro, C. L., Crouzeilles, R., Jakovac, C. C., Braga Junqueira, A., Lacerda, E., Latawiec, A. E., Balmford, A., Brooks, T. M., Butchart, S. H. M., Chazdon, R. L., Erb, K.-H., Brancalion, P., Buchanan, G., Cooper, D., Díaz, S., Donald, P. F., ... Visconti, P. (2020). Global priority areas for ecosystem restoration. Nature, 586(7831), 724-729. https://doi.org/10.1038/s41586-020-2784-9

Styger, E., Rakotondramasy, H. M., Pfeffer, M. J., Fernandes, E. C. M., \& Bates, D. M. (2007). Influence of slash-and-burn farming practices on fallow succession and land degradation in the rainforest region of Madagascar. Agriculture, Ecosystems \& Environment, 119(3-4), 257-269. https://doi.org/10.1016/j.agee.2006.07.012

Sueur, J., Pavoine, S., Hamerlynck, O., \& Duvail, S. (2008). Rapid Acoustic Survey for Biodiversity Appraisal. PLOS ONE, 3(12), e4065. https://doi.org/10.1371/journal.pone.0004065

Sugai, L. S. M., Desjonquères, C., Silva, T. S. F., \& Llusia, D. (2019). A roadmap for survey designs in terrestrial acoustic monitoring. Remote Sensing in Ecology and Conservation, 6(3), 220-235. https://doi.org/10.1002/rse2.131

Sujatha, S., \& Bhat, R. (2010). Response of vanilla (Vanilla planifolia A.) intercropped in arecanut to irrigation and nutrition in humid tropics of India. Agricultural Water Management, 97(7), 988-994. https://doi.org/10.1016/j.agwat.2010.01.031

SVI (2020). The Sustainable Vanilla Initiative (SVI). https://www.idhsustainabletrade.com/sustainable-vanilla-initiative-svi/

Sy, V. D., Herold, M., Achard, F., Avitabile, V., Baccini, A., Carter, S., Clevers, J. G. P. W., Lindquist, E., Pereira, M., \& Verchot, L. (2019). Tropical deforestation drivers and associated carbon emission factors derived from remote sensing data. Environmental Research Letters, 14(9), 094022. https://doi.org/10.1088/1748-9326/ab3dc6

Sykes, L., Santini, L., Etard, A., \& Newbold, T. (2020). Effects of rarity form on species' responses to land use. Conservation Biology, 34(3), 688-696. https://doi.org/10.1111/cobi.13419

Tattersall, I., \& Sussman, R. W. (1975). Notes on Topography, Climate, and Vegetation of Madagascar. In I. Tattersall \& R. W. Sussman (Eds.), Lemur Biology (pp. 13-21). Springer US. https://doi.org/10.1007/978-1-4684-2121-7_2 
Tayleur, C., Balmford, A., Buchanan, G. M., Butchart, S. H. M., Ducharme, H., Green, R. E., Milder, J. C., Sanderson, F. J., Thomas, D. H. L., Vickery, J., \& Phalan, B. (2017). Global Coverage of Agricultural Sustainability Standards, and Their Role in Conserving Biodiversity: Certification standards and biodiversity. Conservation Letters, 10(5), 610-618. https://doi.org/10.1111/conl.12314

Tejeda-Cruz, C., Silva-Rivera, E., Barton, J. R., \& Sutherland, W. J. (2010). Why Shade Coffee Does Not Guarantee Biodiversity Conservation. Ecology and Society, 15(1), art13. https://doi.org/10.5751/ES-02870-150113

Tews, J., Brose, U., Grimm, V., Tielbörger, K., Wichmann, M. C., Schwager, M., \& Jeltsch, F. (2004). Animal species diversity driven by habitat heterogeneity/diversity: The importance of keystone structures. Journal of Biogeography, 31(1), 79-92.

Thorn, J. P. R., Friedman, R., Benz, D., Willis, K. J., \& Petrokofsky, G. (2016). What evidence exists for the effectiveness of on-farm conservation land management strategies for preserving ecosystem services in developing countries? A systematic map. Environmental Evidence, 5(1), 13. https://doi.org/10.1186/s13750-016-0064-9

Tichý, L. (2016). Field test of canopy cover estimation by hemispherical photographs taken with a smartphone. Journal of Vegetation Science, 27(2), 427-435. https://doi.org/10.1111/jvs.12350

Tilman, D., Balzer, C., Hill, J., \& Befort, B. L. (2011). Global food demand and the sustainable intensification of agriculture. Proceedings of the National Academy of Sciences, 108(50), 2026020264. https://doi.org/10.1073/pnas.1116437108

Tittensor, D. P., Walpole, M., Hill, S. L. L., Boyce, D. G., Britten, G. L., Burgess, N. D., Butchart, S. H. M., Leadley, P. W., Regan, E. C., Alkemade, R., Baumung, R., Bellard, C., Bouwman, L., BowlesNewark, N. J., Chenery, A. M., Cheung, W. W. L., Christensen, V., Cooper, H. D., Crowther, A. R., ... Ye, Y. (2014). A mid-term analysis of progress toward international biodiversity targets. Science, 346(6206), 241-244. https://doi.org/10.1126/science.1257484

Toillier, A., Serpantié, G., Hervé, D., \& Lardon, S. (2011). Livelihood Strategies and Land Use Changes in Response to Conservation: Pitfalls of Community-Based Forest Management in Madagascar. Journal of Sustainable Forestry, 30(1-2), 20-56. https://doi.org/10.1080/10549811003742357

Towsey, M., Wimmer, J., Williamson, I., \& Roe, P. (2014). The use of acoustic indices to determine avian species richness in audio-recordings of the environment. Ecological Informatics, 21, 110-119. https://doi.org/10.1016/j.ecoinf.2013.11.007

Trisos, C. H., Merow, C., \& Pigot, A. L. (2020). The projected timing of abrupt ecological disruption from climate change. Nature, 580(7804), 496-501. https://doi.org/10.1038/s41586-0202189-9

Tscharntke, T., Clough, Y., Bhagwat, S. A., Buchori, D., Faust, H., Hertel, D., Hölscher, D., Juhrbandt, J., Kessler, M., Perfecto, I., Scherber, C., Schroth, G., Veldkamp, E., \& Wanger, T. C. (2011). Multifunctional shade-tree management in tropical agroforestry landscapes-A review. Journal of Applied Ecology, 48(3), 619-629. https://doi.org/10.1111/j.13652664.2010.01939.x

Tscharntke, T., Clough, Y., Wanger, T. C., Jackson, L., Motzke, I., Perfecto, I., Vandermeer, J., \& Whitbread, A. (2012). Global food security, biodiversity conservation and the future of agricultural intensification. Biological Conservation, 151(1), 53-59. https://doi.org/10.1016/j.biocon.2012.01.068

Tscharntke, T., Klein, A. M., Kruess, A., Steffan-Dewenter, I., \& Thies, C. (2005). Landscape perspectives on agricultural intensification and biodiversity - ecosystem service management. Ecology Letters, 8(8), 857-874. https://doi.org/10.1111/j.1461-0248.2005.00782.x

Tscharntke, T., Milder, J. C., Rice, R., \& Ghazoul, J. (2014). Conserving biodiversity through certification of tropical agroforestry crops at local and landscape scales. Conservation Letters, 8(1), 14-23. https://doi.org/10.1111/conl.12110 
Tschora, H., \& Cherubini, F. (2020). Co-benefits and trade-offs of agroforestry for climate change mitigation and other sustainability goals in West Africa. Global Ecology and Conservation, 22, e00919. https://doi.org/10.1016/j.gecco.2020.e00919

Turner, I. M. (1996). Species Loss in Fragments of Tropical Rain Forest: A Review of the Evidence. Journal of Applied Ecology, 33(2), 200-209. https://doi.org/10.2307/2404743

Udawatta, R. P., Rankoth, L., \& Jose, S. (2019). Agroforestry and Biodiversity. Sustainability, 11(10), 2879. https://doi.org/10.3390/su11102879

UNEP-WCMC and IUCN (2020). Protected Planet: The World Database on Protected Areas (WDPA). www.protectedplanet.net

United Nations (2015). Transforming our world: The 2030 agenda for sustainable development. General Assembley 70 Session.

United Nations Development Programme (2019). Human development report 2019.

Urbina-Cardona, J. N., Olivares-Pérez, M., \& Reynoso, V. H. (2006). Herpetofauna diversity and microenvironment correlates across a pasture-edge-interior ecotone in tropical rainforest fragments in the Los Tuxtlas Biosphere Reserve of Veracruz, Mexico. Biological Conservation, 132(1), 61-75. https://doi.org/10.1016/j.biocon.2006.03.014

Vaast, P., Bertrand, B., Perriot, J.-J., Guyot, B., \& Génard, M. (2006). Fruit thinning and shade improve bean characteristics and beverage quality of coffee (Coffea arabica L.) under optimal conditions. Journal of the Science of Food and Agriculture, 86(2), 197-204. https://doi.org/10.1002/jsfa.2338

Vaast, P., Harmand, J.-M., Rapidel, B., Jagoret, P., \& Deheuvels, O. (2016). Coffee and Cocoa Production in Agroforestry-A Climate-Smart Agriculture Model. In E. Torquebiau (Ed.), Climate Change and Agriculture Worldwide (pp. 209-224). Springer Netherlands. https://doi.org/10.1007/978-94-017-7462-8_16

Valencia, V., Naeem, S., García-Barrios, L., West, P., \& Sterling, E. J. (2016). Conservation of tree species of late succession and conservation concern in coffee agroforestry systems. Agriculture, Ecosystems \& Environment, 219, 32-41. https://doi.org/10.1016/j.agee.2015.12.004

Vallan, D. (2000). Influence of forest fragmentation on amphibian diversity in the nature reserve of Ambohitantely, highland Madagascar. Biological Conservation, 96(1), 31-43. https://doi.org/10.1016/S0006-3207(00)00041-0

Van Der Maarel, E. (1970). Vegetationsstruktur und Minimum-Areal in Einem Dünen-Trockenrasen. In R. Tüxen (Ed.), Gesellschaftsmorphologie: Strukturforschung (pp. 218-239). Springer Netherlands. https://doi.org/10.1007/978-94-010-3353-4_16

Van Dyk, S., Holford, P., Subedi, P., Walsh, K., Williams, M., \& McGlasson, W. B. (2014). Determining the harvest maturity of vanilla beans. Scientia Horticulturae, 168, 249-257. https://doi.org/10.1016/j.scienta.2014.02.002

van Noordwijk, M., Duguma, L. A., Dewi, S., Leimona, B., Catacutan, D. C., Lusiana, B., Öborn, I., Hairiah, K., \& Minang, P. A. (2018). SDG synergy between agriculture and forestry in the food, energy, water and income nexus: Reinventing agroforestry? Current Opinion in Environmental Sustainability, 34, 33-42. https://doi.org/10.1016/j.cosust.2018.09.003

van Vliet, N., Mertz, O., Heinimann, A., Langanke, T., Pascual, U., Schmook, B., Adams, C., SchmidtVogt, D., Messerli, P., Leisz, S., Castella, J.-C., Jørgensen, L., Birch-Thomsen, T., Hett, C., BechBruun, T., Ickowitz, A., Vu, K. C., Yasuyuki, K., Fox, J., ... Ziegler, A. D. (2012). Trends, drivers and impacts of changes in swidden cultivation in tropical forest-agriculture frontiers: A global assessment. Global Environmental Change, 22(2), 418-429. https://doi.org/10.1016/j.gloenvcha.2011.10.009

Vieilledent, G., Gardi, O., Grinand, C., Burren, C., Andriamanjato, M., Camara, C., Gardner, C. J., Glass, L., Rasolohery, A., Rakoto Ratsimba, H., Gond, V., \& Rakotoarijaona, J.-R. (2016). Bioclimatic envelope models predict a decrease in tropical forest carbon stocks with climate change in Madagascar. Journal of Ecology, 104(3), 703-715. https://doi.org/10.1111/13652745.12548 
Vieilledent, G., Grinand, C., Rakotomalala, F. A., Ranaivosoa, R., Rakotoarijaona, J.-R., Allnutt, T. F., \& Achard, F. (2018). Combining global tree cover loss data with historical national forest cover maps to look at six decades of deforestation and forest fragmentation in Madagascar. Biological Conservation, 222, 189-197. https://doi.org/10.1016/j.biocon.2018.04.008

Vieilledent, G., Grinand, C., \& Vaudry, R. (2013). Forecasting deforestation and carbon emissions in tropical developing countries facing demographic expansion: A case study in Madagascar. Ecology and Evolution, 3(6), 1702-1716. https://doi.org/10.1002/ece3.550

Vieilledent, G., Nourtier, M., Grinand, C., Pedrono, M., Clausen, A., Rabetrano, T., Rakotoarijaona, J.-R., Rakotoarivelo, B., Rakotomalala, F. A., Rakotomalala, L., Razafimpahanana, A., Ralison, J. M., \& Achard, F. (2020). It's not just poverty: Unregulated global market and bad governance explain unceasing deforestation in Western Madagascar. BioRxiv. https://doi.org/10.1101/2020.07.30.229104

Vieites, D. R., Wollenberg, K. C., Andreone, F., Kohler, J., Glaw, F., \& Vences, M. (2009). Vast underestimation of Madagascar's biodiversity evidenced by an integrative amphibian inventory. Proceedings of the National Academy of Sciences, 106(20), 8267-8272. https://doi.org/10.1073/pnas.0810821106

Villanueva-Rivera, L. J., \& Pijanowski, B. C. (2018). Soundecology: Soundscape ecology [R-Package].

Villanueva-Rivera, L. J., Pijanowski, B. C., Doucette, J., \& Pekin, B. (2011). A primer of acoustic analysis for landscape ecologists. Landscape Ecology, 26(9), 1233.

https://doi.org/10.1007/s10980-011-9636-9

von Wehrden, H., Abson, D. J., Beckmann, M., Cord, A. F., Klotz, S., \& Seppelt, R. (2014). Realigning the land-sharing/land-sparing debate to match conservation needs: Considering diversity scales and land-use history. Landscape Ecology, 29(6), 941-948. https://doi.org/10.1007/s10980-014-0038-7

Vongvisouk, T., Mertz, O., Thongmanivong, S., Heinimann, A., \& Phanvilay, K. (2014). Shifting cultivation stability and change: Contrasting pathways of land use and livelihood change in Laos. Applied Geography, 46, 1-10. https://doi.org/10.1016/j.apgeog.2013.10.006

Vorontsova, M. S., Besnard, G., Forest, F., Malakasi, P., Moat, J., Clayton, W. D., Ficinski, P., Savva, G. M., Nanjarisoa, O. P., Razanatsoa, J., Randriatsara, F. O., Kimeu, J. M., Luke, W. R. Q., Kayombo, C., \& Linder, H. P. (2016). Madagascar's grasses and grasslands: Anthropogenic or natural? Proceedings of the Royal Society B: Biological Sciences, 283(1823). https://doi.org/10.1098/rspb.2015.2262

Vu, V. Q. (2011). ggbiplot: A ggplot2 based biplot [R-Package].

Waeber, P. O., Rafanoharana, S., Andry Rasamuel, H., \& Wilmé, L. (2020). Parks and Reserves in Madagascar: Managing Biodiversity for a Sustainable Future. In A. Naqiyuddin Bakar \& M. Nazip Suratman (Eds.), Protected Areas, National Parks and Sustainable Future. IntechOpen. https://doi.org/10.5772/intechopen.85348

Waeber, P. O., Wilmé, L., Mercier, J.-R., Camara, C., \& Lowry, P. P. (2016). How Effective Have Thirty Years of Internationally Driven Conservation and Development Efforts Been in Madagascar? PLOS ONE, 11(8), e0161115. https://doi.org/10.1371/journal.pone.0161115

Waltert, M., Bobo, K. S., Kaupa, S., Montoya, M. L., Nsanyi, M. S., \& Fermon, H. (2011). Assessing Conservation Values: Biodiversity and Endemicity in Tropical Land Use Systems. PLoS ONE, 6(1), e16238. https://doi.org/10.1371/journal.pone.0016238

Wanger, T. C., Hölscher, D., Veldkamp, E., \& Tscharntke, T. (2018). Cocoa production: Monocultures are not the solution to climate adaptation-Response to Abdulai et al. 2017. Global Change Biology, 24(2), 561-562. https://doi.org/10.1111/gcb.14005

Wanger, T. C., Iskandar, D. T., Motzke, I., Brook, B. W., Sodhi, N. S., Clough, Y., \& Tscharntke, T. (2010). Effects of Land-Use Change on Community Composition of Tropical Amphibians and Reptiles in Sulawesi, Indonesia: Effects of Land-Use Change on Herpetofauna. Conservation Biology, 24(3), 795-802. https://doi.org/10.1111/j.1523-1739.2009.01434.x 
Ward, C., Stringer, L., \& Holmes, G. (2018). Changing governance, changing inequalities: Protected area co-management and access to forest ecosystem services: a Madagascar case study. Ecosystem Services, 30, 137-148. https://doi.org/10.1016/j.ecoser.2018.01.014

Warren-Thomas, E., Nelson, L., Juthong, W., Bumrungsri, S., Brattström, O., Stroesser, L., Chambon, B., Penot, É., Tongkaemkaew, U., \& Edwards, D. P. (2020). Rubber agroforestry in Thailand provides some biodiversity benefits without reducing yields. Journal of Applied Ecology, 57(1), 17-30.

Watson, J. E. M., Dudley, N., Segan, D. B., \& Hockings, M. (2014). The performance and potential of protected areas. Nature, 515(7525), 67-73. https://doi.org/10.1038/nature13947

Weiss, D. J., Nelson, A., Gibson, H. S., Temperley, W., Peedell, S., Lieber, A., Hancher, M., Poyart, E., Belchior, S., Fullman, N., Mappin, B., Dalrymple, U., Rozier, J., Lucas, T. C. D., Howes, R. E., Tusting, L. S., Kang, S. Y., Cameron, E., Bisanzio, D., ... Gething, P. W. (2018). A global map of travel time to cities to assess inequalities in accessibility in 2015. Nature, 553(7688), 333336. https://doi.org/10.1038/nature25181

Whittaker, R. J., Araújo, M. B., Jepson, P., Ladle, R. J., Watson, J. E. M., \& Willis, K. J. (2005). Conservation Biogeography: Assessment and prospect. Diversity and Distributions, 11(1), 3-23. https://doi.org/10.1111/j.1366-9516.2005.00143.x

Whytock, R. C., \& Christie, J. (2017). Solo: An open source, customizable and inexpensive audio recorder for bioacoustic research. Methods in Ecology and Evolution, 8(3), 308-312. https://doi.org/10.1111/2041-210X.12678

Williams, J. J., \& Newbold, T. (2020). Local climatic changes affect biodiversity responses to land use: A review. Diversity and Distributions, 26(1), 76-92. https://doi.org/10.1111/ddi.12999

Wilmé, L. (1996). Composition and characteristics of bird communities in Madagascar. In W. R. Lourenço (Ed.), Biogéographie de Madagascar (Centre IRD de Bondy; pp. 349-362). ORSTOM. http://www.documentation.ird.fr/hor/fdi:010008477

Wilmé, L., Goodman, S. M., \& Ganzhorn, J. U. (2006). Biogeographic Evolution of Madagascar's Microendemic Biota. Science, 312(5776), 1063-1065. https://doi.org/10.1126/science. 1122806

Wilmé, L., Waeber, P. O., Moutou, F., Gardner, C. J., Razafindratsima, O., Sparks, J., Kull, C. A., Ferguson, B., Lourenço, W. R., Jenkins, P. D., Ramamonjisoa, L., Burney, D. A., \& Lowry, P. P. (2016). A proposal for ethical research conduct in Madagascar. Madagascar Conservation \& Development, 11(1). https://doi.org/10.4314/mcd.v11i1.8

Wilson, G. A. (2007). Multifunctional Agriculture: A Transition Theory Perspective. CABI.

Wood, S. (2012). mgcv: Mixed GAM Computation Vehicle with GCV/AIC/REML smoothness estimation (1.8-28) [R-Package].

Worldbank (2020). World Bank Data Bank. https://data.worldbank.org/indicator/SP.RUR.TOTL.ZS?most_recent_year_desc=false\&view=map

Zaehringer, J. G., Eckert, S., \& Messerli, P. (2015). Revealing Regional Deforestation Dynamics in North-Eastern Madagascar-Insights from Multi-Temporal Land Cover Change Analysis. Land, 4(2), 454-474. https://doi.org/10.3390/land4020454

Zaehringer, J. G., Ramamonjisoa, B., \& Messerli, P. (2018). Conservation versus local livelihoods? Sustainable development challenges in Madagascar. Centre for Development and Environment (CDE), University of Bern.

Zaehringer, J. G., Schwilch, G., Andriamihaja, O. R., Ramamonjisoa, B., \& Messerli, P. (2017). Remote sensing combined with social-ecological data: The importance of diverse land uses for ecosystem service provision in north-eastern Madagascar. Ecosystem Services, 25, 140-152. https://doi.org/10.1016/j.ecoser.2017.04.004

Zhu, A. (2018). Hot money, cold beer: Navigating the vanilla and rosewood export economies in northeastern Madagascar. American Ethnologist, 45(2), 253-267. https://doi.org/10.1111/amet.12636 
Zomer, R. J., Neufeldt, H., Xu, J., Ahrends, A., Bossio, D., Trabucco, A., van Noordwijk, M., \& Wang, M. (2016). Global Tree Cover and Biomass Carbon on Agricultural Land: The contribution of agroforestry to global and national carbon budgets. Scientific Reports, 6(1). https://doi.org/10.1038/srep29987 


\section{Appendix}

\section{Figures}

Figure 12.1: Species accumulation curves and sample coverage for each land-use type. 258

Figure 12.2: Total number of bird species (gamma-diversity) and number of species per endemism level across all plots $(\mathrm{N}=80)$ and in each land-use type. 259

Figure 12.3: Correlation-plot of covariates for general linear models including correlation coefficients, histograms and boxplots for each land-use type.. 260

Figure 12.4: Self-built SOLO audio recorders used for sound recordings. 272

Figure 12.5: Year of establishment of the 209 vanilla agroforests included in this study. 294

Figure 12.6: Study design overview.

Figure 12.7: Sampling design inside a schematic vanilla agroforest.

Figure 12.8: Analysis path for all 1886 canopy cover photos from 209 agroforests.

Figure 12.9: Analysis path of dynamic thresholding R-script leading to the binary sky/vegetation classification of each pixel.

Figure 12.10: Left: Distribution of 36 vanilla-support-tree-units on a 25 -meter radius plot in a vanilla agroforest. Right: Unique barcode label on vanilla-support-tree-unit. 307

Figure 12.11: Three different types of leaf damage on vanilla leaf: leaf tissue missing, leaf necrosis and leaf rotting (from left to right). 307

Figure 12.12: Study design overview. 308

Figure 12.13: Semi-blocked study design with replicated land-use types across 10 villages and two old-growth forest sites. 309

Figure 12.14: Multidiversity, endemic multidiversity and multifunctionality at stages along a landuse trajectory in north-eastern Madagascar at the 20\%,50\% and $80 \%$ thresholds... 


\section{$\underline{\text { Tables }}$}

Table 12.1: Mean size of each land unit in which we established the plots 261

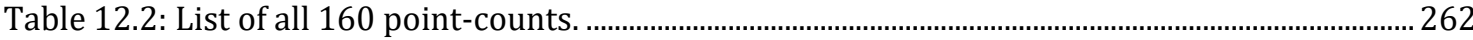

Table 12.3: List of species found within 25m-radius plots, IUCN status and endemism level...........266

Table 12.4: Test-Results for comparing species richness across land-use types ................................. 267

Table 12.5: Test-Results for comparing endemic species richness across land-use types................. 268

Table 12.6: Test-Results for comparing species composition across land-use types .......................... 269

Table 12.7: Computational settings of the multiple_sounds function...................................................... 272

Table 12.8: List of all components used for the self-built SOLO audio recorders..................................273

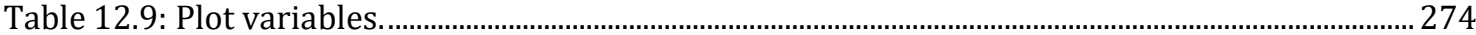

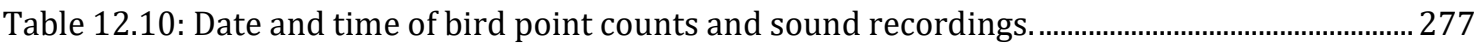

Table 12.11: Results of the Shapiro-Wilk test and the Kruskal-Wallis test for assessing distribution patterns of the Acoustic Complexity Index (ACI), the inverted Acoustic Evenness Index (1-AEI) and the Acoustic Entropy $(\mathrm{H})$.

Table 12.12: Differences between land-use types for the Acoustic Complexity Index (ACI), the inverted Acoustic Evenness Index (1-AEI) and the Acoustic Entropy (H).

Table 12.13: Differences between land-use types for the Acoustic Complexity Index (ACI), the inverted Acoustic Evenness Index (1-AEI) and the Acoustic Entropy (H)

Table 12.14: Results of correlation analysis between bird species richness and the Acoustic Complexity Index (ACI), the Acoustic Diversity Index (ADI), the inverse Acoustic Evenness Index (1-AEI) and the Acoustic Entropy $(\mathrm{H})$ 285

Table 12.15: Results of linear mixed effect models explaining vanilla yields [kg ha-1]. 300

Table 12.16: Results of linear mixed effect models explaining canopy cover [\%]. 301

Table 12.17: Results of linear mixed effect models explaining canopy height [m] 302

Table 12.18: Results of a general additive model explaining change in remotely sensed canopy cover from 2000 to 2010 around 60 focal villages in north-eastern Madagascar. 303

Table 12.19: Overview of published green and black vanilla yield estimates [kg ha-1]. 303 


\subsection{Author's affiliations}

\section{Dominik Schwab, Annemarie Wurz, \& Teja Tscharntke}

Agroecology, University of Goettingen, Göttingen, Germany

Saskia Dröge, Nathaly Guerrero-Ramirez, Dominic Andreas Martin, Holger Kreft, \& Delphine Clara Zemp

Biodiversity, Macroecology and Biogeography, University of Goettingen, Göttingen, Germany

Janna Niens

Biology Didactics, Albrecht-von Haller-Institute for Plant Science, University of Goettingen, Göttingen, Germany

Hery Lisy Tiana Ranarijaona

Biodiversity and Conservation, University of Mahajanga, Mahajanga, Madagascar

\section{Dirk Hölscher, Holger Kreft, \& Teja Tscharntke}

Centre for Biodiversity and Sustainable Land Use (CBL), University of Goettingen, Göttingen, Germany

\section{Maria S. Vorontsova}

Comparative Plant and Fungal Biology, Royal Botanic Gardens Kew, Richmond, United Kingdom

\section{Saskia Dröge \& Torsten Richter}

Department of Biology, University of Hildesheim, Hildesheim, Germany

\section{Zuzana Burivalova}

Department of Forest and Wildlife Ecology \& The Nelson Institute for Environmental Studies, University of Wisconsin-Madison, Madison, USA

\section{Fenohaja Soavita Babarezoto \& Thorien Rabemanantsoa}

Diversity Turn Research Project, Sambava, Madagascar

\section{Marie Rolande Soazafy}

Doctoral School of Natural Ecosystems (EDEN), University of Mahajanga, Mahajanga, Madagascar

\section{Harilala Andriamaniraka \& Fanilo Andrianisaina}

Ecole Supérieure des Sciences Agronomiques (ESSA), Antananarivo, Madagascar 


\section{Ingo Grass}

Ecology of Tropical Agricultural Systems, University of Hohenheim, Stuttgart, Germany

Anjaharinony Andry Ny Aina Rakotomalala \& Lala Harivelo Ravaomanarivo Raveloson

Entomology Department, Faculty of Science University of Antananarivo, Antananarivo, Madagascar

Jan Barkmann \& Lloyd Blum

Faculty of Social Sciences, Risk- and Sustainability Sciences, University of Applied Sciences Darmstadt (h-da), Darmstadt, Germany

Yvonne Franke \& S. Annette Witherspoon

Göttingen Diversity Research Institute, Faculty of Social Sciences, University of Goettingen, Göttingen, Germany.

Nantenaina H. Rakotomalala

Kew Madagascar Conservation Centre (KMCC), Antananarivo, Madagascar

Erosiniot Befidimanana, Ronick Botra, Thio Rosin Fulgence, Romual Randriamanantena, \& Marie Rolande Soazafy

Natural and Environmental Sciences, Regional University Centre of the SAVA Region (CURSA), Antalaha, Madagascar

Lucien Faliniaina, Bakolimalala Rakouth, \& Estelle Raveloaritiana

Plant Biology and Ecology Department, University of Antananarivo, Antananarivo, Madagascar

\section{Viviana Uruena}

Research Centre 'Poverty, Equity and Growth in Developing Countries', Faculty of Economics, University of Goettingen, Göttingen, Germany.

Hendrik Hänke

Research Unit Environmental-and Resource Economics, Department of Agricultural Economics and Rural Development, University of Goettingen, Göttingen, Germany

Dirk Hölscher \& Kristina Osen

Tropical Silviculture and Forest Ecology, University of Goettingen, Göttingen, Germany 


\section{Rouvah Andriafanomezantsoa, Aristide Andrianarimisa, Thio Rosin Fulgence, Eric Rakotomalala, \& Fanomezana Mihaja Ratsoavina}

Zoology and Animal Biodiversity, University of Antananarivo, Antananarivo, Madagascar

\subsection{SI Chapter 2}

Supporting information for:

Martin, D. A., Osen, K., Grass, I., Hölscher, D., Tscharntke, T., Wurz, A., \& Kreft, H. (2020b). Land-use history determines ecosystem services and conservation value in tropical agroforestry. Conservation Letters, 13(5), e12740. 10.1111/conl.12740.

The supporting information 'conl12740-sup-0001-tableS1.xlsx' for Chapter 2 is available at: https://conbio.onlinelibrary.wiley.com/action/downloadSupplement?doi=10.1111\%2Fconl.12740\&file=conl12740-sup-0001-tableS1.xlsx

\subsection{SI Chapter 3}

Supporting information for:

Martin, D. A., Andriafanomezantsoa, R., Dröge, S., Osen, K., Rakotomalala, E., Wurz, A., Andrianarimisa, A., \& Kreft, H. (2020a). Bird diversity and endemism along a land-use gradient in Madagascar: the conservation value of vanilla agroforests. Biotropica. 10.1111/BTP.12859.

The supporting information for Chapter 3 is also available at: https://onlinelibrary.wiley.com/action/downloadSupple-

ment?doi=10.1111\%2Fbtp.12859\&file=btp12859-sup-0001-Supinfo.docx.

The data supporting Chapter 3 is available on Data Dryad: https://doi.org/10.5061/dryad.83bk3j9nm

\subsubsection{Details on selection of villages and plots}

We first selected 10 villages within the 60 study villages of the Diversity Turn project (see Hänke et al. 2018 for choice of 60 villages). Using google earth, we selected villages which did not have coconut plantations, not more than $40 \%$ water (sea, lake or river) but have forest fragments and shifting cultivation, within a $2 \mathrm{~km}$ radius buffer around the village. This produced a list of 17 villages. If two of those 17 villages had overlapping $2 \mathrm{~km}$ buffers, we selected one of them randomly resulting in 14 remaining villages. We then visited those villages in random order to select plots. In one village we did not find the land-use types for 
our study and in one village people were not willing to participate in the study. We thus visited 12 of the 14 villages and chose plots in 10 villages. We did not visit the remaining 2 of the 14 villages because we could already establish suitable plots in 10 villages, which was the targeted number of study villages a priori.

\subsubsection{Details on old-growth forest sites}

Few contiguous forest blocks remain within the study area. Most of them are situated at higher altitudes than our village plots making them unsuitable as an old-growth forest baseline. The only two areas with large connecting low altitude rainforest are Makirovina-Tsihomanaomby Reserve and Marojejy National Park. Talking with local experts about the level of disturbance and forest use in both forests, we disregarded the option of sampling at Makirovina-Tsihomanaomby as the forest there, particularly at low altitude, is heavily used for unauthorized wood extraction and vanilla cultivation. Therefore, we chose all 10 oldgrowth forest plots inside Marojejy National Park.

Marojejy National Park was founded as a strict nature reserve in 1952 and was converted into a National Park in 1998 (Goodman, 2000). The park has a size of 55'500 ha and spans elevation zones from low altitude rainforest to shrub land above the tree line at the peak of Marojejy at 2132m.a.s.l. (Goodman, 2000). The park is widely recognized for its exceptional biodiversity, also in comparison to other protected areas in Madagascar (Goodman, 2000). Five of the plots in Marojejy National Park were in the Manantenina Valley (termed Marojejy Tourist), five further east in the Boangabe area (termed Marojejy East). Forest plots in the Manantenina valley might have experienced some logging in the past, particularly for precious woods (Patel, 2007), but are now well protected as this is the touristic zone of the park. However, some clearings occurred before the park was established as a strict nature reserve in 1952, leading to gaps in the forest cover which we avoided when selecting the plots. In Boangabe, some illegal selective logging and trapping occurred at the time of data collection (personal communication Jean-Chrysostome Bevao) and in the past (Patel, 2007). We did avoid sites with obvious selective logging when selecting the plots.

The old-growth forest plot centers are a minimum of $250 \mathrm{~m}$ from the forest edge and the minimum distance between old-growth forest plot centers is $260 \mathrm{~m}$.

\subsubsection{Details on vanilla plot selection}

Vanilla is the main cash crop in north-eastern Madagascar (Hänke et al., 2018), and the most important export commodity of Madagascar (Comtrade, 2017). In each of the 10 villages, 
we selected three plots, one plot with low, one with intermediate and one with high canopy closure based on visual impressions in the field aiming for a within-village gradient in canopy closure. After plot selection but before data collection, we identified a differentiation based on land-use history (fallow- vs. forest-derived) as an interesting unit of analysis. We thus attributed each of those 30 plots to two categories based on land-use history following confirmation with plot owners. 20 out of 30 agroforests were derived from fallow land and thus termed 'fallow-derived vanilla' while the remaining 10 agroforests were forest-derived and thus termed 'forest-derived vanilla' following the concept of Martin et al. (2020b). Due to the initial selection criteria, both forest-derived and fallow-derived plots have a gradient from low to high canopy closure. The proportion of two-thirds of vanilla agroforests being fallow-derived can be representative for the study region (Hänke et al., 2018) for which fallow-derived vanilla made up $70 \%$ of all vanilla agroforests while forest-derived vanilla accounted for $27 \%$ (excluding agroforests that had been acquired as vanilla by respective households; $3 \%$ of plots had an unknown land-use history).

\subsubsection{Details on point counts}

We conducted two point counts (Bibby, Burgess, Hill, \& Mustoe, 2000) of 40 minutes each on all 80 plots during the breeding season which is from late August to December. Two observers carried out all point counts between 4:45 AM and 8:14 AM. With the exception of old-growth forest plots, we did the first point count between October and December 2017 with DAM as the main observer and RA as the second observer. We conducted a second point count on each plot between August and November 2018 with ER as the main observer and DAM or SD as the second observer. We reversed the order of plot visits over time in the second year to avoid seasonal bias. ER as the main observer conducted old-growth forest point counts once in late August/early September 2018 (DAM as second observer) and once in late November/early December 2018 (SD as second observer). On 73 plots we started one point count around sunrise and one at least one hour after sunrise; on 7 plots this alteration was not possible due to logistical constraints. See Table 2 for times and observers of each point count. After arriving at the plot center, we waited for minimum three minutes to allow birds to settle. We then noted the conditions including rain (no rain, drizzle, light rain, heavy rain) and wind (Beaufort 1-12; Beer, 2013)). We only started point counts if weather conditions were good, meaning no rain and wind equal or less than Beaufort 4. If weather conditions deteriorated for more than $10 \mathrm{~min}$, we aborted the point count and started again later or the next day under better conditions. To improve bird distance estimation, we estimated the distance to landmarks (e.g. trees, huts, plantation borders) at $25 \mathrm{~m}$ distance and, 
if possible, at $50 \mathrm{~m}$ distance in all 4 cardinal directions. We divided each 40 -minutes point count into 8 'mini-counts' of 5 minutes each to avoid counting the same individual more than once, a common problem of long point counts (Bibby et al., 2000; Scott \& Ramsey, 1981). During each mini-count, the main observer identified bird individuals and flocks of birds as unique detections including the estimated distance from the plot center, whether he/she heard or saw them, and, if seen, whether they were in flight or not. For groups of birds, we noted the number of individuals. Number of detections is thus smaller than the total number of individuals as one detection may have included more than one individual. We used a field guide (Hawkins, Safford, \& Skerrett, 2015) along with audio recordings to aid identification (Hawkins and Ranft, 2007). The second observer assisted with finding birds visually and audibly and entered all data into a tablet using the data entry application 'KOBO toolbox' (Harvard Humanitarian Initiative, 2018). Nomenclature followed the BirdLife checklist (BirdLife International, 2018). We recorded unknown vocalizations using an Olympus LS-14 handheld recorder for later identification. 26 individuals which we could not identify with certainty were excluded from analysis. Lesser Vasa Parrot (Coracopsis nigra) and Greater Vasa Parrot (C. vasa) are difficult to distinguish in the field (Hawkins et al., 2015), thus we treated them as one species. We excluded all species only seen in flight and outside the plot from our analysis.

\subsubsection{Data uploaded on DRYAD}

Martin, D. A., Andriafanomezantsoa, R., Dröge, S., Osen, K., Rakotomalala, E., Wurz, A., Andrianarimisa, A., \& Kreft, H. (2020a), Data from: Bird diversity and endemism along a land-use gradient in Madagascar: the conservation value of vanilla agroforests. Data Dryad, https://doi.org/10.5061/dryad.83bk3j9nm

\section{DATA plot characteristics.csv}

List of all 80 plots with plot-code, land-use type, village, burned (yes/no), longitude, latitude, elevation, 2017 landscape-scale forest cover in a 250 m radius around plot centers, canopy closure, basal area, and number of large trees.

Plot coordinates (longitude / latitude) have been reduced to three digits to protect the privacy of land owners.

\section{DATA species by site matrix.csv}

Matrix with all 57 bird species (rows) and 80 plots (columns) showing species presence (1) and absence (0). 


\subsubsection{Literature cited}

Beer, T. (2013). Beaufort Wind Scale. In P. T. Bobrowsky (Ed.), Encyclopedia of Natural Hazards (pp. 42-45). https://doi.org/10.1007/978-1-4020-4399-4_24

Bibby, C. J., Burgess, N. D., Hill, D. A., \& Mustoe, S. (2000). Bird Census Techniques. Amsterdam, The Netherlands: Elsevier.

BirdLife International. (2018). BirdLife International: Data Zone. http://datazone.birdlife.org/home; accessed 26.11.2018.

Comtrade, U. N. (2017). United Nations. https://comtrade.un.org; accessed 30.10.2019

Goodman, S. M. (2000). Chapter 1: Description of the Parc National de Marojejy, Madagascar, and the 1996 biological inventory of the reserve. In S. M. Goodman (Ed.), A floral and faunal inventory of the Parc national de Marojejy, Madagascar: with reference to elevational variation. Chicago, USA: Field Museum of Natural History.

Hänke, H., Barkmann, J., Blum, L., Franke, Y., Martin, D., Niens, J., Osen, K., Uruena, W., Witherspoon, S. A., Wurz, A. (2018). Socio-economic, land use and value chain perspectives on vanilla farming in the SAVA Region (north-eastern Madagascar): The Diversity Turn Baseline Study (DTBS). https://www.doi.org/10.13140/rg.2.2.29848.44809

Harvard Humanitarian Initiative (2018). Kobo Toolbox: Data Collection Tools for Challenging Environments. http://www.kobotoolbox.org, accessed 26.11.2018

Hawkins, A. F. A., Safford, R., \& Skerrett, A. (2015). Birds of Madagascar and the Indian Ocean Islands. London, UK: Christopher Helm.

Hawkins, R. \& Ranft, R. (2007). Bird Sounds of Madagascar: An audio guide to the island's unique birds. London, UK: British Library.

Martin, D. A., Osen, K., Grass, I., Hölscher, D., Tscharntke, T., Wurz, A., \& Kreft, H. (2020b). Land-use history determines ecosystem services and conservation value in tropical agroforestry. Conservation Letters, e12740. https://doi.org/10.1111/conl.12740

Patel, E. R. (2007). Logging of Rare Rosewood and Palisandre (Dalbergia spp.) within Marojejy National Park, Madagascar. Madagascar Conservation \& Development, 2(1). https://doi.org/10.4314/mcd.v2i1.44124

Scott, J. M., \& Ramsey, F. L. (1981). Length of count period as a possible source of bias in estimating bird densities. In C. J. Ralph and J. M. Scott (Ed.), Estimating Numbers of Terrestrial Birds. Cooper Ornithological Society. 


\subsubsection{Figures}
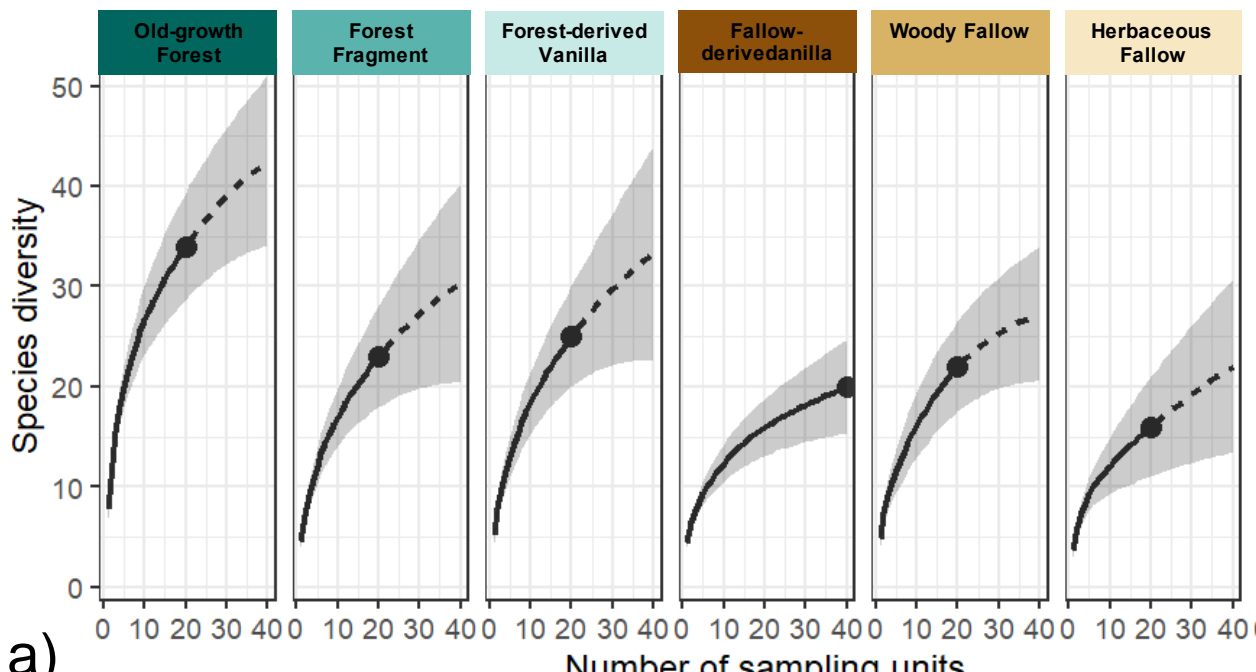

a) Number of sampling units

-interpolated-' 'extrapolated
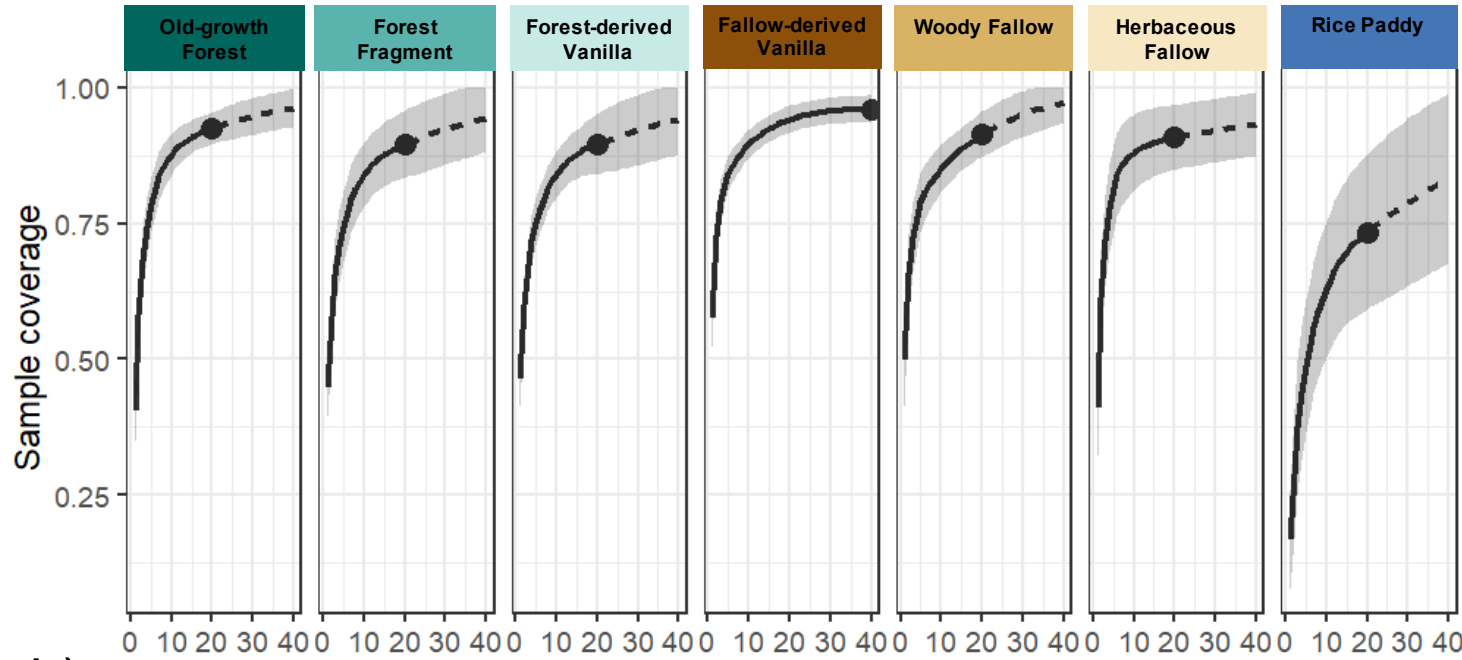

b)

Number of sampling units

Figure 12.1: Species accumulation curves and sample coverage for each land-use type calculated using the R-Package iNEXT. Each plot is treated as one sampling unit, hence 10 sampling units per land-use type with the exception of fallow-derived vanilla with 20 plots. a) Species accumulation curves are still increasing but are starting to level off after 10 plots in all land-use types. b) Sample coverage reached $>80 \%$ for all land-use types except rice paddy. 


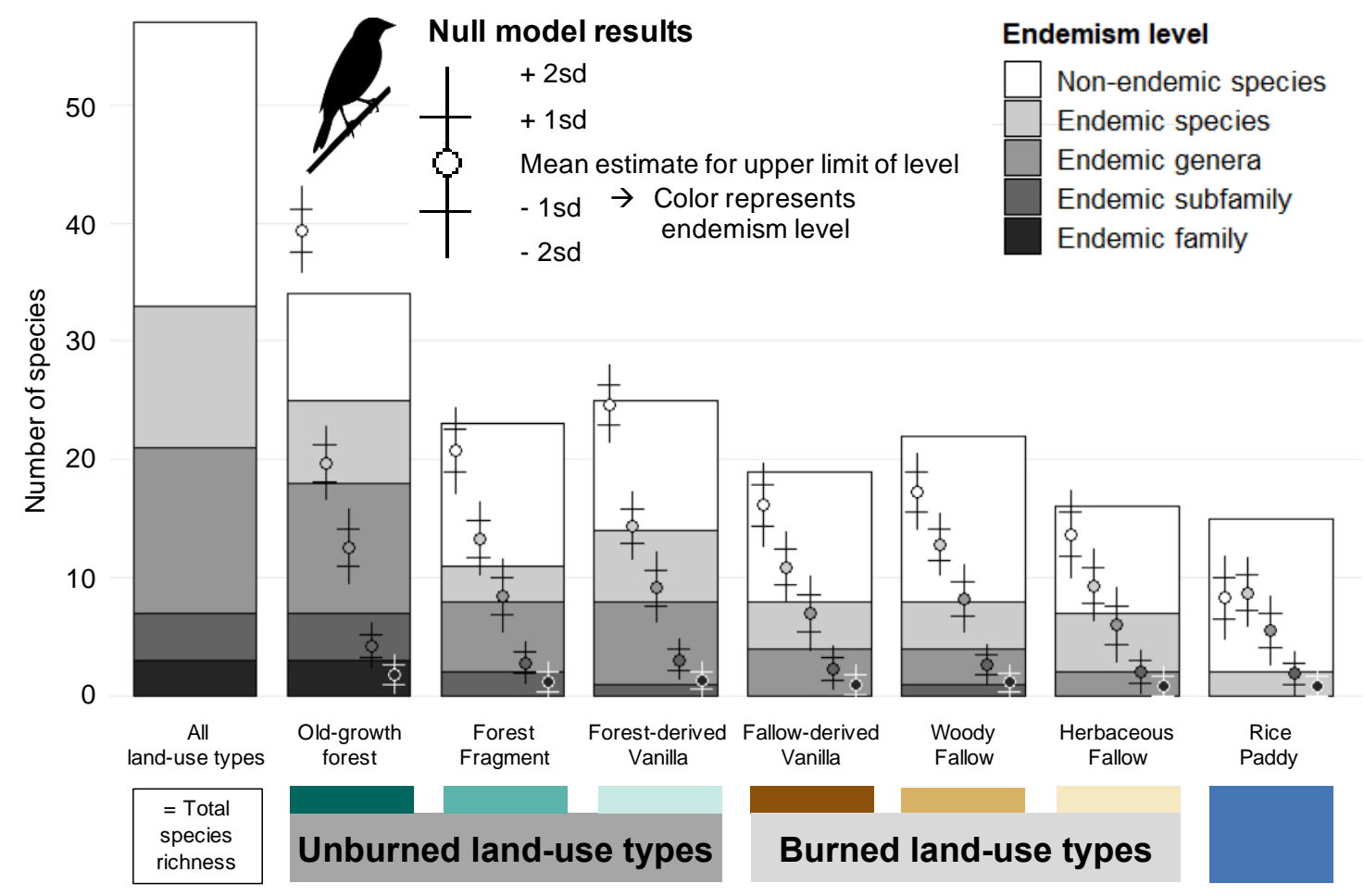

Figure 12.2: Total number of bird species (gamma-diversity) and number of species per endemism level across all plots $(N=80)$ and in each land-use type $(N=10$ plots per land-use type; $10 / 20$ subsampled for fallow-derived vanilla). Endemics make up a larger proportion than expected from a null model in old-growth forests. The unburned land-use types, forest fragment and forest-derived vanilla come closest to the null model, while non-endemic species are heavily overrepresented in burned land-use types and rice paddies. Points represent all null model estimates and the first respectively second whisker represent 1 respectively 2 standard deviations. 


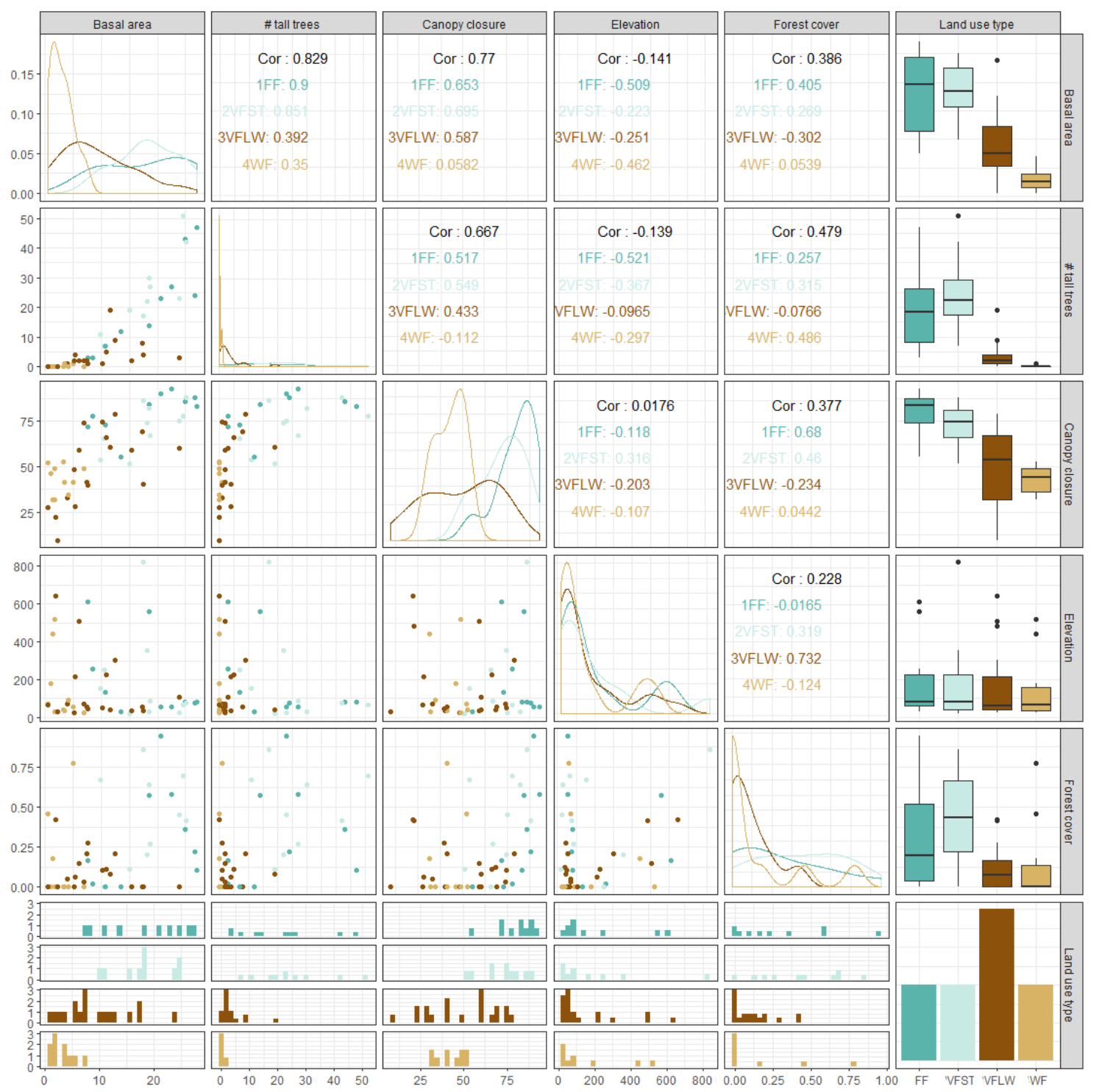

Figure 12.3: Correlation-plot of covariates for general linear models including correlation coefficients, histograms and boxplots for each land-use type. Displayed are only the values for the landuse types included in the GLMs, that is forest fragment (FF), forest-derived vanilla (VFST), fallowderived vanilla (VFLW), and woody fallow (WF). \# tall trees and canopy closure were not included in the models due to collinearity with basal area (Spearman correlation coefficient of 0.829 and 0.770 respectively). 


\subsubsection{Tables}

Table 12.1: Mean size of each land unit in which we established the plots

\begin{tabular}{|l|l|l|l|}
\hline Land-use type & Mean size (ha) & $\begin{array}{l}\text { Standard } \\
\text { deviation }\end{array}$ & Method \\
\hline Old-growth forest & $59^{\prime} 752$ & NA & $\begin{array}{l}\text { National Park Size; https://protect- } \\
\text { edplanet.net/2305 }\end{array}$ \\
\hline Forest fragment & 3.93 & 3.95 & Manual measurement in Google Earth \\
\hline Forest-derived vanilla & 1.01 & 0.80 & GPS device in terrain \\
\hline Fallow-derived vanilla & 0.48 & 0.19 & GPS device in terrain \\
\hline Woody fallow & 0.65 & 0.26 & Manual measurement in Google Earth \\
\hline Herbaceous fallow & 0.49 & 0.30 & GPS device in terrain \\
\hline Rice paddy & 0.63 & 0.28 & GPS device in terrain \\
\hline
\end{tabular}


Table 12.2: List of all 160 point-counts in 80 plots with first and second observer and observation times. All times are AM. ER: Eric Rakotomalala, DAM: Dominic Andreas Martin, SD: Saskia Dröge, RA: Rouvah Andriafanomezantsoa.

\begin{tabular}{|c|c|c|c|c|c|c|c|c|c|c|c|}
\hline \multirow[t]{2}{*}{ plotcode } & \multirow[t]{2}{*}{ land-use type } & \multicolumn{5}{|c|}{ first point count } & \multicolumn{5}{|c|}{ second point count } \\
\hline & & date & $\begin{array}{l}\text { time } \\
\text { start }\end{array}$ & $\begin{array}{l}\text { time } \\
\text { end }\end{array}$ & $\begin{array}{l}\text { main } \\
\text { observer }\end{array}$ & $\begin{array}{l}\text { second } \\
\text { observer }\end{array}$ & date & $\begin{array}{l}\text { time } \\
\text { start }\end{array}$ & $\begin{array}{l}\text { time } \\
\text { end }\end{array}$ & $\begin{array}{l}\text { main } \\
\text { observer }\end{array}$ & $\begin{array}{l}\text { second } \\
\text { observer }\end{array}$ \\
\hline ME-PF1 & Old-growth forest & $29 / 08 / 2018$ & $5: 33$ & $6: 13$ & ER & DAM & $06 / 12 / 2018$ & $5: 51$ & $6: 31$ & ER & SD \\
\hline ME-PF2 & Old-growth forest & $28 / 08 / 2018$ & $5: 45$ & $6: 25$ & ER & DAM & $04 / 12 / 2018$ & $6: 15$ & $6: 55$ & ER & SD \\
\hline ME-PF3 & Old-growth forest & $28 / 08 / 2018$ & $7: 02$ & $7: 42$ & ER & DAM & $04 / 12 / 2018$ & $4: 53$ & $5: 33$ & ER & SD \\
\hline ME-PF4 & Old-growth forest & $30 / 08 / 2018$ & $6: 51$ & $7: 31$ & ER & DAM & $05 / 12 / 2018$ & $4: 59$ & $5: 39$ & ER & SD \\
\hline ME-PF5 & Old-growth forest & $30 / 08 / 2018$ & $5: 32$ & $6: 12$ & ER & DAM & $05 / 12 / 2018$ & $6: 12$ & $6: 52$ & ER & SD \\
\hline MT-PF1 & Old-growth forest & 05/09/2018 & $5: 32$ & $6: 12$ & ER & DAM & $28 / 11 / 2018$ & $6: 17$ & $6: 57$ & ER & SD \\
\hline MT-PF2 & Old-growth forest & $05 / 09 / 2018$ & $6: 57$ & $7: 37$ & ER & DAM & $28 / 11 / 2018$ & $4: 50$ & $5: 30$ & ER & SD \\
\hline MT-PF3 & Old-growth forest & $06 / 09 / 2018$ & $5: 32$ & $6: 12$ & ER & DAM & $29 / 11 / 2018$ & $5: 50$ & $6: 30$ & ER & SD \\
\hline MT-PF4 & Old-growth forest & $04 / 09 / 2018$ & $6: 48$ & $7: 28$ & ER & DAM & $27 / 11 / 2018$ & $4: 57$ & $5: 37$ & ER & SD \\
\hline MT-PF5 & Old-growth forest & $04 / 09 / 2018$ & $5: 32$ & $6: 12$ & ER & DAM & $27 / 11 / 2018$ & $6: 10$ & $6: 50$ & ER & SD \\
\hline V13-FF & Forest fragment & $12 / 12 / 2017$ & $6: 00$ & $6: 40$ & DAM & RA & $01 / 11 / 2018$ & $4: 53$ & $5: 33$ & ER & SD \\
\hline V13-HF & Herbaceous fallow & $07 / 10 / 2017$ & $5: 03$ & $5: 43$ & DAM & RA & $01 / 11 / 2018$ & $6: 15$ & $6: 55$ & ER & SD \\
\hline V13-RP & Rice paddy & $06 / 10 / 2017$ & $5: 28$ & $6: 08$ & DAM & RA & $30 / 10 / 2018$ & $6: 25$ & $7: 05$ & ER & SD \\
\hline V13-VH & Forest-derived vanilla & $05 / 10 / 2017$ & $7: 12$ & $7: 52$ & DAM & RA & $31 / 10 / 2018$ & $4: 52$ & $5: 32$ & ER & SD \\
\hline V13-VL & Fallow-derived vanilla & $04 / 10 / 2017$ & $6: 08$ & $6: 48$ & DAM & RA & $31 / 10 / 2018$ & $7: 04$ & $7: 44$ & ER & SD \\
\hline V13-VM & Fallow-derived vanilla & $06 / 10 / 2017$ & $7: 24$ & $8: 04$ & DAM & RA & $30 / 10 / 2018$ & $4: 56$ & $5: 36$ & ER & SD \\
\hline V13-WF & Woody fallow & $07 / 10 / 2017$ & $6: 47$ & $7: 27$ & DAM & RA & $02 / 11 / 2018$ & $4: 54$ & $5: 34$ & ER & SD \\
\hline
\end{tabular}




\begin{tabular}{|c|c|c|c|c|c|c|c|c|c|c|c|}
\hline V24-FF & Forest fragment & 07/11/2017 & $6: 35$ & $7: 15$ & DAM & RA & $09 / 11 / 2018$ & $4: 57$ & $5: 37$ & ER & SD \\
\hline V24-HF & Herbaceous fallow & 08/11/2017 & $6: 26$ & $7: 06$ & DAM & RA & $08 / 11 / 2018$ & $4: 56$ & $5: 36$ & ER & SD \\
\hline V24-RP & Rice paddy & 09/11/2017 & $6: 20$ & $7: 00$ & DAM & RA & $06 / 11 / 2018$ & $5: 00$ & $5: 40$ & ER & SD \\
\hline V24-VH & Forest-derived vanilla & $10 / 11 / 2017$ & $6: 09$ & $6: 49$ & DAM & RA & $07 / 11 / 2018$ & $4: 51$ & $5: 31$ & $\mathrm{ER}$ & SD \\
\hline V24-VL & Fallow-derived vanilla & 08/11/2017 & $5: 14$ & $5: 54$ & DAM & RA & $08 / 11 / 2018$ & $6: 01$ & $6: 41$ & ER & SD \\
\hline V24-VM & Fallow-derived vanilla & 09/11/2017 & $4: 55$ & $5: 35$ & DAM & RA & $06 / 11 / 2018$ & $6: 54$ & $7: 34$ & ER & SD \\
\hline V24-WF & Woody fallow & $07 / 11 / 2017$ & $5: 14$ & $5: 54$ & DAM & RA & $07 / 11 / 2018$ & $6: 30$ & $7: 10$ & ER & SD \\
\hline V25-FF & Forest fragment & $13 / 12 / 2017$ & $6: 31$ & $7: 11$ & DAM & RA & $24 / 10 / 2018$ & $5: 01$ & $5: 41$ & $\mathrm{ER}$ & SD \\
\hline V25-HF & Herbaceous fallow & $19 / 10 / 2017$ & $5: 20$ & $6: 00$ & DAM & RA & $23 / 10 / 2018$ & $6: 35$ & $7: 15$ & ER & SD \\
\hline V25-RP & Rice paddy & 19/10/2017 & $6: 32$ & $7: 12$ & DAM & RA & $22 / 10 / 2018$ & $5: 08$ & $5: 48$ & ER & SD \\
\hline V25-VH & Forest-derived vanilla & $20 / 10 / 2017$ & $7: 02$ & $7: 42$ & DAM & RA & $25 / 10 / 2018$ & $4: 57$ & $5: 37$ & ER & SD \\
\hline V25-VL & Forest-derived vanilla & $18 / 10 / 2017$ & $5: 16$ & $5: 56$ & DAM & RA & $22 / 10 / 2018$ & $6: 50$ & $7: 30$ & ER & SD \\
\hline V25-VM & Forest-derived vanilla & $18 / 10 / 2017$ & $6: 39$ & $7: 19$ & DAM & RA & $23 / 10 / 2018$ & $5: 01$ & $5: 41$ & ER & SD \\
\hline V25-WF & Woody fallow & $13 / 12 / 2017$ & $5: 10$ & $5: 50$ & DAM & RA & $24 / 10 / 2018$ & $6: 22$ & $7: 02$ & ER & SD \\
\hline V2-FF & Forest fragment & $31 / 10 / 2017$ & $6: 56$ & $7: 36$ & DAM & RA & $16 / 10 / 2018$ & $5: 32$ & $6: 12$ & ER & SD \\
\hline V2-HF & Herbaceous fallow & 03/11/2017 & $5: 29$ & $6: 09$ & DAM & RA & $17 / 10 / 2018$ & $6: 16$ & $6: 56$ & ER & SD \\
\hline V2-RP & Rice paddy & $01 / 11 / 2017$ & $6: 28$ & $7: 08$ & DAM & RA & $18 / 10 / 2018$ & $5: 19$ & $5: 59$ & ER & SD \\
\hline $\mathrm{V} 2-\mathrm{VH}$ & Forest-derived vanilla & $31 / 10 / 2017$ & $5: 26$ & $6: 06$ & DAM & RA & $16 / 10 / 2018$ & $7: 09$ & $7: 49$ & ER & SD \\
\hline V2-VL & Fallow-derived vanilla & 02/11/2017 & $6: 48$ & $7: 28$ & DAM & RA & $17 / 10 / 2018$ & $4: 57$ & $5: 37$ & ER & SD \\
\hline V2-VM & Fallow-derived vanilla & $01 / 11 / 2017$ & $5: 00$ & $5: 40$ & DAM & RA & $19 / 10 / 2018$ & $6: 00$ & $6: 40$ & ER & SD \\
\hline V2-WF & Woody fallow & $02 / 11 / 2017$ & $5: 00$ & $5: 40$ & DAM & RA & $18 / 10 / 2018$ & $6: 41$ & $7: 21$ & ER & SD \\
\hline V39-FF & Forest fragment & $14 / 10 / 2017$ & $7: 11$ & $7: 51$ & DAM & RA & $16 / 11 / 2018$ & $4: 50$ & $5: 30$ & $\mathrm{ER}$ & SD \\
\hline
\end{tabular}




\begin{tabular}{|c|c|c|c|c|c|c|c|c|c|c|c|}
\hline V39-HF & Herbaceous fallow & $13 / 10 / 2017$ & $5: 24$ & $6: 04$ & DAM & RA & $23 / 11 / 2018$ & $5: 53$ & $6: 33$ & ER & SD \\
\hline V39-RP & Rice paddy & $14 / 10 / 2017$ & $5: 03$ & $5: 43$ & DAM & RA & $16 / 11 / 2018$ & $6: 52$ & $7: 32$ & ER & SD \\
\hline V39-VH & Forest-derived vanilla & $11 / 10 / 2017$ & $6: 30$ & $7: 10$ & DAM & RA & $22 / 11 / 2018$ & $6: 29$ & $7: 09$ & ER & SD \\
\hline V39-VL & Fallow-derived vanilla & $12 / 10 / 2017$ & $5: 34$ & $6: 14$ & DAM & RA & $13 / 11 / 2018$ & $6: 42$ & $7: 22$ & $\mathrm{ER}$ & SD \\
\hline V39-VM & Fallow-derived vanilla & $12 / 10 / 2017$ & $6: 49$ & $7: 29$ & DAM & RA & $22 / 11 / 2018$ & $4: 51$ & $5: 31$ & ER & SD \\
\hline V39-WF & Woody fallow & $13 / 10 / 2017$ & $6: 27$ & $7: 07$ & DAM & RA & $23 / 11 / 2018$ & $4: 50$ & $5: 30$ & ER & SD \\
\hline V40-FF & Forest fragment & $13 / 11 / 2017$ & $5: 13$ & $5: 53$ & DAM & RA & $23 / 08 / 2018$ & $7: 07$ & $7: 47$ & ER & DAM \\
\hline V40-HF & Herbaceous fallow & $14 / 11 / 2017$ & $6: 40$ & $7: 20$ & DAM & RA & $21 / 08 / 2018$ & $5: 48$ & $6: 28$ & $\mathrm{ER}$ & DAM \\
\hline V40-RP & Rice paddy & $14 / 11 / 2017$ & $4: 55$ & $5: 35$ & DAM & RA & $21 / 08 / 2018$ & $7: 34$ & $8: 14$ & ER & DAM \\
\hline V40-VH & Forest-derived vanilla & $13 / 11 / 2017$ & $6: 59$ & $7: 39$ & DAM & RA & $23 / 08 / 2018$ & $5: 39$ & $6: 19$ & ER & DAM \\
\hline V40-VL & Fallow-derived vanilla & $16 / 11 / 2017$ & $6: 25$ & $7: 05$ & DAM & RA & $24 / 08 / 2018$ & $5: 45$ & $6: 25$ & ER & DAM \\
\hline V40-VM & Forest-derived vanilla & $15 / 11 / 2017$ & $5: 00$ & $5: 40$ & DAM & RA & $22 / 08 / 2018$ & $7: 26$ & $8: 06$ & ER & DAM \\
\hline V40-WF & Woody fallow & $15 / 11 / 2017$ & $6: 32$ & $7: 12$ & DAM & RA & $22 / 08 / 2018$ & $5: 45$ & $6: 25$ & ER & DAM \\
\hline V45-FF & Forest fragment & $22 / 11 / 2017$ & $5: 10$ & $5: 50$ & DAM & RA & $20 / 09 / 2018$ & $6: 42$ & $7: 22$ & ER & DAM \\
\hline V45-HF & Herbaceous fallow & $21 / 11 / 2017$ & $4: 50$ & $5: 30$ & DAM & RA & $21 / 09 / 2018$ & $7: 20$ & $8: 00$ & ER & DAM \\
\hline V45-RP & Rice paddy & $22 / 11 / 2017$ & $7: 02$ & $7: 42$ & DAM & RA & $20 / 09 / 2018$ & $5: 18$ & $5: 58$ & ER & DAM \\
\hline V45-VH & Forest-derived vanilla & $20 / 11 / 2017$ & $5: 40$ & $6: 20$ & DAM & RA & $18 / 09 / 2018$ & $7: 18$ & $7: 58$ & ER & DAM \\
\hline V45-VL & Fallow-derived vanilla & $23 / 11 / 2017$ & $4: 58$ & $5: 38$ & DAM & RA & $22 / 09 / 2018$ & $6: 20$ & $7: 00$ & ER & DAM \\
\hline V45-VM & Fallow-derived vanilla & $20 / 11 / 2017$ & $6: 57$ & $7: 37$ & DAM & RA & $18 / 09 / 2018$ & $5: 20$ & $6: 00$ & ER & DAM \\
\hline V45-WF & Woody fallow & $21 / 11 / 2017$ & $6: 37$ & $7: 17$ & DAM & RA & $21 / 09 / 2018$ & $5: 15$ & $5: 55$ & ER & DAM \\
\hline V47-FF & Forest fragment & $27 / 11 / 2017$ & $5: 09$ & $5: 49$ & DAM & RA & $09 / 10 / 2018$ & $6: 44$ & $7: 24$ & ER & SD \\
\hline V47-HF & Herbaceous fallow & $28 / 11 / 2017$ & $6: 49$ & $7: 29$ & DAM & RA & $11 / 10 / 2018$ & $5: 03$ & $5: 43$ & $\mathrm{ER}$ & SD \\
\hline
\end{tabular}




\begin{tabular}{|c|c|c|c|c|c|c|c|c|c|c|c|}
\hline V47-RP & Rice paddy & $30 / 11 / 2017$ & $4: 50$ & $5: 30$ & DAM & RA & $12 / 10 / 2018$ & $6: 03$ & $6: 43$ & ER & SD \\
\hline V47-VH & Fallow-derived vanilla & $27 / 11 / 2017$ & $6: 15$ & $6: 55$ & DAM & RA & $09 / 10 / 2018$ & $5: 04$ & $5: 44$ & ER & SD \\
\hline V47-VL & Fallow-derived vanilla & $29 / 11 / 2017$ & $6: 00$ & $6: 40$ & DAM & RA & $10 / 10 / 2018$ & $5: 00$ & $5: 40$ & ER & SD \\
\hline V47-VM & Fallow-derived vanilla & $29 / 11 / 2017$ & $4: 50$ & $5: 30$ & DAM & RA & $11 / 10 / 2018$ & $6: 07$ & $6: 47$ & ER & SD \\
\hline V47-WF & Woody fallow & $28 / 11 / 2017$ & $4: 53$ & $5: 33$ & DAM & $\mathrm{RA}$ & $10 / 10 / 2018$ & $6: 13$ & $6: 53$ & ER & SD \\
\hline V7-FF & Forest fragment & $05 / 12 / 2017$ & $4: 45$ & $5: 25$ & DAM & RA & $13 / 09 / 2018$ & $7: 11$ & $7: 51$ & ER & DAM \\
\hline V7-HF & Herbaceous fallow & $06 / 12 / 2017$ & $6: 00$ & $6: 40$ & DAM & RA & $11 / 09 / 2018$ & $5: 26$ & $6: 06$ & ER & DAM \\
\hline V7-RP & Rice paddy & $05 / 12 / 2017$ & $6: 30$ & $7: 10$ & DAM & $\mathrm{RA}$ & $13 / 09 / 2018$ & $5: 17$ & $5: 57$ & ER & DAM \\
\hline V7-VH & Fallow-derived vanilla & $04 / 12 / 2017$ & $5: 42$ & $6: 22$ & DAM & RA & $12 / 09 / 2018$ & $6: 55$ & $7: 35$ & ER & DAM \\
\hline V7-VL & Fallow-derived vanilla & $04 / 12 / 2017$ & $7: 15$ & $7: 55$ & DAM & RA & $12 / 09 / 2018$ & $5: 19$ & $5: 59$ & ER & DAM \\
\hline V7-VM & Fallow-derived vanilla & $07 / 12 / 2017$ & $6: 00$ & $6: 40$ & DAM & RA & $14 / 09 / 2018$ & $5: 17$ & $5: 57$ & ER & DAM \\
\hline V7-WF & Woody fallow & $06 / 12 / 2017$ & $4: 45$ & $5: 25$ & DAM & RA & $11 / 09 / 2018$ & $6: 58$ & $7: 38$ & ER & DAM \\
\hline V8-FF & Forest fragment & $27 / 10 / 2017$ & $5: 36$ & $6: 16$ & DAM & $\mathrm{RA}$ & $05 / 10 / 2018$ & $6: 16$ & $6: 56$ & ER & SD \\
\hline V8-HF & Herbaceous fallow & $26 / 10 / 2017$ & $6: 30$ & $7: 10$ & DAM & RA & $04 / 10 / 2018$ & $5: 13$ & $5: 53$ & ER & SD \\
\hline V8-RP & Rice paddy & $24 / 10 / 2017$ & $5: 13$ & $5: 53$ & DAM & RA & 03/10/2018 & $6: 33$ & $7: 13$ & ER & DAM \\
\hline V8-VH & Fallow-derived vanilla & $25 / 10 / 2017$ & $5: 00$ & $5: 40$ & DAM & $\mathrm{RA}$ & 02/10/2018 & $6: 55$ & $7: 35$ & ER & DAM \\
\hline V8-VL & Fallow-derived vanilla & $24 / 10 / 2017$ & $6: 51$ & $7: 31$ & DAM & RA & $03 / 10 / 2018$ & $5: 13$ & $5: 53$ & ER & SD \\
\hline V8-VM & Fallow-derived vanilla & $26 / 10 / 2017$ & 5:06 & $5: 46$ & DAM & RA & $04 / 10 / 2018$ & $6: 33$ & $7: 13$ & ER & SD \\
\hline V8-WF & Woody fallow & $25 / 10 / 2017$ & $5: 59$ & $6: 39$ & DAM & RA & $02 / 10 / 2018$ & $5: 19$ & $5: 59$ & $\mathrm{ER}$ & DAM \\
\hline
\end{tabular}


Table 12.3: List of species found within 25m-radius plots, IUCN status and endemism level

\begin{tabular}{|c|c|c|c|}
\hline Species name English & Species name Latin & $\begin{array}{l}\text { IUCN Cat- } \\
\text { egory }\end{array}$ & $\begin{array}{l}\text { Endemism } \\
\text { Level Mada- } \\
\text { gascar }\end{array}$ \\
\hline African Palm Swift & Cypsiurus parvus & $\mathrm{LC}$ & nonendemic \\
\hline Blue Coua & Coua caerulea & $\mathrm{LC}$ & subfamily \\
\hline Blue Vanga & Cyanolanius madagascarinus & LC & nonendemic \\
\hline Broad Billed Roller & Eurystomus glaucurus & $\mathrm{LC}$ & nonendemic \\
\hline Cattle Egret & Bubulcus ibis & $\mathrm{LC}$ & nonendemic \\
\hline Common Jery & Neomixis tenella & $\mathrm{LC}$ & genus \\
\hline Common Myna & Acridotheres tristis & $\mathrm{LC}$ & nonendemic \\
\hline Common Newtonia & Newtonia brunneicauda & $\mathrm{LC}$ & genus \\
\hline Crested Coua & Coua cristata & $\mathrm{LC}$ & subfamily \\
\hline Crested Drongo & Dicrurus forficatus & $\mathrm{LC}$ & nonendemic \\
\hline Cuckoo Roller & Leptosomus discolor & $\mathrm{LC}$ & nonendemic \\
\hline Dusky Tetraka & Crossleyia tenebrosa & $\mathrm{VU}$ & family \\
\hline Forest Fody & Foudia omissa & $\mathrm{LC}$ & species \\
\hline Frances S Goshawk & Accipiter francesiae & $\mathrm{LC}$ & nonendemic \\
\hline Green Jery & Neomixis viridis & $\mathrm{LC}$ & genus \\
\hline Grey Headed Lovebird & Agapornis canus & $\mathrm{LC}$ & nonendemic \\
\hline Harlequin Quail & Coturnix delegorguei & $\mathrm{LC}$ & nonendemic \\
\hline Helmet Vanga & Euryceros prevostii & VU & genus \\
\hline Helmeted Guineafowl & Numida meleagris & $\mathrm{LC}$ & nonendemic \\
\hline Hook Billed Vanga & Vanga curvirostris & $\mathrm{LC}$ & genus \\
\hline Long Billed Bernieria & Bernieria madagascariensis & $\mathrm{LC}$ & family \\
\hline Madagascan Blue Pigeon & Alectroenas madagascariensis & $\mathrm{LC}$ & species \\
\hline Madagascan Buzzard & Buteo brachypterus & $\mathrm{LC}$ & species \\
\hline Madagascan Cisticola & Cisticola cherina & $\mathrm{LC}$ & nonendemic \\
\hline Madagascan Green Pigeon & Treron australis & $\mathrm{LC}$ & species \\
\hline Madagascan Sparrowhawk & Accipiter madagascariensis & NT & species \\
\hline Madagascan Starling & Hartlaubius auratus & $\mathrm{LC}$ & genus \\
\hline Madagascar Bee Eater & Merops superciliosus & $\mathrm{LC}$ & nonendemic \\
\hline Madagascar Brush Warbler & Nesillas typica & $\mathrm{LC}$ & nonendemic \\
\hline Madagascar Bulbul & Hypsipetes madagascariensis & $\mathrm{LC}$ & nonendemic \\
\hline Madagascar Coucal & Centropus toulou & $\mathrm{LC}$ & nonendemic \\
\hline
\end{tabular}




\begin{tabular}{|c|c|c|c|}
\hline Madagascar Cuckoo Shrike & Ceblepyris cinereus & LC & species \\
\hline Madagascar Flufftail & Sarothrura insularis & LC & species \\
\hline Madagascar Kestrel & Falco newtoni & LC & nonendemic \\
\hline Madagascar Magpie Robin & Copsychus albospecularis & LC & species \\
\hline Madagascar Mannikin & Lepidopygia nana & LC & genus \\
\hline Madagascar Nightjar & Caprimulgus madagascariensis & $\mathrm{LC}$ & species \\
\hline Madagascar Paradise Flycatcher & Terpsiphone mutata & LC & nonendemic \\
\hline Madagascar Rail & Rallus madagascariensis & VU & species \\
\hline Madagascar Red Fody & Foudia madagascariensis & $\mathrm{LC}$ & nonendemic \\
\hline Madagascar White Eye & Zosterops maderaspatanus & $\mathrm{LC}$ & nonendemic \\
\hline Madagascar Wood Rail & Mentocrex kioloides & $\mathrm{LC}$ & genus \\
\hline Malagasy Green Sunbird & Cinnyris notatus & LC & species \\
\hline Malagasy Kingfisher & Corythornis vintsioides & $\mathrm{LC}$ & nonendemic \\
\hline Malagasy Turtle Dove & Nesoenas picturatus & $\mathrm{LC}$ & nonendemic \\
\hline Nelicourvi Weaver & Ploceus nelicourvi & LC & species \\
\hline Red Breasted Coua & Coua serriana & LC & subfamily \\
\hline Red Fronted Coua & Coua reynaudii & LC & subfamily \\
\hline Red Tailed Vanga & Calicalicus madagascariensis & LC & genus \\
\hline Sickle Billed Vanga & Falculea palliata & LC & genus \\
\hline Souimanga Sunbird & Cinnyris sovimanga & $\mathrm{LC}$ & nonendemic \\
\hline Striated Heron & Butorides striata & LC & nonendemic \\
\hline Stripe Throated Jery & Neomixis striatigula & $\mathrm{LC}$ & genus \\
\hline Tylas Vanga & Tylas eduardi & LC & genus \\
\hline Vasa Parrot Sp & Coracopsis sp. & $\mathrm{LC}$ & nonendemic \\
\hline White Headed Vanga & Artamella viridis & LC & genus \\
\hline White Throated Oxylabes & Oxylabes madagascariensis & LC & family \\
\hline
\end{tabular}

Table 12.4: Test-Results for comparing species richness across land-use types as displayed with letters in in Figure 3.2 a).

\begin{tabular}{|l|r|r|r|r|l|}
\hline Pair comparison & Estimate & \multicolumn{1}{l|}{ lower } & \multicolumn{1}{l|}{ upper } & \multicolumn{1}{l|}{ p-value } & signif. \\
\hline Forest fragment - Old-growth forest & -5.4 & -8.611 & -2.189 & $<0.001$ & $* * *$ \\
\hline Forest-derived vanilla - Old-growth forest & -4.7 & -7.911 & -1.489 & $<0.001$ & $* * *$ \\
\hline Fallow-derived vanilla - Old-growth forest & -5.95 & -8.730 & -3.170 & $<0.001$ & $* * *$ \\
\hline Woody fallow - Old-growth forest & -5.3 & -8.511 & -2.089 & $<0.001$ & $* * *$ \\
\hline
\end{tabular}




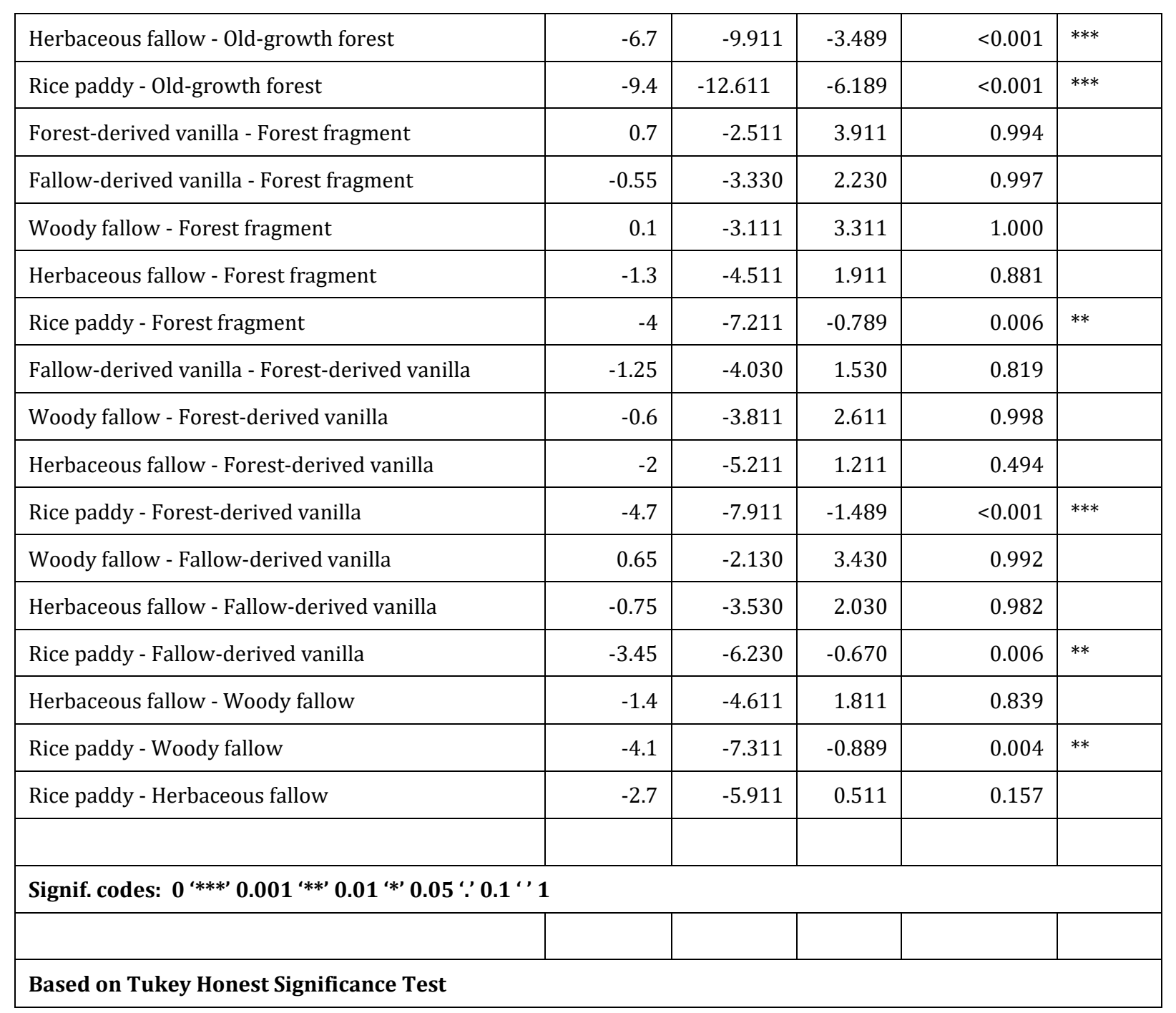

Table 12.5: Test-Results for comparing endemic species richness across land-use types as displayed with letters in Figure 3.2 b).

\begin{tabular}{|l|r|r|r|r|l|}
\hline Pair comparison & Estimate & Std. Error & t value & p-adjusted & signif \\
\hline Forest fragment - Old-growth forest & -5.4 & 1.118 & -4.832 & $<0.001$ & $* * *$ \\
\hline Forest-derived vanilla - Old-growth forest & -5.1 & 1.046 & -4.875 & $<0.001$ & $* * *$ \\
\hline Fallow-derived vanilla - Old-growth forest & -6.55 & 0.990 & -6.616 & $<0.001$ & $* * *$ \\
\hline Woody fallow - Old-growth forest & -6.4 & 1.013 & -6.316 & $<0.001$ & $* * *$ \\
\hline Herbaceous fallow - Old-growth forest & -6.6 & 1.011 & -6.528 & $<0.001$ & $* * *$ \\
\hline Rice paddy - Old-growth forest & -7.2 & 0.966 & -7.453 & $<0.001$ & $* * *$ \\
\hline Forest-derived vanilla - Forest fragment & 0.3 & 0.716 & 0.419 & 0.999 & \\
\hline Fallow-derived vanilla - Forest fragment & -1.15 & 0.631 & -1.823 & & 0.498 \\
\hline Woody fallow - Forest fragment & -1 & 0.667 & -1.5 & 0.712 & \\
\hline
\end{tabular}




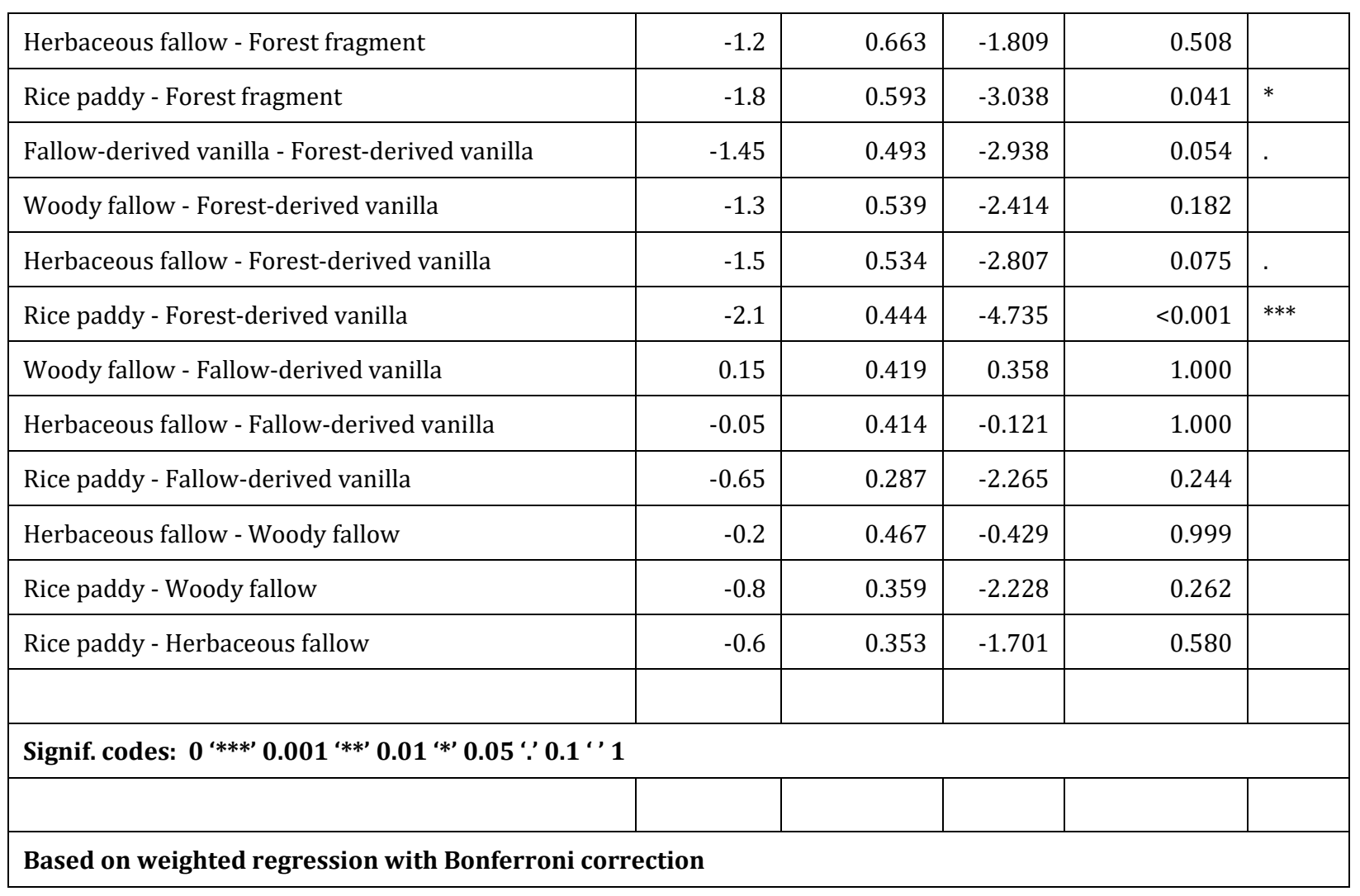

Table 12.6: Test-Results for comparing species composition across land-use types using the pairwise.adonis function.

\begin{tabular}{|c|c|c|c|c|c|}
\hline Pair comparison & $\begin{array}{l}\text { Sums of } \\
\text { Squares }\end{array}$ & F-Model & $\mathbf{R 2}$ & p-adjusted & $\begin{array}{l}\text { sig- } \\
\text { nif }\end{array}$ \\
\hline Old-growth forest - Forest fragment & 0.59 & 4.63 & 0.20 & 0.02 & $*$ \\
\hline Old-growth forest - Herbaceous fallow & 1.78 & 14.78 & 0.45 & 0.02 & * \\
\hline Old-growth forest - Rice paddy & 3.34 & 17.22 & 0.49 & 0.02 & * \\
\hline Old-growth forest - Forest-derived vanilla & 0.53 & 4.21 & 0.19 & 0.02 & $*$ \\
\hline Old-growth forest - Fallow-derived vanilla & 1.66 & 20.98 & 0.43 & 0.02 & * \\
\hline Old-growth forest - Woody fallow & 1.32 & 11.76 & 0.40 & 0.02 & $*$ \\
\hline Forest fragment - Herbaceous fallow & 0.64 & 4.75 & 0.21 & 0.02 & * \\
\hline Forest fragment - Rice paddy & 1.45 & 6.94 & 0.28 & 0.02 & * \\
\hline Forest fragment - Forest-derived vanilla & 0.01 & 0.10 & 0.01 & 1.00 & \\
\hline Forest fragment - Fallow-derived vanilla & 0.26 & 2.92 & 0.09 & 0.10 & . \\
\hline Forest fragment - Woody fallow & 0.28 & 2.22 & 0.11 & 1.00 & \\
\hline Herbaceous fallow - Rice paddy & 0.38 & 1.87 & 0.09 & 1.00 & \\
\hline Herbaceous fallow - Forest-derived vanilla & 0.66 & 4.94 & 0.22 & 0.02 & * \\
\hline
\end{tabular}




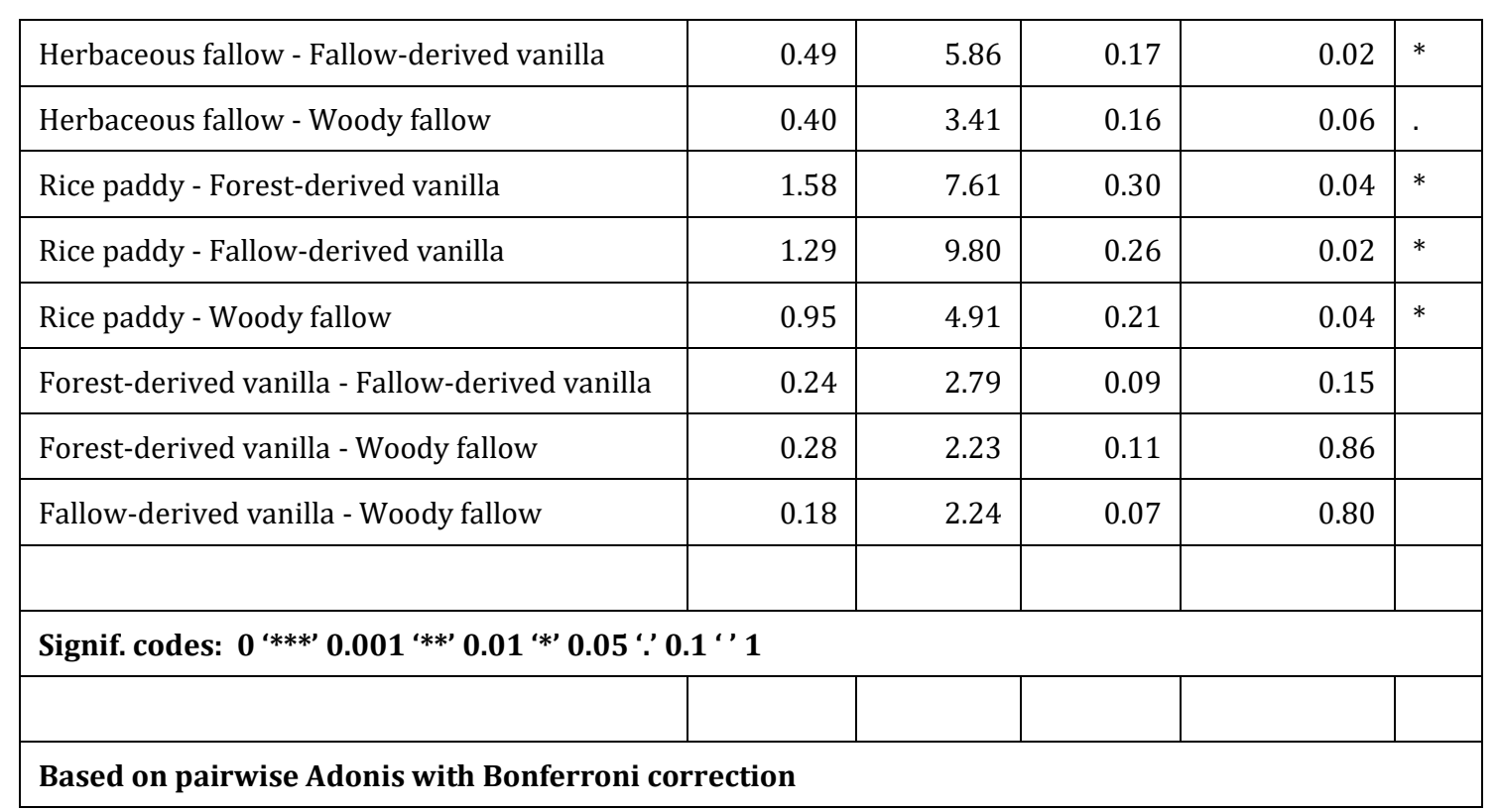




\subsection{SI Chapter 4}

Supporting information for:

Dröge, S., Martin, D. A., Andriafanomezantsoa, R., Burivalova, Z., Fulgence, T. R., Osen, K., Rakotomalala, E., Schwab, D., Wurz, A., Richter, T., \& Kreft, H. (2021). Listening to a changing landscape: Acoustic indices reflect bird species richness and site-scale vegetation structure in the biodiversity hotspot of north-eastern Madagascar. Ecological Indicators, 120, 106929. 10.1016/i.ecolind.2020.106929.

The supporting information for Chapter 4 is also available at: https://ars.els-cdn.com/content/image/1-s2.0-S1470160X20308682-mmc1.pdf.

The data supporting Chapter 4 is available on Mendeley Data: https://doi.org/10.17632/fxxnwtmynv.1.

\subsubsection{Sound recorder characteristics}

We used self-built SOLO audio recorders (Whytock \& Christie, 2017) with two omni-directional microphones including a sound-penetrable vent and microphone windshields for weather protection, a Raspberry Pi A+ model, a PiFace Real Time Clock module and a Cirrus Logic Audio Card (Figure 12.4). We used 128 GB microSD-cards for data storage and the SOLO recorder software 'SOSI' (http://solo-system.github.io/home.html). Power was provided by a 16750 mAh USB battery pack. See Table 12.8 for specifications of all components. Component costs per recorder were $\sim 320 €$. We built eight recorders to sample all seven plots within one village respectively old-growth forest site simultaneously while having one recorder spare. We assigned recorders to plots by randomly setting up a deployment schedule to avoid possible biases due to differences between recorders in e.g. detection ranges. We recorded in CD-quality $(44.1 \mathrm{kHz} / 16 \mathrm{bit})$ with sound files stored in segments of 10 minutes in .wav-format. To archive the sound data after recorder collection in the field, we transferred the sound files to an external hard disk. We used the software and the real time clock module of the recorders to assign each sound file a unique name referring to plot site, the recorder used (colour coding) as well as date and time (exp.: audio-solo_red_V24-FF-2017-11-09_13-00-13.wav).

\subsubsection{Literature cited}

Whytock, R.C. \& Christie, J. (2017) Solo: an open source, customizable and inexpensive audio recorder for bioacoustic research. Methods in Ecology and Evolution, 8(3), 308-312. https://doi.org/10.1111/2041-210X.12678. 


\subsubsection{Figures}

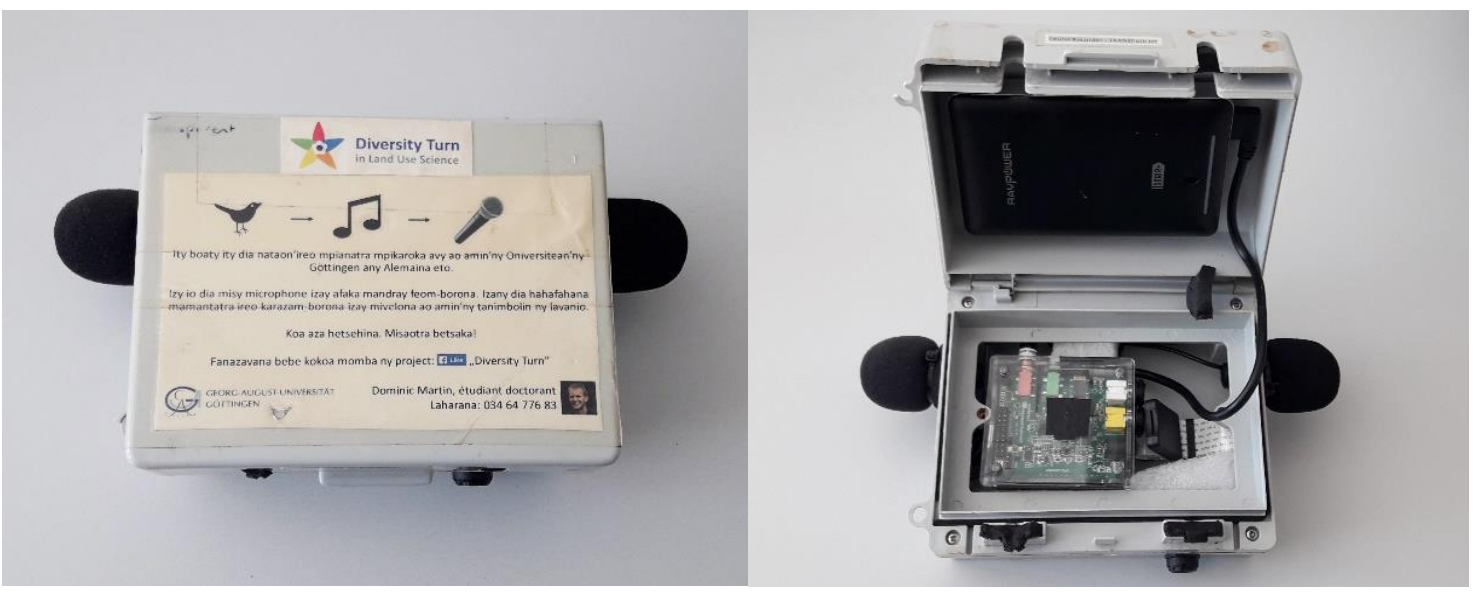

Figure 12.4: Self-built SOLO audio recorders used for sound recordings. a) Closed recorder with two omni-directional microphones including windshield foams and labelling in local Malagasy language to explain research method. b) Opened recorder showing its configuration based on a Raspberry $\mathrm{Pi}$ A+ model, Cirrus Logic audio card, PiFace Real Time Clock Module and a standard USB battery pack.

\subsubsection{Tables}

Table 12.7: Computational settings of the multiple_sounds function of the package soundecology we used to calculate the Acoustic Complexity Index (ACI), the Acoustic Diversity Index (ADI), the Acoustic Evenness Index (AEI) and the Acoustic Entropy (H) in R. Colours indicate if the setting was a default setting or if the value was adjusted. If available, we used an adjusted minimum frequency to exclude low-pitched background noise and an adjusted maximum frequency to limit the computation time on our personal computer. If not specified, the full frequency range of the recording $(0-22.1$ $\mathrm{kHz}$ ) is analysed (default). We set the dB threshold available for the functions ADI and AEI to a higher value (default -50) to exclude background noise.

\begin{tabular}{|l|l|l|l|l|l|l|}
\hline Acoustic index & min_freq & max_freq & $\mathbf{j}$ & $\mathbf{f f t} \_w$ & db_threshold & freq_steps \\
\hline ACI & 200 & 12000 & 5 & 512 & & \\
\hline ADI & & 12000 & & & -40 & 1000 \\
\hline AEI & & 12000 & & & -40 & 1000 \\
\hline H & & & & 512 & & \\
\hline
\end{tabular}

Default setting

Adjusted setting 
Table 12.8: List of all components used for the self-built SOLO audio recorders.

\begin{tabular}{|c|c|c|c|}
\hline Use & Product & Details & Comment \\
\hline Microphone & $\begin{array}{l}\text { Micbooster Rugged } \\
\text { Mount EM172 }\end{array}$ & Primo EM172 capsule & $\begin{array}{l}\text { Signal-to-Noise Ratio (SNR) of } 80 \\
\mathrm{~dB} \text { at } 1 \mathrm{kHz}\end{array}$ \\
\hline Microphone vent & $\begin{array}{l}\text { Gore Acoustic Vent } \\
\text { GAW112 }\end{array}$ & $\begin{array}{l}\text { To avoid water enter- } \\
\text { ing microphone }\end{array}$ & $\begin{array}{l}\text { Attached over Primo capsule } \\
\text { within Rugged Mount EM172 }\end{array}$ \\
\hline Windshield & Monacor WS-40 & & \\
\hline Computer & Raspberry Pi A+ & & \\
\hline Clock & $\begin{array}{l}\text { PiFace Real Time Clock } \\
\text { Module }\end{array}$ & & \\
\hline Audio card & $\begin{array}{l}\text { Cirrus Logic Audio } \\
\text { Card }\end{array}$ & & $\begin{array}{l}\text { This product is not produced any- } \\
\text { more }\end{array}$ \\
\hline Memory card & $\begin{array}{l}\text { SanDisk Ultra Android } \\
\text { microSDXC }\end{array}$ & 128 GB capacity & \\
\hline Card Extender & $\begin{array}{l}\text { Micro SD Card Exten- } \\
\text { sion Cable }\end{array}$ & Generic & $\begin{array}{l}\text { Facilitates changing of memory } \\
\text { card }\end{array}$ \\
\hline Battery & $\begin{array}{l}\text { RavPower Deluxe Se- } \\
\text { ries RP-PB19 }\end{array}$ & $16750 \mathrm{mAh}$ & $\begin{array}{l}\text { Fixed to lid of box using double } \\
\text { sided tape }\end{array}$ \\
\hline USB cable & USB cable & Generic & $\begin{array}{l}\text { Connecting battery to raspberry } \\
\text { Pi computer }\end{array}$ \\
\hline Computer case & $\begin{array}{l}\text { KnowHowTec Style } \\
\text { Case }\end{array}$ & & $\begin{array}{l}\text { Capsule for computer, clock and } \\
\text { audio card }\end{array}$ \\
\hline Box & $\begin{array}{l}\text { Eterna ESR SKB } 2 \mathrm{G} \\
\text { IP65 }\end{array}$ & $\begin{array}{l}\text { Waterproof double } \\
\text { socket box }\end{array}$ & Holes for microphones drilled \\
\hline Box vent & $\begin{array}{l}\text { Screw-in protective } \\
\text { vent }\end{array}$ & $\begin{array}{l}\text { Equalizes pressure } \\
\text { and avoids humidity }\end{array}$ & Built into front wall of box \\
\hline Lock & Oria TSA007 YiF & Number lock & \\
\hline Software & $\begin{array}{l}\text { SOSI (Solo Operating } \\
\text { System Image) }\end{array}$ & $\begin{array}{l}\text { Version 'sosi-2016-09- } \\
\text { 18.img' }\end{array}$ & $\begin{array}{l}\text { https://solo-system.github.io/ } \\
\text { downloads.html }\end{array}$ \\
\hline
\end{tabular}


Table 12.9: Plot variables. Land-use types (LUT): OGF: Old-growth Forest, FF: Forest Fragment, HF: Herbaceous Fallow, RP: Rice Paddy, VFST: Forest-derived Vanilla Agroforests, VFLW: Fallow-derived Vanilla Agroforests, WF: Woody Fallow.

\begin{tabular}{|c|c|c|c|c|c|c|c|}
\hline & Village & LUT & Plotcode & Eleva- & Forest area & Basal & Vegetation \\
\hline V13 & Ambodivohitra & $\mathrm{FF}$ & V13-FF & 609 & 0.17 & 7.59 & 0.62 \\
\hline V2 & Ambavala & $\mathrm{FF}$ & V2-FF & 81 & 0.36 & 24.86 & 0.66 \\
\hline V24 & Andrakata & $\mathrm{FF}$ & V24-FF & 557 & 0.57 & 18.53 & 0.43 \\
\hline V25 & Andramanolotra & $\mathrm{FF}$ & V25-FF & 54 & 0.94 & 20.56 & 0.62 \\
\hline V39 & Antsahanoro & FF & V39-FF & 76 & 0.22 & 26.62 & 0.65 \\
\hline V40 & Antsikory & $\mathrm{FF}$ & V40-FF & 57 & 0.58 & 22.51 & 0.66 \\
\hline V45 & Belambo & $\mathrm{FF}$ & V45-FF & 258 & 0.02 & 8.52 & 0.63 \\
\hline V47 & Bemanevika & $\mathrm{FF}$ & V47-FF & 83 & 0.10 & 27.02 & 0.58 \\
\hline V7 & Ambinanifaho & $\mathrm{FF}$ & V7-FF & 33 & 0.00 & 13.56 & 0.65 \\
\hline V8 & Ambodiala & $\mathrm{FF}$ & V8-FF & 131 & 0.00 & 10.76 & 0.64 \\
\hline V13 & Ambodivohitra & $\mathrm{HF}$ & V13-HF & 536 & 0.00 & 0.00 & 0.32 \\
\hline V2 & Ambavala & $\mathrm{HF}$ & V2-HF & 91 & 0.50 & 0.00 & 0.44 \\
\hline V24 & Andrakata & $\mathrm{HF}$ & V24-HF & 518 & 0.26 & 0.00 & 0.54 \\
\hline V25 & Andramanolotra & $\mathrm{HF}$ & V25-HF & 10 & 0.00 & 0.00 & 0.20 \\
\hline V39 & Antsahanoro & $\mathrm{HF}$ & V39-HF & 45 & 0.00 & 0.00 & 0.45 \\
\hline $\mathrm{V} 40$ & Antsikory & $\mathrm{HF}$ & V40-HF & 37 & 0.00 & 0.00 & 0.65 \\
\hline V45 & Belambo & $\mathrm{HF}$ & V45-HF & 263 & 0.00 & 0.00 & 0.60 \\
\hline V47 & Bemanevika & $\mathrm{HF}$ & V47-HF & 61 & 0.00 & 0.00 & 0.02 \\
\hline V7 & Ambinanifaho & $\mathrm{HF}$ & V7-HF & 20 & 0.04 & 0.00 & 0.30 \\
\hline V8 & Ambodiala & $\mathrm{HF}$ & V8-HF & 18 & 0.00 & 0.00 & 0.32 \\
\hline ME & Marojejy East & OGF & ME-PF1 & 292 & 0.86 & 34.50 & 0.60 \\
\hline $\mathrm{ME}$ & Marojejy East & OGF & ME-PF2 & 241 & 0.66 & 22.69 & 0.53 \\
\hline $\mathrm{ME}$ & Marojejy East & OGF & ME-PF3 & 344 & 0.95 & 59.36 & 0.61 \\
\hline $\mathrm{ME}$ & Marojejy East & OGF & ME-PF4 & 307 & 1.00 & 31.60 & 0.60 \\
\hline $\mathrm{ME}$ & Marojejy East & $\mathrm{OGF}$ & ME-PF5 & 292 & 1.00 & 25.05 & 0.62 \\
\hline MT & Marojejy Tourist & OGF & MT-PF1 & 454 & 0.48 & 61.09 & 0.62 \\
\hline MT & Marojejy Tourist & OGF & MT-PF2 & 348 & 0.79 & 37.57 & 0.65 \\
\hline MT & Marojejy Tourist & OGF & MT-PF3 & 580 & 0.99 & 76.68 & 0.55 \\
\hline MT & Marojejy Tourist & OGF & MT-PF4 & 632 & 0.92 & 55.51 & 0.67 \\
\hline
\end{tabular}




\begin{tabular}{|c|c|c|c|c|c|c|c|}
\hline MT & Marojejy Tourist & OGF & MT-PF5 & 701 & 0.91 & 43.37 & 0.52 \\
\hline V13 & Ambodivohitra & $\mathrm{RP}$ & V13-RP & 488 & 0.00 & 0.00 & 0.03 \\
\hline V2 & Ambavala & $\mathrm{RP}$ & V2-RP & 19 & 0.00 & 0.00 & 0.02 \\
\hline V24 & Andrakata & $\mathrm{RP}$ & V24-RP & 351 & 0.29 & 0.00 & 0.03 \\
\hline V25 & Andramanolotra & $\mathrm{RP}$ & V25-RP & 7 & 0.00 & 0.00 & 0.08 \\
\hline V39 & Antsahanoro & $\mathrm{RP}$ & V39-RP & 18 & 0.00 & 0.00 & 0.18 \\
\hline V40 & Antsikory & $\mathrm{RP}$ & V40-RP & 42 & 0.00 & 0.00 & 0.03 \\
\hline V45 & Belambo & $\mathrm{RP}$ & V45-RP & 103 & 0.00 & 0.00 & 0.15 \\
\hline V47 & Bemanevika & $\mathrm{RP}$ & V47-RP & 47 & 0.00 & 0.00 & 0.03 \\
\hline V7 & Ambinanifaho & $\mathrm{RP}$ & V7-RP & 15 & 0.00 & 0.00 & 0.02 \\
\hline V8 & Ambodiala & $\mathrm{RP}$ & V8-RP & 45 & 0.00 & 0.00 & 0.06 \\
\hline V13 & Ambodivohitra & VFLW & V13-VL & 644 & 0.42 & 2.00 & 0.45 \\
\hline V13 & Ambodivohitra & VFLW & V13-VM & 506 & 0.15 & 6.07 & 0.49 \\
\hline V2 & Ambavala & VFLW & V2-VL & 69 & 0.05 & 3.97 & 0.18 \\
\hline V24 & Ambavala & VFLW & V24-VM & 303 & 0.21 & 12.46 & 0.35 \\
\hline V25 & Andrakata & VFLW & V25-VM & 24 & 0.45 & 23.84 & 0.27 \\
\hline V39 & Antsahanoro & VFLW & V39-VL & 29 & 0.00 & 2.29 & 0.13 \\
\hline V39 & Antsahanoro & VFLW & V39-VM & 38 & 0.00 & 17.55 & 0.32 \\
\hline V40 & Antsikory & VFLW & V40-VL & 46 & 0.28 & 7.69 & 0.45 \\
\hline V45 & Belambo & VFLW & V45-VL & 214 & 0.06 & 5.36 & 0.35 \\
\hline V45 & Belambo & VFLW & V45-VM & 227 & 0.11 & 10.96 & 0.42 \\
\hline V47 & Bemanevika & VFLW & V47-VH & 69 & 0.03 & 7.02 & 0.50 \\
\hline V47 & Bemanevika & VFLW & V47-VL & 68 & 0.00 & 0.60 & 0.22 \\
\hline V47 & Bemanevika & VFLW & V47-VM & 56 & 0.00 & 17.30 & 0.47 \\
\hline V7 & Ambinanifaho & VFLW & V7-VH & 107 & 0.00 & 23.81 & 0.40 \\
\hline V7 & Ambinanifaho & VFLW & V7-VL & 56 & 0.21 & 7.40 & 0.33 \\
\hline V7 & Ambinanifaho & VFLW & V7-VM & 25 & 0.00 & 5.18 & 0.21 \\
\hline V8 & Ambodiala & VFLW & V8-VH & 50 & 0.11 & 10.31 & 0.29 \\
\hline V8 & Ambodiala & VFLW & V8-VL & 43 & 0.08 & 11.70 & 0.39 \\
\hline V8 & Ambodiala & VFLW & V8-VM & 37 & 0.00 & 15.42 & 0.31 \\
\hline V13 & Ambodivohitra & VFST & V13-VH & 819 & 0.86 & 17.56 & 0.45 \\
\hline V2 & Ambavala & VFST & $\mathrm{V} 2-\mathrm{VH}$ & 75 & 0.41 & 25.06 & 0.33 \\
\hline V24 & Andrakata & VFST & V24-VH & 352 & 0.21 & 18.23 & 0.35 \\
\hline V25 & Andramanolotra & VFST & V25-VH & 30 & 0.64 & 18.51 & 0.41 \\
\hline V25 & Andramanolotra & VFST & V25-VL & 20 & 0.11 & 15.08 & 0.44 \\
\hline
\end{tabular}




\begin{tabular}{|l|l|l|l|r|r|r|r|}
\hline V39 & Antsahanoro & VFST & V39-VH & 155 & 0.67 & 9.89 & 0.56 \\
\hline V40 & Antsikory & VFST & V40-VH & 65 & 0.70 & 24.53 & 0.62 \\
\hline V40 & Antsikory & VFST & V40-VM & 87 & 0.27 & 18.62 & 0.46 \\
\hline V45 & Belambo & VFST & V45-VH & 250 & 0.00 & 10.57 & 0.40 \\
\hline V13 & Ambodivohitra & WF & V13-WF & 520 & 0.00 & 1.69 & 0.60 \\
\hline V2 & Ambavala & WF & V2-WF & 31 & 0.00 & 1.84 & 0.58 \\
\hline V24 & Andrakata & WF & V24-WF & 441 & 0.18 & 1.46 & 0.68 \\
\hline V25 & Andramanolotra & WF & V25-WF & 58 & 0.78 & 5.10 & 0.50 \\
\hline V39 & Antsahanoro & WF & V39-WF & 37 & 0.00 & 3.56 & 0.55 \\
\hline V40 & Antsikory & WF & V40-WF & 73 & 0.46 & 0.57 & 0.52 \\
\hline V45 & Belambo & WF & V45-WF & 181 & 0.00 & 1.15 & 0.60 \\
\hline V47 & Bemanevika & WF & V47-WF & 90 & 0.00 & 4.12 & 0.58 \\
\hline V7 & Ambinanifaho & WF & V7-WF & 25 & 0.00 & 7.03 & 0.47 \\
\hline V8 & Ambodiala & WF & V8-WF & 40 & 0.00 & 3.32 & 0.52 \\
\hline V13 & Ambodivohitra & VFLW & V13-VL & 644 & 0.42 & 2.00 & 0.45 \\
\hline V13 & Ambodivohitra & VFLW & V13-VM & 506 & 0.15 & 6.07 & 0.49 \\
\hline
\end{tabular}


Table 12.10: Date and time of bird point counts and sound recordings during 2018 data collection in the predominant land-use types and for 2018 second data collection in primary forest in the SAVA region in north-eastern Madagascar. Land-use types (LUT): OGF: Old-growth Forest, FF: Forest Fragment, HF: Herbaceous Fallow, RP: Rice Paddy, V-FST: Forest-derived Vanilla Agroforests, V-FLW: Fallow-derived Vanilla Agroforests, WF: Woody Fallow. Observers: ER: Eric Rakotomalala, DAM: Dominic Andreas Martin, RA: Rouvah Andriafanomezantsoa, SD: Saskia Dröge. Date AI analysis: Date chosen for acoustic index analysis.

\begin{tabular}{|c|c|c|c|c|c|c|c|c|c|c|c|}
\hline $\begin{array}{l}\text { Vil- } \\
\text { lage }\end{array}$ & LUT & $\begin{array}{l}\text { Date start re- } \\
\text { cording }\end{array}$ & $\begin{array}{l}\text { Time start } \\
\text { recording }\end{array}$ & $\begin{array}{l}\text { Date stop re- } \\
\text { cording }\end{array}$ & $\begin{array}{l}\text { Time stop } \\
\text { recording }\end{array}$ & $\begin{array}{l}\text { Date AI anal- } \\
\text { ysis }\end{array}$ & $\begin{array}{l}\text { Date point } \\
\text { count }\end{array}$ & $\begin{array}{l}\text { Time start } \\
\text { point } \\
\text { count }\end{array}$ & $\begin{array}{l}\text { Time end } \\
\text { point } \\
\text { count }\end{array}$ & $\begin{array}{l}\text { Main ob- } \\
\text { server }\end{array}$ & $\begin{array}{l}\text { Second } \\
\text { observer }\end{array}$ \\
\hline ME & OGF & $2018-12-04$ & 08:55:00 & $2018-12-07$ & 08:11:00 & $2018-12-05$ & $2018-12-06$ & 05:51:00 & 06:31:00 & ER & SD \\
\hline ME & OGF & $2018-12-04$ & 06:10:00 & $2018-12-07$ & 08:10:00 & $2018-12-05$ & $2018-12-04$ & $06: 15: 00$ & 06:55:00 & ER & SD \\
\hline ME & OGF & $2018-12-04$ & 05:46:00 & $2018-12-07$ & 07:36:00 & $2018-12-05$ & $2018-12-04$ & 04:53:00 & 05:33:00 & ER & SD \\
\hline ME & OGF & $2018-12-03$ & $15: 16: 00$ & $2018-12-06$ & $14: 35: 00$ & $2018-12-04$ & $2018-12-05$ & 04:59:00 & 05:39:00 & ER & SD \\
\hline ME & OGF & $2018-12-03$ & $15: 56: 00$ & $2018-12-06$ & $15: 12: 00$ & $2018-12-04$ & $2018-12-05$ & $06: 12: 00$ & 06:52:00 & ER & SD \\
\hline MT & OGF & $2018-11-26$ & 16:10:00 & $2018-11-30$ & 10:39:00 & $2018-11-29$ & $2018-11-28$ & $06: 17: 00$ & $06: 57: 00$ & ER & SD \\
\hline MT & OGF & $2018-11-26$ & $15: 31: 00$ & $2018-11-30$ & 12:18:00 & $2018-11-29$ & $2018-11-28$ & 04:50:00 & 05:30:00 & ER & SD \\
\hline MT & OGF & $2018-11-27$ & $10: 34: 00$ & $2018-11-30$ & 08:10:00 & $2018-11-28$ & $2018-11-29$ & 05:50:00 & 06:30:00 & ER & SD \\
\hline MT & OGF & $2018-11-27$ & 04:50:00 & $2018-11-30$ & 09:36:00 & $2018-11-28$ & $2018-11-27$ & 04:57:00 & 05:37:00 & ER & SD \\
\hline MT & OGF & $2018-11-27$ & 06:05:00 & $2018-11-30$ & 09:24:00 & $2018-11-28$ & $2018-11-27$ & $06: 10: 00$ & 06:50:00 & ER & SD \\
\hline V13 & $\mathrm{FF}$ & $2018-10-30$ & $14: 15: 00$ & 2018-11-02 & 07:32:00 & $2018-10-31$ & 2018-11-01 & 04:53:00 & 05:33:00 & ER & SD \\
\hline V13 & $\mathrm{HF}$ & $2018-10-30$ & 14:19:00 & 2018-11-02 & 08:02:00 & $2018-10-31$ & 2018-11-01 & $06: 15: 00$ & 06:55:00 & ER & SD \\
\hline V13 & $\mathrm{RP}$ & $2018-10-29$ & $19: 56: 00$ & 2018-11-02 & 08:13:00 & $2018-10-31$ & $2018-10-30$ & $06: 25: 00$ & 07:05:00 & ER & SD \\
\hline V13 & VFST & $2018-10-30$ & $08: 46: 00$ & 2018-11-02 & 09:02:00 & 2018-11-01 & $2018-10-31$ & 04:52:00 & 05:32:00 & ER & SD \\
\hline V13 & VFLW & $2018-10-30$ & 08:44:00 & 2018-11-02 & 08:50:00 & 2018-11-01 & $2018-10-31$ & 07:04:00 & 07:44:00 & ER & SD \\
\hline
\end{tabular}




\begin{tabular}{|c|c|c|c|c|c|c|c|c|c|c|c|}
\hline V13 & VFLW & 2018-10-29 & 19:59:00 & 2018-11-02 & 07:53:00 & $2018-10-31$ & $2018-10-30$ & 04:56:00 & 05:36:00 & ER & SD \\
\hline V13 & $\mathrm{WF}$ & 2018-10-29 & 07:39:00 & 2018-11-02 & 06:07:00 & $2018-10-31$ & 2018-11-02 & 04:54:00 & 05:34:00 & ER & SD \\
\hline V24 & $\mathrm{FF}$ & 2018-11-06 & $11: 46: 00$ & 2018-11-09 & 06:24:00 & 2018-11-08 & 2018-11-09 & 04:57:00 & 05:37:00 & ER & SD \\
\hline V24 & $\mathrm{HF}$ & 2018-11-05 & $14: 54: 00$ & 2018-11-08 & $18: 45: 00$ & 2018-11-07 & 2018-11-08 & 04:56:00 & 05:36:00 & ER & SD \\
\hline V24 & $\mathrm{RP}$ & 2018-11-06 & 04:55:00 & 2018-11-09 & 08:18:00 & 2018-11-08 & 2018-11-06 & 05:00:00 & 05:40:00 & ER & SD \\
\hline V24 & VFST & 2018-11-06 & $10: 20: 00$ & 2018-11-09 & 07:28:00 & 2018-11-08 & 2018-11-07 & 04:51:00 & 05:31:00 & ER & SD \\
\hline V24 & VFLW & 2018-11-05 & $15: 18: 00$ & 2018-11-08 & 19:45:00 & 2018-11-07 & 2018-11-08 & 06:01:00 & 06:41:00 & ER & SD \\
\hline V24 & VFLW & 2018-11-06 & 06:41:00 & 2018-11-09 & 10:19:00 & 2018-11-08 & 2018-11-06 & $06: 54: 00$ & 07:34:00 & ER & SD \\
\hline V24 & $\mathrm{WF}$ & 2018-11-06 & 11:04:00 & 2018-11-09 & 06:52:00 & 2018-11-08 & 2018-11-07 & 06:30:00 & 07:10:00 & ER & SD \\
\hline V25 & $\mathrm{FF}$ & 2018-11-19 & $16: 16: 00$ & $2018-11-22$ & $18: 15: 00$ & 2018-11-21 & $2018-10-24$ & 05:01:00 & 05:41:00 & ER & SD \\
\hline V25 & $\mathrm{HF}$ & $2018-11-20$ & 07:48:00 & $2018-11-23$ & 11:35:00 & $2018-11-21$ & $2018-10-23$ & $06: 35: 00$ & 07:15:00 & ER & SD \\
\hline V25 & $\mathrm{RP}$ & $2018-10-22$ & 05:04:00 & $2018-10-25$ & 07:50:00 & $2018-10-23$ & $2018-10-22$ & 05:08:00 & 05:48:00 & ER & SD \\
\hline V25 & VFST & $2018-10-22$ & $10: 14: 00$ & $2018-10-25$ & 05:45:00 & $2018-10-23$ & $2018-10-25$ & 04:57:00 & 05:37:00 & ER & SD \\
\hline V25 & VFST & $2018-10-22$ & 06:48:00 & 2018-10-25 & 06:32:00 & 2018-10-24 & $2018-10-22$ & 06:50:00 & 07:30:00 & ER & SD \\
\hline V25 & VFST & $2018-10-22$ & 08:18:00 & $2018-10-25$ & 06:09:00 & $2018-10-24$ & $2018-10-23$ & 05:01:00 & 05:41:00 & ER & SD \\
\hline V25 & $\mathrm{WF}$ & 2018-11-19 & $15: 19: 00$ & $2018-11-22$ & $12: 14: 00$ & $2018-11-21$ & $2018-10-24$ & $06: 22: 00$ & 07:02:00 & ER & SD \\
\hline V2 & $\mathrm{FF}$ & $2018-10-16$ & 05:30:00 & 2018-10-19 & 07:03:00 & 2018-10-18 & $2018-10-16$ & 05:32:00 & 06:12:00 & ER & SD \\
\hline V2 & $\mathrm{HF}$ & 2018-11-18 & 10:51:00 & $2018-11-23$ & $14: 19: 00$ & 2018-11-21 & 2018-10-17 & $06: 16: 00$ & 06:56:00 & ER & SD \\
\hline V2 & $\mathrm{RP}$ & $2018-10-16$ & $15: 19: 00$ & 2018-10-19 & 07:56:00 & 2018-10-17 & $2018-10-18$ & 05:19:00 & 05:59:00 & ER & SD \\
\hline V2 & VFST & $2018-10-16$ & 07:05:00 & 2018-10-19 & 07:04:00 & 2018-10-18 & $2018-10-16$ & 07:09:00 & 07:49:00 & ER & SD \\
\hline V2 & VFLW & $2018-10-16$ & 10:08:00 & 2018-10-19 & 08:30:00 & 2018-10-18 & $2018-10-17$ & 04:57:00 & 05:37:00 & ER & SD \\
\hline V2 & VFLW & $2018-10-16$ & 08:34:00 & 2018-10-19 & 06:47:00 & $2018-10-18$ & 2018-10-19 & 06:00:00 & 06:40:00 & ER & SD \\
\hline
\end{tabular}




\begin{tabular}{|c|c|c|c|c|c|c|c|c|c|c|c|}
\hline V2 & WF & $2018-10-15$ & 21:12:00 & 2018-10-19 & 07:48:00 & $2018-10-17$ & $2018-10-18$ & 06:41:00 & 07:21:00 & ER & SD \\
\hline V39 & $\mathrm{FF}$ & 2018-11-13 & $15: 29: 00$ & 2018-11-16 & 05:36:00 & 2018-11-14 & 2018-11-16 & 04:50:00 & 05:30:00 & ER & SD \\
\hline V39 & $\mathrm{HF}$ & 2018-11-13 & $12: 00: 00$ & 2018-11-16 & 08:30:00 & 2018-11-14 & $2018-11-23$ & 05:53:00 & 06:33:00 & ER & SD \\
\hline V39 & $\mathrm{RP}$ & 2018-11-13 & $10: 16: 00$ & 2018-11-16 & 07:38:00 & 2018-11-15 & 2018-11-16 & 06:52:00 & 07:32:00 & ER & SD \\
\hline V39 & VFST & 2018-11-13 & $16: 38: 00$ & 2018-11-16 & 08:24:00 & 2018-11-15 & $2018-11-22$ & 06:29:00 & 07:09:00 & ER & SD \\
\hline V39 & VFLW & 2018-11-13 & 06:35:00 & 2018-11-16 & 08:26:00 & 2018-11-14 & 2018-11-13 & 06:42:00 & 07:22:00 & ER & SD \\
\hline V39 & VFLW & 2018-11-13 & 04:55:00 & 2018-11-16 & 08:05:00 & 2018-11-14 & $2018-11-22$ & 04:51:00 & 05:31:00 & ER & SD \\
\hline V39 & $\mathrm{WF}$ & 2018-11-13 & $12: 47: 00$ & 2018-11-16 & 08:38:00 & 2018-11-14 & $2018-11-23$ & 04:50:00 & 05:30:00 & ER & SD \\
\hline $\mathrm{V} 40$ & $\mathrm{FF}$ & 2018-08-21 & $15: 49: 00$ & 2018-08-24 & 09:13:00 & 2018-08-22 & $2018-08-23$ & 07:07:00 & 07:47:00 & ER & DAM \\
\hline V40 & $\mathrm{HF}$ & 2018-08-21 & 05:43:00 & 2018-08-23 & 10:28:00 & 2018-08-22 & $2018-08-21$ & 05:48:00 & 06:28:00 & ER & DAM \\
\hline V40 & $\mathrm{RP}$ & 2018-08-21 & 08:20:00 & 2018-08-24 & 09:42:00 & 2018-08-23 & 2018-08-21 & 07:34:00 & 08:14:00 & ER & DAM \\
\hline V40 & VFST & 2018-08-21 & $14: 43: 00$ & 2018-08-24 & 08:25:00 & 2018-08-22 & $2018-08-23$ & 05:39:00 & 06:19:00 & ER & DAM \\
\hline $\mathrm{V} 40$ & VFLW & 2018-08-21 & $16: 58: 00$ & 2018-08-24 & 07:06:00 & 2018-08-23 & $2018-08-24$ & 05:45:00 & $06: 25: 00$ & ER & DAM \\
\hline V40 & VFST & 2018-08-21 & 14:07:00 & 2018-08-24 & 08:48:00 & 2018-08-23 & $2018-08-22$ & 07:26:00 & 08:06:00 & ER & DAM \\
\hline V40 & $\mathrm{WF}$ & 2018-08-21 & $17: 14: 00$ & $2018-08-24$ & 08:15:00 & $2018-08-23$ & $2018-08-22$ & 05:45:00 & $06: 25: 00$ & ER & DAM \\
\hline V45 & $\mathrm{FF}$ & 2018-09-17 & $14: 36: 00$ & 2018-09-20 & 07:30:00 & 2018-09-18 & 2018-09-20 & 06:42:00 & 07:22:00 & ER & DAM \\
\hline V45 & $\mathrm{HF}$ & 2018-09-18 & $10: 46: 00$ & 2018-09-21 & 08:02:00 & 2018-09-20 & 2018-09-21 & 07:20:00 & 08:00:00 & ER & DAM \\
\hline V45 & $\mathrm{RP}$ & 2018-09-17 & 13:39:00 & 2018-09-20 & 09:08:00 & 2018-09-18 & $2018-09-20$ & 05:18:00 & 05:58:00 & ER & DAM \\
\hline V45 & VFST & 2018-09-18 & 07:13:00 & 2018-09-21 & 11:06:00 & 2018-09-19 & 2018-09-18 & 07:18:00 & 07:58:00 & ER & DAM \\
\hline V45 & VFLW & 2018-09-18 & $14: 40: 00$ & 2018-09-22 & 07:04:00 & 2018-09-21 & 2018-09-22 & 06:20:00 & 07:00:00 & ER & DAM \\
\hline V45 & VFLW & 2018-09-21 & $10: 41: 00$ & 2018-09-25 & $16: 16: 00$ & 2018-09-24 & 2018-09-18 & 05:20:00 & 06:00:00 & ER & DAM \\
\hline V45 & WF & 2018-09-18 & $16: 55: 00$ & 2018-09-21 & 06:00:00 & 2018-09-20 & $2018-09-21$ & 05:15:00 & 05:55:00 & ER & DAM \\
\hline
\end{tabular}




\begin{tabular}{|c|c|c|c|c|c|c|c|c|c|c|c|}
\hline V47 & $\mathrm{FF}$ & 2018-10-18 & 11:40:00 & $2018-10-25$ & 07:20:00 & 2018-10-19 & 2018-10-09 & 06:44:00 & 07:24:00 & ER & SD \\
\hline V47 & $\mathrm{HF}$ & 2018-10-09 & 08:12:00 & $2018-10-12$ & 07:07:00 & $2018-10-10$ & 2018-10-11 & 05:03:00 & 05:43:00 & ER & SD \\
\hline V47 & $\mathrm{RP}$ & 2018-10-09 & $14: 12: 00$ & 2018-10-12 & 06:50:00 & 2018-10-10 & 2018-10-12 & 06:03:00 & 06:43:00 & ER & SD \\
\hline V47 & VFLW & 2018-10-09 & 04:57:00 & $2018-10-12$ & 07:32:00 & 2018-10-11 & 2018-10-09 & 05:04:00 & 05:44:00 & ER & SD \\
\hline V47 & VFLW & 2018-10-09 & $10: 24: 00$ & $2018-10-12$ & 07:30:00 & 2018-10-11 & 2018-10-10 & 05:00:00 & 05:40:00 & ER & SD \\
\hline V47 & VFLW & 2018-10-09 & 11:07:00 & $2018-10-12$ & 07:16:00 & $2018-10-10$ & 2018-10-11 & 06:07:00 & 06:47:00 & ER & SD \\
\hline V47 & $\mathrm{WF}$ & 2018-10-09 & 09:16:00 & 2018-10-12 & 07:34:00 & 2018-10-11 & 2018-10-10 & 06:13:00 & 06:53:00 & ER & SD \\
\hline V7 & $\mathrm{FF}$ & 2018-09-11 & 10:04:00 & 2018-09-13 & 08:03:00 & 2018-09-12 & 2018-09-13 & 07:11:00 & 07:51:00 & ER & DAM \\
\hline V7 & $\mathrm{HF}$ & 2018-09-11 & 05:20:00 & 2018-09-14 & 08:37:00 & 2018-09-12 & 2018-09-11 & 05:26:00 & 06:06:00 & ER & DAM \\
\hline V7 & $\mathrm{RP}$ & 2018-09-11 & $16: 45: 00$ & 2018-09-14 & 09:50:00 & 2018-09-12 & 2018-09-13 & 05:17:00 & 05:57:00 & ER & DAM \\
\hline V7 & VFLW & 2018-09-11 & $15: 30: 00$ & 2018-09-14 & 09:08:00 & 2018-09-13 & 2018-09-12 & 06:55:00 & 07:35:00 & ER & DAM \\
\hline V7 & VFLW & 2018-09-11 & $13: 55: 00$ & 2018-09-14 & 09:53:00 & 2018-09-13 & 2018-09-12 & 05:19:00 & 05:59:00 & ER & DAM \\
\hline V7 & VFLW & 2018-09-11 & 11:51:00 & 2018-09-14 & 06:12:00 & 2018-09-12 & 2018-09-14 & 05:17:00 & 05:57:00 & ER & DAM \\
\hline V7 & WF & 2018-09-11 & 06:55:00 & 2018-09-14 & 08:56:00 & 2018-09-12 & 2018-09-11 & 06:58:00 & 07:38:00 & ER & DAM \\
\hline V8 & $\mathrm{FF}$ & 2018-10-02 & $15: 45: 00$ & 2018-10-05 & 07:27:00 & 2018-10-03 & 2018-10-05 & 06:16:00 & 06:56:00 & ER & SD \\
\hline V8 & $\mathrm{HF}$ & 2018-10-02 & $14: 46: 00$ & 2018-10-05 & 08:24:00 & 2018-10-03 & 2018-10-04 & 05:13:00 & 05:53:00 & ER & SD \\
\hline V8 & $\mathrm{RP}$ & 2018-10-02 & 10:48:00 & 2018-10-05 & 08:23:00 & 2018-10-04 & 2018-10-03 & 06:33:00 & 07:13:00 & ER & DAM \\
\hline V8 & VFLW & 2018-10-05 & 09:07:00 & $2018-10-10$ & 09:25:00 & 2018-10-07 & 2018-10-02 & 06:55:00 & 07:35:00 & ER & DAM \\
\hline V8 & VFLW & 2018-10-02 & 09:51:00 & 2018-10-05 & 08:43:00 & 2018-10-04 & 2018-10-03 & 05:13:00 & 05:53:00 & ER & SD \\
\hline V8 & VFLW & 2018-10-02 & $15: 35: 00$ & 2018-10-05 & 08:20:00 & 2018-10-03 & 2018-10-04 & 06:33:00 & 07:13:00 & ER & SD \\
\hline V8 & $\mathrm{WF}$ & 2018-10-02 & 05:09:00 & 2018-10-05 & 08:10:00 & 2018-10-04 & 2018-10-02 & 05:19:00 & 05:59:00 & ER & DAM \\
\hline
\end{tabular}


Table 12.11: Results of the Shapiro-Wilk test and the Kruskal-Wallis test for assessing distribution patterns of the Acoustic Complexity Index (ACI), the inverted Acoustic Evenness Index (1-AEI) and the Acoustic Entropy (H) during the different time intervals (24 hrs; night-time, dawn chorus; daytime) and differences in index values between land-use types. Significant differences marked with stars according to following levels: ${ }^{*} \mathrm{p}<0.05,{ }^{* *} \mathrm{p}<0.01,{ }^{* * *} \mathrm{p}<0.001$. Significant differences between land-use types can be found for all four acoustic indices and during all four different time intervals.

\begin{tabular}{|c|c|c|c|c|c|c|c|}
\hline & Index & & Wilk test & & & & \\
\hline & & $\mathbf{w}$ & $\mathbf{p}$ & Chi squared & df & $\mathbf{p}$ & \\
\hline \multirow{4}{*}{ 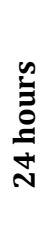 } & ACI & 0.9156 & 0.0001 & 38.9504 & 6 & 0.0000 & $* * *$ \\
\hline & ADI & 0.8808 & 0.0000 & 28.5389 & 6 & 0.0001 & $* * *$ \\
\hline & 1-AEI & 0.9912 & 0.8655 & 28.3959 & 6 & 0.0001 & $* * *$ \\
\hline & H & 0.9675 & 0.0391 & 42.5292 & 6 & 0.0000 & $* * *$ \\
\hline \multirow{4}{*}{ 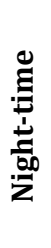 } & ACI & 0.8992 & 0.0000 & 28.9569 & 6 & 0.0001 & $* * *$ \\
\hline & ADI & 0.8705 & 0.0000 & 17.0204 & 6 & 0.0092 & $* *$ \\
\hline & 1-AEI & 0.9815 & 0.3004 & 17.6866 & 6 & 0.0071 & $* *$ \\
\hline & H & 0.9825 & 0.3456 & 27.7100 & 6 & 0.0001 & $* * *$ \\
\hline \multirow{4}{*}{ 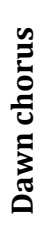 } & ACI & 0.9631 & 0.0208 & 38.2999 & 6 & 0.0000 & $* * *$ \\
\hline & ADI & 0.9185 & 0.0001 & 15.5444 & 6 & 0.0164 & * \\
\hline & 1-AEI & 0.9774 & 0.1684 & 15.8488 & 6 & 0.0146 & $*$ \\
\hline & $\mathbf{H}$ & 0.9753 & 0.1238 & 20.8173 & 6 & 0.0020 & $* *$ \\
\hline \multirow{4}{*}{ 莺 } & ACI & 0.9426 & 0.0013 & 39.1429 & 6 & 0.0000 & $* * *$ \\
\hline & ADI & 0.9235 & 0.0001 & 52.2614 & 6 & 0.0000 & $* * *$ \\
\hline & 1-AEI & 0.9615 & 0.0166 & 52.6355 & 6 & 0.0000 & *** \\
\hline & $\mathbf{H}$ & 0.8739 & 0.0000 & 48.3719 & 6 & 0.0000 & $* * *$ \\
\hline
\end{tabular}


Table 12.12: Differences between land-use types for the Acoustic Complexity Index (ACI), the inverted Acoustic Evenness Index (1-AEI) and the Acoustic Entropy $(\mathrm{H})$ during the 24-hour-time-interval and night-time. Results (p-values) of the pairwise Wilcoxon rank sum test including Bonferroni correction for multiple testing performed in R. Grey colour mark significant differences ( $<$ < 0.05) between land-use types. Land-use types: OGF: Old-growth Forest, FF: Forest Fragment, HF: Herbaceous Fallow, RP: Rice Paddy, VFST: Forest-derived Vanilla Agroforests, VFLW: Fallow-derived Vanilla Agroforests, WF: Woody Fallow.

\begin{tabular}{|c|c|c|c|c|c|c|c|c|c|c|c|c|c|}
\hline & & \multicolumn{6}{|c|}{ 24-Hour } & \multicolumn{6}{|c|}{ Night-time } \\
\hline & & OGF & FF & VFST & VFLW & WF & HF & OGF & FF & VFST & VFLW & WF & HF \\
\hline \multirow{6}{*}{ ত্র } & FF & 1.0000 & & & & & & 1.0000 & & & & & \\
\hline & VFST & 1.0000 & 1.0000 & & & & & 1.0000 & 1.0000 & & & & \\
\hline & VFLW & 0.0341 & 0.2327 & 1.0000 & & & & 1.0000 & 1.0000 & 1.0000 & & & \\
\hline & WF & 0.0027 & 0.0316 & 1.0000 & 1.0000 & & & 0.0605 & 0.0605 & 0.9084 & 1.0000 & & \\
\hline & HF & 0.0002 & 0.0002 & 0.0005 & 0.0684 & 0.0316 & & 0.0005 & 0.0009 & 0.0043 & 0.0578 & 0.1091 & \\
\hline & $\mathbf{R P}$ & 0.0002 & 0.0102 & 1.0000 & 1.0000 & 1.0000 & 0.3894 & 0.3085 & 0.1875 & 1.0000 & 1.0000 & 1.0000 & 0.7447 \\
\hline \multirow{6}{*}{$\overline{\mathrm{e}}$} & FF & 1.0000 & & & & & & 0.3894 & & & & & \\
\hline & VFST & 0.2414 & 1.0000 & & & & & 0.0439 & 1.0000 & & & & \\
\hline & VFLW & 0.0234 & 1.0000 & 1.0000 & & & & 0.1110 & 1.0000 & 1.0000 & & & \\
\hline & $\mathbf{W F}$ & 0.1091 & 1.0000 & 1.0000 & 1.0000 & & & 1.0000 & 1.0000 & 1.0000 & 1.0000 & & \\
\hline & HF & 0.0027 & 0.0816 & 1.0000 & 1.0000 & 1.0000 & & 0.0068 & 1.0000 & 1.0000 & 1.0000 & 1.0000 & \\
\hline & $\mathbf{R P}$ & 0.0043 & 0.1437 & 1.0000 & 1.0000 & 1.0000 & 1.0000 & 0.4878 & 1.0000 & 1.0000 & 1.0000 & 1.0000 & 1.0000 \\
\hline \multirow{3}{*}{$\sum_{i}^{\mathbb{1}}$} & FF & 0.7447 & & & & & & 0.1091 & & & & & \\
\hline & VFST & 0.1091 & 1.0000 & & & & & 0.0439 & 1.0000 & & & & \\
\hline & VFLW & 0.0129 & 1.0000 & 1.0000 & & & & 0.0684 & 1.0000 & 1.0000 & & & \\
\hline
\end{tabular}




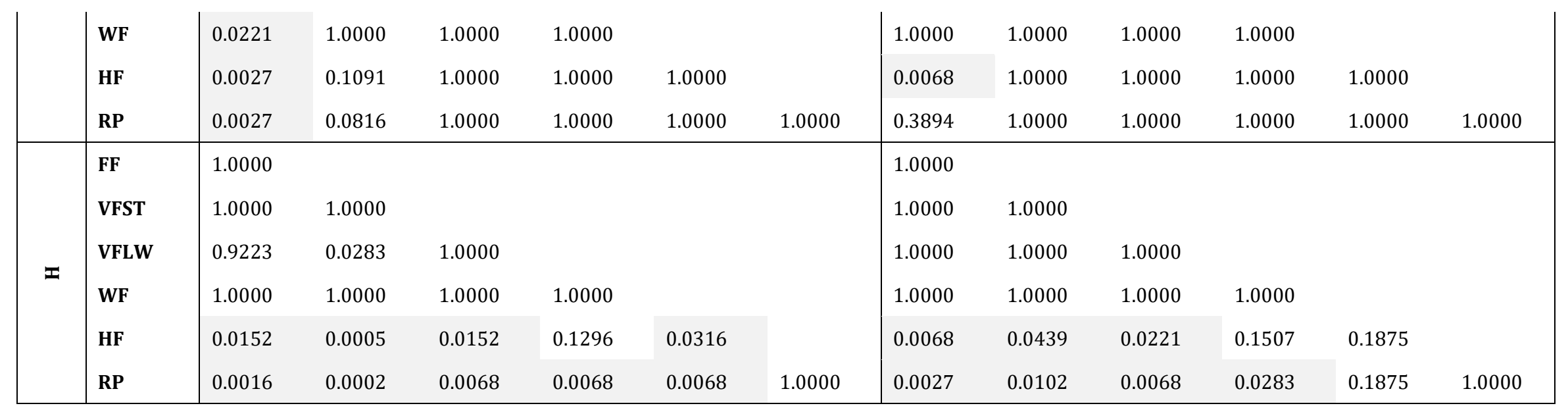

Table 12.13: Differences between land-use types for the Acoustic Complexity Index (ACI), the inverted Acoustic Evenness Index (1-AEI) and the Acoustic Entropy $(\mathrm{H})$ during dawn chorus and daytime. Results (p-values) of the pairwise Wilcoxon rank sum test including Bonferroni correction for multiple testing performed in R. Grey colour mark significant differences ( $\mathrm{p}<0.05)$ between land-use types. Land-use types: OGF: Old-growth Forest, FF: Forest Fragment, HF: Herbaceous Fallow, RP: Rice Paddy, VFST: Forest-derived Vanilla Agroforests, VFLW: Fallow-derived Vanilla Agroforests, WF: Woody Fallow.

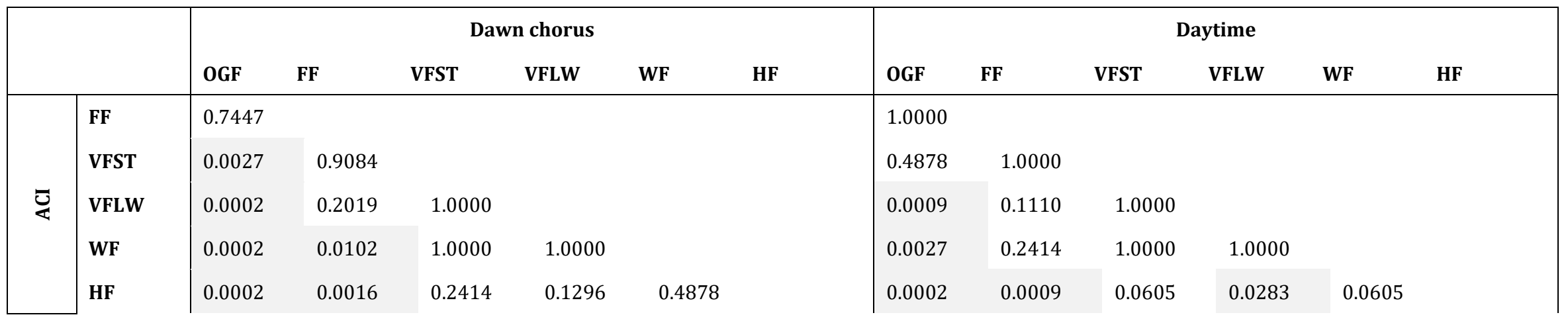




\begin{tabular}{|c|c|c|c|c|c|c|c|c|c|c|c|c|c|}
\hline & $\mathbf{R P}$ & 0.0316 & 1.0000 & 1.0000 & 1.0000 & 1.0000 & 0.0439 & 0.0009 & 0.0439 & 0.9084 & 1.0000 & 1.0000 & 1.0000 \\
\hline \multirow{6}{*}{$\overline{8}$} & FF & 1.0000 & & & & & & 1.0000 & & & & & \multirow[b]{6}{*}{1.0000} \\
\hline & VFST & 1.0000 & 1.0000 & & & & & 0.1875 & 1.0000 & & & & \\
\hline & VFLW & 0.1507 & 1.0000 & 1.0000 & & & & 0.0001 & 0.0068 & 1.0000 & & & \\
\hline & WF & 0.9084 & 1.0000 & 1.0000 & 1.0000 & & & 0.0009 & 0.0316 & 1.0000 & 1.0000 & & \\
\hline & HF & 0.0316 & 1.0000 & 1.0000 & 1.0000 & 1.0000 & & 0.0005 & 0.0016 & 0.2414 & 0.0807 & 0.2414 & \\
\hline & $\mathbf{R P}$ & 0.0102 & 0.3894 & 1.0000 & 0.3985 & 1.0000 & 1.0000 & 0.0002 & 0.0009 & 0.0439 & 0.0027 & 0.0102 & \\
\hline \multirow{6}{*}{$\sum_{4}^{\mathbb{4}}$} & FF & 1.0000 & & & & & & 0.7447 & & & & & \multirow[b]{6}{*}{1.0000} \\
\hline & VFST & 1.0000 & 1.0000 & & & & & 0.1875 & 1.0000 & & & & \\
\hline & VFLW & 0.0948 & 1.0000 & 1.0000 & & & & 0.0001 & 0.0012 & 0.7348 & & & \\
\hline & WF & 0.7447 & 1.0000 & 1.0000 & 1.0000 & & & 0.0016 & 0.0439 & 1.0000 & 1.0000 & & \\
\hline & HF & 0.0316 & 0.9084 & 1.0000 & 1.0000 & 1.0000 & & 0.0005 & 0.0043 & 0.1875 & 0.1747 & 0.2414 & \\
\hline & $\mathbf{R P}$ & 0.0152 & 0.3894 & 1.0000 & 0.4527 & 1.0000 & 1.0000 & 0.0002 & 0.0005 & 0.0316 & 0.0016 & 0.0027 & \\
\hline \multirow{6}{*}{$I$} & FF & 1.0000 & & & & & & 1.0000 & & & & & \multirow[b]{6}{*}{1.0000} \\
\hline & VFST & 1.0000 & 1.0000 & & & & & 1.0000 & 1.0000 & & & & \\
\hline & VFLW & 0.6534 & 0.1507 & 1.0000 & & & & 0.0193 & 0.0001 & 0.3062 & & & \\
\hline & WF & 1.0000 & 1.0000 & 1.0000 & 1.0000 & & & 1.0000 & 0.1437 & 1.0000 & 0.5129 & & \\
\hline & HF & 0.0816 & 0.0102 & 0.6049 & 1.0000 & 0.6049 & & 0.0005 & 0.0002 & 0.0027 & 0.0129 & 0.0043 & \\
\hline & $\mathbf{R P}$ & 0.0816 & 0.0152 & 0.2414 & 0.4527 & 0.1437 & 1.0000 & 0.0002 & 0.0002 & 0.0016 & 0.0001 & 0.0005 & \\
\hline
\end{tabular}


Table 12.14: Results of correlation analysis between bird species richness and the Acoustic Complexity Index (ACI), the Acoustic Diversity Index (ADI), the inverse Acoustic Evenness Index (1-AEI) and the Acoustic Entropy (H). Based on the lower AIC value, we used a linear or polynomial model to assess a correlation. The correlation is significant for all time intervals except one with a positive and stronger correlation between bird species richness, ADI, 1-AEI and $\mathrm{H}$ during daytime.

\begin{tabular}{|c|c|c|c|c|c|c|c|c|c|c|}
\hline & Index & AIC lin & AIC polyn & Best fit & $\mathbf{F}$ & Res. standard error & $\operatorname{adj} R^{2}$ & Cohen $\mathbf{f}^{2}$ & p & \\
\hline \multirow{4}{*}{ 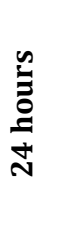 } & ACI & 711.64 & 713.57 & Linear & 5.58 & 20.16 & 0.05 & 0.06 & 0.0206 & $*$ \\
\hline & ADI & 75.59 & 73.81 & Linear & 13.77 & 0.38 & 0.14 & 0.16 & 0.0004 & $* * *$ \\
\hline & 1-AEI & -101.99 & -102.22 & Linear & 13.42 & 0.12 & 0.14 & 0.16 & 0.0005 & $* * *$ \\
\hline & $\mathrm{H}$ & -275.79 & -282.30 & Polynomial & 13.87 & 0.04 & 0.25 & 0.33 & 0.0000 & $* * *$ \\
\hline \multirow{4}{*}{ 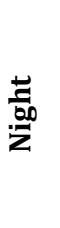 } & ACI & 769.66 & 770.04 & Linear & 9.21 & 28.98 & 0.09 & 0.10 & 0.0033 & $* *$ \\
\hline & ADI & 67.55 & 68.78 & Linear & 7.30 & 0.36 & 0.07 & 0.08 & 0.0085 & $* *$ \\
\hline & 1-AEI & -81.45 & -80.13 & Linear & 11.45 & 0.14 & 0.12 & 0.13 & 0.0011 & $* *$ \\
\hline & $\mathrm{H}$ & -265.75 & -267.58 & Linear & 9.28 & 0.04 & 0.09 & 0.10 & 0.0032 & $* *$ \\
\hline \multirow{4}{*}{ 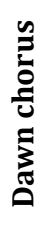 } & ACI & 768.54 & 768.38 & Linear & 6.10 & 28.78 & 0.06 & 0.06 & 0.0157 & $*$ \\
\hline & ADI & 77.22 & 73.81 & Polynomial & 6.30 & 0.37 & 0.12 & 0.13 & 0.0029 & $* *$ \\
\hline & 1-AEI & -75.83 & -76.25 & Linear & 3.88 & 0.15 & 0.04 & 0.04 & 0.0523 & \\
\hline & $\mathrm{H}$ & -239.63 & -242.53 & Polynomial & 5.10 & 0.05 & 0.09 & 0.10 & 0.0083 & $* *$ \\
\hline \multirow{4}{*}{$\overrightarrow{\tilde{\sigma}}$} & $\mathrm{ACI}$ & 684.34 & 686.34 & Linear & 3.76 & 17.11 & 0.07 & 0.07 & 0.0277 & $*$ \\
\hline & ADI & 128.37 & 119.18 & Polynomial & 25.57 & 0.49 & 0.38 & 0.62 & 0.0000 & $* * *$ \\
\hline & 1-AEI & -96.75 & -99.76 & Polynomial & 17.74 & 0.13 & 0.30 & 0.42 & 0.0000 & $* * *$ \\
\hline & $\mathrm{H}$ & -176.77 & -193.08 & Polynomial & 26.36 & 0.07 & 0.39 & 0.64 & 0.0000 & $* * *$ \\
\hline
\end{tabular}




\subsection{SI Chapter 5}

Supporting information for:

Fulgence, T. R., Martin, D. A., Befidimanana, E., Botra, R., Osen, K., Randriamanantena, R., Wurz, A., Kreft, H., Andrianarimisa, A., \& Ratsoavina, F. M. (in prep.). Differential responses of amphibians and reptiles to land-use change in the biodiversity hotspot of north-eastern Madagascar.

Table 12.15: List of all 119 amphibian and reptile species with IUCN red list status and abundance for each land-use type. IUCN status column: NA: not available (undescribed species); NE: not evaluated (described species); LC: least concern; NT: near threatened; VU: vulnerable; EN: endangered. Land-use types: OGF: old-growth forest; FF: forest fragment; VFST: forest-derived vanilla agroforest; VFLW: fallow-derived vanilla agroforest; WF: woody fallow; HF: herbaceous fallow; RP: rice paddy.

\begin{tabular}{|c|c|c|c|c|c|c|c|c|c|c|}
\hline Family & Genus & Species & 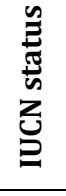 & 它 & 坫 & $\stackrel{5}{5}$ & $\underset{3}{3}$ & $\sum_{3}^{5}$ & 至 & 业 \\
\hline \multicolumn{11}{|l|}{ Amphibians } \\
\hline Hyperoliidae & Heterixalus & Heterixalus andrakata & LC & 0 & 1 & 30 & 97 & 55 & 127 & 1 \\
\hline Hyperoliidae & Heterixalus & Heterixalus carbonei & LC & 0 & 0 & 0 & 4 & 0 & 0 & 0 \\
\hline Hyperoliidae & Heterixalus & Heterixalus madagascariensis & $\mathrm{LC}$ & 0 & 0 & 9 & 11 & 4 & 2 & 1 \\
\hline Hyperoliidae & Heterixalus & Heterixalus punctatus & LC & 0 & 9 & 75 & 89 & 28 & 11 & 0 \\
\hline Hyperoliidae & Heterixalus & Heterixalus sp. & NA & 0 & 1 & 0 & 0 & 0 & 0 & 0 \\
\hline Mantellidae & Aglyptodactylus & Aglyptodactylus inguinalis & LC & 0 & 4 & 1 & 0 & 0 & 0 & 0 \\
\hline Mantellidae & Aglyptodactylus & $\begin{array}{l}\text { Aglyptodactylus madagascari- } \\
\text { ensis }\end{array}$ & $\mathrm{LC}$ & 1 & 1 & 0 & 1 & 0 & 0 & 0 \\
\hline Mantellidae & Blommersia & Blommersia sp. CaNEW & NA & 0 & 10 & 0 & 0 & 0 & 0 & 0 \\
\hline Mantellidae & Blommersia & Blommersia wittei & $\mathrm{LC}$ & 0 & 6 & 7 & 5 & 1 & 0 & 0 \\
\hline Mantellidae & Boophis & Boophis albilabris & $\mathrm{LC}$ & 0 & 3 & 1 & 1 & 0 & 0 & 0 \\
\hline Mantellidae & Boophis & Boophis blommersae & VU & 1 & 0 & 0 & 0 & 0 & 0 & 0 \\
\hline Mantellidae & Boophis & Boophis englaenderi & $\mathrm{VU}$ & 1 & 0 & 2 & 0 & 1 & 0 & 0 \\
\hline Mantellidae & Boophis & Boophis roseipalmatus & $\mathrm{LC}$ & 18 & 6 & 0 & 1 & 0 & 0 & 0 \\
\hline Mantellidae & Boophis & Boophis septentrionalis & LC & 0 & 0 & 0 & 1 & 0 & 0 & 0 \\
\hline Mantellidae & Boophis & Boophis sp. & NA & 0 & 0 & 1 & 0 & 0 & 0 & 0 \\
\hline Mantellidae & Boophis & $\begin{array}{l}\text { Boophis sp. CaNEW aff. } \\
\text { englaenderi }\end{array}$ & NA & 0 & 0 & 1 & 0 & 0 & 0 & 0 \\
\hline Mantellidae & Boophis & $\begin{array}{l}\text { Boophis sp. CaNEW aff. rappi- } \\
\text { odes }\end{array}$ & NA & 0 & 0 & 0 & 1 & 0 & 0 & 0 \\
\hline Mantellidae & Boophis & Boophis sp1 & NA & 0 & 0 & 0 & 1 & 0 & 0 & 0 \\
\hline Mantellidae & Boophis & Boophis sp3 & NA & 0 & 1 & 0 & 2 & 0 & 0 & 0 \\
\hline Mantellidae & Boophis & Boophis tephraeomystax & $\mathrm{LC}$ & 6 & 125 & 91 & 175 & 82 & 75 & 89 \\
\hline Mantellidae & Gephyromantis & Gephyromantis ambohitra & VU & 1 & 0 & 0 & 0 & 0 & 0 & 0 \\
\hline
\end{tabular}




\begin{tabular}{|c|c|c|c|c|c|c|c|c|c|c|}
\hline Mantellidae & Gephyromantis & Gephyromantis granulatus & $\mathrm{LC}$ & 1 & 24 & 2 & 0 & 0 & 0 & 0 \\
\hline Mantellidae & Gephyromantis & Gephyromantis luteus & $\mathrm{LC}$ & 66 & 0 & 0 & 0 & 0 & 0 & 0 \\
\hline Mantellidae & Gephyromantis & Gephyromantis pseudoasper & $\mathrm{LC}$ & 6 & 0 & 0 & 0 & 0 & 0 & 0 \\
\hline Mantellidae & Gephyromantis & Gephyromantis redimitus & $\mathrm{LC}$ & 16 & 3 & 0 & 2 & 0 & 0 & 0 \\
\hline Mantellidae & Gephyromantis & omantis sp.Ca17 & NA & 109 & 1 & 0 & 0 & 0 & 0 & 0 \\
\hline Mantellidae & Gephyromantis & Gephyromantis striatus & $\mathrm{VU}$ & 3 & 0 & 0 & 0 & 0 & 0 & 0 \\
\hline Mantellidae & Gephyromantis & Gephyromantis tandroka & $\mathrm{VU}$ & 1 & 0 & 0 & 0 & 0 & 0 & 0 \\
\hline Mantellidae & Guibemantis & Guibemantis sp. Ca16 & NA & 0 & 0 & 10 & 0 & 0 & 0 & 0 \\
\hline Mantellidae & Guibemantis & Guibemantis sp. CaNEW & NA & 7 & 0 & 0 & 0 & 0 & 0 & 0 \\
\hline Mantellidae & Guibemantis & Guibemantis tornieri & $\mathrm{LC}$ & 1 & 0 & 0 & 0 & 0 & 0 & 0 \\
\hline Mantellidae & Mantella & Mantella ebenaui & $\mathrm{LC}$ & 0 & 3 & 0 & 0 & 0 & 0 & 0 \\
\hline Mantellidae & Mantella & Mantella manery & VU & 1 & 0 & 0 & 0 & 0 & 0 & 0 \\
\hline Mantellidae & Mantella & Mantella nigricans & $\mathrm{LC}$ & 1 & 0 & 0 & 0 & 0 & 0 & 0 \\
\hline Mantellidae & Mantidactylus & $\begin{array}{l}\text { Mantidactylus sp. aff. } \\
\text { 'betsileanus North Clade' }\end{array}$ & NA & 0 & 1 & 0 & 0 & 0 & 0 & 0 \\
\hline Mantellidae & Mantidactylus & Mantidactylus sp. Ca12 & $\mathrm{NA}$ & 5 & 0 & 0 & 0 & 0 & 0 & 0 \\
\hline Mantellidae & Mantidactylus & Mantidactylus sp. Ca41 & NA & 2 & 0 & 0 & 0 & 0 & 0 & 0 \\
\hline Mantellidae & Mantidactylus & Mantidactylus sp. CaNEW2 & NA & 0 & 1 & 0 & 0 & 0 & 0 & 0 \\
\hline Mantellidae & Mantidactylus & Mantidactylus sp1FF & NA & 0 & 2 & 0 & 0 & 0 & 0 & 0 \\
\hline Mantellidae & Spinomantis & Spinomantis aglavei & $\mathrm{LC}$ & 2 & 0 & 0 & 0 & 0 & 0 & 0 \\
\hline Mantellidae & Spinomantis & Spinomantis fimbriatus & $\mathrm{LC}$ & 2 & 0 & 0 & 0 & 0 & 0 & 0 \\
\hline Microhylidae & Cophyla & Cophyla fortuna & $\mathrm{NE}$ & 0 & 2 & 0 & 0 & 0 & 0 & 0 \\
\hline Microhylidae & Platypelis & Platypelis grandis & $\mathrm{LC}$ & 1 & 0 & 0 & 0 & 0 & 0 & 0 \\
\hline Microhylidae & Platypelis & Platypelis tetra & EN & 1 & 0 & 0 & 0 & 0 & 0 & 0 \\
\hline Microhylidae & Plethodontohyla & Plethodontohyla notostica & $\mathrm{LC}$ & 4 & 1 & 0 & 0 & 0 & 0 & 0 \\
\hline Microhylidae & Rhombophryne & Rhombophryne sp & NA & 1 & 0 & 0 & 0 & 0 & 0 & 0 \\
\hline Microhylidae & Rhombophryne & Rhombophryne sp. CaNEW & NA & 3 & 0 & 0 & 0 & 0 & 0 & 0 \\
\hline Microhylidae & Stumpffia & Stumpffia achyllei & $\mathrm{NE}$ & 67 & 0 & 0 & 0 & 0 & 0 & 0 \\
\hline Microhylidae & Stumpffia & Stumpffia diutissuma & $\mathrm{NE}$ & 24 & 0 & 0 & 0 & 0 & 0 & 0 \\
\hline Microhylidae & Stumpffia & Stumpffia iharana & $\mathrm{NE}$ & 0 & 5 & 0 & 0 & 0 & 0 & 0 \\
\hline Microhylidae & Stumpffia & Stur & $\mathrm{NE}$ & 21 & 152 & 39 & 29 & 11 & 1 & 0 \\
\hline Microhylidae & Stumpffia & Stumpffia sorata & $\mathrm{NE}$ & 16 & 5 & 0 & 0 & 0 & 0 & 0 \\
\hline Microhylidae & Stumpffia & Stumpffia sp & NA & 3 & 0 & 0 & 0 & 0 & 0 & 0 \\
\hline Microhylidae & Stumpffia & Stumpffia sp. aff. edmondsi & $\mathrm{NA}$ & 0 & 1 & 0 & 0 & 0 & 0 & 0 \\
\hline Microhylidae & Stumpffia & Stumpffia sp. CaNEW1 & NA & 0 & 6 & 0 & 0 & 0 & 0 & 0 \\
\hline Microhylidae & Stumpffia & Stumpffia sp. CaNEW2 & NA & 1 & 0 & 0 & 0 & 0 & 0 & 0 \\
\hline Microhylidae & Stumpffia & Stumpffia sp1 & NA & 0 & 5 & 0 & 0 & 0 & 0 & 0 \\
\hline Ptychadenidae & Ptychadena & Ptychadena mascareniensis & $\mathrm{LC}$ & 0 & 0 & 18 & 29 & 49 & 83 & 1074 \\
\hline
\end{tabular}

\section{Reptiles}

\begin{tabular}{lllllllllll}
\hline Boidae & \multirow{2}{*}{ Acrantophis } & $\begin{array}{l}\text { Acranthophis madagascari- } \\
\text { ensis }\end{array}$ & LC & 0 & 1 & 0 & 0 & 0 & 0 & 1 \\
\hline Boidae & Sanzinia & Sanzinia madagascariensis & LC & 1 & 0 & 0 & 0 & 0 & 0 & 0 \\
\hline Chamaeleonidae & Brookesia & Brookesia griveaudi & NT & 17 & 2 & 1 & 0 & 0 & 0 & 0 \\
\hline Chamaeleonidae & \multirow{2}{*}{ Brookesia } & Brookesia karchei & EN & 2 & 1 & 0 & 0 & 0 & 0 & 0
\end{tabular}




\begin{tabular}{|c|c|c|c|c|c|c|c|c|c|c|}
\hline Chamaeleonidae & Brookesia & Brookesia sp. & NA & 8 & 1 & 6 & 0 & 0 & 0 & 0 \\
\hline Chamaeleonidae & Calumma & Calumma cf nasutum & $\mathrm{NA}$ & 0 & 0 & 2 & 0 & 0 & 0 & $\underline{0}$ \\
\hline Chamaeleonidae & Calumma & Calumma cf. marojezense & NT & 13 & 0 & 0 & 0 & 0 & 0 & $\underline{0}$ \\
\hline Chamaeleonidae & Calumma & Calumma cucullatum & VU & 1 & 0 & 0 & 0 & 0 & 0 & 0 \\
\hline Chamaeleonidae & Calumma & Calumma nasutum & $\mathrm{LC}$ & 8 & 30 & 38 & 34 & 24 & 4 & 0 \\
\hline Chamaeleonidae & Calumma & Calumma sp. & NA & 1 & 0 & 1 & 0 & 0 & 0 & 0 \\
\hline Chamaeleonidae & Furcifer & Furcifer pardalis & $\mathrm{LC}$ & 2 & 24 & 85 & 166 & 85 & 142 & 32 \\
\hline Chamaeleonidae & Furcifer & Furcifer timoni & NT & 1 & 0 & 0 & 0 & 0 & 0 & $\underline{0}$ \\
\hline Gekkonidae & Blaesodactylus & Blaesodactylus antongilensis & $\mathrm{LC}$ & 3 & 0 & 0 & 0 & 0 & 0 & 0 \\
\hline Gekkonidae & Ebenavia & Ebenavia cf. inuinguis & $\mathrm{LC}$ & 2 & 2 & 7 & 1 & 1 & 0 & 0 \\
\hline Gekkonidae & Geckolepis & Geckolepis cf. maculata & $\mathrm{LC}$ & 24 & 28 & 23 & 1 & 3 & 0 & 0 \\
\hline Gekkonidae & Hemidactylus & Hemidactylus sp. & $\mathrm{LC}$ & 0 & 0 & 1 & 0 & 11 & 3 & 0 \\
\hline Gekkonidae & Lygodactylus & Lygodactylus heterurus & $\mathrm{LC}$ & 0 & 6 & 19 & 7 & 7 & 0 & 0 \\
\hline Gekkonidae & Lygodactylus & Lygodactylus sp. & NA & 1 & 7 & 3 & 2 & 1 & 0 & 0 \\
\hline Gekkonidae & Paroedura & Paroedura gracilis & $\mathrm{LC}$ & 13 & 1 & 0 & 0 & 0 & 0 & $\underline{0}$ \\
\hline Gekkonidae & Paroedura & Paroedura stumpffi & $\mathrm{LC}$ & 0 & 27 & 19 & 0 & 0 & 0 & 0 \\
\hline Gekkonidae & Phelsuma & Phelsuma abbotti & $\mathrm{LC}$ & 0 & 0 & 2 & 0 & 0 & 0 & 0 \\
\hline Gekkonidae & Phelsuma & Phelsuma cf. lineata & NA & 0 & 0 & 0 & 4 & 1 & 0 & 0 \\
\hline Gekkonidae & Phelsuma & Phelsuma dorsivittata & NT & 0 & 0 & 2 & 0 & 0 & 0 & $\underline{0}$ \\
\hline Gekkonidae & Phelsuma & Phelsuma guttata & $\mathrm{LC}$ & 8 & 14 & 5 & 0 & 0 & 0 & $\underline{0}$ \\
\hline Gekkonidae & Phelsuma & Phelsuma laticauda & $\mathrm{LC}$ & 0 & 7 & 18 & 137 & 43 & 5 & 4 \\
\hline Gekkonidae & Phelsuma & Phelsuma lineata & $\mathrm{LC}$ & 3 & 15 & 30 & 74 & 47 & 4 & 0 \\
\hline Gekkonidae & Phelsuma & Phelsuma madagascariensis & $\mathrm{LC}$ & 0 & 37 & 39 & 54 & 17 & 2 & 1 \\
\hline Gekkonidae & Phelsuma & Phelsuma masohoala & $\mathrm{CR}$ & 0 & 0 & 0 & 0 & 0 & 0 & 0 \\
\hline Gekkonidae & Phelsuma & Phelsuma quadriocellata & $\mathrm{LC}$ & 5 & 1 & 0 & 1 & 0 & 0 & $\underline{0}$ \\
\hline Gekkonidae & Phelsuma & Phelsuma seippi & EN & 10 & 12 & 2 & 0 & 1 & 0 & $\underline{0}$ \\
\hline Gekkonidae & Phelsuma & Phelsuma sp. & NA & 0 & 0 & 1 & 0 & 0 & 0 & $\underline{0}$ \\
\hline Gekkonidae & Uroplatus & Uroplatus fimbriatus & $\mathrm{LC}$ & 2 & 0 & 0 & 0 & 0 & 0 & 0 \\
\hline Gekkonidae & Uroplatus & Uroplatus finaritra & $\mathrm{NE}$ & 1 & 0 & 0 & 0 & 0 & 0 & 0 \\
\hline Gekkonidae & Uroplatus & Uroplatus giganteus & VU & 11 & 0 & 0 & 0 & 0 & 0 & 0 \\
\hline Gekkonidae & Uroplatus & Uroplatus lineatus & $\mathrm{LC}$ & 1 & 0 & 0 & 0 & 0 & 0 & 0 \\
\hline Gekkonidae & Uroplatus & Uroplatus sikorae & $\mathrm{LC}$ & 1 & 0 & 0 & 0 & 0 & 0 & $\underline{0}$ \\
\hline Gekkonidae & Uroplatus & Uroplatus sp. aff. fimbriatus & NA & 1 & 0 & 0 & 0 & 0 & 0 & 0 \\
\hline Gerrhosauridae & Zonosaurus & Zonosaurus madagascariensis & $\mathrm{LC}$ & 0 & 1 & 8 & 21 & 3 & 0 & 5 \\
\hline Gerrhosauridae & Zonosaurus & Zonosaurus rufipes & NT & 65 & 52 & 5 & 0 & 1 & 0 & $\underline{0}$ \\
\hline Gerrhosauridae & Zonosaurus & Zonosaurus subinicolor & EN & 0 & 2 & 0 & 0 & 0 & 0 & 0 \\
\hline Lamprophiidae & Alluaudina & Alluaudina bellyi & $\mathrm{LC}$ & 2 & 0 & 0 & 0 & 0 & 0 & $\underline{0}$ \\
\hline Lamprophiidae & Dromicodryas & Dromicodryas quadrilineatus & $\mathrm{LC}$ & 0 & 1 & 2 & 2 & 1 & 0 & 4 \\
\hline Lamprophiidae & Elapotinus & Elapotinus picteti & $\mathrm{LC}$ & 1 & 0 & 0 & 0 & 0 & 0 & $\underline{0}$ \\
\hline Lamprophiidae & Ithycyphus & Ithycyphus miniatus & $\mathrm{LC}$ & 0 & 2 & 0 & 1 & 0 & 0 & 0 \\
\hline Lamprophiidae & Ithycyphus & Ithycyphus perineti & $\mathrm{LC}$ & 1 & 0 & 1 & 0 & 0 & 0 & 0 \\
\hline Lamprophiidae & Langaha & Langaha madagascariensis & $\mathrm{LC}$ & 0 & 2 & 1 & 0 & 0 & 0 & 0 \\
\hline
\end{tabular}




\begin{tabular}{lllllllllll} 
Lamprophiidae & Leioheterodon & $\begin{array}{l}\text { Leioheterodon madagascari- } \\
\text { ensis }\end{array}$ & LC & 0 & 0 & 3 & 0 & 1 & 0 & 3 \\
\hline Lamprophiidae & Leioheterodon & Leioheterodon modestus & LC & 0 & 0 & 0 & 1 & 0 & 0 & 2 \\
\hline Lamprophiidae & Liophidium & Liophidium torquatum & LC & 2 & 0 & 0 & 0 & 0 & 0 & 0 \\
\hline Lamprophiidae & Lycodryas & Lycodryas granuliceps & LC & 0 & 0 & 2 & 0 & 1 & 0 & 0 \\
\hline Lamprophiidae & Madagascarophis & Madagascarophis colubrinus & LC & 0 & 0 & 0 & 0 & 0 & 0 & 0 \\
\hline Lamprophiidae & Pseudoxyrhopus & Pseudoxyrhopus cf sokosoko & NA & 0 & 1 & 0 & 0 & 0 & 0 & 0 \\
\hline Lamprophiidae & Pseudoxyrhopus & Pseudoxyrhopus heterurus & LC & 2 & 0 & 0 & 0 & 0 & 0 & 0 \\
\hline Lamprophiidae & Pseudoxyrhopus & Pseudoxyrhopus sp. & NA & 0 & 1 & 0 & 0 & 0 & 0 & 0 \\
\hline Lamprophiidae & Thamnosophis & Thamnosophis lateralis & LC & 0 & 2 & 1 & 5 & 0 & 0 & 1 \\
\hline Lamprophiidae & Thamnosophis & Thamnosophis martae & EN & 0 & 0 & 0 & 1 & 0 & 0 & 0 \\
\hline Lamprophiidae & Thamnosophis & Thamnosophis sp. & NA & 2 & 0 & 0 & 0 & 0 & 0 & 0 \\
\hline Scincidae & Amphiglossus & Amphiglossus cf spilostichus & NA & 1 & 0 & 0 & 0 & 0 & 0 & 0 \\
\hline Scincidae & Madascincus & Madascincus minutus & LC & 2 & 1 & 0 & 0 & 0 & 0 & 0 \\
\hline Scincidae & Trachylepis & Trachylepis elegans & LC & 0 & 1 & 1 & 0 & 4 & 28 & 1 \\
\hline Scincidae & Trachylepis & Trachylepis gravenhorstii & LC & 0 & 6 & 21 & 24 & 46 & 31 & 4
\end{tabular}


Table 12.16: Results of pairwise comparison tests between land-use types for plot-level species richness of amphibians. Relates to letters in Figure 5.2. Land-use types: OGF: old-growth forest; FF: forest fragment; VFST: forest-derived vanilla agroforest; VFLW: fallow-derived vanilla agroforest; WF: woody fallow; HF: herbaceous fallow; RP: rice paddy.

\begin{tabular}{|c|c|c|c|c|c|}
\hline Comparison & Estimate & Std. Error & $\mathrm{z}$ value & $\operatorname{Pr}(>|\mathrm{z}|)$ & Signif. \\
\hline $\mathrm{FF}-\mathrm{OGF}$ & -0.60077 & 0.17424 & -3.448 & 0.000565 & $* * *$ \\
\hline VFST - OGF & -0.70396 & 0.18025 & -3.905 & $9.41 \mathrm{E}-05$ & $* * *$ \\
\hline VFLW - OGF & -0.71489 & 0.14745 & -4.848 & $1.25 \mathrm{E}-06$ & $* * *$ \\
\hline WF - OGF & -0.86904 & 0.19077 & -4.555 & $5.23 \mathrm{E}-06$ & $* * *$ \\
\hline $\mathrm{HF}-\mathrm{OGF}$ & -1.09861 & 0.20739 & -5.297 & $1.17 \mathrm{E}-07$ & $* * *$ \\
\hline RP - OGF & -1.58816 & 0.25176 & -6.308 & $2.82 \mathrm{E}-10$ & $* * *$ \\
\hline VFST - FF & -0.10318 & 0.20334 & -0.507 & 0.61184 & \\
\hline VFLW - FF & -0.11411 & 0.17492 & -0.652 & 0.514158 & \\
\hline WF - FF & -0.26826 & 0.21272 & -1.261 & 0.207261 & \\
\hline $\mathrm{HF}-\mathrm{FF}$ & -0.49784 & 0.22774 & -2.186 & 0.028814 & $*$ \\
\hline $\mathrm{RP}-\mathrm{FF}$ & -0.98739 & 0.26877 & -3.674 & 0.000239 & $* * *$ \\
\hline VFLW - VFST & -0.01093 & 0.18091 & -0.06 & 0.951828 & \\
\hline WF - VFST & -0.16508 & 0.21767 & -0.758 & 0.448213 & \\
\hline HF - VFST & -0.39465 & 0.23237 & -1.698 & 0.089434 & . \\
\hline RP - VFST & -0.8842 & 0.27271 & -3.242 & 0.001186 & $* *$ \\
\hline WF - VFLW & -0.15415 & 0.19139 & -0.805 & 0.420571 & \\
\hline HF - VFLW & -0.38373 & 0.20796 & -1.845 & 0.065004 & . \\
\hline RP - VFLW & -0.87327 & 0.25223 & -3.462 & 0.000536 & $* * *$ \\
\hline $\mathrm{HF}-\mathrm{WF}$ & -0.22957 & 0.24062 & -0.954 & 0.340032 & \\
\hline $\mathrm{RP}-\mathrm{WF}$ & -0.71912 & 0.27977 & -2.57 & 0.010158 & $*$ \\
\hline $\mathrm{RP}-\mathrm{HF}$ & -0.48955 & 0.29136 & -1.68 & 0.092909 & . \\
\hline
\end{tabular}

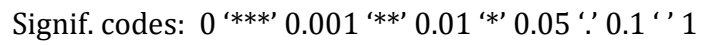


Table 12.17: Results of pairwise comparison tests between land-use types for plot-level species richness of reptiles. Relates to letters in Figure 5.2. Land-use types: OGF: old-growth forest; FF: forest fragment; VFST: forest-derived vanilla agroforest; VFLW: fallow-derived vanilla agroforest; WF: woody fallow; HF: herbaceous fallow; RP: rice paddy.

\begin{tabular}{|c|c|c|c|c|c|}
\hline \multicolumn{6}{|l|}{ Reptiles } \\
\hline Comparison & Estimate & Std. Error & z value & $\operatorname{Pr}(>|z|)$ & Signif. \\
\hline $\mathrm{FF}-\mathrm{OGF}$ & -0.02062 & 0.1436 & -0.144 & 0.885825 & \\
\hline VFST - OGF & -0.04167 & 0.14437 & -0.289 & 0.772846 & \\
\hline VFLW - OGF & -0.35813 & 0.1323 & -2.707 & 0.00679 & $* *$ \\
\hline WF - OGF & -0.42608 & 0.16071 & -2.651 & 0.008021 & $* *$ \\
\hline $\mathrm{HF}-\mathrm{OGF}$ & -1.02962 & 0.19691 & -5.229 & $1.71 \mathrm{E}-07$ & $* * *$ \\
\hline RP - OGF & -1.36609 & 0.22406 & -6.097 & $1.08 \mathrm{E}-09$ & $* * *$ \\
\hline VFST - FF & -0.02105 & 0.1451 & -0.145 & 0.884638 & \\
\hline VFLW - FF & -0.33751 & 0.1331 & -2.536 & 0.01122 & $*$ \\
\hline WF - FF & -0.40547 & 0.16137 & -2.513 & 0.011985 & $*$ \\
\hline $\mathrm{HF}-\mathrm{FF}$ & -1.009 & 0.19745 & -5.11 & $3.22 \mathrm{E}-07$ & $* * *$ \\
\hline $\mathrm{RP}-\mathrm{FF}$ & -1.34547 & 0.22454 & -5.992 & $2.07 \mathrm{E}-09$ & $* * *$ \\
\hline VFLW - VFST & -0.31646 & 0.13393 & -2.363 & 0.018134 & $*$ \\
\hline WF - VFST & -0.38441 & 0.16206 & -2.372 & 0.01769 & $*$ \\
\hline HF - VFST & -0.98795 & 0.19801 & -4.989 & $6.06 \mathrm{E}-07$ & $* * *$ \\
\hline RP - VFST & -1.32442 & 0.22503 & -5.886 & $3.97 \mathrm{E}-09$ & $* * *$ \\
\hline WF - VFLW & -0.06795 & 0.15141 & -0.449 & 0.653581 & \\
\hline HF - VFLW & -0.67149 & 0.1894 & -3.545 & 0.000392 & $* * *$ \\
\hline RP - VFLW & -1.00796 & 0.21748 & -4.635 & $3.58 \mathrm{E}-06$ & $* * *$ \\
\hline HF - WF & -0.60354 & 0.21023 & -2.871 & 0.004094 & $* *$ \\
\hline $\mathrm{RP}-\mathrm{WF}$ & -0.94001 & 0.23585 & -3.986 & $6.73 \mathrm{E}-05$ & $* * *$ \\
\hline $\mathrm{RP}-\mathrm{HF}$ & -0.33647 & 0.26186 & -1.285 & 0.198818 & \\
\hline
\end{tabular}

Signif. codes: 0 (***) $0.001^{(* * \prime} 0.01^{(*)} 0.05$ '? $0.1^{\prime \prime} 1$ 
Table 12.18: Extrapolated encounter-based diversity estimates of amphibian species richness per land-use type (LUT) calculated with the estimateD function of the iNEXT R-package (Hsieh et al., 2016). Land-use types (LUT): OGF: old-growth forest; FF: forest fragment; VFST: forest-derived vanilla agroforest; VFLW: fallow-derived vanilla agroforest; WF: woody fallow; HF: herbaceous fallow; RP: rice paddy. m: extrapolation base (5000 encounters). order (q): Hill number order [0, 1, 2]. SC: sample coverage. qD: diversity estimate at q. qD.LCL: low 95\% confidence level for qD. qD.UCL: upper 95\% confidence level for qD.

\begin{tabular}{|c|c|c|c|c|c|c|c|}
\hline \multicolumn{8}{|c|}{ Amphibians } \\
\hline LUT & $\mathbf{m}$ & method & $\operatorname{order}(q)$ & SC & qD & qD.LCL & qD.UCL \\
\hline OGF & 5000 & extrapolated & 0 & 1 & 59.971 & 20.356 & 99.585 \\
\hline OGF & 5000 & extrapolated & 1 & 1 & 11.615 & 10.009 & 13.221 \\
\hline OGF & 5000 & extrapolated & 2 & 1 & 6.869 & 6.024 & 7.715 \\
\hline $\mathrm{FF}$ & 5000 & extrapolated & 0 & 1 & 46.108 & 12.41 & 79.807 \\
\hline $\mathrm{FF}$ & 5000 & extrapolated & 1 & 1 & 6.542 & 5.451 & 7.633 \\
\hline $\mathrm{FF}$ & 5000 & extrapolated & 2 & 1 & 3.639 & 3.232 & 4.045 \\
\hline VFST & 5000 & extrapolated & 0 & 1 & 17.986 & 9.082 & 26.89 \\
\hline VFST & 5000 & extrapolated & 1 & 1 & 6.636 & 5.919 & 7.353 \\
\hline VFST & 5000 & extrapolated & 2 & 1 & 4.939 & 4.35 & 5.528 \\
\hline VFLW & 5000 & extrapolated & 0 & 1 & 24.97 & 7.005 & 42.935 \\
\hline VFLW & 5000 & extrapolated & 1 & 1 & 5.552 & 4.966 & 6.139 \\
\hline VFLW & 5000 & extrapolated & 2 & 1 & 4.072 & 3.68 & 4.464 \\
\hline WF & 5000 & extrapolated & 0 & 1 & 8.996 & 7.375 & 10.616 \\
\hline WF & 5000 & extrapolated & 1 & 1 & 4.843 & 4.446 & 5.24 \\
\hline WF & 5000 & extrapolated & 2 & 1 & 4.135 & 3.707 & 4.562 \\
\hline $\mathrm{HF}$ & 5000 & extrapolated & 0 & 1 & 6.498 & 3.898 & 9.099 \\
\hline $\mathrm{HF}$ & 5000 & extrapolated & 1 & 1 & 3.492 & 3.212 & 3.771 \\
\hline $\mathrm{HF}$ & 5000 & extrapolated & 2 & 1 & 3.128 & 2.878 & 3.379 \\
\hline $\mathrm{RP}$ & 5000 & extrapolated & 0 & 1 & 4.998 & 4.348 & 5.648 \\
\hline $\mathrm{RP}$ & 5000 & extrapolated & 1 & 1 & 1.331 & 1.276 & 1.386 \\
\hline $\mathrm{RP}$ & 5000 & extrapolated & 2 & 1 & 1.169 & 1.13 & 1.208 \\
\hline
\end{tabular}


Table 12.19: Extrapolated encounter-based diversity estimates of reptile species richness per land-use type (LUT) calculated with the estimateD function of the iNEXT R-package (Hsieh et al., 2016). Land-use types (LUT): OGF: old-growth forest; FF: forest fragment; VFST: forest-derived vanilla ag-roforest; VFLW: fallow-derived vanilla agroforest; WF: woody fallow; HF: herbaceous fallow; RP: rice paddy. m: extrapolation base (5000 encounters). order (q): Hill number order [0, 1, 2]. SC: sample coverage. qD: diversity estimate at q. qD.LCL: low $95 \%$ confidence level for qD. qD.UCL: upper 95\% confidence level for qD.

\begin{tabular}{|c|c|c|c|c|c|c|c|}
\hline \multicolumn{8}{|c|}{ Reptiles } \\
\hline LUT & $\mathbf{m}$ & method & order & SC & $q D$ & qD.LCL & qD.UCL \\
\hline $\mathrm{OGF}$ & 5000 & extrapolated & 0 & 1 & 41.963 & 20.405 & 63.522 \\
\hline OGF & 5000 & extrapolated & 1 & 1 & 16.282 & 13.376 & 19.188 \\
\hline $\mathrm{OGF}$ & 5000 & extrapolated & 2 & 1 & 8.267 & 6.192 & 10.341 \\
\hline $\mathrm{FF}$ & 5000 & extrapolated & 0 & 1 & 40.048 & 10.192 & 69.904 \\
\hline $\mathrm{FF}$ & 5000 & extrapolated & 1 & 1 & 15.463 & 13.557 & 17.368 \\
\hline $\mathrm{FF}$ & 5000 & extrapolated & 2 & 1 & 10.935 & 9.614 & 12.256 \\
\hline VFST & 5000 & extrapolated & 0 & 1 & 35.318 & 18.21 & 52.426 \\
\hline VFST & 5000 & extrapolated & 1 & 1 & 14.355 & 12.633 & 16.077 \\
\hline VFST & 5000 & extrapolated & 2 & 1 & 9.323 & 7.998 & 10.647 \\
\hline VFLW & 5000 & extrapolated & 0 & 1 & 26.949 & 8.198 & 45.699 \\
\hline VFLW & 5000 & extrapolated & 1 & 1 & 6.902 & 6.268 & 7.535 \\
\hline VFLW & 5000 & extrapolated & 2 & 1 & 5.075 & 4.631 & 5.519 \\
\hline WF & 5000 & extrapolated & 0 & 1 & 46.603 & 11.526 & 81.679 \\
\hline $\mathrm{WF}$ & 5000 & extrapolated & 1 & 1 & 8.715 & 7.464 & 9.965 \\
\hline WF & 5000 & extrapolated & 2 & 1 & 6.236 & 5.415 & 7.057 \\
\hline $\mathrm{HF}$ & 5000 & extrapolated & 0 & 1 & 8 & 6.83 & 9.17 \\
\hline $\mathrm{HF}$ & 5000 & extrapolated & 1 & 1 & 3.227 & 2.748 & 3.705 \\
\hline $\mathrm{HF}$ & 5000 & extrapolated & 2 & 1 & 2.194 & 1.88 & 2.507 \\
\hline $\mathrm{RP}$ & 5000 & extrapolated & 0 & 1 & 18.862 & 4.312 & 33.413 \\
\hline $\mathrm{RP}$ & 5000 & extrapolated & 1 & 1 & 6.046 & 3.255 & 8.836 \\
\hline $\mathrm{RP}$ & 5000 & extrapolated & 2 & 1 & 3.129 & 1.79 & 4.468 \\
\hline
\end{tabular}




\subsection{SI Chapter 6}

Supporting information for:

Martin, D. A., Wurz, A., Osen, K., Grass, I., Hölscher, D., Rabemanantsoa, T., Tscharntke, T., \& Kreft, H. (2020c). Shade-tree rehabilitation in vanilla agroforests is yield neutral and may translate into landscape-scale canopy cover gains. Ecosystems. https://doi.org/10.1007/s10021-020-00586-5

The supporting information for Chapter 6 is also available Open Science Framework (OSF): https://oi.org/10.17605/OSF.IO/J64M8.

The data supporting Chapter 6 is available on the Open Science Framework (OSF): https://doi.org/10.17632/fxxnwtmynv.1.

\subsubsection{Vanilla agroforest establishment over time}

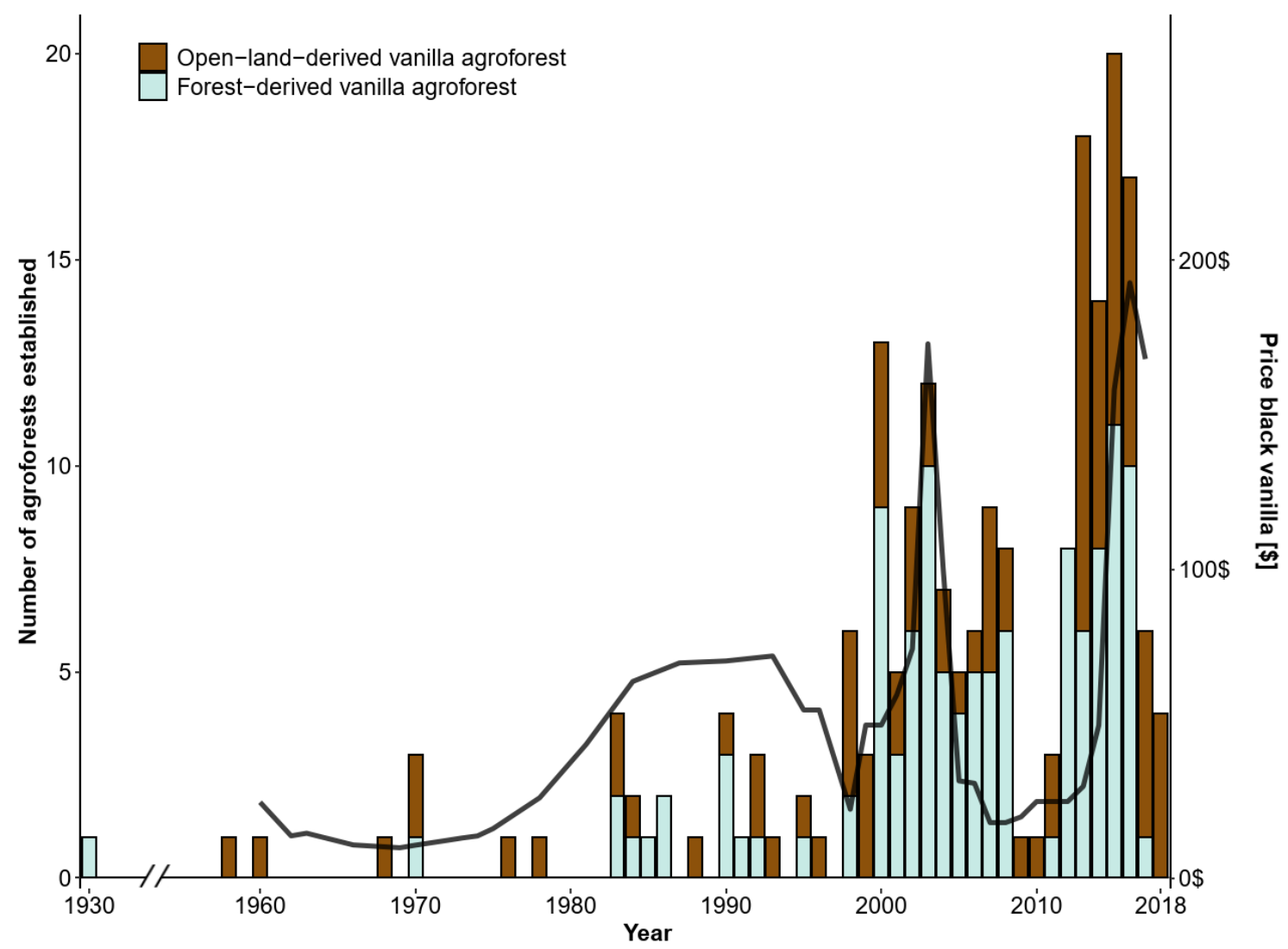

Figure 12.5: Year of establishment of the 209 vanilla agroforests which are included in this study. More agroforests were established when prices were high (Prices per kg of black vanilla, data from DRAE (2018). There is no clear trend towards more forest- or more open-land derived agroforests over time. Note that this figure does not necessarily indicate an expansion of vanilla agroforestry in recent years as vanilla agroforests established in the past might have been abandoned before this 
inventory took place, thus excluding them from our sample of currently active vanilla agroforests. Additionally, the numbers for 2017 and 2018 are likely underestimated as we specifically visited agroforests listed by farmers during interviews in 2017 (Hänke et al., 2018). At that time, agroforests established later in 2017 and 2018 did not exist yet and we thus did not ask farmers to visit such agroforests during data collection in 2018. Therefore, all agroforests established in 2018 and some established in 2017 in the present sample were not included in the interviews in Hänke et al. (2018).

\subsubsection{Map of study region}

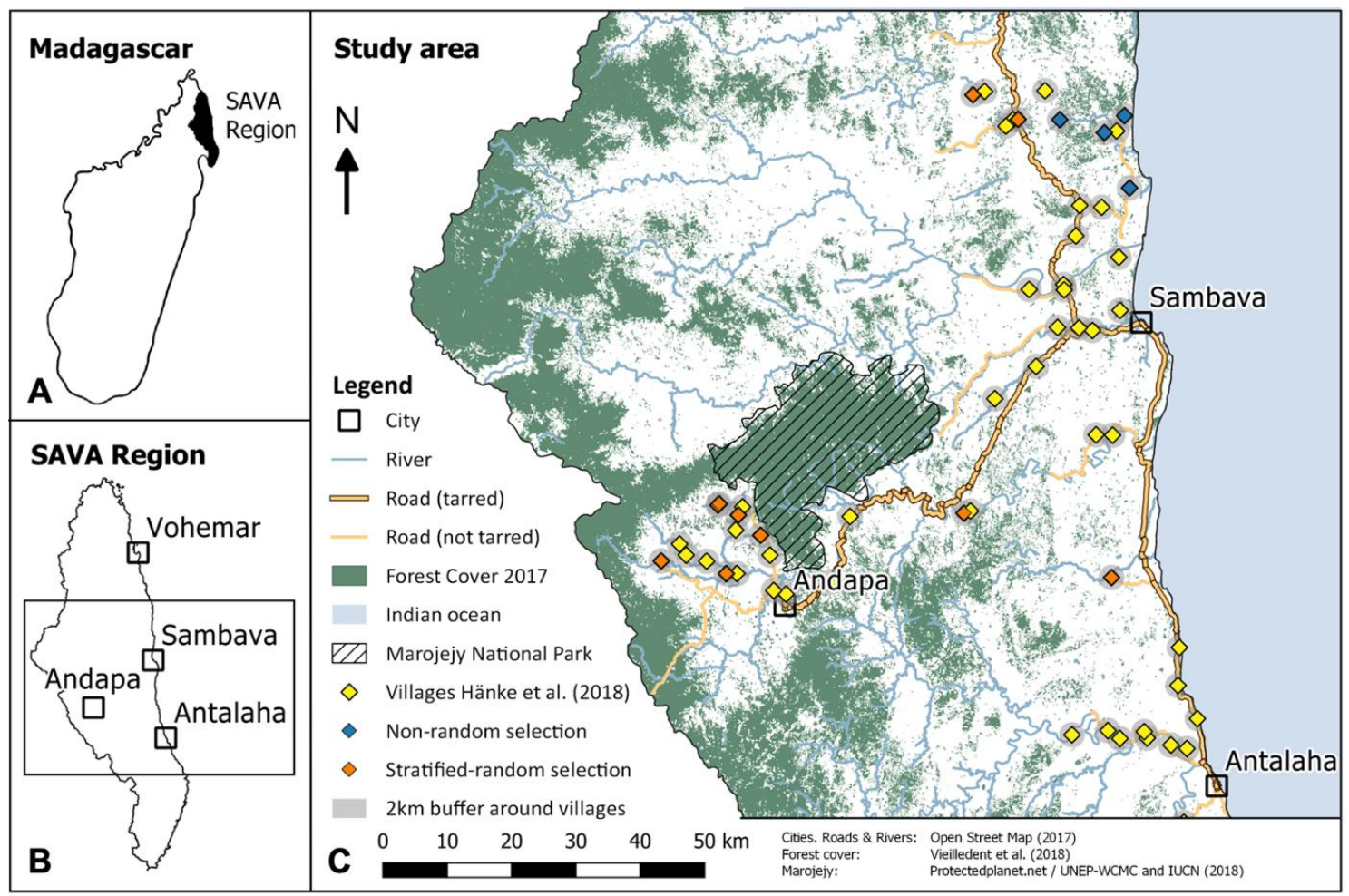

Figure 12.6: Study design overview. A: The island of Madagascar off East Africa with the SAVA region. B: SAVA region including a rectangle depicting the study area. C: Study area with forest cover 2017 (Vieilledent et al., 2018), roads, rivers and the three major cities Sambava, Antalaha and Andapa as well as Marojejy National Park. We collected agroforest data in 10 villages selected in stratifiedrandom way (orange) from 60 villages selected for a previous study (Hänke et al., 2018). We additionally collected data in 4 villages selected in a non-random way (see Methods). Those villages were also part of Hänke et al. (2018). Grey circles around the 60 villages depict area for which we calculated landscape-scale canopy cover trends.

\subsubsection{Method canopy cover}

\section{Data collection}

We took nine photos per agroforest as the mean canopy cover between several photos per plot provides more reliable results (Tichý, 2016). Of the nine photos, we took one in the plot 
centre, another four $10 \mathrm{~m}$ from the centre in all cardinal directions, respectively, and the last four $10 \mathrm{~m}$ further in all cardinal directions (Figure 12.7). Some agroforests were too small to take photos at $20 \mathrm{~m}$ distance from the centre, so we took the respective photos at the edge of such agroforest. We took all photos with the built-in camera (Lenovo 5C28C02840) of a Tablet (Lenovo Yoga YT3-850F) without a lens converter added. This approach, without a lens converter (fish eye) has been demonstrated to provide satisfactory results for canopy cover estimation (Tichý, 2016). We applied no special settings, auto-exposure, 2:3 format, $2448 \times 3264$ pixels, and took RGB images. We took photos above the head of the observer (circa $190 \mathrm{~cm}$; higher than most vanilla pieds), levelled and facing to the zenith.

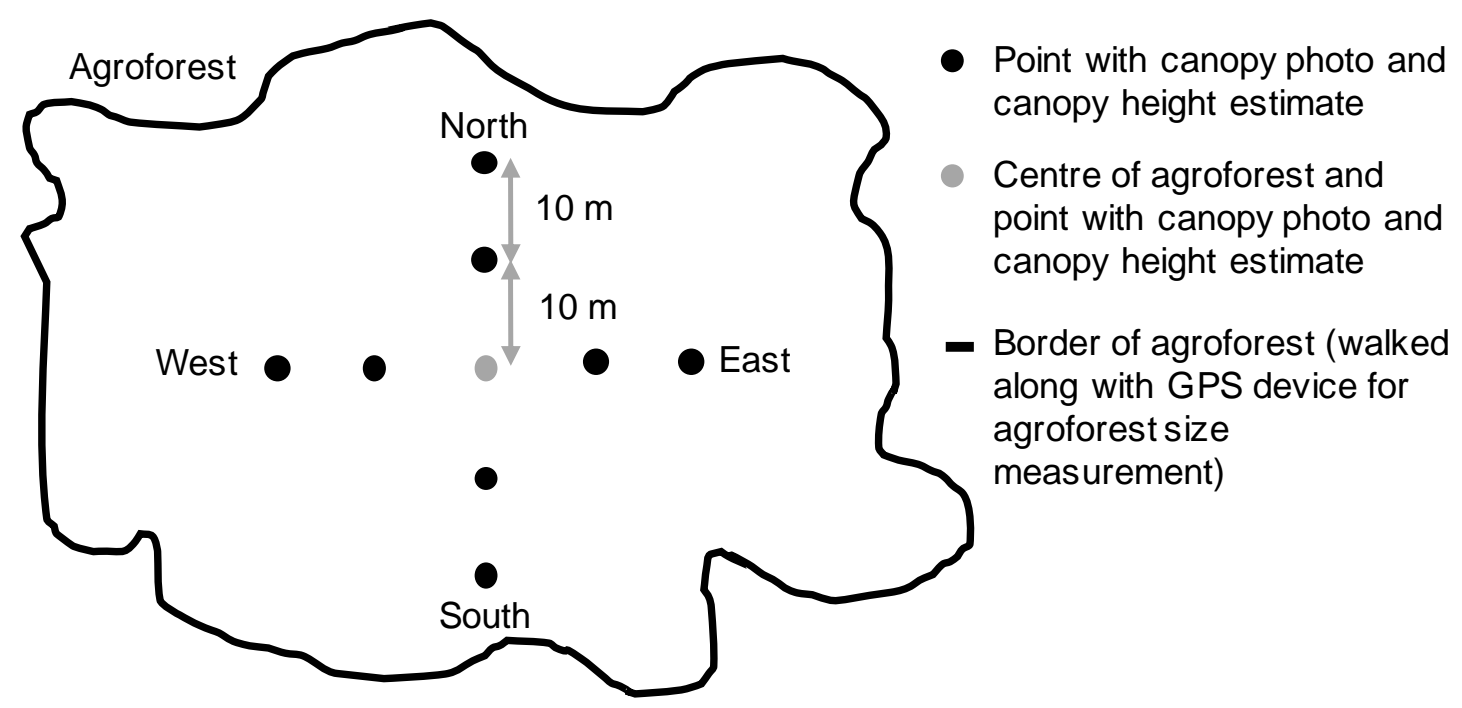

Figure 12.7: Sampling design inside a schematic vanilla agroforest. Points for canopy cover photos and canopy height estimates are the agroforest centre, $10 \mathrm{~m}$ and $20 \mathrm{~m}$, respectively, in all cardinal directions, resulting in 9 measurements/estimates per agroforest. We determined agroforest size by walking at the edge of each agroforest using a handheld GPS device. 


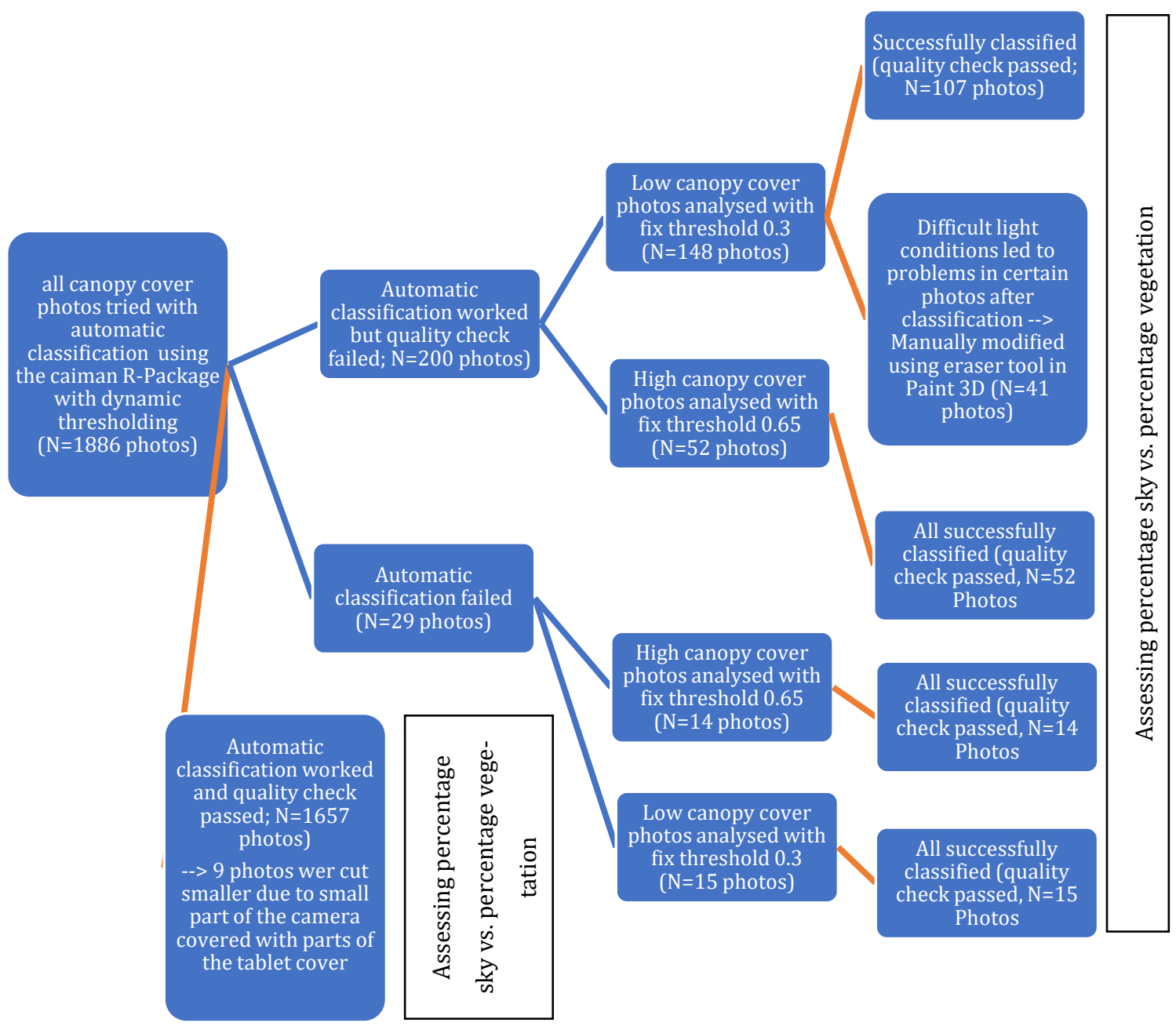

Figure 12.8: Analysis path for all 1886 canopy cover photos from 209 agroforests. Orange lines represent that photos passed quality checks, that is a visual comparison of the raw .jpg images and the classified tif revealed satisfactory results. Blue lines represent that the photo did not pass the quality check, leading to a separation for subsequent analysis.

\section{Automatic classification R-Script}

We used the batch processing mode of the R-Package caiman (CAnopy IMage ANalysis; Version GitHub commit a1ad464; https://github.com/GastonMauroDiaz/caiman) to automatically classify the RGB photos into vegetation/sky. We applied a three-level hierarchical classification process. Firstly, we assessed the amount of open sky in the photo. For photos with less than $25 \%$ open sky, we classified pixels as sky/vegetation using the enhanceHP function of the caiman package which uses fuzzy logic. We then used the autothreshold function to attribute each pixel to sky/vegetation. For photos with more than $25 \%$ of open sky, 
we tested whether the open sky was mainly blue or not using colorfulness function of the caiman R-package. If the sky was blue (colourfulness value $>1$ ), we classified pixels in vegetation respectively sky using the enhanceHP function on hue values only. Photos with overcast sky, in contrast, were classified using a rough mask. Figure 12.9 depicts the analysis path as described here. The procedure described here is implemented in a single function called adaptive_binarization (as of caiman R-Package release https://doi.org/10.5281/zenodo.3366346).

\section{Fix thresholding R-Script}

We only applied the fix thresholding script on photos for which the automatic classification R-script did not produce good results or where the procedure failed entirely (see Figure 12.8). Those photos were manually separated in two groups: Very high canopy cover and very low canopy cover. Photos with medium/normal canopy cover were generally classified well using the automatic classification script. For those photos, we applied the following procedure: Firstly, we used the normalize function of the R-package caiman on each photo to set the range of pixel intensity values between 0 and 255 . Secondly, we pre-set the threshold to 0.3 for very open pictures and to 0.65 for very high canopy cover pictures. Using these fix thresholding value yielded good results for all but 41 photos.

\section{Approach for photos where the results were still bad after fix thresholding (41 photos)}

For 41 photos, the results were still unsatisfactory after using fix thresholding (see Figure 12.8). These photos were almost all taken under very difficult light conditions and/or had strongly contrasting clouds leading to the classification of sky as vegetation. In such cases, we opened the original RGB .jpg photo on one screen and the badly classified .tif image (sky/vegetation binary) on the other screen in 'Paint 3D' and manually used the rubber tool to reclassify cloud pixels that were classified as vegetation into the class sky (white). In very few cases (10/41 photos), patches with little vegetation were completely classified as continuous vegetation. In those cases, we also used the rubber tool and changed some of the vegetation classified pixels to sky, roughly imitating the vegetation pattern visually seen in the original .jpg photo. However, the part of the photo with such area never exceeded circa $25 \%$ of the photo and errors introduced through this technique should be negligible.

\section{Smaller photos}

There are 9 photos from different agroforests in which the protective case of the tablet partly covered the lens. However, the part of the photo obstructed with the tablet cover never exceeded more than circa $10 \%$ of the photos. We cut off the part of the .tif image that 
was covered by the protective case, leading to smaller photos on which we assessed the percentage sky vs. percentage vegetation. There are 31 photos from 4 plantations that were not taken in the $2: 3$ format ( $2448 \times 3264$ pixels) but in a $16: 9$ format (1080x1920 pixels). For those photos, we applied the same procedures as for all other photos.
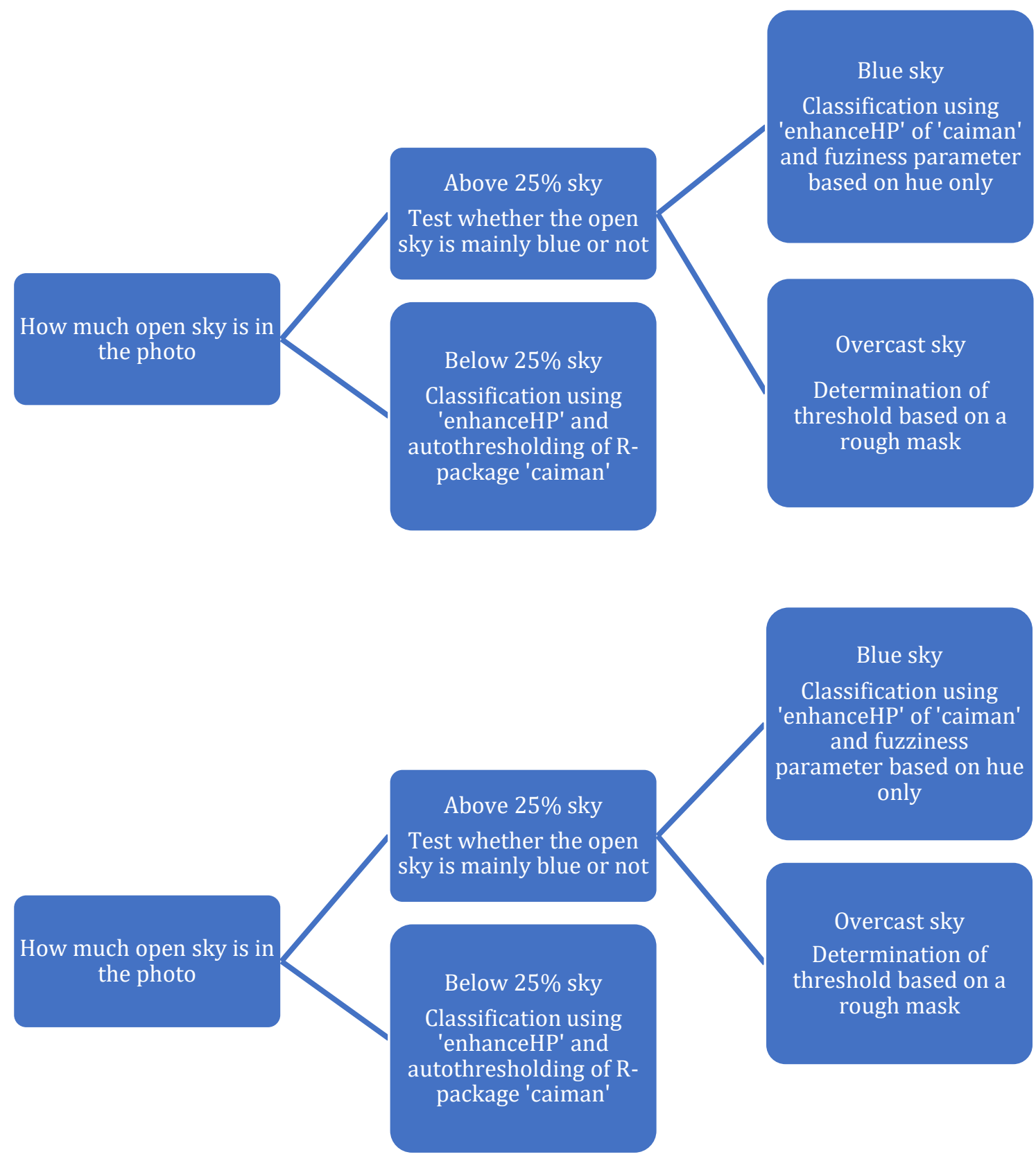

Figure 12.9: Analysis path of dynamic thresholding R-script leading to the binary sky/vegetation classification of each pixel. 


\subsubsection{Result tables}

Table 12.20: Results of linear mixed effect models explaining vanilla yields [kg ha-1] (scaled and BoxCox transformed with lambda 0.25) across 209 vanilla agroforests Madagascar.

\begin{tabular}{|c|c|c|c|c|c|c|}
\hline \multirow[b]{2}{*}{ Predictors } & \multicolumn{3}{|c|}{ Full model } & \multicolumn{3}{|c|}{ Reduced model } \\
\hline & Estimates & $C I$ & $p$ & Estimates & $C I$ & $p$ \\
\hline Intercept & 0.03 & $-0.12-0.18$ & 0.716 & -0.00 & $-0.15-0.15$ & 0.983 \\
\hline $\begin{array}{l}\text { Land-use history } \\
\text { (forest- vs. open- } \\
\text { land-derived) }\end{array}$ & 0.08 & $-0.06-0.22$ & 0.261 & 0.07 & $-0.07-0.21$ & 0.301 \\
\hline Mean canopy cover & 0.08 & $-0.07-0.22$ & 0.311 & 0.11 & $-0.03-0.26$ & 0.137 \\
\hline Age of agroforest & 0.39 & $0.26-0.52$ & $<0.001$ & 0.38 & $0.26-0.51$ & $<0.001$ \\
\hline Planting density & 0.20 & $0.07-0.33$ & 0.003 & 0.22 & $0.09-0.35$ & 0.001 \\
\hline Annual precipitation & 0.11 & $-0.05-0.27$ & 0.169 & 0.09 & $-0.07-0.24$ & 0.274 \\
\hline $\begin{array}{l}\text { Land-use history * } \\
\text { canopy cover }\end{array}$ & -0.07 & $-0.21-0.08$ & 0.358 & & & \\
\hline $\begin{array}{l}\text { Land-use history * } \\
\text { age of agroforest }\end{array}$ & -0.06 & $-0.19-0.06$ & 0.320 & & & \\
\hline $\begin{array}{l}\text { Land-use history * } \\
\text { planting density }\end{array}$ & -0.13 & $-0.26-0.00$ & 0.053 & & & \\
\hline $\begin{array}{l}\text { Land-use history * } \\
\text { annual precipitation }\end{array}$ & 0.09 & $-0.06-0.23$ & 0.229 & & & \\
\hline \multicolumn{7}{|l|}{ Random Effects } \\
\hline$\sigma^{2}$ & 0.56 & & & 0.55 & & \\
\hline$\tau_{00}$ & 0.19 hhcode & & & 0.21 hhcode & & \\
\hline & 0.01 village & & & 0.02 village & & \\
\hline ICC & 0.27 & & & 0.30 & & \\
\hline $\mathrm{N}$ & 14 village & & & 14 village & & \\
\hline & 152 hhcode & & & 152 hhcode & & \\
\hline Observations & 209 & & & 209 & & \\
\hline Marginal $R_{2}$ & 0.242 & & & 0.216 & & \\
\hline Conditional $R_{2}$ & 0.445 & & & 0.450 & & \\
\hline
\end{tabular}


Table 12.21: Results of linear mixed effect models explaining canopy cover [\%] (scaled) across 209 vanilla agroforests in north-eastern Madagascar.

\begin{tabular}{|c|c|c|c|c|c|c|}
\hline \multirow[b]{2}{*}{ Predictors } & \multicolumn{3}{|c|}{ Full model } & \multicolumn{3}{|c|}{ Reduced model } \\
\hline & Estimates & $C I$ & $p$ & Estimates & $C I$ & $p$ \\
\hline Intercept & 0.04 & $-0.16-0.23$ & 0.718 & 0.02 & $-0.17-0.22$ & 0.838 \\
\hline $\begin{array}{l}\text { Land-use history } \\
\text { (forest- vs. open- } \\
\text { land-derived) }\end{array}$ & 0.15 & $0.00-0.29$ & 0.048 & 0.16 & $0.02-0.30$ & 0.023 \\
\hline Age of agroforest & 0.26 & $0.14-0.38$ & $<0.001$ & 0.27 & $0.15-0.39$ & $<0.001$ \\
\hline Elevation & -0.43 & $-0.63--0.23$ & $<0.001$ & -0.41 & $-0.61--0.21$ & $<0.001$ \\
\hline Forest cover $250 \mathrm{~m}$ & 0.12 & $-0.02-0.26$ & 0.093 & 0.10 & $-0.04-0.23$ & 0.151 \\
\hline Planting density & -0.02 & $-0.15-0.11$ & 0.751 & -0.02 & $-0.14-0.11$ & 0.788 \\
\hline $\begin{array}{l}\text { Land-use history * } \\
\text { age of agroforest }\end{array}$ & -0.09 & $-0.21-0.02$ & 0.109 & & & \\
\hline $\begin{array}{l}\text { Land-use history * } \\
\text { elevation }\end{array}$ & 0.06 & $-0.10-0.22$ & 0.477 & & & \\
\hline $\begin{array}{l}\text { Land-use history } \\
\text { forest cover } 250 \mathrm{~m}\end{array}$ & -0.04 & $-0.18-0.11$ & 0.627 & & & \\
\hline $\begin{array}{l}\text { Land-use history * } \\
\text { planting density }\end{array}$ & -0.10 & $-0.22-0.02$ & 0.103 & & & \\
\hline \multicolumn{7}{|l|}{ Random Effects } \\
\hline$\sigma^{2}$ & 0.51 & & & 0.51 & & \\
\hline$\tau_{00}$ & 0.14 hhcode & & & 0.15 hhcode & & \\
\hline & 0.07 village & & & 0.08 village & & \\
\hline ICC & 0.29 & & & 0.31 & & \\
\hline $\mathrm{N}$ & 14 village & & & 14 village & & \\
\hline & 152 hhcode & & & 152 hhcode & & \\
\hline Observations & 209 & & & 209 & & \\
\hline Marginal $R_{2}$ & 0.346 & & & 0.337 & & \\
\hline Conditional $R_{2}$ & 0.536 & & & 0.542 & & \\
\hline
\end{tabular}


Table 12.22: Results of linear mixed effect models explaining canopy height [m] (scaled and BoxCox transformed with lambda 0.35) across 209 vanilla agroforests in north-eastern Madagascar.

\begin{tabular}{|c|c|c|c|c|c|c|}
\hline \multirow[b]{2}{*}{ Predictors } & \multicolumn{3}{|c|}{ Full model } & \multicolumn{3}{|c|}{ Reduced model } \\
\hline & Estimates & $C I$ & $p$ & Estimates & $C I$ & $p$ \\
\hline Intercept & 0.03 & $-0.13-0.20$ & 0.675 & 0.03 & $-0.12-0.17$ & 0.716 \\
\hline $\begin{array}{l}\text { Land-use history (for- } \\
\text { est- vs. open-land-de- } \\
\text { rived) }\end{array}$ & 0.42 & $0.29-0.54$ & $<0.001$ & 0.41 & $0.29-0.53$ & $<0.001$ \\
\hline Age of agroforest & 0.09 & $-0.01-0.19$ & 0.074 & 0.09 & $-0.01-0.19$ & 0.068 \\
\hline Elevation & -0.18 & $-0.35--0.02$ & 0.030 & -0.21 & $-0.36--0.05$ & 0.008 \\
\hline Forest cover $250 \mathrm{~m}$ & 0.12 & $-0.00-0.24$ & 0.058 & 0.12 & $0.01-0.24$ & 0.034 \\
\hline Planting density & 0.03 & $-0.09-0.15$ & 0.626 & 0.02 & $-0.09-0.14$ & 0.675 \\
\hline $\begin{array}{l}\text { Land-use history * age } \\
\text { of agroforest }\end{array}$ & -0.15 & $-0.25--0.05$ & 0.004 & -0.16 & $-0.26--0.06$ & 0.002 \\
\hline $\begin{array}{l}\text { Land-use history * ele- } \\
\text { vation }\end{array}$ & 0.06 & $-0.09-0.21$ & 0.428 & & & \\
\hline $\begin{array}{l}\text { Land-use history * for- } \\
\text { est cover } 250 \mathrm{~m}\end{array}$ & 0.07 & $-0.06-0.20$ & 0.318 & & & \\
\hline $\begin{array}{l}\text { Land-use history * } \\
\text { planting density }\end{array}$ & -0.02 & $-0.13-0.10$ & 0.749 & & & \\
\hline \multicolumn{7}{|l|}{ Random Effects } \\
\hline$\sigma^{2}$ & 0.27 & & & 0.26 & & \\
\hline$\tau_{00}$ & 0.36 hhcode & & & 0.36 hhcode & & \\
\hline & 0.02 village & & & 0.02 village & & \\
\hline ICC & 0.59 & & & 0.59 & & \\
\hline $\mathrm{N}$ & 14 village & & & 14 village & & \\
\hline & 152 hhcode & & & 152 hhcode & & \\
\hline Observations & 209 & & & 209 & & \\
\hline Marginal $R_{2}$ & 0.352 & & & 0.352 & & \\
\hline Conditional $R_{2}$ & 0.734 & & & 0.735 & & \\
\hline
\end{tabular}


Table 12.23: Results of a general additive model explaining change in remotely sensed canopy cover from 2000 to 2010 around 60 focal villages in north-eastern Madagascar.

\section{Landscape-scale canopy cover model}

\begin{tabular}{|c|c|c|c|c|}
\hline Parametric coefficients & Estimate & Std. Error & t-value & $p$ \\
\hline Intercept & 2.63 & 0.42 & 6.33 & $<0.001$ \\
\hline Smooth terms & $e d f$ & $\operatorname{Ref.df}$ & F-value & $p$ \\
\hline Baseline & 6.99 & 6.99 & 3653.38 & $<0.001$ \\
\hline \multicolumn{5}{|l|}{ Random effects } \\
\hline Village (Random effect) & 58.90 & 59.00 & 550.23 & $<0.001$ \\
\hline Longitude (Random effect) & 0.00 & 1.00 & 0.00 & 0.206 \\
\hline Latitude (Random effect) & 0.00 & 1.00 & 0.00 & 0.613 \\
\hline \multirow[t]{3}{*}{$\mathrm{N}$} & 60 village & & & \\
\hline & $809^{\prime} 889$ longitude & & & \\
\hline & 809 '889 latitude & & & \\
\hline Observations & $809^{\prime} 889$ & & & \\
\hline$R_{2}$ adjusted & 0.08 & & & \\
\hline
\end{tabular}

\subsubsection{Yield estimates from other studies}

Table 12.24: Overview of published green and black vanilla yield estimates [kg ha-1] including selected FAO data. Some data is only available as $\mathrm{kg} v$ vine $^{-1}$ or as $\mathrm{kg} \mathrm{plant}^{-1}$; other data represents ranges rather than point estimates.

\begin{tabular}{|l|l|l|l|l|l|}
\hline $\begin{array}{l}\text { Yearly } \\
\text { green va- } \\
\text { nilla yield }\end{array}$ & $\begin{array}{l}\text { Yearly } \\
\text { black va- } \\
\text { nilla yield }\end{array}$ & Location & $\begin{array}{l}\text { Growing sys- } \\
\text { tem }\end{array}$ & Method & Reference \\
\hline NA & $\begin{array}{l}77.4 \\
\text { kg ha-1 }^{-1}\end{array}$ & Global & Various & FAO Data year 2018 & (FAO, 2020) \\
\hline NA & $\begin{array}{l}43.1 \\
\text { kg ha-1 }^{-1}\end{array}$ & Madagascar & Various & FAO Data year 2018 & (FAO, 2020) \\
\hline $\begin{array}{l}154.6 \\
\text { kg ha-1 }\end{array}$ & NA & $\begin{array}{l}\text { SAVA Re- } \\
\text { gion, Mada- } \\
\text { gascar }\end{array}$ & Agroforestry & $\begin{array}{l}\text { Interview on field; } \\
\text { measurement of field } \\
\text { size (N = 209) }\end{array}$ & This study \\
\hline $\begin{array}{l}54.7 \\
\text { kg ha }^{-1 *}\end{array}$ & NA & $\begin{array}{l}\text { SAVA Re- } \\
\text { gion, Mada- } \\
\text { gascar }\end{array}$ & $\begin{array}{l}\text { Agroforestry } \\
\text { (all Fairtrade } \\
\text { certified) }\end{array}$ & $\begin{array}{l}\text { Interview at home of } \\
\text { farmer; land size in- } \\
\text { terviewed (N = 252 } \\
\text { households) }\end{array}$ & $\begin{array}{l}\text { International, } \\
\text { 2019) }\end{array}$ \\
\hline $\begin{array}{l}163.3 \\
\text { kg ha-1 }\end{array}$ & NA & $\begin{array}{l}\text { Western } \\
\text { Uganda }\end{array}$ & $\begin{array}{l}\text { Agroforestry } \\
\text { (all Fairtrade } \\
\text { certified) }\end{array}$ & $\begin{array}{l}\text { Interview at home of } \\
\text { farmer; land size }\end{array}$ & $\begin{array}{l}\text { (Hänke \& Fairtrade } \\
\text { International, } \\
\text { 2019) }\end{array}$ \\
\hline
\end{tabular}




\begin{tabular}{|c|c|c|c|c|c|}
\hline & & & & $\begin{array}{l}\text { interviewed ( } \mathrm{N}=242 \\
\text { households) }\end{array}$ & \\
\hline $\begin{array}{l}1.5 \\
\mathrm{~kg} \text { vine } \\
1630.9 \\
\text { kg ha-1 }^{-1}\end{array}$ & NA & Uganda & $\begin{array}{l}\text { Smallholder } \\
\text { plantation }\end{array}$ & $\begin{array}{l}\text { Expert knowledge (es- } \\
\text { timated per vine; mul- } \\
\text { tiplied with planting } \\
\text { density } \\
(1087 / \text { pied/ha)) }\end{array}$ & (Komarek, 2010) \\
\hline $\begin{array}{l}1680- \\
1800 \\
\mathrm{~kg} \mathrm{ha}^{-1}\end{array}$ & NA & $\begin{array}{l}\text { Veracruz, } \\
\text { Mexico }\end{array}$ & $\begin{array}{l}\text { Monoculture / } \\
\text { Citrus-vanilla } \\
\text { system }\end{array}$ & Unclear $(\mathrm{N}=4)$ & $\begin{array}{l}\text { (Krishnamurthy \& } \\
\text { Reddiar, 2011) }\end{array}$ \\
\hline $\begin{array}{l}200- \\
10^{\prime} 000 \\
\mathrm{~kg} \mathrm{ha}^{-1}\end{array}$ & NA & $\begin{array}{l}\text { Veracruz } \\
\text { and Puebla, } \\
\text { Mexico }\end{array}$ & $\begin{array}{l}\text { Monoculture } \\
\text { with mesh } \\
\text { shade }\end{array}$ & $\begin{array}{l}\text { Interview with } 99 \\
\text { farmers }\end{array}$ & $\begin{array}{l}\text { (Barrera- } \\
\text { Rodríguez et al., } \\
\text { 2009) }\end{array}$ \\
\hline $\begin{array}{l}0-1200 \\
\mathrm{~kg} \mathrm{ha}^{-1}\end{array}$ & NA & $\begin{array}{l}\text { Veracruz } \\
\text { and Puebla, } \\
\text { Mexico }\end{array}$ & $\begin{array}{l}\text { Orange-vanilla } \\
\text { system }\end{array}$ & $\begin{array}{l}\text { Interview with } 99 \\
\text { farmers }\end{array}$ & $\begin{array}{l}\text { (Barrera- } \\
\text { Rodríguez et al., } \\
\text { 2009) }\end{array}$ \\
\hline $\begin{array}{l}200 \\
\text { kg ha-1 }^{-1}\end{array}$ & NA & Mexico & Agroforestry & $\begin{array}{l}\text { Expert knowledge } \\
\text { (same expert and esti- } \\
\text { mate in two publica- } \\
\text { tions) }\end{array}$ & $\begin{array}{l}\text { (Havkin-Frenkel \& } \\
\text { Belanger, 2018) / } \\
\text { (Odoux \& Grisoni, } \\
\text { 2010) }\end{array}$ \\
\hline $\begin{array}{l}1000- \\
2000 \\
\mathrm{~kg} \mathrm{ha}^{-1}\end{array}$ & NA & Mexico & $\begin{array}{l}\text { Monoculture } \\
\text { (rainfed) }\end{array}$ & $\begin{array}{l}\text { Expert knowledge } \\
\text { (same expert and esti- } \\
\text { mate in two publica- } \\
\text { tions) }\end{array}$ & $\begin{array}{l}\text { (Havkin-Frenkel \& } \\
\text { Belanger, 2018) / } \\
\text { (Odoux \& Grisoni, } \\
\text { 2010) }\end{array}$ \\
\hline $\begin{array}{l}2000- \\
4000 \\
\mathrm{~kg} \mathrm{ha}^{-1}\end{array}$ & NA & Mexico & $\begin{array}{l}\text { Monoculture } \\
\text { (irrigated) }\end{array}$ & $\begin{array}{l}\text { Expert knowledge } \\
\text { (same expert and esti- } \\
\text { mate in two publica- } \\
\text { tions) }\end{array}$ & $\begin{array}{l}\text { (Havkin-Frenkel \& } \\
\text { Belanger, 2018) / } \\
\text { (Odoux \& Grisoni, } \\
\text { 2010) }\end{array}$ \\
\hline $\begin{array}{l}500- \\
2500 \mathrm{~kg} \\
\mathrm{ha}^{-1} / 500 \\
-3000 \mathrm{~kg} \\
\mathrm{ha}^{-1}\end{array}$ & NA & Mexico & $\begin{array}{l}\text { Citrus-vanilla } \\
\text { system }\end{array}$ & $\begin{array}{l}\text { Expert knowledge } \\
\text { (same expert and esti- } \\
\text { mate in two publica- } \\
\text { tions) }\end{array}$ & $\begin{array}{l}\text { (Havkin-Frenkel \& } \\
\text { Belanger, 2018) / } \\
\text { (Odoux \& Grisoni, } \\
\text { 2010) }\end{array}$ \\
\hline $\begin{array}{l}500- \\
5140 \mathrm{~kg} \\
\mathrm{ha}^{-1}\end{array}$ & NA & Mexico & Shade house & $\begin{array}{l}\text { Expert knowledge } \\
\text { (same expert and esti- } \\
\text { mate in two publica- } \\
\text { tions) }\end{array}$ & $\begin{array}{l}\text { (Havkin-Frenkel \& } \\
\text { Belanger, 2018) / } \\
\text { (Odoux \& Grisoni, } \\
\text { 2010) }\end{array}$ \\
\hline $\begin{array}{l}1655- \\
2453 \\
\mathrm{~kg} \mathrm{ha}^{-1}\end{array}$ & NA & Mexico & Shade house & Expert knowledge & $\begin{array}{l}\text { (Hernández \& Hé- } \\
\text { ctor Guillermo, } \\
\text { 2014) }\end{array}$ \\
\hline $\begin{array}{l}484-800 \\
\mathrm{~kg} \mathrm{ha}^{-1}\end{array}$ & NA & Mexico & $\begin{array}{l}\text { Orange-vanilla } \\
\text { system }\end{array}$ & Expert knowledge & $\begin{array}{l}\text { (Hernández \& Hé- } \\
\text { ctor Guillermo, } \\
\text { 2014) }\end{array}$ \\
\hline $\begin{array}{l}70-100 \\
\mathrm{~kg} \mathrm{ha}^{-1}\end{array}$ & NA & Mexico & $\begin{array}{l}\text { Traditional sys- } \\
\text { tem }\end{array}$ & Expert knowledge & $\begin{array}{l}\text { (Hernández \& Hé- } \\
\text { ctor Guillermo, } \\
\text { 2014) }\end{array}$ \\
\hline $\begin{array}{l}0.55-1.5 \\
\text { kg plant }^{-1}\end{array}$ & NA & Colombia & Shade house & $\begin{array}{l}\text { Fertilization experi- } \\
\text { ment ( } 5 \text { treatments, } 4 \\
\text { replicates each, } 320 \\
\text { plants in total) }\end{array}$ & $\begin{array}{l}\text { (Díez, Osorio, and } \\
\text { Moreno 2016) }\end{array}$ \\
\hline $\begin{array}{l}667 \\
\text { kg ha }^{-1}\end{array}$ & NA & $\begin{array}{l}\text { Karnataka, } \\
\text { India }\end{array}$ & $\begin{array}{l}\text { Arecanut-va- } \\
\text { nilla system on } \\
\text { Research sta- } \\
\text { tion }\end{array}$ & $\begin{array}{l}\text { Management experi- } \\
\text { ment; } \mathrm{N}=9 \text { subplots } \\
\text { within one experi- } \\
\text { mental plot }\end{array}$ & $\begin{array}{l}\text { (Sujatha \& Bhat, } \\
\text { 2010) }\end{array}$ \\
\hline
\end{tabular}




\begin{tabular}{|c|c|c|c|c|c|}
\hline $\begin{array}{l}0.2 \\
\text { kg vine }^{-1}\end{array}$ & NA & Indonesia & $\begin{array}{l}\text { Gliricidia- / } \\
\text { Leuceana tutors }\end{array}$ & Expert knowledge & $\begin{array}{l}\text { (Odoux \& Grisoni, } \\
\text { 2010) }\end{array}$ \\
\hline $\begin{array}{l}0.2-1.5 \\
\mathrm{~kg}^{-} \text {vine}^{-1} \\
240- \\
2400 \mathrm{~kg} \\
\text { ha-1 }^{-1}\end{array}$ & NA & $\begin{array}{l}\text { West Java, } \\
\text { Indonesia }\end{array}$ & Agroforestry & $\begin{array}{l}\text { Interviews with } 10 \\
\text { farmers (estimated } \\
\text { per vine; multiplied } \\
\text { with planting density } \\
(1600- \\
1200 / \text { pied/ha)) }\end{array}$ & $\begin{array}{l}\text { (Santosa et al., } \\
\text { 2005) }\end{array}$ \\
\hline $140 \mathrm{~kg}^{-} \mathrm{ha}^{-}$ & NA & Indonesia & Unknown & Expert knowledge & $\begin{array}{l}\text { (De La Cruz Me- } \\
\text { dina et al., 2009) }\end{array}$ \\
\hline NA & $\begin{array}{l}400-500 \\
\mathrm{~kg} \mathrm{ha}^{-1}\end{array}$ & India & $\begin{array}{l}\text { Plantation in- } \\
\text { tercrop }\end{array}$ & Expert knowledge & $\begin{array}{l}\text { (Odoux \& Grisoni, } \\
2010)\end{array}$ \\
\hline NA & $\begin{array}{l}48-113 \\
\mathrm{~kg} \mathrm{ha}^{-1}\end{array}$ & India & Various & $\begin{array}{l}2000-2007 \text {, estimates } \\
\text { by 'Spices board of In- } \\
\text { dia' }\end{array}$ & $\begin{array}{l}\text { (Odoux \& Grisoni, } \\
\text { 2010) }\end{array}$ \\
\hline NA & $\begin{array}{l}75-300 \\
\mathrm{~kg} \mathrm{ha}^{-1}\end{array}$ & $\begin{array}{l}\text { Hainan Is- } \\
\text { land, China }\end{array}$ & $\begin{array}{l}\text { Arecanut-va- } \\
\text { nilla and artifi- } \\
\text { cial shade }\end{array}$ & Expert knowledge & $\begin{array}{l}\text { (Odoux \& Grisoni, } \\
\text { 2010) }\end{array}$ \\
\hline
\end{tabular}

* possibly too low as households in the study are supposed to sell exclusively to 'Fairtrade' traders, possibly prompting respondents to underreport harvests as they may have been engaged in contractually forbidden 'side selling' to other traders (Hänke \& Fairtrade International, 2019)

\subsubsection{Literature cited}

Barrera-Rodríguez, A. I., Herrera-Cabrera, B. E., Jaramillo-Villanueva, J. L., Escobedo-Garrido, J. S., \& Bustamante-González, Á. (2009). Characterization of vanilla production systems (Vanilla planifolia A.) on orange tree and mesh shade in the Totonacapan Region. Tropical and Subtropical Agroecosystems, 10, 199-212.

De La Cruz Medina, J., Rodriguez Jiménes, G. C., \& García, H. S. (2009). Vanilla Post-harvest Operations (INPhO - Post-Harvest Compendium).

Díez, M. C., Osorio, N. W., \& Moreno, F. (2016). Effect of dose and type of fertilizer on flowering and fruiting of vanilla plants. Journal of Plant Nutrition, 39(9), 1297-1310. https://doi.org/10.1080/01904167.2015.1098673

DRAE (2018). Database of vanilla prices between 1960-2017 in the SAVA Region. Direction Régionale de l'Agriculture et Élevage.

FAO (2020). FAOSTAT. Food and Agriculture Organisation of the United Nations. http://www.fao.org/faostat/en/\#home

Hänke, H., Barkmann, J., Blum, L., Franke, Y., Martin, D. A., Niens, J., Osen, K., Uruena, V., Witherspoon, S. A., \& Wurz, A. (2018). Socio-economic, land use and value chain perspectives on vanilla farming in the SAVA Region (north-eastern Madagascar): The 
Diversity Turn Baseline Study (DTBS). July 2019 Edition. https://doi.org/DOI: 10.13140/RG.2.2.22059.80163

Hänke, H., \& Fairtrade International. (2019). Living Income Reference Price for Vanilla from Uganda and Madagascar. Fairtrade International.

Havkin-Frenkel, D., \& Belanger, F. C. (Eds.). (2018). Handbook of vanilla science and technology (Second edition). Wiley.

Hernández, J. V., \& Héctor Guillermo, G. V. (2014). Producción de Vanilla en Tres Sistemas de Producción en la Sierra Huasteca Potosina. Instituto Nacional de Investigaciones Forestales, Agrícolas y Pecuarias.

Komarek, A. M. (2010). Crop diversification decisions: The case of vanilla in Uganda. Quarterly Journal of International Agriculture, 49(3), 227-242. https://doi.org/10.22004/ag.econ.155551

Krishnamurthy, P. K., \& Reddiar, K. L. (2011). Agrobiodiversity for Livelihood Security: A Case Study of Agroforestry Technologies in Mexico. Journal of Life Sciences, 5(2), 108-119.

Odoux, E., \& Grisoni, M. (Eds.). (2010). Vanilla. CRC Press.

Santosa, E., Sugiyama, N., Nakata, M., \& Kawabata, S. (2005). Profitability of Vanilla Intercropping in Pine Forests in West Java, Indonesia. Japanese Journal of Tropical Agriculture, 49(3), 207-214. https://doi.org/10.11248/jsta1957.49.207

Sujatha, S., \& Bhat, R. (2010). Response of vanilla (Vanilla planifolia A.) intercropped in arecanut to irrigation and nutrition in humid tropics of India. Agricultural Water Management, 97(7), 988-994. https://doi.org/10.1016/j.agwat.2010.01.031

Tichý, L. (2016). Field test of canopy cover estimation by hemispherical photographs taken with a smartphone. Journal of Vegetation Science, 27(2), 427-435. https://doi.org/10.1111/jvs.12350

Vieilledent, G., Grinand, C., Rakotomalala, F. A., Ranaivosoa, R., Rakotoarijaona, J.-R., Allnutt, T. F., \& Achard, F. (2018). Combining global tree cover loss data with historical national forest cover maps to look at six decades of deforestation and forest fragmentation in Madagascar. Biological Conservation, 222, 189-197. https://doi.org/10.1016/j.biocon.2018.04.008 


\subsection{SI Chapter 7}

Supporting information for:

Wurz, A., Tscharntke, T., Martin, D. A., Osen, K., Raveloaritiana, E., Andriafanomezantsoa, R., Andrianisaina, F., Fulgence, T. R., Dröge, S., Rakotomalala, A. N. A., Randriamanantena, R., Soazafy, M. R., Andrianarimisa, A., Babarezoto, F. S., Barkmann, J., Hänke, H., Hölscher, D., Kreft, H. L. T., Rakouth, B., Guerrero-Ramirez, N., Ranarijaona, H. L. T., Ratsoavina, F. M., Ravaomanarivo Raveloson, L. H., \& Grass, I. (in prep.) High crop yields without biodiversity losses in tropical agroforestry.

Please note: numeric result tables are under preparation.

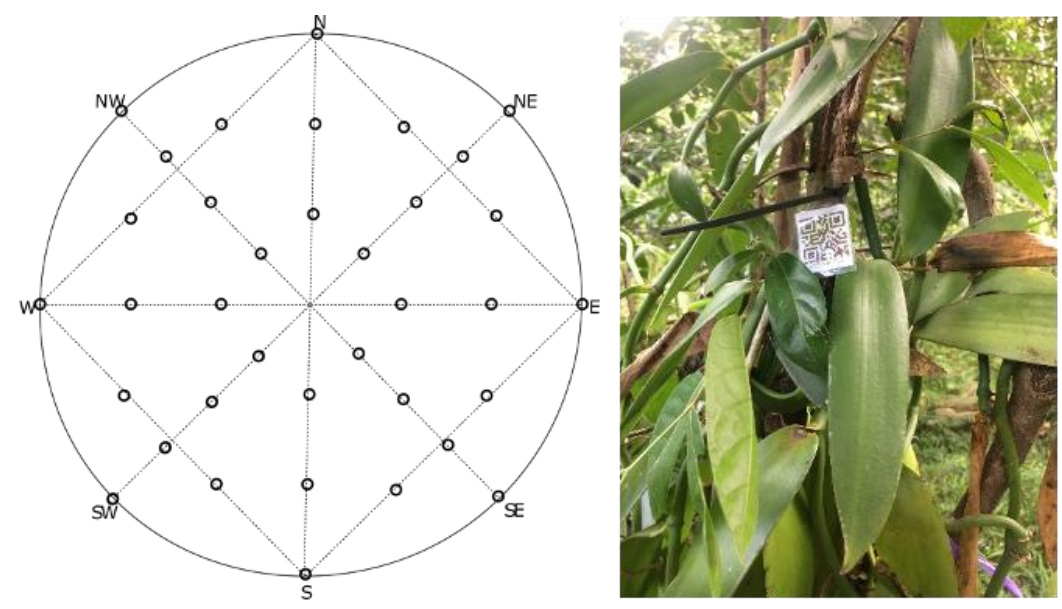

Figure 12.10: Left: Distribution of 36 vanilla-support-tree-units on a 25 -meter radius plot in a va-nilla agroforest. Right: Unique barcode label on vanilla-support-tree-unit.
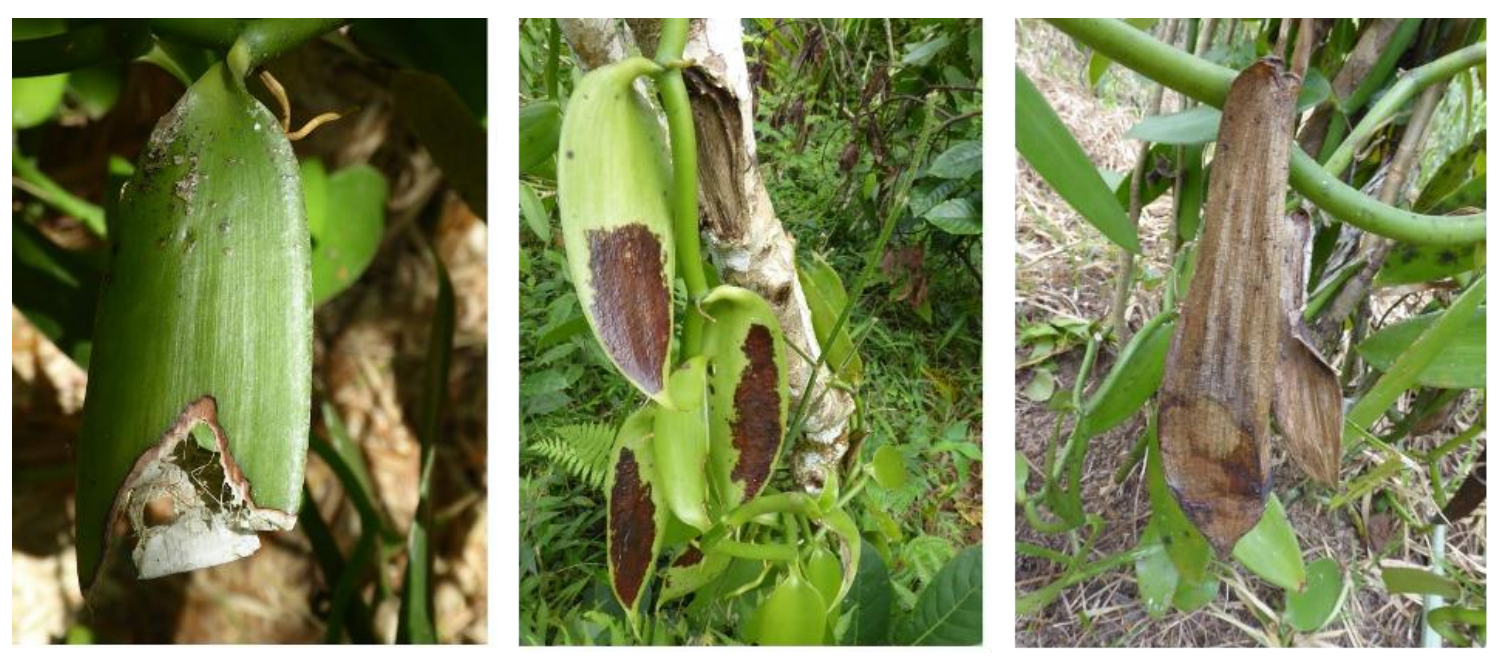

Figure 12.11: Three different types of leaf damage on vanilla leaf: leaf tissue missing, leaf necrosis and leaf rotting (from left to right). 


\subsection{SI Chapter 8}

Supporting information for:

Martin, D. A., Andrianisaina, F., Fulgence, T. R., Osen, K., Rakotomalala, A. A. N. A., Raveloaritiana, E., Soazafy, M. R., Wurz, A., Andriafanomezantsoa, R., Andriamaniraka, H., Andrianarimisa, A., Barkmann, J., Dröge, S., Grass, I., Guerrero-Ramirez, N., Hänke, H., Hölscher, D., Rakouth, B., Ranarijaona, H. L. T., Randriamanantena, R., Ratsoavina, F. M., Ravaomanarivo, L. H., Raveloaritiana, E., Schwab, D., Tscharntke, T., Zemp, D. C., Kreft, H. (in prep.). Uncovering conservation opportunities in a global biodiversity hotspot.

Please note: numeric result tables are under preparation.

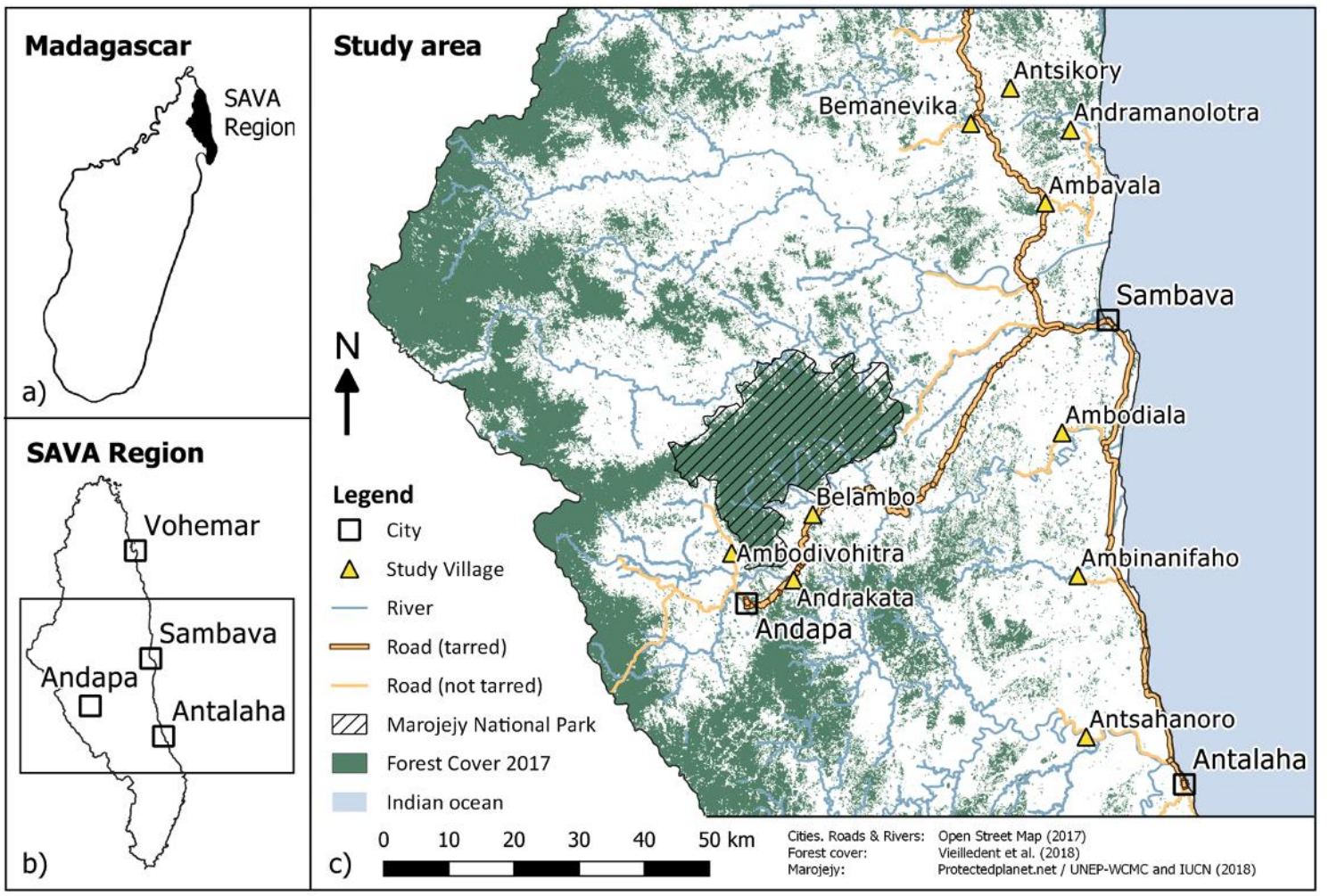

Figure 12.12: Study design overview. a) The island of Madagascar off East Africa with the SAVA region. b) SAVA region c) Study area with forest cover 2017 (Vieilledent et al., 2018), roads, rivers and the three major cities Sambava, Antalaha and Andapa as well as the 10 study villages and Marojejy National Park where we collected data on biodiversity and ecosystem functions. The villages where we collected data on yields and profits are not displayed. 


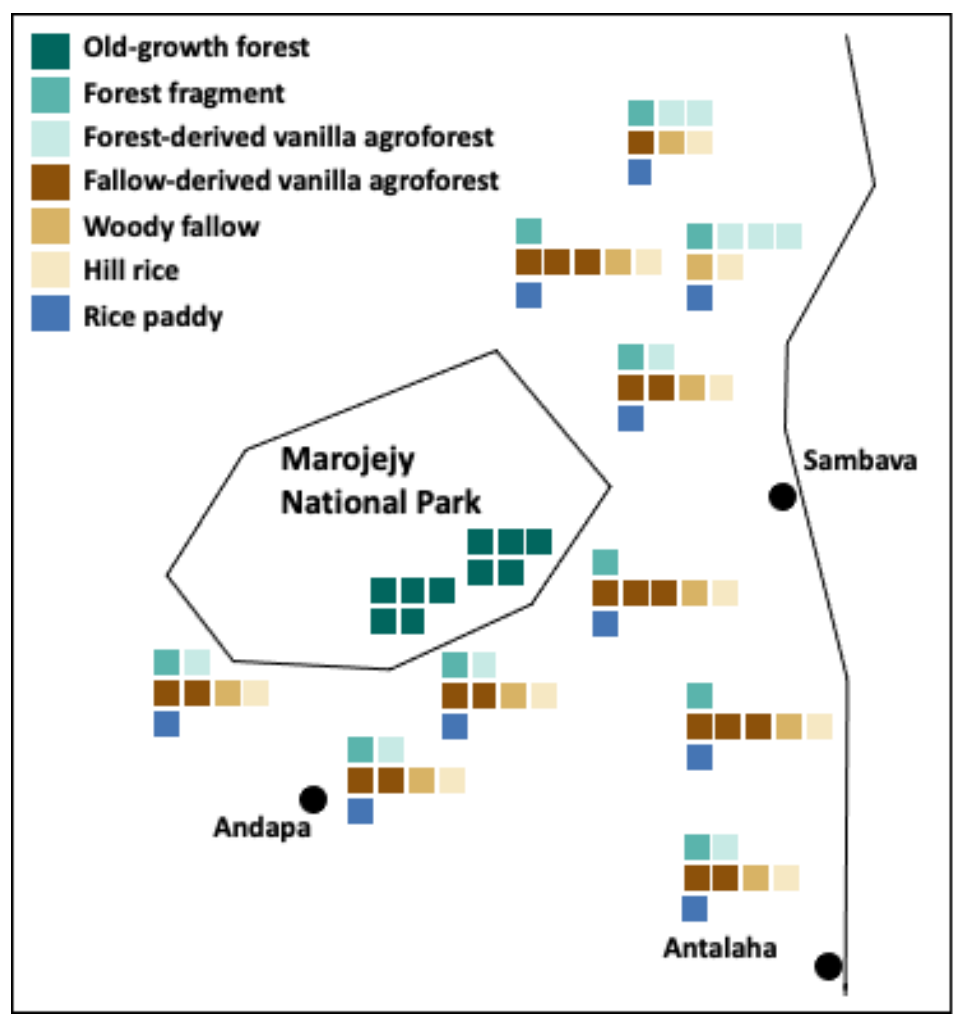

Figure 12.13: Semi-blocked study design with replicated land-use types across 10 villages and two old-growth forest sites where we collected data on biodiversity and ecosystem functions. Each square represents one plot, squares are arranged in 12 blocks according to the site respectively village of the plot. 

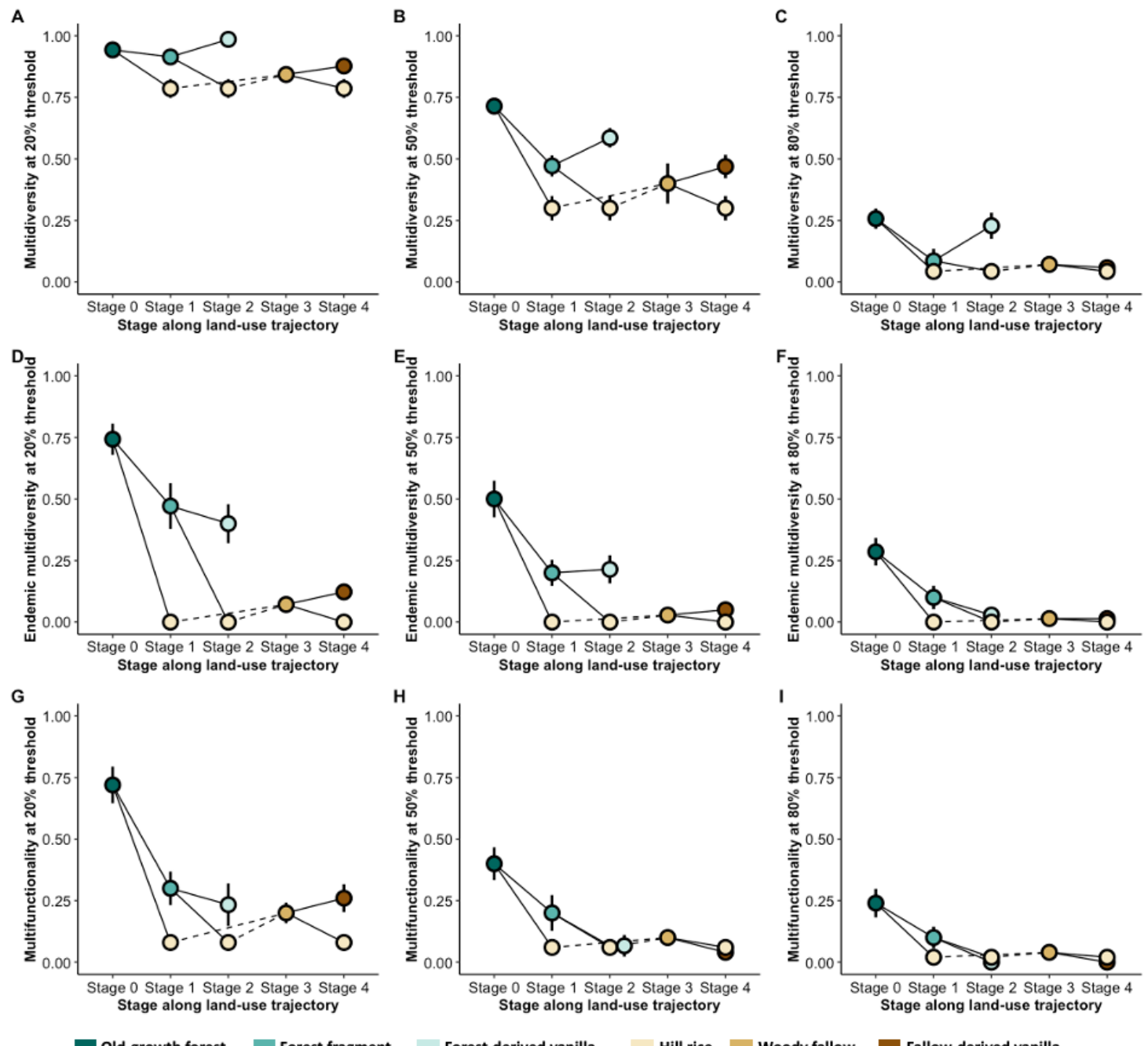

Old-growth forest

Stage along land-use trajectory Stage along land-use trajectory

Figure 12.14: Multidiversity, endemic multidiversity and multifunctionality at stages along a landuse trajectory in north-eastern Madagascar at the 20\%, 50\% and 80\% thresholds. Differences in multidiversity (A, B \& C) between stages along the land-use trajectory are strongest at the 50\% threshold. The conservation opportunity with the strongest potential, i.e. most taxa failing to pass the threshold after conversion, is conservation opportunity 1 (old-growth forest). Differences in endemic multidiversity (D, E $\boldsymbol{\&}$ F) between land-use types along the land-use trajectory are strongest at the $20 \%$ threshold. The conservation opportunity with the strongest potential, i.e. most taxa failing to pass the threshold after conversion, is conservation opportunity 1 (old-growth forest). Multifunctionality (G, H \& I) shows less pronounced differences between land-use types at the 50\% and 80\% threshold but is most different at the $20 \%$ threshold. Points coloured according to the land-use type represent the mean value for each land-use type while error bars represent standard errors. 


\section{Acknowledgements}

My PhD would not have been possible without many amazing people around me and was greatly facilitated by my privilege - growing up as a white man in one of the richest countries in the world has made everything easier.

Institutions

I'm thankful to Volkswagen Foundation which funded the Diversity Turn project ('Niedersächsisches Vorab'; Grant number: 11-76251-99-35/13 (ZN3119)) and thereby my salary over the last four years. The German Academic Exchange Service (DAAD) granted us further funding (Project Nr. 57449386), and in particular enabled the stay of my Malagasy colleagues in Germany. The Ministry of Environment and Sustainable Development in Antananarivo provided research permits. The Faculty for Forestry and Forest Ecology at the University of Goettingen offered all the facilities a PhD student could hope for.

\section{Farmers and authorities in study villages}

I'm furthermore grateful to everyone in our ten core study villages who made the research possible, particularly to the more than sixty families who let us access their lands, and to the chef de fokontany and their families who welcomed us to the village, guided us around, and hosted us in their homes. Misaotra betsaka!

\section{$\underline{\text { Supervisors }}$}

I'm grateful to my main supervisor, Prof Holger Kreft who supported me in an excellent way throughout my $\mathrm{PhD}$, who had great ideas and suggestions, and whose contributions made the papers what they are today. I'm also grateful to my co-supervisors Prof Ingo Grass, Prof Dirk Hölscher, and Prof Teja Tscharntke whose guidance, advice and exchange were indispensable. 


\section{Biodiversity, Macroecology and Biogeography colleagues and friends}

Your feedback greatly contributed to the success of my research and your friendship made my four years in Göttingen unforgettable. Thank you all for the time together. And thank you, Nathaly, for being the best office mate and for becoming a mentor.

\section{Diversity Turn colleagues and friends}

Annette, Fanilo, Janna, Lloyd, and Viviana, you were great colleagues, co-authors, and friends. Thank you so much for all the memories. Thank you, Yvonne, for being there whenever needed, for holding the project together, and for supporting me. Thank you, Hendrik, for organizing our Sambava lives, for setting everything up, and for the scientific exchange. Estelle, Rolande, and Andry, I'm grateful for the scientific discussions, the non-scientific discussions, the time together in our house in Sambava, as well as the moments we spent together in Göttingen and Tana, and the friendship.

Thank you, Fulgence, for all the weeks in the field, for being the most patient translator, for forming a great team, and for always being such a great motivator to me and others, and for your friendship.

Annemarie, you were holding us all together during the most difficult times in the field and in Göttingen. I will always remember your positivity and passion. And thank you for being a great friend and supporting me in so many ways over the years.

Thank you, Kristina, for your friendship, your support, and for challenging me on the things I was not great at. Your spirit was so important for our team from the first day you initiated meeting up in our group, up to the current day.

Thank you, Saskia, Thalita, Rouvah, and Lilith for trusting me to advise your theses, for the work in the field and in front of the screen.

Thanks to all our field assistants in Sambava, particularly Evrard and Thorien. You were the best field assistance one could imagine; and thank you Eric, for sharing your knowledge of Malagasy birds with us. Thank you Fenohaja for your reliable and tireless support with logistics and finances.

Family

Elisabeth, Patrick, and Simon, thank you for making me who I am.

Harry, thank you for everything, you are the very best. You carry me through it all. 